\title{
Update of Assessment of Geotechnical Risks, Strategic Petroleum Reserve, Weeks Island Site.
}

\author{
Edited by Stephen J. Bauer
}

\author{
Prepared by \\ Sandla Natjonal Laboratorles \\ Albuquerque, Now Mexlco 87185 and Livermore, Callfornia 94550 \\ for the United States Department of Energy \\ under Contract DE-AC04-94AL85000 \\ Approved for public release distribution is unlimited.
}


Issued by Sandia National Laboratories, operated for the United States Department of Energy by Sandia Corporation.

NOTICE: This report was prepared as an account of work sponsored by an agency of the United States Government. Neither the United States Government nor any agency thereof, nor any of their employees, nor any of their contractors, subcontractors, or their employees, makes any warranty, express or implied, or assumes any legal liability or responsibility for the accuracy, completeness, or usefulness of any information, apparatus, product, or process disclosed, or represents that its use would not infringe privately owned rights. Reference herein to any specific commercial product, process, or service by trade name, trademark, manufacturer, or otherwise, does not necessarily constitute or imply its endorsement, recommendation, or favoring by the United States Government, any agency thereof or any of their contractors or subcontractors. The views and opinions expressed herein do not necessarily state or reflect those of the United States Government, any agency thereof or any of their contractors.

Printed in the United States of America. This report has been reproduced directly from the best available copy.

Available to DOE and DOE contractors from

Office of Scientific and Technical Information

PO Box 62

Oak Ridge, TN 37831

Prices available from (615) 576-8401, FTS 626-8401

Available to the public from

National Technical Information Service

US Department of Commerce

5285 Port Royal RD

Springfield, VA 22161

NTIS price codes

Printed copy: A18

Microfiche copy: A06 


\section{DISCLAIMER}

Portions of this document may be illegible in electronic image products. Images are produced from the best available original document. 


\title{
UPDATE OF ASSESSMENT OF GEOTECHNICAL RISKS, STRATEGIC PETROLEUM RESERVE, WEEKS ISLAND SITE
}

\author{
Edited by Stephen J. Bauer \\ Underground Storage Technology Department 6113 \\ Sandia National Laboratories \\ Albuquerque, New Mexico, 87185
}

\begin{abstract}
This report is a critical reassessment of the geotechnical risks of continuing oil storage at the Weeks Island Strategic Petroleum Reserve site. It reviews all previous risk abatement recommendations, subsequent mitigative actions, and new information. Of increased concern, due to the discovery of a surface sinkhole and the conclusion that the sinkhole is due to water entry into the oil storage levels, is the long term maintainability of the mine as an oil storage repository. Mine operational changes are supported in order to facilitate monitoring of water entry diagnostics. These changes are also intended to minimize the volume in the mine available for water entry. Specific recommendations are made to implement the mine changes.
\end{abstract}

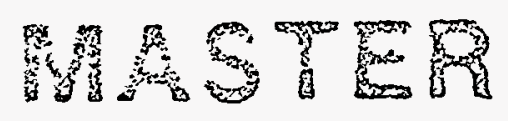




\section{Acknowledgments}

The report which follows is the culmination of a true team effort. Sandy Ballard, Steve Bauer, Brian Ehgartner, Chad Harding, Ron Jacobson, Jim Linn, Marty Molecke, Jim Neal, Ray Ostensen, Tony Russo and Jim Todd of Sandia National Laboratories, Mike Bertoldi, Tom Eyerman, Jim McHenry, and Ken Mills of DynMcDermott, Whitney Autin and others at the L.S.U. Environmental Studies Institute, Paul Knauth of Arizona State University, Rick Miller and Don Steeples of the University of Kansas and members of the Kansas Geological Survey all contributed text to the body and/or appendices of this manuscript. The report was reviewed by members of the Underground Storage Technology Department at Sandia National Laboratories and personnel from the U.S. D.O.E. Strategic Petroleum Reserve Project Management Office in New Orleans, DynMcDermott, PB-KBB, and Acres International. 


\section{TABLE OF CONTENTS}

EXECUTIVE SUMMARY. vi-viii

INTRODUCTION 1

1 REVIEW OF PRIOR WEEKS ISLAND RISK ASSESSMENT. .2

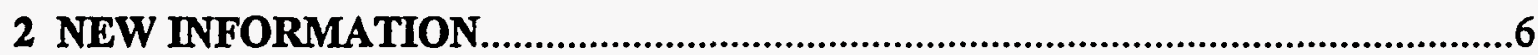

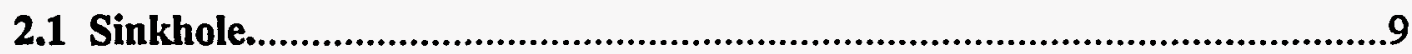

2.1.1 Sinkhole Development...............................................................9

2.1.2 Similarity to Other Sinkholes.............................................................

2.1.3 Sinkhole Current Status.............................................................11

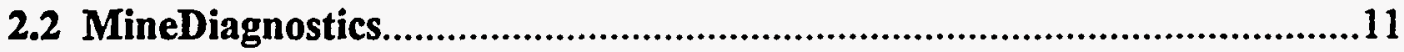

2.2.1 Fillhole Brine Inflow..................................................................11

2.2.2 Mine Pressurization....................................................................12

2.2.3 Identification of Water Entry ...................................................12

2.2.4 Other Possible Indications of Water Entry.....................................13

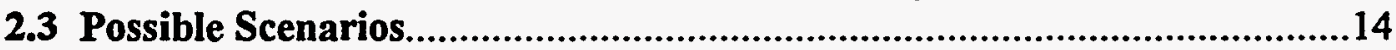

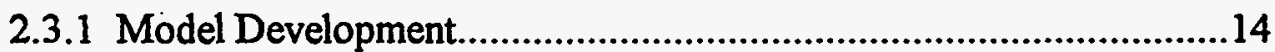

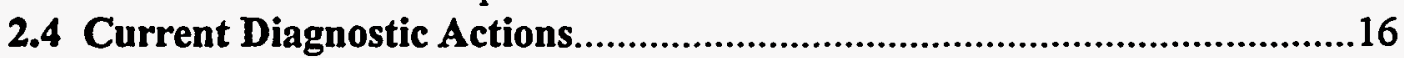

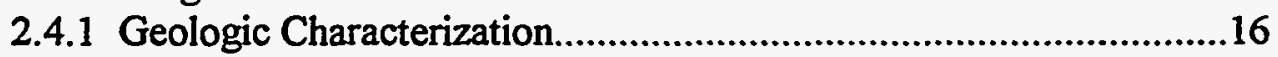

2.4.2 Surface Geophysics.................................................................18

2.4.3 Borehole Seismic Survey............................................................19

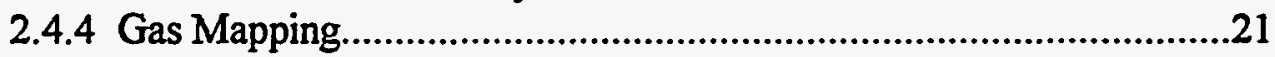

2.4.5 Downhole Flow Measurements......................................................22

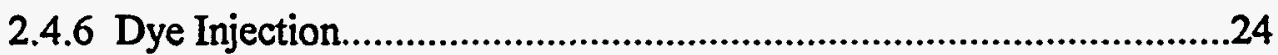

2.4.7 Surface Self Potential Survey...........................................................25

2.4.8 Stable Isotope Constraints on the Origin of Brine..............................25

2.4.9 Brine Injection and Sinkhole Monitoring......................................26

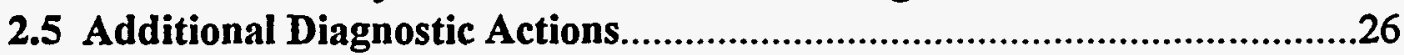

2.5.1 Inspection for Other Sinkholes......................................................26

2.5.2 Markel Mine Inspection....................................................................26

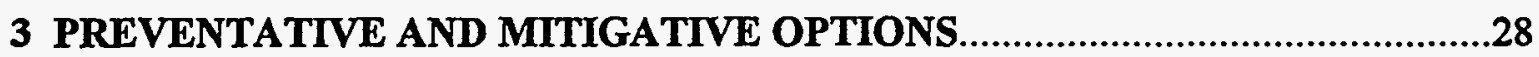

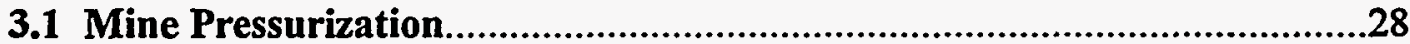

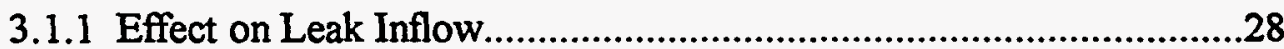

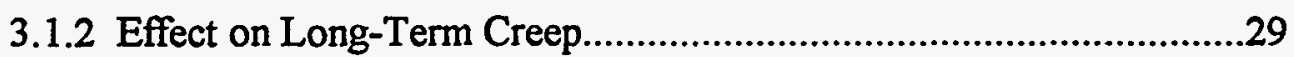

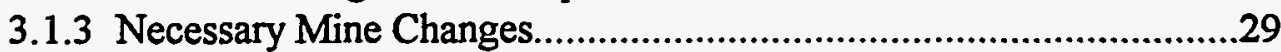

3.2 Grouting.............................................................................................

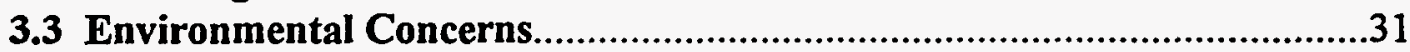




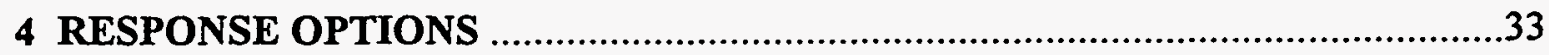

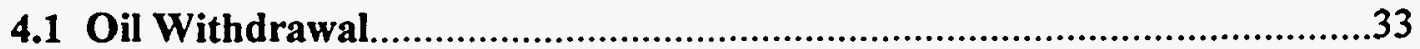

4.1.1 Conventional Drawdown..............................................................33

4.1.2 Geotechnical Emergency - Water Leak Above the Bulkheads............33

4.1.3 Geotechnical Emergency - Water Leak into the Storage Chamber...33

4.1.4 Water Leak During Conventional Drawdown...................................34

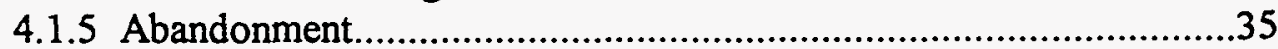

4.1.6 Disadvantages to Pressurizing the Mine...........................................35

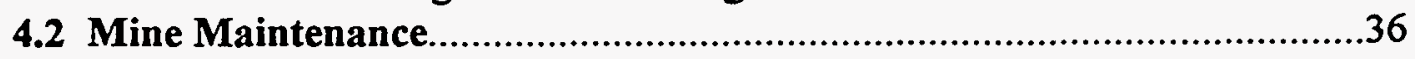

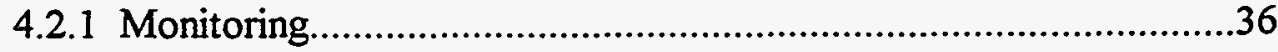

4.2.2 Maintenance Grouting .................................................................36

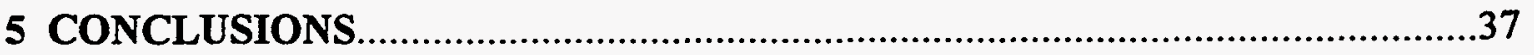

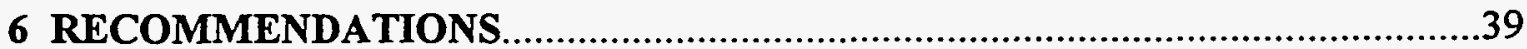

REFERENCES

Appendices

A1 Fillhole Brine Inflow

A2 Preliminary Weeks Island Mine Inflow Calculations

A3 Sediment/Core Descriptions and Daily Drilling Reports

A4 Gas Survey, Drilling Report from L.S.U.

A5 High Resolution Surface Seismic Reflection Survey Near SPR

Surface Collapse Feature at Weeks Island, Louisiana

A6 Borehole Seismic Survey

A7 Near-Surface Gas Mapping Program

A8 Near-Surface Gas Mapping Results

A9 Fluid Flow Measurements

A10 Dye Injection

A11 Surface Self Potential Survey

A12 Capillary Pressure in Weeks Island Sand

A13 Grouting

A14 Stable Isotope Constraints on the Origin of Brine in the Weeks Island Strategic Petroleum Reserve

A15 Brine Injection, Sinkhole Monitoring, and Backfilling 


\section{LIST OF FIGURES}

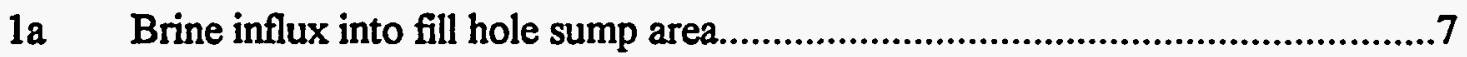

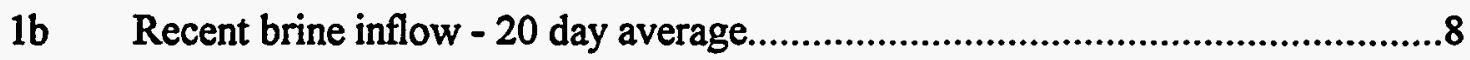

2 Observed sinkhole volume changes. Note that the method used to estimate the sinkhole volume is different beginning in mid-March, 1994

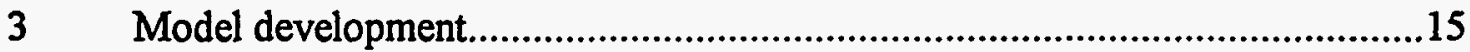

$4 \quad$ Map showing relative location of Weeks Island sinkhole and boreholes drilled. 


\section{UPDATE OF ASSESSMENT OF GEOTECHNICAL RISKS STRATEGIC PETROLEUM RESERVE WEEKS ISLAND SITE}

\section{EXECUTIVE SUMMARY}

This report is an update of the current geotechnical status, risks, and concerns of the Weeks Island (WI) Strategic Petroleum Reserve oil storage site. This report updates a 1985 study which had identified concerns associated with the potential for underground failure of existing shafts and mined openings. The 1985 study recognized that such a failure would have led to uncontrolled solutioning around the bulkheads isolating the accessible manways above the oil storage from the two previously - mined oil storage levels. Following the study, new bulkhead construction was undertaken, existing systems were upgraded, and new withdrawal and monitoring capabilities were developed to directly address the concern raised in the study. In 1992 a surface sinkhole was discovered over the southern edge of the mine. By late 1993 the size of the sinkhole had begun to increase measurably, and an increase in brine inflow into the mine was detected. The initial phase of a major diagnostic effort was completed to identify the cause of the sinkhole, and develop possible mitigative options, if necessary.

The diagnostics effort was successful in locating a significant leached zone or crevasse in the salt below the sinkhole and measuring the downward flow of partially saturated brine and sediments well below the top of salt. Simultaneously, the brine inflow into the fill holes area in the mine was significantly increasing in concert with the volume of fill material being used to fill the sinkhole at the surface. Since early 1992 the isotopic composition of brine in the fill holes has been evolving toward that of ground water sampled over the salt dome. The evidence was sufficient to conclude that the sinkhole is due to sediment subsidence into voids created by salt dissolution from ground water flow into the mine.

Recent geomechanics simulations of WI indicate the salt zones above the outer mine boundaries to be in tension, from which dilation or increased permeability (possibly cracking) may follow. Modeling of a simulated fissure into the mine with sand fill in the available dissolutioned volume suggests that the current sinkhole volume might represent an ongoing leak taking many years to develop. Such modeling indicates that a leak may increase 10 fold in 5 years if unmitigated.

Diagnostic measurements in the form of geotechnical investigations (geologic, geophysical, and hydrologic) have been completed which indicate the following: (1) the sinkhole is a surface expression of nearly vertical chimney(s) or crevasse(s) in the top of salt into which overlying sediment has flowed, (2) the geometry of a funnel/chimney-like sediment filled feature has been estimated through surface geophysics and crosswell tomography, (3) sediment is currently estimated to be flowing downward at about $1 \mathrm{inch/day,} \mathrm{(4)} \mathrm{water} \mathrm{in} \mathrm{that} \mathrm{sediment} \mathrm{is} \mathrm{flowing}$ 
predominantly downward at approximately 1 foot/day, (5) water in the sump is becoming more connate with time, and (6) there appears to be a direct connection between injection of brine into the crevasse below the sinkhole and surface displacement (enlargement) of the sinkhole. Current mine leak diagnostics indicate an increased brine accumulation but have not yet detected dye injected into the downward flowing brine near the top of salt and in the subsurface below the sinkhole.

Considering the existence and location of the sinkhole and the associated leak, the geomechanics modeling, the experience of a similar mine, the limitations of the geotechnical and mine diagnostics, and the mitigative options available, there is real concern over the long-term viability of continued oil storage at Weeks Island. There is no historical experience either successful or unsuccessful of attempted long-term storage of oil (or other fluids) under these conditions. Based on the experience of others with leaking mines, stopping water entry over the long term is anticipated to be extremely difficult, if not impossible. Initial efforts at leak control are encouraging which provide near term confidence in continued operations. Long term operation is anticipated to become more difficult with the possibility for additional leaks and their cost implications, although accurately predicting the timing of future leaks is impossible.

The leak increases the concern of maintaining total control of oil during normal drawdowns. Of major consequence during a normal drawdown would be the washout of permeable overburden material in the leak path which may be limiting rapid salt solutioning and high-volume water inflow. The likelihood of such an event may be quite low but the consequences would be extremely serious if sufficient water is available in the saturated zone above the salt to greatly increase the dimensions of the leak path through dissolutioning, and saturate or prevent operation of the mine withdrawal pumping capacity. Increased pressurization of the mine, development of a raw water or brine source, and the adaptation of the withdrawal system to accommodate maintenance of a liquid-filled mine during withdrawal is an approach that will minimize potential consequences under any conditions, but it is a more complex oil withdrawal method.

In order to evaluate the consequences of a washout during a normal drawdown, and investigate other seismic anomalies and possible leak detection techniques, an ongoing diagnostics program has been approved and its current results are described very briefly. 


\section{INTRODUCTION}

Geotechnical concerns associated with oil storage at Weeks Island were first assessed in a 1985 study. At that time experience with continued brine/water leaks associated with the shafts into the accessible drifts above the storage levels, and into the Wet Drift area had generated concern over continued long term storage. In response to the study and subsequent analyses, the SPR program undertook the construction of two new bulkheads, upgraded several existing bulkheads, developed an emergency withdrawal capability and greatly enhanced their surveillance and monitoring capabilities and program. Additionally, many analyses were completed which addressed issues or concerns. As a result of the work, all previously identified concerns with continued oil storage identified in the 1985 study were dispelled.

Since 1985 two events have occurred that in retrospect appear related, and which at the time raised concerns. In 1987, a significant quantity of brine (over $40 \mathrm{Kbbl}$ was found in the mine in the area of the fill holes. The resulting investigation was inconclusive as to the significance or source of the brine due to the possibility that the brine was the result of water disposed of in the mine following pipeline testing, and/or water associated with the bottom sediments and water (BS\&W) fraction within the oil. The conclusion did prompt continual monitoring of brine in the fill hole area with the conclusion that an increase in brine flow into the fill hole area was probably an indication of a water leak.

In 1992, a surface sinkhole over the south edge of the mine was discovered. The sinkhole had existed for a period of time but was not an old feature. At that time, the sinkhole appeared stable in size, hence a "wait and watch" approach was adopted. By mid 1993, evidence of sinkhole enlargement began to appear, and the program initiated an investigation as to the source and significance of the sinkhole. By March of 1993, enough information was available to conclude that there was some likelihood that the sinkhole was a result of a leak into the mine. Actual drilling and downhole seismic diagnostic data acquisition were undertaken in June 1993, resulting in the current conclusion that there is a leak into the mine, and the sinkhole is a result of salt dissolutioning by water associated with the leak into the mine. Further, the brine inflow in the fill holes in all probability also results from a leak into the mine.

In an attempt to understand the significance of the leak and possible future implications, modeling of leaks has been completed, and the experiences of other mine operators have been sought. Additionally, leak mitigative efforts have been initiated by the site operations (specifically brine injection), along with contingency planning, and further diagnostics effort definition.

This report recognizes the work that has been done in earlier mitigative efforts, references the major analytic efforts, and summarizes recent diagnostic information learned while investigating the sinkhole. Additionally it identifies the concerns associated with a leak and possible future mitigative options. 


\section{REVIEW OF PRIOR WEEKS ISLAND RISK ASSESSMENT}

A report describing the results of an evaluation of risks to continued safe oil storage at the Weeks Island Strategic Petroleum Reserve facility was published in June 1985 by Sandia National Laboratories (Beasley et al, 1985). It identified five major areas of risk that were believed to jeopardize oil storage at Weeks Island. The five major risk locations were:

1. Wet Dritt

2. Production Shaft

3. Service Shaft

4. Markel mine

5. Vent and fillholes

In addition to identifying these risk areas, the report described four essential activities for risk reduction, which were:

1. Inspections

2. Emergency grouting

3. Protection of the oil withdrawal capability

4. Construction of isolation bulkheads and shaft liners

Significant progress has been made to alleviate or mitigate the then identified major risks to continued safe oil storage at Weeks Island. Weekly inspections and findings in the Production Shaft, Service Shaft and the Wet Drift are performed and documented in a weekly report. Semi-annual inspections by an independent grouting engineering contractor are performed and documented. Extensive grouting in the Wet Drift, Production Shaft and Service Shaft has taken place. An emergency grouting plan and contract are in place. Construction was completed in 1992 to provide oil withdrawal capability from the fillholes should it be necessary to do so. In addition to this project, integrity tests have been performed in the vent and fillholes and an interface detector has been installed in the west fillhole. The abandoned commercial Markel Mine has been isolated with the construction of two concrete bulkheads, and the oil isolation bulkheads have been evaluated for capability to contain hydrostatic pressure should a leak develop into the storage chamber. Three of the oil isolation bulkheads were upgraded to ensure their ability to withstand this pressure.

The report provided fifteen risk abatement recommendations. The four recommendations which were considered most urgent to undertake were:

1. Continue monitoring and inspection of the DOE mine and shafts,

2. Develop and implement emergency grouting program,

3. Monitor water leaks in the Wet Drift and other areas, and

4. Protect the oil withdrawal capability.

The site mining engineer performs a weekly visual inspection of the Service Shaft, Production Shaft, and all accessible mine areas. He prepares a report weekly of the findings and changes in oil and brine level measurements. Site Operations performs a daily 
underground check including monitoring gas pressures on the oil side of the Service Shaft, Raisebores \#1 and \#2, Production Shaft, and Markel Incline bulkheads, and in the vent hole. This daily monitoring also includes the oil/brine interface level in the Service Shaft and manually strapping the oil/gas interface at the Service Shaft. These data are reported in the Weeks Island Readiness Report. A program and subcontracts with Rembco Engineering Corporation (standby grouting contractor) and Dynatec Mining Corporation (grouting engineer) are in place to perform semiannual inspections of the manways and mine shafts. Routine inspections of the Markel Mine were discontinued in 1989 due to safety concerns of the conditions in the mine.

Inspection and monitoring of the vent and fillholes with casing caliper instruments and a borehole televiewer have not been performed. The east and west fillholes are equipped with 4-1/2" logging casing for running instruments on electric wirelines to measure the brine interface depth. Presently, a capacitance-type interface detector is suspended in the west fillhole for continuous monitoring. Comprehensive monitoring and inspection processes are in-place and capable of providing early warning of changes or problems.

An emergency grouting program and a standby grouting contract, which is renewed annually, are in place (Emergency Grouting Program, 1984). The standby grouting subcontractor at present is Rembco Engineering Corporation. Additional grouting engineering support is provided by Dynatec Mining Corporation. Specific grouting procedures have been developed, as well as grouting criteria, which are documented in the standby grouting contract.

Brine accumulation monitoring is performed in the Wet Drift, Service Shaft, and other areas of the mine and reported weekly. Independent overview is performed and reported by the standby grouting subcontractor and the grouting engineering subcontractor during semi-annual inspections.

The "Emergency Drawdown System" project (WI-MM-079B), completed in 1992, provides an alternative means of recovering oil from the storage caverns in event of flooding of the manifold room or any other event that may render the manifold room pumps inaccessible. Piping, valving and pumping configuration changes and additions have been made to withdraw oil through the fillholes.

Progress has been made towards implementing eight additional risk abatement recommendations which were considered of lesser urgency. These eight recommendations and their current status are:

1. Monitor surface subsidence, (ongoing)

2. Investigate shear zones and geometry, (ongoing)

3. Sample water and test, (ongoing)

4. Measure brine in sumps, (ongoing)

5. Collect condensation data and analyze, (ongoing)

6. Perform dimensional surveys of Wet Drift, Markel Incline, shafts and associated drifts, (ongoing)

7. Expand sediment, salt and geohydrology study, and (partially completed)

8. Measure mine convergence, (ongoing in the manways, but not in Markel Mine). 
The SPR Management and Operating contractor (DynMcDermott) has overall responsibility for the subsidence program. Included are: identification of need and construction of new monuments, maintenance of existing monuments, providing adequate surveying specifications, subcontracting surveying services, and analysis and reporting of survey results. Survey results are published in the annual subsidence report.

A detailed surface subsidence monitoring program of the Weeks Island salt dome was developed (PB-KBB, 1986) under contract with Boeing Petroleum Services. The purpose of the program was to provide a plan to identify, quantify and predict surface and underground subsidence as a partial solution to the risk assessment recommendation pertaining to monitoring surface subsidence. Eighty-two surface subsidence monitors and eight deep monitors and inclinometers have been installed based on the PB-KBB recommendations.

Shear zones and geometry were investigated (Acres International Corporation, 1987) in a detailed geologic site characterization of the Weeks Island salt dome under contract with Sandia National Laboratories. The three principal areas covered by this study were:

1. Stratigraphy and lithology of the sediments adjacent to the dome,

2. Structure within the sediments adjacent to the dome, and

3. Geometry and structure of the salt dome.

Water samples from the mine are collected and analyzed at random times. Samples have always been meteoric in origin. Heavy stable isotopic analysis were performed between 1987 and 1990 (Arizona State University, 1990). The present method of monitoring for brine influx into the mine utilizes brine/oil interface instruments in probe holes in the Service Shaft bulkhead, and a brine/oil interface monitor in the west fillhole. The total fluid in the mine is obtained from a manual strapping of the oil/gas interface in the Service Shaft. This strapping was replaced by a new automatic instrument in May 1994. Additionally, a second instrument for continuous monitoring of brine in the fillholes was installed in the east fillhole in May 1994.

An attempt was made to collect and analyze condensation data in the Production Shaft. Humidity readings near 100 percent precluded meaningful data collection. A mine air treatment system was subsequently installed to dehumidify the air in the Production Shaft. The recommendation was to install continuous read-out instrumentation measuring wet and dry bulb temperatures at the top of the Production and Service Shafts; this was largely negated by the air dryer system.

The recommendation to perform dimensional surveys of the Wet Drift, Markel Incline, shafts and associated drifts was substantially completed (Freyou, 1986), although new surveys may need to be performed. The Weeks Island Production Shaft was surveyed in 1988 (PB-KBB, 1990) and resurveyed in 1990. No analysis has been performed.

The response to the recommendation to expand sediment, salt and geohydrology studies is incomplete. A report summarizing the stratigraphy, soil and salt properties over the Weeks Island dome was completed (Acres International Corporation, 1987) under contract with Sandia National Laboratories. The recommendation also called for 
determining the degree of fracturing and fissuring of the upper part of the salt; predictions of the maximum rate of water inflow into breaches in the dome; and development of a detailed knowledge of the Pleistocene and Recent sediments overlying the dome; due to the very significant efforts required and the perceived importance, these were not undertaken.

A monitoring program with Morton to accurately measure convergence in the new Morton Mine, Markel Mine, and associated dritts has not been initiated. Monitoring equipment has been installed in the DOE mine or manways, and baseline data collection has begun.

Three risk abatement recommendations of lesser urgency which have yet to be undertaken are:

1. Monitor oil/gas drilling around the dome,

2. Seal well \#16, and

3. Monitor Morton blasting.

The Louisiana Department of Natural Resources monitors oil and gas drilling around the dome. Reviewing and monitoring all subsurface drilling, brining, and other associated activities, as recommended has not been rigorously pursued due to the general low level of activity around the dome and the perceived cost/benefit. The only ongoing brining at Weeks Island is conducted by Morton Salt Co. in two small caverns. An attempt is planned to locate the coordinates of well \#16; further work is dependent upon the results of the search. The entire area where the well may be located is heavily wooded; clearing to access the well is severely limited because the area is an endangered species habitat. Although monitoring Morton's blasting procedures was recommended, the cost/benefit could not be supported.

Listed are the specific recommendations which were already completed or withdrawn by the time the earlier risk assessment study was completed:

1. Construct bulkhead in Wet Drift. (completed)

2. Remove dry side steel bulkhead in the Wet Drift to facilitate leak detection. (completed)

3. Fill Wet Drift with brine. (withdrawn)

4. Study possibility of forming a caprock. (withdrawn) 


\section{NEW INFORMATION}

During the period (1985-1993) following the earlier Weeks Island Risk Assessment the SPR Program has initiated and taken responsive actions in several other geotechnical areas.

1. Designed and built two massive underground bulkheads to isolate the DOE manways or drifts above the oil storage levels from the Markel Mine.

2. Completed extensive analyses of the structural capabilities of the five downhole oil isolation bulkheads.

3. Designed and completed structural upgrades for the two raisebores and Service Shaft bulkheads.

4. Identified and analyzed a significant quantity of brine in the fillholes below the oil. Developed and implemented an ongoing plan for monitoring and removing brine in the fillholes below the oil storage.

5. Completed the design and construction of an air dryer system for removing water from the manways ventilation air.

The first responsive action addressed the earlier identified concern of uncontrolled water entry into the manways above the oil storage levels causing significant dissolution and erosion around the existing bulkheads and loss of withdrawal capability. Additionally, the upgrades to the existing bulkheads address the concern of bulkhead adequacy to pressure exerted from below, i.e., the oil storage chambers. The air dryer system was recommended in the earlier risk assessment work to eliminate the masking of incipient leaks, and further solutioning in the shafts and manways by water condensation from the ventilation system.

Most notable during the period, two additional events occurred:

1. Brine was discovered in the fillholes, initiating additional investigations, and

2. A sinkhole was discovered over the edge of the mine.

In 1987 a sizable quantity of brine was discovered in the fillhole sump. The brine was analyzed by radiochemistry methods and tentatively concluded to be meteoric, i.e., basically surface connected water in origin. Additional investigation identified the potential sources of the water as possibly attributable to the Weeks Island pipeline pressure testing (hydrotesting). An additional source of water was part of the BS\&W (bottom sediment and water) contained within the purchased oil. With the quantity of meteoric water known to be in the mine, no conclusion was possible regarding mine leakage.

The existing brine in the sump was pumped out and monitoring instrumentation installed to monitor any new influx into the fillhole sump area. Over the next few years, the rate of influx into the fillhole continued to decline but then recently the rate of influx increased, as shown in Figure 1b. In order to understand the effect that oil circulation exercises appeared to have on the brine in the fillhole sump, a scale model of the fillhole area was constructed at Louisiana State University (Louisiana State University, 1990), and oil circulated as occurs during recirculation exercises. Modeling results indicated clearly 


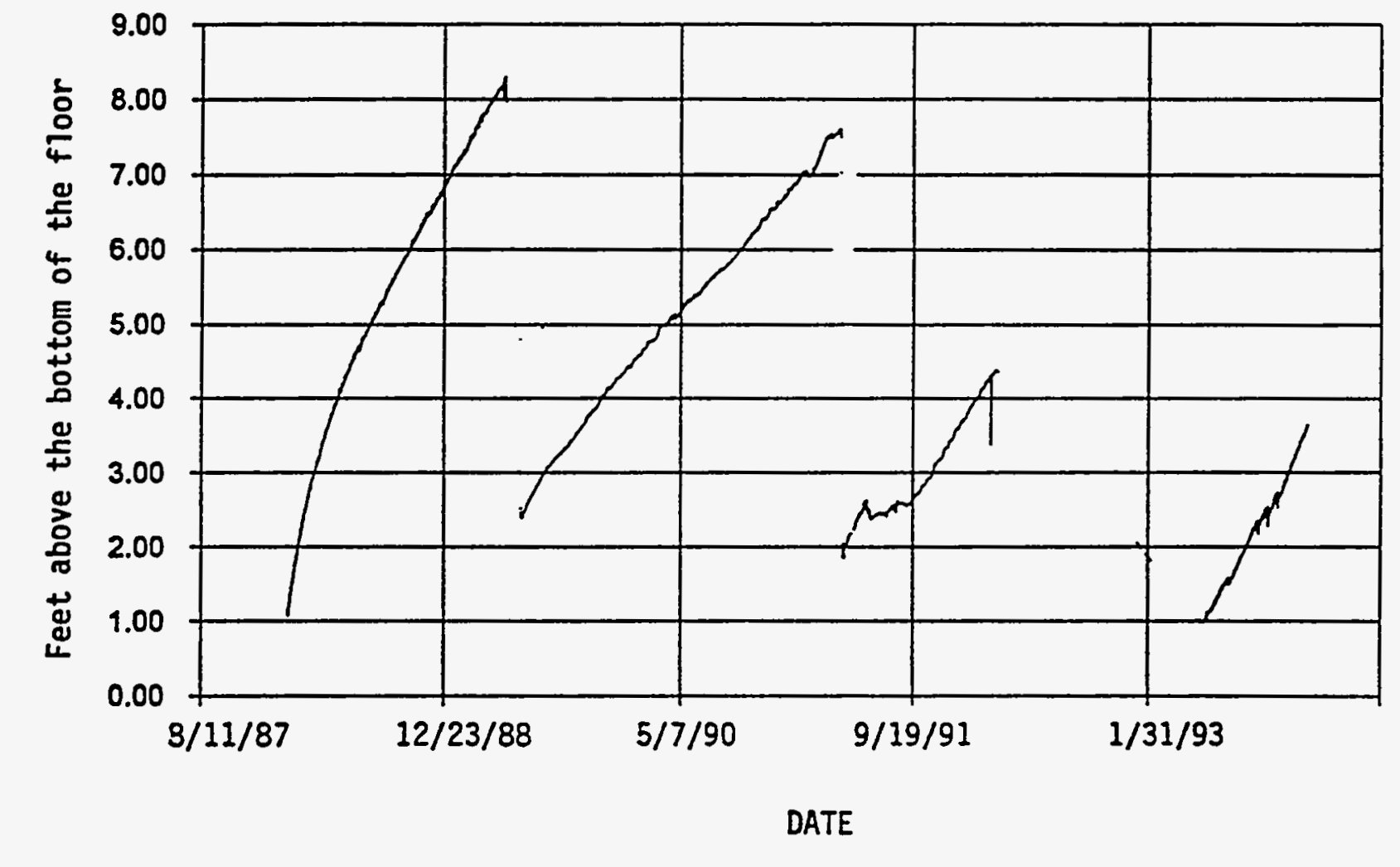

Figure la. Brine influx into fill hole sump area. 


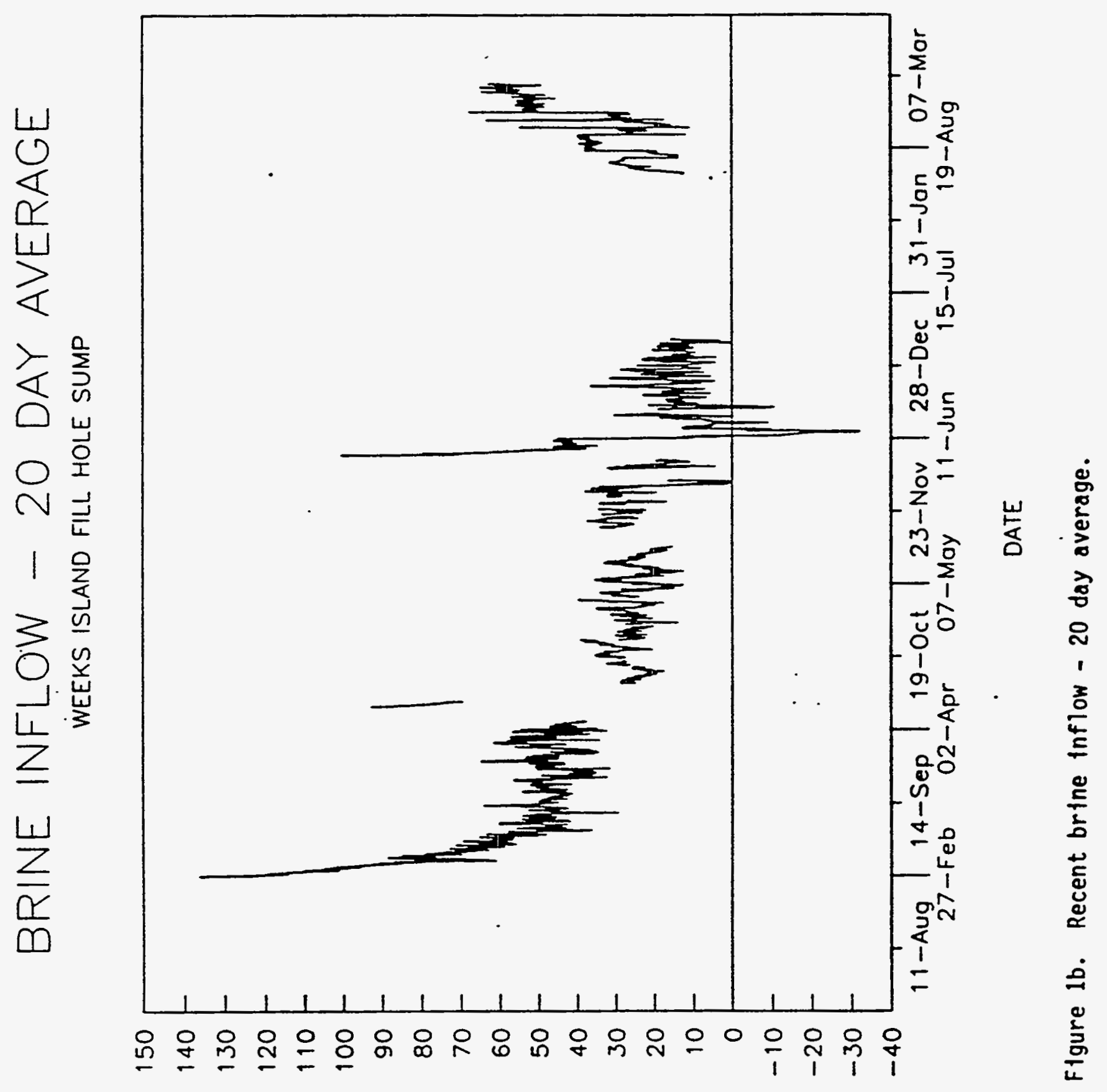

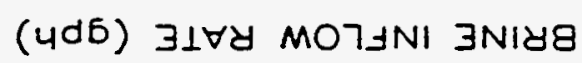


that as the flow rate of oil into the fillhole increases, interaction of the oil and brine occurs forming an emulsion. The emulsion easily transports brine from the fillhole sump into the mine. Over time such brine eventually leaves the emulsion and migrates to the floor of the mine. Brine return to the fillhole sump could be delayed or might not occur, depending of the quantity of oil circulated, the exact grading of the mine floor, and the cut "channels." Consensus of the Weeks Island Risk Abatement Committee and Site Operations had been that a decreasing brine influx rate was indicative of existing water migration into the fillhole sump, and not indicative of water from leakage into the mine migrating to the sump. Interpretation of inflow into the fillhole sump is. summarized in Section 2.2.1 and Appendix 1 for the time period following these previous investigations.

The other notable event which took place since the 1985 report was the appearance of a sinkhole over the upper level of the oil storage chamber. The sinkhole was first noticed in May 1992 and has progressively grown since its discovery. The discovery of the sinkhole and follow on work to learn its genesis have prompted this risk re-evaluation.

\subsection{SINKHOLE}

\subsubsection{Sinkhole Development}

On May 18, 1992, a security guard working for the SPR incidentally stumbled across the large, steep-sided and deep depression (now identified as the sinkhole) very close to the main access road to Morton Salt and DOE facilities at Weeks Island. The hole was in proximity to a mowed apron, but had evidently previously not been observed. The hole received immediate attention as a safety hazard, and was examined and identified as a sinkhole by Neal and Magorian on the 19th of May. There was an original assumption that it was a dissolution feature as a result of water/salt interaction at the top of salt. This is common over many salt bodies, both domal and bedded. The sinkhole appeared to be stable in size for about a year even though some change of shape occurred continually due to precipitation and side sloughs. By the early part of 1993, it was recognized that the hole was enlarging. Surveys show it to be increasing in size by about 20 cubic yards/month (Figure 2). A very complete geological description of the sinkhole, its possible origin, and location was completed by Neal (Neal, 1994). The precise date of its formation is unknown although Neal has been able to estimate it roughly in the fall of 1990, or early spring of 1991.

\subsubsection{Similarity to Other Sinkholes}

One reason for SPR concern with the sinkhole is the similarity to other sinkholes witnessed by mine operators in salt mines. In one other domal salt mine, the operator has confided that their experience has been to see water entry in the downhole workings precede sinkhole formation by about a year. Such water entry was typically grouted without fanfare, and emergence of a sinkhole at a later date simply noted. It might be noted that the appearances on the surface of other such sinkholes do not resemble the Weeks Island sinkhole. More typical of other sinkholes viewed has been gradually sloping depressions, usually with standing water. The WI sinkhole surface manifestation is due to the ability of loess to support near vertical walls. Elsewhere there has not always been an 


\section{Weeks Island Sinkhole Volume Changes}

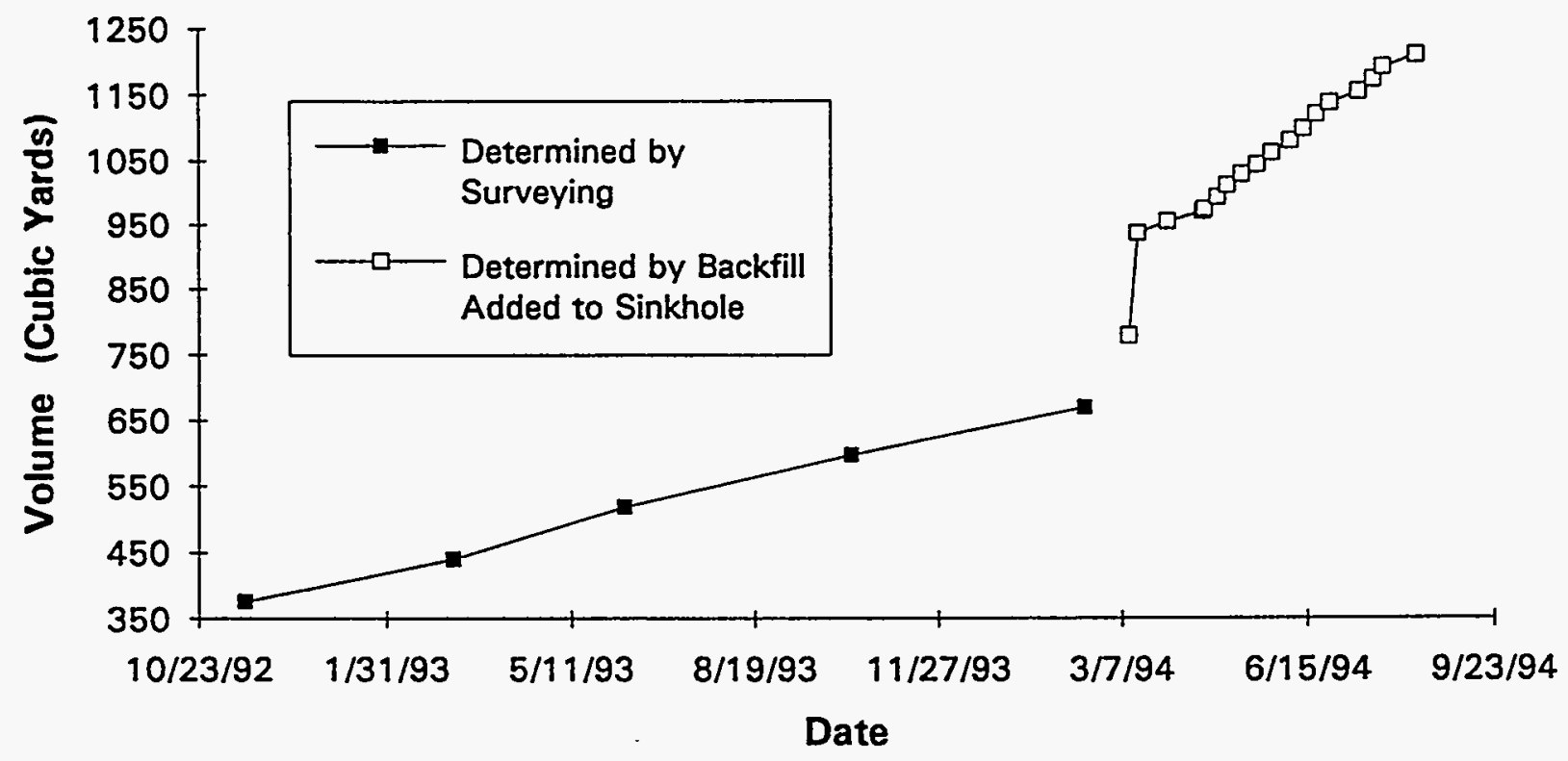

Figure 2. Observed sinkhole volume changes. Note that the method used to estimate the sinkhole volume is different beginning in mid-March, 1994. 
exact location match between the mine seepage and the sinkhole location, that is thought to be attributable to the particular mine opening geometry and local salt and soil conditions. There does appear to be consistency in the general observations that such mining associated sinkholes occur near long time outer boundaries of at least one mine.

Another similarity might be drawn between the sinkhole location and the Wet Drift location. The Wet Drift was so named as water was encountered in driving a drift between the existing manways above the mine and the planned new Morton International mining area in the dome. The water was encountered in an area roughly $100 \mathrm{ft}$ above and slightly out from the edge of the historical mined levels. Although it may only be coincidence, it should be noted that no explanation for the water in the Wet Drift area has been confirmable, i.e., faulting, significant inhomogeneities, etc.

\subsubsection{Sinkhole Current Status}

The sinkhole was surveyed on five occasions from November 1992 until February 1994. During this time it increased in size from about 380 cubic yards to about 670 cubic yards, with the measured rate of increase being nearly linear with time. In March 1994 the sinkhole was filled with sand. Several subsequent sand additions has resulted in over 1100 cubic yards of sand fill to date.

This filling of the sinkhole does not prevent continued development of the sinkhole or the underlying mechanism responsible. With time, the surface expression of the sinkhole will redevelop if solutioning is allowed to continue or cannot be controlled. The filling of the sinkhole was done in order to reduce risk to personnel while the seismic and drilling investigations to determine its cause were underway around it, and to simplify continued monitoring of its growth.

\subsection{MINE DIAGNOSTICS}

\subsubsection{Fillhole Brine Inflow}

In March 1987, brine was discovered in the fillhole sump while running a wireline $\log$ in one of the fillholes. This log was the first that had been run in the fillholes since fill began. After an intense investigation in the latter half of 1987, the Project concluded that the brine was a combination of connate water, bottom sediment and water (BS\&W) from the stored oil, and hydrotest water from the St. James pipeline. The determination at that time was that the brine did not indicate a leak into the mine.

From February 1988, following brine removal from the sump, through February 1992 the data from a wireline suspended interface tool in the fillholes showed a trend of declining or level rate of inflow of brine into the sump. During this time, brine was removed from the sump on two additional occasions. The interface tool was removed in February 1992 in order to install and test the emergency drawdown pumps in the fillholes. It was reinstalled in March 1993 . Brine was again removed from the sump in May 1993. Since the May removal, the inflow rate has increased in rate from about 15 gallons per - hour (gph) to a high of about $127 \mathrm{gph}$ in July 1994. Brine injection and mine pressurization were initiated in late July and early August of 1994, decreasing the inflow rate and resulting in a current leak rate of slightly over $100 \mathrm{gph}$. 


\subsubsection{Mine Pressurization}

Since the mine was filled in 1983, the pressurization rates in the accessible gasfilled spaces under the bulkheads and at the vent hole have been monitored. The observed pressurization rates, the original measured volume of the mine, and data from oil movement exercises or opportunities were used to determine the creep closure rate of the mine. The measured volume of the mine used was that derived from the original survey of the mine conducted by Rice and Associates in 1978 during the mine conversion. These data indicated that the overall annual creep closure rate of the mine has been about 160,000 barrels per year (at the normal operating pressure). Geomechanics studies of the expected creep closure concur with this estimate (Preece, 1987). This ongoing loss of volume in the mine can be expected to continue at about this rate unless the operating pressure is changed.

Over the years, the mine has been operated with a maximum pressure on the gas under the bulkheads of $7 \mathrm{psig}$, with minor exceptions. This has required the frequent bleeding of gas from under the bulkheads to maintain the pressure within the prescribed limits. As the gas has been bled and the mine has closed, the oil level in the mine has risen progressively higher. Most recently, in July 1994, additional oil was transferred into the mine in an effort to more completely fill the mine and to strap the operating level of the mine to enhance leak detection. Even with this transfer some gas volume still exists in isolated gas pockets throughout the mine, but the volume has been greatly reduced by the transfer. Efforts are currently underway to more accurately estimate the volume of gas from the strapping data. Additionally the mine roof survey data has been contoured which provides spacial location and quantity information on the gas pockets within the mine.

\subsubsection{Identification of Water Entry}

Water intrusion into the oil storage levels is ultimately identifiable by monitoring the brine levels in the fillhole and Service Shaft sumps and by monitoring the pressurization rate in the mine. The brine in the mine, however, can come from multiple sources, not all of which are leaks from outside. Non-leak sources include BS\&W from the stored oil, connate seeps in the mine, and water that was in the pipeline from its hydrotests and was pushed into the mine at the initial fill.

The source of the water in the mine can be inferred by chemical and isotopic analysis. The chemical analysis can differentiate connate brine from surface and ground waters. The isotopic analysis can also be used to differentiate connate and meteoric waters and between different sources of the meteoric water. The source identification of non-connate waters requires that a baseline sample from the possible sources be available for comparison to the assays of the water collected from the mine. Analyses to date of the brine from the fillhole, indicate that the brine is a combination of connate and meteoric water, and it is becoming more meteoric with time (please see Appendix 14). This trend is interpreted to be the direct result of the continuous inflow of brine from the Weeks Island aquifer fed leak into the mine.

- The Service Shaft sump has shown no unexplained brine inflow since late 1987. The fillhole sump has continued to have brine collecting in it. The rate of inflow generally decreased from 1988 to 1992 but has increased since 1993, notwithstanding the decrease 
attributable to oil pressurization in late July 1994. This is covered above in 2.2.1 Fillhole Brine Inflow and in Appendix 1.

Water entering the mine in the upper level would flow along the floor to the Service Shaft or one of about seven raisebores which were drilled between the two levels. Water entering the lower level of the mine might flow to either the Service Shaft sump, the fillhole sump or an area at the north end of the mine which has a low elevation. The floor of the lower level was reportedly graded to drain towards either the Service Shaft or the fillhole sump. Trenches were cut into the floor of the mine nominally to a set elevation although a person present at the time indicates that the trenches were instead cut to a set depth. These trenches were intended to aid in draining oil to the Service Shaft and from the fillholes, and they would allow brine to flow in either location. The trenches could have become blocked by a salt fall, collapse, or one of the numerous salt piles left in the mine. Such a blockage would negate the intent of the trenches to some extent and allow drainage to follow the floor contours which indicate a divide between the fillholes and the Service Shaft. The continued inflow of brine, from the current sinkhole associated leak, into the fillhole sump and not to the Service Shaft, indicates that current water/brine entering the lower level preferentially flows to the fillhole sump. Thus brine monitoring in the fillhole sump is currently probably a better indicator of leakage into the mine than monitoring of the Service Shaft sump.

The pressurization rate of the mine is mainly affected by creep closure. There is a negligible affect from thermal warming of the oil which is decreasing with time as the oil approaches the in-situ temperature of the salt. (The thermal effect on oil was never large at Weeks Island due to the cool, approximately $80^{\circ} \mathrm{F}$, ambient temperature of the salt surrounding the storage chamber.) The inflow of water into the mine at its currently concluded rate of somewhat over $100 \mathrm{gph}$ is marginally detectable via current mine pressurization data. If the mine is assumed to be closing at about 160,000 barrels per year, the mine volume is changing by approximately 750 gallons per hour. If it is assumed that data uncertainty is at least $10 \%$, then brine inflows of less than 75 gallons per hour could not be identified by changes in the volume loss rate alone. This subject is discussed more fully in 2.2.2 Mine Pressurization, above.

\subsubsection{Other Possible Indicators of Water Entry}

During the very early stages of investigation of the sinkhole, it had been suggested that inflow may be detected by monitoring changes in ground water piezometric head around the sinkhole. This suggestion was investigated by the SPR in two studies in 1993. The first study implied that it may be possible to monitor inflow into the oil storage chamber using a system of piezometers (McHenry, 1993). A second study which assumed implied permeabilities from the earlier Acres work in the low Darcy range implied that monitoring inflow into the oil storage was not possible (Ehgartner, 1993).

During the recent seismic and diagnostic drilling investigation, information was obtained that indicated directly that the water table was depressed in the sinkhole area. If confirmed, this provides a future technique for detection of incipient sinkholes or monitoring existing sinkholes. A part of the follow on diagnostic program includes piezometer installation in areas near the sinkhole and areas remote from the sinkhole. 


\subsection{POSSIBLE SCENARIOS}

\subsubsection{Model Development}

In late summer of 1993 Ehgartner at SNL completed simulations of mine development at Weeks Island that showed tensile stresses sufficient to crack salt would have developed over the mine edges in the 1970 time frame (Ehgartner, 1993) (see Figures 7-11). At the end of that decade, some 10 years later, leaks were encountered during the driveage of the "Wet Drif," at a location coincident with the high stress regions in the Ehgartner report. This occurrence is noted and may be significant because there was never general agreement on the specific cause of the Wet Drift leaks. However, that route was abandoned and an alternate approach to the interim Markel Mine was established. Ehgartner's calculations represent recent understanding of salt and have validity because of their background development over a number of years, and also because the resulting subsidence predictions correlate very well with measured survey data. Rather than showing previous factors of three variance between predictions and measured values, the new subsidence predictions easily fall within the range of actual values. More detailed 3-D finite element analyses by Hoffman (Hoffman, 1994) confirm the prediction of a tensile zone near the top of salt over the mine boundaries when the upper and lower level boundaries are vertically aligned. At Weeks Island this occurs on the South and West boundaries. This vertical alignment condition results in more abrupt flexure as the salt creeps, and thus the tensile zone. Additionally, a dilatant zone which grows with time is predicted to form in the salt. As noted above, the sinkhole and Wet Drift both formed over vertically aligned boundaries of the mine within time frames predicted. A conceptual diagram of possible crack development is shown in Figure 3. The deepening with time of a single crack is shown in the vicinity of the mine edge. A single crack is depicted because once the stress field is disrupted, there is no reason for other cracks to form. The drilling program was successful in locating one major crevasse at a depth 72 feet below the top of salt, probably a crack enlarged by dissolutioning. The crosswell seismic work identified a major low velocity region within the salt and extending downward. Weather there actually only a single dissolution feature of multiple features has not been ascertained. The known dissolution feature is sand or sediment filled thus, as modeling indicates, limiting the flow through the solutioned volume. Ehgartner did model solutioning within an open crack in salt, in a hydrologic regime similar to Weeks Island. This work concluded that a leak through an open crack in salt which does not fill with granular material goes uncontrolled within days.

Russo (Russo, 1994, Appendix 2) further modeled the situation whereby the crack (modeled as an equivalent round hole) continually fills with overburden material with a definable permeability. The flow and further salt dissolution are subsequently reduced, and the leak continues to enlarge for many years before becoming uncontrollable. Most important from this work is the confirmation that water inflow into the mine, through a crack(s) caused by the overall mine closure, has probably been occurring for a significant period of time ( 3 to 10 years) albeit at very low levels. (Although not directly confirmable, this is directly supported by the fillhole brine discovery and long term inflow.) 


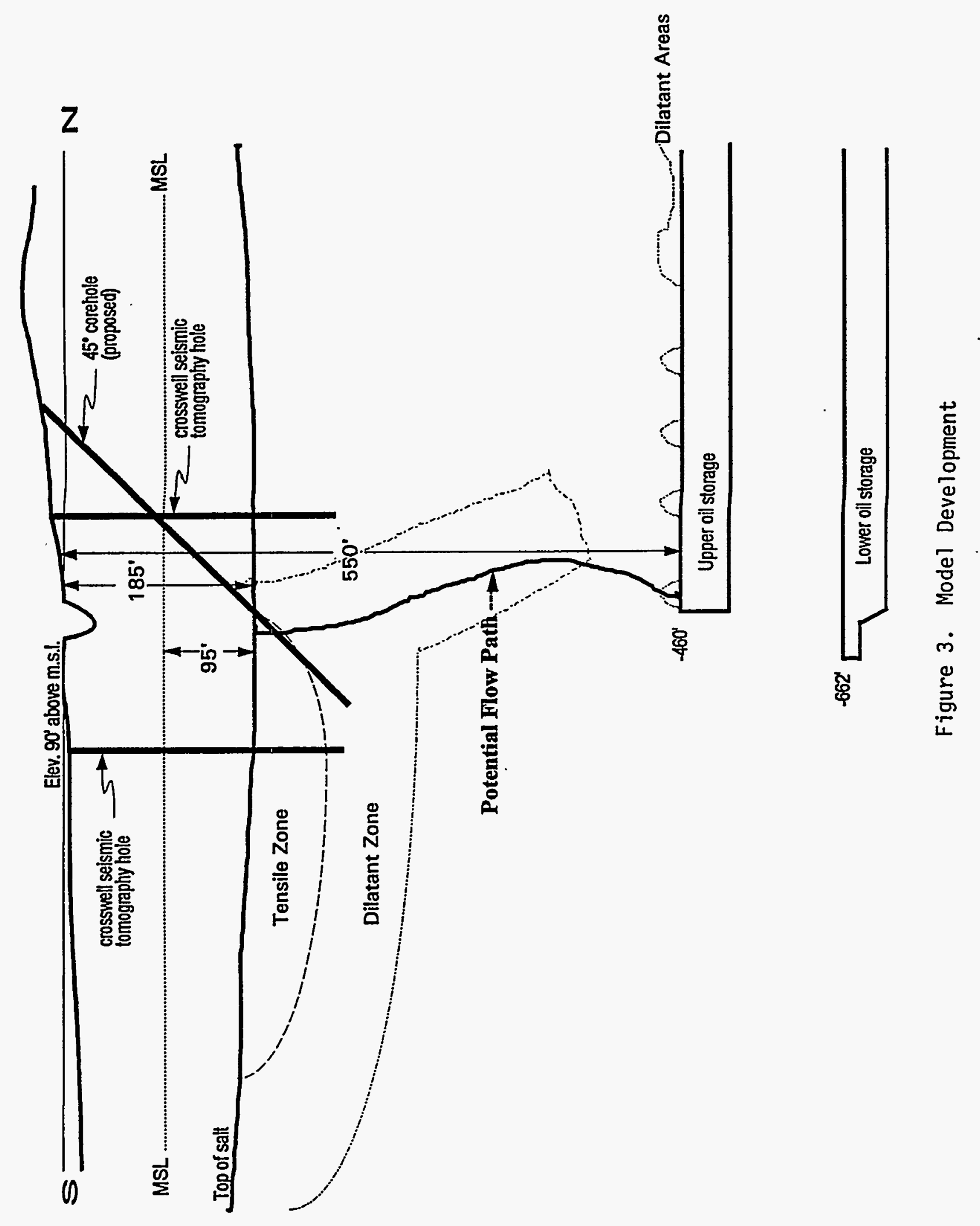


Russo's model predicts that any current inflow would increase 10 fold within five years. If the volume of the sinkhole were assumed to be an indication of the total volume of salt dissolved within the crack at this point in time, the average equivalent radius of the crack as modeled is now somewhat under two feet at a current inflow in the $120 \mathrm{gph}$ range.

\subsection{CURRENT DIAGNOSTIC ACTIONS}

\subsubsection{Geologic Characterization}

Geologic characterization during the diagnostic work at Weeks island consisted primarily of coring, core description and geologic interpretations of data. Six boreholes (Figure 4) were drilled for multiple purposes: (1) to establish geotechnical understanding of the area around the sinkhole and identify the reflecting horizon noted on the seismic reflection profiles; (2) to establish the crosswell configuration wherein seismic tomography could image the sinkhole; (3) to establish locations for hydrocarbon vapor sensing and/or tracer dye introduction, and (4) direct observations of sinkhole geometry and material properties, such as fracturing in salt. Core descriptions made on site are contained in Appendix 3.

BH6 was drilled first and continuous core was sought to establish the normal sedimentary section at the sinkhole. The core obtained in BH6 was generally continuous, but overall recovery was incomplete, amounting to about $25 \%$ of the total section down to $175 \mathrm{ft}$. At that depth the drill pipe stuck and no additional material was obtained until washover operations freed the pipe and coring reconvened (Appendix 3). Samples taken in subsequent boreholes were extracted from the fluid returns by bucket settling, thus some fine material was probably washed out of the sample.

The sedimentary sections on top of salt are predominantly ancestral Mississippi River sands of medium $(\sim 1 \mathrm{~mm})$ grain size, and relatively low content of fine material. Occasional gravel fragments or lenses were noted, but none were more than a few inches thick or laterally consistent, suggesting they are flood deposits. Limonitic stains outlined faint bedding planes in $\mathrm{BH} 6$, but other distinctive features or sedimentary structures were not noted, until approaching the sediment/salt transition. The sediment/salt boundary was characterized by a zone of black wood fragments up to several feet thick. The fragments were sufficiently dense (presumably brine saturated) that they readily sank in water. This wood is thought to be of Wisconsinan age, probably representing back swamp forest along the ancestral river environment.

The top of salt was at or very nearly at $-104 \mathrm{ft}$ msl in five of the six boreholes; all five intersections were within $100 \mathrm{ft}$ from the center of the sinkhole. The drilled depth to top of salt corresponded almost exactly with that interpolated from Acres (1987), i. e., $185 \mathrm{ft}$ below the surface. No evidence of fracturing was noted in any of the holes, but the salt was uniformly soft, wet, and rather crumbly. High angle banding or other essentially vertical structure in the salt was not noted. Of the five holes that were cored, only $\mathrm{BH} 3$ provided reasonably competent salt and good core quality, even though it was also soft. $\mathrm{BH} 5$ core was entirely disaggregated, and $\mathrm{BH} 4$ and $\mathrm{BH} 6$ showed substantial disking and broken core. $\mathrm{BH7a}$ core was smaller in diameter, and although had $100 \%$ recovery, was

sufficiently soft that it could not be handled without breaking. Salt was generally 

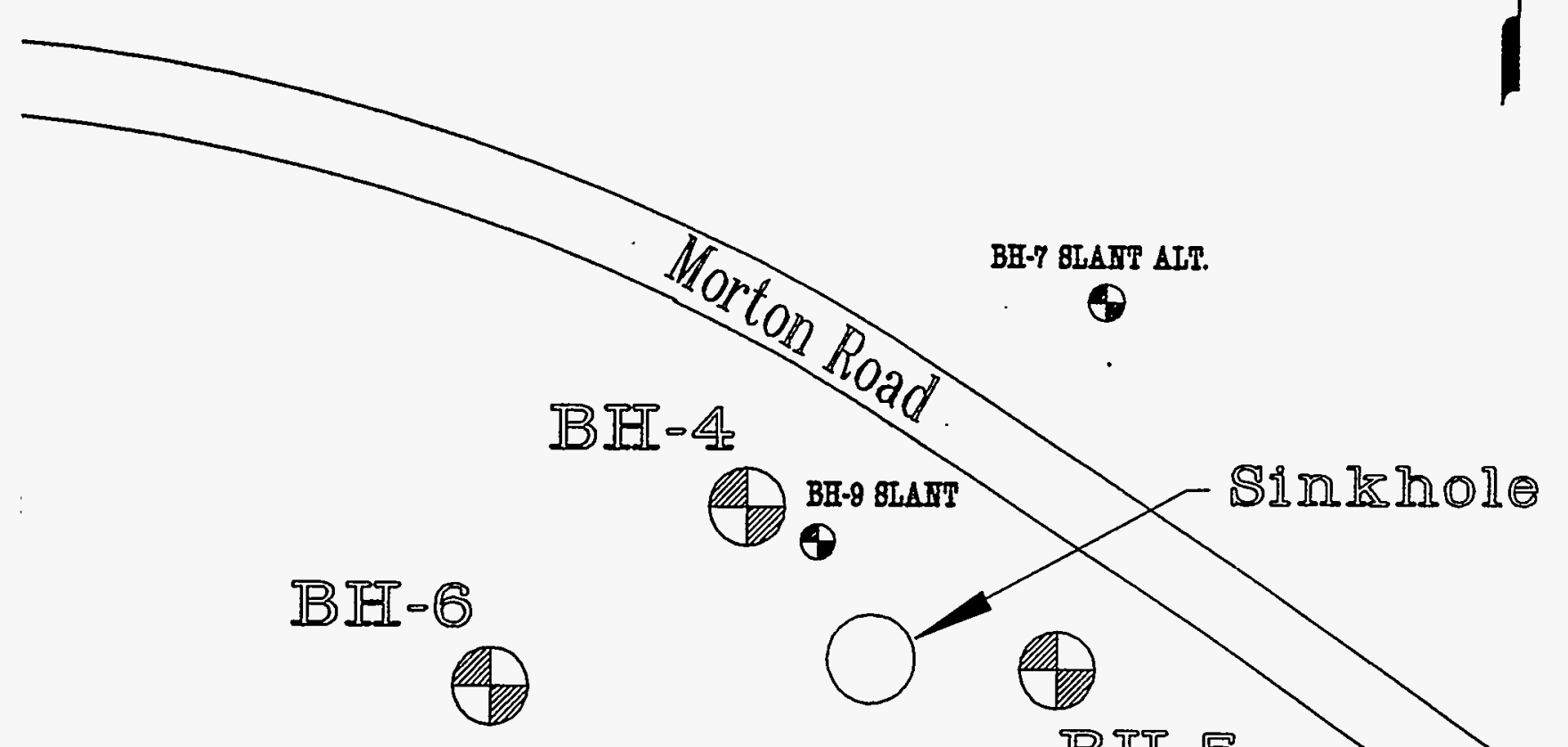

BH-7 8LAET ALT.

的近 4
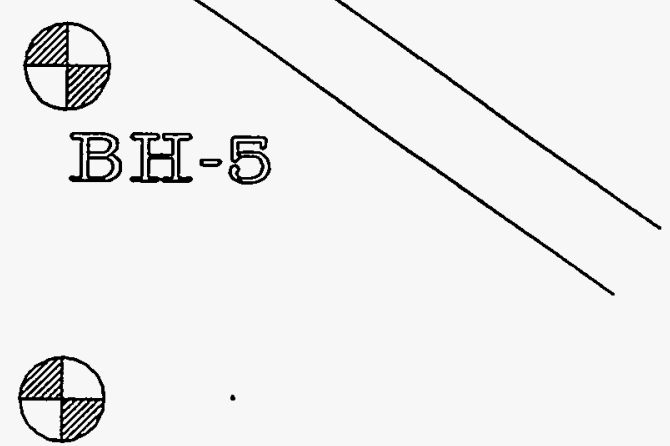

BIE[-3

Scale

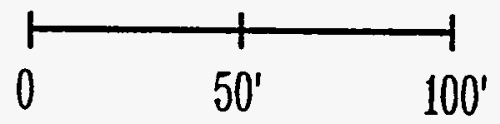

Figure 4. Map showing relative location of Weeks Island sinkhole and boreholes drilled. 
uniformly granular, with crystal size about $1-1.5 \mathrm{~cm}$. Salt was usually very wet and this probably resulted from the saturated brine drilling fluid.

Boreholes $\mathrm{BH} 3,4,5$, \& 6 were constructed primarily for the purpose of providing a test bed for crosswell tomography, but they also provided salt core and top of salt information described above. They also outlined in general the sinkhole geometry by narrowing its areal extent within the boreholes, and they provided limited data on static water levels. They may still be used for hydrologic observations, or for additional geophysics.

Angled borehole BH9 encountered disturbed sand at depths below the elevation of the top of salt in the other boreholes. This sand was judged to be Prairie formation, and not the sand used as sinkhole fill (Appendix 4). As this point at depth was only $8 \mathrm{ft}$ from the sinkhole center, it is likely that the hole bottomed in the dissolution feature. Angled borehole BH7a entered salt outside the dissolution zone and penetrated salt for another 60 feet vertically. At 250 vertical feet, or $-161 \mathrm{ft} \mathrm{msl}$, the drill bit entered an apparent sandfilled dissolution crevasse. The drill bit eventually extended another 16 feet (angled), taking it 4.5 feet from the sinkhole center. The opposite side of the crevasse was not reached. The sand encountered in this crevasse, at least $72 \mathrm{ft}$ below the top of the salt, was similar to sand recovered from BH6. This saturated-sand environment provided the opportunity for installation of the Sandia in situ hydrological flowmeter (Appendix 9).

The geological evidence suggests the sinkhole structure is quite vertical, based on surface features, the continued strong downward motion of fill sand and the surface monitoring pipe, and the essentially vertical continuity observed in $\mathrm{BH} 7 \mathrm{a}$. This vertical structure may continue on downward for substantial depth. However, the geometry below $-175 \mathrm{ft}$ is unknown and must be surmised to some extent, based on calculations and hydrological evidence.

\subsubsection{Surface Geophysics}

Historically, high-resolution seismic reflection surveys at shallow depths $(<1000$ feet) over salt bodies have been accomplished at numerous locations. They have met with mixed results, presumably because of the continuity and velocity contrast of principal subsurface reflectors (Neal et al., 1993).

Miller (Miller et al., 1993) conducted shallow reflection surveys of a salt dissolution well field near Hutchinson, KS, and was able to image collapse features at depths of 200 to 250 feet, similar in geometry to the potential voids at Weeks Island. Using similar methods, Miller and Steeples from the Kansas Geological Survey acquired similar data at Weeks Island in March 1994.

This seismic reflection survey was designed to detect and delineate geologic or hydrologic features associated with the Weeks Island sinkhole. The details of this study are contained in Appendix 5 and are summarized here. Some 6000 linear feet of seismic reflection data were gathered along 4 profile lines, each approximately 1500 feet in length and centered in the sinkhole area. Geophones and seismic cables were placed along these lines to record reflected seismic signals from the seismic source. The reflected energy was recorded, processed, and.used to construct profiles showing the nature of subsurface materials. The field recording parameters and quality control were based on the reflection interpreted during walkaway tests to be from a reflector about $150 \mathrm{ft}$ deep. This coherent 
reflection event interpretable on all four lines is altered on the east/west line in the proximity of the sinkhole. An offset in the prominent reflection interpretable on all four lines traces a southwest/northeast trend across the study area.

The disturbed reflection on the east/west line, presumed associated with the sinkhole, structurally resembles a chimney type feature or may be associated with the water table.

\subsubsection{Borehole Seismic Survey}

Crosswell seismic tomography is similar in some respects to medical tomography, except that in the latter x-rays are used to construct computer-derived images of internal organs and structures. Seismic tomography depends on sonic and impulse sources, and on the ability to access the subject of interest through boreholes. The construction of images is accomplished through the processing of the seismic velocity data obtained through the region of interest, i. e., between the boreholes. The determination of discontinuities between source and geophone result in seismic images that may show dissolution and/or karst structure in the salt.

In June 1994, on a radius surrounding the sinkhole, four steel-cased holes (6" I.D. minimum casing is required for the seismic tools) were constructed to obtain seismic images across the subsurface geometry of the sinkhole (Figure 4, showing location of holes and drillpads relative to the sinkhole). The cased holes were used for locating a seismic source (an airgun or non-explosive impulse device) and recording geophones in opposite holes, respectively.

The primary purpose of the borehole seismic survey (For detail please see Appendix 6.) was to provide seismic images of dissolution features in the salt beneath the sinkhole area. Important secondary goals were to identify the seismic reflector imaged at the site by the Kansas Geological Survey earlier this year (Appendix 5), and to image water table drawdown, and any other features related to subsurface collapse and/or anomalous fluid flow related to the sinkhole.

Seismic data acquisition at the site was designed to provide the raw data for crosswell seismic tomograms, vertical seismic profiles (VSP), and crosswell reflection images. At this time, two preliminary crosswell seismic velocity tomograms of the salt and a preliminary single-well vertical seismic profile have been processed. The data acquisition and processing procedures used in generating the tomography and VSP images are described briefly below.

Crosswell tomography: The raw data for crosswell seismic velocity tomography consists of the observed travel times of seismic waves which propagate from multiple energy source positions in one borehole to multiple receiver positions in another borehole. Crosswell seismic data were recorded in two borehole pairs at the sinkhole site, $\mathrm{BH} 4$ to BH3, and BH5 to BH6 (Figure 1, Appendix 6). The imaging planes between these borehole pairs are roughly perpendicular to each other, and intersect at the center of the 'sinkhole. During the crosswell survey at the sinkhole site, source and receiver depths ranged from 5 to 230 feet.

In crosswell seismic tomography processing the planar area between the two boreholes is divided into polygons called "pixels", and the seismic P wave velocity in each 
pixel is computed from the first arrival travel time observations by a tomographic imaging algorithm. The 2-D display of seismic velocities within the pixels is called a "tomogram". Travel time picking and tomogram processing was performed on site, as the crosswell data were acquired.

The $P$ wave velocity in saturated undisturbed soil at the site is approximately 6,100 feet/second, while salt velocity ranges from 12,000 to $14,000 \mathrm{feet} / \mathrm{second}$. It is expected that salt dissolution "cavities" filled with disturbed saturated soil would cause observable low velocity anomalies in the crosswell seismic tomograms. Figures 2 and 3 (Appendix 6) are the preliminary $\mathbf{P}$ wave velocity tomograms for the borehole pairs $\mathrm{BH} 3$ and $\mathrm{BH} 4$, and BH5 and BH6, respectively. These tomograms show only the depth range from 170 to 230 feet below ground surface, and were processed to emphasize imaging within the salt. Source depths from ground surface to 230 feet, and receiver depths from 90 to 230 feet were used in generating these images. Seismic velocities are color coded with the highest velocities in red and yellow and the lowest velocities in blue and green.

Both tomograms clearly display substantial low velocity features which presumably are due to salt dissolution. The shallowest low velocity anomaly in the BH5/BH6 tomogram intersects the top of the salt more or less directly beneath the sinkhole. In the $\mathrm{BH} 3 / \mathrm{BH} 4$ tomogram the shallowest velocity anomaly is centered about 17 feet south of the sinkhole centerline (toward $\mathrm{BH} 3$ ). The low velocity features on both tomograms trend southward with increasing depth, and show a generally irregular or complex spatial distribution. Drawing a quantitative relationship between tomogram velocity and the boundaries of the salt dissolution surface is difficult at present since a continuum of velocities from about $9,000 \mathrm{ft} / \mathrm{sec}$ to $12,000 \mathrm{ft} / \mathrm{sec}$ is present in the tomograms. In general the vertical resolution of velocity tomography is superior to the lateral resolution. One approach to using the tomography images to guide placement of grout injection wells would be to drill the center of the anomaly first, to verify the existence and vertical extent of the dissolution cavities. By placing subsequent wells toward the edges of the anomaly, until the edge of dissolution is detected, the correspondence between seismic velocity and the lateral extent of the dissolution cavity can be established.

The reduction of crosswell seismic tomography data (Appendix 6) is still in progress, however the following preliminary results have been obtained: (1) there is a lower-velocity zone below the sinkhole which implies the presence of a sediment filled dissolution feature, and (2) evidence of the implied water table deflection below the sinkhole observed in the surface seismic and well measurements is substantiated.

Vertical Seismic Profile (VSP): Raw data for a VSP were acquired in borehole BH5 by using a 20 cubic inch airgun deployed at the surface as the seismic energy source (Figure 4, Appendix 6). This seismic source provided ample energy for observing first arrival and reflected events. Shot records were taken with the borehole receivers placed at 2.5 vertical intervals from 5 to 230 feet below ground surface. With this recording geometry it was possible to construct a time-depth table (Figure 5, Appendix 6) which shows the vertical seismic (one-way) travel time from ground surface for each receiver depth. This information is useful for converting surface reflection two-way times to depth.

After wavefield separation and filtering of the VSP image (Figure 6, Appendix 6), two up going reflected events are clearly visible. The depths of the two reflecting 


\subsubsection{Surface Self Potential Survey}

The primary purpose of the self potential (SP) survey was to establish whether this technique could provide a rapid and relatively inexpensive means of locating water table drawdown features related to sinkhole development. This technique is the only geophysical surveying method in which the signal response is derived primarily from groundwater movement. In this application, SP surveying is based on the streaming potential effect, in which a DC electric field is established by fluid flow through permeable soil and rock.

Based on details provided in Appendix 11, the following observations are warranted:

(1) SP data quality were generally good over the roughly 9,000 feet of data acquired. Although significant cultural noise was present within the surveyed area, standard potential field data analysis techniques were sufficient to separate signal from the noise.

(2) The data analysis indicates significant streaming potentials (100 mV peak-to-peak) in the area of the sinkhole and the two seismic anomalies north of Morton Road.

(3) Matching synthetic data with the observed SP field indicates that the anomalous streaming potentials are likely to result from vertical fluid flow along a set of vertical or near-vertical planar surfaces, probably shear zones or faults.

(4) At the sinkhole site, the depth to the field source is very shallow (about 5 feet), indicating probable vadose zone flow. North of Morton Road, close to the seismic anomalies, the top of the field source appears to coincide roughly with the water table depth (90 feet).

These findings are consistent with the results obtained from surface seismic and other geotechnical data.

\subsubsection{Stable Isotope Constraints on the Origin of Brine}

There is a small amount of the heavier stable isotope of oxygen $\left({ }^{18} \mathrm{O}\right)$ and hydrogen (D, deuterium) in all natural waters. The amounts of these isotopes in water samples are highly variable and depend upon the source and history of the water. In effect, the stable isotopes can often be used as natural tracers to understand the source(s) of mine leaks, aquifer contamination, and other problems involving surface-ground water interactions.

The brine in the fill holes has been has been studied for isotopic amounts since 1987. The results of this study are detailed in Appendix 14 and are summarized here. From 1987 to 1990 the data evolved steadily toward more ${ }^{18} \mathrm{O}$ - and D-depleted values. From 1992 to 1993 , the data became more D-rich as ${ }^{18} \mathrm{O}$ continued to decrease. The current trajectory is directly toward the values of the overlying aquifer (as sampled in the well over the fill-holes and Morton Salt Co Well \#7). The data provide evidence implying that external water has been leaking into the facility since at least March, 1992. 
east of the sinkhole; these two observed high-gas regions may be indicative of the subsurface anomalous Shear Zone E. Along discontinuous segments of Transects $F$ and $F^{\prime}$, north of Morton Rd., somewhat east of the sinkhole; data observations provide a weak correlation with observed seismic lows in the vicinity. Just north of the fill hole area; and, directly above the buried SPR pipeline. Correlation of any of the high gas zones directly with the sinkhole is difficult. The high gas zones do apparently correspond well to one or more of the notable seismic features and/or surface indications of subsurface geologic anomalies.

The gas mapping survey did not find a direct, gas-release pathway from the SPR oil to the immediate vicinity of, or in, the sinkhole. Our original assumptions that the sinkhole was functioning as a direct chimney vent to funnel gases to the surface through a presumed fracture network and could be detected by means of gas mapping, has not proven to be conclusive with the available gas data. It is possible that other factors occurring at the Weeks Island site, e.g., downward and lateral flow of groundwater in the sinkhole vicinity may have perturbed gas seepage patterns enough to mask a conclusive result. Further sampling in concentric patterns about the immediate sinkhole in the vicinity might resolve the uncertainties.

Observed patterns of the gas seeps, in conjunction with or in comparison to the geophysical diagnostic work at Weeks Island and results, suggest -- but not definitively -a structural control associated with fracture development processes. Fracture permeability may be associated within and near any of the mapped geologic anomalous zones. It is possible that the patterns generated by the gas mapping survey data are surrogates of the overburden fracture pattern(s) produced by stresses that created the sinkhole.

Further substantiation of the above interpretations and conclusions could potentially be obtained by a somewhat expanded near-surface gas mapping program -particularly by using the enhanced analytical equipment and techniques implemented near the end of the current survey.

The opportunity to obtain down hole brine and gas samples from the bottom of the slant hole in salt, in the vicinity of the sinkhole, did not present itself. These samples could not be obtained due to the early injection of dye into the bottom of the slant hole.

Based on the evaluations, it is not planned to proceed with gas analyses from drilling returns, nor downhole positive pressure gas permeability tests. Planned laboratory tests on salt cores obtained will probably provide more benefit to the SPR Project.

\subsubsection{Downhole Flow Measurements}

An In Situ Permeable Flow Sensor was emplaced into borehole BH7a to measure the direction and magnitude of the groundwater flow velocity in the throat of the sinkhole. The details of this study are contained in Appendix 9 and are summarized here. The goal of this effort was to help distinguish between two competing hypotheses regarding the significance of the sinkhole. One hypothesis is that the sinkhole is part of a fissure or topographic canyon in the top of the salt which is carrying water horizontally off the top of the dome. The other possibility is that there exists a hydrologic connection between fresh water above the salt and the petroleum reserve. Measurements of groundwater flow directly in the conduit, below the top of the salt, can help to resolve this issue. If predominantly horizontal flow is observed then flow of water off the salt dome is probable 
whereas if predominantly downwardly directed flow is detected then flow into the reserve is likely.

In Situ Permeable Flow Sensors are new, Sandia-developed instruments which use a thermal perturbation technique to directly measure the magnitude and direction of the full three dimensional groundwater flow velocity vector characteristic of an approximately $1 \mathrm{~m}^{3}$ volume of the subsurface (Ballard et al., 1994).

The basic principle of operation is to bury a long thin heated cylinder with an array of surface mounted temperature sensors in direct contact with the formation at the point where the flow velocity measurement is to be made. The heat emanating from the probe warms the ground and the water surrounding the instrument. In the absence of any flow past the device, the temperature distribution on the surface of the cylinder will be independent of azimuthal position on the probe and symmetric about the vertical midpoint on the probe. The ends of the probe will be cooler than the vertical midpoint because heat transfer away from the ends of a finite length heated cylinder is more efficient than from the midsection. If there is flow past the device then the heat emanating from the surface of the probe will be advected around the device by the flowing water with the result that the probe will be somewhat cooler overall than when there is no flow and the upstream side of the probe will be cooler than the downstream side.

Figure 2 (Appendix 9) shows the temperatures measured by the 30 temperature sensors on the surface of the probe as a function of time. Before activation of the heater, the temperature of the subsurface was approximately $23{ }^{\circ} \mathrm{C}$. When the heater was activated, the temperature of the surface of the probe increased dramatically with the temperature at some locations increasing much more than at other locations. After a day, the temperature of the probe continued to increase even though the power output of the heater remained constant. In addition, the spread of temperatures decreased with time. Figure 3 (Appendix 9) illustrates the vertical temperature distribution on the surface of the probe as a function of time. Each curve in Figure 3 (Appendix 9) shows the temperature distribution on a different day. The most important feature to note is that throughout the time that measurements were made, the top of the probe was relatively cool and the bottom of the probe relatively warm, indicating that the heat emanating from the probe was being advected downward by groundwater flowing vertically downward past the probe. A small component of flow oriented in a direction perpendicular to the long axis of the probe was also observed but is consistent with the fact that probe was not oriented vertically in the ground. The temperature distribution is unambiguous; large, downwardly directed flow with insignificant horizontal flow was observed. The fact that the probe increased in temperature and the vertical temperature distribution became more symmetric with time indicates that the downward flow velocity decreased in magnitude significantly during the course of the measurement period.

Figure 4 (Appendix 9) illustrates the magnitude of the downwardly directed flow velocity as a function of time. At first the magnitude of the flow was around 4 feet/day. The flow decreased rapidly at first but appeared to be leveling off at about 0.5 to 1.0 $\mathrm{ft} /$ day by the end of the data collection period. The permeability around the probe decreased during the two week measurement period due to the dynamic nature of the fluid conditions or possibly the disturbed nature of the sand in the vicinity of the sand in the conduit. Please see Appendix 9 for a detailed discussion. 
Another observation is that the flow sensor was apparently being carried downhole by sand flowing downward in the conduit. As previously mentioned, the probe was connected to the surface by 1 inch diameter PVC pipe. Figure 5 (Appendix 9) shows the downward displacement of the top of this pipe as a function of time. The data indicate that the pipe was being carried into the hole at a rate of $1 \mathrm{inch} /$ day. A second flow sensor, which was emplaced in borehole BH9 at a depth of approximately 180 feet below the sinkhole, is also being carried downhole at a rate of $1 \mathrm{inch} /$ day. At the time of this writing, no groundwater flow velocity data has yet been obtained from this probe. There is also a pipe which was inserted directly into the sinkhole at the ground surface and the bottom of which is now at a depth of approximately 85 feet. The pipe is also moving downward at about 1 inch/day (Dick Berry, pers. comm.). Altogether there are three observation points at depths of 85,180 and 250 below ground surface where downward flow of sand of about 1 inch/day has been observed.

The downward groundwater flow observed in BH7a strongly suggests that groundwater is leaking into the oil repository. The alternative explanation, that the sinkhole is connected to a channel in the top of salt where water is flow off the dome would seem to require horizontal flow; only vertical flow was observed.

The observation that sand is flowing downward at a similar rate at depths of 85 , 180 and 250 below the surface suggests that the cross sectional area of the conduit is reasonably constant down to at least 250 feet depth.

\subsubsection{Dye Injection}

Rembco Engineering Corporation, under contract to DynMcDermott Petroleum Operations Company, injected dyed tracer dye into boreholes BH7a and BH9 during June and July 1994. The dye injection was performed to establish irrefutable proof of a hydrologic connection between the oil storage chamber and the overlying aquifer.

The basic procedure for injection of dye into the sinkhole dissolution zone was to mix a $10 \%$ concentration of Rhodamine WT in saturated brine on the surface. This concentration is the highest concentration achievable. The dye was then pumped down the borehole, using a tremie tube, while monitoring the brine level in the well casing to ensure that injection pressures are kept low. Actual procedures used are in Appendix 10.

Attempts at injecting dye into the bore of borehole $\mathrm{BH} 9$ resulted in a backflow of brine in the annulus of the well casing. The tremie tube was jetted into the formation to improve dye intake. A total of 2,000 gallons of dye saturated brine were injected at $5 \mathrm{gpm}$ using this procedure. Samples of brine are being taken from the fill hole sump on a daily basis for analysis for Rhodamine WT.

No tracer dye has yet been identified in the fill hole sump to this date. It is difficult to estimate transit time for water/dye once it enters the mine given the many potentially tortuous paths that are possible.

The possibility that the dye has a preference for dispersion in oil has been examined and is apparently not a factor. Oil sampling could be started but the lack of oil circulation in the mine may result in a very long time until diffusion places a detectable amount of dye under the service shaft. 


\subsubsection{Surface Self Potential Survey}

The primary purpose of the self potential (SP) survey was to establish whether this technique could provide a rapid and relatively inexpensive means of locating water table drawdown features related to sinkhole development. This technique is the only geophysical surveying method in which the signal response is derived primarily from groundwater movement. In this application, SP surveying is based on the streaming potential effect, in which a DC electric field is established by fluid flow through permeable soil and rock.

Based on details provided in Appendix 11, the following observations are warranted:

(1) SP data quality were generally good over the roughly 9,000 feet of data acquired. Although significant cultural noise was present within the surveyed area, standard potential field data analysis techniques were sufficient to separate signal from the noise.

(2) The data analysis indicates significant streaming potentials (100 mV peak-to-peak) in the area of the sinkhole and the two seismic anomalies north of Morton Road.

(3) Matching synthetic data with the observed SP field indicates that the anomalous streaming potentials are likely to result from vertical fluid flow along a set of vertical or near-vertical planar surfaces, probably shear zones or faults.

(4) At the sinkhole site, the depth to the field source is very shallow (about 5 feet), indicating probable vadose zone flow. North of Morton Road, close to the seismic anomalies, the top of the field source appears to coincide roughly with the water table depth ( 90 feet).

These findings are consistent with the results obtained from surface seismic and other geotechnical data.

\subsubsection{Stable Isotope Constraints on the Origin of Brine}

There is a small amount of the heavier stable isotope of oxygen $\left({ }^{18} \mathrm{O}\right)$ and hydrogen (D, deuterium) in all natural waters. The amounts of these isotopes in water samples are highly variable and depend upon the source and history of the water. In effect, the stable isotopes can often be used as natural tracers to understand the source(s) of mine leaks, aquifer contamination, and other problems involving surface-ground water interactions.

The brine in the fill holes has been has been studied for isotopic amounts since 1987. The results of this study are detailed in Appendix 14 and are summarized here. From 1987 to 1990 the data evolved steadily toward more ${ }^{18} \mathrm{O}$ - and D- depleted values. From 1992 to 1993, the data became more D-rich as ${ }^{18} \mathrm{O}$ continued to decrease. The current trajectory is directly toward the values of the overlying aquifer (as sampled in the well over the fill-holes and Morton Salt Co Well \#7). The data provide evidence implying that external water has been leaking into the facility since at least March, 1992. 


\subsubsection{Brine Injection and Sinkhole Monitoring}

In March of 1994 a monument was established in the sinkhole. The elevation and positioning of that monument and subsequent additions to it have been monitored continuously since. Also in March, the sinkhole was filled with sand, and has been continuously refilled on an as needed basis. Beginning in August of 1994, saturated brine has been introduced into the crevasse below the sinkhole through the bottom of BH7a at rates of 2-3 gpm. There was a coincidence between introduction of brine and cessation of the need to backfill the sinkhole (and downward displacement of the monument). This indicates a possible cause and effect relationship. The introduction of brine into the crevasse has decreased the potential for leaching of salt leading into the mine. Presumably it is the leaching and removal of salt which is being infilled by sediment, and subsequently replaced at the surface as backfill. A tablification of the results of the monitoring, backfilling, and brine injection are contained in Appendix 15.

\subsection{ADDITIONAL DIAGNOSTIC ACTIONS}

\subsubsection{Inspection for Other Sinkholes}

In December, 1993, Sandia and DynMcDermott personnel scouted a portion of the surface overlying the perimeter of the mine. During this inspection, no additional sinkholes were discovered. A more detailed survey of the entire perimeter of the mine may be required. Such an inspection would have the purpose of determining the existence of other sinkholes to be identified as possible targets for future grouting and for partial verification of the modeling which indicates that sinkhole formation is likely over the mine perimeter. The inspections should be made on some routine basis in the future to determine if new sinkholes are developing.

A major problem with surface inspection for sinkholes is maintaining orientation of the search crews through the thick underbrush. This problem will overcome shortly by establishing monuments over the corners of the mine and intervals along the perimeter. Clearing of the thick underbrush may be eventually accomplished. Use of a portable LORAN system could also provide better orientation for personnel making the surface inspection. Current systems provide positioning within about 25 to 50 feet if properly initiated.

\subsubsection{Markel Mine Inspection}

The original Weeks Island Risk Assessment Study (Beasley et al., 1985) identified the Markel Mine as posing a major risk which could jeopardize oil storage and withdrawal. The study recommended monthly inspection of the Markel Mine as well as a dimensional survey of the structure.

The recommendations of the risk assessment study were later followed by Risk Abatement Committee recommendations to build isolation bulkheads in the Johnston and Sandrik Drifts which included access doors for Mine inspection. It was further agreed that inspection of the Markel Mine should be performed quarterly. 
The isolation bulkheads have been completed for more than a year with the isolation doors still open. The doors need to be closed to assure complete mitigation of the risk associated with the Markel Mine serving as a large reservoir for water that may flood the DOE facility as a result of a shaft failure. A standing recommendation to close the doors by the Risk Abatement Committee currently exists.

Inspection of the Markel Mine was suspended in 1989 due to safety concerns. These safety concerns were a topic of discussion until October 1992 when the mine safety was assessed by the Mine Safety and Health Administration (MSHA). MSHA found that the mine, as is, was unsafe for human access and concluded their inspection by questioning the stability of the mine structure. No further inspections of the Markel Mine were made pending a decision to perform maintenance of the mine.

The risk associated with the Markel Mine has recently become an issue as a result of the MSHA concerns on the mine stability. Continuing studies by the SPR indicate that the probability of pillar failure in the Markel may be higher than assessed earlier, and that such failure may result in inflow into the Markel mine. The studies identify that there is risk to the Morton Mine due to the proximity of the Morton Production Shaft to the Markel Mine.

In conclusion, the Markel Mine poses a real risk to the Morton Mine and, to some extent, to the DOE Oil Storage. Based upon this risk, inspections and the necessary maintenance to accomplish such inspections on a quarterly basis, need to be initiated. Additionally, some action is necessary to develop a grouting plan for the Markel Mine and to insure that equipment capable of drilling and grouting in the Markel Mine is available. 


\section{PREVENTATIVE AND MITIGATIVE OPTIONS}

\subsection{MINE PRESSURIZATION}

With the development of a sinkhole and diagnosed leak, increasing the pressure within the mine to a level somewhat below the hydrostatic pressure will reduce or delay the possibility of future leak development, reduce the rate of solutioning of a possible existing leak(s), and minimize the consequences of a leak. Operating the mine at a significantly increased pressure, however, will require a safety analysis to ensure that it can be safely operated from personnel and equipment perspectives.

In July 1994, slightly over $800 \mathrm{kbbl}$ of oil were transferred into the mine over a two week period. The reported inflow rate decreased from $127 \mathrm{bbl} /$ day to $103 \mathrm{bbl} /$ day, confirming the anticipated inflow rate response to mine pressurization. Ostensen has analyzed the anticipated benefits of mine pressurization assuming various crack orientations or geometries. Most important is the conclusion that mine pressures (at the mine roof below the sinkhole) will have to be in excess of 180 psi for oil to escape from the salt. The time dependence of oil movement upward through the leak in the event of mine pressurization has also been analyzed. It is significant that even under a full hydrostatic head pressurization, it requires several months for oil to permeate upward through the sediments filling the leak path before oil could be lost to the environment.

Increased pressure in the storage chamber also improves the ongoing monitoring of integrity of the facility. With increased pressure, the existing inert gas pockets becomes smaller and less compressible, and therefore not as readily mask minor pressure changes that would result from small quantities of water leaking into the mine. The effect of the recent oil transfer is still being analyzed as to how much improved is the leak detection and water inflow monitoring capability using mine pressure.

The mine could be converted to operate as a pressurized cavern, similar to the way the solution mined caverns are operated if the leak can be plugged. This would require a large volume brine source and brine disposal capability which would be used for any oil withdrawal and refill of the pressurized mine. It might require that the manifold room as it now exists be abandoned. In such case, a new means of controlling flow from the mine would be required, such as control valves on the surface.

An alternative, but less desirable, method of achieving some of the benefit of operating the mine at an increased pressure would be to maintain the high pressure only during the drawdown readiness mode. The mine would be depressurized either prior to or at the start of oil movements for exercises or drawdown. In order to minimize pressure fluctuations and salt stability problems in the mine, exercises would have to be limited if the mine is to be operated at an elevated pressure. This approach requires minimal new facilities be installed at the site as the present drawdown system would continue to be usable as long as a significant leak does not develop. This method does not consider, however, the consequences of a leak part way through a drawdown (4.1.4 below).

\subsubsection{Effect on Leak Inflow}

Consideration of an increase in operating pressure in the mine is driven by a need to minimize (1) the hydraulic pressure difference that would drive brine flow into the mine, 
and (2) the lithostatic pressure difference which drives salt creep. Estimates of the capillary pressure within a sand-filled fissure conclude the pressure is too low to prevent oil migration through brine-filled sand (Ostensen, 1994, Appendix 12), therefore, the static pressure head of the oil must be maintained below the top of the salt. This pressure, about $140 \mathrm{psi}$ on the oil at the Service Shaft bulkhead, will prevent oil from being driven through the existing or future flow paths into the overburden above the salt, but will reduce the driving pressure of a brine leak from about $230 \mathrm{psi}$ to about $90 \mathrm{psi}$ at the roof of the storage chamber. Additionally, the pressurization will decrease the volume of brine which can leak into the facility by approximately 55,000 barrels. This decrease in available space would result in decreased risk of surface damage and additional dissolutioning should an uncontrollable inflow occur. Also, the ongoing salt creep will be appreciably reduced thus diminishing the perceived ultimate source of inflow concern (see following discussion).

\subsubsection{Effect on Long-Term Creep}

Reduction of cavern creep has two benefits. One is that with reduced creep, the loss of mine volume, now estimated to be at least 160,000 barrel per year, will decrease. This will help stabilize the storage capacity over the life of the mine. The second, and more significant result of decreased creep, is that the tensile stresses imposed on the salt near the top of the dome will be decreased. This will result in a decrease in or slowing of fracture development in the salt and resulting other leak path(s) development into the storage chamber.

Analyses (Hoffman, 1994) show the magnitude and extent of both the tensile and dilatancy (microfractured) zones to slightly decrease as the mine is pressurized to oil head at top of salt. Most significant, surface subsidence rates and volumetric creep closure are reduced by approximately an order of magnitude. Pillar stability in the oil storage levels is improved due to the added confining pressure. Prior to pressurization, tensile stresses and dilatant behavior are predicted in the pillars. Some of these effects were noted prior to oil fill by Acres (Acres, 1977) when pillar decay up to $15 \mathrm{ft}$ into the pillars was observed. Pressurizing the mine eliminates tensile stressing in the pillars and dilatant behavior, which will extend its life. It will also reduce the stress and deformation characteristics that cause fracture and potential flow paths through the overlying salt.

\subsubsection{Necessary Mine Changes}

In order to safely operate the mine at an increased pressure, several actions must be completed. These actions include:

1. Complete the upgrades of the submersible pump system and wireline penetrations to withstand increased pressure in the storage chamber,

2. Upgrade or install hydrocarbon sensors on the Service Shaft bulkhead to detect spills,

3. Consider locking in or blinding all valves on the bulkhead penetrations to minimize spills,

4. Install at least one emergency drawdown pump in a fillhole to provide a means to depressure the mine should an oil spill occur in the manifold room, and 
5. Space the submersible pumps to allow removal of oil from either the bottom or top of the mine, (in process currently) and

6. Provide a source of fluid to maintain pressure during drawdown.

The Risk Abatement Program upgraded the bulkheads in Raisebores 1 and 2 and the Service Shaft and investigated the bulkheads in the Production Shaft and Markel Incline. These studies and upgrades were made only to the bulkheads themselves and not to the submersible pumping system and the various pipes that penetrate the bulkheads. The pumps and penetrations were investigated at a later date to determine if they will withstand the increased pressure that could develop in the storage chamber if a brine leak develops. The result of this investigation is that some upgrades are required. The upgrades which are currently in the process of being completed are:

1. Replacement of the gaskets on the pump casing flanges,

2. Sealing of the submersible pump electric cable penetrations,

3. Installation of packoffs around instrumentation cables in the Service Shaft and the fillholes, and

4. Upgrading the pump motor lubrication oil system to ensure that it will always be at a higher pressure than the oil in the mine.

A pump(s) needs to be installed in the fillholes if the mine is pressurized so that the mine can be depressurized in the event oil spills or leaks in the manway. If an oil spill occurs, it could not be shut off or cleaned up except by depressurizing the mine to remove the driving force for the oil spill. With an oil leak in the manway, operators could not safely enter the manifold room to align the submersible pump manifold to allow their use for depressurizing the mine.

Use of an emergency drawdown pump(s) in the fillholes for this purpose would require a change in recovery criteria that require recovery equipment be stored at an offsite location. The emergency drawdown pumps are designated as recovery pumps for the submersible pumping system.

The possibility of an oil spill occurring in the manway can be minimized by isolating the piping in the mine from the bulkhead penetrations. This piping includes the oil withdrawal pipes and the nitrogen venting system. The isolation can be accomplished by either locking the connecting valves in the closed position or physically disconnecting the piping and installing blind flanges.

Early detection of a oil leak can be accomplished by installing hydrocarbon sensors on the bulkheads. These sensors would signal the control room that oil fumes had been detected so that prompt action could be initiated to depressure the mine and minimize the size of the leak. The existing hydrocarbon warning system may be sufficient to provide this capability but verification is needed.

Vertically spacing the pumps in the Service Shaft below the bulkhead is required to -allow removal of oil for a conventional drawdown due to water leakage, or an emergency drawdown due to water leakage into the mine. The specific arrangement of the pumps will need to be determined with consideration of system hydraulics. However, the intent would be to space them in a pattern such that there are some pumps left in the Service 
Shaft sump, some pumps are repositioned just below the Service Shaft bulkhead, and possibly some pumps are positioned near the mid-point of the mine. The pumps near the bulkhead would not be used during a conventional drawdown while the pumps in the sump would not be used in the event of an uncontrollable water inflow. The pumps near the middle of the mine could be used in either scenario until the oil level reached the suction (or NPSH requirements) of those pumps. In the event of a conventional drawdown, some of the pumps from below the bulkhead or at the mid-point could be lowered back to the Service Shaft sump to maintain required drawdown capabilities.

In order to space the pumps in the Service Shaft; they need to be relocated before any oil pressure increase, either planned or as a result of water inflow. Due to space limitations in the manifold room, it is impractical to develop a system to control the oil and allow movement of the pumps while the storage chamber is pressurized.

\subsection{GROUTING}

It may be possible to stop the water inflow into the mine by grouting from the surface. This technique has been tried at both Weeks Island over the Wet Drift in 1977 and 1978 and at other salt mines in salt domes. Generally, the technique has not been greatly successful, primarily due to the high cost and time involved as compared to grouting from underground. Drilling to intersect and grout off leaks from underground is generally cheaper and quicker, and the visible leak provides a more definitive target for grouting than can be obtained from the surface. However, in the case of water leaking into the storage chamber, access from underground is not possible; and surface grouting is the only available option.

The difficulties associated with surface grouting involve determining a target zone, and real time diagnostics on its effectiveness. Due to the hydraulics of water flow after it enters the mine, any actual measured inflow may not be impacted by a grouting program for a significant period of time. Additionally, a leak from the surface may consist of numerous small channels near the top of salt which funnel, with depth, into one zone. If this major zone is not found, grouting of small feeder channels will only temporarily impede the leak into the mine.

Now that a sand channel to the mine has been inferred, grouting from the surface may be effective. Any surface grouting program is likely to be expensive and short lived requiring repeated grouting to maintain the seal. Openings that have been temporarily sealed by grouting are likely to be reopened as the salt extension that initiated the fractures continues to occur. A more thorough discussion of surface grouting is given in Appendix 13 and in the DRAFT Weeks Island Surface Grouting Plan (DynMcDermott, 1994).

\subsection{ENVIRONMENTAL CONCERNS}

An uncontrolled water leak into the oil storage chamber could result eventually in environmental damages from either the loss of oil into the aquifer and possibly onto the surface or into waters overlying the dome or from damage to the ground water and surface that may result from subsidence over the mine. 
Currently, water can leak into the storage chamber without oil leaking out of the mine. This water leakage with no oil outflow will, if allowed to continue, fill the mine and pressurize the oil to near hydrostatic pressure. Once the mine pressure is in equilibrium with the ground water hydrostatic pressure (approximately $230 \mathrm{psi}$ in the upper level), oil could simultaneously float up through the leak path that allowed water to enter (Section 3.1.1). The presence of overburden materials would greatly retard this exchange. The rate of oil flow will depend upon the size and configuration of the leak path. This oil could eventually contaminate the aquifer, and depending upon characteristics of the overlying sediments and rate of oil leakage, may appear in Weeks Bay and the wetlands around Weeks Island. It is unlikely that oil would actually reach the surface on the Island with this scenario. Once released from the storage chamber, oil would be extremely difficult to contain or clean up, particularly in the aquifer.

If a leak into the mine were allowed to continue sufficiently that a large conduit or leak was developed, or the supporting mine pillars in the vicinity of the leak become unstable and collapsed due to solutioning, the leakage path into the mine could wash existing sediments or overburden from above the mine or in the flow path into the mine. This could create a much larger surface sinkhole. The size of the sinkhole and immediate further solutioning would be limited by the volume in the mine available for filling. If the velocity of the inflow after it entered the mine was low, the volume available in the mine for filling with overburden material is essentially a cone, or some portion of a cone, approximately 75 feet high (the height of the rooms in the upper level) with an angle of repose approximately equal to that of sand. This cone would be restricted somewhat by the presence of the mine pillars. The velocity of any inflow in the mine will be low provided the mine remains essentially fluid filled. If the mine were only partially fluid filled, overburden materials could be washed or carried away from the vicinity of the entry point and the size of the sinkhole formed would be greatly increased.

Depending upon the location, rate and quantity of material movement, surface facilities could be severely damaged. This damage could result either from the sinkhole formation and subsidence occurring adjacent to the surface facilities or due to movement of ground water into the mine which could result in additional subsidence related to the local dewatering. Underground facilities such as the shafts could also be adversely impacted by a rapid movement of ground water towards a sinkhole. 


\section{RESPONSE OPTIONS}

\subsection{OIL WITHDRAWAL}

\subsubsection{Conventional Drawdown}

As long as the current leak or leakage into the mine remains small, normal drawdowns (national emergency or exercises) can be conducted essentially in the present design mode. If the pumps are vertically spaced within the Service Shaft as discussed above in Section 3.1.3, the number of pumps available for an extended drawdown may be reduced, depending upon the results of the hydraulic study for spacing them. The Service Shaft submersible pumps may also be supplemented by pumps installed in the fillholes, if these have been installed as a result of operating the mine at an elevated pressure during periods of drawdown readiness.

\subsubsection{Geotechnical Emergency - Water Leak Above the Bulkheads}

In the event a water leak develops above the oil isolation bulkheads, which would render the manifold room unusable, oil withdrawal could be accomplished using the emergency drawdown system placed in the fillholes. This requires no change from present plans.

\subsubsection{Geotechnical Emergency - Water Leak into the Storage Chamber}

Should the water leak into the storage chamber greatly increase, both the Service Shaft sump and the fillhole sump would become flooded with brine. The existing submersible pumps cannot lift the brine to the surface due to discharge head limitations. This would prevent drawdown by the existing drawdown systems.

In this type of emergency, oil could be removed either by allowing the mine to reach to full hydrostatic pressure and allowing oil to flow out of the vent hole, or by using selected submersible pumps in the Service Shaft (if they have been relocated to just below the Service Shaft bulkhead). In the event the vent hole was used for oil withdrawal, it would need to be connected to the oil pipeline to St. James. A design and piping for this contingency do not presently exist. This connection could probably be designed so that in the event of an emergency, fabrication could be quickly started. This system would allow oil flow at about 120,000 barrels per day or a rate equal to the rate of water inflow if it is less and no supplemental source of fluid is available for injection into the mine. It is emphasized that this use of the submersible pumps requires that they be previously positioned below the bulkhead. The obtainable rate will depend upon the number of pumps that are moved and the pressure in the mine.

During an emergency drawdown due to water leaking into the mine, consideration should be given to controllably injecting water or brine to replace the quantity of oil withdrawn. This would (1) decrease the amount of water leaking into the mine through the leak path (and thus minimize further dissolution within the leak path), (2) reduce the inflow velocity and possible movement of overburden material washed into the mine, and (3) maximize the rate of oil withdrawal. The oil withdrawal rate will be limited by the rate at which the water leak, if not supplanted or supplemented by intentional fluid injection, 
keeps the oil level at the pump suction or at the top of the vent hole. Particularly in the initial stages of a leak, and possibly throughout the entire time a leak is occurring, the water inflow rate will most likely be at a much lower rate than oil could otherwise be removed either by use of the submersible pumps or the vent hole connection.

Ideally this displacement fluid should be brine so as to minimize dissolution of the pillars in the storage chamber. As Thoms (Thoms 1994) notes however, the significant quantity of loose salt in the mine, currently, would be preferentially dissolved. There is appreciable uncertainty in relying on this loose salt, however, and some consideration should be given to possible brine sources.

Possible sources of brine are development of caverns specifically for that purpose or recovery of natural brine from the base of the aquifer at the top of the salt. Development of caverns for a brine source would require obtaining land and salt on the dome, construction of a pipeline and pumping facilities, cavern wells, and disposal capability, at least during the initial cavern development. The brine could probably be injected safely into the fillholes.

Use of naturally occurring brine from the aquifer would require land acquisition, wells, pumps, and a pipeline. A hydrologic study would need to be conducted before this option is chosen to insure that the brine removal could be accomplished at the desired rates and would not affect surface facilities. Use of naturally occurring brine may not be a feasible alternative.

Another source of fluid is water from Weeks Bay or the intracoastal waterway. Use of surface waters reduces the cost of installing a system by eliminating the need for wells and some piping and reducing the size of the required pumps. However, the surface waters are essentially unsaturated with respect to sodium chloride; and their use will result in a substantial amount of salt dissolution in the mine. Some dissolution of the mine pillars will occur resulting in increased subsidence, compared to brine displacement. However, this increased subsidence resulting from the use of unsaturated water will be minimal in both extent and time, based upon comparisons to both the Belle Isle and Jefferson Island salt mines which have been flooded.

There is an advantage to using unsaturated surface waters intentionally pumped into the mine rather than allowing the mine to fill with water leaking into it as discussed above. This option would still require obtaining land, and construction of a pipeline, pumping facility, and an injection well into the mine. The location of the injection well will require study to determine the location that will result in the least impact from the salt dissolution associated with injecting raw water.

\subsubsection{Water Leak During Conventional Drawdown}

Potentially the most consequential scenario involving drawdown would occur if a major leak developed into the storage chamber during a conventional drawdown (mine at essentially zero pressure with all the pumps in the Service Shaft sump) after a significant amount of the oil had been removed. In this event, a large quantity of water, approximately equal to the amount of withdrawn oil, could flow into the mine before an increase in the mine pressure would slow the inflow rate. The Service Shaft submersible pumps and the emergency drawdown pumps would not be usable for drawdown as the intakes would be flooded with brine. The large amount of water flooding into the mine 
would result in the development of a large channel which would permit oil to readily flow out of the mine once the mine pressure equalized with the ground water hydrostatic pressure.

Response to such a scenario would depend upon configuration of the mine when it occurred. If a source of brine or water had been developed (4.1.3) the leak inflow would be lessened by injecting water or brine into the mine, and oil withdrawal could then resume via the vent hole. If no alternate fluid source had been developed, oil withdrawal would be delayed until the mine pressurized due to the leak. Oil withdrawal could be done either by connecting the vent hole to the St. James pipeline and allowing the oil to flow out under hydrostatic pressure or by using pumps stationed below the Service Shaft manifold, if they had been previously positioned there and not relocated during the drawdown (3.1.3) In either case, the withdrawn oil should be replaced with intentionally injected water/brine in order to minimize the leak inflow. If there is no developed source of water/brine, oil withdrawal could occur only at the rate of water leakage, and the leak into the mine would continue to enlarge with a corresponding increase in the rate and likelihood that oil would leak out of the mine into the overlying aquifer.

\subsubsection{Abandonment}

A brine or water source would be useful not only if water is leaking into the mine, requiring that the oil be removed, but also at such time as the mine is finally abandoned as a storage site. The brine or water would be used to remove as much oil as possible off the floor and walls of the mine. The brine or water would also provide increased long-term stability for the mine, reducing ongoing surface subsidence and the potential for eventual leak development, or the possibility of mine collapse.

\subsubsection{Disadvantages to Pressurizing the Mine}

The disadvantages of operating the mine in a pressurized mode relate to personnel safety and maintenance of the submersible pumps. Both concerns require a safety assessment of possible impact before the mine can safely be operated at an increased pressure.

With the oil storage chamber under pressure, the oil pressure head will be above the bulkheads in the mine. A leak in the piping system or any of the oil isolation bulkheads would result in oil spilling into the manway, a condition which is potentially hazardous and difficult to cleanup. This condition already exists to a limited extent when the site is pumping oil to St. James or for recirculation through the fillholes. The concern can be mitigated to some extent by isolating the piping in the manifold room from the pump columns by either keeping the valves on top of the pumps shut (which is normal procedure) or disconnecting the piping and installing blind flanges. Similarly, the nitrogen injection/equalization piping would need to be isolated from the penetrations in the various bulkheads.

Maintenance of the pumps requires periodic running of the pumps as well as occasional removal of the pumps for repairs. The pumps probably can be operated when the mine is pressurized if the motor lubricating oil system is pressurized and the piping is not disconnected. Removal of the pumps for repairs would require that the mine be depressurized and the pumps removed as they are presently. Should the mine become 
pressurized as a result of a water leak, it will not be possible to remove the pumps for maintenance.

\subsection{MINE MAINTENANCE}

\subsubsection{Monitoring}

There are a limited number of mine parameters that can be monitored effectively. The brine levels in the fillhole sump and the Service Shaft sump are presently monitored. Additionally the oil/gas level at the Service Shaft is also monitored as are the pressures at each of the oil isolation bulkheads and the vent hole at the surface. These are discussed early under Mine Diagnostics.

\subsubsection{Maintenance Grouting}

Grouting at Weeks Island is presently undertaken as needed in the shafts and the accessible manway. Grouting of leaks in the mine has been quite effective in stopping water inflow, for at least short periods of time. The ability to grout the shafts and the manway level should be maintained and exercised as needed to control leaks as they develop in these areas. The flexibility achieved by an outside standby grouting contractor is needed even if routine grouting is performed by an in-house crew.

Although not currently performed, an additional grouting task that may be needed is the grouting of the peripheries of all bulkheads in the manway. The Markel Mine isolation bulkheads were peripherally grouted after construction. Others may have but no records exist. As grouts age and minor salt movement occurs, occasional regrouting may be required. This will become more important if the oil isolation bulkheads are operated under pressure. It may also be important to grout the bulkheads prior to oil pressurization to avoid wetting the surfaces with oil.

The capability to grout from the surface has not been developed at Weeks Island, although the concept has been maintained in the scope of the emergency grouting contract. Grouting was conducted from the surface over the Wet Drift after the wet zone was first encountered, and the leak rate was high. This grouting appears to have had at best a short term effect in reducing the leak into the Wet Drift. With the development of the sinkhole and the numerical modeling that indicates that fractures may be developing into the storage levels of the mine, a study of the feasibility and effectiveness of grouting from the surface should be initiated. This study may lead to recommendations of means to control the leak(s) rather than stopping them. However, successful grouting will require definition of the leak location. The requirements of surface grouting are described more fully above (3.2 Grouting). 


\section{CONCLUSIONS}

This study was initiated in response to the request by the Project Management Office to update a 1985 SPR Risk Assessment of Weeks Island geotechnical concerns. All previous recommendations have been reviewed and much new information and data have been obtained and analyzed. The conclusions that are drawn are necessarily based on the view developed from all information as of August 1994. Most significantly, (1) the sinkhole has continued to enlarge, (2) increased brine inflow into the fill hole area is observed, (3) dilatant zones in the salt are predicted from analyses, (4) the water table may be observed to be depressed immediately below the sinkhole, (5) there is a low seismic velocity channel mapped below the top of salt, (6) there is a sediment-filled crevasse located 72 feet below the top of salt, (7) there is water/brine moving downward at approximately one foot per day, and sediments moving downward at approximately one inch per day in the crevasse 72 feet below the top of salt, (8) there is a general correlation between volumes leached (sinkhole fill), brine inflow, and measured downward fluid velocity, (9) since early 1992 the isotopic composition of brine in the fill holes has been evolving toward that of ground water sampled over the salt dome, and (10) there is historical experience with sinkholes resulting from mine leakage elsewhere.

From this information, a consistent and logical conclusion is that there exists a leak into the mine through the salt below the sinkhole. Individual observations in most cases could be separately caused by other underground phenomena. For example, an increased brine inflow into the fill holes could be a transient phenomena associated with floor heave, or salt creep (the precise geometry of the floor is not known due to small amounts of leaching since the mine was shut in). The sinkhole could theoretically be caused by leaching of the top of the dome by fresh water flowing over the dome or down a natural trough in the top of the dome. Downward flow of water/brine 72 feet below the top of salt in a sediment filled crevasse is observed. This observation is difficult to explain, given that the top of salt was accurately mapped at four locations around the sinkhole and found to be approximately level. The simultaneous occurrence of alternate scenarios required to produce the current sequence of observed events is assessed to be sufficiently remote that a leak into the mine can be concluded.

The only data not directly indicating a leak is the lack of an indication of tracer dye in the fill hole brine samples. However, the downward velocity measured in the water/brine of 1 foot per day in the crevasse where much of the dye was injected, and the total additional distance of about 300 feet to the mine from the injection point leads to the expectation of at least several months before dye could be expected in the fill holes. (It is anticipated, however, that the downward velocity of the brine/water increases with depth since the cross sectional area of the leak is anticipated to be smaller with depth, due to the diminished solutioning as the water/brine becomes more salt saturated. Modeling supports this premise, but crosswell data in the first $\mathbf{1 5}$ feet of salt is inconclusive on this point. Additionally, the time required to transit from the entry point in the mine to the fill hole area sample location is difficult to estimate, but may be appreciable depending on path.) 
With the principal conclusion that there is currently a water/brine leak into the oil storage levels in the vicinity of the sinkhole, other conclusions follow:

1. Continued water inflow into the mine creates a risk for uncontrolled water inflow and potential displacement of oil to the sediments above the salt or surface, causing environmental damage and oil loss.

2. Mitigation of the water intrusion may be feasible; however, success of mitigative techniques is not assured, may be temporary and/or expensive due to mine inaccessibility.

3. Based on salt structure stress created by mine subsidence, and experiences of at least one other mine, additional sinkholes can be expected in the future.

4. Changes in the underground operations can reduce the ongoing risks or of a major accident or event occurring.

5. It may be very important to maintain a fluid-filled mine, even during drawdown, to assure control under leak scenarios.

6. With current technology, the ability to grout a leak in the oil storage levels from the surface may be limited.

7. The Markel Mine maintenance and inspections are not directly related to the sinkhole concerns, but are important for long-term oil storage.

8. All previously identified major geotechnical risks have been mitigated; some minor recommendations were not addressed.

These conclusions make it clear that continued oil storage will require additional effort in terms of operational changes, monitoring, etc. Since many of the changes require engineering designs, or major system configuration changes, time may be extremely important. There is much ongoing data collection, some of which will provide a better assessment of the seriousness and time urgency of the situation. An ongoing diagnostics program is currently underway with the express purpose of understanding the potential of the existing leak, and of detecting any other impending leak conditions. 


\section{RECOMMENDATIONS}

The conclusions summarize the assessed status of the Project. As requested by the Project, recommendations were developed which, if implemented, will address the need for and the possible leak mitigation actions, and to provide better future leak detection.

1. Maintain the mine fluid-filled, even during drawdown unless a washout can be prevented or otherwise controlled.

- Develop a water or brine source sufficient to support oil drawdown (4.1.3, 4.1.4)

- Develop a brine disposal capability sufficient to support oil transfers in (4.1.3)

2. Change the mine operation to accommodate pressurization (3.1.3)

- Conduct a Safety Assessment of increasing the mine pressure (4.1.6)

- Pressure the mine to about 120 psi (3.1.1)

- Reposition some or all of the main withdrawal pumps (3.3.1)

- Upgrade any necessary equipment in the manifold room to support pressurized operation (3.1.3)

3. Continue and improve water entry diagnostics

- Fully analyze the mine strapping data (2.2.2)

- Continue the follow on diagnostics effort

- Refine the current water entry monitoring procedures (2.2)

- Fully implement the program for inspection for new surface sinkholes (2.5.1)

4. Reinstate inspections of the Markel Mine to support long-term oil storage

- Initiate a maintenance program (2.5.2)

5. Develop and implement leak stabilization or reduction actions, specifically brine injection, and surface grouting when leak sources can be near positively located. (It is important to note that brine injection was initiated in August 1994, and a grouting plan is nearly complete.)

6. Investigate the feasibility of leak detection via piezometers and flowmeters, i.e., water table changes.

It is anticipated that the Project will critically review these recommendations and implement those recommendations consistent with its overall long term storage program. 


\section{REFERENCES}

Acres International Corporation (1987) Additional Geotechnical Studies - Strategic Petroleum Reserve (SPR)-Weeks Island, Louisiana, February.

Acres International Corporation (1987) Weeks Island Strategic Petroleum Reserve Geological Site Characterization Report, SAND87-7111 Sandia National Laboratories .

Arizona State University (1990) Stable Isotope Constraints on the Origin of Brine in the Weeks Island Strategic Petroleum Reserve, Arizona State University.

Autin, W. J. (1994) Personal communication, Louisiana State University, Env. St. Inst.

Autin, W. J. (1984) Observations and Significance of Sinkhole Development at Jefferson Island. Geol. Pamphlet No. 7, LA Geol. Surv., Baton Rouge, 75 pp.

Autin, W. J. (1993) Weeks Islands Observations, In Anomalous Zones in Gulf Coast Salt Domes, with Special Reference to Big Hill, TX, and Weeks Island, LA., SAND92-2283, pp. 19-21, Sandia National Laboratories.

Beasley, R. R., et al, (1984) Results of a Geotechnical Risk Assessment Study of the SPR Storage Facility at Weeks Island, Louisiana, SAND84-2072, Sandia National Laboratories.

DynMcDermott (1993) Feasibility Study and Implementation Plan - Monitoring of Changes in Piezometric Surface Document WIE6400.46A0., July.

DynMcDermott (1993b) Memorandum to W. C. Gibson from C. C. Johnson, Sinkhole Tracer Dye Study, 18 Oct 1993.

Ehgartner, B. L. (1993) Internal SNL Memorandum to J. K. Linn, Dept. 6113, Weeks Island Stress Prediction and Relationship to Sinkhole Formation, 18 Oct. 1993.

Ehgartner, B. L. (1993) Internal SNL Memorandum to J. T. Neal, Piezometer Installation at Weeks Island, 4 Nov 1994.

Emergency Grouting Program (1984), Cavern Engineering, Petroleum Operations and Support Services, Inc., September 15, 1984.

Freyou, S. J. (1986) Reported in (PB-KBB, 1986, Part A)

Harding R. S. Jr. (1993) Internal SNL Memorandum to J. T. Neal, Proposed Seismic 'Investigations of Weeks Island Sinkhole, 2 Nov. 93. 
Louisiana State University (1990) Fluid Dynamics of Oil Storage and Production Cycles in the Weeks Island Strategic Petroleum Reserve, Part 4 - Visual Analog Study of Fillhole Drifts, 1 July, 1990.

Magorian, T. R. (1993) Memorandum to J.T. Neal, Sinkhole at Weeks Isląnd, 30 Sept., 1993

McHenry, J. M. (1993) Personal communication, DynMcDermott Pet. Ops. Co., N.O., LA.

Miller, R. D, Steeples, D. W., Schulte, L., Davenport, J., (1993) Shallow Seismic Reflection Study of a Salt Dissolution Well Field Near Hutchinson, KS, Mine Eng., Oct. 1993.

Neal, J. T., T. R. Magorian, R. L. Thoms, W. J. Autin, R. P. McCulloh, S. Denzler, K. O. Byme, (1993) Anomalous Zones of Gulf Coast Salt Domes, with Special Reference to Weeks Island, LA, and Big Hill, TX, SAND93-2283, Sandia National Labs. Alb., NM.

Neal, J. T. (1994) Dissolution Features over the Weeks Island, La. Salt Mines: Origin, Development, and Detection, Working Paper Draft, Feb., 1994, Sandia National Laboratories.

Neal, J. T. (1994) Surface Features Indicative of Subsurface Evaporite Dissolution: Impl. for Storage and Mining. Sol. Min. Res. Inst. Ann. Mtg., Houston, TX, 25 April, 1994.

Ostensen, R. W. (1994) Capillary Pressure in Weeks Island Sand, Internal Letter to Distribution, Sandia National Laboratories, March 14, 1994.

PB-KBB (1986), Weeks Island Stewardship Plan, Part A: Weeks Island Subsidence Monitoring Program, Part B: Weeks Island Convergence Monitoring Program, Contract to Boeing Petroleum Services, November, 1986.

PB-KBB (1990), Weeks Island Production Shaft, Shaft Axis Deflection and Shaft Wall Deformation.

Russo, A. J. (1994) Preliminary Weeks Island Inflow Calculation, Ltr. to J. Linn, Sandia National Laboratories, March, 1994.

Sandia National Labs Dept. 6113 (1992) Memorandum to D. W. Whittington, DOE SPR PMO, from J. T. Neal and T. R. Magorian, Weeks Island Sinkhole Observations.

Sandia National Labs Dept. 6113 (1993) Memorandum to R. E. Myers, DOE SPR PMO, from J. K. Linn and J. T. Neal, Additional Characterization of Weeks Island Sinkhole.

Sandia National Labs (1993) Assessment of the Feasibility of Monitoring Brine Inflow into the Weeks Island Oil Storage Chamber.

Thoms, R. L. (1994) Weeks Island Sinkhole, Draft Report to Sandia National Laboratories, AGM, February 23. 
Distribution:

U.S. DOE SPR PMO (10) 900 Commerce Road East New Orleans, LA 70123

Attn: J. C. Kilroy, FE 443

J. Culbert, FE 4431

J. W. Kunkel, FE 4422

R. E. Myers, FE 4422 (3)

L. J. Rousseau, FE 433

G. B. Berndsen, FE 443.1 TDCS (2)

Tucker \& Associates, Inc. 800 Commerce Road West Suite 500

New Orleans, LA 70123

Attn: C. Sherman

U.S. Department of Energy (3)

Strategic Petroleum Reserve 1000 Independence Avenue SW Washington, D.C. 20585

Attn: D. Johnson

D. Buck

H. Giles

DynMcDermott (5)

850 South Clearview Parkway

New Orleans, LA 70123

Attn: J. McHenry

K. Mills

H. Kubicek

B. Gump

K. Wynn

Weeks Island SPR Site (2)

P.O. Box 434

New Iberia, LA 70560

M. Bertoldi

M. Jackson
Acres International Corporation (2) 140 John James Audubon Parkway Amherst, NY 14228-1180

Attn: S. Thompson (2)

R. L. Thoms

AGM Inc.

P.O. Box 10358

College Station, TX 77842

Sandia Internal:

MS 0701 R. W. Lynch, 6100

MS 0661 R. E. Parks, 13212

MS 0469 A. J. Russo, 1511

MS 1033 J. Dunn, R. Jacobson, 6111

MS 0705 A. R. Sattler, 6111

MS 0706 J. K. Linn, 6113 (10)

MS 0706 S. J. Bauer, 6113 (3)

MS 0706 B.L Ehgartner, 6113

MS 0706 T.E. Hinkebein, 6113

MS 0706 P.S. Kuhlman, 6113

MS 0706 M.A. Molecke, 6113

MS 0706 J. T. Neal, 6113 (3)

MS 0706 R. W. Ostensen, 6113

MS 0706 J. L. Todd, 6113

MS 0705 R. S. Harding, 6114

MS 0750 M. C. Walck, 6116

MS 0750 S. Ballard, 6116

MS 9018 Central Tech. Files, 8523-2

MS 0899 Technical Library, 13414 (5)

MS 0619 Technical Publications, 12613

MS 0100 Document Processing (2) for DOE/OSTI), 7613-2 


\section{APPENDICES}

1 Fillhole Brine Inflow

2 Preliminary Weeks Island Mine Inflow Calculations

3 Sediment/Core Descriptions and Daily Drilling Reports

4 Gas Survey, Drilling Report from L.S.U.

5 High Resolution Surface Seismic Reflection Survey Near SPR Surface Collapse Feature at Weeks Island, LA

6 Tomographic Study

7 Near-Surface Gas Mapping Program

8 Near-Surface Gas Mapping Results

9 Fluid Flow Measurements

10 Dye Injection

11 Surface Self Potential Survey

12 Capillary Pressure in Weeks Island Sand

13 Grouting

14 Stable Isotope Constraints on the Origin of Brine in the Weeks Island Strategic Petroleum Reserve

15. Brine Injection, Sinkhole Monitoring and Backfilling 


\section{APPENDIX 1}

\section{FILLHOLE BRINE INFLOW}

A-1-1 


\section{A1 FILLHOLE BRINE INFLOW}

\section{A1.1 HISTORICAL PERSPECTIVE}

During the summer of 1987 the SPR performed a wireline density survey of the fillhole sump. The survey revealed several interfaces, making log interpretation impossible. Subsequent to this survey, wireline sampling was performed to identify the various interfaces identified in the density survey. The sampling identified a perched oil column in the 13 3/8-inch tubing with the entire fillhole sump being full of brine.

Upon locating the brine in the fillhole sump, a crisis management team was formed by the SPR to investigate the brine's presence in the fillhole sump. During the investigation, integrity tests were performed on both fillholes. The result of the testing indicated that the fillholes were not leaking, however, the testing was inconclusive regarding leakage into the oil storage chamber. The fillhole sump was subsequently equipped with a continuous oil/brine interface detector.

During 1989 the SPR contracted with AGM Inc. to perform an independent analysis of the inflow into the fillhole sump. After analysis of all available information regarding inflow into the fillhole sump, AGM concluded (1) that there is no evidence that inflow into the fillhole sump was the result of a leak into the oil storage chamber. AGM additionally concluded that the inflow into the sump likely resulted from brine, which may have been pumped into the oil storage chamber following pipeline hydrotesting, flowing back into the fillhole sump.

At the time of the report by AGM there was only one strong piece of evidence which implied leakage into the oil storage chamber. This evidence was isotopic analysis of brines to determine their origin, which was performed by Arizona State University $(2,3,4)$. In the opinion of Arizona State University, the most likely origin of brine in the fillhole sump was a leak from the surface.

\section{A1.2 PRESENT UNDERSTANDING}

The brine inflow curve for the period between 1987 and the present is provided in Figure A.1. The data shown are the brine inflow rates versus time. Rates were calculated by dividing the change in sump brine volume (due to interface rise) over a twenty day integration period by the number of hours in 20 days. Sump interface and volume of brine pumped were determined during pumpdown exercises in 1988, 1989, and 1991. Strapping curves were developed from each of these pumpdowns. The strapping curve used to calculate the 1988 data was a linear curve and is believed to be approximately $20 \%$ higher than the two subsequent pumpdown data. This disparity is attributed to downhole leakage of the pump shroud during the 1988 operations. If the 1988 data is corrected by the nominal $20 \%$ correction it falls much more in line with the later data, as can be seen in Figure A.2.

As can be seen in Figure A.2, the inflow rate temporarily rises dramatically following pumpdown exercises, drops off, and stabilizes at a nearly flat inflow rate. The figure plots data developed using three different strapping curves. The linear curve developed from the 1988 pumpdown (adjusted to approximately $2000 \mathrm{bbls} / \mathrm{ft}$ ) and two polynomial curves developed during subsequent pumpdowns. There is little disparity 
between the three strapping curves. From this figure it is difficult to ascertain any trend line changes.

To aid in evaluating the inflow it seems appropriate to investigate the change in interface with time. This data has been plotted in Figure A.3. This Figure shows the interface rise curves each plotted as days from pumpdown versus height of brine in the sump. All plots assume that the datum of one foot above the sump floor is constant. It is likely that the datum is plus or minus one foot in each case. As can be seen, little trend information can be gathered from this plot. Subsequently, Figure A.4 was produced by adding the interface prior to pumpdown to the interface changes after pumpdown. This figure indicates an initial non-linearity following the first pumpdown in 1987 followed by a relatively linear increase in depth until the 1993 pumpdown. The data, however, is not conclusive of a change in inflow. It is apparent from the exercises involving interface that the data does not adequately scale to facilitate interpretation.

Observation of Figure A.4 possibly suggests an apparent increase in inflow following the 1993 pumpdown, however, the data scatter resulting from recirculation exercises on $7 / 25,9 / 26,10 / 10$, and $11 / 7$ of 1993 make interpretation difficult. To improve interpretability, the data was corrected for the decrease in interface caused by recirculation. This data is presented in Figure A.5 for data following the 1993 pumpdown. As can be seen in the plot, this adjusted data implies increased inflow. This data was inserted into the data from Figure A.2 and is shown in Figure A.6. From this figure it is apparent that the inflow was decreasing prior to removal of the probe for testing of the emergency drawdown system in 1991. Following installation of the probe in 1993, the inflow rate increased to well beyond previously recorded inflow rates. This data is evidence of an increase in brine inflow at the fillhole site and consequently a possible indicator of leakage.

Preliminary verification of the interface detector accuracy was performed during February and March 1994. Testing indicates that a shift in the detector calibration has occurred since installation of the probe. There is, however, no indication of shift in zero offset. During previous probe failure no calibration shift was noted; however, a shift in zero offset was present. Probe data has been corrected for a shift in calibration factor beginning with probe installation and becoming progressively worse, and for the possibility that the probe was canted in the borehole. These two possible error scenarios are plotted in Figure A.7. As can be seen, the canted probe would drop the total inflow rate approximately $10 \mathrm{gpm}$ while the effect of a linearly deteriorating calibration slope would result in an underestimate of the inflow rate by approximately $15 \mathrm{gal} / \mathrm{hr}$. All data indicate a current inflow of $60-75 \mathrm{gph}$. This inflow has shown a significant increase from a nominal $10 \mathrm{gph}$ in June 1993.

To eliminate the potential for future hardware problems the SPR is currently purchasing a second wireline unit. These actions will allow full redundancy of the interface measurement in the future.

\section{A1.3 CONCLUSIONS AND RECOMMENDATIONS}

Data from the fillhole inflow can be interpreted to suggest that a leak exists into the SPR oil storage chamber. There is no other identified mechanism to explain the increasing inflow rate since June other than a leak. Final steps in verifying probe output 
are ongoing. These steps include slickline and wireline measurements as well as installation of a second probe. 


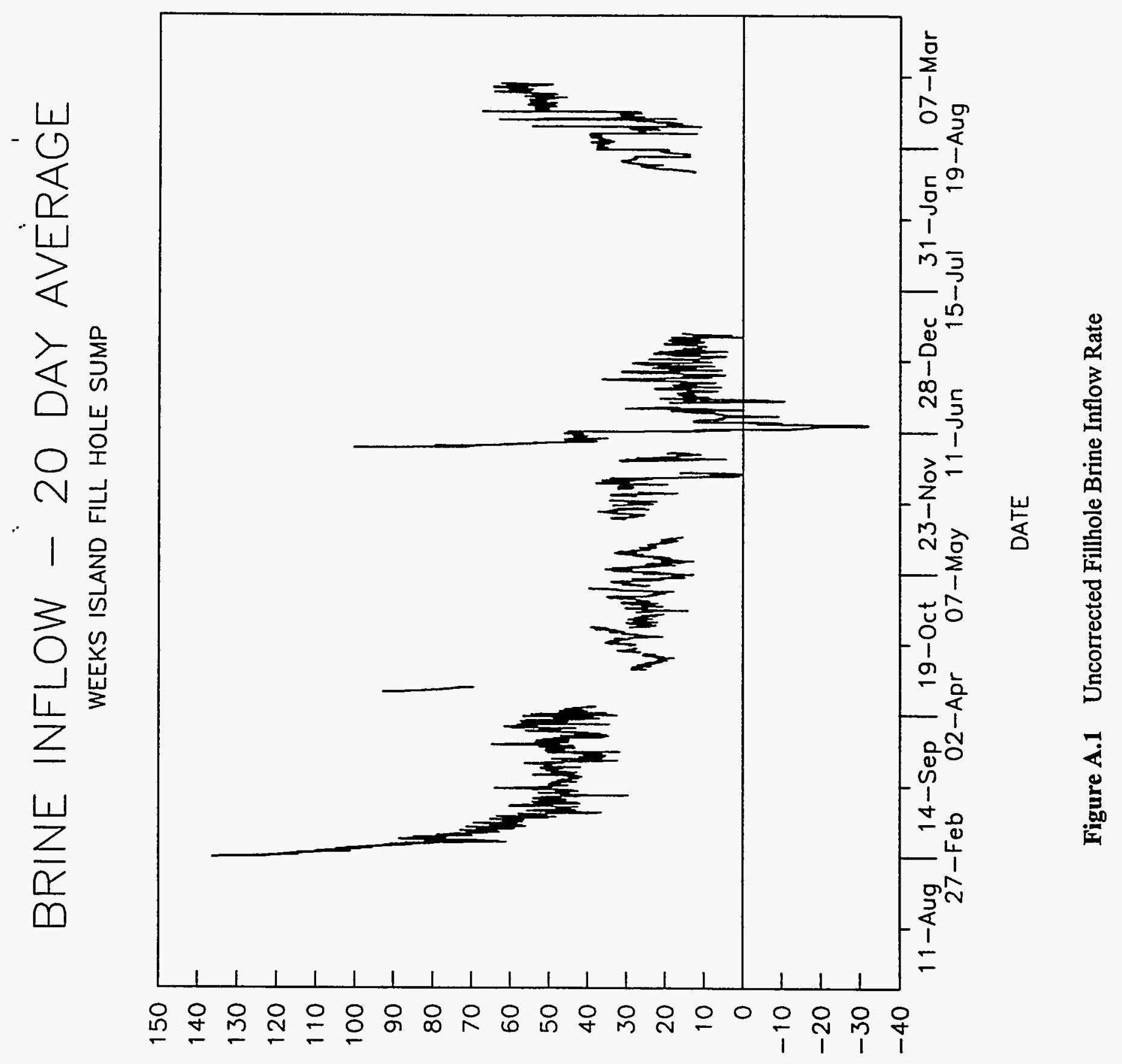

(udD) $3 \perp \forall Y$ MOר $\exists N I$ INIU8

$$
\text { A-1-5 }
$$




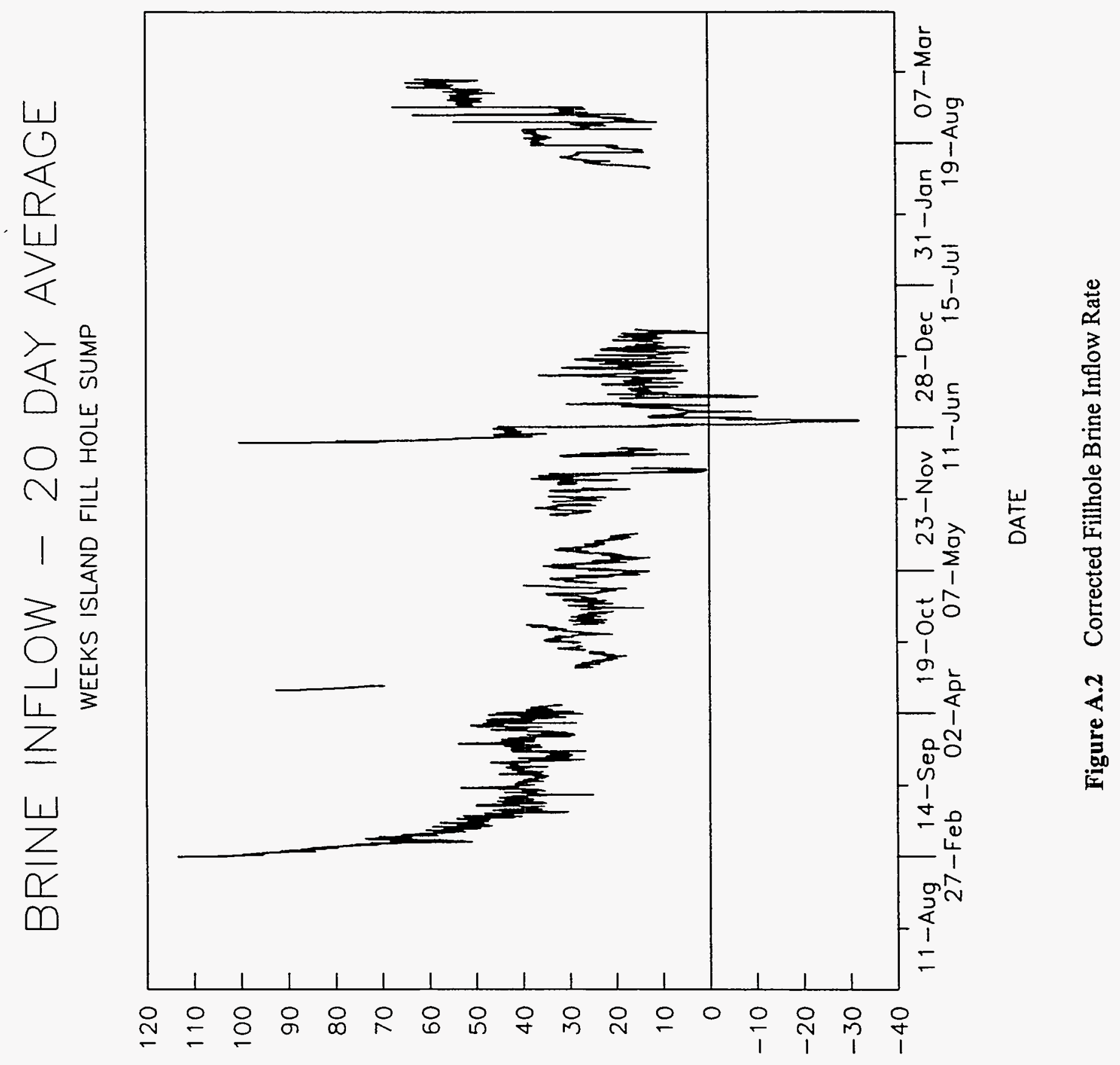

(Ud6) $\exists \perp \forall y ~ M O ר \exists N I ~ \exists N I Y G$

A-1-6 


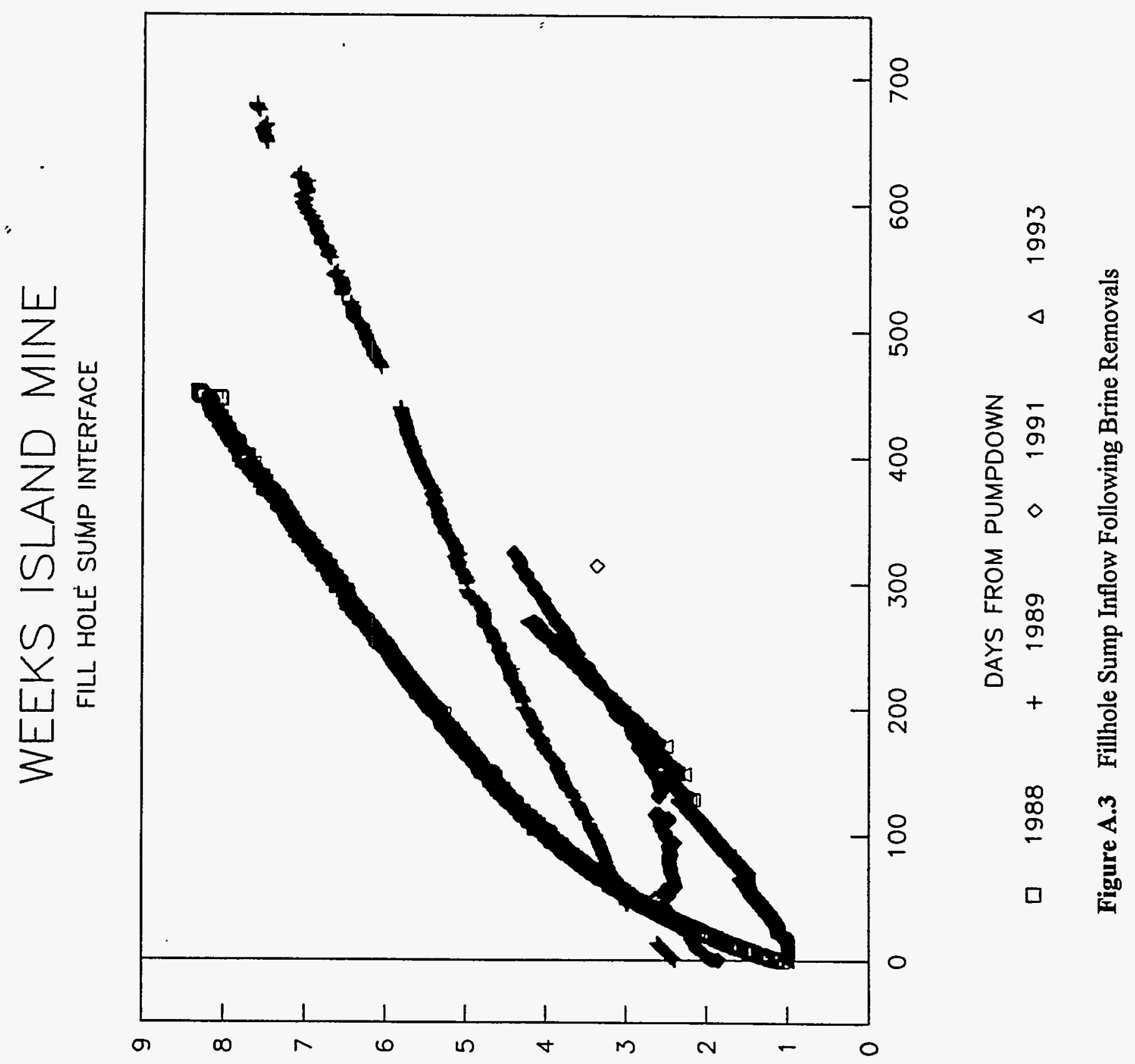

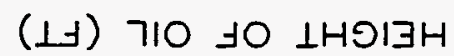

A-1-7 


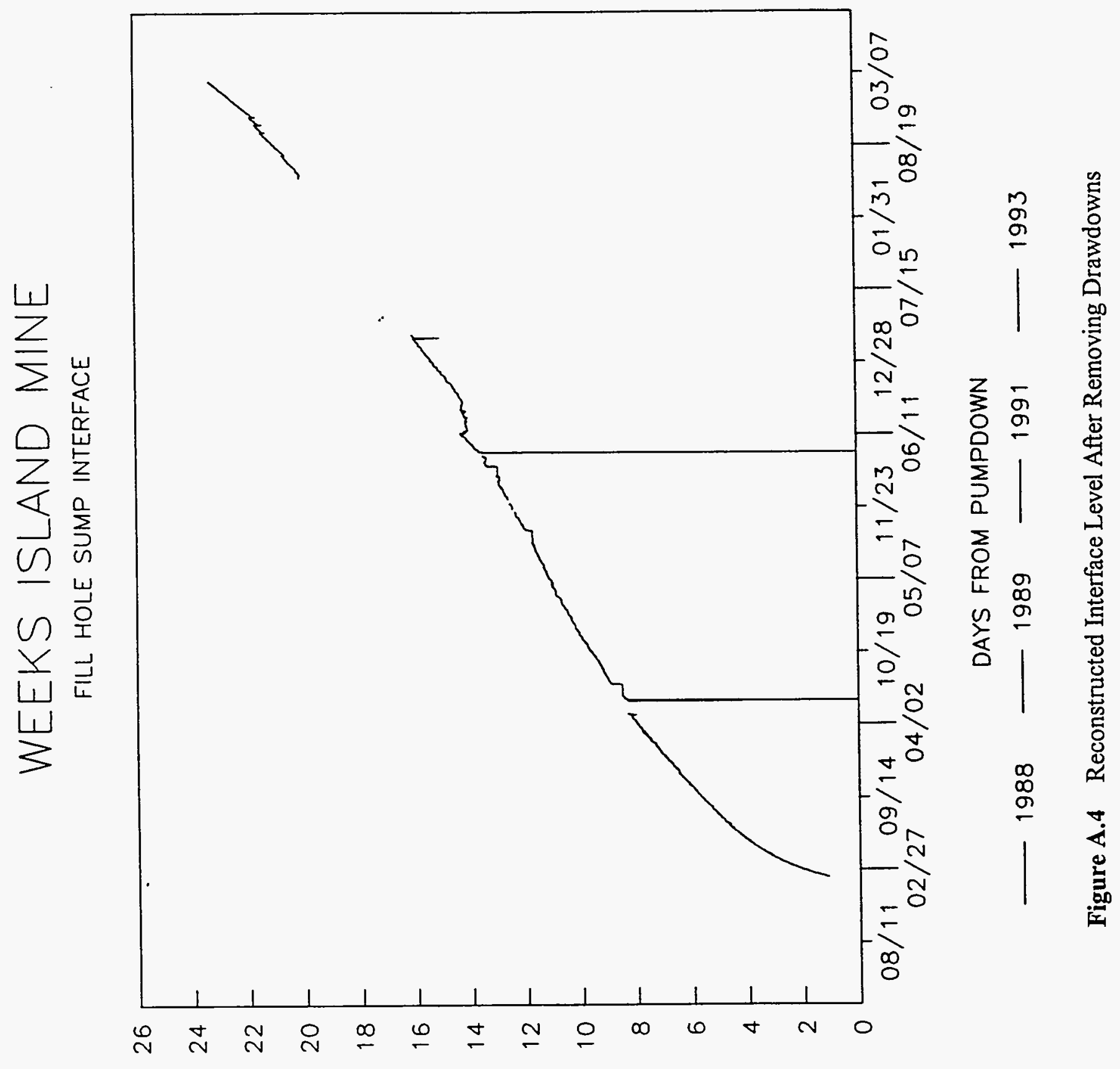

(ـ)

A-1-8 


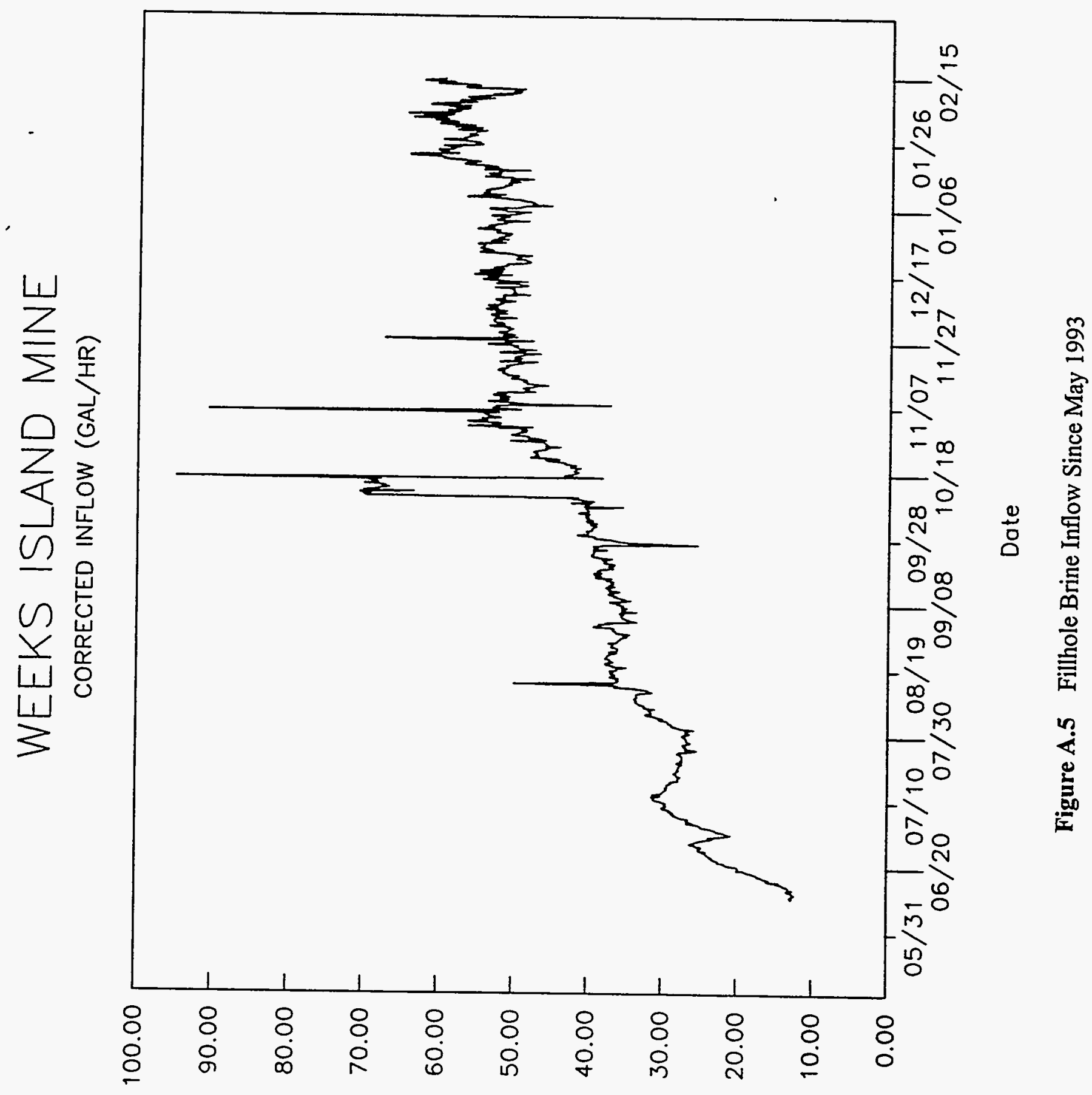

УกOH / SNOTרช

A-1-9 


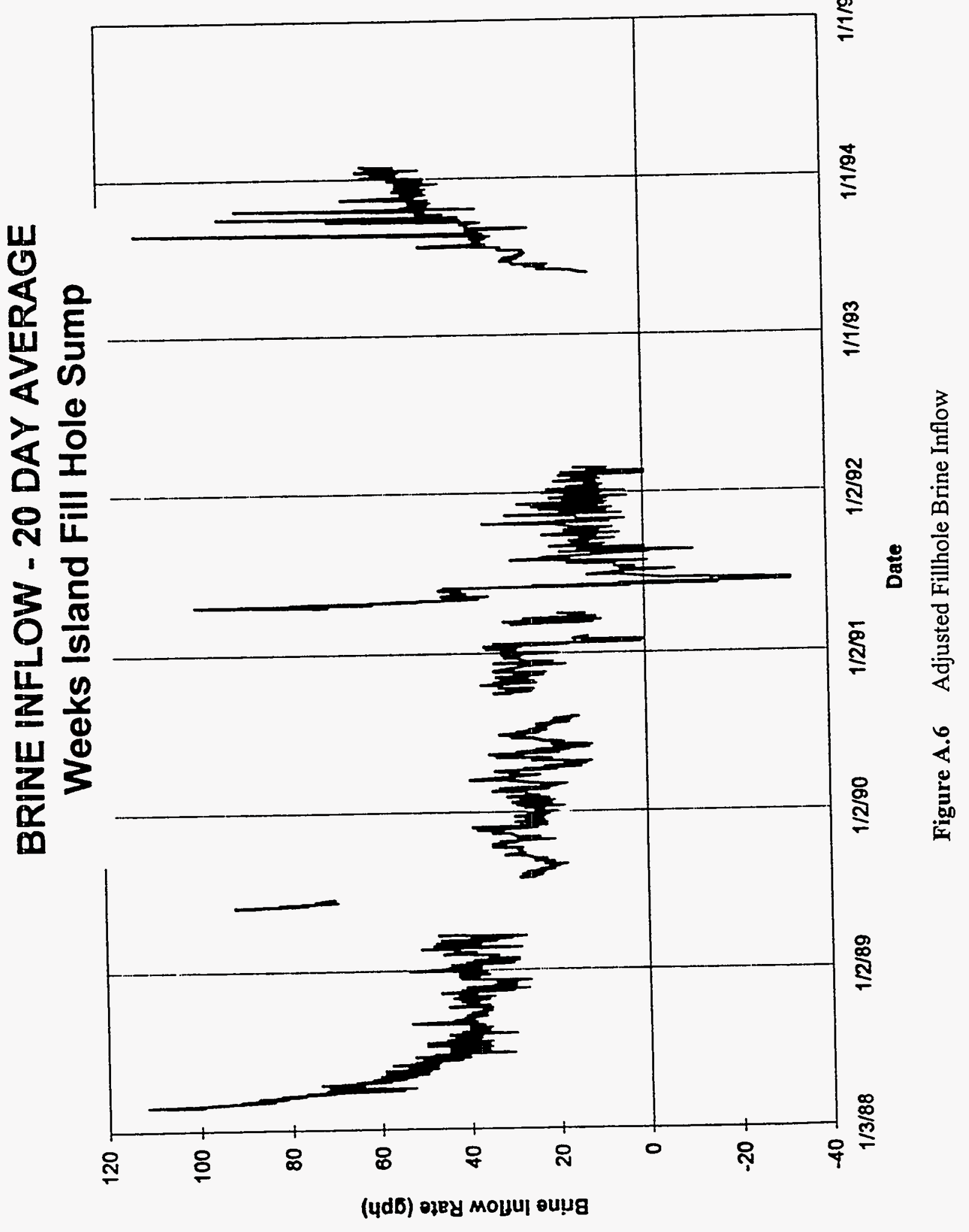

A-1-10 


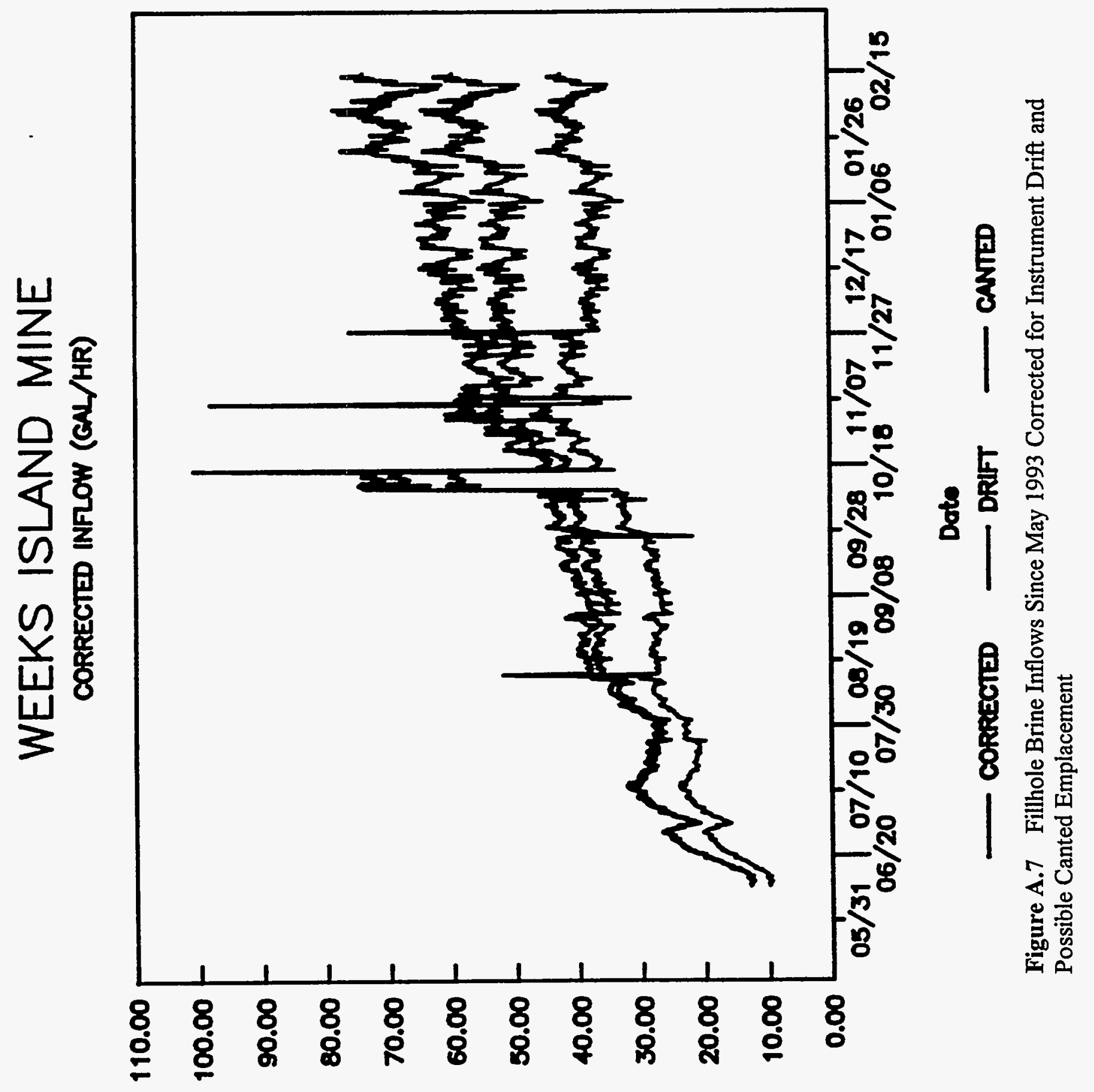

YNOH / SNOTINO 


\section{APPENDIX 1 REFERENCES}

1 BRINE IN THE WEEKS ISLAND SPR FACILITY. R. L. Thoms. AGM Inc. 22 September 1989.

2 STABLE ISOTOPE CONSTRAINTS ON THE ORIGIN OF BRINE IN THE WEEKS ISLAND STRATEGIC PETROLEUM RESERVE. L. Paul Knauth. Arizona State University. 13 August 1987.

3 STABLE ISOTOPE CONSTRAINTS ON THE ORIGIN OF BRINE IN THE WEEKS ISLAND STRATEGIC PETROLEUM RESERVE - UPDATE FOLLOWING ANALYSES OF SAMPLES TAKEN IN 1989. L. Paul Knauth. Arizona State University. 25 November 1989.

4 STABLE ISOTOPE CONSTRAINTS ON THE ORIGIN OF BRINE IN THE WEEKS ISLAND STRATEGIC PETROLEUM RESERVE - UPDATE FOLLOWING ANALYSES OF SAMPLES TAKEN IN 1990. L. Paul Knauth. Arizona State University. 15 November 1990.

5 STRATEGIC PETROLEUM RESERVE - WEEKS ISLAND FILLHOLE SUMP BRINE PUMPDOWN. DOCUMENT NO. D506-02289-05. J. McHenry and K. Simon. Boeing Petroleum Services Inc. 17 July 1989.

6 STRATEGIC PETROLEUM RESERVE - WEEKS ISLAND MINE FILLHOLE SUMP BRINE PUMPDOWN - APRIL 1991. DOCUMENT NO. D506-02828-05. J. McHenry, et al Boeing Petroleum Services Inc. October 1991.

7 "FILLHOLE PROBE RECOMMENDATIONS". Letter no. 10440-JMM-940064. Eyermann to Phillips. 23 February 1994. 


\section{BRINE INFLOW - 20 DAY AVERAGE \\ WEEKS ISLAND FILL HOLE SUMP}

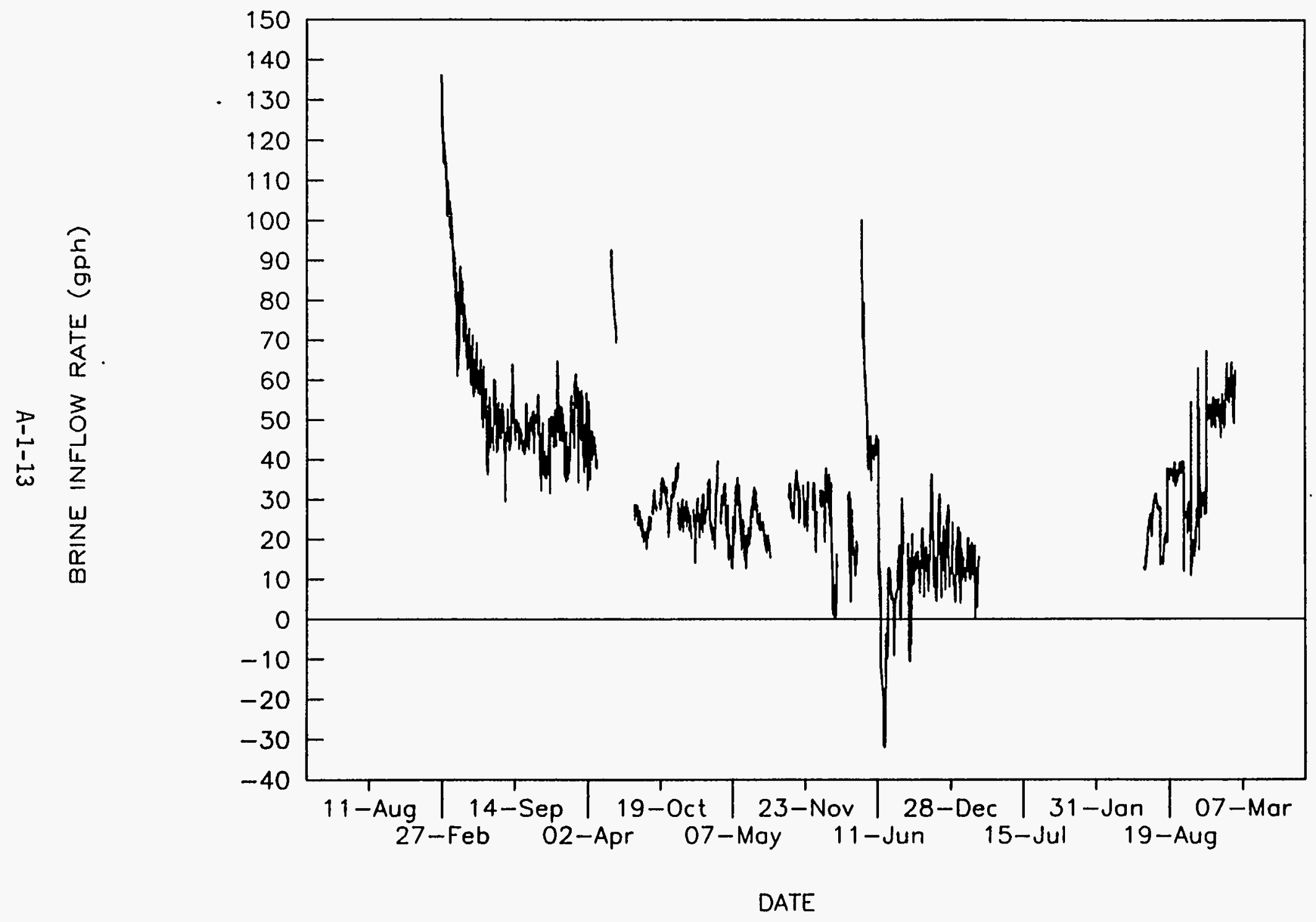

Figue till 


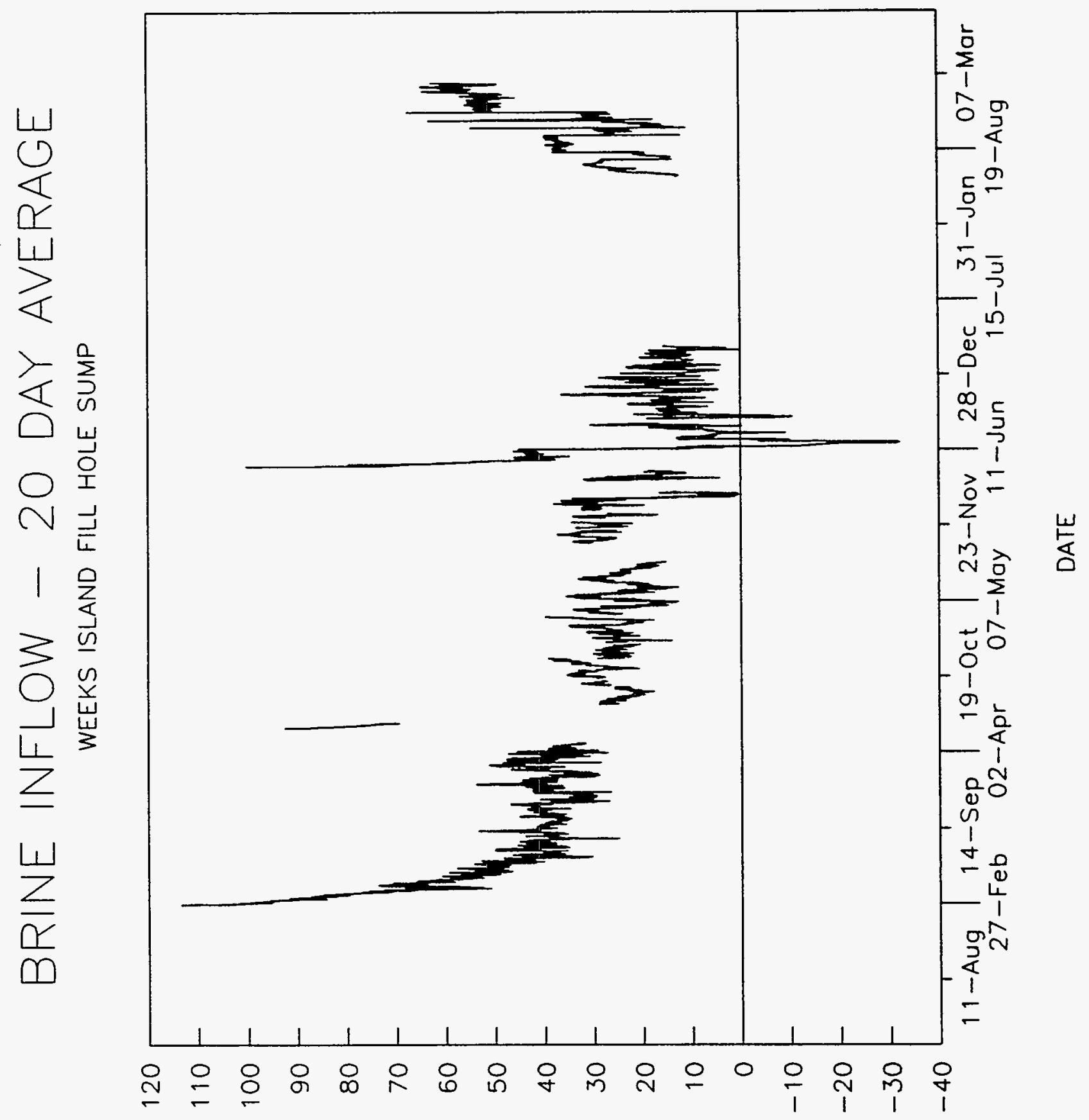

(५d5) $\exists \perp \forall Y ~ M O ר \exists N I ~ \exists N I Y G$

A-1-14 


\section{WEEKS ISLAND MINE \\ FILL HOLE SUMP INTERFACE}

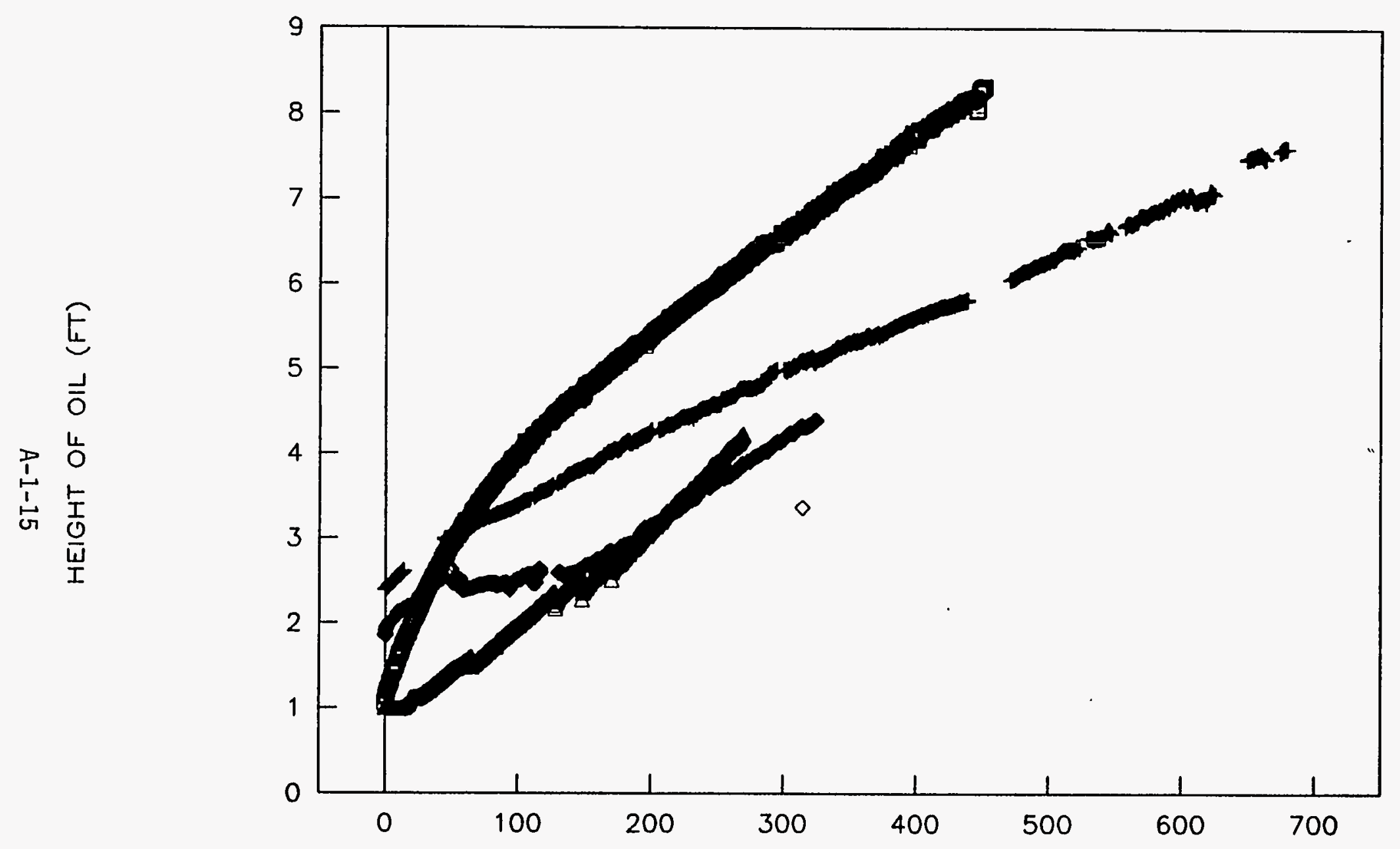

DAYS FROM PUMPDOWN
ㅁ 1988
$+\quad 1989$
$\diamond \quad 1991$
$\triangle 1993$

Figum Al.3 


\section{WEEKS ISLAND MINE}

FILL HOLE SUMP INTERFACE

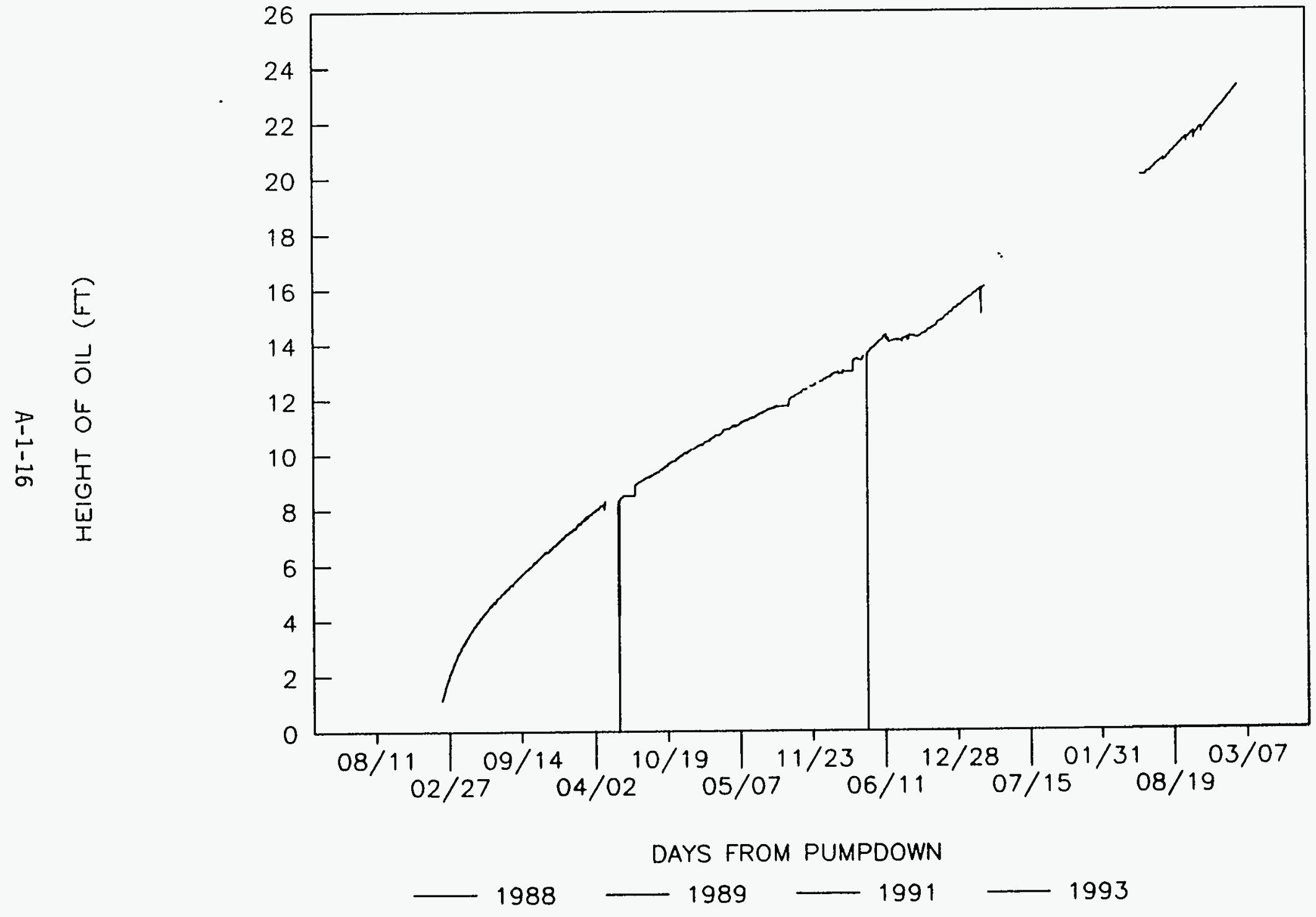




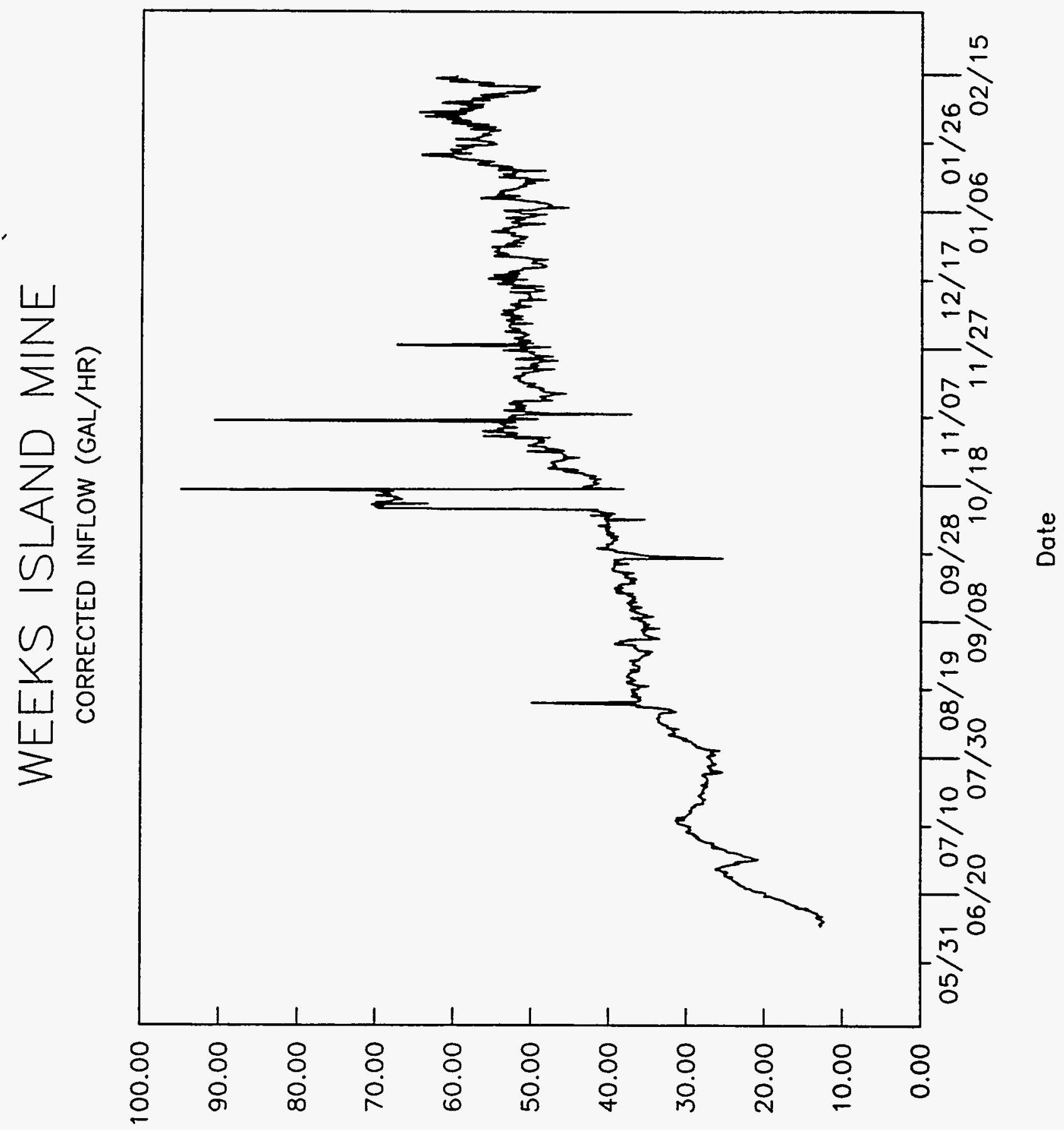

צחOH / SNOר7ళO

A-1-17 


\section{BRINE INFLOW - 20 DAY AVERAGE}

Weeks Island Fill Hole Sump

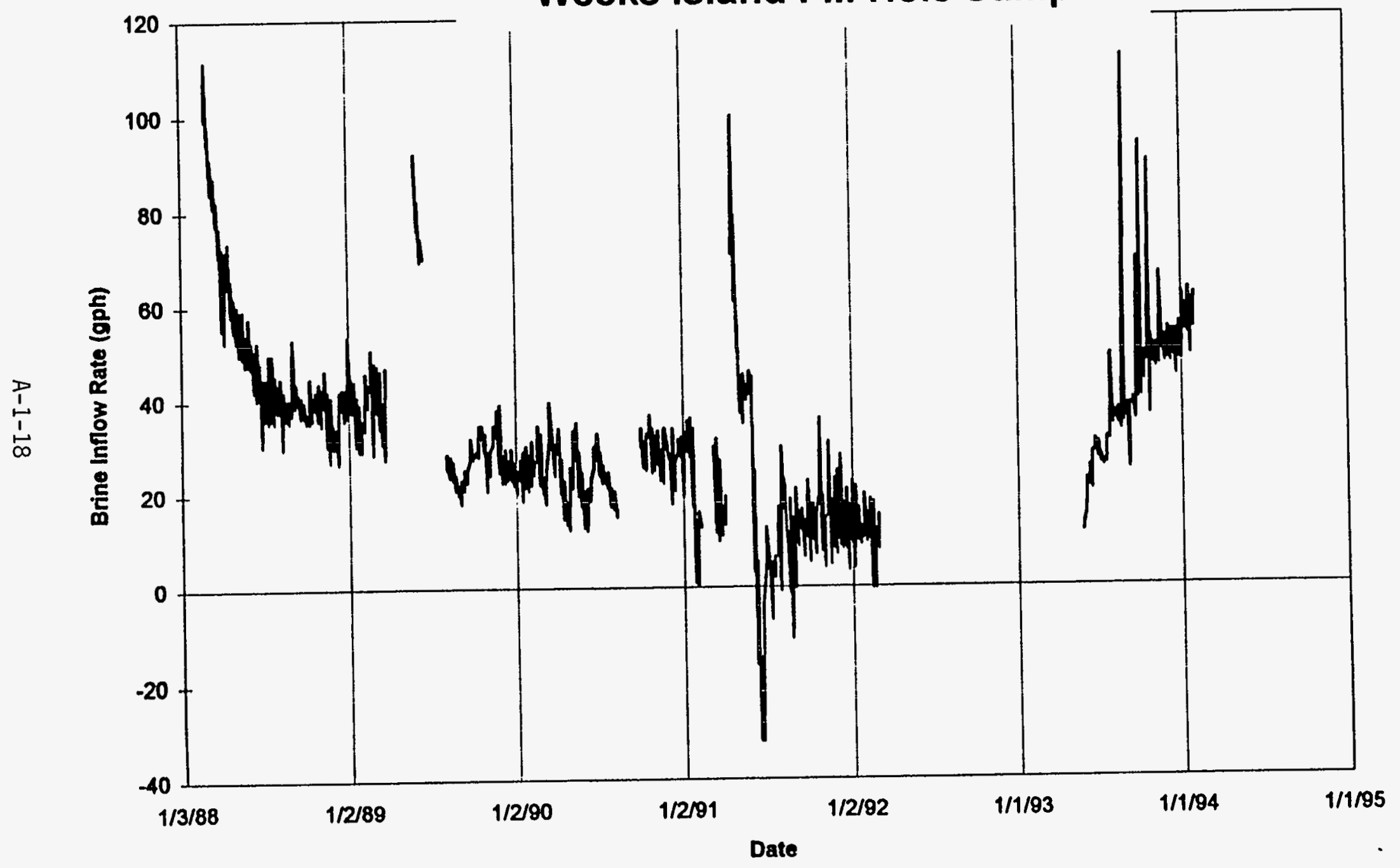




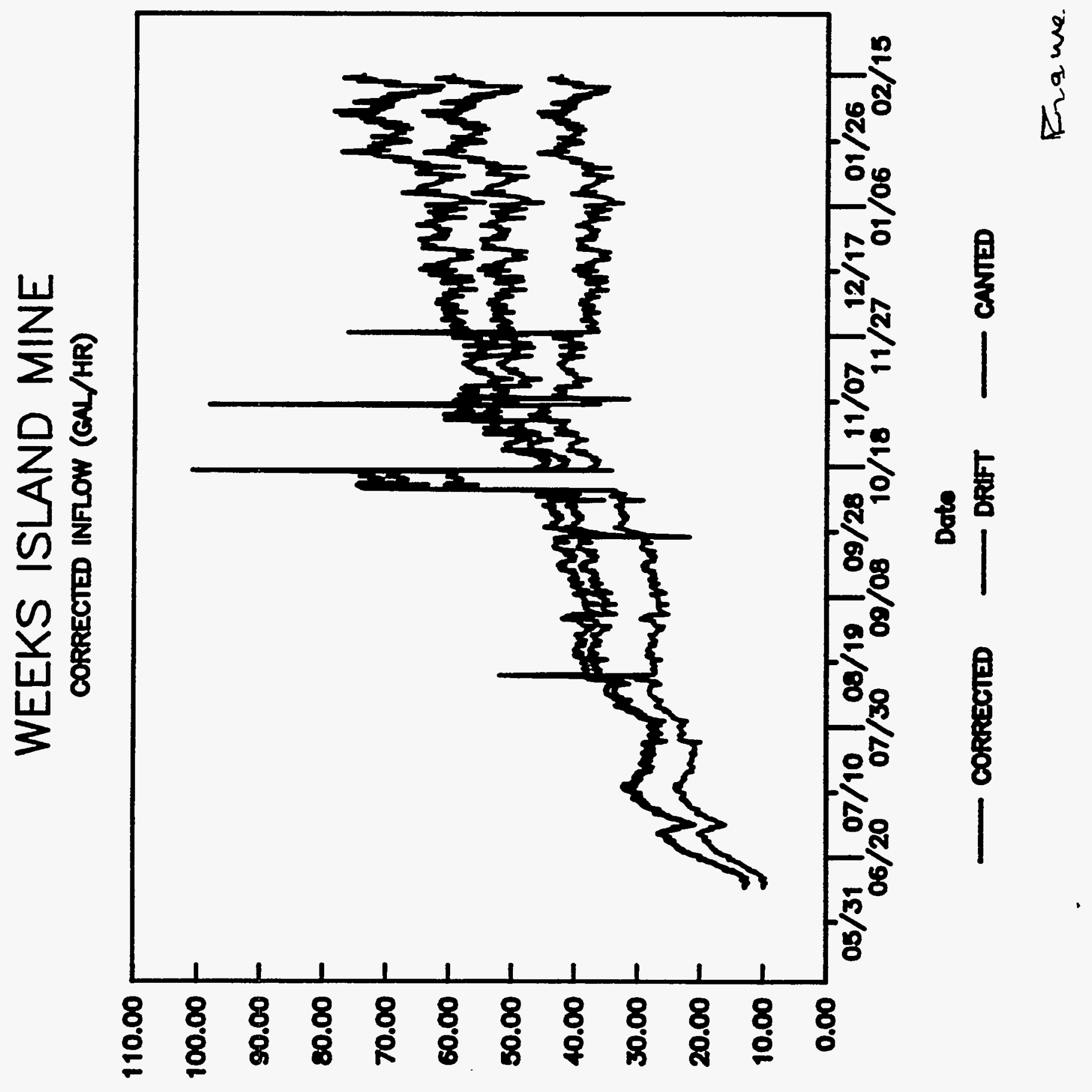

\&NOH / SNOTTYO

A-1-19 
Figure A.1 Uncorrected Fillhole Brine Inflow Rate

A-1-20 
Figure A.2 Corrected Fillhole Brine Inflow Rate

$A-1-21$ 
Figure A.3 Fillhole Sump Inflow Following Brine Removals 
Figure A.4 Reconstructed Brine Height After Removing Drawdowns

A-1-23 
Figure A.5 Fillhole Brine Inflow Since May 1993 
Figure A.6 Adjusted Fillhole Brine Inflow

A-1-25 
Figure A.7 Fillhole Brine Inflows Since May 1993 Corrected for Instrument Dritt and Possible Canted Emplacement 


\section{APPENDIX 1 \\ REFERENCES}

1 BRINE IN THE WEEKS ISLAND SPR FACILITY. R. L. Thoms. AGM Inc. 22 September 1989.

2 STABLE ISOTOPE CONSTRAINTS ON THE ORIGIN OF BRINE IN THE WEEKS ISLAND STRATEGIC PETROLEUM RESERVE. L. Paul Krauth. Arizona State University. 13 August 1987.

3 STABLE ISOTOPE CONSTRAINTS ON THE ORIGIN OF BRINE IN THE WEEKS ISLAND STRATEGIC PETROLEUM RESERVE - UPDATE FOLLOWING ANALYSES OF SAMPLES TAKEN IN 1989. L. Paul Knauth. Arizona State University. 25 November 1989.

4 STABLE ISOTOPE CONSTRAINTS ON THE ORIGIN OF BRINE IN THE WEEKS ISLAND STRATEGIC PETROLEUM RESERVE - UPDATE FOLLOWING ANALYSES OF SAMPLES TAKEN IN 1990. L. Paul Knauth. Arizona State University. 15 November 1990.

5 STRATEGIC PETROLEUM RESERVE - WEEKS ISLAND FILLHOLE SUMP BRINE PUMPDOWN. DOCUMENT NO. D506-02289-05. J. McHenry and K. Simon. Boeing Petroleum Services Inc. 17 July 1989.

6 STRATEGIC PETROLEUM RESERVE - WEEKS ISLAND MINE FILLHOLE SUMP BRINE PUMPDOWN - APRIL 1991. DOCUMENT NO. D506-02828-05. J. McHenry, et al Boeing Petroleum Services Inc. October 1991.

7 "FILLHOLE PROBE RECOMMENDATIONS". Letter no. 10440-JMM-940064. Eyermann to Phillips. 23 February 1994. 


\section{APPENDIX 2}

\section{PRELIMINARY WEEKS ISLAND MINE INFLOW CALCULATIONS}

A-2-1 
date: March 9, 1994

Sencia National Laboratories

s to: J.K. Linn, 6113 MSO706

Albuquerque, New Mexico 87185

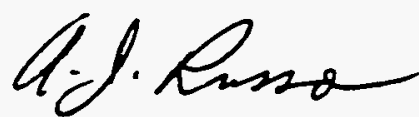

from: A.J. Russo, 1511

subject: Preliminary Weeks Island Mine Inflow Calculations

The development of a sinkhole at the surface over the location of the DOE SPR Weeks Island mine has prompted some speculation as to the cause of that localized subsidence. One of the possibilities considered is the occurrence of salt fracture in a region of the dome above the oil-filled mine, which finite element calculations predict to be in a state of tensile stress and dilatancy [Ehgartner, 1993 and Hoffman, 1994].

If the overlying salt is damaged, water from the sandy overburden which covers the domal salt, could flow into the mine carrying sand into the fractured region and enlarging the flow path by dissolution of the salt. The resulting void would be filled with the sediment or overburden from above causing the appearance of a sinkhole. The purpose of this memo is report progress on modeling of the possible inflow of water into the mine and to estimate the growth rate of a flow path through the salt

There are two conditions which have been investigated. Both assume that the flow path can be represented by a circular hole of some initially constant diameter which extends from the water bearing sediment to the mine. The first assumes that any sand that enters the hole washes all the way through, so that the hole is just water filled. The flow rate is mostly limited by the porous bed at the upper entrance to the hole. The flow rate can be estimated from [Harr, 1962]

$$
Q=\pi D K\left(h_{f}-h_{h}\right)
$$

where $Q$ is the flow through the overburden formation and hole, $D$ is the hole diameter, $K$ is the hydraulic conductivity and, $h_{f}$ and $h_{h}$ are the head in the formation and the top of the hole, respectively. As the water flows through the salt it will dissolve part of the salt until the water becomes saturated brine. To model this process a modified form of the solution mining code SANSMIC was used [Russo, 1983]. Although SANSMIC was 
developed to treat large scale cavern dissolution problems, it has also been used successfully on laboratory scale models [Russo, 1986].

One of the input parameters required to use SANSMIC is the specific gravity of the water entering the salt cavity. In the case being considered this water is drawn from the saturated sediment layer above the salt dome, which has a vertical salinity gradient in regions away from the hole. If the flow in the sediment layer is assumed to be governed by Darcy's equation, it can be shown that in regions away from the hole entrance, the flow becomes only a function of radial distance from the hole (i.e. the flow is horizontal and uniform) [Yih,1980]. The specific gravity of the entering fluid can then be calculated by appropriate averaging of the salt concentration away from the hole, if it is assumed that the fluid is mixed as it approaches the hole. In the present problem the salinity variation in the water saturated zone was taken to be a 12 foot salt saturated layer above the salt dome, and linearly diluted to a specific gravity of 1.04 at the water table, which is 95 feet above the dome [Ehgartner, 1994 and Hoffman, 1994]. This resulted in a mixed salinity of 1.13 at the hole entrance.

The results of this model predict that the hole rapidly enlarges from an initial 0.2 inch diameter, with a few bbl/d flow rate, to over 6 feet in diameter with more than a $10000 \mathrm{bbl} / \mathrm{d}$ flow rate in about two weeks. It then continues to grow even faster. The calculated hole-volume and flow-rate are shown in Figures 1 and 2.

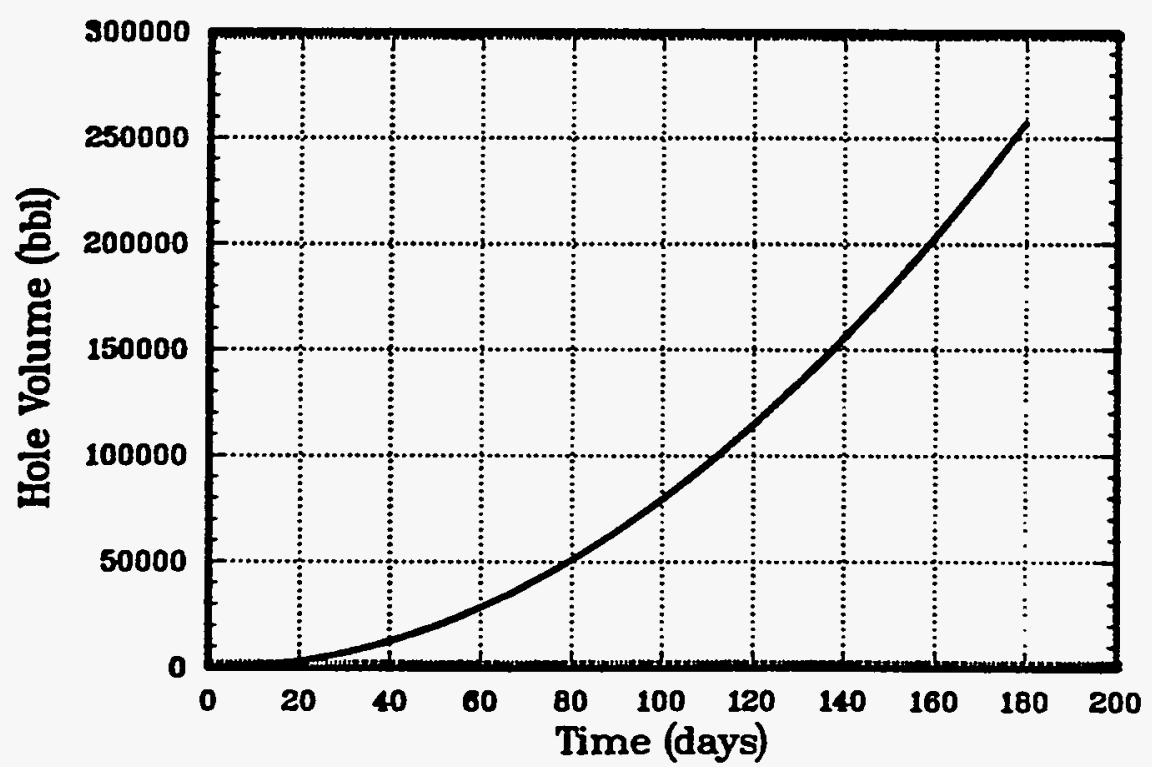

Figure 1. Calculated volume of a water-filled hole. Initial diameter $=0.2$ in .

This is clearly a limiting case since oil would be driven out of the mine by the rapid inflow of brine, and the brine entering the mine, which is unsaturated at high flow rates, could dissolve the supporting pillars and cause a mine collapse, driving the oil out even faster. The fact that this has not yet happened indicates that any fractures that exist are filled with sediment which is the second case considered. . 
The dissolution rates which are used in SANSMIC are based on data taken from cavities filled with unsaturated brine. In that situation the dissolution rate is found to be independent

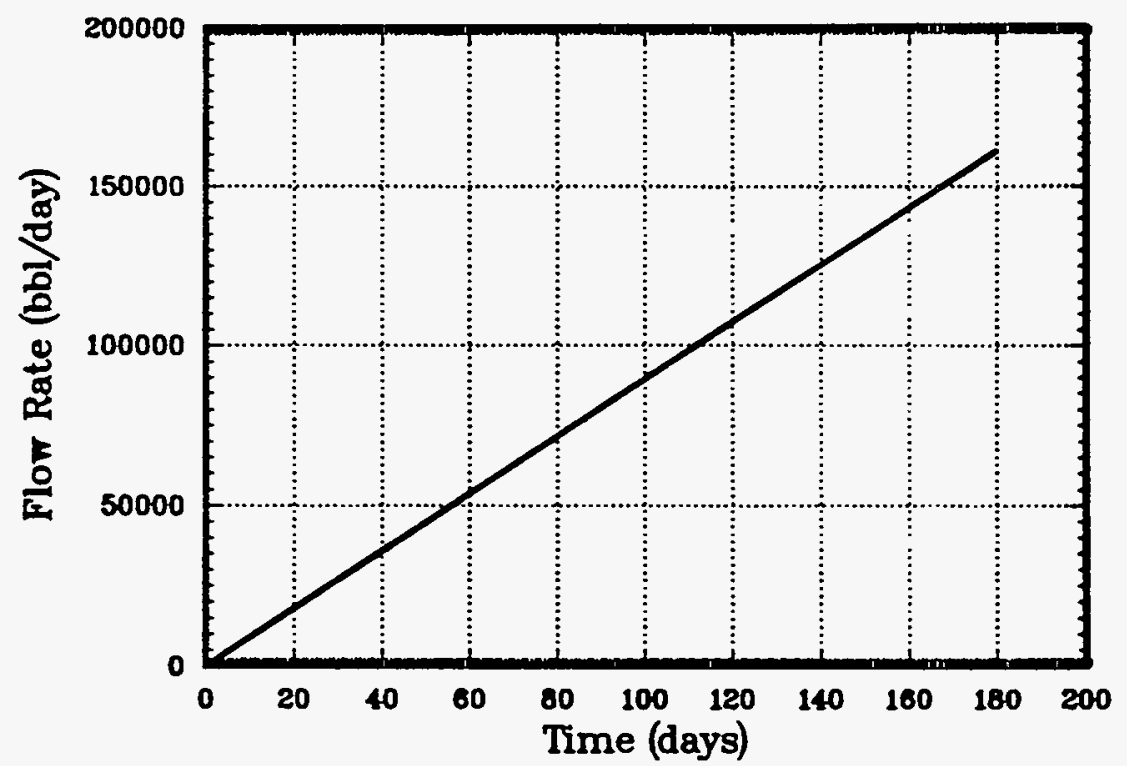

Figure 2. Calculated flow-rate of a water-filled hole. Initial diameter $=0.2$ in.

of flow rate, except for very high flow velocities ( $>3 \mathrm{ft} / \mathrm{s})$. This is because salt is removed from the surface in a boundary layer formed by natural convective flows, which are somewhat independent of geometry and generally exceed the forced convective flow velocities used in cavern formation. The dissolution rate may then be calculated from a polynomial function of concentration only [Russo, 1983]. If a salt cavity is filled with sand however, the natural convective cells are suppressed and Darcian flow will be the dominant flow mechanism. In that case the dissolution rate will be reduced and salt will be removed from the surface by dispersion and molecular diffusion. Dispersion in porous media, which for our case, is the dominant mechanism, is generally taken to be proportional to the flow velocity and the sand grain size.

To estimate the effect of dispersion on removal of salt from a wall adjacent to a porous flow an ion diffusion code, IONMIG, [Russo, 1984] was used. Calculations were performed for flow through a $40 \mathrm{~cm}$ diameter, $3 \mathrm{~m}$ long, sand filled cylinder with a salt saturation concentration boundary condition at the cylinder walls. Fresh water was introduced at one end at a constant velocity, and the steady state flux of salt at the outflow end was computed. The dissolution rates estimated in this way are weakly dependent on the geometry selected, so the length chosen corresponds to the mesh increment used in SANSMIC, and the diameter chosen is one for which the concentration at the center of the cylinder is only slightly changed for flow through that length increment.

The salt removal rate was $0.002 \mathrm{lb} / \mathrm{ft}^{2} \mathrm{~min}$. for a sand grain size of $0.6 \mathrm{~mm}$ and a flow rate of $0.36 \mathrm{~m} / \mathrm{hr}$ (which corresponds to unity head gradient and the average sediment sand grain diameter at Weeks Island). This yields a recession rate of $0.001 \mathrm{ft} / \mathrm{hr}$ compared to a pure 
water recession rate of $0.0446 \mathrm{ft} / \mathrm{hr}$, so that the sand reduces the dissolution rate to about 2 percent of the empty pipe rate for that case. In these calculations the ratio of transverse to longitudinal dispersivity was assumed to be 0.1 as is commonly practiced. Similar calculations showed that the recession rate varied linearly with velocity. SANSMIC was modified to use dissolution rates which were equal to the water-filled (concentration . dependent) rate times a velocity dependent factor which made the result equal to the IONMIG calculated rate for pure water.

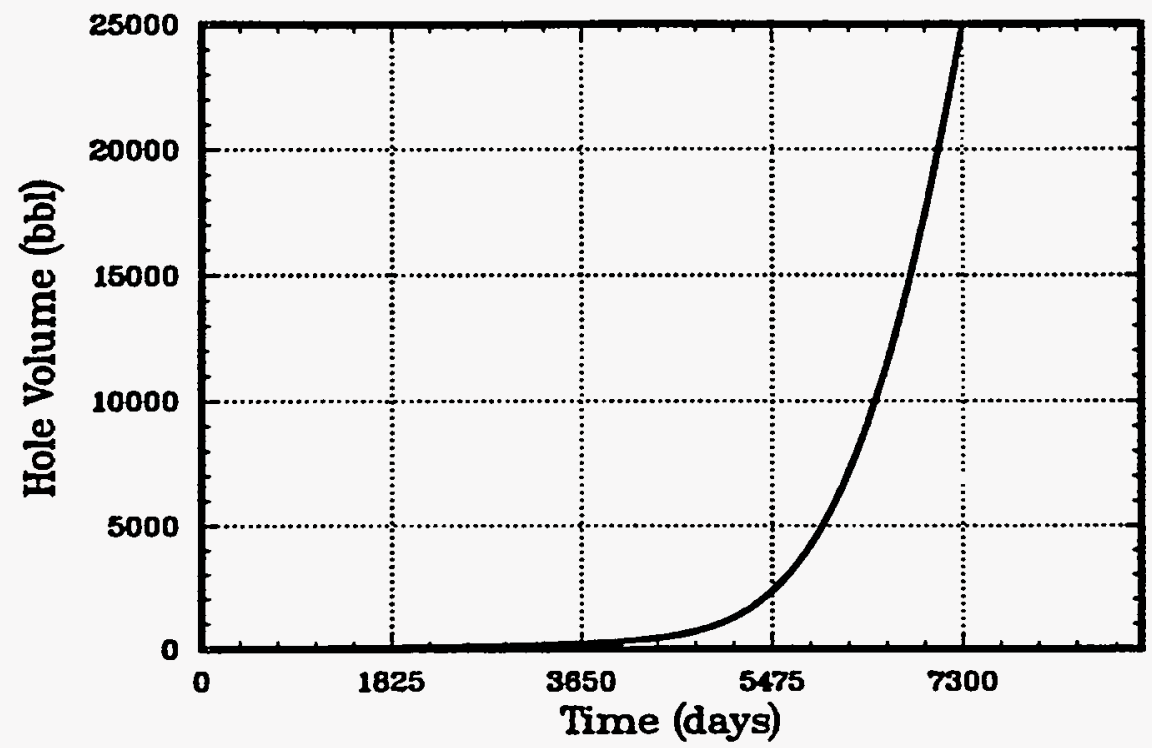

Figure 3. Calculated hole volume for a sand-filled hole. Initial diameter $=4$ in.

The flow resistance of the sand-filled hole and overburden was accounted for by calculating the equivalent hydraulic conductance of the flow system. The sand-filled hole was represented as a series of slices where the hydraulic conductance is proportional to the permeability of the sand times the hole diameter at that elevation. As before the hydraulic conductance of the overburden was calculated assuming semi-spherical flow. The flow through this system provided the required flow rate input to SANSMIC, iterating at each time step.

The results of the calculations for the sand-filled case are shown in Figures 3-5. Figure 3 presents the volume of the hole as a function of time. This calculation assumed an initial effective hole diameter of 4 inches, completely filled with sand. The hydraulic conductivity was taken to be $3.28 \times 10^{-4} \mathrm{ft} / \mathrm{s}(0.01 \mathrm{~cm} / \mathrm{s})$, the length of the hole in the salt was $415 \mathrm{ft}$, and the formation head above the hole was $95 \mathrm{ft}$. The hydraulic conductivity is representative of the overburden [Acres 1986], and is considered appropriate for the unconsolidated sand in the hole [Bureau of Recl., 1977]. The pressure at the bottom of the hole was assumed to be atmospheric.

If it were assumed that all the soil from the sinkhole (about $3000 \mathrm{bbl}$ ) displaced into the hole and remained there, this figure shows that the hole age would be about 15 years. About 
$100,00 \mathrm{bbl}$ of brine would have flowed into the mine at that time. If half the soil has washed through the hole and into the mine, it would be about 14 years old. The large $60 \mathrm{ft}$. wide by $75 \mathrm{ft}$. high rooms in the mine could accumulate as much as 70,000 bbl. of sediment before piling up to a leak in the roof. Figure 4 shows that the corresponding flow rates for those two assumptions are about $200 \mathrm{bbl} / \mathrm{d}$ and $75 \mathrm{bbl} / \mathrm{d}$ respectively. Figure 5 shows the change in size and shape of the hole with time.

Although the above assumptions are thought to be the most realistic, at this time, there is considerable uncertainty in a number of values. In order to assess the effects of variations in some of these parameters a number of additional calculations were performed.

If the initial hole diameter is made smaller, it is found that the early flat portion of the holevolume and flow-rate curves are extended, so that the curves of volume and flow-rate are just shifted in time. For example cutting the initial diameter in half to 2 inches shifts the curves 5 years to the right. Because it is known that before the mine was filled $(-1980)$, there was no leakage (or very small leakage) into the mine, and because there is a noticeable volume of soil which has been displaced at this time, an initial hole diameter of 4 inches was selected for presentation because it meets those conditions. Although other sizes may also meet these conditions, the predicted future flow rates (assuming a current hole volume of $3000 \mathrm{bbl}$.) are similar for the various initial hole sizes.

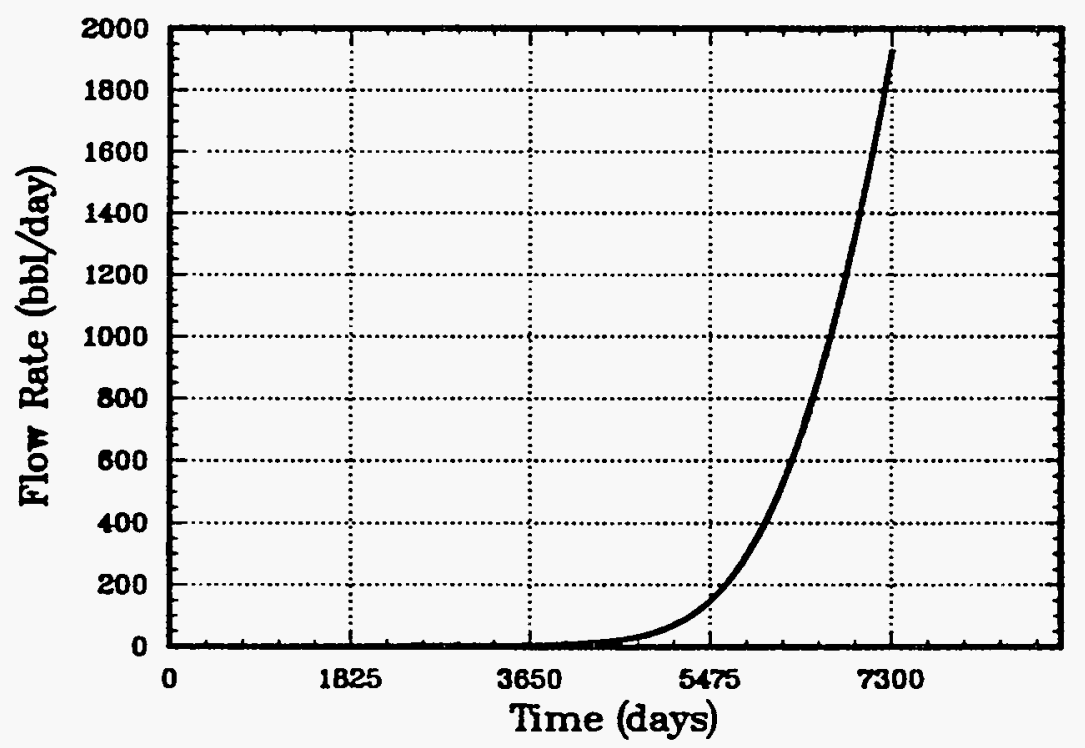

Figure 4. Calculated flow rate for a sand-filled hole. Initial diameter $=4$ in. 


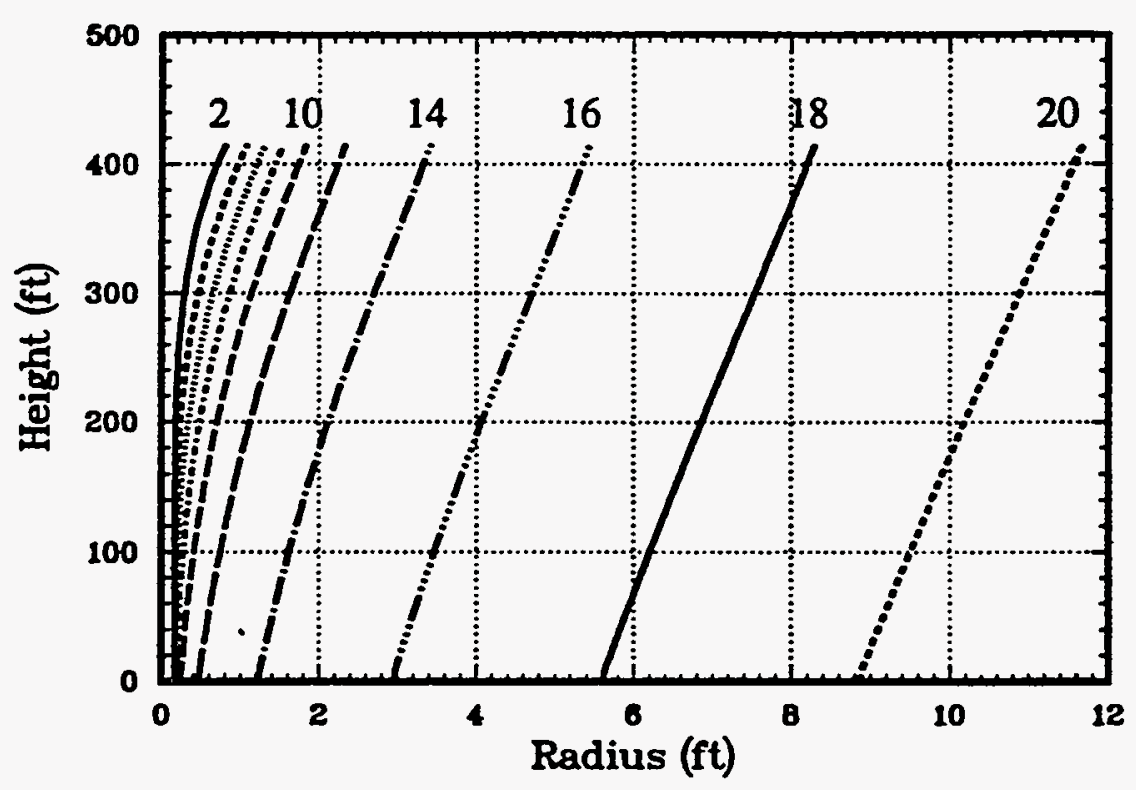

Figure 5. Calculated hole shapes of a sand-filled hole in two year intervals

If the sand grain diameter increases, without changing the permeability or porosity, the dispersion coefficient and dissolution rate increase. This also shifts the hole-volume and flow-rate curves to the right because the brine saturates faster near the top of the hole which reduces the growth rate of the hole near the bottom, which further, restricts the flow rate and hole growth. The hole shape also changes in that case to a wider angle funnel shape.

\section{Conclusions}

A model of the growth of a leak through a salt region has been developed to investigate the Weeks Island Mine sinkhole problem. This model indicates that after a period of relatively slow growth, the hole size and flow-rate increase very rapidly. There is currently not enough known about the hole size and shape, or flow characteristics to determine with much confidence the present location on the growth curves. If it is assumed that all of the displaced soil from the sinkhole still resides in the leak path, the model suggests that we are within a few years of very rapid and noticeable flow increases. Even if this were a poor assumption, if at any time the sediment filling the hole should wash out, the growth rate of the hole and the flow rate would increase rapidly until the free volume in the mine filled, and the mine pressurized to hydrostatic equilibrium. This would require only about 50 days and would result in a $15 \mathrm{ft}$. diameter hole at the roof of the mine. Should the sediment fill wash out during a drawdown of the mine, where up to $73 \mathrm{MMb}$ of free space may exist, a much larger hole is predicted (up to $120 \mathrm{ft}$. diameter). 


\section{References}

B.L. Ehgartner, "Weeks Island Stress Prediction and Relationship to Sinkhole Formation," Internal Sandia Memo to J.K. Linn, October 15, 1993.

E.L. Hoffman, "Three Dimensional Structural Evaluation of the SPR Weeks Island Oil Storage Facility," Internal Sandia Memo to J.K. Linn, January 13, 1994.

M.E. Harr, 1962, Groundwater and Seepage, McGraw-Hill, New York.

A.J. Russo, "A User's Manual for the Salt Solution Mining Code SANSMIC," Sandia National Laboratories Report SAND83-1150, September, 1983.

A.J. Russo and D.C. Reda, "Experimental Studies of Oil Withdrawal From Salt Cavities by Freshwater Injection," SPE Production Engineering, January, 1986, p 75-86.

C.S. Yih, Stratified Flows, Academic Press, New York, p302, 1980. and personal communication from C.E. Hickox, Dept. 1511.

B.L. Ehgartner, "Weeks Island Inflow Model," Internal Sandia Memo to J.K. Linn, January $25,1994$.

A.J. Russo, "A Users Manual for the Radionuclide Migration Code IONMIG," Sandia National Labs. Report SAND83-1276, November, 1984.

Acres, "Additional Geotechnical Studies SPR," Sandia National Labs. Report SAND867181, Acres International for Sandia National Labs, 1986.

Bureau of Reclamation, Groundwater Manual, U.S. Dept. of Interior, p 480, 1977.

AJR:1511

Distribution:

1500 MS $0841 \quad$ D.J. McClosky

1502 MS 0827 P.J. Hommert

1511 MS 0827 C.E. Hickox

1511 MS $0827 \quad$ J.S. Rottler

6100 MS $0701 \quad$ R.W. Lynch

6113 MS $0706 \quad$ B.L. Ehgartner

Copy to:

1511 Day File 


\section{APPENDIX 3}

SEDIMENT/CORE DESCRIPTIONS

and

DAIIY DRILLING REPORTS 


\section{Weeks Island Sinkhole BH-3}

Coordinates: $X=1,849,892.99 ; Y=414,006.63 ;$ Elevation $=82.6 \mathrm{msl}$

Footage Core / Sample Description Remarks

34-54 sand, medium; grab samples taken $34-188^{\prime}$

10YR 6/8 (brownish yellow; color same to 180 )

54 -74 sand; scattered fine gravel; chert and quartz. Broken black rock fragments; very faint efflorescence; limestone \&/or chert (?)

Seismic reflector?

74 - 94 sand, coarse; scattered fine gravel; chert Broken black rock fragments

94-114 sand, coarse; chert

114 - $134 \quad$ sand, very coarse; chert

134 - 154 sand, very coarse; chert

154 - $174 \quad$ sand; medium to coarse

180 - $185 \quad$ sand; medium to coarse

185 - $187 \quad$ sand, coarse chert and anhydrite (?) "black" sand

$188 \quad$ sand, coarse; chert and anhydrite; salt $\quad$ top of salt @ $187^{\prime}$ from logs

188 - 250 SALT; clear, crystalline with average crystals $\sim 1-1.5 \mathrm{~cm}$; structure lacking but some vertical elongation of crystals 196-200; milky exterior and some rubble 220-225 (probable core barrel compaction); slightly larger crystals averaging 1.5-2 cm @ 235-245 ft

Core recovery virtually $100 \%$; many intact $5 \mathrm{ft}$ sections; most runs $3-4$ pieces. Should provide good samples for lab testing.

Drillsite geologists: Autin, Neal and Vogt. Salt core examination and handling from 1700 hrs, 20 June to 0400 hrs, 21 June 1994. Samples for laboratory testing shipped to RE/SPEC.

Static Water Level interpreted from neutron log @ +3-4 ‘ msl. 


\section{Weeks Island Sinkhole BH4}

Coordinates: $X=1,849,810.55 ; Y=414,126.46$; Elevation $=86.6 \mathrm{ft} \mathrm{msl}$ Footage

Core / Sample Description

85

95

105

115

125

137

145

160

170

$(-. .+$.

181

182

183 sand, coarse, w/ some fine gravel "

" sand, same as $85-105$

1

1

"1

$--$ of cuttings.

same

\section{$\underline{\text { Remarks }}$}

cuttings grab sample

gravel, sandy (pea gravel). Distinct variation in otherwise similar sandy section. See photos.

Black chert gravel. Coloration mainly a rind on chert. Abundant wood fragments, probably $\sim 5-10 \%$

same, but with halite crystals. Wood is probably Wisconsinan Prairie Fm., says Whitney Autin. Wood readily sinks in water.

Chatter in drilling indicates major change, probably entering top of salt stock.

Start coring 10 June, 1400 hrs. Vogt, Neal, Autin, Lock initially, then Neal / Autin.

$183-190$

185

$195-250$
Transition, salt

SALT, top of stock

Salt, crystalline, $1 \mathrm{~cm}$ average. Absence recovery of structural features in core, e. g., anhydrite banding, etc. Generally clear, clean salt, but drilling-induced horizontal banding is evident Core is very soft and cannot support own weight; longest piece $\sim 12$ in. Most $5 \mathrm{ft}$ runs contain at least 15 pieces. Shorter $(4 \mathrm{ft})$ trips tried for last $16 \mathrm{ft}$ but no change was noted in condition of salt.
First core barrel empty

TOS@ 188; nat. $\gamma$

"Disking" from over- $100 \%$ packing (?) in core barrel. Less disking below $195 \mathrm{ft}$.

See photos.

Coring complete @ 0100, 11 June

Static Water Level interpreted @ +3-4 ft msl, from neutron log. 


\section{Weeks Island' Sinkhole BH5}

Coordinates: $X=1,849,893.05 ; Y=414,085.04$; Elevation $=84.7 \mathrm{ft} \mathrm{msl}$ Footage Core / Sample Description

35 - 55 sand; medium to coarse; abundant to fine gravel; chert and quartz

$\underline{\text { Remarks }}$

10YR 6/8; brownish yellow; color same to $177-184^{\prime}$

$55-75 \quad$ sand, medium

75 -95 gravel; fine; mostly chert; $10 \%$ black gravel and rock fragments

95 - 115 sand, coarse; scattered fine gravel, chert

$115-135 \quad$ sand, coarse

135 - 155 sand, medium to coarse

$155-177$ sand, medium; yellowish clay chips in returns

177 - $184 \quad$ sand, coarse; mostly anhydrite; few chert gravel fragments

no salt crystals noticed; Top-of-salt from logs@189 ft (natural gamma)

$184-245$ SALT, crystalline; grain size $\sim 1-1.5 \mathrm{~cm}$ average; salt was entirely rubble-ized except for a few feet near top of section. Salt has somewhat milkish character

Drillsite geologists: Autin / Vogt

Static Water Level was not interpretable on the neutron log. 


\section{Weeks Island Sinkhole BH6}

Coordinates: $X=1,849,742.33 ; Y=414,081.06$ Elevation: $83.8 \mathrm{msl}$

Drillsite geologists: Neal; Autin; Bauer

Start 6 June 94; 2200 hrs.

Footage

4-6

$16-19$

$21-26$

\section{Core /Sample Description}

silty clay loam, scattered $2-4 \mathrm{~mm}$ gravel

8 " recovery

sandy clay loam, coarse, water saturated

2 " recovery

sand, medium

6" recovery $\underline{\text { Remarks }}$

10 YR $5 / 8$

(yellowish brown)

@ transitional boundary of loess / Prairie Fm.

5YR 5/8

(yellowish red)

10 YR 7/6

(yellow)

Conductor casing set 07 Jun and cemented at 0800 hrs - drilling to resume @ 2000

Drillsite geologists: Autin; Neal

8 June, 0400

$42-46$

sand, medium to coarse, cohesive, minor clay (?); continuous core bedded, mottled 2-5 mm Mn stains

10 YR 6/8

(yellowish brown)

$50-52$

sand, medium, with coarse fragments; becoming more coarse from previous; mottled w/ Mn stains

10 YR $6 / 8$

57

sand, coarse, with 3" zone of rounded gravel

10 YR 7/4

fragments up to $10 \times 25 \mathrm{~mm}$, grading into medium sand

(strong brown)

$64-65$

sand, medium, mottled, with iron staining

10 YR $7 / 4$

Drillsite geologists: Autin; Neal

8 June, $1100 \mathrm{hrs}$.

70 -75 sand, medium; faint bedding; few Mn nodules (stains) 6" recovery

10 YR $7 / 4$

some iron stains

$75-80$

sand, medium, faintly laminated, few Mn stains;

10 YR 7/6

6" recovery some iron stains (10 YR 7/6)

(yellow)

$80-90$

sand, laminated

10 YR 7/6

no recovery

(yellow)

$90-95$

sand, medium; becoming coarse, $w / 2 \mathrm{~cm}$ gravel

10 YR $7 / 6$

12 " recovery fragments and $\mathrm{Mn}$ stained nodules; then becoming

medium again

$95-100$

sand, medium; isolated gravel fragments $(2 \mathrm{~cm})$;

8 " recovery faint lamination

10 YR 7/6

All of these sediments are characteristic point bar deposits of the ancestral Mississippi River, says Prof. Whitney Autin.

$$
A-3-5
$$


8 June; 1640 hrs.

100 -105 sand, medium, with few coarse sand zones and

$10 \mathrm{YR} 7 / 6$

with a few (rare) gravel pebbles $(2 \mathrm{~cm})$; manganese

layering @ 105 (3 distinct, irregular layers, 4-12 mm)

$30^{\prime \prime}$ recovery

$105-125$

sand, medium predominantly, with a few gravel

10 YR $6 / 4$

pebbles $(1 / 2-2 \mathrm{~cm})$ and a few $\mathrm{Mn}$ stains.

(lt. yellowish brown)

Faintly laminated; 24 " recovery $\mathrm{pH} 8-8.5$

8 June; 1900 hrs

$125-150 \quad$ sand, medium; textures disturbed.

10 YR $7 / 4$ to $7 / 8$

v. low recovery; about 12 " total, quite disturbed.

$150-155$

sand, medium, becoming cleaner; very faint

10 YR $7 / 4$

38 " recovery, laminations, with some iron stains.

(v. pale brown)

$155-160$

no core

$160-165$

sand, medium, uniform; disbursed Fe staining:

yellowish brown

36 " recovered very faint bedding; absence of Mn stains.

$165-170$

no core

9 June; 1000 hrs.

Autin; Neal

170 - $172.5 \quad$ sand, medium, uniform, Fe stained; no Mn stains.

$100 \%$ recovery. Faint laminations.

yellowish brown

$172.5-175$

sand, medium, uniform. Faint laminations.

yellowish brown

$100 \%$ recovery

175

pipe stuck; stop drilling

84 - $185 \quad$ Overwash of stuck pipe and subsequent reaming produced considerable extraneous sand in section. Material highly permeable, mostly medium sand. At very bottom black wood was encountered, similar to BH4, except no accompanying sand or chert pebbles.

185 -189 Black wood fragments. Some float, others sink. Grab samples Not a minor facies, as no other material was washed.

189 - 192 Conspicuous drill chatter henceforth, presumably

Salt pick@189’ on marking top of salt (@189-190). Finer shredded natural gamma log

wood continued circulating, but no salt crystals were seen 
Salt coring 29-30 June by Tim Vogt (RE/SPEC) and Brian Ehgartner (SNL)

188 - 192 included cement and sediment $+1.6 \mathrm{ft}$ of salt; angular . chert gravel at interface + rounded globular gray gravel-size pebbles resembling cement.

192 sand, coarse, uniform; 1-2 mm , rounded. With dark gray orange-brown chert (?) grains, similar to chert gravel noted above. Below wood.

190 - 248 SALT; crystalline; grains 1-1.5 cm average, similar to previous recovery in BH3, BH4, and BH5. Very minor "wisps" of anhydrite noted at $\sim-230 \mathrm{ft}$. Grains show slight elongation vertically. Cement falling from interface along with chert gravel impeded good core recovery, and only a limited amount may be suitable for testing because of broken core. $248 \mathrm{TD}$

Static water table uninterpretable on neutron $\log$ 


\section{Weeks Island Sinkhole BH7a (slanthole)}

This hole was initiated to intersect the presumed dissolution feature at top of salt directly below the sinkhole. A $45^{\circ}$ inclination was initially desired, but a $61^{\circ}\left(29^{\circ}\right.$ from vertical) was started for practical reasons involving equipment. The final inclination upon completion was $\sim 68^{\circ}\left(22^{\circ}\right.$ from vertical). Grab samples were taken by bucket wash, allowing time for settling, rather than screening. Thus samples are only partly representative of in situ sediments.

Coordinates: $\mathrm{X}: 1,849,906.59$; Y: $414,184.70$; Elevation: $89.0 \mathrm{msl}$ Drillsite Geologists: Vogt, Neal, Ehgartner

\section{Footage (slant) Core / Sample Description \\ $41-51$ sand, fine to medium}

$51-61$

61 - 131 sand, medium to coarse (coarser than above)

131 - 133.5 sand, medium-fine (finer than above)

$135 \quad$ per $61-131$

135 - 145 no samples

145 - $165 \quad$ sand; finer, per 131

165 - $175 \quad$ clayey silt (distinctly different facies)

175 - 195 sand, medium

195 - 205 sand, medium, with minor wood fragments

205 - 215 sand, medium, uniform. Very closely resembles sand in BH9 at $189 \mathrm{ft}$, but is slightly grayer. (see photos)

215 - 275 SALT; crystalline, $1-1.5 \mathrm{~cm}$ grain size; general absence of any structural features or textural variation, although hint of vertical grain elongation exists occasionally. Core generally crumbly and not suitable for testing. (a) 225-235 somewhat more "unconsolidated" (a) 235-245 somewhat milky; from 245-255 salt crumbly, only 245-248 intact. From 265-275 clean, clear, salt. @ 275+4" circulation lost and pipe fell 3-4 ft.

275.5

$275-280$
Salt, prior to entering dissolution void (4" piece) filled with sediment. Salt piece shows evidence of erosion.

mud, sludge, sand (mixed with attapulgite drilling fluid)

sand, medium, stained with limonite; disturbed: (very small sample at bottom stuck on above drilling mud and sediment). This more resembles "formation material" in BH6 than bottom material from BH9 @189 ft)
27, 28 June 94

\section{Remarks}

10 YR 6/6 (brownish yellow)

10YR 6/4 (light yellowish brown)

10 YR 3/4 (dark brown)

10YR 5/3 (brown)

10YR 6/4 light yellowish brown)

10YR 5/2 (grayish brown)

essentially continuous core Vertical Depth $=192$ (top salt)

Vertical Depth $=250^{\prime}$

10YR 5/4 (yellowish brown) 
The directional survey on this slanthole shows the bottom to be approximately $\sim 114.5$ feet horizontal distance from the wellbore initiation, or $\sim 9.5$ feet from the sinkhole centerline. The additional extension downward added another $5.2 \mathrm{ft}$ horizontally, or approximately $4.5 \mathrm{ft}$ from the sinkhole center.

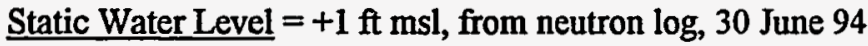

Rhodamine WT dye (50 lbs in 1000 gallons of brine) was introduced into this hole on July 2, 1994, at an approximate inflow rate of $5 \mathrm{gal} / \mathrm{min}$. This supplements the earlier introduction of $100 \mathrm{lbs}$ in 2000 gallons of brine into BH-9 at $-175 \mathrm{ft}$ TVD.

Hydrologic flow measurements were initiated on $3 \mathrm{Jul} 94$ with the implantation of the Sandia 3-D directional flowmeter by Sanford Ballard. Sensor depth is $-287 \mathrm{ft}$ (slant depth), essentially within the apparent dissolution crevasse, determined by this hole to be at least 72-73 feet deep below the top of salt. 


\section{Weeks Island Sinkhole BH9 (slanthole)}

This high-angle borehole was initiated at DOE's request for the express purpose of introducing Rhodamine-WT dye directly into the esophagus below the sinkhole. It was drilled and cased to $175 \mathrm{ft}$, cemented, and then deepened to $190.4 \mathrm{ft}$. Cores were obtainable only in the last 5 feet, and no salt was . encountered, even though the hole bottomed below the depth to top-of-salt seen in BH3 and 4.

Coordinates: $X=1,849,833.36 ; Y=414,121.659$; Elevation: $86.5 \mathrm{ft} \mathrm{msl}$

The material is a uniform, medium sand, disturbed and reworked, and showing no original sedimentary features whatsoever. It is much different in appearance than the sand at the bottom of BH6, having a dark gray-brown color (10YR 4/2). The material in BH6 was yellow-brown, finer grained, and had faint original banding and staining.

This raises a question as to its origin. It more resembles the infill sand that was emplaced in the sinkhole than the BH6 in situ material. It is desirable to examine the vendor's source sand from St. Martinville; Whitney Autin at LSU will take a detailed look at this question of correlation. (Note: point counts of these two materials at the LSU sedimentology laboratory showed them to be different; the bottom sand is believed to be in situ Prairie formation, however disturbed. JTN, $29 \mathrm{Jul} 94$ ).

Bottom material was examined by J. Neal (SNL) and T. Vogt (RE/SPEC), 24 June 94.

Static Water Level interpreted @ $-13 \mathrm{ft}$ msl on neutron log. This raises the question whether there is drawdown in the vicinity of the sinkhole.

Rhodamine WT dye (100 lbs in 2000 gallons of brine) was introduced into this hole on 27, 28 Jun 94. 


\section{Daily Drilling Reports}

from the drill holes developed for the Weeks Island diagnostic work

completed June 7 through July 6, 1994

by

Sandia National Laboratories 


\section{SNL DAILY DRILING REPORT \\ WEEKS ISLAND SNKHOLE DRILLING PROGRAM \\ IBERIA PARISH, LOUISIANA \\ Date of report: 07 June 94 \\ Time of repon: 0800}

Well number: DOE BH-6

Depth today 35

Hole diameter: $9.7 / 8$ "
Rig on hole - Longyear 44 Drilling days sioce spud 1

Hole advance las $24 \mathrm{hr}-35$ Cored / recovered $30 / 2$

Casing: 7-5/8"

Drilling assembly.

$\begin{array}{lllll}\text { Bit Number } & \text { Type } & \text { Size } & \text { In } & \text { Out } \\ 1 & \text { LY } & \text { HQ } & 0 & 35 \\ 2 & \text { Mill tooth } & 9-7 / 8 & 0 & 35\end{array}$

Driling fruid: Artapulgite Viscosity $32 \mathrm{sec}$ Weight $8.6 \mathrm{Ib} / \mathrm{gal} \quad$ Pump rate $20 \mathrm{gpm}$

Suminary of events last 24 hours:

Unload and rig up equipment. Start coring HQ at 1900 hrs. Rework mud system and core to 35 . Core recovery very poor, send. Open bole to $9.7 / 8$ and set $7.5 / 8$ casing to $35 \mathrm{ft}$. Cernent in place at 0810.

Well number. DOE BH-3

Depth today 30

Hole diameter. $21^{\circ}$
Rig on hole - Faiting 2000 Drilling days since spud 1

Hole advance las $24 \mathrm{hr}-30$ Cored / recovered $0 / 0$

Casing: Not yet

Driting assembly:

$\begin{array}{lllll}\text { Bit Numbet } & \text { Type } & \text { Size } & \text { Dut } & \text { Out } \\ 1 & \text { Mill tooth } & 21^{*} & 0 & 34\end{array}$

Drilling fruid: Water

Summary of events last 12 hours:

Rig up and get ready to spud. Spot office trailer and unload equipment Spud hole at 7:15

Drill to 34. Ready to run casing.

Report by Ron Jacobson 


\section{SNL DAII Y DRILLING REPORT \\ WEEKS ISLAND SDKHOLE DRUIING PROGRAM \\ IBERIA PARISH, LOUISIANA \\ Date of report: 08 June 94 \\ Time of report: 0800}

Well number: DOE BH-6

Depth today 80

Hole diameter. 3.76"
Rig on hole - Longyear 44 Drilling days since spud 2

Hole advance last 24 irs- 45 Cored / recovered 45/3

Casing: 7-5/8" to $34^{\circ}$

\begin{tabular}{lllll}
\hline Bit Number & Type & Size & in & Out \\
1 & LY & HQ & 0 & \\
2 & MNll tooth & $9-7 / 8$ & 0 & 35
\end{tabular}

IRR

Drilling fhuid: Attapulgite

Viscosity $52 \mathrm{sec}$

Weight $8.6 \mathrm{~B} / \mathrm{gal} \quad$ Pump rate $20 \mathrm{gpm}$

Summary of events last 24 bours:

Clean pits and rigus wellhead valve. Good cement job with lots of centent retums in cellar.

Tagged $10 \mathrm{ft}$ of cement in casing and cored cut with pater. Mixed new mud. Start coring formation with HQ at 0300 hr's. Tried various core catchers but core recovery still very poor, sand.

Well number: DOE BH-3 Rig on tole - Faiting 2000

Depht todsy 34

Hole diameter: 21" Casing: $14^{*}$ to $34^{\circ}$

Hole advarce last $24 \mathrm{hr}-0$

Drilling days since spud 2

\begin{tabular}{lllll}
\hline Bit Number & Type & Size & In & Out \\
1 & Mill tooth & $21^{*}$ & 0 & 34
\end{tabular}

Drilling fluid: Water

Summary of events lase 12 bours:

Run conductor casing and cement. Good cement job. Move rig off hole. After 6 hours pull cement head and DP with palling rig. Hole resdy for core rig.

\begin{tabular}{|c|c|c|}
\hline $\begin{array}{l}\text { Well number. DOE BH-4 } \\
\text { Depth today } 34 \text {. }\end{array}$ & $\begin{array}{l}\text { Rig on bole - Failing } 2000 \\
\text { Hole advance last } 24 \mathrm{br}-34\end{array}$ & $\begin{array}{l}\text { Drilling days since spud } 1 \\
\text { Cored / recovered } 0 / 0\end{array}$ \\
\hline Hole diameter: $2 I^{\circ}$ & Casing: $14^{\circ}$ to $34^{\circ}$ & \\
\hline
\end{tabular}

\begin{tabular}{lllll}
\hline Bit Number & Type & Size & In & Out \\
IRR & Mill tooth & $21^{*}$ & 0 & 34 \\
Drilling fluid: Warer & & &
\end{tabular}

Surmutary of events last 12 hours:

Rig up on hole, drill to 34', run and cement conductor casing. Good cement job.

Report by Ron Jacobson 


\section{SNL DAII Y DRILING REPORT \\ WEEKS ISLAND SINKHOLE DRILING PROGRAM \\ IBERIA PARISH, LOUISIANA \\ Date of report: 09 Jane 94 \\ Time of report: 0800}

\begin{tabular}{|c|c|c|c|c|}
\hline \multicolumn{2}{|c|}{$\begin{array}{l}\text { Well number: DOE BH-6 } \\
\text { Depth today } 80 \\
\text { Hole diamerer. } 3.76^{*}\end{array}$} & \multicolumn{2}{|c|}{$\begin{array}{l}\text { Rig on bole - Longyear } 44 \\
\text { Hole advance last } 24 \text { tr-95 } \\
\text { Casing: } 7-5 / 8^{-} \text {to } 34^{\prime}\end{array}$} & \multirow{2}{*}{$\begin{array}{l}\text { Drilling days since spud } 3 \\
\text { Cored / recovered } 95 / 12.5 \\
\text { Out }\end{array}$} \\
\hline $\begin{array}{l}\text { Bin Number } \\
1\end{array}$ & $\begin{array}{l}\text { Type } \\
\text { LY }\end{array}$ & $\begin{array}{l}\text { Size } \\
\text { HQ }\end{array}$ & $\begin{array}{l}\text { In } \\
0\end{array}$ & \\
\hline 2 & Mall tooth & $9.7 / 8$ & 0 & 35 \\
\hline
\end{tabular}

Driling fluid: Artapulgite Viscosity $52 \mathrm{sec}$ Weight $8.6 \mathrm{lb} / \mathrm{gal}$ Punp rate $20 \mathrm{gpm}$

Surmary of events las 24 hours:

Stall trying various core catchers but eore recovery still very poor, sand. At 160 'started to switch to salt mud. Core recovery getring better. At 2100 hours after pulling the first $100 \%$ recovery core run at 175' the rods got stuck. Worked stuck pipe untl 0300 the started rigging up SW casing advancer to wash over stuck pipe. HQ pipe appears to be differentially stuck or sanded in
Well number. DOE BHA
Depts today 34
Rig on hole - Failing 2000
Drilling days sioce spud 2
Hole diameter. $21^{*}$
Hole advance last $24 \mathrm{hr}-34$
Cored / recovered a/o
Casing: $14^{\circ}$ to $34^{\prime}$

$\begin{array}{lllll}\text { Bit Number } & \text { Type } & \text { Size } & \text { In } & \text { Out } \\ \text { IRR } & \text { Mill tooth } & 21^{\prime \prime} & 0 & 34 \\ 2 & \text { Mill tooth } & 9-5 / 8^{\circ} & 34 & \end{array}$

Drilling thid: Saburated salt

Summary of events last 12 hours:

Pull cement head and drill out cenent with wrter. Install wellhead valve. Wedd up flow line, mud tanks and cleaners. Mix salt mud.

Ready to start drilling

Report by Ron Jacobson 


\section{SNL DAILY DRULING REPORT \\ WEEKS ISLAND SINKHOLE DRILING PROGRAM \\ IBERIA PARISH, LOUISIANA \\ Date of report: 10 June 94 \\ Time of report: 0800}

Well number: DOE BH-6

Depth today 175

Hole diameter. 3.76"
Rig on hole - Longyear 44 Drilling days since spud 4

Hole advance last $24 \mathrm{hr}-00$ Cored / recovered $0 / 0$

Casing: $7-5 / 8^{n}$ to $34^{\prime}$

\begin{tabular}{lllll}
\hline Bit Number & Type & Size & In & Out \\
I & LY & HQ & 0 & \\
2 & Mill tooth & $9-7 / 8$ & 0 & 35 \\
IRR & & & 35 &
\end{tabular}

IRR

Viscosity $52 \mathrm{sec}$

Weight $8.6 \mathrm{lb} / \mathrm{gal} \quad$ Pump rate $20 \mathrm{gpm}$

Summary of events last 24 hours:

Cleaned mud system and mixed mud. Run SW casing advance to $40^{\prime}\left(6-5 / 8 \times 6^{4}\right)$. Tried to conncet kelley rod to SW but could not. Core rig had moved to far off hole. Tried to screw into HQ but to much fill on top of rod. Top of $H Q$ at 40 to $45^{\prime}$ and $5^{\prime}$ off bottom. Will move rig and try to wash over $\mathrm{HQ}$. Yesterdays report listed TD at 80 but it was 175'.

Well number: DOE BH-4

Depth today 183

Hole diameter. $95 / 8^{4}$
Rig on hole - Failing 2000 Drilling days since spud 3

Hole advance last $24 \mathrm{hr}-149$ Cored / recovered $0 / 0$

Casing: $14^{\prime \prime}$ to $34^{\circ}$

$\begin{array}{lllll}\text { Bit Number } & \text { Type } & \text { Size } & \text { In } & \text { Out } \\ \text { IRR } & \text { Mill tooth } & 21^{n} & 0 & 34 \\ 2 & \text { Mill tooth } & 9-5 / 8^{n} & 34 & \end{array}$

Drilling fluid: Saturated salt

Summary of events last 16 hours:

Drill 9. 5/8 to top of salt Condition hole. Run SW casing for core bushing string. While adjusting SW casing length the casing got stuck 2' off bottom Rig to circulate through SW and rig up power swivel. Will try to work SW to bottom and start coring.

Report by Ron Jacobson 
SNL DAIIY DRILIING REPORT

\section{WEEKS ISLAND SINKHOLE DRULING PROGRAM}

IBERTA PARISF, LOUISTANA

Date of report: 11 June 94

Time of report: 0800

Well number: DOE BH-6

Depth today $175^{\circ}$

Hole diameter. $3.76^{\prime \prime}$
Rig on hole - Longyear 44 Drilling days since spud 5

Hole advance last $24 \mathrm{hr}-00$ Cored / recovered $0 / 0$

Casing: $7-5 / 8^{\prime \prime}$ to $34^{\prime}$

\begin{tabular}{lllll}
\hline Bit Number & Type & Size & In & Out \\
1 & LY & HQ & 0 & \\
2 & Mill tooth & $9-7 / 8$ & 0 & 35 \\
IRR & & & 35 &
\end{tabular}

Drilling fluid:

Summary of events last 24 hours:

Pulled SW casing and washed in with open ended HQ rod to top of fish. Ran tapered NQ rod inside to align rod and screwed in to fish. Left HQ rods in hole for future fishing with larger mud pumps and mud system. Longyear rig moved off hole.

Well number: DOE BH-4

Depth today $250^{\circ}$

)

Hole diameter: $5-7 / 8$
Rig on hole - Failing 2000

Hole advance last $24 \mathrm{hr}-6 \mathrm{~T}$

Casing. $14^{\pi}$ to $34^{\circ}$
Drilling disys since spud 4

Cored/ recovered $67 / 60^{\circ}$

Casinge $14^{\circ}$ to $34^{4}$

$\begin{array}{lllll}\text { Bit Number } & \text { Type - } & \text { Size } & \text { In } & \text { Out } \\ \text { IRR } & \text { Mill tooth } & 21^{n} & 0 & 34 \\ 2 & \text { Mill tooth } & 9-5 / 8^{n} & 34 & 183 \\ 3 & \text { LY \#2 impreg } & \text { BSF } & 183 & \\ 4 & \text { Wash over } & 12-1 / 4 & 0 & \\ \text { Drilling fluid: Saturated salt } & & & \end{array}$

Summary of events last 24 hours:

Unable to move SW casing. Makeup coring tolls and run in hole. Wash down BSF down to 185 and started ) coring. Pulled tube at $190^{\prime}$ with no core. Pieked up weight at 190 and cored to $195^{\prime}$ and retrieved 5 ft of salt. Continued coring to $250 \mathrm{ft}$ with $100 \%$ core recovery.

Worked stuck SW casing but could not move. Pick up 8-5/8 line pipe with 12-1/4 wash over shoe. Washing

- over SW casing at $\sim 45^{\prime}$

Report by Ron Jacobson 
SNL DAILY DRILLNG REPORT

WEEKS ISLAND SINKHOLE DRULING PROGRAM

IBERIA PARISH, LOUISLANA

Date of report. 12 June 94

Time of report: 0800

Well number. DOE BH-4

Depth today $250^{\circ}$

Hole diameter: $5-7 / 8$
Rig on hole - Failing 2000

Hole advance last $24 \mathrm{hr}-0$

Casing. 14" to $34^{\prime}$
Drilling days since spud 4

Cored/recovered o/0

$\begin{array}{lllll}\text { Bit Number } & \text { Type } & \text { Size } & \text { In } & \text { Out } \\ \text { IRR } & \text { Mill tooth } & 21^{\prime \prime} & 0 & 34 \\ 2 & \text { Mill tooth } & 9-5 / 8^{\prime \prime} & 34 & 183 \\ 3 & \text { LY \#2 impreg BSF } & 183 & \\ 4 & \text { Wash over } & 12-1 / 4 & 0 & \end{array}$

Drilling fiuid: Saturated salt gel

Summary of events last 24 hours:

Wash over SW casing and BSF core pipe to 184'. SW casing dropped S', BSF did not drop.

Pulled on BSF and they moved up - $I^{\prime}$ and appeared free. Cut hole in $14^{n}, 8^{\prime \prime}$, and SW casings.

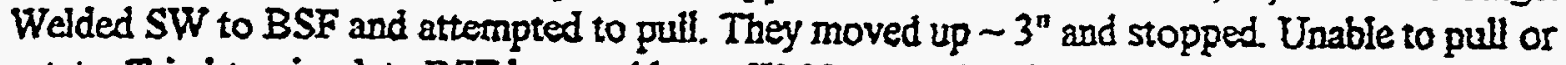
rotate. Tried to circulate BSF but could not. Weld $14^{\prime \prime}$ and $8^{n}$ holes close. Circulate and rotate $8^{n}$ until daylight. WII weld box on SW and cut in it lose from BSF and tTy to pull SW then BSF.

Continue to fish.

Report by Ron Jacobson 
SNL DAIIY DRILIING REFORT

WEEKS ISLAND SINKTHOLE DRIIIING PROGRAM

IBERIA PARISH, LOUISIANA

Date of report: 13 June 94

Time of report: 0800

Well number. DOE BH-4

Depth today 250'

Hole diameter: 12-1/4
Rig on hole - Failing 2000

Hole advance last $24 \mathrm{ls}-0$

Casing: $8-5 / 3^{n}$ to $250^{\circ}$
Drilling days since spud 7

Cored / recovered $0 / 0$

\begin{tabular}{|c|c|c|c|c|}
\hline Bit Number & Type & Size & In & Out \\
\hline IRR & Mill tooth & $21^{n}$ & 0 & 34 \\
\hline 2 & Mill tooth & $9-5 / 8^{\prime \prime}$ & 34 & 183 \\
\hline 3 & LY 42 impreg & BSF & 183 & 250 \\
\hline 4 & Wash over & $12-1 / 4$ & 0 & \\
\hline \multicolumn{5}{|c|}{ Drilling fluid: Sazurated sait gel } \\
\hline $\begin{array}{l}\text { Surnmary of } \\
\text { Pull on SW } \\
\text { 250. Pull BS } \\
\text { bottom. Nip } \\
\text { 5:50 AM G }\end{array}$ & $\begin{array}{l}\text { reats last } 24 \text { ho } \\
\text { ing and recuv } \\
\text { core pipe and } \\
\text { up cement he } \\
\text { d cement job. }\end{array}$ & $\begin{array}{l}\text { urs: } \\
\text { lay down } \\
\text { ad and pr }\end{array}$ & $\begin{array}{l}\text { shoe } \\
\text { menties } \\
\text { mest }\end{array}$ & $\begin{array}{l}\text { and open salt hole to } 12-1 / 4 \text { to } \\
\text { ole with open ended drill pipe and tag } \\
\text { with mud. 8-5/8 cemented in place at }\end{array}$ \\
\hline
\end{tabular}

Report by Ron Iscobson 


\section{SNL DAII Y DRILIING REPORT \\ WEEKS ISLAND SINKHOLE DRILING PROGRAM \\ IBERIA PARISH, LOUISIANA \\ Date of report: 14 June 94 \\ Time of report: 0800}

Well number. DOE BH-4

Depth today 250:

Hole diameter: $12-1 / 4$
Rig on hole - Failing 2000

Hole advance last $24 \mathrm{hr}-0$

Casing: $8-5 / 8^{\prime \prime}$ to $250^{\circ}$
Drilling days since spud 8

Cored/recovered $0 / 0$

\begin{tabular}{lllll} 
Bit Number & Type & Size & In & Out \\
\hline IRR & Mill tooth & $21^{*}$ & 0 & 34 \\
2 & Mill tooth & $9-5 / 8^{*}$ & 34 & 183 \\
3 & LY \#2 impres BSF & 183 & 250 \\
4 & Wash over & 12-1/4 & 0 &
\end{tabular}

Drilling fluid: Saturated salt gel

Summary of events last 24 hours:

Clean mud pits, tools and location. Wait on cement for 10 hours then pull drill pipe from tole. Will WOC without crews until $6 / 15$ then clean out 8-7/8 to 245'

Report by Ron Jäcobson 


\section{June 15, 1994}

No Daily Report Issued 
SNL DAILY DRILLING REPORT

WEEKS ISLAND SINKHOLE DRILLING PROGRAM

IBERIA PARISH, LOUISIANA

Date of report: 16 June 94

Tinc of report: 0800

Wcll numbcr: DOE BH-4 Rig on hole - Failing 2000

Depth today $250^{\circ}$

Hole diameter. $12-1 / 4$

Hole advance last $24 \mathrm{hr}-0$

Driling days since spud 9

Casing: $8.5 / 8^{\circ}$ to $250^{\circ}$

Cored / rccovered $0 / 0$

\begin{tabular}{lllll}
\hline & & & \\
Bit Number & Type & Size & In & Out \\
\hline IRR & Mill tooth & $21^{n}$ & 0 & 34 \\
2 & Mill tooth & $9-5 / 8^{n}$ & 34 & 183 \\
3 & IY $\$ 2$ impreg BSF & 183 & 250 \\
4 & Wash over & 12-1/4 & 0 &
\end{tabular}

Drilling fluid: Casing filled with fresh water

Summary of events last 24 hours:

Clean out to $246^{\prime}$ and displace mud with fresh water. Tag cement on the back side at 34'. Mix.

) cement and do top job. Rig down and move off hole. Weld flange on 8-5/8 casing. Set up to do cased bole logs.

Well number. DOEE BH-3 Rig on hole - Failing 2000 Driling days since spud 1

Depth roday $34^{\prime}$

Hole diameter. 13-1/4

Hole advance last $24 \mathrm{hr}-0^{\circ}$ Cored/recovered $0 / 0$

Casing: $14^{n}$ to $34^{*}$

\begin{tabular}{|c|c|c|c|c|}
\hline Bit Number & Type & Size & In & Qut \\
\hline IRR & Mill tooth & $21^{\prime \prime}$ & 0 & 34 \\
\hline 2 & Mill tooth & $13^{n}$ & 34 & \\
\hline
\end{tabular}

Drilling fluid: Saturated salt gel

Summary of cvents last 24 hours:

Move and rig up on hole. Weld well head and fow line. Mix mud and get ready to drill.

Report by Ron Jacobson 


\section{SNL DAII Y DRILLING REPORT \\ WEEKS ISLAND SINKHOLE DRIIIING PROGRAM \\ IBERIA PARISH, LOUISIANA \\ Date of report: 17 Jane 94 \\ Tine of report: 0800}

Well number: DOE BH-4 Rig on hole - None

Depth today $250^{\circ}$

Hole diameter: $12-1 / 4$
Hole advance last $24 \mathrm{hr}-0$

Casing: $8-5 / 8^{\prime \prime}$ to $250^{\circ}$
Drilling days since spud 9

Cored/ secovered $0 / 0$

\begin{tabular}{lllll} 
Bit Numbor & Type & Size & In & Out \\
\hline IRR & Mill tooth & $21^{n}$ & 0 & 34 \\
2 & Mill tooth & $9-5 / 8^{*}$ & 34 & 183 \\
3 & LY \#2 impreg BSF & 183 & 250 \\
4 & Wash over & $12-1 / 4$ & 0 &
\end{tabular}

Drilling fluid: Casing filled with fresi water

Summary of events last 24 hours:

Ran cased hole logs. Gamma, Gamma-Gamma Density, Neutron Porosity and CBL.

Well number: DOE BH-3 Rig on hole - Failing 2000 Drilling days since spud 2

Depth today $187^{\circ}$

Hole diameter: 13

Hole advance last $24 \mathrm{hr}-153$. Cored / recovered $0 / 0$

Casing: $10-3 / 4^{n}$ to $187^{\prime \prime}$

\begin{tabular}{lllll} 
Bit Number & Type & Size & In & Out \\
\hline IRR & Mill rooth & $21^{\circ}$ & 0 & 34 \\
2 & Mall tooth & $13^{*}$ & 34 & 187
\end{tabular}

Drilling fluid: Saturated salt gel

Summary of events last 24 hours:

Drill picked up weight at 185 '. Salt at 187 . Circulate and pull out of hole. Ran Natural Gamma, Electric, Induced Polarization, Sonic and Caliper open hole logs from top of salt. Set 10-3/4 casing and cemented to surface with salt saturated cement. Good cement returns. Moving rig to BH-5.

) Report by Ron Jacobson 
SNL DAILY DRILLING REPORT

WEEKS ISLAND SINKHOLE DRILING PROGRAM

IBERIA PARISH, LOUISIANA

Date of report: 18 Junc 94

Time of report: 0800

Well number: DOE BII-5

Depth today $34^{\prime}$

Hole diameter: $21^{\prime \prime}$
Rig on hole - Failing 2000 Drilling days since spud 1

Hole advance last $24 \mathrm{hr}-34$ Cored / recovered $0 / 0$

Cașing: $14^{\prime \prime}$ to $34^{\prime}$

\begin{tabular}{lllll} 
Bit Number & Type & Size & In & Out \\
\hline IRR & Mill tooth & $21^{\prime \prime}$ & 0 & 34
\end{tabular}

Drilling fluid: Fresh water

Sunmary of events last 12 hours:

Rigged up on hole. Drill surface hole with $21^{\prime \prime}$ bit to $34^{\prime}$ with fresh water. Run $14^{\prime \prime}$ conductor casing and cement in place. Clean mud and solids tanks and mix salt gel mud. Ready to drill 13" to TOS.

Pull mat and dig cellar for BH-9 (die injection well).

Reportiby Ron Jacobson

\section{DOE BH-4 AS DRULED}

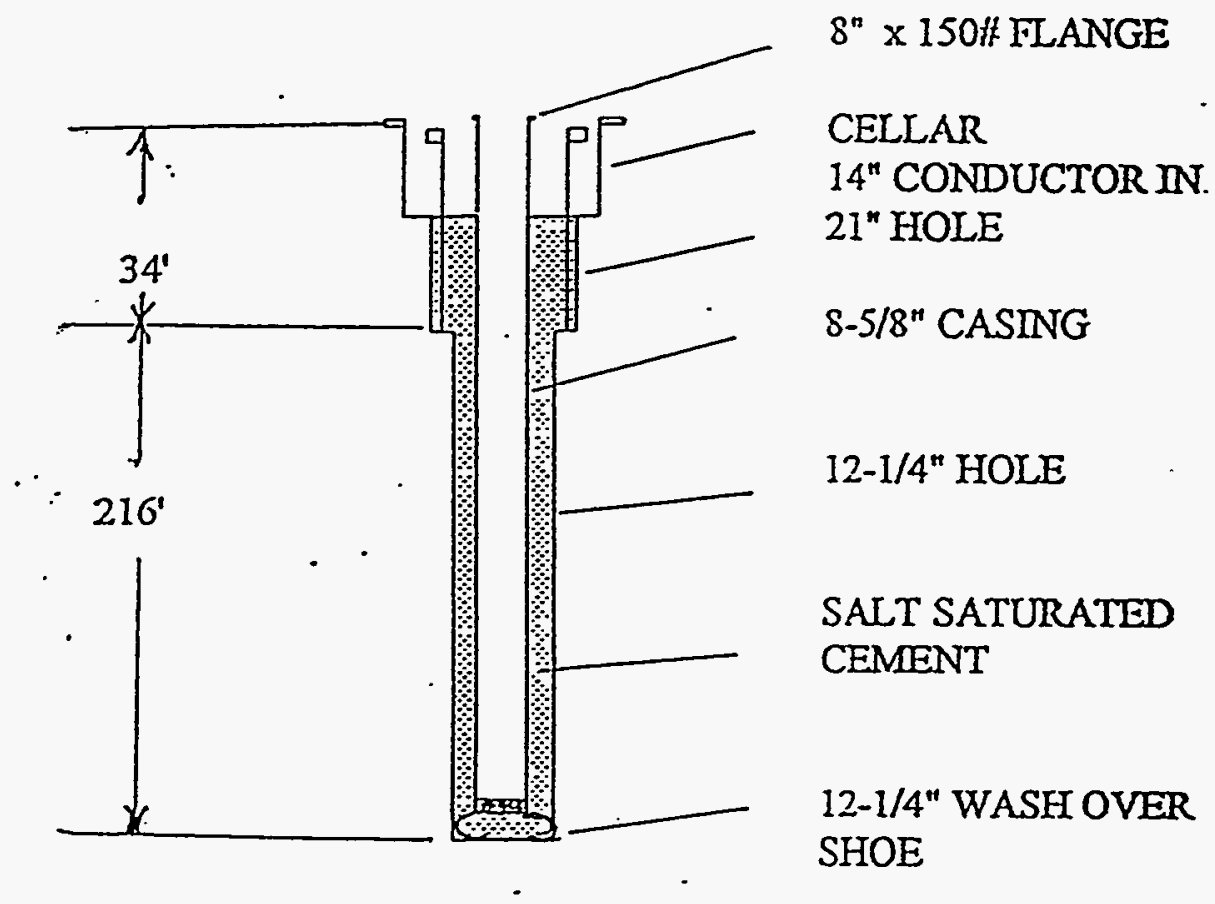


SNL DAILY DRULLING REPORT

WEEKS ISLAND SINKHOLE DRILING PROGRAM

IBERIA PARISH, LOUISIANA

Date of report: 19 June 94

Time of report: 0800

Well number: DOE BH-5

Depth today $188^{\circ}$

Hole diameter: 13 "
Rig on hole - Failing 2000 Drilling days since spud 2

Hole advance last $24 \mathrm{hr}-154^{\prime}$ Cored / recovered $0 / 0$

Casing: $14^{\prime \prime}$ to $34^{\circ}$

\begin{tabular}{lllll} 
Bit Number & Type & Size & In & Out \\
\hline 1RR & Mill Tooth & $21^{\prime \prime}$ & 0 & 34 \\
2RR & Mill Tooth & 13 & 34 & $188^{\prime}$
\end{tabular}

Drilling fluid: Saturated salt gel

Summary of events last 24 hours:

Drill 13" hole to $188^{\prime}$ and picked up weight. Should be at top of salt. Circulate hole and prepare for open hole logs. Pull out of hole and rig up loggers. Run Gamma, Electric, Sonic, EM andCaliper logs. Make wiper trip and circulate. Run 10-3/4 welded casing to $\sim 155^{\prime}$ but would not go to bottom. Pull casing and lay down. It appears that factory bevels on the line pipe were not square causing the welded pipe to be crooked. Will make a wiper trip and either under ream to $15^{\prime \prime}$ and try $10-3 / 4$ casing or core with oil field $8-5 / 8^{\prime \prime} \times 4^{\prime \prime}$ core barrel to $250^{\prime}$ and set $6-5 / 8^{\prime \prime}$ casing.

Loggers ran Gamma, Gamma-Gamma Density, Neutron Porosity and Cement Bond logs in 10$3 / 4^{\prime \prime}$ casing to top of cement in $\mathrm{BH}-3$.

Report by Ron Jacobson 
SNL DAILY DRULING REPORT

WEEKS ISLAND SINKHOLE DRILLING PROGRAM

IBERIA PARISH, LOUISIANA

Date of report: 20 June 94

Time of report: 0800

Well number: DOE BH-5

Depth today $250^{\circ}$

Hole diameter: $13^{\prime \prime}$
Rig on hole - Failing 2000 Drilling days since spud 3

Hole advance last $24 \mathrm{hr}-62^{\prime}$ Cored / recovered $55 / 42$

Casing: $14^{\prime \prime}$ to $34^{\prime}$

\begin{tabular}{lllll} 
Bit Number & Type & Size & In & Out \\
\hline IRR & Mill Tooth & $21^{\prime \prime}$ & 0 & 34 \\
2RR & Mill Tooth & 13 & 34 & $188^{\prime}$ \\
3 & DBS Core & $8-5 / 8$ & 188 & $246^{\prime}$ \\
2RR & Mill Tooth & $13^{\prime \prime}$ & 188 & $250^{\prime}$
\end{tabular}

Drilling fluid: Saturated salt gel

Summary of events last 24 hours:

Run 13" bit to bottom and circulate. Pick up DBS core barrel and core from 190 to 220' with $100 \%$ recovery. Run back in and core to $245^{\prime}$ and recover 12 '. Left $13 \mathrm{ft}$ on bottom. Pick up 13" bit and drill to $250^{\prime}$. Run Gamma, Electric and Sonic open hole logs. Ready to set $6-5 / 8$ welded casing and cement to surface.

\section{$-\because-$}

Well number: DOE BH-3

Depth today $187^{\prime}$

Hole diameter: $13^{\prime \prime}$
Rig on hole - Longyear 44

Hole advance last $24 \mathrm{hr}-0$

Casing: $10^{n}$ to $187^{\circ}$
Drilling days since spud 3

Cored / recovered $0 / 0$

\begin{tabular}{lllll}
\hline Bit Number & Type & Size & In & Out \\
\hline 1RR & Mill Tooth & $21^{\prime \prime}$ & 0 & 34 \\
2RR & Mill Tooth 13 & 34 & 187 \\
3 & LY-SYNDAX 5-7/8 & 156 &
\end{tabular}

Drilling fluid: Saturated salt

Summary of events last 24 hours:

Set rig over hole and rig up. Run and drill SW casing to 157, just into cement. Run BSF core rods to $128^{\prime}$ and get ready to core cement and salt

Report by Ron Jacobson 
SNL DAILY DRILCING REPORT

WEEKS ISLAND SINKHOLE DRILLING PROGRAM

IBERIA PARISH, LOUISIANA

Date of report: 21 June 94

Time of report: 0800

Well number: DOE BH-5

Depth today 250'

Hole diameter: 13"
Rig on hole - Failing 2000

Hole advance last $24 \mathrm{hr}-0$

Casing: $6-5 / 8^{\prime \prime} 250^{\prime}$ to surface
Drilling days since spud 4

Cored / recovered $55 / 42$

\begin{tabular}{lllll} 
& & & & \\
Bit Number & Type & Size & In & Out \\
\hline IRR & Mill Tooth & $21^{\prime \prime}$ & 0 & 34 \\
$2 \mathrm{RR}$ & Mill Tooth & 13 & 34 & $188^{\prime}$ \\
3 & DBS Core & $8-5 / 8$ & 188 & $245^{\prime}$ \\
2RR & Mill Tooth & $13^{\prime \prime}$ & 188 & $250^{\prime}$
\end{tabular}

Drilling fluid: Saturated salt gel

Summary of events last 24 hours:

Run in with 13" bit and circulate out 12; of fill with heavy salt mud. Set 6-5/8 casing on bottom and cement in place with salt cement at 11:00 AM. Clean mud and solids tanks. Will wait on cement until $6 / 22$ and then clean out casing. Placed $5^{\prime}$ of cement in the bottom of BH-4

Well number: DOÉ BH-3 Rig on hole - Longyear 44 Drilling days since spud 4

Depth today 250'

Hole diameter $5-7 / 8^{n}$

Hole advance last $24 \mathrm{hr}-63^{\prime}$ Cored / recovered 61/59

Casing: $10^{\prime \prime}$ to 187

\begin{tabular}{lllll}
\hline Bit Number & Type & Size & In & Out \\
\hline IRR & Mill Tooth & $21^{\prime \prime}$ & 0 & 34 \\
2RR & Mill Tooth. & 13 & 34 & $187^{\prime}$ \\
3 & LY-SYNDAX 5-7/8 & 156 & $250^{\prime}$
\end{tabular}

Drilling fluid: Saturated salt

Summary of events last 24 hours:

Finish rigging up and wash BSF core pipe to top of cement. Cored cement and float shoe. 3' of cement below shoe. Three hour rain and lightning delay. Cored to $250^{\prime}$ with excellent core quality and recovery. Pull BSF rods and SW casing out of hole. . No significant loss circulation zones encountered in this hole. Will rig down and move Longyear rig to BH-9. Stamm-Scheele rig will open the core hole to $9-7 / 8$ and set hang down casing.

Report by Ron Jacobson 
SNL DAILY DRILLING REPORT

WEEKS ISLAND SINKHOLE DRULING PROGRAM

IBERIA PARISH, LOUISIANA

Date of report: 22 June 94

Time of report: 0800

Well number: DOE BH-9

Depth today $110^{\prime}$

Hole diameter: $6-5 / 8^{\prime \prime}$
Rig on hole - Longyear 44 Driffing days since spud 1

Hole advance last $24 \mathrm{hr}-110$ Cored / recovered $0 / 0$

Casing: None

\begin{tabular}{lllll} 
Bit Number & Type & Size & In & Out \\
\hline 1 & Wash Shoe & $6-5 / 8^{\prime \prime}$ & 0 &
\end{tabular}

Drilling fluid: Fresh water gel

Summary of events last 12 hours:

Rigged up on hole and set angle at $12.5 \mathrm{deg}$ off of vertical. Advance HW $\left(4.5^{n} \times 4^{n}\right)$ casing to $110^{\prime \prime}$. Will continue to advance casing to $180^{\prime}$ slant depth, $175^{\circ}$ true vertical depth and cement in place.

Report by Ron Jacobson

\section{DOE BH-5 AS DRMLED}

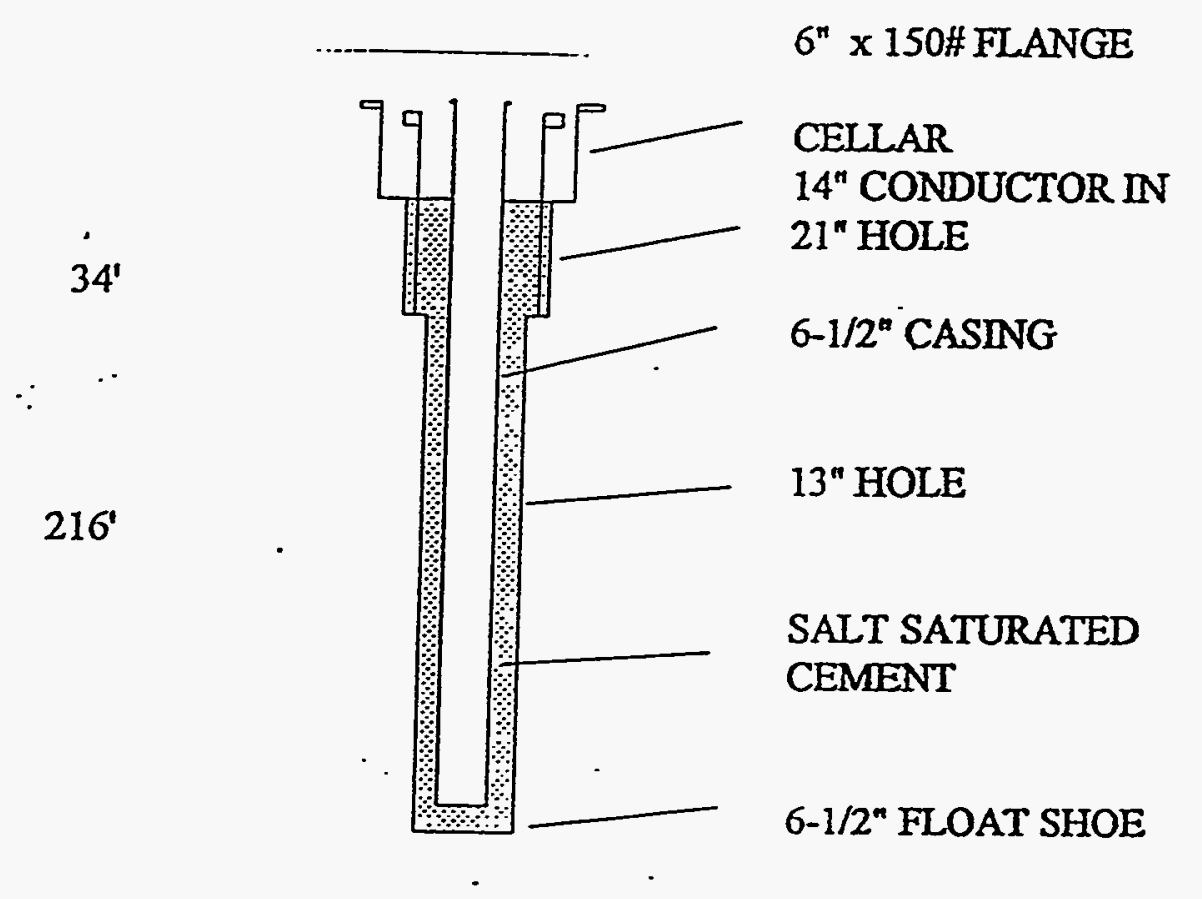




\title{
SNL DAILY DRILLING REPORT \\ WEEKS ISLAND SINKHOLE DRILLING PROGRAM \\ IBERIA PARISH, LOUISIANA \\ Date of report: 23 June 94 \\ Time of report: 0800
}

\begin{abstract}
Well number: DOE BH-9 Rig on hole - Longyear 44 Drilling days since spud 2
Depth today $180^{\prime}$ Slant

Hole advance last $24 \mathrm{hr}-70$ Cored / recovered $0 / 0$

Hole diameter: 6-5/8"

Casing: HW $\left(4-1 / 2 \times 4^{\prime \prime}\right)$ to $180^{\prime}$
\end{abstract}

\begin{tabular}{lllll}
\hline Bit Number & Type & Size & In & Out \\
1 & Wash Shoe & $6-5 / 8^{\prime \prime}$ & 0 & Cemented in place at $180^{\circ}$
\end{tabular}

Drilling fluid: Fresh water gel

Summary of events last 24 hours:

Cleaned mud pits and and rigged desander. Two-plus hour weather delay. Cleaned mud.

Advanced casing to $136^{\prime}$ where lost complete returns. Mixed and spotted LCM pill (Kwik-Seal), but did no good. Drilled blind to $180^{\prime}$ (175' TVD) and pumped $150 \%$ cement with no returns to surface. Have done four top jobs $(10,10,14$, and 10 sacks cement) in the annulus, cement is back to surface.

Well number: DOE BH-3 Rig on hole - Failing 2000 Drilling days since spud $\mathrm{n} / \mathrm{a}$

Depth today $250^{\prime}$

Hole diameter: 9-7/8" Hole advance last $24 \mathrm{hr}-0$ Cored / recovered $0 / 0$

Casing: $10-3 / 4^{\prime \prime}$ to $187^{\prime \prime}$

\begin{tabular}{lllll}
\hline Bit Number & Type & Size & In & Out \\
\hline IRR & Mill Tooth & $21^{\prime \prime}$ & 0 & 34 \\
2RR & Mill Tooth & $13^{\prime \prime}$ & 34 & $187^{\prime}$ \\
3 & LY-SYNDAX 5-7/8 & 156 & $250^{\prime}$ \\
4RR & Mill Tooth $9-7 / 8^{\prime \prime}$ & 187 & 250
\end{tabular}

Drilling fluid: Saturated salt gel

Summary of events last 24 hours:

Reamed sait from $187^{\prime}$ to $250^{\prime}$. Rigging up to run and cement casing.

Recap BH-3: (vertical) $13^{\prime \prime}$ hole, $10-3 / 4^{\prime \prime}$ casing to $187^{\prime} ; 9-5 / 8^{\prime \prime}$ hole from $187^{\prime}$ to $250^{\prime}$

$\mathrm{BH}-4$ : (vertical) $12-1 / 4^{\prime \prime}$ hole, $8-5 / 8^{\prime \prime}$ casing to $250^{\prime}$

BH-5: (vertical) $13^{\prime \prime}$ hole, $6-5 / 8^{\prime \prime}$ casing to $250^{\prime}$

BH-6: (vertical) $9-7 / 8^{\prime \prime}$ hole, $7-5 / 8^{\prime \prime}$ casing to $34^{\prime}$; HQ core rods (stuck) from $175^{\circ}$ (TD) to surface

BH-9: (slant) $6-5 / 8^{\prime \prime}$ hole, $4-1 / 2^{\prime \prime}$ casing to $180^{\prime}$ (175' TVD)

Total project cost through 20 June: $\$ 349,000$

Report by Ron Jacobson/John Finger 


\title{
SNL DAILY DRILLING REPORT \\ WEEKS ISLAND SINKHOLE DRILLING PROGRAM \\ IBERIA PARISH, LOUISIANA \\ Date of report: 24 June 94 \\ Time of report: 0800
}

\begin{abstract}
Well number: DOE BH-9
Depth today $180^{\prime}$ Slant

Hole diameter. $6-5 / 8^{n}$

Rig on hole - Longyear 44 Drilling days since spud 3

Hole advance last $24 \mathrm{hr}-0$ Cored / recovered $0 / 0$

Casing. HW (4-1/2 $\left.\times 4^{\prime \prime}\right)$ to $180^{\prime}$
\end{abstract}

\begin{tabular}{|c|c|c|c|c|}
\hline Bit Number & Type & Size & In & Out \\
\hline 1 & Wash Shoe & $6-5 / 8^{n}$ & 0 & Cemented in place at 180 \\
\hline
\end{tabular}

Summary of events last 24 hours:

Waited on cement until 1500. Ran in hole with HQ core string and washed cement to $170^{\prime}$.

Cement would not take string weight, continued WOC until 0600 .

Note: Total fluid lost in drilling BH-9 $\sim 120$ barrels; total cement $=110$ cubic feet

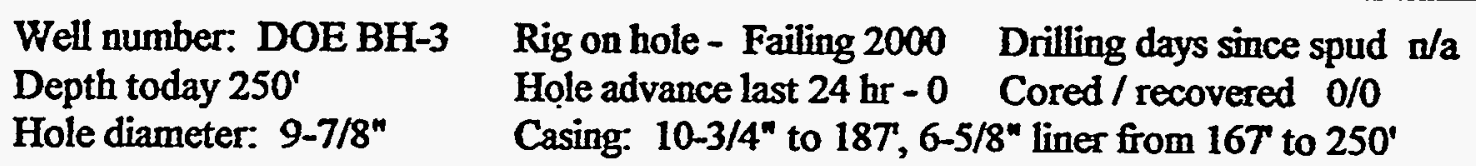

\begin{tabular}{lllll}
\hline Bit Number & Type & Size & In & Out \\
\hline 1RR. & Mill Tooth & $21^{\prime \prime}$ & 0 & 34 \\
2RR & Mill Tooth $13^{\prime \prime}$ & 34 & 187 \\
3 & LY-SYNDAX 5-7/8" & 156 & $250^{\prime}$ \\
4RR & Mill Tooth 9-7/8" & 187 & 250
\end{tabular}

Drilling fluid: Saturated sait gel

Summary of events last 24 hours:

After intermittent rain delays, welded float shoe to $6-5 / 8^{\mathrm{m}}$ hang down casing, ran and cemented casing with 20' lap. Got excellent cement job. Rig down SSI and moved to BH-6 for repair and fishing.

Recap BH-3: (vertical) $13^{\prime \prime}$ hole, $10-3 / 4^{\prime \prime}$ casing to $187 ; 6-5 / 8^{\prime \prime}$ casing from 167 to $250^{\prime}$

BH-4: (vertical) $12-1 / 4^{\prime \prime}$ hole, $8-5 / 8^{\prime \prime}$ casing to $250^{\prime}$

BH-5: (vertical) $13^{\prime \prime}$ hole, $6-5 / 8^{\prime \prime}$ casing to $250^{\prime}$

BH-6: (vertical) 9-7/8" hole, 7-5/8" casing to $34^{\prime}$; HQ core rods (stuck) from $175^{\circ}$ (TD) to surface

BH-9: (slant) $6-5 / 8^{\prime \prime}$ hole, 4-1/2" casing to $180^{\circ}$ (175' TVD)

Total project cost through 20 June: $\$ 349,000$

Report by Ron Jacobson/John Finger 


\section{SNL DAM,Y DRIIIING REPORT \\ WEEKS ISLAND SINKHOLE DRILNRG PROGRAM \\ IBERIA PARISH, LOUISIANA \\ Date of report: 25 June 94 \\ Time of report: 0800}

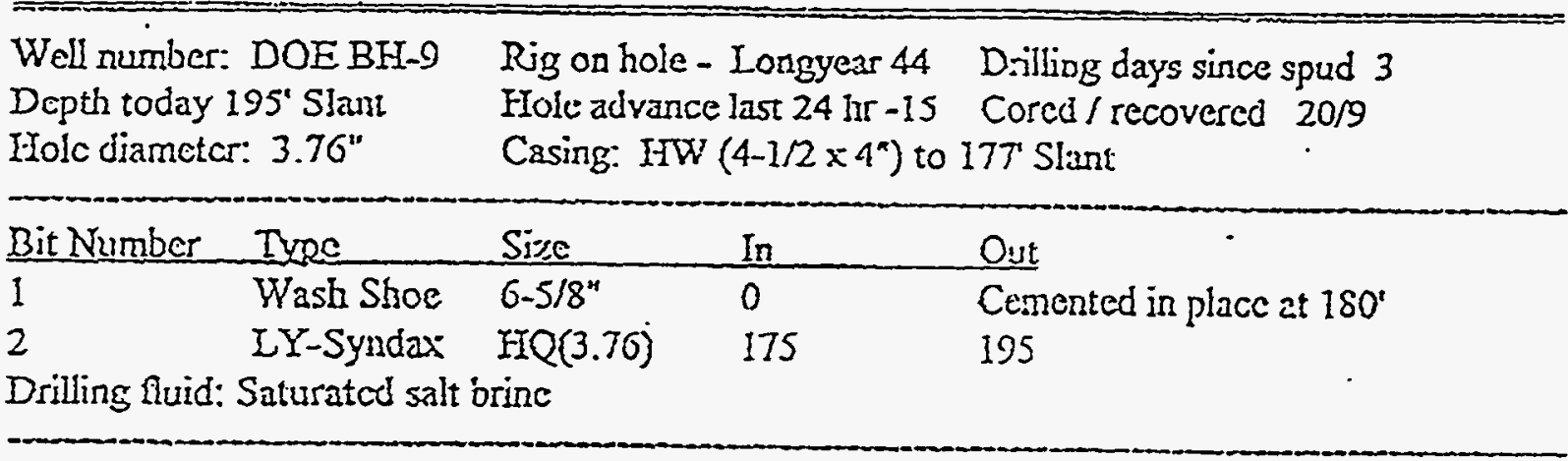

Summary of events last 24 hours:

Corcd $5^{\prime}$ of ccment Urough shoc and lost circulation at 180. Cored without returns or corc recovery to 190. Hole (sand) caving badly. Fiad to drill back to boitom after cach core run. Tried various corc catchers. Last core run recovcred 4' of pure sand. Left corc bartel at $180^{\prime}$ (to close cnd of corc string) and ran Gamma, Gamme-Gamma Density, and Neutron Porosily logs. POOEI with IYQ; running CBI and Dircctional logs at report time. Rig lown Longyear, move them to BIf-3.to polish cement in 6-5/8" lincr. Start of dye iojection delayed until at lcast Monday, alvaiting State : :pproval.

\begin{tabular}{|c|c|c|}
\hline Wall number: DOE BII-6 & Rig on holc - Fuiling 2000 & Driling days since sp::i $\sigma$ \\
\hline $\begin{array}{l}\text { Depith today } 35^{\circ} \\
\text { Ifolc dinmeter } 6-5 / 3^{\prime \prime}\end{array}$ & $\begin{array}{l}\text { Hole advancc last } 24 \mathrm{br}-0 \\
\text { Cissing. }\end{array}$ & Cored/rccovered o/o \\
\hline
\end{tabular}

\begin{tabular}{lllll}
\hline Bit Number & IVRS & Size & In & Dut \\
\hline 1 & LY & IIQ & 0 & 35 \\
2 & Mill lootil & $0-7 / 5$ & 0 & 35 \\
IRli & & & 35 & 175 \\
3 & Wash siloe & $0-5 / 8$ & 35 & 175 \\
Drilling Ruid: Salt saturated gel & &
\end{tabular}

Summary of crents list 24 hours:

Washed over sluck HQ core rods to $175^{\prime}$, pulled out $40^{\prime}$ of HQ that was not made up to the remainder of the string. RCI with spicar-type swage and pull rest of $H Q$. POOH wilh wash pipc. Rig up to begin washing over conductor.

Fecap BIE-3: (vertical) $13^{\prime \prime}$ hole, 10-3/4" casing to $187^{\prime}$; $6-5 / 8^{\prime \prime}$ casing from $167^{\circ}$ to $250^{\circ}$

BI- A: (vertical) $12-1 / 4^{\prime \prime}$ hole, $\delta-5 / 8^{\prime \prime}$ casing to $250^{\prime}$

BHI-5: (vertical) $13^{\prime \prime}$ lole, $6-5 / 8^{\prime \prime}$ casing to $250^{\circ}$

BII-6: (vertical) 9-7/8" hole, 7-5/8" casing to $34^{\prime \prime}, 6-5 / 8^{\prime \prime}$ holc to $175^{\prime \prime}$

BH-9: (slant) $6-5 / 8^{\prime \prime}$ hole, $4-1 / 2^{\prime \prime}$ casing to $180^{\prime}$ (175' TVD), $3.76^{\prime \prime}$ hole to $195^{\prime}$ (siant) Total project cost through 23 June: $\$ 406,000$ 


\section{SNL D $R L Y^{Y}$ DRILLING REPORT \\ VEEKS ISLAND SINKHOLE DRILLING PROGRAM \\ MBERTA PARISH, LOUISIANA \\ Date of report: 26 June 94 \\ Time of report: 0800}

Well number: DOE BY-9

Summary of cvents last 24 hours:

Completed CBL and Directional logs Directional survey indicated that hole inclination gradually decreased from approximately $10.5^{\circ}$ at the surface to approximately $8^{0}$ at $160^{\prime}$. Lateral hole displacement at a measured depth of 136 (start of lost circulation) is $~ 24$, which coincides with a vertical projection of the sinkhole's edge.

$\begin{array}{lll}\text { Well number: DOE BH-6 } 6 & \text { Rig on hole - Failing } 2000 & \text { Drilling days since spud } 6 \\ \text { Depth today 35' } & \text { Hole advance last 24 hr - } 0 & \text { Cored / recovered 0/0 } \\ \text { Hole dianneter: 21" } & \text { Casing: 16" to 34' } & \end{array}$

\begin{tabular}{lllll}
\hline Bit Number & Type & Size & In & Out \\
\hline 1 & LY & HQ & 0 & 35 \\
2 & Mill tooth & $9-7 / 8$ & 0 & 35 \\
IRR & & & 35 & 175 \\
3 & Wash shoc & $6-5 / 8$ & 35 & 175 \\
4 & Wash sioe & 15 & 0 & 35 \\
$5 \cdot$. & Mill tooth & 21 & 0 & 35
\end{tabular}

Drilling fluid: Salt saturated gel

Summary of events last 24 hours:

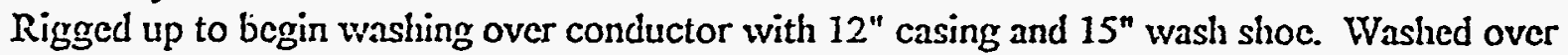
conductor to 35', haid down wash pipe, retrieved conductor, reamed $21^{\prime \prime}$ hole to $35^{\prime}$, ran 16" casing to $34^{\prime}$, and cemented. WOC until report time.

Report by Ron Jacobson/Jolnn Finger

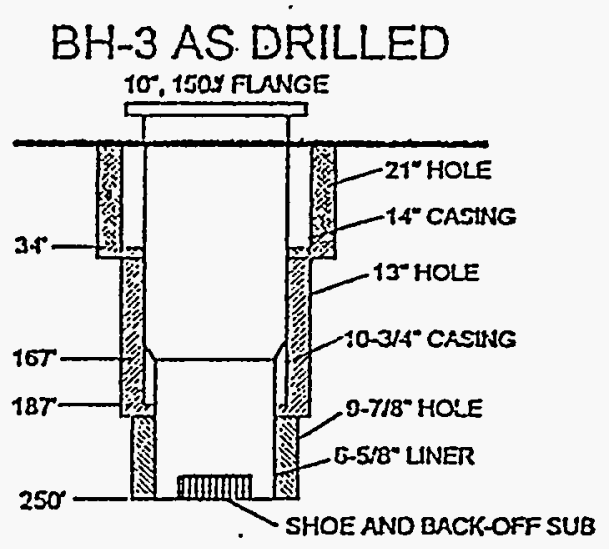

\section{BH-9 AS DRILLED}

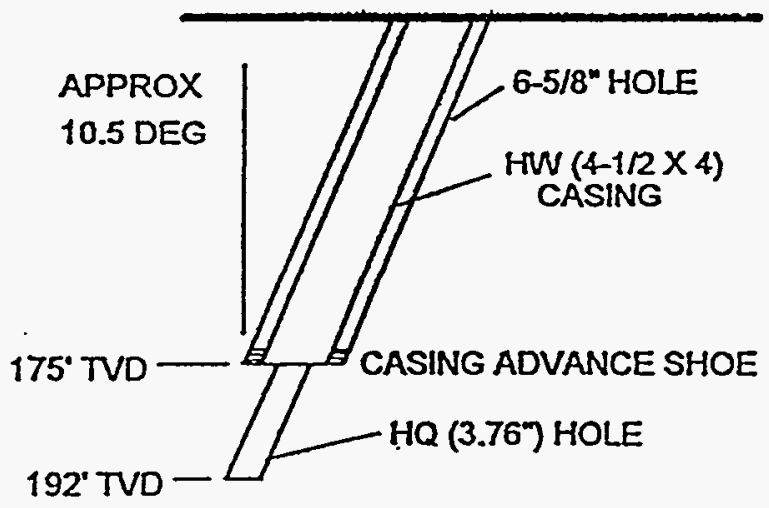


SNL DAILY DRILLING REPORT

WEEKS ISLAND SINKHOLE DRILLING PROGRAM

IBERIA PARISH, LOUISIANA

Date of report: 27 June 94

Time of report: 0800

Well number: DOE BH-9

Summary of events last 24 hours:

Waiting on approval from Louisiana Department of Environmental Quality before beginning dye injection.

\begin{tabular}{|c|c|c|c|c|}
\hline \multicolumn{2}{|c|}{$\begin{array}{l}\text { Well number: DOE BH-6 } \\
\text { Depth today } 192^{\prime} \\
\text { Holc diamcter: } 15^{\prime \prime}\end{array}$} & \multicolumn{3}{|c|}{$\begin{array}{l}\text { Hole advance last } 24 \mathrm{hr}-157 \text { Corcd / recovered } 0 / 0 \\
\text { Casing: } 10-3 / 4^{\prime \prime} \text { to } 189^{\prime}\end{array}$} \\
\hline Bit Number & Type & Size & In & Out \\
\hline 1 & LY & $\mathrm{HQ}$ & 0 & 35 \\
\hline 2 & Mill tooth & $9-7 / 8$ & 0 & 35 \\
\hline $1 R R$ & & & 35 & 175 \\
\hline 3 & Wash shoe & $6-5 / 8$ & 35 & 175 \\
\hline 4 & Wash shoc & 15. & 0 & 35 \\
\hline 5 & Mill tooth & 21 & 0 & 35 \\
\hline 6 & Mill tooth & 15 & 35 & 192 \\
\hline Drilling Ruid & Salt saturatc & & & \\
\hline
\end{tabular}

Summary. of events last 24 hours:

Pick up 15" bit and clean out conductor. Open hole (6-5/8" to $\left.15^{\prime \prime}\right)$ from $35^{\prime}$ to $175^{\prime}$. Drill $15^{\prime \prime}$ to 192 , no salt cuttings in returns, but drilling is much harder. POOH, attempt to run casing; casing will not go below $\sim 80^{\prime}$. Lay down casing, make bit trip, attempt to run casing again. Casing finally gocs, rcluctantly, to bottom. Pump cement, good returns, excellent cement job. WOC.

$\begin{array}{lll}\text { Well number: DOE BH-7 } & \text { Rig on hole - Longyear } 44 & \text { Drilling days since spud } \mathrm{n} / \mathrm{a} \\ \text { Depth today } \mathrm{n} / \mathrm{a} & \text { Holc advance last } 24 \mathrm{hr}- & \text { Cored } / \text { recovered } 0 / 0 \\ \text { Holc diamcter: } \mathrm{n} / \mathrm{a} & \text { Casing: } \mathrm{n} / \mathrm{a} & \end{array}$

Summary of events last 24 hours:

Longycar is rigged up over holc, awaiting approval from DOE to begin drilling.

- Recap BH-3: (vertical) 13" hole, 10-3/4" casing to $187^{\prime \prime} ; 6-5 / 8^{\prime \prime}$ casing from $16 T^{\prime \prime}$ to $250^{\prime}$

$\mathrm{BH}-4$ : (vertical) $12-1 / 4^{\prime \prime}$ hole, $8-5 / 8^{\prime \prime}$ casing to $250^{\circ}$

BH-5: (vertical) 13" hole, 6-5/8" casing to $250^{\prime}$

BH-6: (vertical) 21" hole, $16^{\prime \prime}$ casing to $34^{\prime} ; 15^{\prime \prime}$ hole to $192^{\prime}, 10-3 / 4^{\prime \prime}$ casing to $189^{\prime \prime}$

BH-9: (slant) $6-5 / 8^{\prime \prime}$ hole, 4-1/2" casing to $180^{\prime}$ (175' TVD), 3.76" hole to $195^{\prime}$ (slant)

Total project cost through 23 June: $\$ 406,000$

Report by Ron Jacobson/John Finger 
SNL DAILY DRILLING REPORT

WEEKS ISLAND SINKHOLE DRILLING PROGRAM

IBERIA PARISH, LOUISIANA

Date of report: 28 June 94

Time of report: 0800

Well number: DOE BH-9

Summary of events last 24 hours:

Began dye injection in early afternoon. Hole would only take $\sim 75$ gallons of dye solution.

Well number: DOE BH-6

Depth today 192'

Hole diameter: $15^{\text {" }}$
Rig on hole - Failing 2000

Hole advance last $24 \mathrm{hr}-0$

Casing: $10-3 / 4^{\prime \prime}$ to $189^{\prime}$
Drilling days since spud 8

Cored / recovered $0 / 0$

\begin{tabular}{llll}
\hline Bit Number & Type $\quad$ Size $\quad$ In & Out \\
As described in previous reports &
\end{tabular}

- Drilling fluid: Salt saturated gel

Summary of events last 24 hours:

Wait on cement. Clean mud and solids tanks.

Well number: DOE BH-7 Rig on hole - Longyear 44 Drilling days since spud 1

Depth today $133^{\prime}$ (slant) Hole advance last $24 \mathrm{hr}-133^{\prime}$ Cored $/$ recovered $0 / 0$

Hole diameter: 6-5/8' Casing: n/a

\begin{tabular}{lllll}
\hline Bit Number & Type $^{-}-$ & Size & In & Out \\
\hline 1 & Csg Adv Shoe 6-5/8" & Surface &
\end{tabular}

Drilling fluid: Salt saturated gel

Summary of events last 24 hours:

Spudded hole about 1100 yesterday, washing casing down as in $\mathrm{BH}-9$, except that the nominal angle of this hole is $30^{\circ}$ from vertical. Made single-shot surveys every $50^{\prime}$ to check inclination, it was dropping about $2 \% / 50^{\prime}$ drilled. Twisted off casing while drilling at $133^{\prime}$ slant distance. Shoe and $40^{\prime}$ of HW casing left on bottom. Running fishing tools in hole at report time.

Recap BH-3: (vertical) $13^{\prime \prime}$ hole, $10-3 / 4^{\prime \prime}$ casing to $187^{\prime} ; 6-5 / 8^{\prime \prime}$ casing from $167^{\prime}$ to $250^{\prime}$

BH-4: (vertical) $12-1 / 4^{\prime \prime}$ hole, $8-5 / 8^{\prime \prime}$ casing to $250^{\prime}$

BH-5: (vertical) $13^{\prime \prime}$ hole, $6-5 / 8^{\prime \prime}$ casing to $250^{\prime}$

BH-6: (vertical) $21^{\prime \prime}$ hole, $16^{\prime \prime}$ casing to $34^{\prime} ; 15^{\prime \prime}$ hole to $192^{\prime}, 10-3 / 4^{\prime \prime}$ casing to $189^{\prime}$

BH-7A (slant) $6-5 / 8^{\prime \prime}$ hole at $30^{\circ}$ from vertical, depth

BH-9: (slant) $6-5 / 8^{\prime \prime}$ hole, $4-1 / 2^{\prime \prime}$ casing to $180^{\prime}$ (175' TVD), $3.76^{\prime \prime}$ hole to $195^{\prime}$ (slant)

Total project cost through 23 June: $\$ 406,000$

Report by Ron Jacobson/John Finger 
SNL DAILY DRILLING REPORT

WEEKS ISLAND SINKHOLE DRILLING PROGRAM

IBERIA PARISH, LOUISIANA

Date of report: 29 June 94

Time of report: 0800

Well number: DOE BH-9

Summary of events last 24 hours:

Washed $1 / 2^{\prime \prime}$ pipe to bottom for dye injection at 5 gpm. Injection complete.

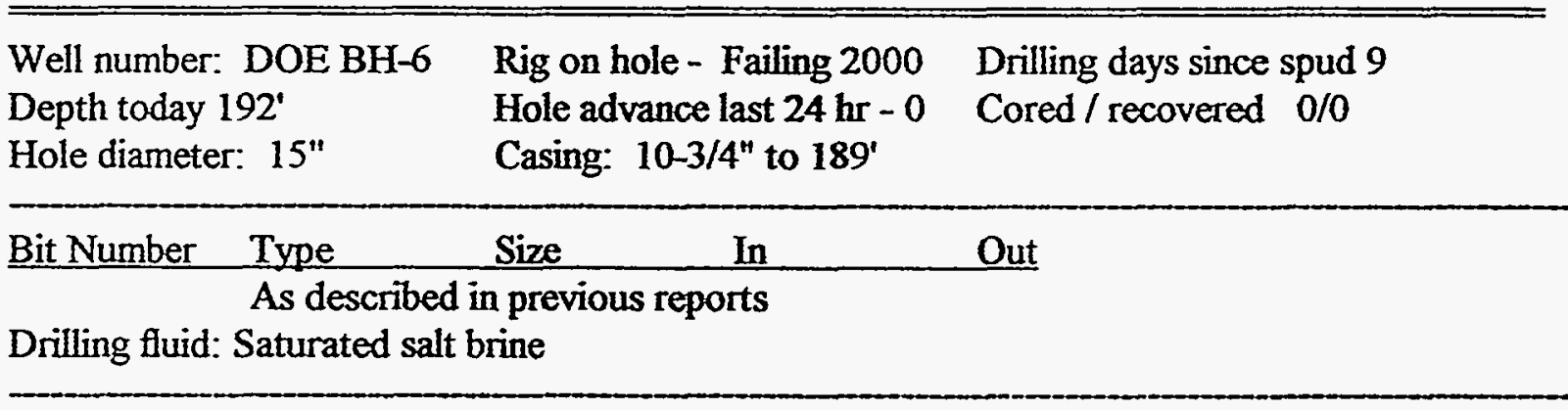

Summary of events last 24 hours:

Drilled cement to 170'. Run in hole with SW casing and drill $1^{\prime}$ into cement. Rigged up BSF wireline coring system and start coring cement. If salt core quality is good core to TD. If core quality is not good rig down and move core rig over hole.

Well number: DOE BH-7A Rig on hole - Longyear 44 Drilling days since spud 2

Depth today $214^{\prime}$ (slant) Hole advance last $24 \mathrm{hr}-81^{\prime}$ Cored / recovered $0 / 0$

Hole diameter: 6-5/8, Casing: $n / a$

\begin{tabular}{|c|c|c|c|}
\hline Bit Number & Type & In & Out \\
\hline 1 & Csg Adv Shoe 6-5/8" & Surface & $133^{\prime}$ \\
\hline 2 & Washovr Shoe 6-5/8" & $133^{\circ}$ & \\
\hline Drilling fluid & Salt saturated gel & & \\
\hline
\end{tabular}

Summary of events last 24 hours:

RIH with spear and work fish. It rotates freely and moves up and down $\sim 3^{\prime}$ but doesn't want to come out. Change chuck to "drill up" and come out of hole with fish at 1430. Pick up washover shoe and BSF drill pipe (which is stronger than HW casing) to re-drill. Inclination surveys during drilling show hole angle dropping $\sim 2 \% / 50^{\prime}$ drilled. Ready to cement at salt( 192 'TVD).

Recap BH-3: (vertical) $13^{\prime \prime}$ hole, $10-3 / 4^{\prime \prime}$ casing to 187 ; 6-5/8" casing from 167 to $250^{\prime \prime}$

$\mathrm{BH}-4$ : (vertical) $12-1 / 4^{\prime \prime}$ hole, $8-5 / 8^{\prime \prime}$ casing to $250^{\prime}$

BH-5: (vertical) $13^{\prime \prime}$ hole, $6-5 / 8^{\prime \prime}$ casing to $250^{\prime}$

BH-6: (vertical) $21^{\prime \prime}$ hole, $16^{\prime \prime}$ casing to $34^{\prime} ; 15^{\prime \prime}$ hole to $192^{\prime}, 10-3 / 4^{\prime \prime}$ casing to $189^{\prime \prime}$

$\mathrm{BH}-7 \mathrm{~A}$ (slant) $6-5 / 8^{\prime \prime}$ hole at $30^{\circ}$ from vertical

BH-9: (slant) $6-5 / 8^{\prime \prime}$ hole, 4-1/2" casing to $180^{\prime}$ (175' TVD), $3.76^{\prime \prime}$ hole to $195^{\prime}$ (slant)

Total project cost through 23 June: $\$ 406,000$

Report by Ron Jacobson/John Finger 


\section{SNL DAIIY DRILLING REPORI \\ WEEKS ISIAND SINKHOLE DRULING PROGRAM \\ IBERIA PARISH, LOUISIANA \\ Date of report: 30 June 94 \\ Time of report: 0800}

Well number: DOE BIF-6 Rig on hole - Failing 2000 Drilling days since spud 10

Depth today 209'

Hole diameter: $5-7 / 8^{n}$

Hole advance last $24 \mathrm{hr}-19^{\prime}$ Cored / recovered $19 / 19$

Casing: $10-3 / 4^{x}$ to $189^{\prime}$

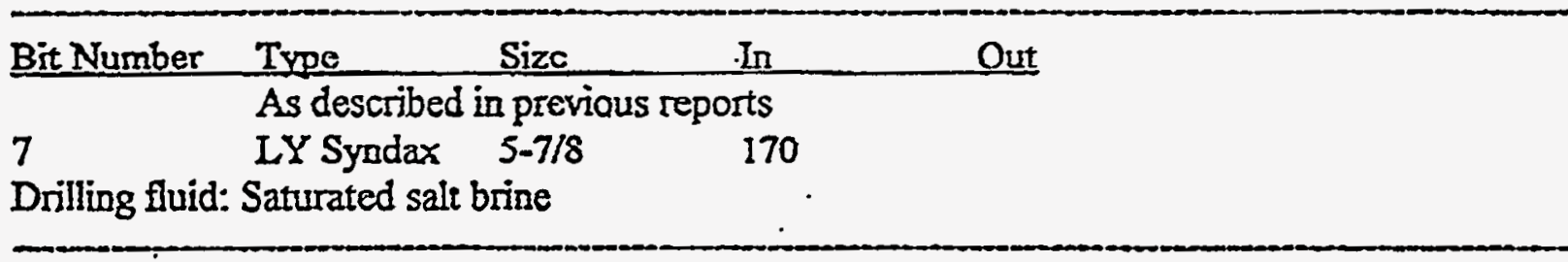

Summary of events last 24 hours:

Cored/cleaned out cement from $171^{3}$ to casing shoe at $189^{\prime}$. There was some cherty debris, mixed with wood, in one core barrel but most of the salt core was competent. There was direct contact between the salt and cement at a nominal 190', but there is a slight discrepaney between the hole depth from rotary drilling and from core drilling.

Well number: DOE BI-7A Rig on hole - Longyear 44 Driling days since spud 3

Depth today $214^{\prime}$ (slant) Hole advance last $24 \mathrm{hr}-81^{\prime}$ Cored / recovered $0 / 0$

Hole diameter: $6-5 / 8^{2}$

Casing: BSF core rods 5-1/2"x 4-7/8" to 214'

\begin{tabular}{|c|c|c|c|}
\hline Bit Number & Type & In & Out \\
\hline 1 & Csg.Adv Slooe 6-5/S" & Surface & $133^{\circ}$ \\
\hline & Washovr Shoe 6-5/8" & $133^{\prime}$ & cemented in place at $214^{\circ}$ \\
\hline \multicolumn{4}{|c|}{ Drilling fluid: Salt saturated gel } \\
\hline
\end{tabular}

Summary of erents last 24 hours:

Cement in place with full returns at $1200,6 / 29$. WOC until report time.

Recap BH-3: (vertical) 13" hole, 10-3/4" casing to $187^{\prime} ; 6-5 / 8^{\prime \prime}$ casing from $167^{\circ}$ to $250^{\prime}$

BII-4: (vertical) $12-1 / 4^{\prime \prime}$ hole, $8-5 / 8^{n}$ casing to $250^{\circ}$

BH-5: (vertical) $13^{\prime \prime}$ hole, $6-5 / 8^{\prime \prime}$ casing to $250^{\prime}$

BH-6: (vertical) $21^{\prime \prime}$ hole, $16^{\prime \prime}$ casing to $34^{\prime \prime}, 15^{\prime \prime}$ hole to $192^{\prime}, 10-3 / 4^{\prime \prime}$ casing to $189^{\prime}$

BH-7A (slant) $6-5 / 8^{\prime \prime}$ hole at $30^{\circ}$ from verrical, $5-1 / 2^{\prime \prime}$ casing to $214^{\circ}$ (192. TVD)

BH-9: (slant) $6-5 / 8^{\prime \prime}$ hole, 4-1/2" casing to $180^{\prime \prime}\left(175^{\prime}\right.$ TVD), 3.76" hole to $195^{\prime}$ (slant)

Total drilling project cost through 28 June: $\$ 4.58,000$

Repor by Ron Jacobson/John Finger 
SNL DAULY DRILLING REPORT

WEEKS ISLAND SINKHOLE DRILLING PROGRAM

IBERIA PARISH, LOUISIANA

Date of report: 1 JULY 94

Time of report: 0800

\begin{tabular}{|c|c|c|}
\hline $\begin{array}{l}\text { Well number: } \text { DOE BH-6 } \\
\text { Depth today } 248^{\prime} \\
\text { Hole diameter: } 5-7 / 8^{\prime \prime}\end{array}$ & $\begin{array}{l}\text { Rig on hole - Failing } 2000 \\
\text { Hole advance last } 24 \mathrm{hr}-39^{\prime} \\
\text { Casing: } 10-3 / 4^{\prime \prime} \text { to } 189^{\prime}\end{array}$ & $\begin{array}{l}\text { Drilling days since spud } 11 \\
\text { Cored / recovered } 58 / \text { most }\end{array}$ \\
\hline Bit Number & Size In & Out \\
\hline \multicolumn{3}{|c|}{ As described in previous reports } \\
\hline LY Syndax & $5-7 / 8 \quad 170$ & $248^{\prime}$ \\
\hline $8 \quad$ Mill tooth & $9-7 / 8$ & \\
\hline \multicolumn{3}{|c|}{ Drilling fluid: Saturated salt gel } \\
\hline
\end{tabular}

Summary of events last 24 hours:

Cored to $248^{\prime}$ with good core recovery down to approximately $235^{\prime}$. At that point, an increasing amount of gravel was falling from around the casing shoe into the hole alongside the core string, causing vibration, eccentric rotation, and poor core recovery. POOH with core string and SW casing (core string bushing) from 248: Wireline logger could not get tools below $175^{\prime}$ because of step from 10-3/4" casing to 5-7/8" hole; aborted cased-hole logs. Picking up 9-7/8" bit to ream to TD at report time.

Well number: DOE BH-7A Rig on hole - Longyear 44 Drilling days since spud 4

Depth today 264' (slant) Hole advance last $24 \mathrm{hr}-50^{\prime}$ Cored/ recovered 50/50

Hole diameter: $3.76^{\prime \prime} \quad$ Casing: BSF core rods $5-1 / 2^{\prime \prime} \times 4-7 / 8^{\prime \prime}$ to $214^{\prime}$

\begin{tabular}{|c|c|c|c|}
\hline Bit Number & Type $\quad$ Size & In & Out \\
\hline 1 & Csg Adv Shoe 6-5/8" & Surface & $133^{\prime}$ \\
\hline 2 & Washovr Shoe 6-5/8" & $133^{\prime}$ & cemented in place at $214^{\prime}$ \\
\hline 3 & LY Syndax $\quad 3.76^{\prime \prime}$ & 214 & 264 \\
\hline
\end{tabular}

Summary of events last 24 hours:

Clean cement to $190^{\prime}$ with HQ. POOH with HQ and run cased hole logs. Cored out of shoe into salt at 214', continued coring salt to $264^{\prime}$ (249' TVD) where we lost complete returns. Advanced drill string $\sim 2$ ', apparently in sand (recovering no core). Last piece of salt core has marks similar to erosion. The lateral coordinate of the borehole at this point is approximately 8-9' from the centerline of the sinkhole, indicating that a depression in the top of salt exists down to at least this depth.

Report by Ron Jacobson/John Finger 
SNL DAILY DRILING REPORT

WEEKS ISLAND SINKHOLE DRILING PROGRAM

IBEULAA PARISII, LOUISIANA

Date of report: 1 JULY 94

Time of report: 0800

\begin{tabular}{lll}
\hline Well number: DOE BH-6 & Rig on hole - Failing 2000 & Drilling days since spud 11 \\
Depth today $248^{\prime}$ & Hole advance last $24 \mathrm{br}-39^{\prime}$ & Cored / recovered 58/most \\
Hole diameter: $5-7 / 8^{\prime \prime}$ & Casing: $10-3 / 4^{\prime \prime}$ to $189^{\prime}$ &
\end{tabular}

\begin{tabular}{lllll}
\hline Bit Number & Type & Size & In & Out \\
7 & As described in previous reports & \\
8 & LY Syndax & $5-7 / 8$ & 170 & $248^{\prime}$
\end{tabular}

Drilling fluid: Saturacied salt gel

Summary of events last 24 hours:

Cored to $248^{\prime}$ with good core recovery down to approximately 235'. At that point, an increasing amount of gravel was falling from around the casing shoe into the hole alongside the core string, causing vibration, eccentric rotation, and poor core recovery. POOH with core string and SW casing (core string bushing) from 248'. Wireline logger could not get tools below $175^{\prime}$ bccause of step from 10-3/4" casing to 5-7/8" hole; aborted cased-hole logs. Picking up 9-7/8" bit to ream to TD at report time.

Well number: DOE BH-7A Rig on hole - Longyear 44 Drilling days since spud 4 Depth today 264' (slant) Hole advance last $24 \mathrm{hr}-50^{\circ}$ Cored / recovered $50 / 50$ Holc diameter: $3.76^{n}$ : $\quad$ Casing: BSF core rods $5-1 / 2^{n} \times 4-7 / 8^{\prime \prime}$ to $214^{\prime}$

\begin{tabular}{|c|c|c|c|}
\hline Bit Number & Type & In & Out \\
\hline 1 & Csg Adv Shoe 6-5/8 & Surface & $133^{\circ}$ \\
\hline 2 & Washovr Shoe 6-5/8" & $133^{\prime}$ & cemented in place at $214^{\prime}$ \\
\hline 3 & LY Syndax $\quad 3.76^{\prime \prime}$ & 214 & 264 \\
\hline
\end{tabular}

Drilling fluid: Salt saturated gel

Summary of events last 24 hours:

Clean cement to $190^{\prime}$ with HQ. POOH with HQ and run cased hole logs. Cored out of shoe into salt at 214', continued coring salt to $264^{\prime}$ (249' TVD) where we lost complete returns. Advanced drill string $\sim 2$ ', apparently in sand (recovering no core). Last piece of salt core has marks similar to erosion. The lateral coordinate of the borehole at this point is approximately 8-9' from the centerline of the sinkhole, indicating that a depression in the top of salt exists down to at least this depth.

Report by Ron Jacobson/John Finger 
SNL DAILY DRULING REPORT

WEEXS ISLAND SIRHOLE DRULING PROGRAM

IBERIA PARISH, LOUISIANA

Date of report: 2 July 94

Time of report: 0800

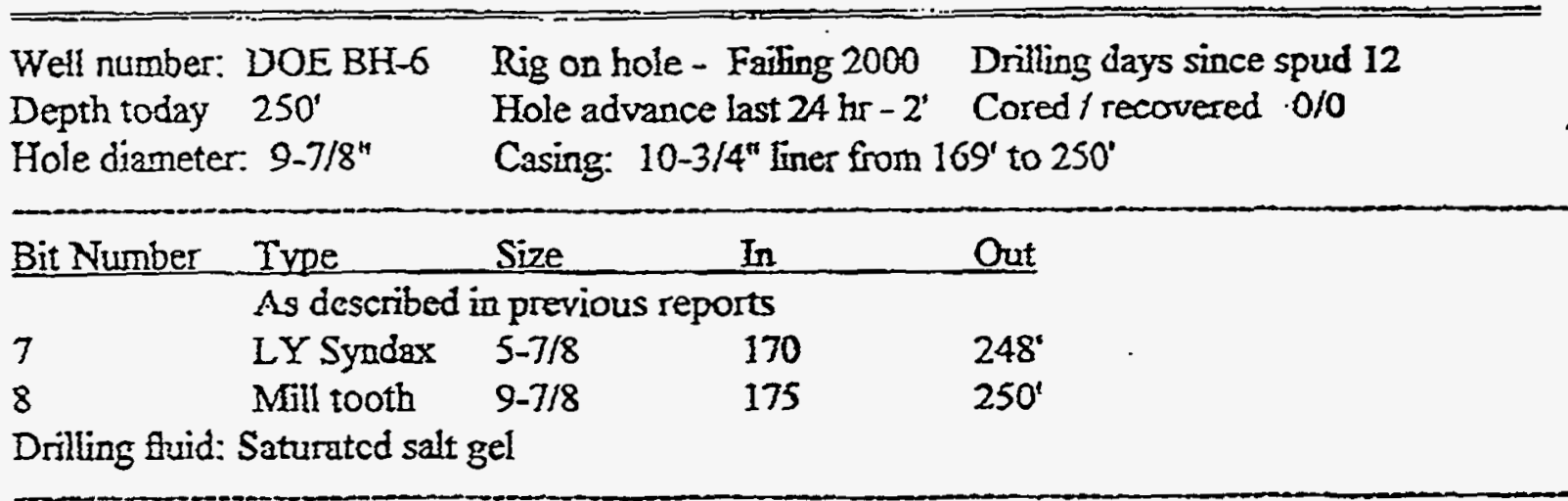

Summary of events last 24 hours:

Opened 9-7/8" hole to $248^{\prime}$, drilled to $250^{\prime}, \mathrm{POOH}$, and ran 6-5/8 liner from $169^{\prime}$ to $250^{\prime \prime}$.

Pumped cement, WOC.

Well number: DOE BH-7A Rig on hole - Longyear 44 Drilling days since spud 5

Depth today $275^{\prime}$ (slant) Hole advance last $24 \mathrm{hr}-0^{\prime}$ Cored/recovered $0 / 0$

Hole diameter: $3.76^{\prime \prime} \quad$ Casing: BSF core rods $\left(5-1 / 2^{n} \times 4-7 / 8^{n}\right)$ to $214^{\prime}$

\begin{tabular}{|c|c|c|c|c|}
\hline Bit Number & Type & Size & In & Out \\
\hline 1 & $\operatorname{Csg} A$ & $6-5 / 8^{\prime \prime}$ & Surface & $133^{\circ}$ \\
\hline 2 & Wash & $6-5 / 8^{\prime \prime}$ & $133^{*}$ & cemented in place at $214^{\prime}$ \\
\hline 3 & LYS & $3.76^{\circ}$ & 214 & 275 \\
\hline
\end{tabular}

Drilling fluid: Salt sanurated gcl

Summary of events last 24 hours:

Ran natural gamma log, and took fluid sample from hole. Released all but two men from

Longyear crew; will use LY rig to run H-rods into bole for deployment of Sandia flow measurement sensor. Will attempt to emplace that tool into the formetion sand beyond the sait breakthrough. Rigging up to run directional survey at report time.

Recap BH-3: (vertical) $13^{\prime \prime}$ hole, $10-3 / 4^{\prime \prime}$ casing to $187^{7} ; 6-5 / 8^{\prime \prime}$ liner from 167 to $250^{\prime}$

BE-4: (vertical) $12-1 / 4^{\prime \prime}$ hole, $8-5 / 8^{\prime \prime}$ casing to 250 !

BH-5: (vertical) $13^{\prime \prime}$ hole, $6-5 / 8^{\prime \prime}$ casing to $250^{\circ}$

BH-6: (vertical) $15^{\prime \prime}$ hole to $192^{\prime}$, $10-34^{\prime \prime}$ casing to $189^{\prime} ; 6-5 / 8^{*}$ liner from $169^{\prime \prime}$ to $250^{\prime \prime}$

BH-7A (slant) 6-5/8" hole, 5-1/2" casing to 214'/192' TVD; 3.76 hole to 275/249' IVD

BH-9: (slant) $6-5 / 8^{\prime \prime}$ hole, $4-1 / 2^{\prime \prime}$ casing to $180^{\circ}$ (175' TVD), $3.76^{\prime \prime}$ hole to $195^{\prime}$ (slant)

Total drilling project cost through 28 Junc: $\$ 469,000$

Report by Ron Jacobsos/John Finger 
SNL DAILY DRILLING REPORT

WEEKS ISLAND SINKHOLE DRLLING PROGRAM

IBERIA PARISH, LOUISIANA

Date of report: 3 July 94

Time of report: 0800

Well number: DOE BH-6 Summary of events since last report:

Waited on cement.

Well number: DOE BH-7A Summary of events since last report:

Rigged up for dye injection beginning 1300, 2 July. Dye injection complete at 1730 . Rigging up to run flow sensor into hole at 0800,3 July.

Recap BH-3: (vertical) 13" hole, 10-3/4" casing to $187^{\prime} ; 6-5 / 8^{\prime \prime}$ liner from $167^{\prime}$ to $250^{\prime}$

BH-4: (vertical) 12-1/4" hole, 8-5/8" casing to $250^{\prime}$

BH-5: (vertical) 13" hole, 6-5/8" casing to $250^{\prime}$

BH-6: (vertical) $15^{\prime \prime}$ hole to $192^{\prime}, 10-3 / 4^{\prime \prime}$ casing to $189^{\prime}$; 6-5/8" liner from $169^{\prime}$ to $250^{\prime}$

BH-7A (slant) 6-5/8" hole, 5-1/2" casing to $214^{\prime} / 192^{\prime}$ TVD; 3.76 hole to $275^{\prime} / 249^{\prime}$ TVD

BH-9: (slant) $6-5 / 8^{\prime \prime}$ hole, $4-1 / 2^{\prime \prime}$ casing to $180^{\prime}$ (175' TVD), 3.76" hole to $195^{\prime}$ (slant)

Total drilling project cost through 28 June: $\$ 469,000$

Report by Ron Jacobson/John Finger

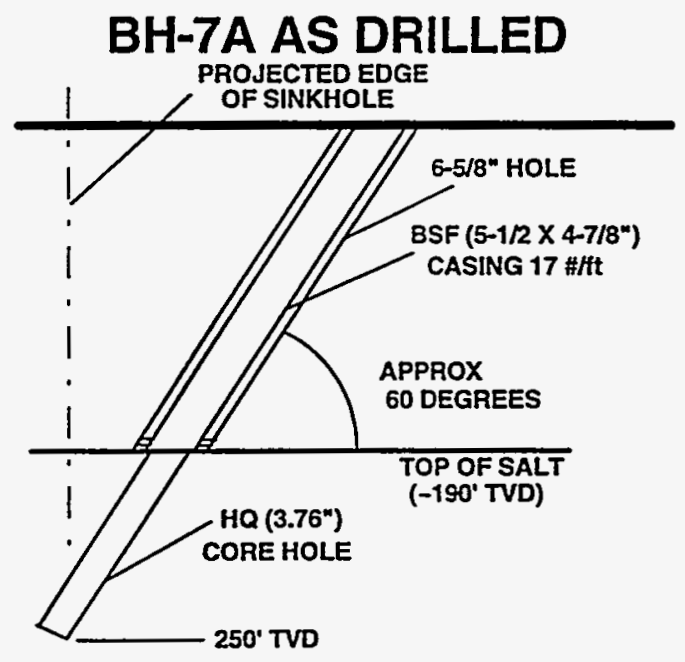




\section{SNL DAILY DRILLNG REPORT \\ WEEKS ISLAND SINKHOLE DRILLING PROGRAM \\ IBERIA PARISH, LOUISIANA \\ Date of report: 4 July 94 \\ Time of report: 0800}

Well number: DOE BH-6 Summary of events since last report:

Ran in hole with 9-7/8 bit to top of lap. No cement. ran in with a 5-7/8 bit to back off shoe, no cement. Ran CBL, no bonding. Ran in hole and stabbed into shoe and broke circulation. Washed out cement water. Rigged up Halliburton and pumped cement with no fluid returns to surface.

Waited on cement.

Well number: DOE BH-7A Summary of events since last report:

Washed flow sensor in with HQ core pipe to 288 slant depth. Pulled core pipe and left sensor in place. Rigged down Longyear and released crews. Rig and tools on standby.

Recap BH-3: (vertical) $13^{\prime \prime}$ hole, $10-3 / 4^{\prime \prime}$ casing to $187^{\prime \prime}$; 6-5/8" liner from $167^{\prime}$ to $250^{\prime}$

BH-4: (vertical) $12-1 / 4^{\prime \prime}$ hole, $8-5 / 8^{\prime \prime}$ casing to $250^{\circ}$

BH-5: (vertical) $13^{\prime \prime}$ hole, $6-5 / 8^{\prime \prime}$ casing to $250^{\circ}$

BH-6: (vertical) $15^{\prime \prime}$ hole to $192^{\prime}, 10-3 / 4^{\prime \prime}$ casing to $189^{\prime} ; 6-5 / 8^{\prime \prime}$ liner from $169^{\prime}$ to $250^{\prime}$

BH-7A (slant) $6-5 / 8^{\prime \prime}$ hole, $5-1 / 2^{\prime \prime}$ casing to $214^{\prime \prime} / 192^{\prime}$ TVD; 3.76 hole to $275^{\prime} / 249^{\prime}$ TVD

BH-9: (slant) $6-5 / 8^{\prime \prime}$ hole, $4-1 / 2^{\prime \prime}$ casing to $180^{\prime}$ (175' TVD), $3.76^{\prime \prime}$ hole to $195^{\prime}$ (slant)

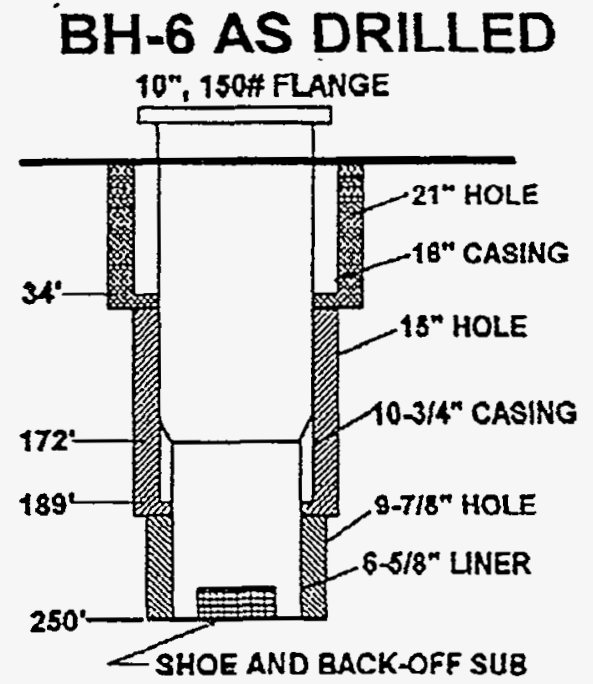

$\$ 469,000$

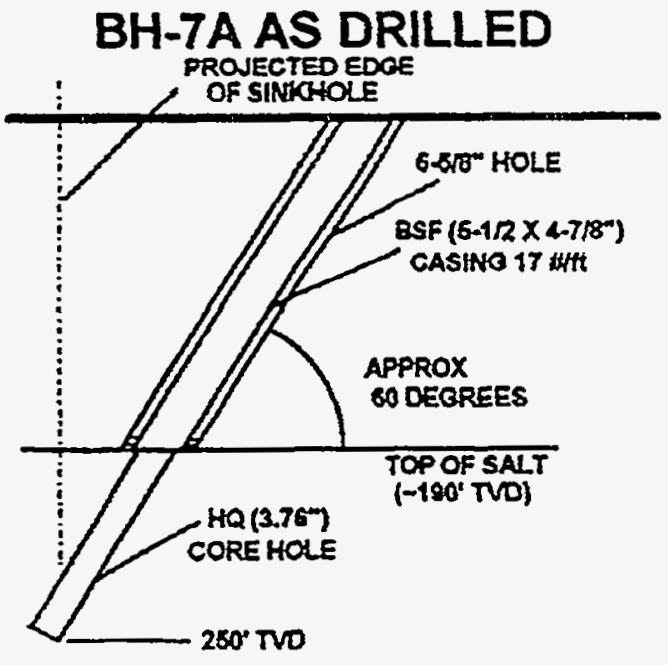

Total drilling project cost through 28 June:

Report by Ron Jacobson/John Fingi 


\section{SNL DAILY DRILING REPORT \\ WEEKS ISLAND SINKHOLE DRILLING PROGRAM \\ IBERIA PARISH, LOUISIANA \\ Date of report: 5 July 94 \\ Time of report: 0800}

Well number: DOE BH-6 Summary of events since last report:

Filled hole with brine. Still taking lots of fluid. Ran in hole with 9-7/8 bit to top of lap. No cement. ran in with a 5-7/8 bit and tagged cement at 242'. Ran open ended drill pipe to just above top of lap. Rigged up Halliburton and pumped 50 sacks of salt saturated cement into the lap with no fluid returns to surface. Water level $\sim 28^{\prime}$ below ground level. Wait on cement. Filed hole with brine and it is holding. Will drill out cement and run CBL.

Well number: DOE BH-7A Summary of events since last report:

Flow sensor in place and working.

Recap BH-3: (vertical) 13" hole, 10-3/4" casing to $187^{\prime} ; 6-5 / 8^{\prime \prime}$ liner from $167^{\prime}$ to $250^{\prime}$

BH-4: (vertical) 12-1/4" hole, 8-5/8" casing to $250^{\prime}$

BH-5: (vertical) 13" hole, 6-5/8" casing to $250^{\prime}$

BH-6: (vertical) 15" hole to $1922^{\prime}, 10-3 / 4^{\prime \prime}$ casing to $189^{\prime} ; 6-5 / 8^{\prime \prime}$ liner from $169^{\prime}$ to $250^{\prime}$

BH-7A (slant) 6-5/8" hole, 5-1/2" casing to 214'/192' TVD; 3.76 hole to 275'/249' TVD

BH-9: (slant) $6-5 / 8^{\prime \prime}$ hole, 4-1/2" casing to $180^{\prime}$ (175' TVD), 3.76" hole to $195^{\prime}$ (slant)

Total drilling project cost through 28 June: $\$ 469,000$

Report by Ron Jacobson/John Finger 
SNL DARY DRUXRIS REPORT

WEEKS ISLAND SINKHIOLE DRILLING PROGRAM

IBERIA PARISH, IOUTSIANA

Date of repor: $6 \mathrm{July} 94$

Time of repont: 0800

Well number. DOE BH-6 Summary of cvents since last report:

Drilled out cement to top of lap and washed to bottom Hole staying full Changed fluid over to fresh water and ran CBL. Released SSI finl rig. Dewater well and nun TV log to check finex top. Holc ready for cased bole logs.

Recap BH-3: (vertica) $13^{x}$ bole, $10-3 / 4^{\prime \prime}$ casing to $18 T ; 6-5 / 8^{*}$ liner from 167 to $250^{\circ}$

BH-4: (vertical) 12-1/4" hole, 8-5/8" casing to 250'

BH-5: (vertical) $13^{\prime \prime}$ hole; $6-5 / 8^{*}$ casing to $250^{\circ}$ -

BHI-6: (vertical) 15" hole to 192", 10-3/4" casing to $189^{\circ} ; 6-5 / 8^{\prime \prime}$ liner from $171^{\prime}$ to $250^{\circ}$

BHE-TA (siant) $6-5 / 8^{\circ}$ hole, $5-1 / 2^{\prime \prime}$ casing to $214^{\prime} / 192^{\prime}$ TVD; 3.76 hole to $2751249^{\prime}$ TVD

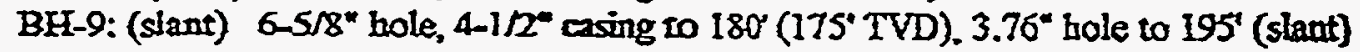

Total drilling project cost through 28 June: $\$ 469,000$

This is the Fural Sarrdia Drilting Report for this phose

Report by Ron JacobsowJohn Finger

BH-6 AS DRILLED

10", 150\# FLANGE

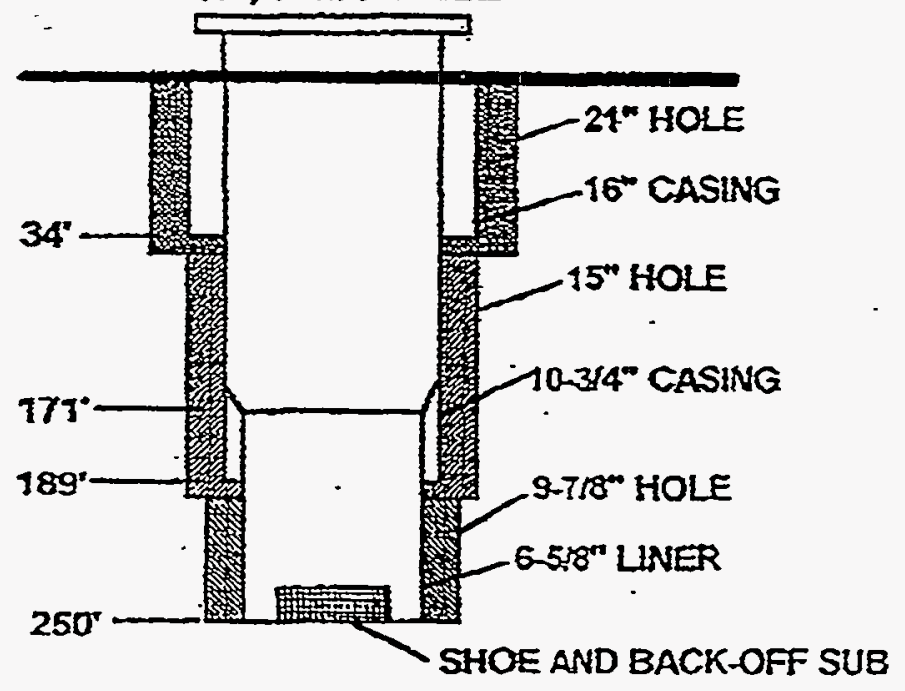


APPENDIX 4

GAS SURVEY, DRILING REPORT FROM L.S.U.

$A-4-1$ 


\section{$M \quad E \quad M \quad O \quad R \quad A \quad N \quad D \quad U \quad M$}

To: $\quad$ JAMES T. NEAL AND MARTIN A. MOLECKE SANDIA NATIONAL LABORATORIES

CC: $\quad$ STEVE BAUER, SANDIA LABORATORIES

KEN CARNEY, IES, LSU

EZAT HEYDARI, BRI, LSU

ED OVERTON, IES, LSU

TIM VOGT, RESPEC, INC.

MARK WALTHALL, DEPT. OF AGRONOMY, LSU

From: WHITNEY J. AUTIN

Date: August 22, 1994

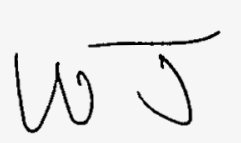

Subject: WEEKS ISLAND SINKHOLE REPORT

Enclosed is my final summary report of my findings on the Weeks Island sinkhole project. I would be happy to provide additional explanations or appropriate revisions to this report where necessary.

From The Desk Of...

WHITNEY J. AUTIN

ASSISTANT PROFESSOR - RESEARCH

INSTITUTE FOR ENVIRONMENTAL STUDIES

LOUISIANA STATE UNIVERSITY

BATON TOUGE, LA 70803

(504) 388 - 3420

Fax: (504) $388-4286$ 


\section{WEEKS ISLAND SINKHOLE PROJECT}

Letter report of August 22, 1994

Submitted to James T. Neal and Martin A. Molecke

Sandia National Laboratories (SNL)

Whitney J. Autin

Institute for Environmental Studies (IES)

Louisiana State University

Baton Rouge, LA 70803

\section{ACTIVITIES SUMMARY}

GAS SURVEY. I assisted the gas survey field work directed by Ken Carney of IES on May $9-11$, May $18-19$ and June $28-29,1994$. The locations for field gas sampling were surveyed by tape and compass method and referenced to subsidence benchmark locations on Weeks Island. These benchmarks are surveyed to the Louisiana plane coordinate system, used to describe locations in the Weeks Island mine and boreholes contracted by Sandia National Laboratories during the sinkhole investigation. Approximate locations of gas survey transects are illustrated as Figure 1. The geochemical results of the gas survey were summarized by Ken Carney and transmitted to Martin Molecke on July 29, 1994.

IES ran transects in the vicinity of the sinkhole parallel to Morton Road along the road's southern median (Line A of the gas survey; seismic line 4). A 10 meter average spacing was generally used, and 5 meter spacing was used in areas where higher resolution was desired. A set of four gas samples were taken adjacent to the sinkhole perimeter, and one in the center of the infilled hole. Three transects were oriented perpendicular to Shear Zone E (Acres International, 1987). The median along the east side of Advanced Materials road was surveyed from the corner with Morton Road to Snyder Road. A $10 \mathrm{~m}$ spacing was initially used, then the transect was resurveyed at 5 meter spacing (Line B of the gas survey, seismic line 3). Seismic line right of ways near the sinkhole (Line $C$ of the gas survey; seismic line 2) and to the east (Line $D$ of the gas survey; seismic line 1) were surveyed at $10 \mathrm{~m}$ intervals. Parts of Line $D$ were resurveyed at $5 \mathrm{~m}$ intervals. Line E was oriented perpendicular to the SPR pipeline and surveyed at $5 \mathrm{~m}$ intervals. Line $F$, surveyed at $5 \mathrm{~m}$ intervals, was placed perpendicular to Line $C$ in the vicinity of a seismic anomaly. Line $F$ was placed along the tree line north of the Morton Road between Lines $A$ and $F$. Line $G$ was placed along the eastern side of the island in an attempt to estimate background gas concentrations. This transect was located perpendicular to 


\section{W. J. AUTIN, LETTER REPORT, p. 2}

LA 83 and surveyed at $50 \mathrm{~m}$ intervals. Line $\mathrm{H}$ was placed between the SPR fill holes and the sinkhole at $5 \mathrm{~m}$ intervals.

DRILLUNG AND GEOPHYSICAL SURVEYS. I worked at the sinkhole drill site as part of a team of site geologists coordinated by Jim Neal of Sandia National Laboratories. I was at the site June 7 - 9, June 13-14, June 16,18 , and 28 . During this time, 1 described and logged core samples and cuttings from drilling operations. Descriptive logs were provided to Jim Neal and samples of the materials described were boxed for storage. Samples were selected for lithologic and mineralogic analysis in collaboration with Jim Neal.

I also conducted walking and automobile reconnaissance of parts of Weeks Island. Most of the walking consisted of field inspections of features in gullies, observations of micro-scale characteristics of topography and drainage, and soil fractures and erosional features in the general vicinity of the sinkhole. The automobile survey was mostly in the Devil's Backbone area, the eastern side of the island near the background transect, and near the actively developing sinkhole at Avery Island.

The walking inspection centered on observations of the topography in the vicinity of the sinkhole and surficial lineation that roughly coincides with Shear Zone $E$ in the subsurface (Acres International, 1987). $I$ also walked along the slope between the sinkhole and the fill yard. Nothing special was noticed, mostly because of the dense vegetation. The headwall in the ravine to the east of the Devil's Backbone appears to be retreating, based on a comparison with my observations from a 1993 visit.

I also went to the developing sinkhole at Avery Island. The sinkholes I observed in 1986 and 1990 have become considerably overgrown with vegetation. The general low area has developed into a broad area of notable subsidence covering several hundreds of square meters. Several linear surface fractures have developed away from the sinkhole. 
W. J.AUTIN, LETTER REPORT, p. 3

\section{GAS SURVEY INTERPRETATIONS}

There are four possible sources of hydrocarbon gasses in the Weeks Island area, 1) soil and paleosol gasses, 2) black sand at the base of overburden near the salt/sediment contact, 3) Weeks Island oil, and 4) SPR oil.

1) Soil and paleosol gasses are eliminated from consideration since the GC experimental technique should accurately factor out biogenic hydrocarbon sources.

2) The black sand at the base of the overburden contains organic materials_in the form of unmineralized wood fragments. The large quantities of wood fragments sampled in drill cuttings are possibly tree stumps or logs contained in the strata. Salt dissolution is evidenced by anhydrite fragments and chemical reduction, including the presence of fresh wood and pyrite growths on sand and gravel grains. Although organic matter is abundant in this strata, it is not likely to be the source of isobutane or heavier hydrocarbons.

3) Although oil and gas production from the Weeks Island oil and gas field is mostly on the northern and eastem perimeters of the island, local oil fields are a significant source of gas seeps. Oil and gas has been produced along the flanks of the Weeks Island dome from primarily Miocene strata at depths generally greater than 10,000 ft below sea level (Atwater and Forman, 1959; Acres International, 1987; Neal et al., 1993). Elevated concentrations along transect $\mathrm{G}$ reported by Ken Carney strongly suggest that oil and gas traps and/or production at Weeks Island can be detected by the field gas survey procedure. Although the presence of significant quantities of oil and gas over the crest of the dome are unlikely, it would be beneficial to assess the characteristics of oil from a producing well to eliminate local oil fields as a source of the vapor measured during the gas survey. Continued analysis of the chemical characteristics of oil stored in the SPR repository will help to identify differences in hydrocarbon sources.

4) Areas of high concentration directly over the SPR storage facility strongly point to the repository as the source of the gas seeps. Patterns of gas seeps suggest a structural control associated with fracture development processes. Fractures and/or fracture networks may occur 1) in the rock salt and overburden sediments, and 2) surficial fractures associated with soil development processes. Assuming hydrocarbon gas 


\section{W. J.AUTIN, LETTER REPORT, p. 4}

is rising from a source in the SPR facility, the following gas seep pathways are available for upward gas migration.

In the rock salt, pathways through the granular spaces between salt crystals should be almost nil. Due to the shallow depths involved, the rock salt is likely to be brittle between the top of the repository and the top of the salt. Fracture permeability may occur in or near any of the mapped anomalous zones (Acres International, 1987).

The general stratigraphy above the salt consists of a loamy deposit overlying a sandy deposit. The loamy deposit consists of a surficial silty loess $5 \mathrm{~m}$ or less in thickness, and a sandy loam or clay loam alluvial paleosol of $5 \mathrm{~m}$ or less in thickness (Autin and McCulloh, 1993). The sandy deposit is generally a medium to coarse sand with few lenses of granule gravel. Thickness of the sandy deposit is at least $40 \mathrm{~m}$ in the sinkhole area. The sandy deposit has few occasional loamy to clayey interbeds and lenses. The following gas seep pathways are possible within this overburden sequence above the salt.

1) Granular space occurs in all overburden deposits. This granular space has the following characteristic sequence: an unsaturated loamy zone, an unsaturated sandy zone, a fresh water saturated sandy aquifer, and a saline water saturated sandy aquifer (Figure 2).

2) Soil structure is the combination or aggregation of primary soil particles into aggregates or clusters (called peds), which are separated from adjacent peds by surfaces of weakness. Soil structure occurs in the upper $5 \mathrm{~m}$ or less below the land surface in the loessial and alluvial loamy paleosol strata. At Weeks Island the primary soil structure is a subangular blocky form that produces hexagonal prisms with rounded to subrounded facets. Individual peds range in size from centimeter to decimeter scale.

3) Shear fractures are cracked or displaced masses of overburden material. Displacement of soil materials can occur by faulting and or mass movement. Existing evidence from the Five Islands suggests that shear fractures occur on Weeks Island. Apparent shear fractures have been observed at two locations in surficial gullies on Weeks Island and in some of the borings collected in a previous investigation (Autin and McCulloh, 1993).

In cores, tectonic shear fractures are commonly long enough to completely cut across a $5 \mathrm{~cm}$ core. They typically produce slickensided surfaces, especially in clayey sediments, and may occur as conjugate pairs.

$$
A-4-6
$$




\section{W. J.AUTIN, LETTERREPORT, p. 5}

The orientation data reported at Avery Island by Autin et al. (1986) was based on an excellent exposure that coincides with the position of a documented shear zone. Orientation data suggested that the Avery Island shear zone produced a preferred pattern of tensional stress on the overburden sediments. It is possible that the pattern generated by the gas survey data at Weeks Island is a surrogate of a fracture structure that has developed in the overburden by the stress instability that created the sinkhole.

4) Fracture structure and associated subsidence features may be occurring on a meso-scale, on the order of hundreds of meters in areal extent. Possible structural forms (Figure 3) include 1) an individual chimney structure that has been defined beneath the sinkhole, 2) a chimney structure network over an undetermined portion of the SPR repository, 3) a linear structure of overburden fracturing and land subsidence coincident with Shear Zone E (Acres International, 1987) generally parallel to Morton Road from Advanced Materials Road to the vicinity of Plantation Lake, and 4) a broad area of incremental subsidence coincident with the SPR repository (Sandia National Laboratories, Memorandum from P. S. Kuhiman to J. K. Linn, May 8 , 1994).

Patterns of gas seeps defined by the gas survey transects suggest a seep process that is possibly controlled by surficial soil fracture patterns and deeper-seated rock salt fractures and/or chimney structures. The following discussion accepts the assumption that elevated peaks in hydrogen response ratios correlate with locations of higher concentrations and rates of gas seep relative to assumed background hydrogen concentrations. It is also assumed that the SPR repository is the ultimate source of the hydrocarbon vapors measured in the gas survey. The data and interpretations included in final report memoranda from Ken Carney, IES - LSU to Martin Molecke, Sandia National Laboratories (July 29, 1994) and Martin Molecke to SNL and DOE distribution list (August 5,1994 ) provide the basis for the following interpretations.

Line A, aligned parallel to Morton Road, illustrates a fairly broad area of low response ratio levels near the sinkhole, but elevated levels occur east of the intersection with Line D. Line C, aligned parallel to seismic line 2, has a fairly broad area of high response ratio levels south of the sinkhole, and north of the sinkhole near the intersection with Line F.

Line B, aligned parallel to Advanced Materials Road, showed areas of elevated response ratio levels along the steeper slope of the monoclinal flexure associated with the topographic lineation. The steepened 
W. J. AUTIN, LETTERREPORT, p. 6

topographic slope could be an area of greater overburden tensional stress, therefore an area of higher fracture density.

Line $D$, aligned parallel to seismic line 1 , has elevated response ratio levels near the intersection with Line $A$ and along the southern part of the transect. This area of elevated concentration at the intersection of Lines $A$ and $D$ may correlate to the surface expression of Shear Zone $E$. Also, the area of elevated concentration south of the fill holes may also relate to Shear Zone E. However, the higher soil moisture content of the grayish soils in this topographic low could also be elevating background concentrations relative to brownish soils of higher topographic positions.

Line $F$, aligned perpendicular to Line $C$ in the vicinity of a seismic anomaly, is another area of elevated response ratios. This area is in linear alignment with the elevated concentrations along Line $B$ and the surface drainage gully to the east between seismic lines 1 and 2 . At this time, it is not possible to positively correlate the elevated response ratios near the intersection of Line $C$ and Lines $F$ and $F^{\prime}$ with those of Line $B$ into a single concentration area. However, these areas of concentration are not likely to be diffusing from a single elevated concentration area south of Morton Road.

The implication of the general gas seep pattern is that multiple gas seep pathways appear to exist over the SPR repository. A diffuse east-west alignment of elevated concentration coincides with geomorphic anomalies observed in the general vicinity. The lack of a general gradient of decreasing concentration from a single area of high concentration supports the concept of multiple gas seep sources at depth. As an alternative, a single source at depth could be splintering into multiple fractures near the surface. The degree to which elevated gas concentrations correlate with the general alignment of geomorphic anomalies and possible subsurface structures needs to be further evaluated.

The low response ratios in the sinkhole and its surroundings lends itself to the following possibilities. As pointed out by Ken Camey, the higher permeability of the fill sand relative to the silty surface soils could have produced a setting that is directly open to the atmosphere, therefore no enhanced response ratio could be measured. The sinkhole may be functioning as an open vent to allow gas vapors to interact with atmospheric gasses at the surface. As suggested by Martin Molecke, the chimney structure and the associated hydrologic anomaly may be disrupting the pattern of diffusion through the granular void space and shear fractures in the 


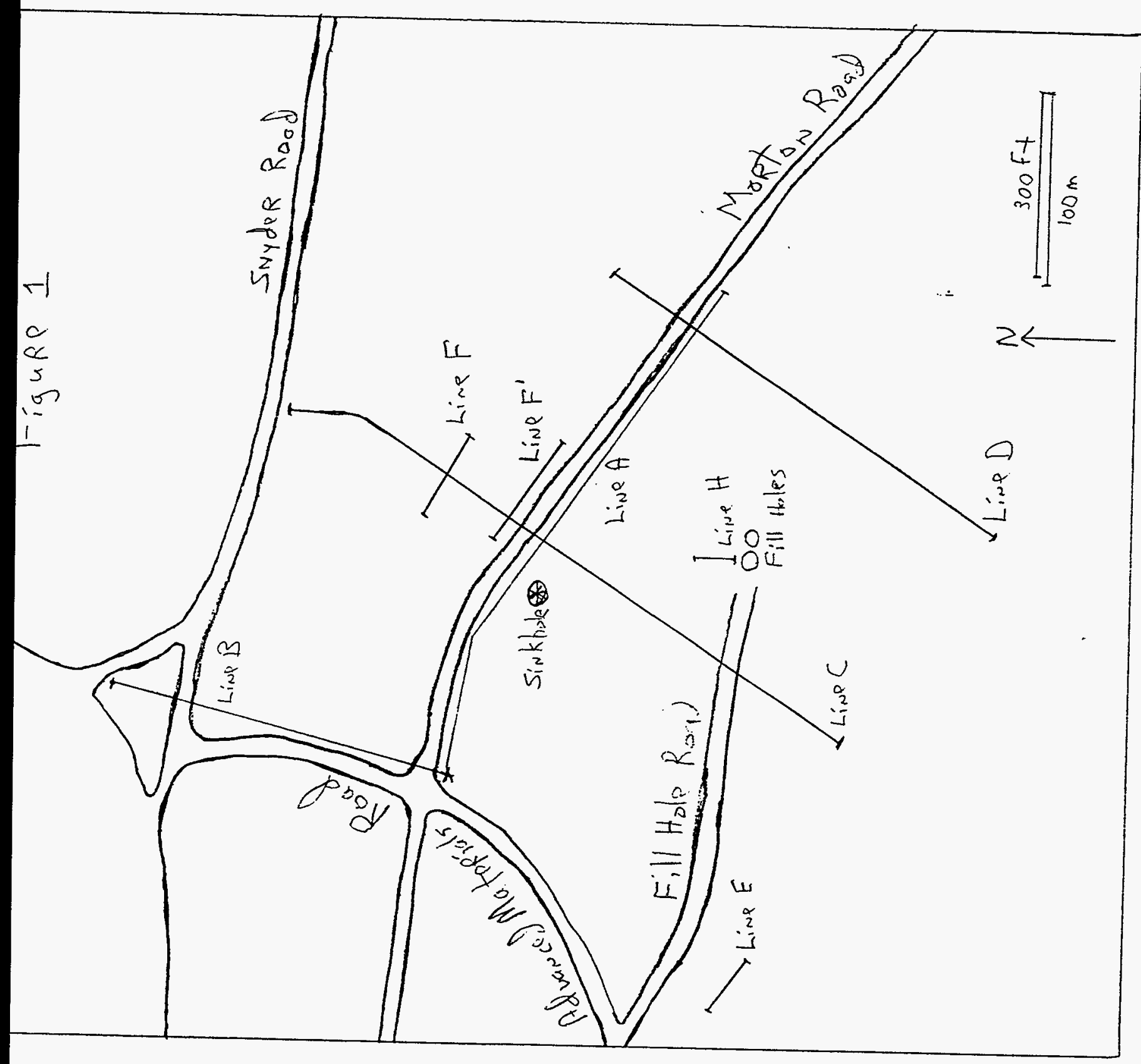

A-4-9 


\title{
COMPOSITIONAL AND TEXTURAL ANALYSES OF WEEKS ISLAND SANDS
}

\author{
Ezat Heydari \\ Basin Research Institute \\ Louisiana State University \\ Baton Rouge, LA 70803
}




\section{COMPOSITIONAL AND TEXTURAL ANALYSES OF WEEKS ISLAND SANDS}

\section{INTRODUCTION}

Compositional and textural analyses were conducted to determine the origin of the sand in the Weeks Island sinkhole. The location of the samples and the regional stratigraphy of the area are shown in Figure 1. Two sand layers overly the salt. The lower one is the Anhydrite Sand and the upper one is the Prairie Sand (Fig. 1). The samples that were analyzed include: (1) BH3 185-187 from the Anhydrite Sand, (2) BH3 180-185 and BH6 154 from the Prairie Sand, (3) BH9 188 and BH7 190 from the sinkhole above the salt, and (4) BH7 254 from the sinkhole within the salt (Fig. 1).

\section{METHODS}

Sample were first washed with tab water to remove salt. Dried samples were impregnated with blue-dyed epoxy and standard petrographic thin-sections were prepared. Compositional analysis was conducted by counting about 500 point in each sample. The components counted are: (1) monocrystalline quartz, (2) polycrystalline quartz, (3) undulose quartz, (4) chert, (5) sedimentary rock fragments (sandstone, shale, and carbonate), (6) metamorphic rock fragments, (7) igneous rock fragments (volcanic and plutonic), (8) potassium feldspars (orthoclase and microcline), and (9) plagioclase. Rounding of grains was estimated.

Grain size analysis was conducted by sieving pre-washed samples. Grains sizes were converted to phi $(\Phi)$ units and cumulative graphs were constructed.

\section{RESULTS OF COMPOSITIONAL ANALYSES}

The results of compositional analyses are presented in Table 1 and Figure 2. Compositionally, the sands constitute two groups. The Anhydrite Sand (sample 1, Figs. 1 and 2) is feldspathic litharenite and is characterized by high percentage of chert (10.6\%) and sedimentary rock fragments ( $4.4 \%$ ). The grains are $50 \%$ well rounded, $40 \%$ surrounded, and $10 \%$ subangular. Petrographic characteristics of Anhydrite Sand are shown in Figure 4 and 5. 
The Prairie Sand (samples 2 and 3, Figs. 1 and 2) is subfeldsarenite and are characterized by high percentage of quartz (about $70 \%$ ) and feldspars (about 10\%) (Table 1; Fig. 2). The grains are $20 \%$ well rounded, $40 \%$ rounded, $10 \%$ subangular, and $10 \%$ subangular. Petrographic characteristics of the Prairie Sand are shown in Figure 6 and 7.

Two samples which were taken in the Sinkhole within the Prairie Sand show compositions similar to the Prairie Sand itself (samples 4 and 6, Figs. 1 and 2). Grains are $15 \%$ well rounded, $40 \%$ rounded, $30 \%$ surrounded, and $15 \%$ subangular. Petrographic characteristics of the Sinkhole samples are shown in Figures 8 and 9.

Of particular importance is the sample BH7 254 which was take within the salt. The composition of this sample (point 7, Fig. 2) is intermediate between the Prairie and Anhydrite sands (Fig. 2). It contains chert and sedimentary rock fragments derived from the Anhydrite Sand, and feldspars from the Prairie Sand. The grains are 30\% well rounded, 30\% rounded, $30 \%$ subrounded, and $10 \%$ subangular. Petrographic characteristics of this sand are shown in Figures 10 and 11.

One sample from the Fill Sand (sample 5, Table 1, Fig. 2) has lithic arkose composition. This sand is compositionally distinct from the Anhydrite and Prairie sands. This suggest that the sand which has been used to fill the sinkhole has not yet reached the salt. The grains are $30 \%$ rounded, $30 \%$ subrounded, and $40 \%$ subangular. Petrographic characteristics of this sand are shown in Figure 12.

\section{RESULTS OF GRAIN SIZE ANALYSES}

The results of grain size analyses are shown in Table 2 and Figure 3. The results support conclusions derived from the compositional analyses. The Anhydrite Sand (sample 1, Fig. 3) is characterized its coarse sand size fraction. The two samples from the Prairie Sand (samples 2 and 3, Fig. 3) show similar trends but with different size fractions. Samples from the sinkhole above the salt (samples 4, 5, and 6, Fig. 3) show patterns similar to the two samples from the Prairie Sand. No sample from the sinkhole within the salt was analyzed. 


\section{CONCLUSIONS}

1. The Anhydrite Sand is characterized by predominance of coarse sand grain sizes, high percentage of rounded grains, high amount of chert and sedimentary rock fragments.

2. The Prairie Sand is distinguished by predominance of medium sand grain sizes, low percentage of well rounded grains, and high amount of feldspars.

3. The sand from the sinkhole above the Anhydrite Sand are texturally and compositionally similar to the Prairie Sand, and therefore derived from this sand.

4. The sand from the sinkhole within the salt shows textural and compositional features intermediate between the Anhydrite and Prairie sand and therefore derived from both sand layers.

5. The Fill Sand is compositionally different from the Anhydrite and Prairie sands. Compositionally analyses indicate that the Fill Sand has not yet reached the salt.

6. Compositional and textural analyses of the sands have been useful in characterizing sand bodies and provided information regarding geologic processes in the study area. 
Table 1. Mineralogical composition of sand fraction of Weeks Island samples (in volume \%) determined by counting about 500 point in each sample.

\begin{tabular}{|c|c|c|c|c|c|c|c|}
\hline & 1 & 2 & 3 & 4 & 5 & 6 & 7 \\
\hline QUARTZ (Q) & $\underline{70.0}$ & 79.9 & $\underline{83.8}$ & $\underline{81.2}$ & 67.4 & $\underline{82.6}$ & 76.5 \\
\hline 1. Monocrystalline & $\overline{50.8}$ & 65.1 & 68.8 & $\overline{70.5}$ & $\overline{59.5}$ & $\overline{74.0}$ & $\overline{66.4}$ \\
\hline 2. Polycrystalline & 9.9 & 9.8 & 6.9 & 6.2 & 5.3 & 4.5 & 7.4 \\
\hline 3. Undulose & 9.3 & 4.8 & 8.1 & 4.5 & 2.6 & 2.7 & 2.7 \\
\hline ROCK FRAGMENTS (L) & $\underline{17.3}$ & 7.7 & 5.4 & 6.5 & 13.8 & $\underline{5.9}$ & 11.4 \\
\hline 4. Chert & 10.6 & 5.3 & 2.7 & 3.4 & 8.3 & 3.4 & 7.7 \\
\hline $\begin{array}{l}\text { 5. Sedimentary } \\
\text { (Carbonate) } \\
\text { (Sandstone) } \\
\text { (Shale) }\end{array}$ & 4.4 & 0.5 & 2.7 & 2.5 & 3.1 & 2.5 & 2.6 \\
\hline 6. Metamorphic & 0.5 & 0.0 & 0.0 & 0.2 & 0.2 & 0.0 & 1.1 \\
\hline $\begin{array}{l}\text { 7. Igneous } \\
\text { (Volcanic) } \\
\text { (Plutonic) }\end{array}$ & 1.8 & 1.9 & 0.0 & 0.4 & 2.2 & 0.0 & 0.0 \\
\hline FELDSPARS (F) & 13.0 & $\underline{12.5}$ & 10.8 & $\underline{12.1}$ & 18.8 & $\underline{11.5}$ & $\underline{12.2}$ \\
\hline 8. K-Feldspar & $\overline{11.9}$ & 11.5 & 4.2 & 5.1 & 5.0 & 7.9 & 5.8 \\
\hline 9. Plagioclase & 1.1 & 1.0 & 6.6 & 7.0 & 13.8 & 3.6 & 6.4 \\
\hline $\begin{array}{l}Q=1+2+3 \\
L=4+5+6+7 \\
F=8+9 \\
Q+L+F=100 \%\end{array}$ & & & & & & & \\
\hline
\end{tabular}

\section{Samples}

1: BH3- 185-187: The Anhydrite Sand

2: BH3-180-185: The Prairie Sand

3: BH6-154: The Prairie Sand

4: BH9-188: Sinkhole in the Prairie Sand

5: F-11

6: BH7-190: Sinkhole in the Prairie Sand

7: BH7-254: Sinkhole in the salt 
Table 2. Weight percentages of sand fraction of samples from Weeks Island.

\begin{tabular}{lccccc} 
& \multicolumn{5}{c}{ Grain Size Intervals in millimeters } \\
& $\mathbf{2 - 1}$ & $\mathbf{1 - 0 . 5}$ & $\mathbf{0 . 5 - 0 . 2 5}$ & $\mathbf{0 . 2 5 - 0 . 1 0 6}$ & $\mathbf{0 . 1 0 6 - 0 . 0 5 3}$ \\
1: BH3-185-187 & 19.9 & 68.8 & 10.1 & 0.8 & 0.5 \\
2: BH3-180-185 & 0.8 & $\mathbf{7 7 . 4}$ & 21.1 & 0.5 & 0.3 \\
3: BH6-154 & 0.0 & 0.7 & 87.6 & 10.4 & 1.3 \\
4: BH9-188 & 0.5 & 14.7 & 73.3 & 10.3 & 1.1 \\
5: Sinkhole & 0.8 & 10.4 & 48.6 & 37.5 & 2.8 \\
6: BH7-190 & 0.0 & 13.8 & 82.6 & 3.2 & 0.4
\end{tabular}

\section{Samples}

1: BH3-185-187: The Anhydrite Sand

2: BH3-180-185: The Prairie Sand

3: BH6-154: The Prairie Sand

4: BH9-188: Sinkhole in the Prairie Sand

5: Sinkhole

6: BH7-190: Sinkhole in the Prairie Sand 
W

E

Sinkhole

(fill sand)

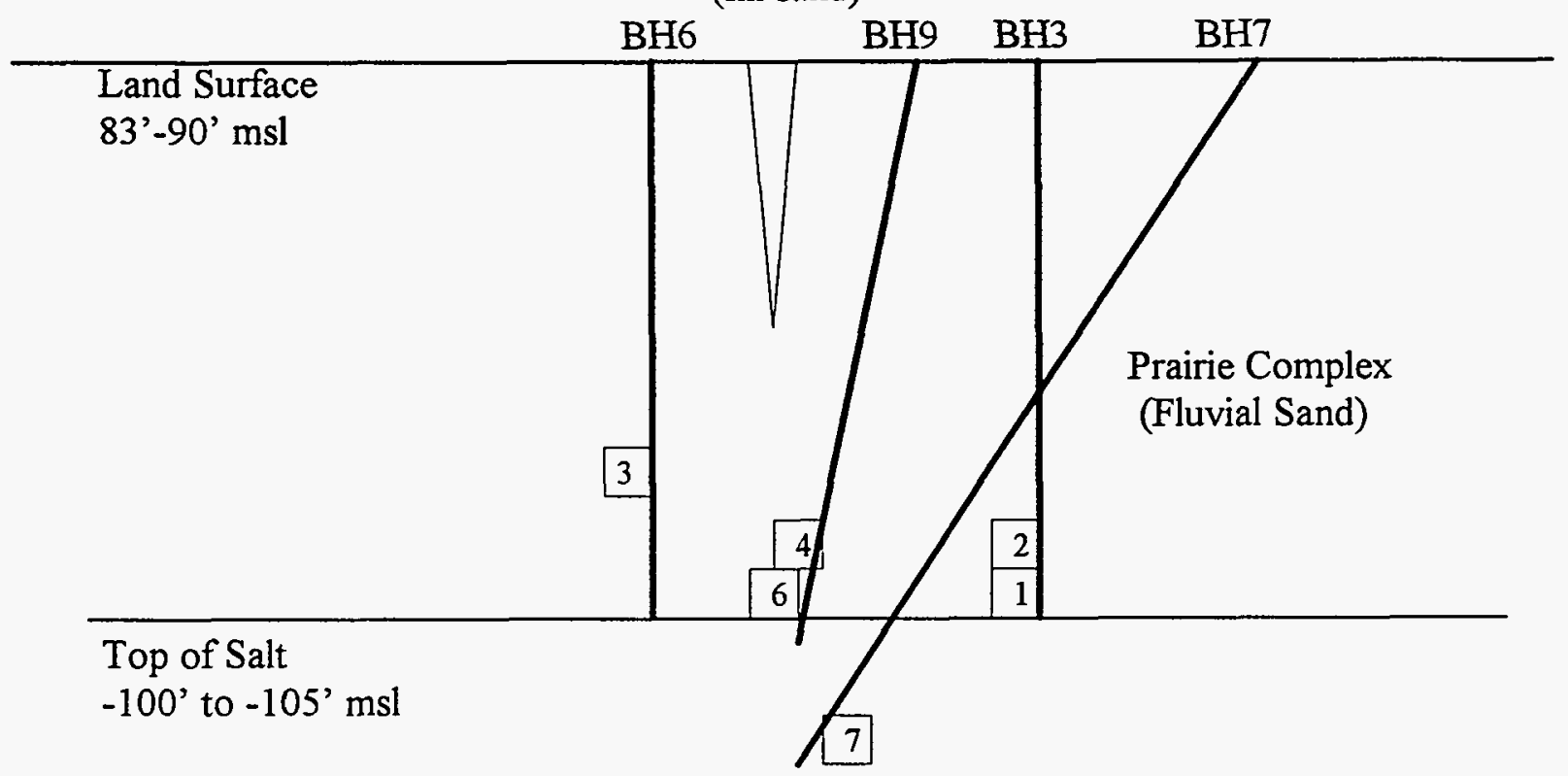

SALT

Oil Storage

Figure 1. Schematic cross-section showing the locations of the bore holes and samples from Weeks Island. 


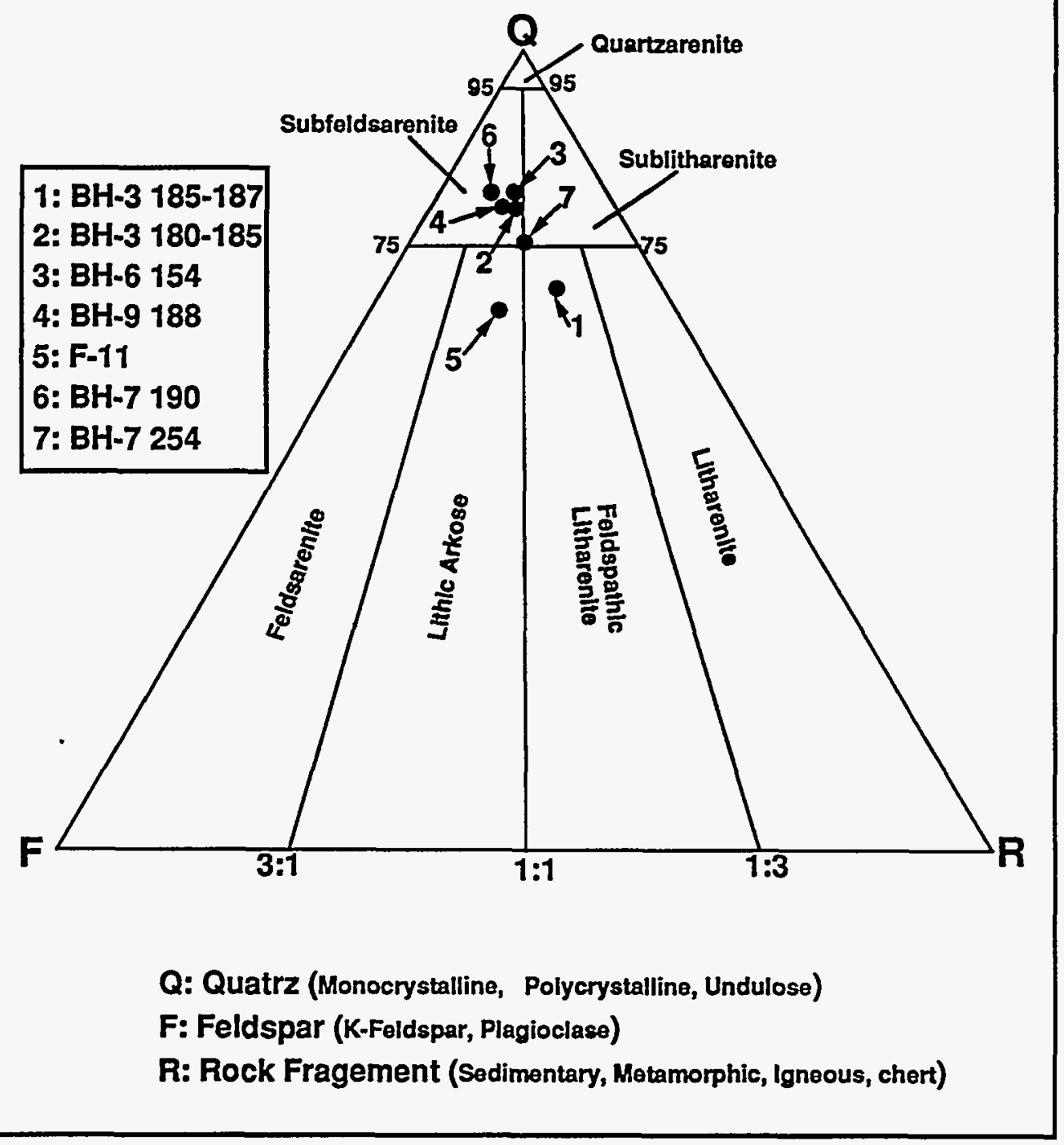

Figure 2. Triangular QFL plot showing mineralogical compositions of sand fractions of samples from the Week Island according to sandstone classification of Folk (1968). Note that Sample 6 (BH7-254) which was recovered in the salt shows a composition between the two end members. $Q=$ the sum of monocrystalline, polycrystalline, and undulose quarts; $F=$ the sum of potassium and plagioclase feldspars; $L=$ the sum of sedimentary, igneous, and metamorphic rock fragments. 


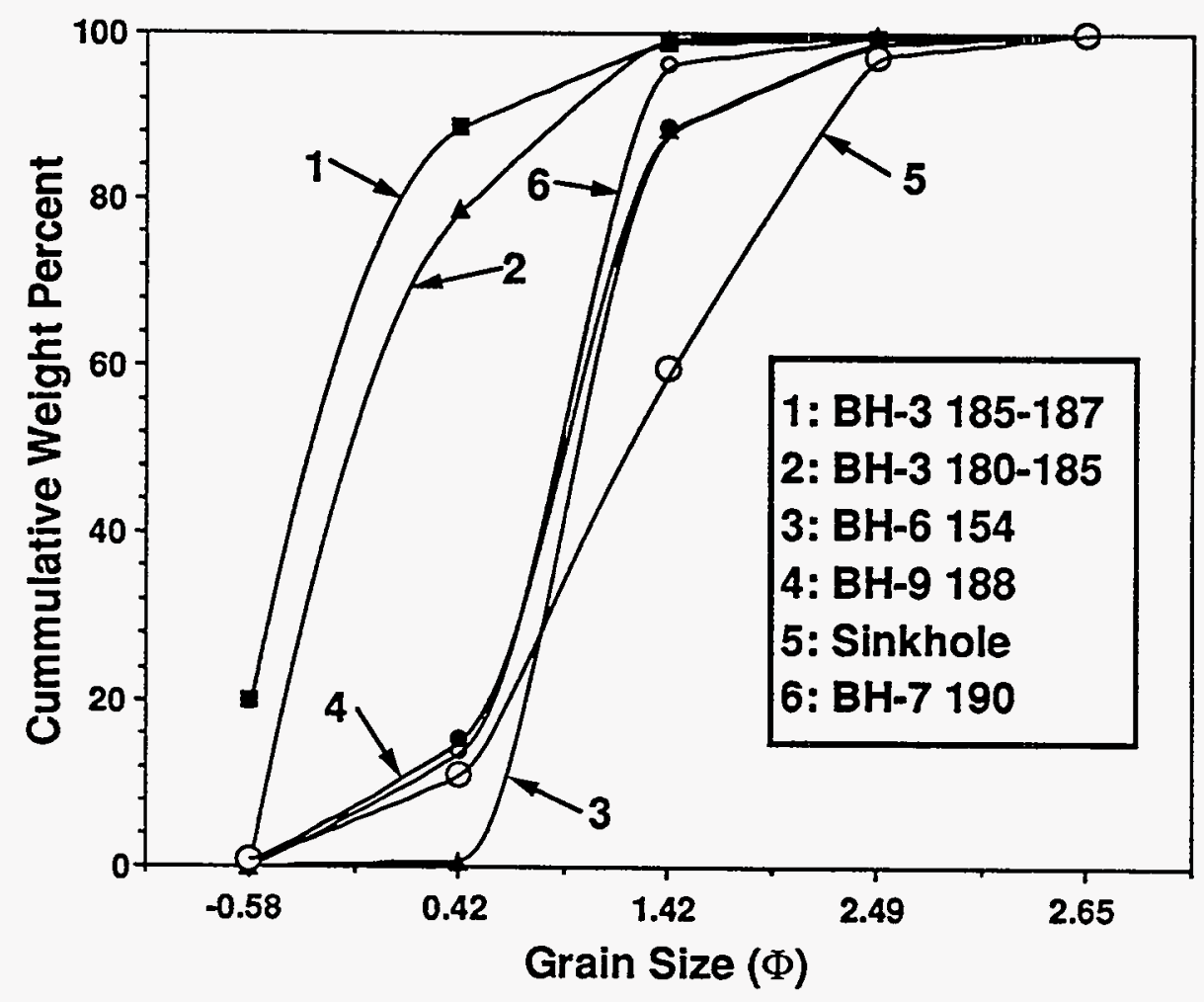

Figure 3. Cumulative grain size analyses of Weeks Island sands. 


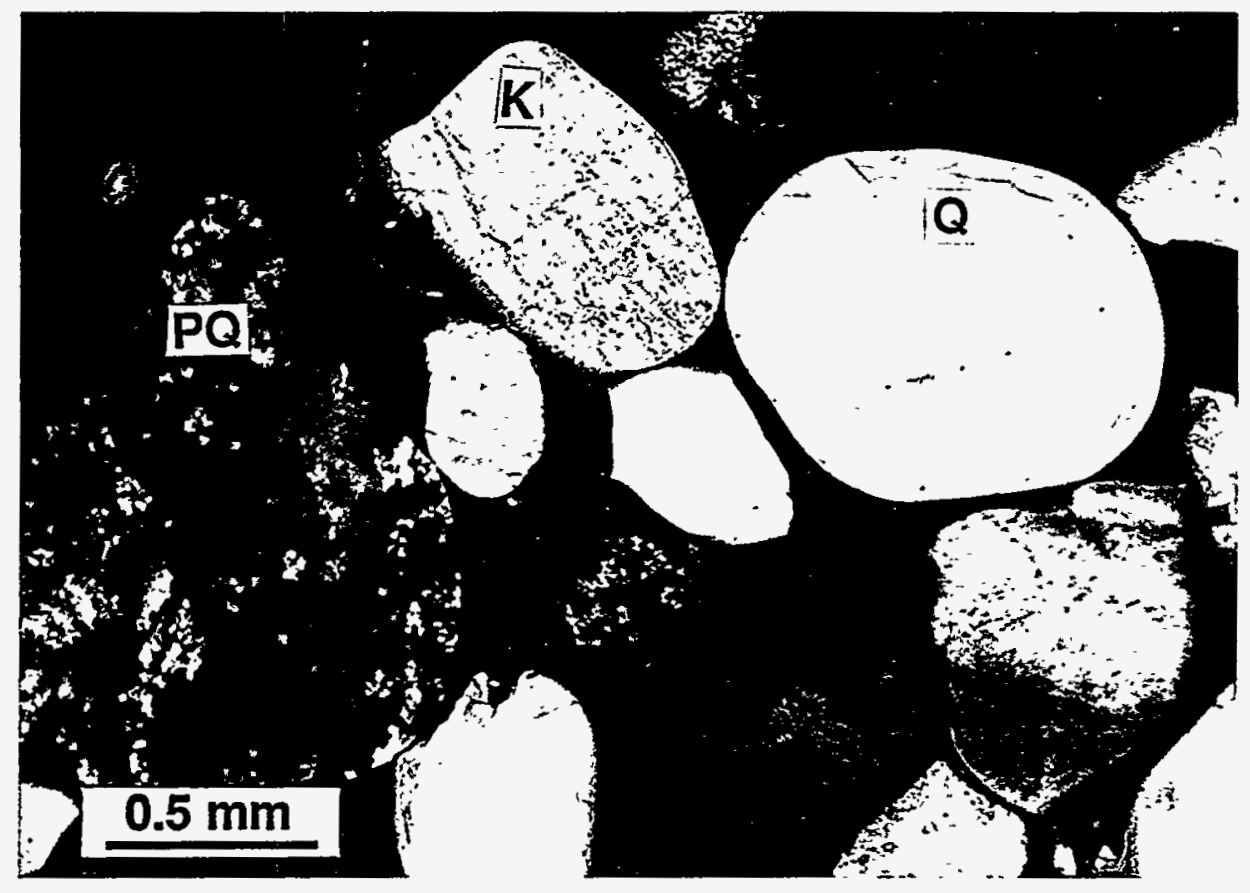

Figure 4. Photomicrograph (crossed-polars) of sample BH3 185-187 (the Anhydrite Sand). The sand grains in this sample are coarser and better rounded than other samples. K: potassium feldspar (orthoclase); PQ: polycrystalline quartz; Q: monocrystalline quartz. 

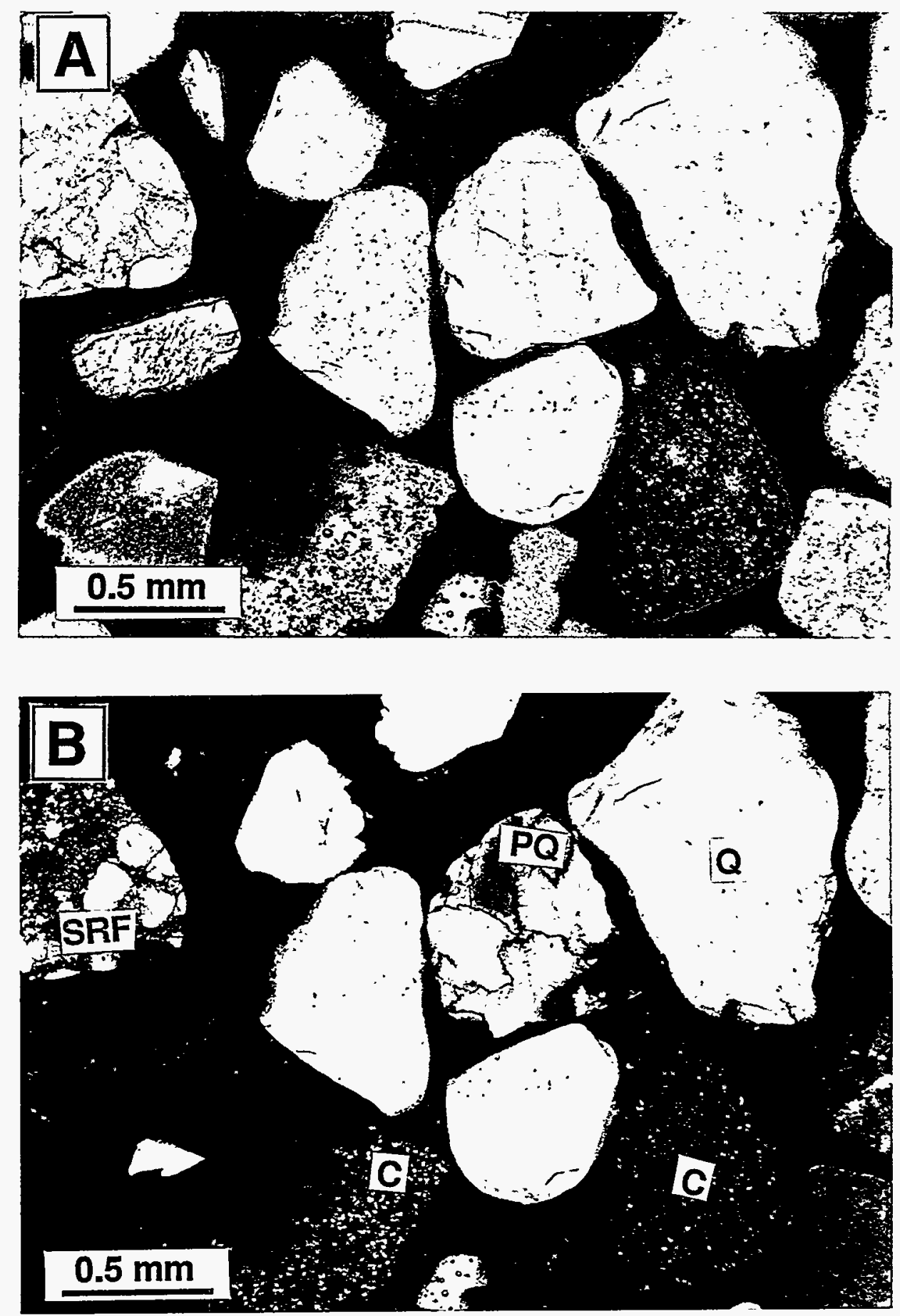

Figure 5. Plane-polarized light (A) and crossed-polars (B) photomicrographs showing grain types, shape, sorting, and rounding of sample BH3 185-187 (the Anhydrite Sand). The sand grains in this sample are coarser and better rounded than other samples. Blue represent dyed epoxy. C: chert; PQ: polycrystalline quartz; Q: monocrystalline quartz; SRF: sedimentary rock fragment (sandstone). 

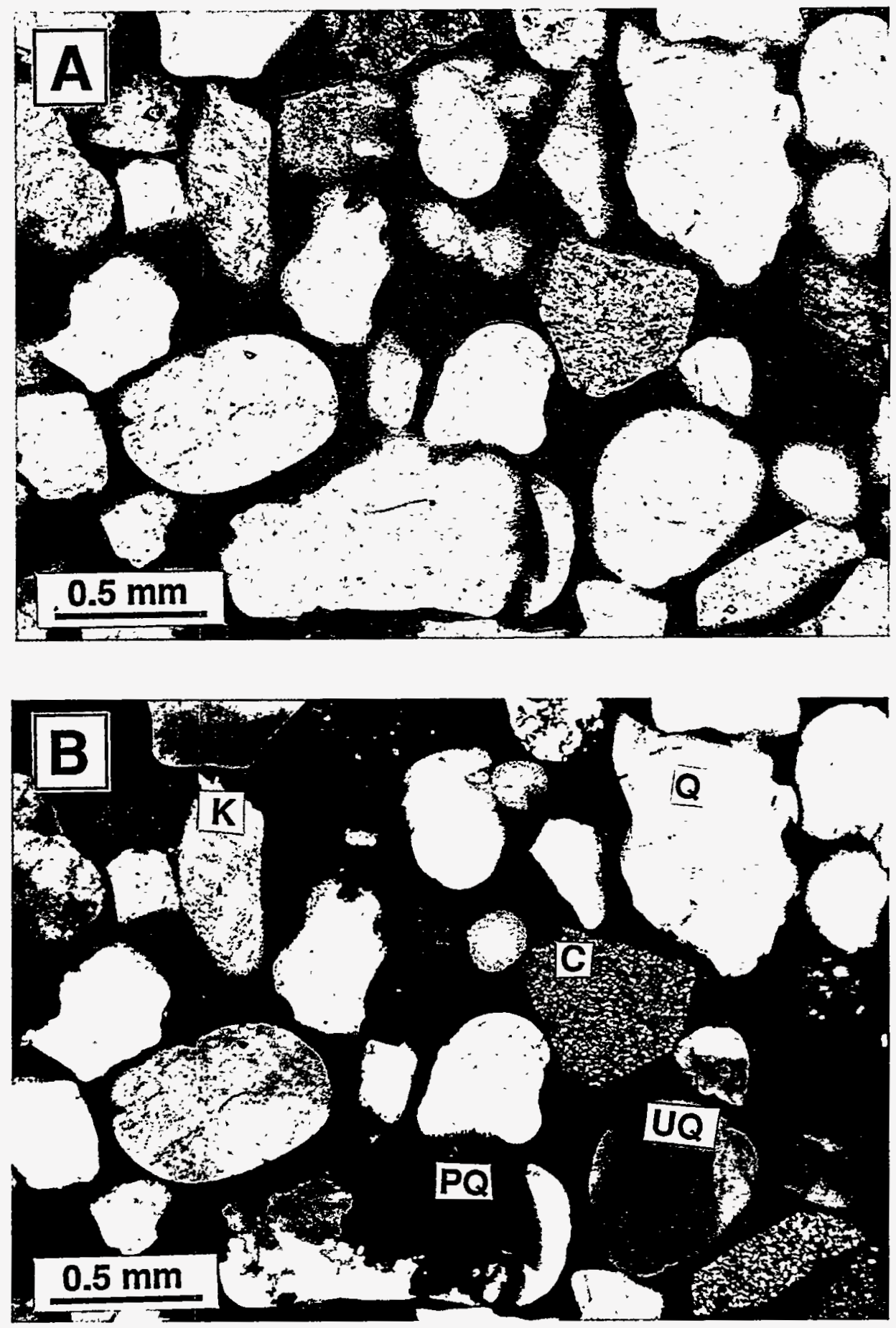

Figure 6. Plane-polarized light (A) and crossed-polars (B) photomicrographs showing grain type, shape, rounding, and sorting of sample BH3 180-185 (the Prairie Sand). The sand grains in this sample are well rounded. Blue represent dyed epoxy. C: chert; $\mathrm{K}$ : potassium feldspar (orthoclase); PQ: polycrystalline quartz; Q: monocrystalline quartz; UQ: undulose quartz. 

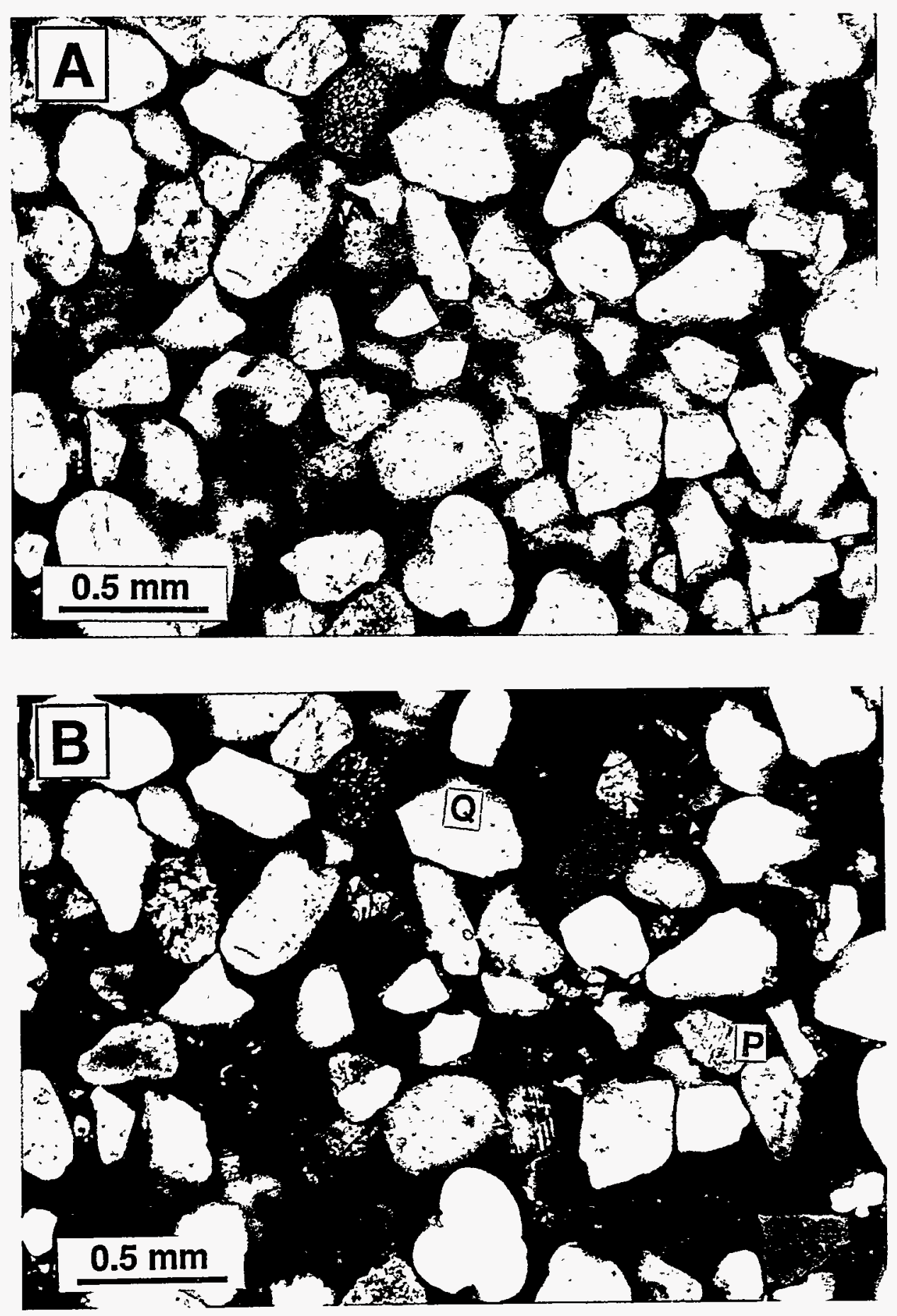

Figure 7. Plane-polarized light (A) and crossed-polars (B) photomicrographs showing grain type, shape, rounding, and sorting of sample BH6 154 (the Prairie Sand). Blue represent dyed epoxy. P: plagiocalse; Q: monocrystalline quartz. 

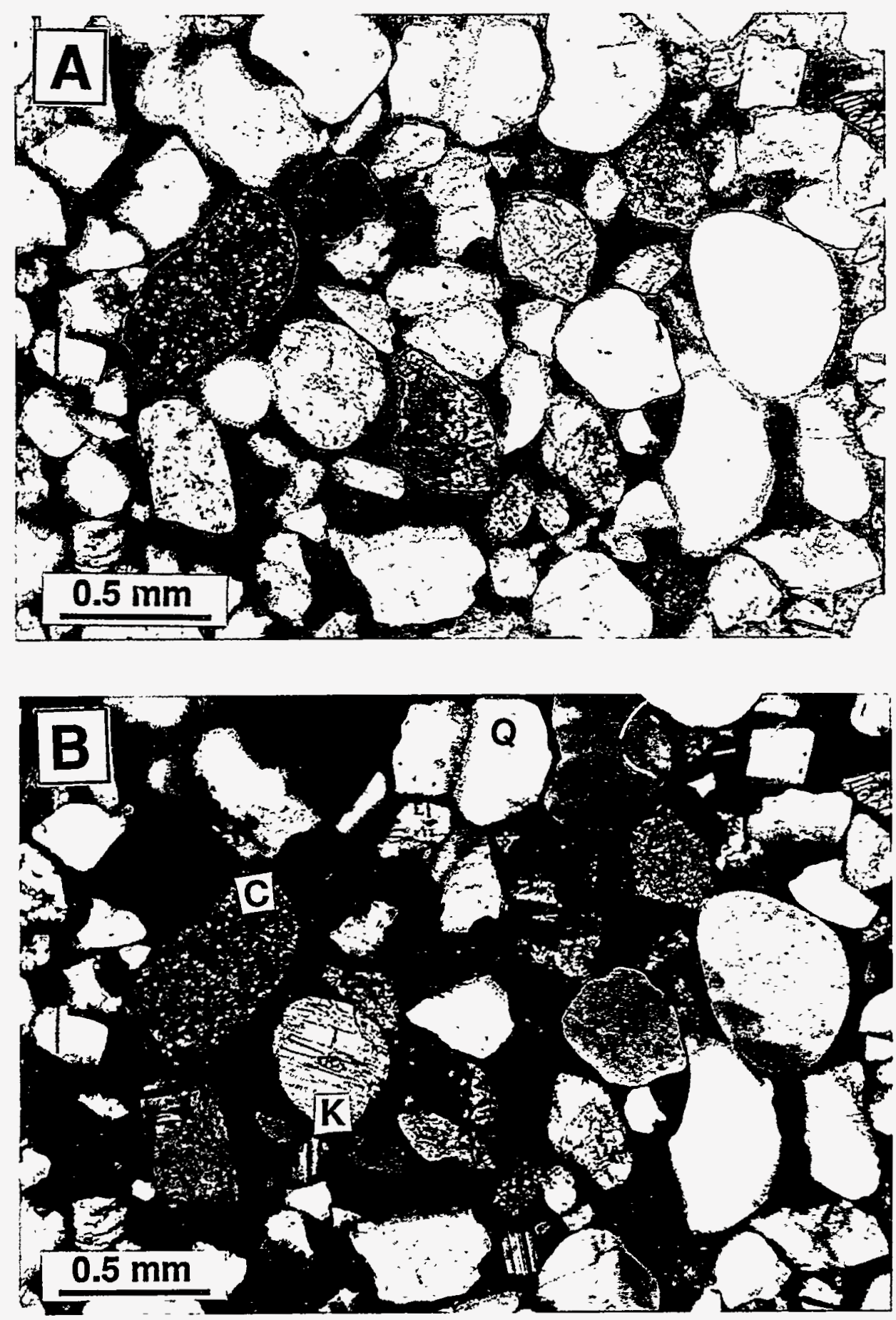

Figure 8. Plane-polarized light (A) and crossed-polars (B) photomicrographs showing grain types, shape, rounding, and sorting of sample BH9 188 (sinkhole in the Prairie Sand). Blue represent dyed epoxy. C: chert; K: potassium feldspar (perthite); Q: monocrystalline quartz. 

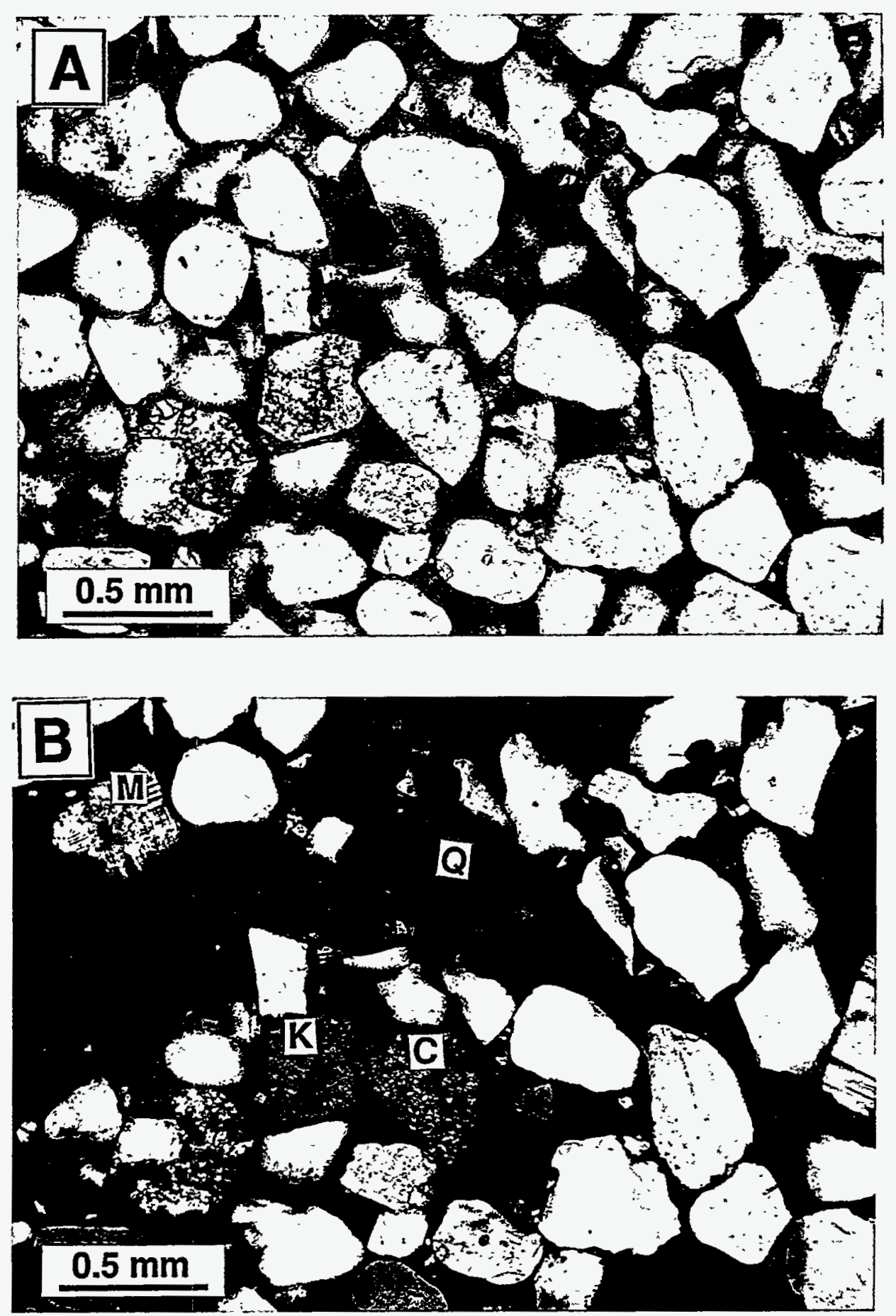

Figure 9. Plane-polarized light (A) and crossed-polars (B) photomicrographs of sample BH7 190 (sinkhole in the Prairie Sand) showing grain types, shape, rounding, and sorting. C: chert; K: potassium feldspar; M: microcline; Q: monocrystalline quartz; SRF: sedimentary rock fragment (sandstone). 

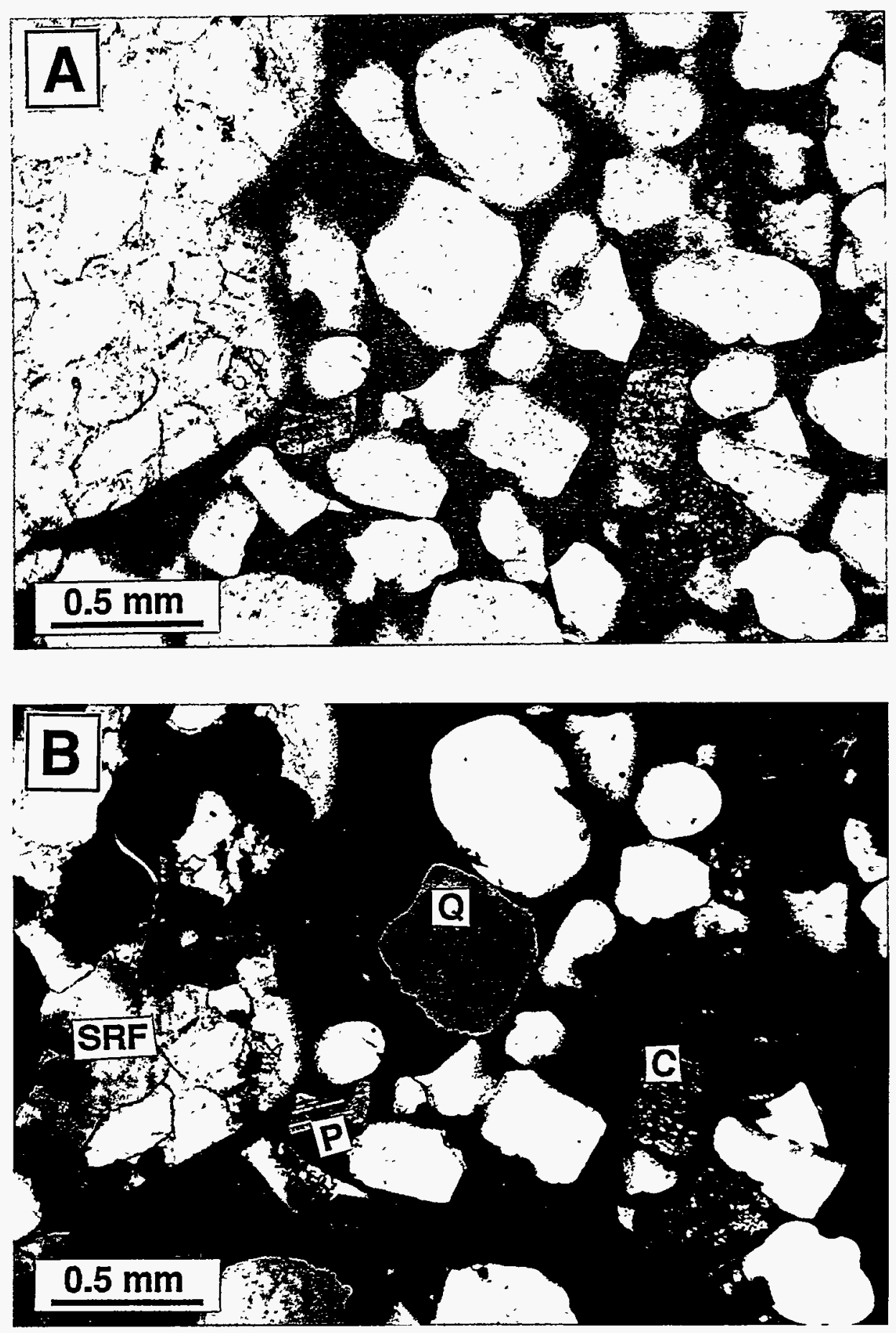

Figure 10. Plane-polarized light (A) and crossed-polars (B) photomicrographs showing grain types, shape, rounding, and sorting of sample BH7 254 (sinkhole in the salt). This sample has combined characteristics all other samples. For example, well rounded grains and sedimentary rock fragments, and large chert fragment which are found in $\mathrm{BH} 3$ samples also occur in this sample. Blue represent dyed epoxy. C: chert; P: plagiocalse; Q: monocrystalline quartz; SRF: sedimentary rock fragment (sandstone). 

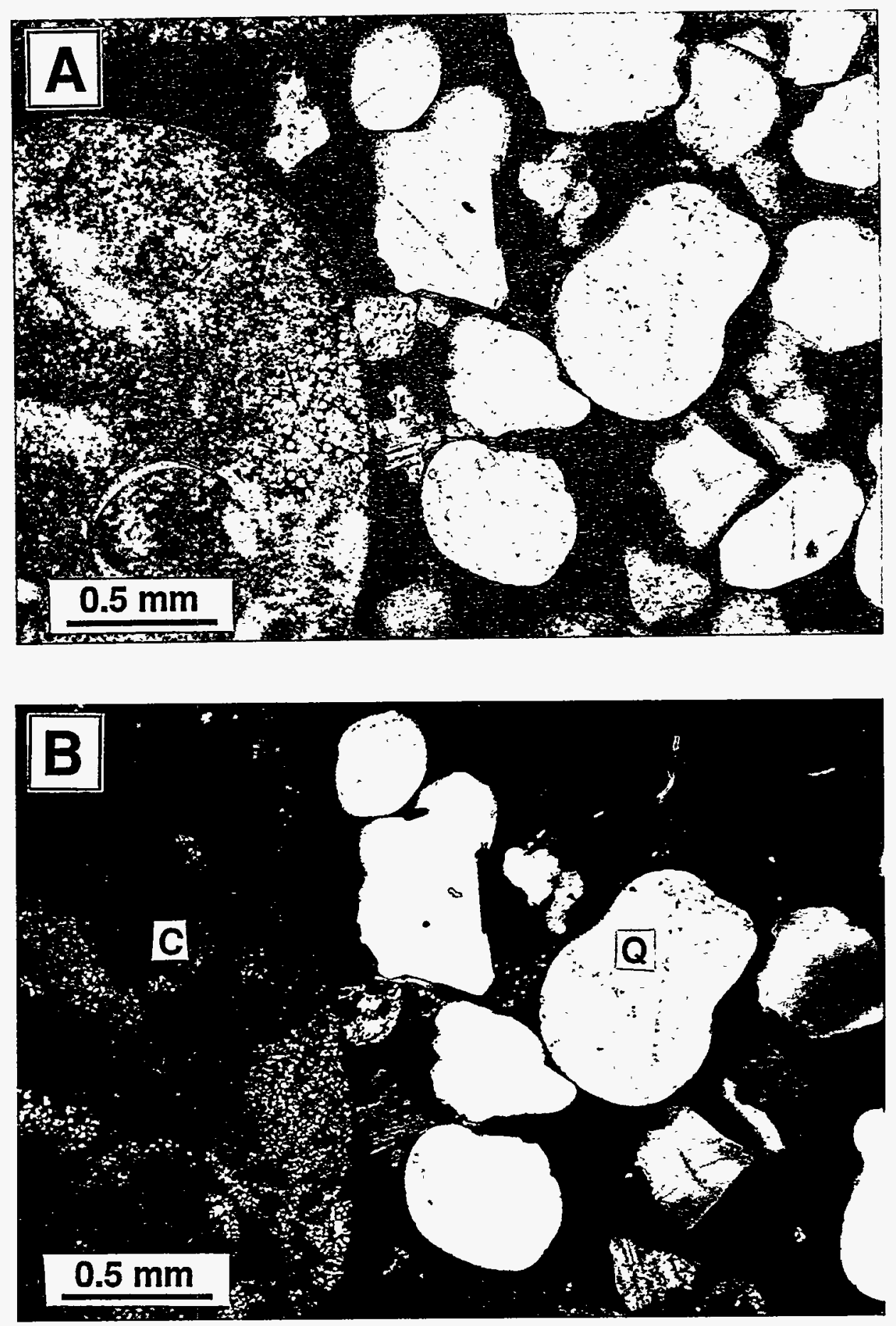

Figure 11. Plane-polarized light (A) and crossed-polars (B) photomicrographs showing grain types, shape, rounding, and sorting of sample BH7 254 (sinkhole in the salt). This sample has combined characteristics all other samples. For example well rounded grains and sedimentary rock fragments, and large chert fragment which are found in BH3 samples. Blue represent dyed epoxy. C: chert; $\mathrm{Q}$ : monocrystalline quartz. 

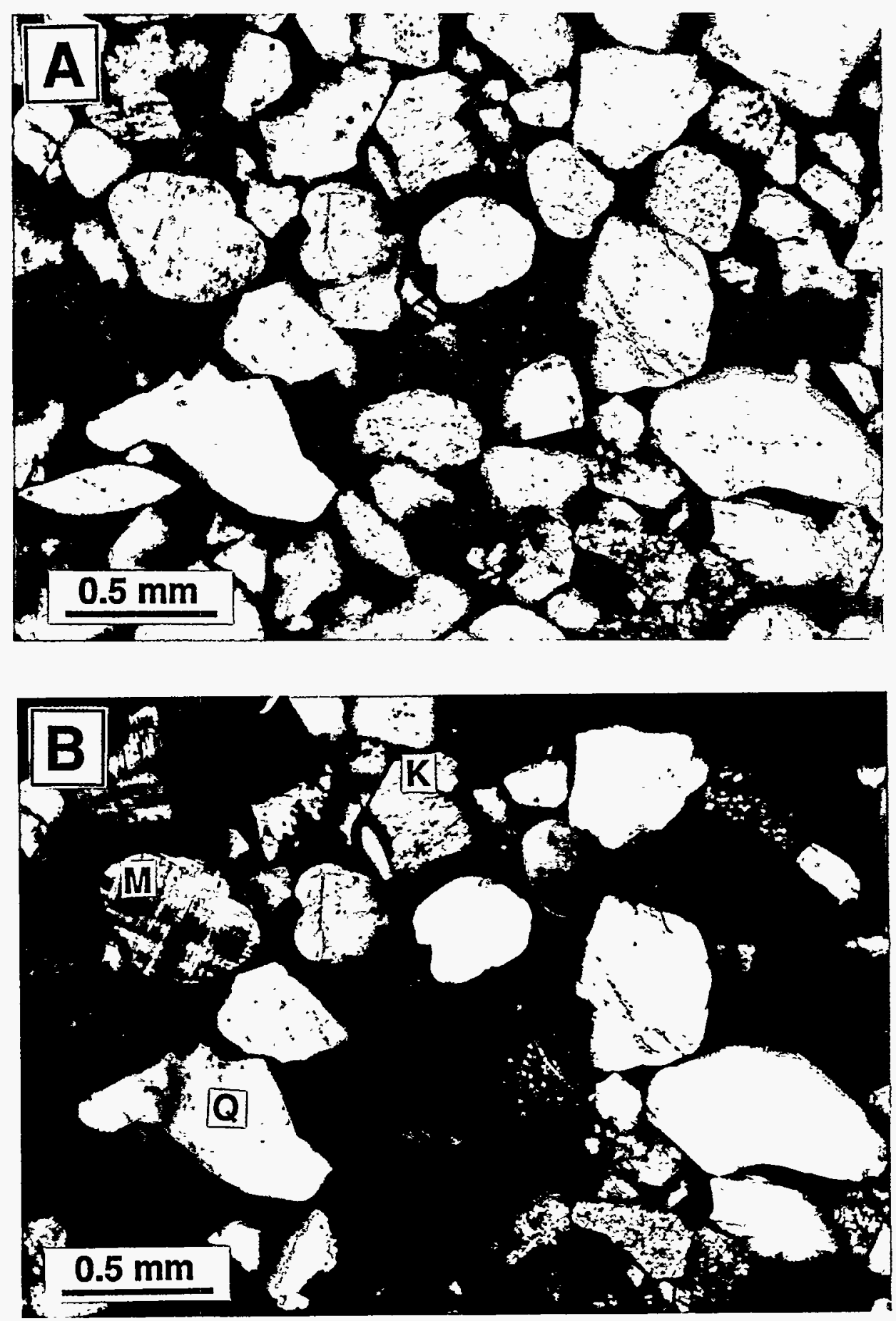

Figure 12. Plane-polarized light (A) and crossed-polars (B) photomicrographs showing grain type, shape, rounding, and sorting of sample F-11 (?). Blue represent dyed epoxy. K: potassium feldspar (orthoclase); M: microcline; Q: monocrystalline quartz. 


\section{APPENDIX 5}

HIGH RESOLUTION SURFACE SEISMIC REFLECTION SURVEY NEAR SPR SURFACE COLLAPSE FEATURE AT WEEKS ISLAND, LOUISIANA 


\title{
High Resolution Seismic Reflection Survey near SPR Surface Collapse Feature at Weeks Island, Louisiana
}

\author{
by \\ Richard D. Miller \\ Jianghai Xia \\ Joe M. Anderson \\ David R. Laflen \\ Jeffrey M. Erickson \\ Patricia M. Acker \\ Mary C. Brohammer \\ of the \\ Kansas Geological Survey \\ and \\ Don W. Steeples \\ Ross A. Black \\ of the \\ Department of Geology \\ University of Kansas
}
noninterpretive expanded final report submitted to Sandia National Laboratory Albuquerque, NM on work completed for the United States Department of Energy under Contract DE-AC04-94AL85000

August 11, 1994 


\section{Summary}

Shallow, high resolution seismic reflection techniques detected the subsurface expression of a $40 \mathrm{ft}$ wide and $30 \mathrm{ft}$ deep sinkhole above DOE's Strategic Petroleum Reserve (SPR) storage cavities at Weeks Island, Louisiana. The underground cavities that presently hold 73 million barrels of crude oil are two levels of a former room and pillar salt mine. The mine is within a salt dome that at the sinkhole is approximately $180 \mathrm{ft}$ below the ground surface and responsible for the more than $125 \mathrm{ft}$ of topographic uplift that produced Weeks Island. Four nominal 180 shotpoint, 24-fold P-wave CDP lines acquired with $8 \mathrm{ft}$ station spacing possess interpretable reflections with an average dominant frequency of approximately $80 \mathrm{~Hz}$ and apparent NMO velocities ranging from 1350 to $2100 \mathrm{ft} / \mathrm{sec}$. The field recording parameters and quality control were based on the reflection interpreted during walkaway tests to be from a reflector about $150 \mathrm{ft}$ deep. This coherent reflection event interpretable on all four lines is dramatically altered on the east/west line in the proximity of the sinkhole. An offset in the prominent reflection interpretable on all four lines traces a southwest/northeast trend across the study area. The disturbed reflection on the east/west line, presumed associated with the sinkhole, structurally resembles a chimney type feature or possibly a water table drawdown.

\section{Introduction}

This seismic reflection survey was designed to detect and delineate geologic or hydrologic features associated with the small sinkhole discovered on May 18, 1992, as well as identify areas potentially susceptible to subsidence above the SPR storage cavities. The two-level underground cavities, presently holding 73 million barrels of crude oil, are a former room and pillar salt mine. The old mineworks range in depth from about $500 \mathrm{ft}$ to more than $700 \mathrm{ft}$ below the ground surface. The top of the salt dome is approximately $180 \mathrm{ft}$ below the ground surface at the sinkhole and is responsible for the more than $125 \mathrm{ft}$ of topographic uplift that produced Weeks Island. The water table near the sinkhole is about $90 \mathrm{ft}$ below the ground surface. The absence of a cap rock (at least in a classic sense) leaves the salt boundaries of this dome in direct contact with overlying unconsolidated marine sediments. At the time of this survey the sinkhole was approximately $35-40 \mathrm{ft}$ in diameter, slightly more than $30 \mathrm{ft}$ deep, and had surface expression within $50 \mathrm{ft}$ of the south side of Morton Road (Figure 1). 
The proposed high-resolution seismic survey originally consisted of five lines, each approximately $1500 \mathrm{ft}$ in length: four P-wave (compressional wave) lines and one S-wave (shear wave) line. The lines were laid out to maximize the potential of imaging the subsurface expression of the present sinkhole and to identify other areas that might be susceptible to subsidence. The primary target was the top of the salt dome. The secondary target was the water table, followed by structural or stratigraphic signatures within the salt dome. Dissolution features associated with evaporite beds have produced easily interpreted signatures on shallow seismic sections (Miller et al., 1993; Steeples and Miller, 1987; Steeples et al., 1986). Based on work at other salt domes (Black and Voigt, 1982; Leading Edge, August 1994 issue), a very irregular salt/sediment contact is likely at this site. Direct imaging of the salt-sediment contact has proved challenging on previous surveys at this salt dome (Kinsland and Rutter, 1994). Irregularities in the surface of the salt associated with either dissolution or joints and their expression in overlying sediments are of particular interest.

The acquisition portion of the seismic reflection survey was conducted between March 2 and 4, 1994. The project consisted of several walkaway noise tests and four nominal 180 shotpoint, 24-fold P-wave CDP lines (Figure 1). The surface conditions varied from heavily wooded (hand-cleared $5 \mathrm{ft}$ wide path) to manicured lawn to asphalt roads. Some secondary clearing was necessary along wooded paths previously cleared for elevation surveying. The asphalt and gravel roads were obstacles that not only resulted in minor reductions in fold but also provided a source for traffic noise. No shots were recorded while vehicles were close enough to active recording stations to produce more than $0.1 \mathrm{mV}$ peak-to-peak of background noise. Underground utilities including a petroleum pipeline, a propane pipeline, high voltage power lines, a fiber optic communications link, standard telephone lines, and water lines inhibited continuous coverage across several sections of the four lines. The ground surface was damp, with several significant topographic and cultural obstacles including ditches, relatively steep terraces, partially buried foundations from previous surface structures, and about $55 \mathrm{ft}$ of relative elevation change on lines 1,2 , and 3 . The field recording parameters and quality control were based on the $150 \mathrm{ft}$ deep reflector interpreted during walkaway tests on the north end of line 1. Future borehole logging, both geologic and geophysical, based on the surface seismic data should greatly enhance the quality and quantity of seismic interpretations. 


\section{Data Acquisition}

Data for this study were acquired on a 48-channel EG\&G Geometrics 2401x seismograph. The seismograph amplifies, filters (analog), digitizes the analog signal into a 15-bit word, and stores the digital information in a demultiplexed format. Analog filters have an $18 \mathrm{~dB}$ /octave rolloff from the selected $-3 \mathrm{~dB}$ point. The $1 / 2 \mathrm{msec}$ sampling interval resulted in a record length of $500 \mathrm{msec}$ and a $1000 \mathrm{~Hz}$ Nyquist frequency. A $500 \mathrm{~Hz}$ high-cut filter with a $24 \mathrm{~dB}$ /octave rolloff acted as an anti-alias filter and to reduce high frequency noise. The dynamic range of this floating point seismograph was more than adequate to allow the recording of highquality reflection information in the presence of source-generated and cultural noise at this site.

Walkaway noise tests were conducted on the northeast end of line 1 (Figure 1). The source (8-gauge auger gun) (Healey et al., 1991) and receivers (three Mark Products L28E $40 \mathrm{~Hz}$ ) were selected based on field conditions, resolution requirements, target depth, and previous experience. On-site testing concentrated on source/receiver geometries and recording parameters. Test data were recorded with analog low-cut filters out, $50 \mathrm{~Hz}, 100 \mathrm{~Hz}$, and $200 \mathrm{~Hz}$, station spacing of $8 \mathrm{ft}$, and source-to-receiver-offsets ranging from 8 to $384 \mathrm{ft}$ (Figure 2). The analog filters effectively attenuate ground roll while increasing the dominant frequency of the reflection wavelets (Steeples, 1990). A strong reflection with a zero-offset time of about 140 to $150 \mathrm{msec}$ can be interpreted on all the walkaway files. The calculated NMO velocity is about $2100 \mathrm{ft} / \mathrm{sec}$, which correlates to a depth of around $150 \mathrm{ft}$ (Figure 3). This depth (based on the boreholes near the sinkhole) is about $15 \%$ to $20 \%$ shallower than expected for the top of the salt and almost double the measured depth to water table. The data quality was sufficient to allow selection of optimum recording parameters and source/receiver geometries targeting reflectors between 50 and $250 \mathrm{ft}$ deep.

Direct waves, refractions, ground roll, reflections, and air-coupled waves can all be identified on the walkaway data (Figure 4). The direct wave possesses a very uniform $1700 \mathrm{ft} / \mathrm{sec}$ velocity from the source out to about $300 \mathrm{ft}$ of offset. A refraction arrival is interpretable from about $304 \mathrm{ft}$ to the end of the spread $(384 \mathrm{ft})$, with an apparent linear velocity of around $10,000 \mathrm{ft} / \mathrm{sec}$ (this is an unreversed velocity). Two-layer refraction analysis places this first significant acoustic interface at a depth of about 130 to $140 \mathrm{ft}$. Ground roll velocities range from 800 to $1300 \mathrm{ft} / \mathrm{sec}$. The previously identified $150 \mathrm{msec}$ reflection possesses the greatest potential resolving 
power and depth control at near source offsets (i.e., $<200 \mathrm{ft}$ ). The prominent reflection may be from the same interface as the refracted waves.

Based on the walkaway data and available equipment, the source-receiver geometry was split-spread with a source-to-nearest-receiver spacing of $12 \mathrm{ft}$ and a furthest offset of $196 \mathrm{ft}$. The recording parameters included an analog low-cut filter of $50 \mathrm{~Hz}$ and a $0.5 \mathrm{msec}$ sampling rate. Identification of coherent arrivals on walkaway data allowed confident selection of parameters and geometries used for the CDP portion of the survey.

The production (CDP) portion of the survey took just over 2 days and included 673 shotpoints of 2-D data along three northwest/southeast lines and one southwest/northeast tie line and a 45 shotpoint 3-D test near the sinkhole at the intersection of lines 2 and 4. The 8-gauge auger gun allowed detonation of a 400 grain black powder load 2 to $3 \mathrm{ft}$ below the ground surface in a water saturated, tightly stemmed 2" hole. The rough wooded terrain, rubble and fill material, shallow tree roots, as well as the narrow paths made the auger gun an ideal source for conditions and required data quality. Three geophones were placed in a $3 \mathrm{ft}$ inline array at each station to help attenuate source-generated air-coupled waves and other coherent in-line noise. The source was detonated and receivers were planted into competent material beneath the organic surface layer. The seismograph was configured to focus on reflections within the upper $250 \mathrm{msec}$ possessing average velocities from 1200 to $6000 \mathrm{ft} / \mathrm{sec}$. The analog amplitude/frequency spectrum was shaped with $50 \mathrm{~Hz}$ analog low-cut filters to enhance and balance the higher frequency components of the reflection energy. This emphasis on spectral shaping was necessary to maximize the chances of separating the water table reflection from the top of the salt and any continuous reflectors between water table and the top of salt.

\section{Data Processing}

Data processing was done on an Intel 80486-based microcomputer using Eavesdropper, a set of commercially available algorithms. The processing flow was similar to those used in petroleum exploration (Table 1). The main distinctions relate to the conservative use and application of correlation statics, precision required during velocity and spectral analysis, and the accuracy of muting operations. A very low percentage allowable NMO stretch $(<20 \%)$ was extremely critical in reducing contributions of shallow reflected energy significantly beyond the critical angle, maximizing resolution potential, and avoiding distortion in the stacked 
wavelets (Miller, 1992). Many processing techniques not routinely effective on shallow data sets (including $f-k$ migration, deconvolution, and $f-k$ filtering) were tested to evaluate their potential on this data set. Due to a lack of reflection information shallower than the prominent reflection arrival (Figure 5), data processing beyond brute stack focused on enhancing events deeper than $50 \mathrm{msec}$.

For most basic shallow high-resolution seismic reflection data the processing steps/operations are a simple scaling down of established petroleum-based processing techniques and methods. However, processes such as deconvolution (especially spiking) have basic assumptions (Yilmaz, 1987) that are violated by most shallow data sets, this data set being no exception. Migration is another operation that, due to non-conventional scaling (vertical and/or horizontal), many times may appear to be necessary when in actuality geometric distortion may be simple scale exaggeration (Black et al., 1994). Migration for this data set was effective in reducing the apparent distortion associated with the subsidence and effectively focusing interpreted reflections. Processing/processes used on data for this report has/have been carefully executed with no a priori assumptions and with care not to create anything through processing, but to simply enhance what can be identified on unstacked data.

Datum corrections and time/depth conversions were based on stacking velocities. In the absence of sonic logs and/or checkshot surveys, depth estimations using stacking velocities, estimated arrival times, and multiple sloping datums represents the most accurate method. As many as five sloping datums per line were used to minimize the effects of topography on velocity and static analysis (Figures $6 \mathrm{~A}$ through 9A). After generation of final stacked sections, data were corrected to a conventional flat datum of $48 \mathrm{ft}$ sea level elevation (Figures 6B through $9 \mathrm{~B}$ ) and were then time/depth converted using the same stacking velocities (Figures $6 \mathrm{E}$ through 9E). An adjustment was made to the stacking velocities on lines 1, 2, and 3, to compensate for surface dip. This adjustment is similar in nature to DMO and effectively decreased stacking velocities by less than $10 \%$ (Table 3 ). The result of this topographic velocity adjustment is a perfect tie at the intersection points of all four lines. The elevation corrections and velocity adjustments are site specific and were necessary to accurately represent the geometry of reflecting events.

The experimental 3-D reflection array was collected at the intersection of lines 2 and 4. This data set possesses one-fold redundancy and was processed using parameters established through analysis of 2-D data from line 2 and line 4. The data have been filtered, scaled, muted (based on source offset), elevation corrected, 
deconvolved, sorted (binned), NMO corrected, and displayed. The software used was a special set of algorithms developed for the PC in association with Eavesdropper.

\section{Results}

Unequivocal identification of reflection energy on field files is essential for accurate interpretation of CDP stacked sections. Raw field files acquired during the production portion of the survey from each line have reflection events identifiable between 70 and $150 \mathrm{msec}$ (Figure 5A). The reflections have an average dominant frequency of approximately $80 \mathrm{~Hz}$ and an apparent $\mathrm{NMO}$ velocity ranging from 1350 to $2100 \mathrm{ft} / \mathrm{sec}$. Approximate depth to the primary reflector was between 50 and $150 \mathrm{ft}$ on most field files (most of the apparent change in depth is a direct result of the more than $70 \mathrm{ft}$ change in surface elevation across the line). The signal-to-noise ratio on the raw field files is very good and allows confident identification of reflections on $90 \%$ of the raw field files.

Digital filtering, first-arrival muting, appropriate trace balancing, bad-trace editing, and conservative application of correlation statics were key processes in improving the pre-stack appearance of coherent events interpretable on raw field files (Figure 5B). The coherent event identifiable on filtered and scaled files possesses an arrival pattern consistent with the classic hyperbolic moveout of a reflection. The digital filter applied to this field file narrowed the bandwidth enough to produce a very cyclic or ringy wavelet. Even with the interpretation confidence allowed by these high quality field files, it is still prudent to practice care and a conservative approach to interpretations of coherent energy on stacked data (Steeples and Miller, 1990).

A strong coherent event can be interpreted across all the nominal 24-fold CDP stacked sections (Figures 6 through 9). The irregularity of the reflection over parts of each line is suggestive of either a highly variable (dissolved/faulted and folded) surface or significant velocity variation in the near surface. From analysis of field files, very little variation in velocity of direct, refracted, or reflected waves is observed within the length of a spread. However, across the expanse of some lines the near-surface velocity changes by as much as $30 \%$. The single strong reflection event ties extremely well line-to-line both before and after correction to a flat datum.

The reflection wavelet characteristics are relatively consistent on all four stacked sections. The very high amplitude of the reflection suggests the interface 
responsible for this event possesses a high acoustic impedance contrast. From drill data, the velocity at the water table interface changes from around $1800 \mathrm{ft} / \mathrm{sec}$ to over $5000 \mathrm{ft} / \mathrm{sec}$, therefore energy incident to the water table interface at angles greater than about $20^{\circ}$ will result in nearly total reflectance. Classically, the water table interface, in an unconsolidated (alluvial/colluvial) setting, is a high acoustic contrast (Merey et al., 1992; Hunter et al., 1984). At this site no salt reflections will be recorded at receiver offsets greater than about $140 \mathrm{ft}$.

The prominent reflection event identified on field files is interpretable across the expanse of lines 1,2,3, and 4 (Figures 6A through 9A). The reflection event is coherent and well defined north of about Morton Road but displays a decreased signal-to-noise ratio and reflection wavelet bandwidth to the south (Figure 6A). The dominant frequency drops from about $80 \mathrm{~Hz}$ on the north to $50 \mathrm{~Hz}$ on the south. The near-surface velocity ranges from $1700 \mathrm{ft} / \mathrm{sec}$ on the north to less than 1250 $\mathrm{ft} / \mathrm{sec}$ on the south, while the stacking velocity ranges from $2000 \mathrm{ft} / \mathrm{sec}$ on the north, $1900 \mathrm{ft} / \mathrm{sec}$ in the center, and back to over $2100 \mathrm{ft} / \mathrm{sec}$ on the south (Table 2). These changes in velocity do not seem to correlate to bandwidth but are consistent with the variability in surface material and elevation across the line.

Indications of a disturbed reflecting surface at several places along line 1 are prevalent (Figure 6D). An apparent disturbance at about CDP 120 is coincident with a 10 to $12 \mathrm{ft}$ deep ditch observed at the ground surface. At best, the ditch could be partially responsible for a very localized portion of this static shift if inaccurate elevation and/or velocity corrections were made during processing. The surface ditch might also somehow be the effect of previous subsurface activity. With the apparent uniformity of the upthrown and downthrown sides and the very localized nature of this "offset zone" it is unlikely the $20 \mathrm{msec}$ offset is due solely to static or velocity problems. South of CDP 190 data quality drops drastically. The reflection event is confidently interpretable out to about CDP 300, but beyond that point the very periodic nature of the energy and the lack of a strong reflection wavelet makes interpretation speculative. The northern half of line 1 clearly suggests an irregular reflecting surface.

General wavelet characteristics, irregularity in the reflecting surface, apparent change in spectral properties, and a drop in signal-to-noise ratio on the southern end of line 2 are consistent with observations of line 1 (Figure 7A). The severe surface topography at the start of line 2 inhibited the acquisition of high fold data between CDP 0 and about 40 . The surface of the shallowest reflection on the north 
end of the line is very irregular and similar to the character in the northern end of line 1. The surface of the reflector on the south seems to be much smoother with less abrupt changes than on the north.

Line 2 passes within about $50 \mathrm{ft}$ of the eastern edge of the sinkhole. There seems to be no significant disturbance in the reflection that can be attributed to subsidence over the portion of the line adjacent to the sinkhole. The shallowest reflection interpreted north of the intersection of lines 2 and 4 appears disturbed from the southern road ditch to about CDP 125 (Figure 7B). CDP 125 is in about the middle of the wooded area between Morton Road and Snyder Road. The flat datum corrected sections should be free of topographic effect (Figures 7B, 7C, and 7D). The offset north of the intersection of lines 2 and 4 is the most pronounced feature on the section. Based on the general appearance of the stacked section from line 2, the only interpreted feature that could be related to the sinkhole is between CDP 125 and CDP 185.

The stacked section from line 3 has several localized features suggestive of significant offset or irregularities in the surface of the reflection (Figure 8A). An apparent offset in the reflector at CDP 125 is pronounced on data processed with sloping datums. This feature does not correlate to any surface expression or apparent change in near-surface acoustic properties (based on field file analysis). From the northern end of the line to about CDP 185 the shallowest reflection possesses a distinct or focused appearance. In general line 3 is very similar in appearance to the other north/south lines. As with the other north/south lines, the distinct change in data characteristics about midway through the line could be suggestive of either changes in the reflecting interface or changes in material between the reflector and the ground surface.

The distinct offsets at CDP 60 and CDP 125, as well as the change in wavelet characteristics at CDP 185, represent the most significant features on line 3 (Figure 8B). On these data the apparent offsets in the reflecting surface are very localized with no apparent associated energy scatter (Figure 8B). After topographic correction, both offset features are still very pronounced and not likely related to near-surface anomalies. Adjustments for surface terrain altered the apparent dip of the reflection. Based on the general appearance of the reflection, the offset features interpreted on the north half of line 3 are not likely the effects of recent dissolution. These offset features may relate to lineament and shear zones previously suggested, from remote sensing methods, to be present on Weeks Island (Martinez et al., 1976). 
The uniformity in the near-surface material and the lack of significant elevation variation across line 4 was key to the wavelet consistency on this stacked section (Figure 9A). With the dominant stacked reflection frequency about $80 \mathrm{~Hz}$ and an approximate average velocity of $1500 \mathrm{ft} / \mathrm{sec}$, the vertical resolution based on $1 / 4$ wavelength criteria of Widess (1973) is approximately $5 \mathrm{ft}$ and the radius of the first Fresnel zone is about $25 \mathrm{ft}$. The most striking feature on this line is the depression between CDP 180 and 210. This feature is directly adjacent to the sinkhole. Based on the stacking velocities, the depth to the shallowest reflecting interface on the edge of the disturbed zone is about $80 \mathrm{ft}$. The depth of the depression, as interpreted from the seismic data, is about $15 \mathrm{ft}$. Due to edge effects it is unlikely that the vertical extent of the depression could be fully resolved with these data.

The apparent depth of the reflector changes slightly across line 4 . With lower stacking velocity on the east end of the line, the calculated depth to the reflector is relatively consistent at between 75 and $80 \mathrm{ft}$ between CDP 10 and CDP 180. The increase in stacking velocity from about CDP 250 to the west end of the line corresponds to an increase in depth to the reflector on the west (CDP $260=94 \mathrm{ft}$; CDP $250=110 \mathrm{ft}$ ). Acquisition limitations at the intersection of Advanced Products Road and Morton Road resulted in a significant drop in fold and may be responsible for the slight offset between CDP 275 and CDP 280 (Figure 9B). The only other noteworthy features on line 4 are the changes in reflection wave character observable at CDPs 110, 240, and 310. These are near or over a large area of suspected rubble fill, a culvert and surface drainage channel, and an area with the remains of a structure. These changes in wavelet characteristics are similar to those observed on all three north/south lines. Since line 4 was acquired approximately parallel to the topographic gradient, very little relative change in reflection orientation can be observed after correction to a flat datum (Figure 9B). Based on the stack of line 4, the anomaly observed in the shallowest reflection between CDP 180 and CDP 210 is directly related to the surface subsidence near station 100 (CDP 200).

A variety of signal enhancement processes were evaluated on these data. The primary goal was to determine if any reflection signal deeper than the primary reflection could be enhanced. The effectiveness of second-zero crossing and spiking deconvolution was likely inhibited by violation of two of the three basic premises associated with deconvolution (random time series/large number of unique reflections and high signal-to-noise). Along portions of the CDP stacked sections with high signal-to-noise $(\mathrm{S} / \mathrm{N})$ ratios deconvolution did seem to suppress the 
reflection wavelet and broaden the bandwidth (Figures $6 \mathrm{C}$ through $9 \mathrm{C}$ ). The application of a constant velocity $f-k$ migration made the most noticeable improvement to the stacked data, especially on line 4 in the area adjacent to the sinkhole (Figures 6D through 9D). Migration only mildly enhanced signal deeper than the prominent reflection. F-k filtering (velocity filter) was no more effective than a simple NMO stretch mute in removing wide-angle reflection energy present on field files, but it did narrow the effective pass band and resulted in a ringy appearance. The improvement observed after $\mathrm{f}-\mathrm{k}$ filtering was not sufficient to justify the subtle artifacts of the operation. Some of the more sophisticated signal processing operations improved $\mathrm{S} / \mathrm{N}$ and reduced geometric distortion, allowing more confidence in suggestions that reflections from the salt and a single intermediate layer between the shallowest reflection and the salt may be interpretable.

\section{3-D Results}

Forty-five shotpoints of one-fold 3-D data were acquired at the intersection of lines 2 and 4 (Figure 1). The data for the 3-D survey were acquired coincident with the acquisition of line 4. During the process of rolling through the 2-D line (line 4), acquisition was halted when the spread was equally split by line 2 . At that point the source was moved 24 stations off-line to the north along line 2. Maintaining a fixed spread, the source was walked south along line 2, crossing Morton Road and line 4 until 24 shotpoints south of line 4 had been recorded. The survey effectively consisted of a fixed 48-channel, $376 \mathrm{ft}$ split-spread source/receiver geometry between stations 66 and 113 on line 4 with 45 unique off-line offsets, each separated by $8 \mathrm{ft}$ and starting $188 \mathrm{ft}$ north of the intersection of lines 2 and 4 and ending $188 \mathrm{ft}$ south of that intersection. The surface configuration of this one-fold survey was a 90degree cross with the 45 shotpoints along one arm and the 48 receivers along the other.

The 3-D data quality (i.e., signal-to-noise) was sufficiently high to allow an interpretation when displayed in a volumetric wiggle-trace diagram (Figure 11). The processing parameters were determined using the analysis already completed for lines 2 and 4 . The lack of redundancy would have inhibited accurate processing of the 3-D data without the 2-D data. The resulting data clearly show the depression on the surface of the prominent reflector identified on the high-fold 2-D lines. 


\section{Conclusions}

The subsurface expression of the sinkhole was effectively imaged with shallow seismic reflection techniques. The effects of dissolution and the resulting subsidence that produced the Weeks Island sinkhole have a distinctive acoustic expression on multi-fold 2-D and single-fold 3-D. Both interpretations of the 2-D data suggest an active hydrologic setting with continued subsidence likely along a northeast/southwest lineament.

The coherent reflection event interpretable on all four lines is dramatically altered on line 4 adjacent to the sinkhole. Line 2 possesses a depression in the reflection consistent in depth with line 4 but not as dramatic. The drill data suggest the depression in the reflection on line 4 near the sinkhole is a drawdown in the water table similar to drawdown experienced during classic pumping tests. The depression imaged by line 2 is either a subsurface subsidence without surface expression or an irregular surface not directly related or hydraulically connected to the present sinkhole or active subsidence. From the seismic section along line 4 the subsurface expression of the sinkhole is very steep and probably best described as a chimney feature.

The shallowest reflection in close proximity to the sinkhole was drill confirmed to be water table. The offset in the shallowest reflection is suggestive of a severe hydrologic pressure gradient across a distance of less than $100 \mathrm{ft}$ and a subsea level water table less than a mile from the Gulf (Figure 10). The high amplitude nature of the shallowest reflection is related to acoustic contrast and not necessarily a criterion for reflector continuity.

Correlation of the sinkhole with the edge of the mined area and the seismically inferred lineament is probably more than a coincidence. The previously suggested shear zone that marks the southern edge of the mine could be represented acoustically by a localized change in signal characteristics or discontinuities in reflecting interfaces. It is likely that future dissolution and associated subsidence in the area examined with shallow reflection will be concentrated along this lineament.

\section{Recommendations}

The data presented and interpreted here needs more ground truth (i.e., several checkshot velocity surveys). These data have undergone CDP processing without incorporation of other geologic or geophysical data. The velocity, and 
therefore depths, are based on curve matching techniques that could possess as much as $20 \%$ error (Hughes, 1985). With the extreme variation in velocity across this site and with the need for a high level of depth accuracy, stacking velocities need to be replaced with true average velocities for depth calculations.

The area suggested in this report as susceptible to subsidence needs confirmation drilling. A drill hole at least $400 \mathrm{ft}$ north of the lineament (between stations 30 and 40 on lines 1,2 , and 3 ) is critical to determine the interface responsible for the reflection at $-50 \mathrm{ft}$. A drill hole placed at approximately station 85 on line 2 would determine if the disturbed reflecting surface identified on line 2 and speculated to be related to the sinkhole was truly an extension of the subsidence feature identified on line 4 or the result of uplift or previous dissolution. If drilling encounters a void or any indication of active subsidence, a second drill hole should be attempted near station 60 to determine northern extent. If no void is encountered, the disturbed surface probably should not be considered an immediate threat.

The 3-D test survey clearly shows the utility of the method in this area when incorporated into a thorough 2-D program. A more extensive survey, possibly including multi-fold 3-D data, would be an effective method to improve the accuracy of the interpretation of this feature as well as delineate other potential subsidence features as directed by these and future 2-D lines. It is clear from this study that in this area 3-D data can be most efficiently be used when acquired coincident with 2-D. The 3-D data acquired as a test on this survey could undergo more extensive processing. However, the gain versus cost might not be justified. The velocity variation observed across the area included with this 3-D survey suggests conventional 3-D velocity analysis and possibly migration should improve the accuracy of future 3-D surveys. 


\section{References}

Black, W.E. and J.O. Voigt, 1982, The use of seismic refraction and mine-to-surface shooting to delineate salt dome configuration and map fracture zones [Exp. Abs.]: Soc. Explor. Geophys., p. 465-466.

Black, R.A., D.W. Steeples, and R.D. Miller, 1994, Migration of shallow seismic reflection data: Geophysics, v. 59, p. 402-410.

Healey, J., J. Anderson, R.D. Miller, D. Keiswetter, D.W. Steeples, and B. Bennett, 1991, Improved shallow seismic-reflection source: Building a better Buffalo [Exp. Abs.]: Soc. Explor. Geophys. v. 1, p. 588-591.

Hughes, D.R., 1985, Velocity without tears: The Leading Edge, v. 4, n. 2, p. 50-52.

Hunter, J.A., S.E. Pullan, R.A. Burns, R.M. Gagne, and R.S. Good, 1984, Shallow seismicreflection mapping of the overburden-bedrock interface with the engineering seismograph-Some simple techniques: Geophysics, v. 49, p. 1381-1385.

Kinsland, G.L. and A.W. Rutter, III, 1994, Shallow seismic survey on Weeks Island, Louisiana, ... an attempt to define "top of salt," submitted to Gulf Coast Association of Geological Societies.

The Leading Edge, 1994, Special issue on subsalt imaging: Soc. Explor. Geophys. v. 13, n. 8, August.

Martinez, J.D., et al., 1976, An investigation of the utility of gulf coast salt domes for the storage or disposal of radioactive wastes: Office of Waste Isolation, Union Carbide Corporation-Nuclear Division, U.S. Energy Research and Development Administration. Report ORNL-Sub-4112-25 prepared by the Institute for Environmental Studies, Louisiana State University.

Martinez, J.D., et al., 1977, An investigation of the utility of gulf coast salt domes for the storage or disposal of radioactive wastes: Office of Waste Isolation, Union Carbide Corporation-Nuclear Division, U.S. Energy Research and Development Administration. Report Y/OWI/SUB-4112/37 prepared by the Institute for Environmental Studies, Louisiana State University.

Merey, C. R.D. Miller, E.J. Ticken, and J.S. Lewis, 1992, Hydrogeologic characterization using a shallow seismic reflection survey at Fort Ord, California [Exp. Abs.]: Soc. Explor. Geophys., v. 1, p. 370-373.

Miller, R.D., 1992, Normal moveout stretch mute on shallow-reflection data: Geophysics, v. 57, p. 1502-1507.

Miller, R.D., D.W. Steeples, L. Schulte and J. Davenport, 1993, Shallow seismic-reflection feasibility study of the salt dissolution well field at North American Salt Company's Hutchinson, Kansas, facility: Mining Engineering, October, p. 1291-1296.

Steeples, D.W., 1990, Spectral shaping during acquisition of seismic-reflection data [Exp. Abs.]: Society of Explor. Geophys., v. 1, p. 917-920.

Steeples, D.W., R.W. Knapp, and C.D. McElwee, 1986, Seismic reflection investigations of sinkholes beneath Interstate Highway 70 in Kansas: Geophysics, v. 51, p. 295-301.

Steeples, D.W., and R.D. Miller, 1987, Direct detection of shallow subsurface voids using high-resolution reflection techniques; in Sinkholes: Their geology, engineering, and environmental impact, 2nd edition., ed. Barry Beck and W.L. Wilson: A.A. Balkema, Boston, p. 179-183.

Steeples, D.W., and R.D. Miller, 1990, Seismic-reflection methods applied to engineering, environmental, and ground-water problems: Soc. Explor. Geophys. Investigations in Geophysics, Investigations in Geophysics no. 5, Stan Ward, ed., Volume 1: Review and Tutorial, p. 1-30.

Widess, M.D., 1973, How thin is a thin bed?: Geophysics, v. 38, p. 1176-1180.

Yilmaz, O., 1987, Seismic data processing; S. M. Doherty, Ed.; in Series: Investiga tions in Geophysics, no. 2, Edwin B. Neitzel, Series Ed.: Soc. of Explor. Geophys., Tulsa, Oklahoma. 


\title{
TABLE 1
}

\section{Processing Flow}

\author{
Primary Processing \\ format from SEG2 to KGSEGY \\ preliminary editing (automatic bad trace edit with $10 \mathrm{msec}$ noise \\ window) \\ trace balancing ( $150 \mathrm{msec}$ window) \\ first arrival muting (direct wave and refraction) \\ surgical muting (removal of groundroll based on trace-by-trace arrival) \\ assign geometries (input source and receiver locations) \\ elevation correction to multiple, floating datums \\ sort into CDPs (re-order traces in common midpoints) \\ velocity analysis (whole data set analysis on $100 \mathrm{ft} / \mathrm{sec}$ increments) \\ spectral analysis (frequency vs amplitude plots) \\ NMO correction (station dependent ranging from 1350 to 2,500 ft/sec) \\ correlation statics ( $2 \mathrm{msec}$ max shift, 7 pilot traces, $100 \mathrm{msec}$ window) \\ digital filtering (bandpass 25-50 250-375) \\ secondary editing (manual review and removal of bad or noisy traces) \\ CDP stack \\ amplitude normalization (whole trace with 40 msec delay) \\ correct to flat datum ( $48 \mathrm{ft}$ above sea level) \\ display

\section{Secondary Processing} \\ f-k filtering \\ f-k migration \\ deconvolution (spiking and second zero crossing)
}

Table 1. Processing flow for CDP stacked data. Parameters were determined by analysis for each prior step as well as through iterative analysis of particular operations. 
TABLE 2

Normal Noveout Velocities, Weeks Island, LA

$\begin{array}{lrrrrr} & \text { CDP\# } & \begin{array}{c}\text { Time } \\ (\mathrm{ms})\end{array} & \begin{array}{c}\text { Velocity } \\ (\mathrm{ft} / \mathrm{s})\end{array} & \begin{array}{c}\text { Time } \\ (\mathrm{ms})\end{array} & \begin{array}{c}\text { Velocity } \\ (\mathrm{ft} / \mathrm{s})\end{array} \\ \text { Line 1 (A) } & 1 & 200 & 2000 & & \\ & 100 & 200 & 1900 & & \\ & 195 & 200 & 1400 & & \\ \text { Line 2 (B) } & 21 & 200 & 2000 & 300 & 2100 \\ & 100 & 200 & 2200 & 300 & 2300 \\ & 200 & 200 & 1400 & 300 & 1900 \\ \text { Line 3 (C) } & 150 & 200 & 2100 & 300 & 2400 \\ & 190 & 200 & 1700 & 300 & 2400 \\ & 220 & 200 & 1600 & 300 & 1900 \\ & 250 & 200 & 1300 & 300 & 2400 \\ \text { Line 4 (D) } & 10 & 140 & 1400 & & \\ & 100 & 140 & 1400 & 180 & 2100 \\ & 170 & 140 & 1400 & 180 & 2000 \\ & 200 & 140 & 1500 & 180 & 1900 \\ & 250 & 140 & 1700 & 180 & 1900\end{array}$




\section{TABLE 3}

Velocities Used for Elevation and Depth Calculation

CDP \# $\frac{\begin{array}{c}\text { Datum } \\ \text { Correction }\end{array}}{\text { Velocity }(\mathrm{ft} / \mathrm{sec})} \quad \frac{\begin{array}{c}\text { Time/Depth } \\ \text { Conversion }\end{array}}{\text { Velocity }(\mathrm{ft} / \mathrm{sec})}$

$\begin{array}{lrrr}\text { Line } 1 & 1 & 2000 & 1850 \\ & 100 & 1900 & 1750 \\ \text { Line } 2 & 195 & 1400 & 1250 \\ & 1 & 2000 & \\ & 21 & 2000 & 1850 \\ \text { Line 3 } & 100 & 2200 & 2050 \\ & 195 & 1400 & 1250 \\ & 1 & 2100 & 1950 \\ & 150 & 2100 & 1950 \\ & 190 & 1700 & 1450 \\ \text { Line } 4 & 220 & 1600 & 1150 \\ & 250 & 1300 & 1400 \\ & & & 1400 \\ & 1 & 1400 & 1400 \\ & 100 & 1400 & 1500 \\ & 170 & 1400 & 1700\end{array}$




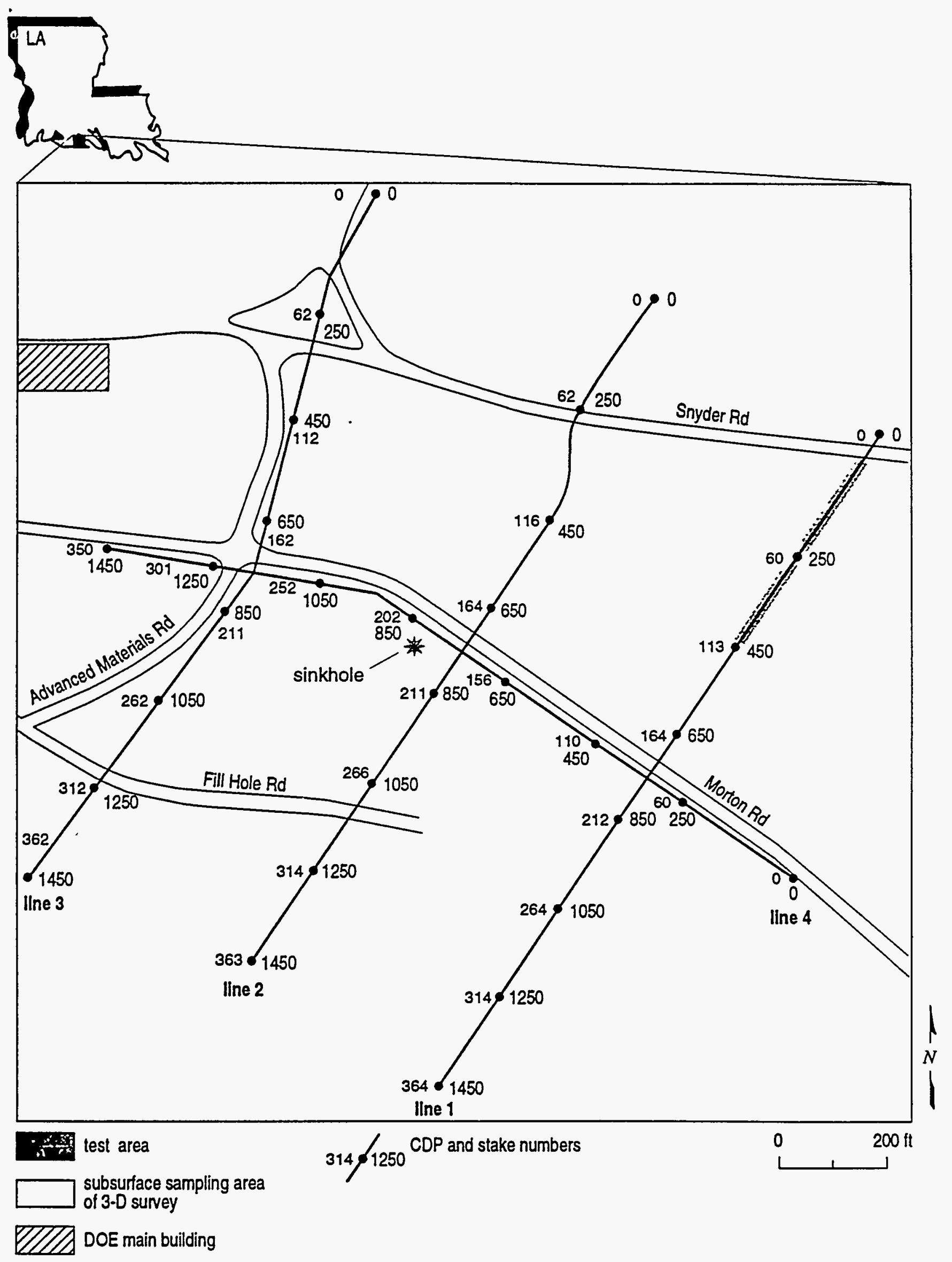

Figure 1. Site map indicating the relative location of Weeks Island and the layout of the survey. The four seismic lines are annolated with both survey distance measurements and CDP numbers. The shaded area represents the subsurface footprint of the 3-D test survey. The walkaway tests were conducted on the northeast end of line 1. 


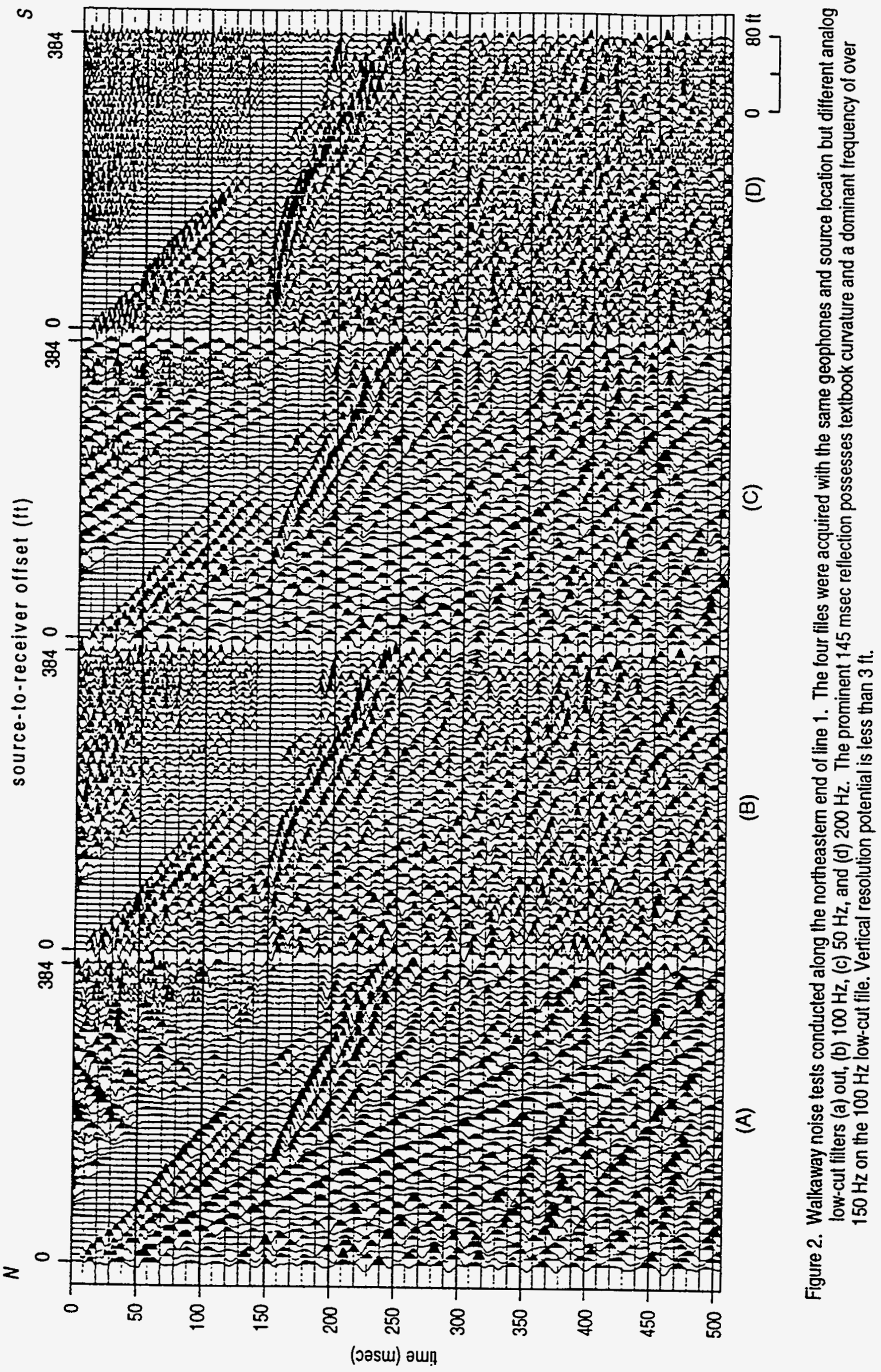




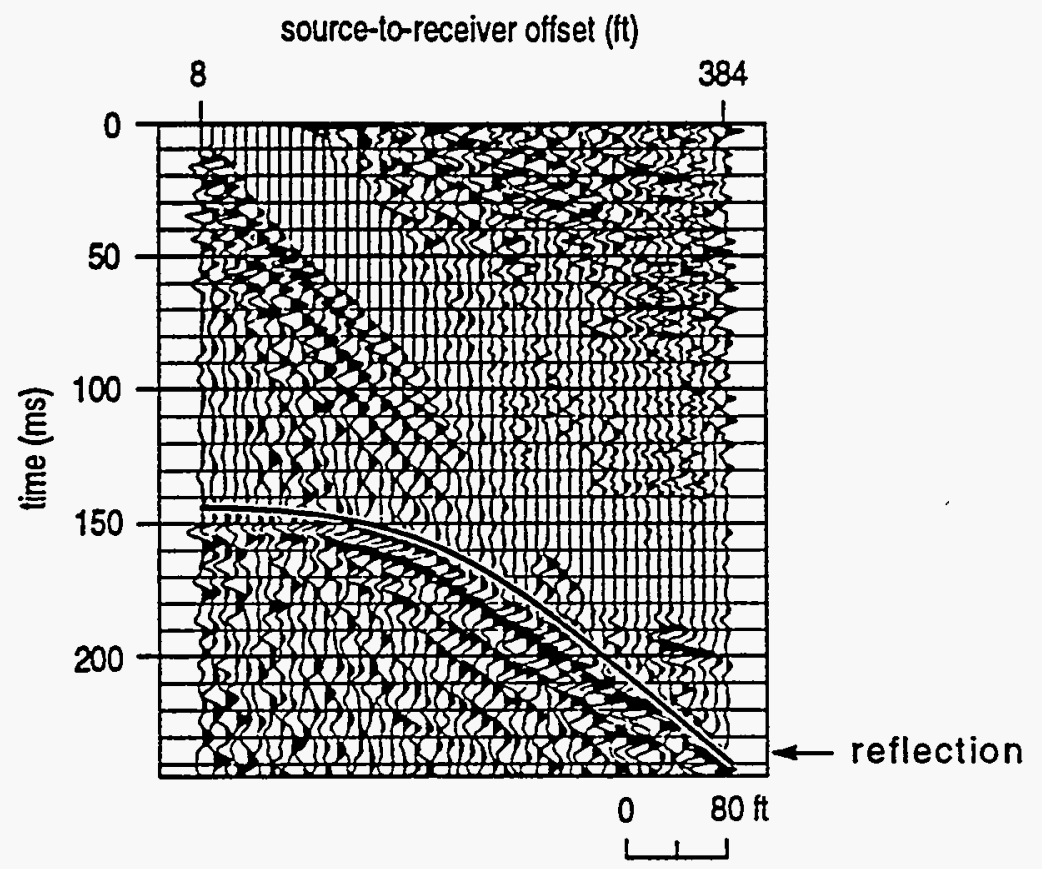

Figure 3. A computer simulated, $2100 \mathrm{ftsec}$ reflection hyperbola is displayed over field file (b) from the walkaway noise test (Figure 2). The theoretical curve is a perfect match. Depth conversion indicates the reflector is $150 \mathrm{ft}$ deep. 


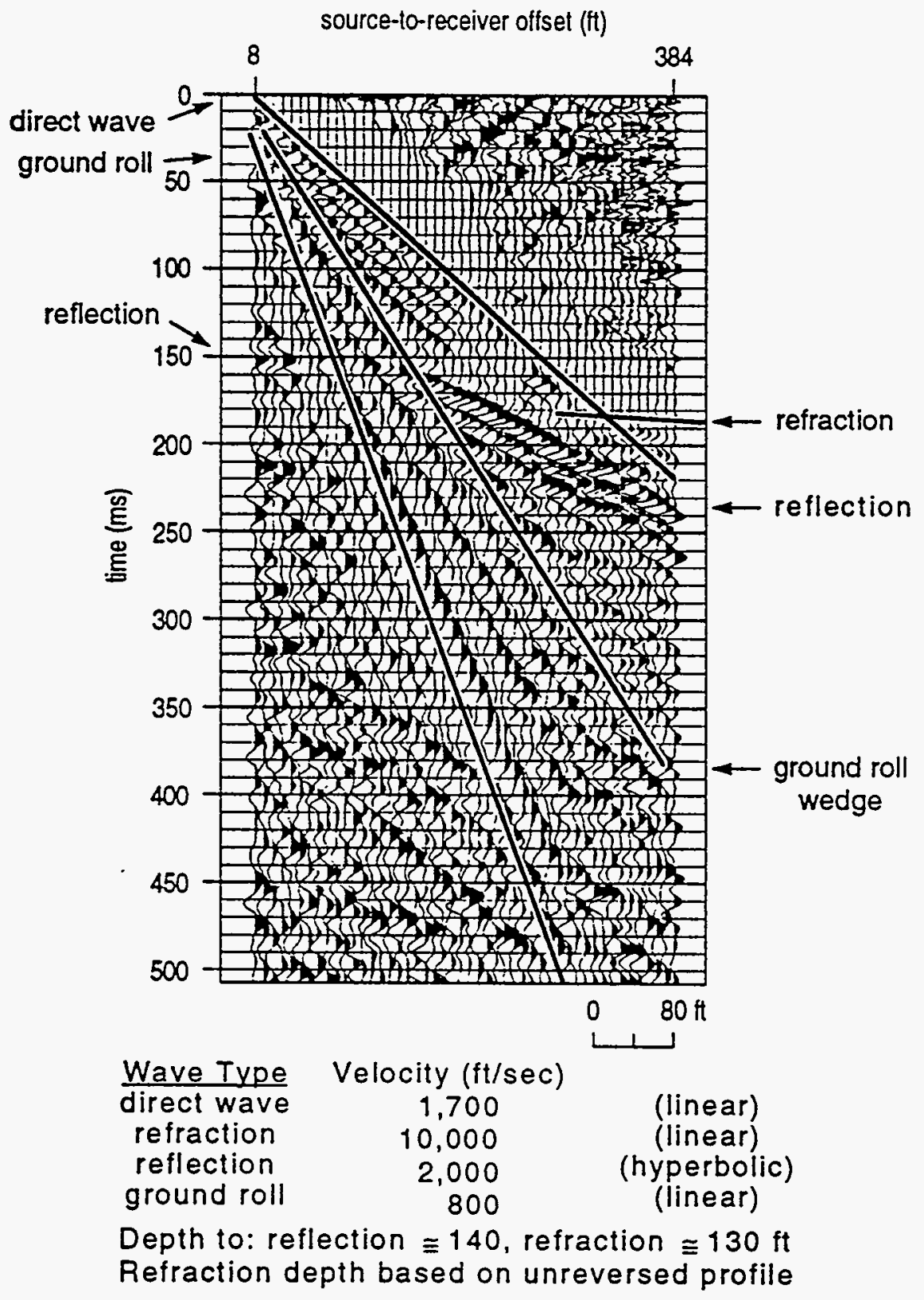

Figure 4. Walkaway file collected with a $50 \mathrm{~Hz}$ analog low-cut filter, then AGC scaled, and highlighted interpretation of coherent arrivals. The analysis suggests the prominent refiection and refraction are from the same interface. 


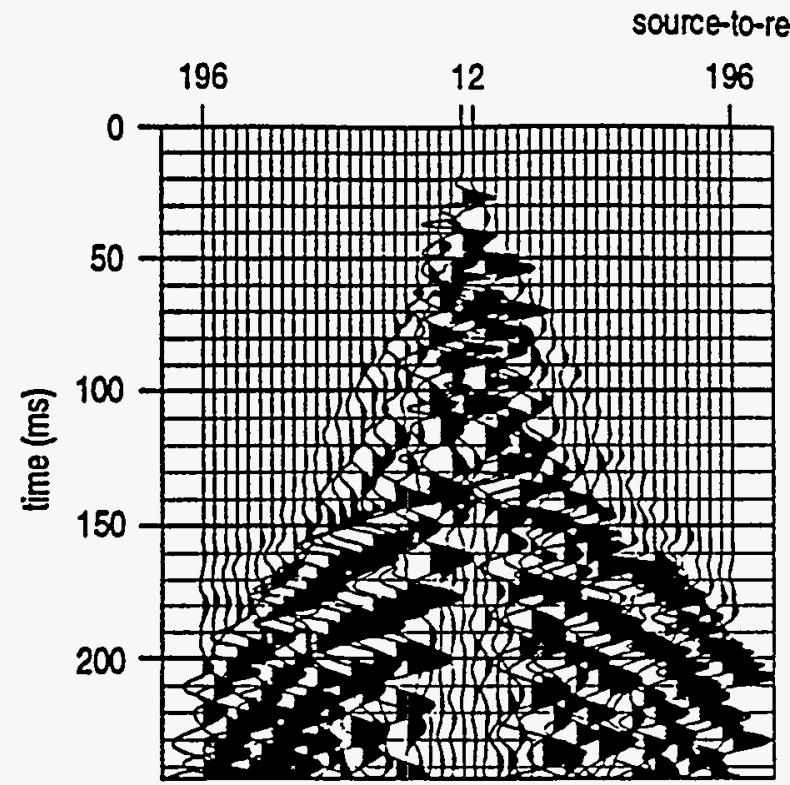

(A)

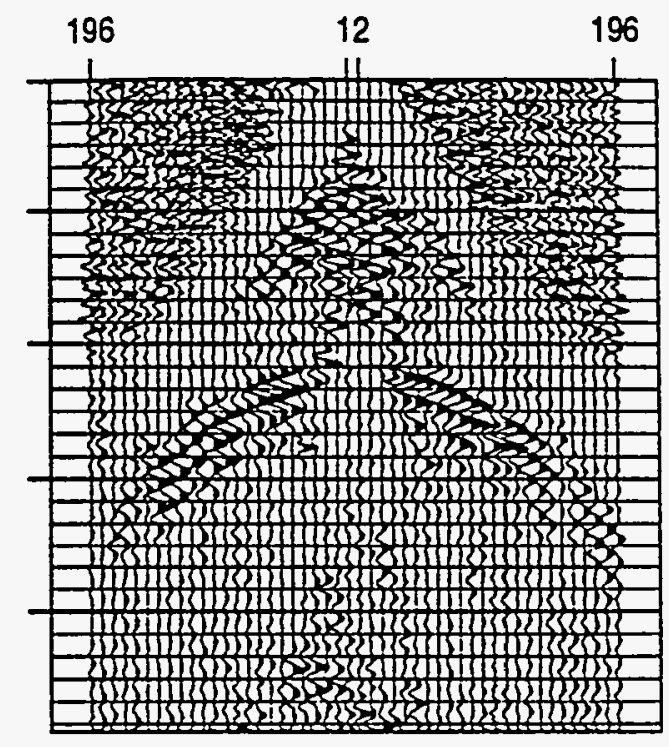

(B)

$80 \mathrm{ft}$

Figure 5. Raw field file (A) and nomalizedfiltered field file (B) from along line 4. In this split-spread source/receiver geometry the reflection traces a symmetric hyperbola near offset of $12 \mathrm{ft}$ and far offset of $196 \mathrm{ft}$. 

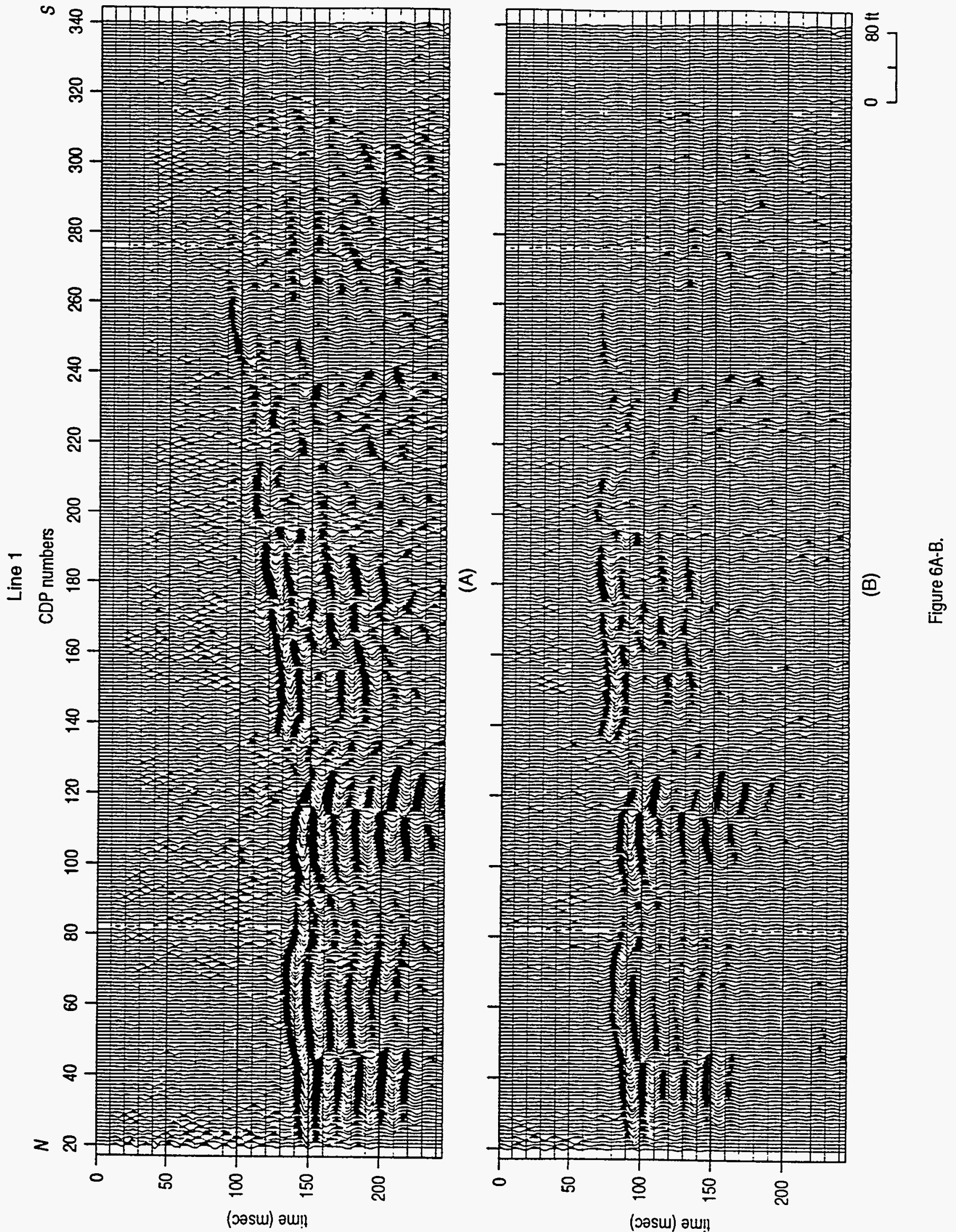

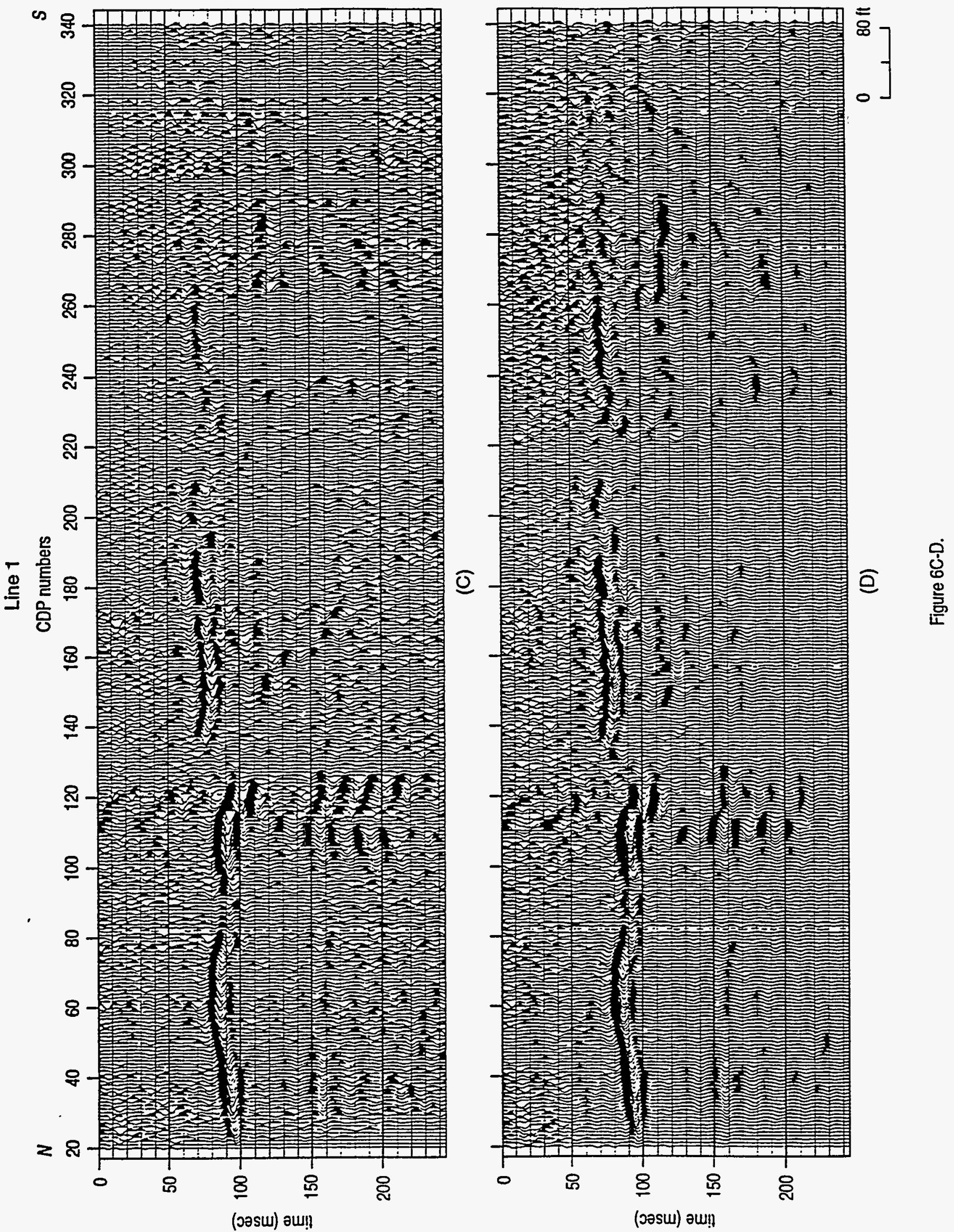


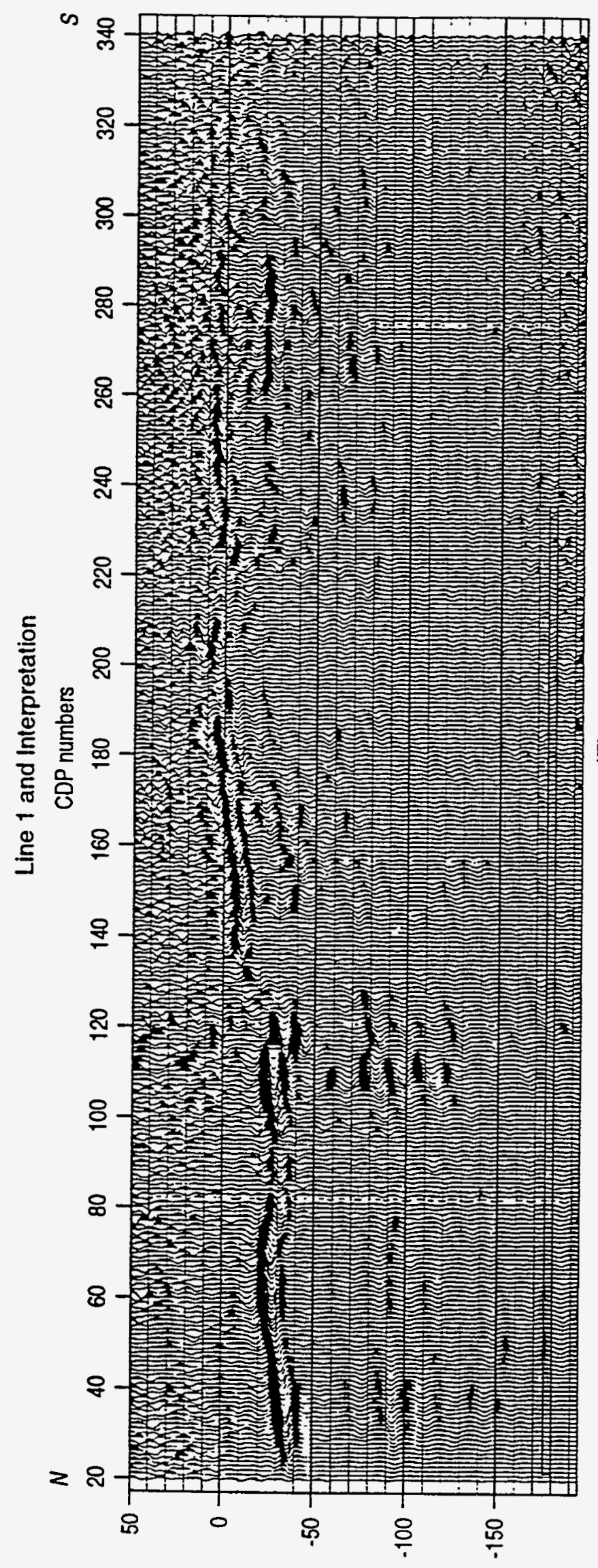

(น) บо!̣еләра

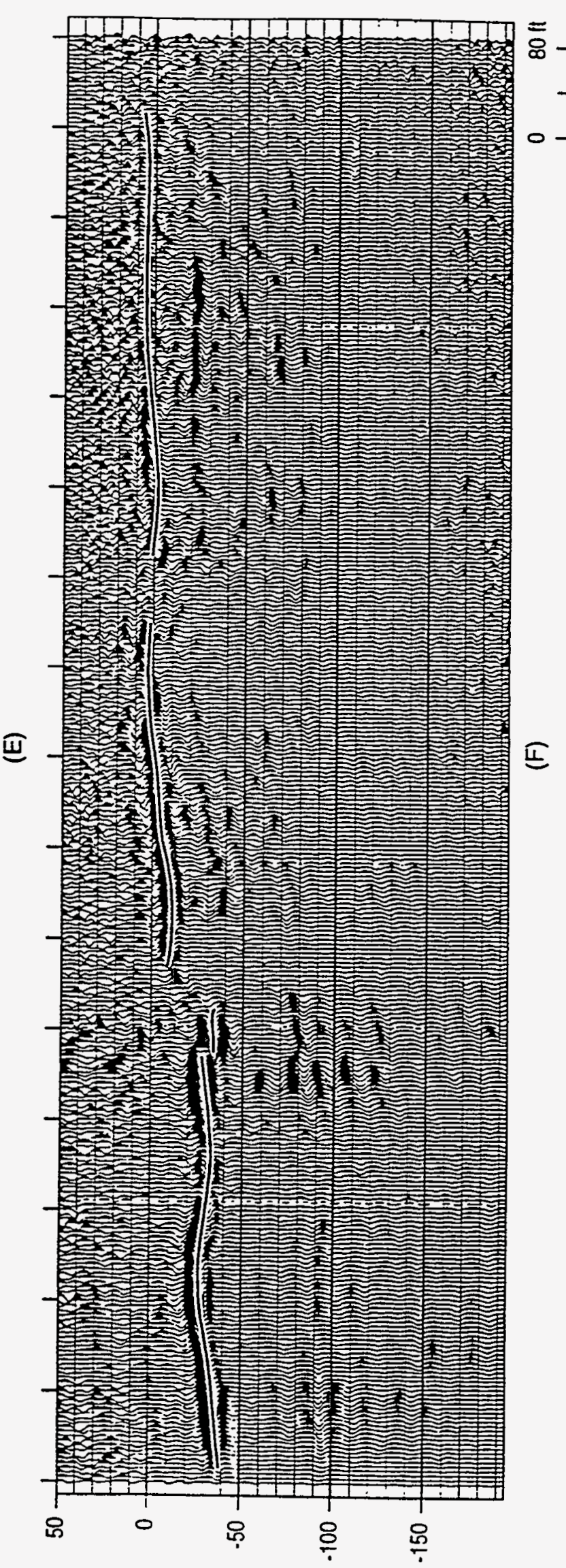

(i1) บоำелара

넗
인 
Line 1 and Interpretation

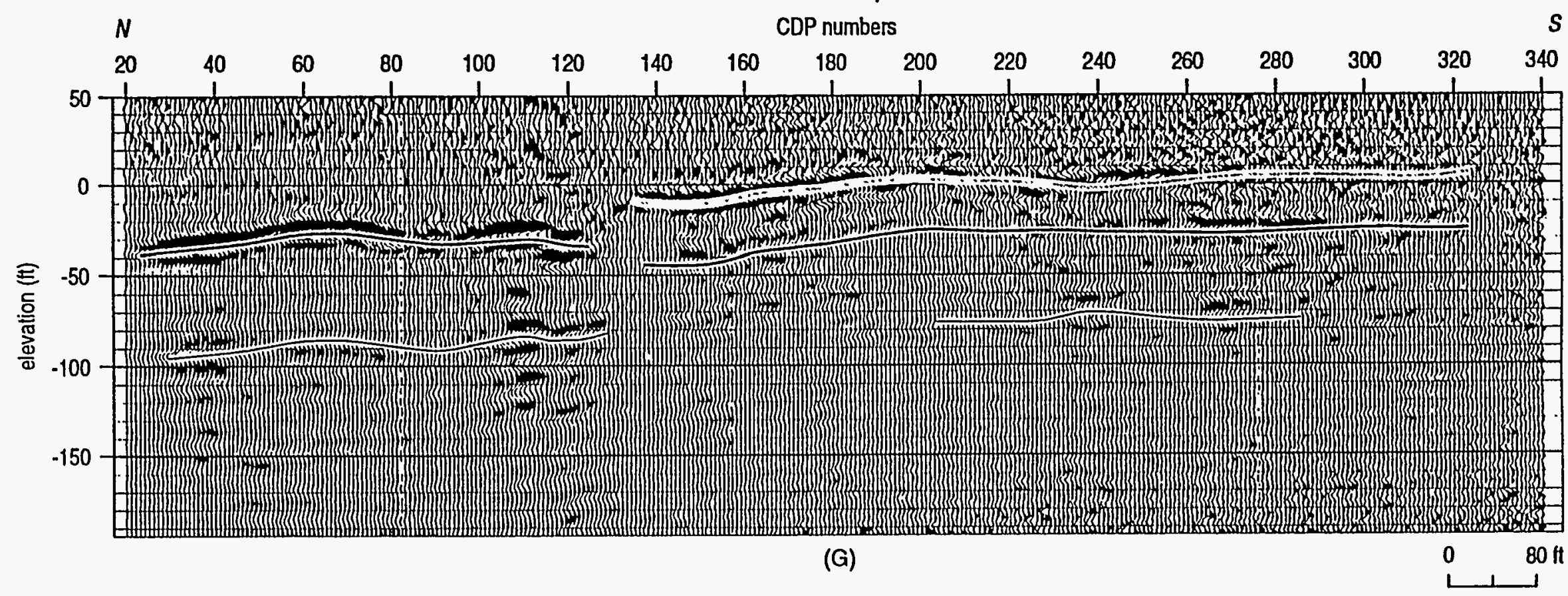

Figure 6A-G. Line 1, 24-fold, CDP stacked section. A) Elevation corrected to multiple sloping datums. B) Same CDP data as (A) elevalion corrected to a single flat $48 \mathrm{ft}$ sea level datum. C) Deconvolved (B). D) F-k migrated (C). E) Deplh converted (D) using the stacking velocities. F) Interpreted (E) assuming the shallowest reflection is from the same reflector across the line. G) Interpretation of (E) if the shallowest reflection is discontinuous at the apparent offset. 

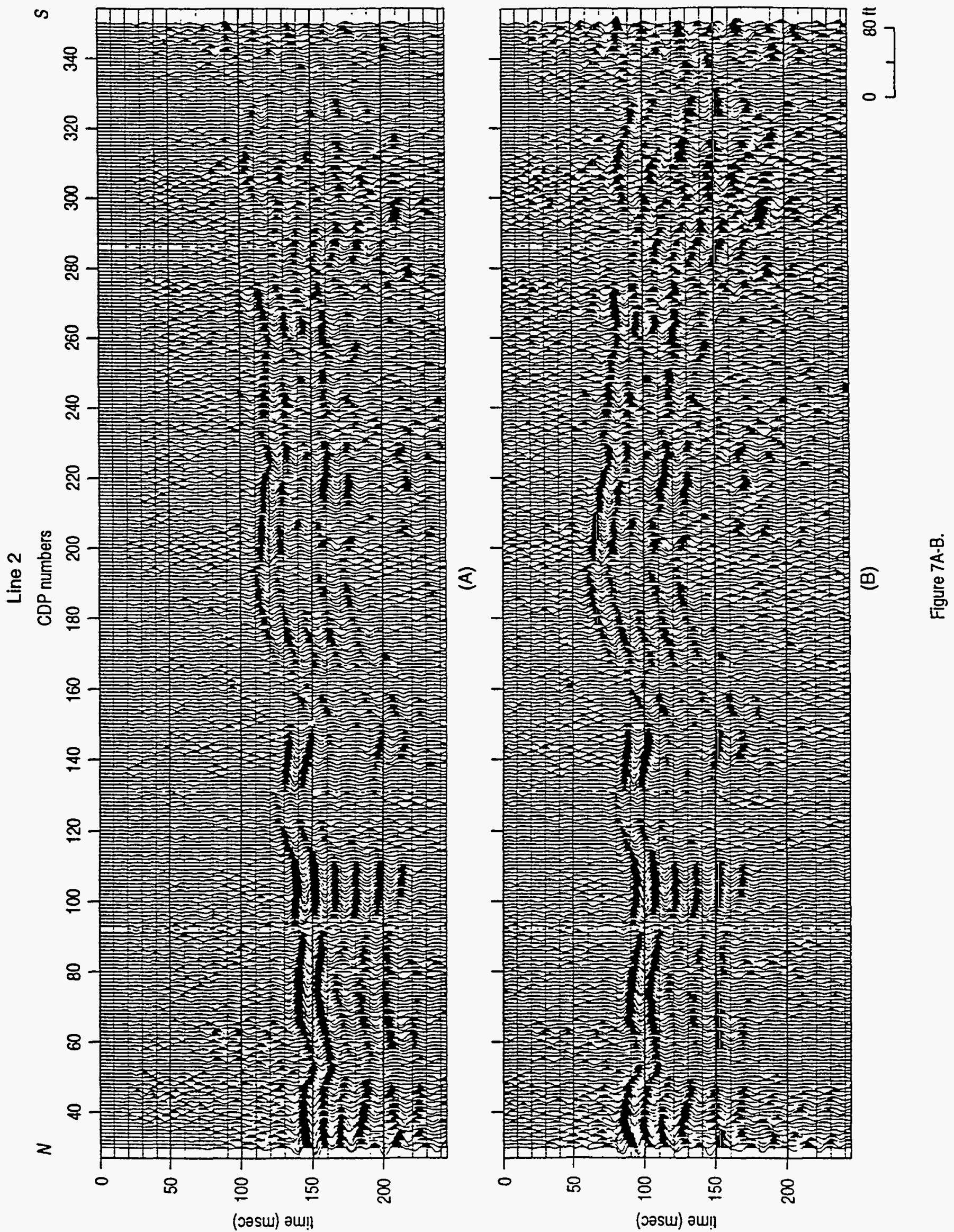

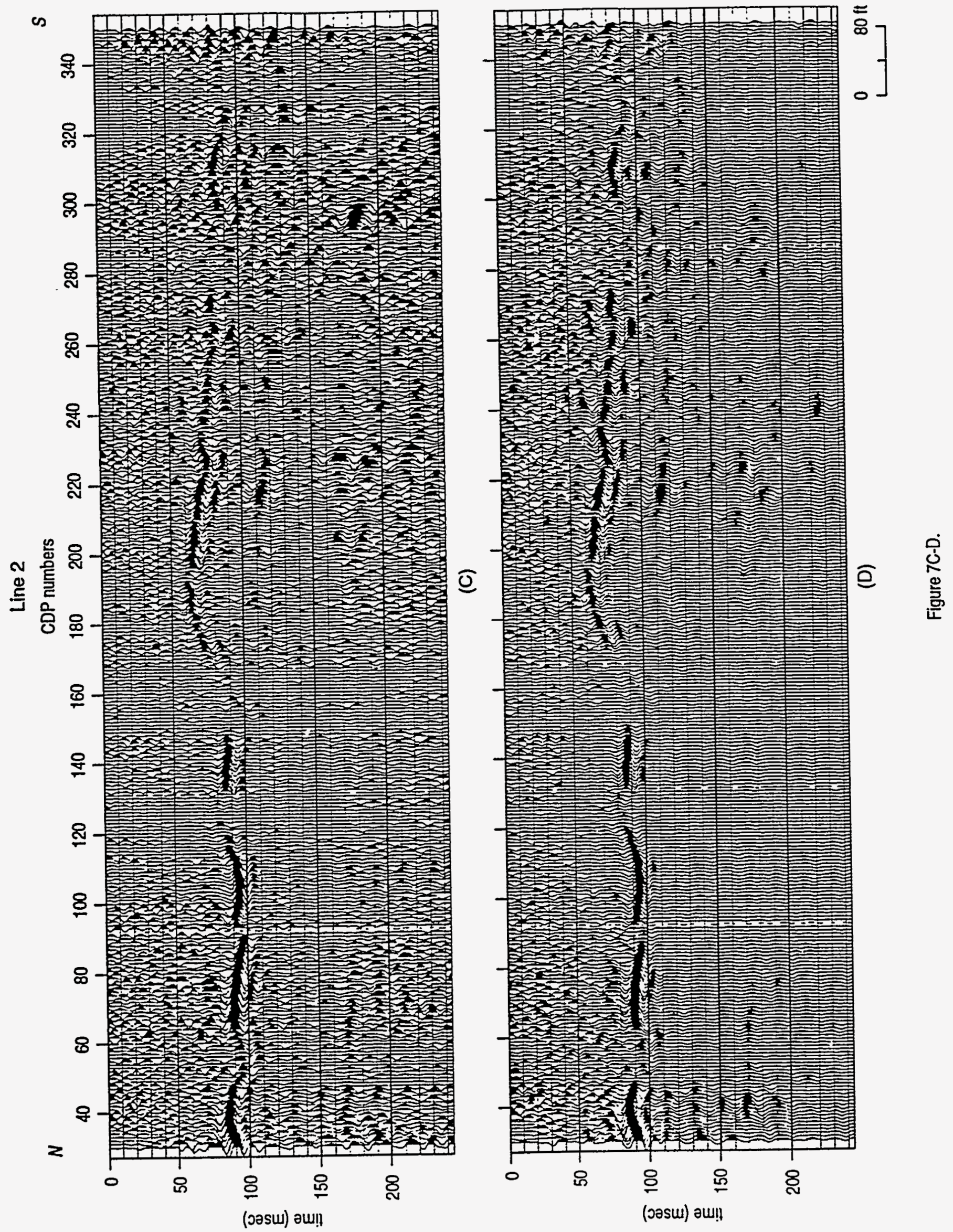

A-5-29 


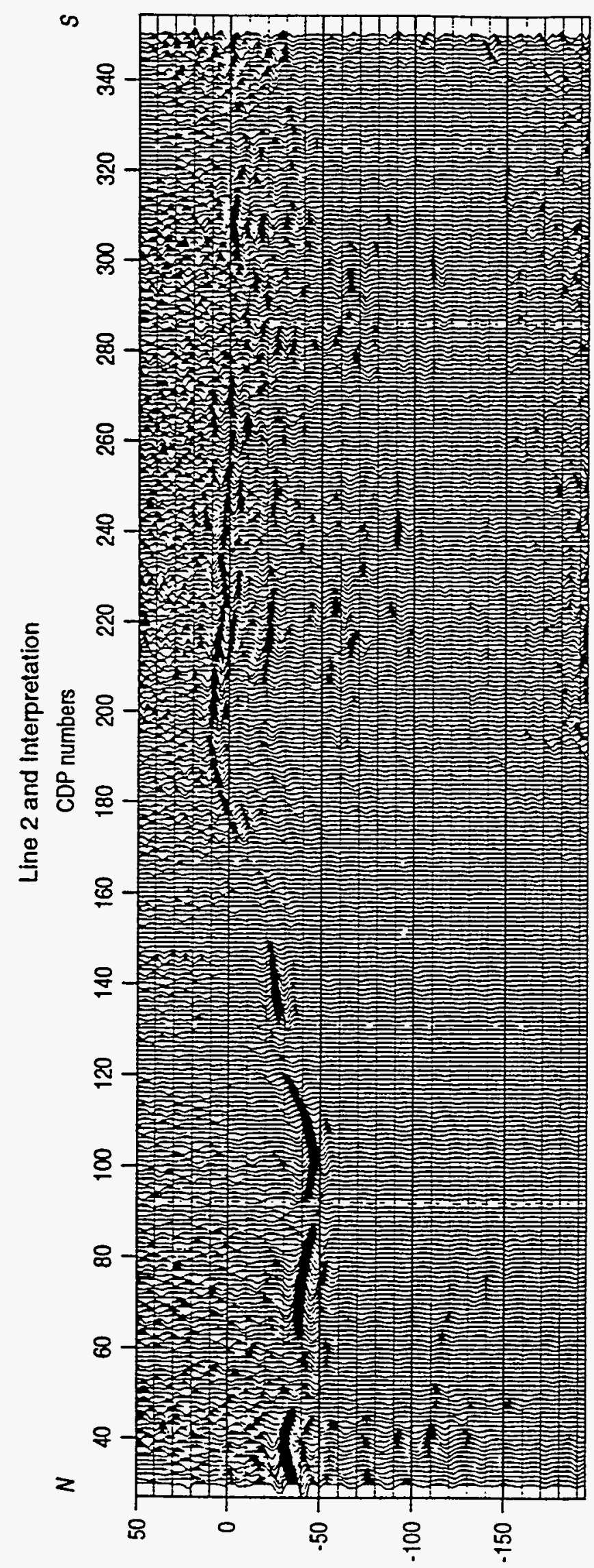

(H) บо!̣елә|а

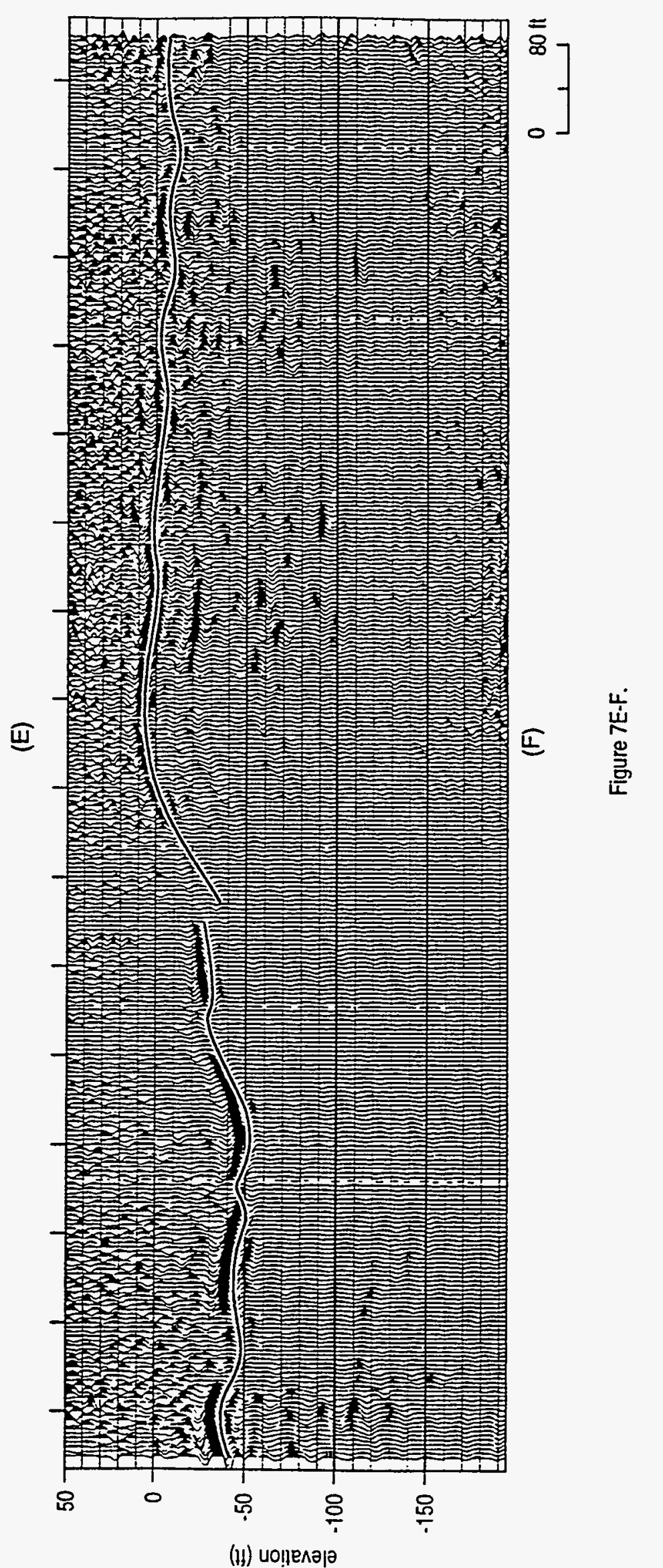

A-5-30 

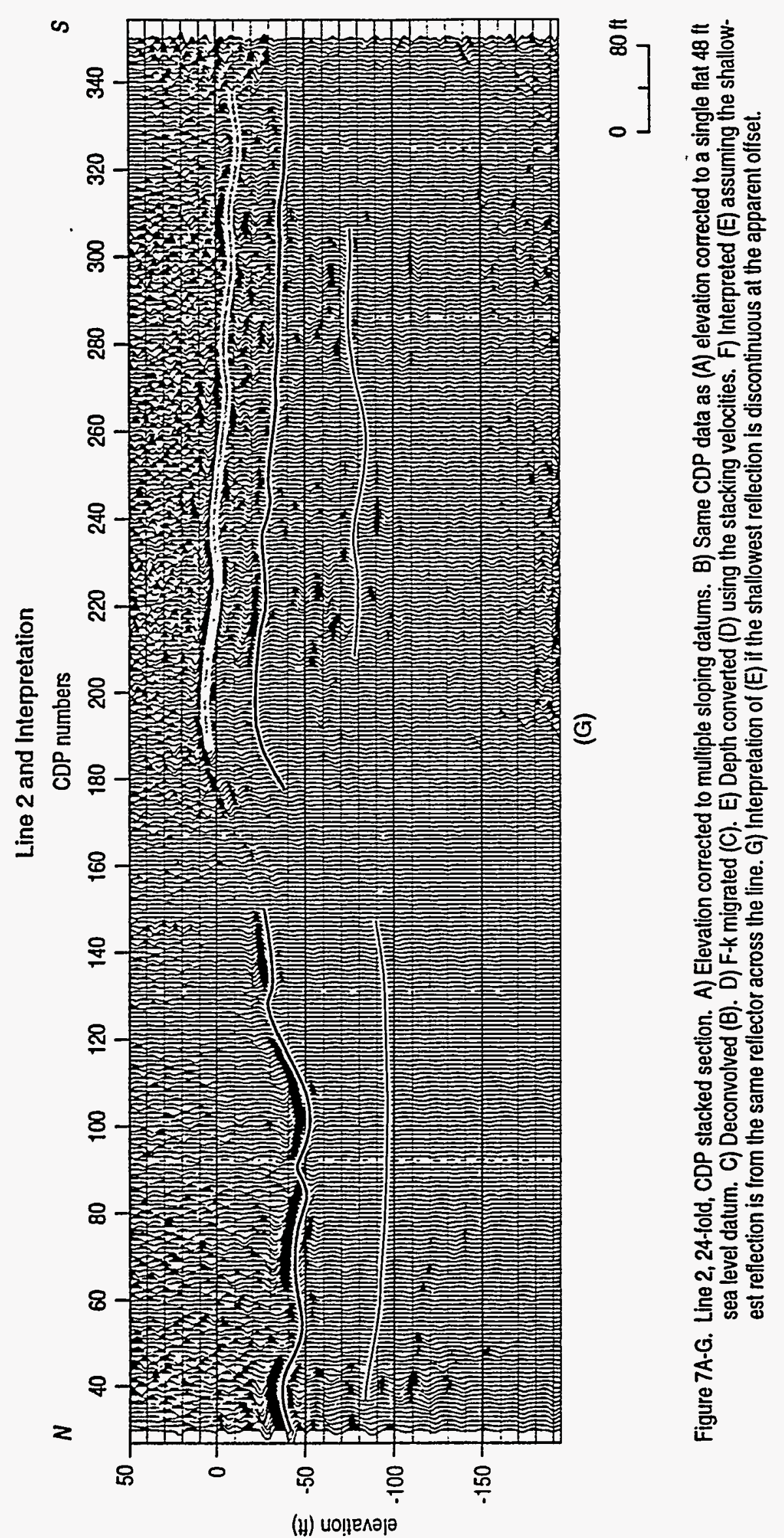

A-5-31 

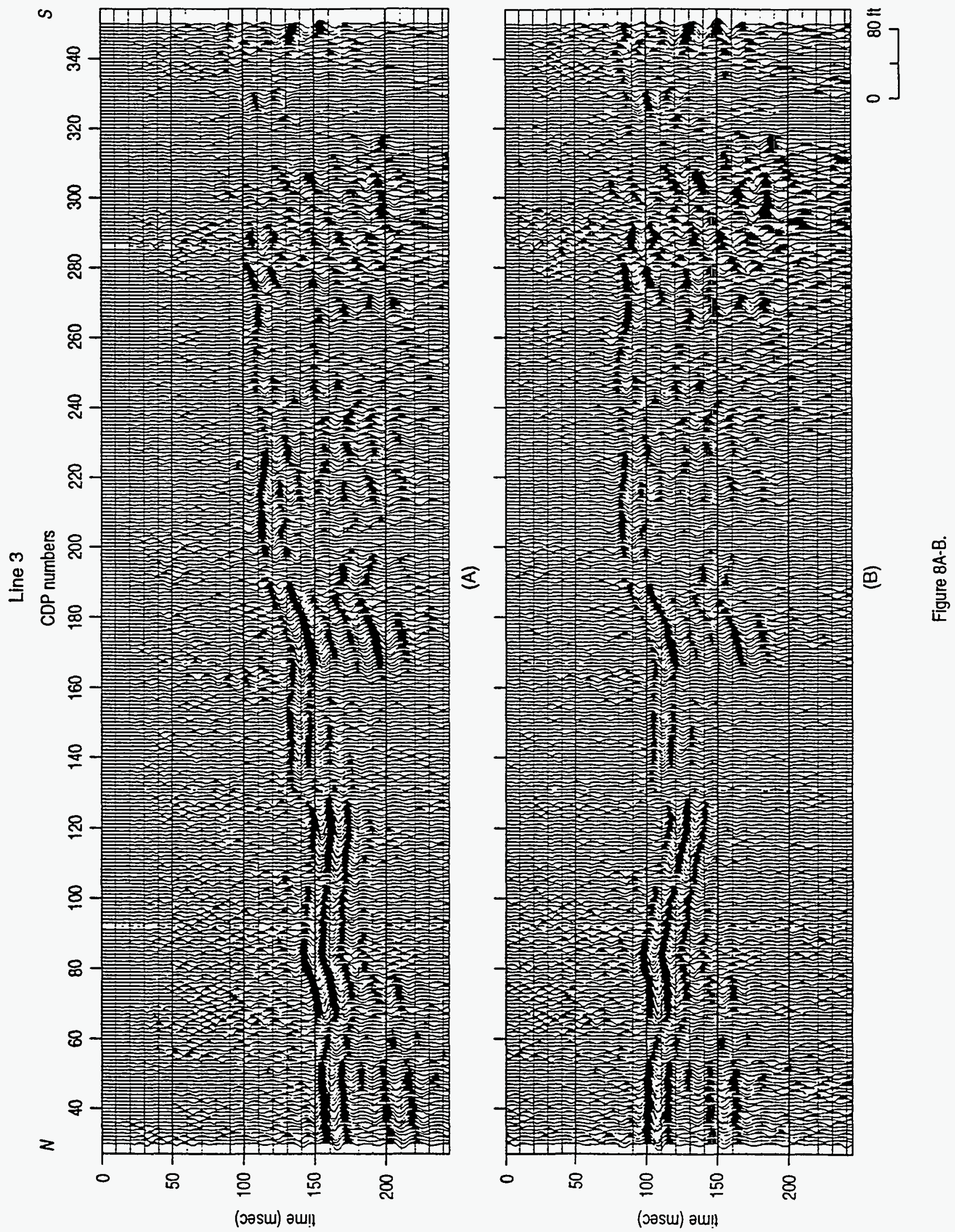

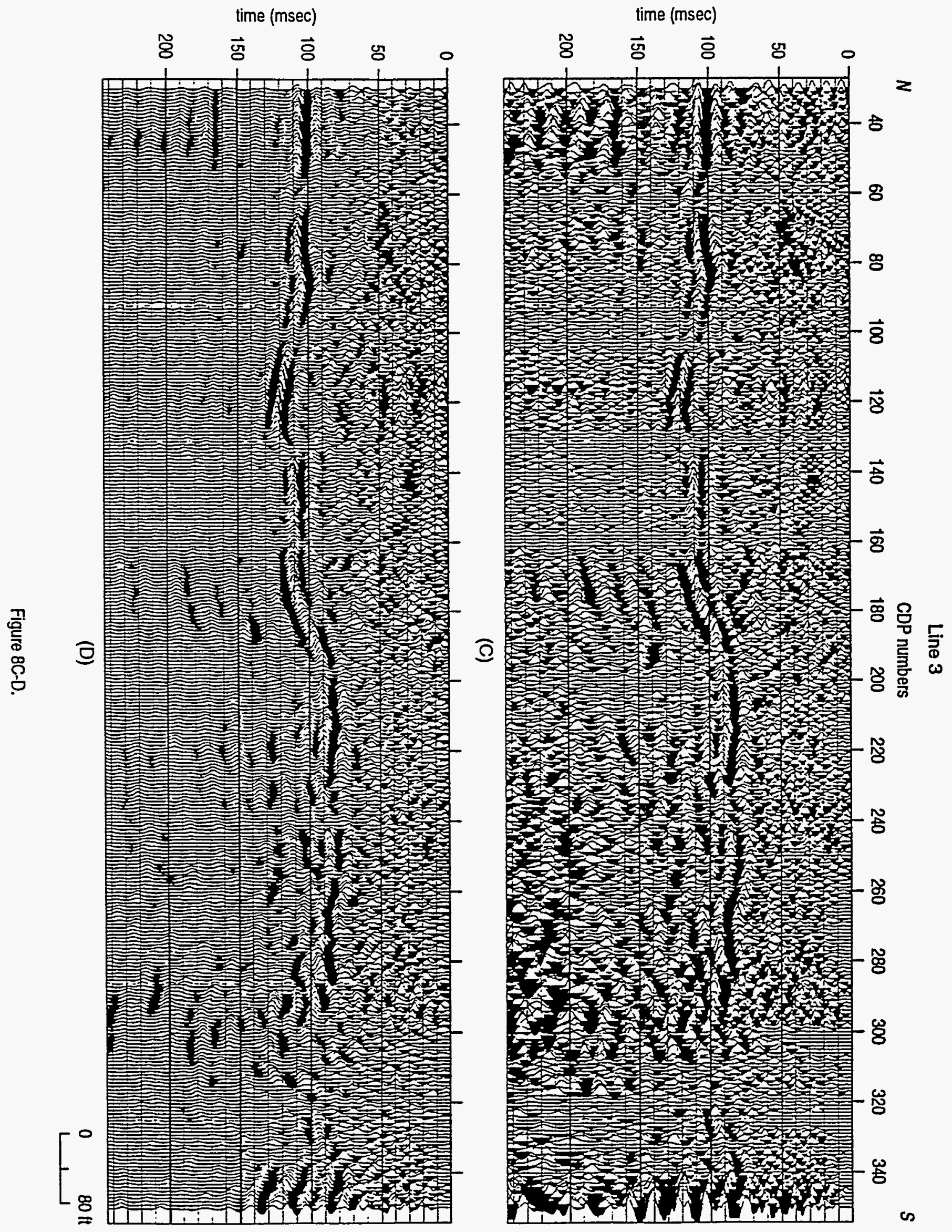


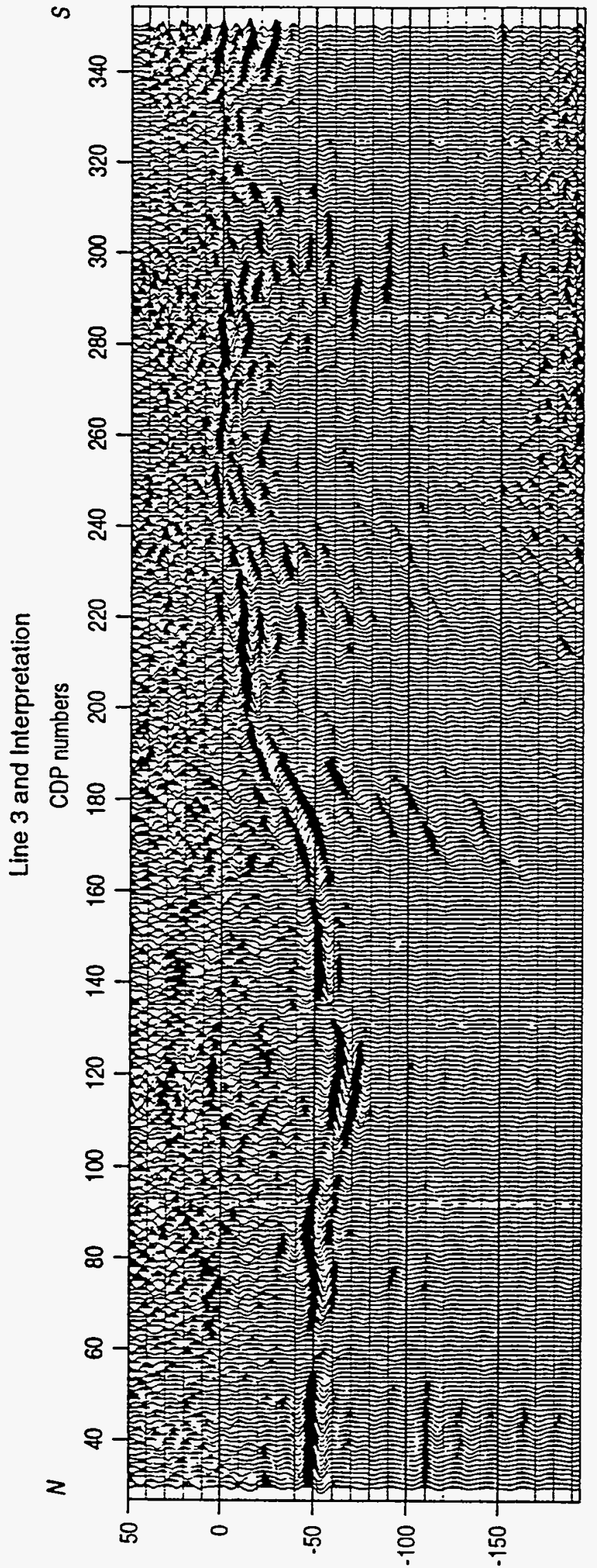

(H) บоп̣еләра

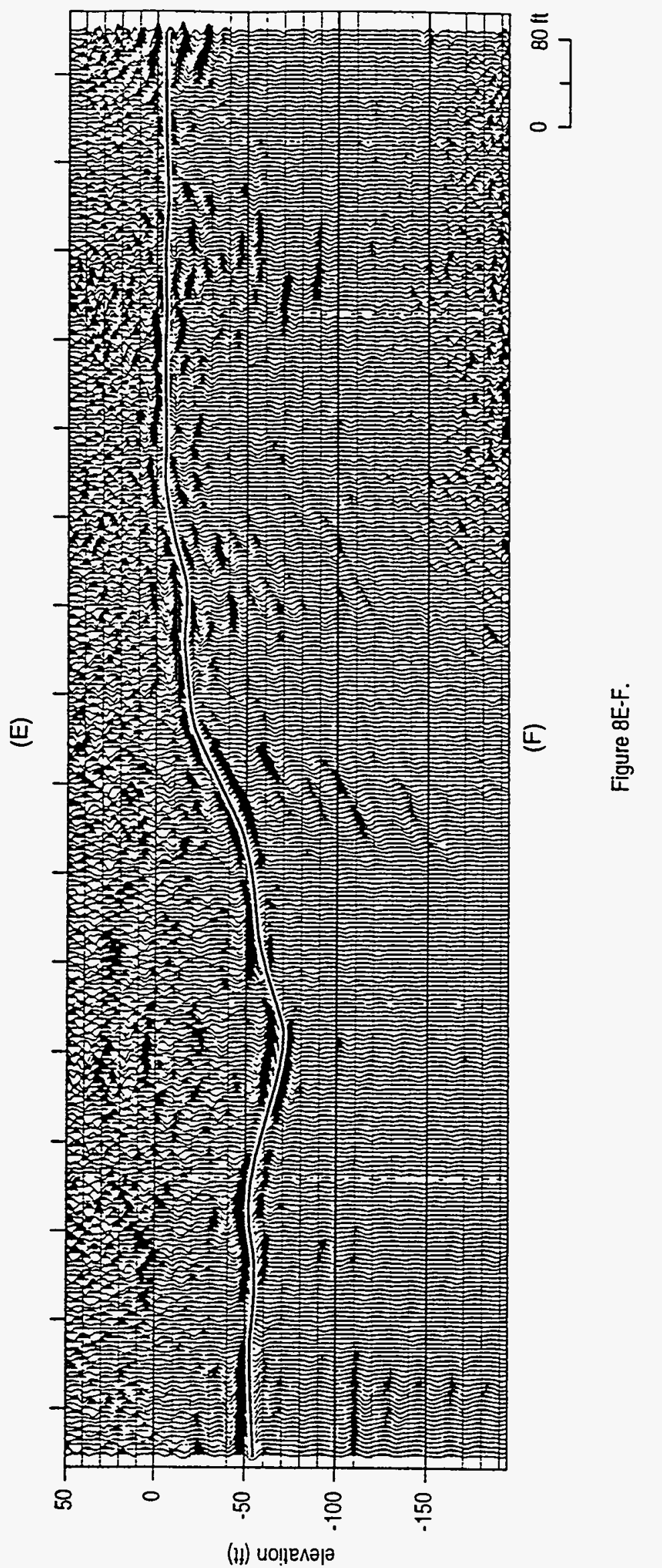




\section{Line 3 and Interpretation}

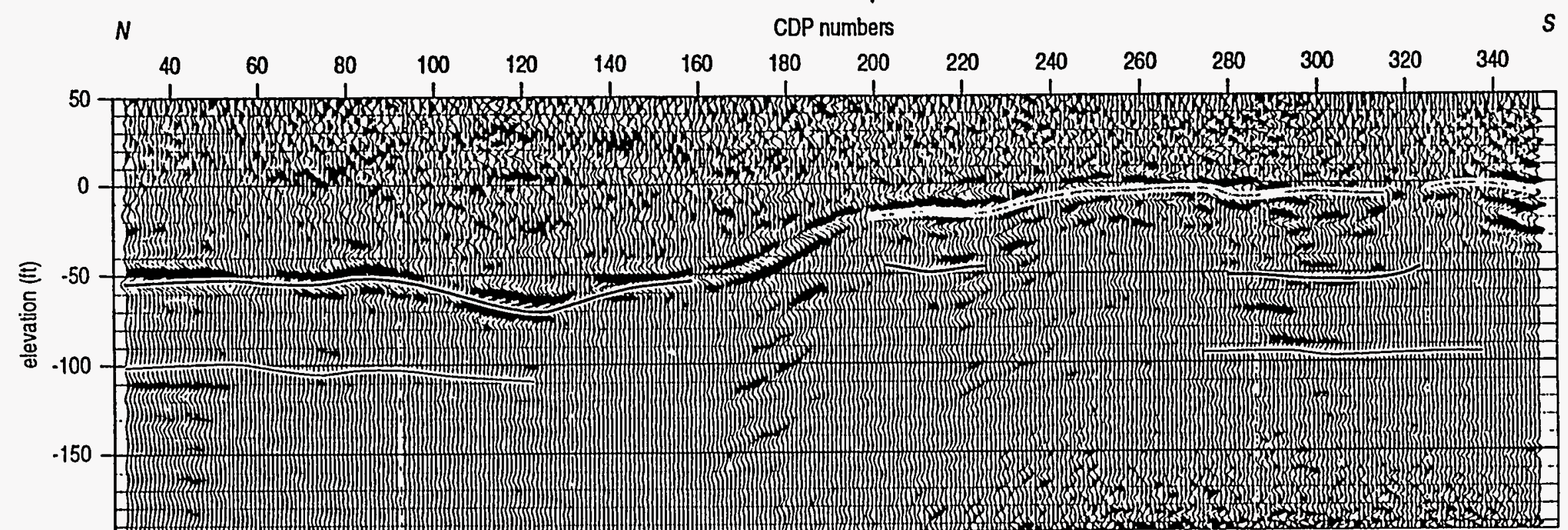

Figure 8A-G. Line 3, 24-fold, CDP slacked section. A) Elevation corrected to multiple sloping datums. B) Same CDP dala as (A) elevation corrected to a single flat $48 \mathrm{ft}$ sea level datum. C) Deconvolved (B). D) F-k migrated (C). E) Depth converted (D) using the stacking velocities. F) Interpreted (E) assuming the shallowest reflection is irom the same refleclor across the line. G) Interpretation of $(E)$ if the shallowest reflection is discontinuous at the apparent oflset. 

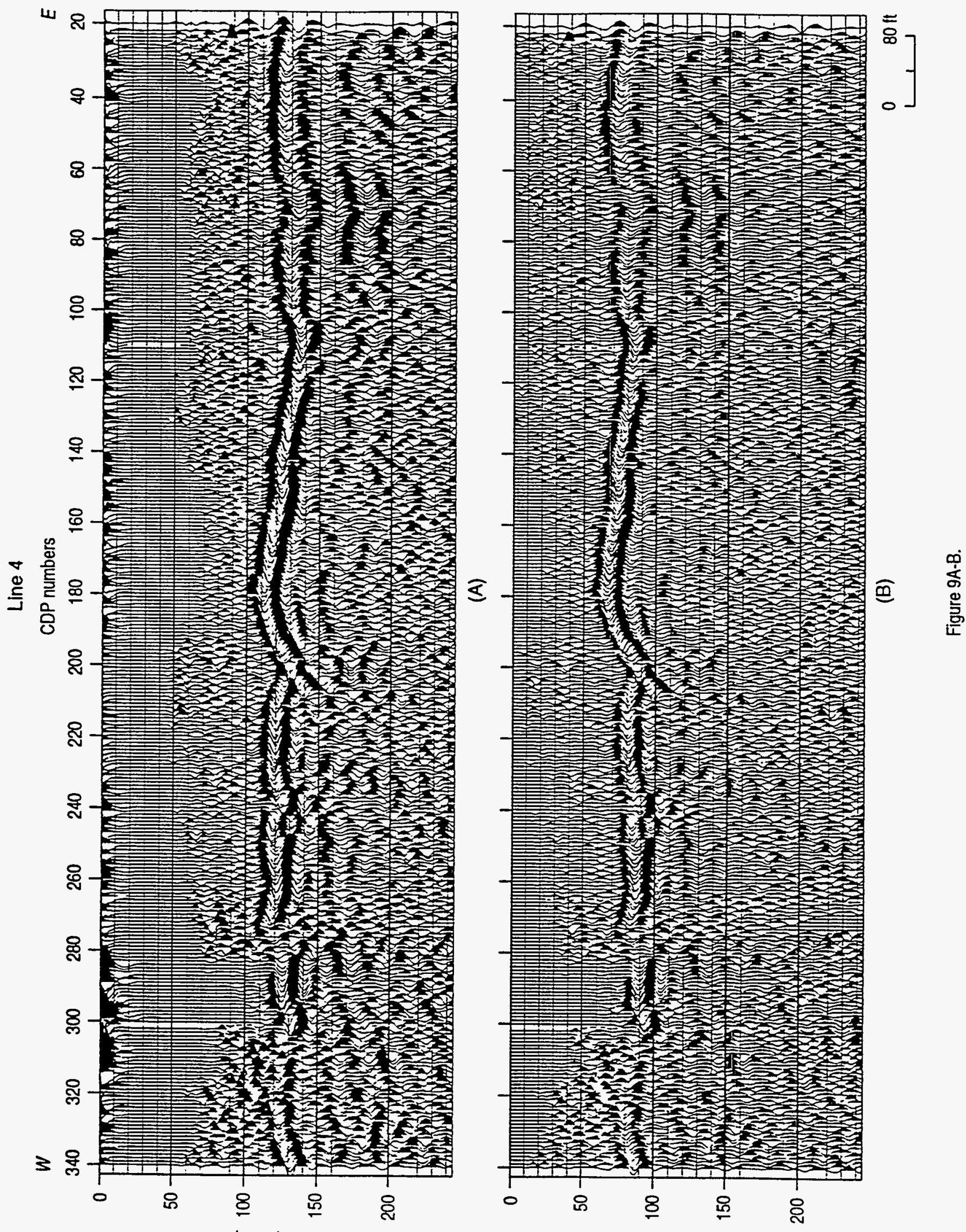

(วəsw) әш!

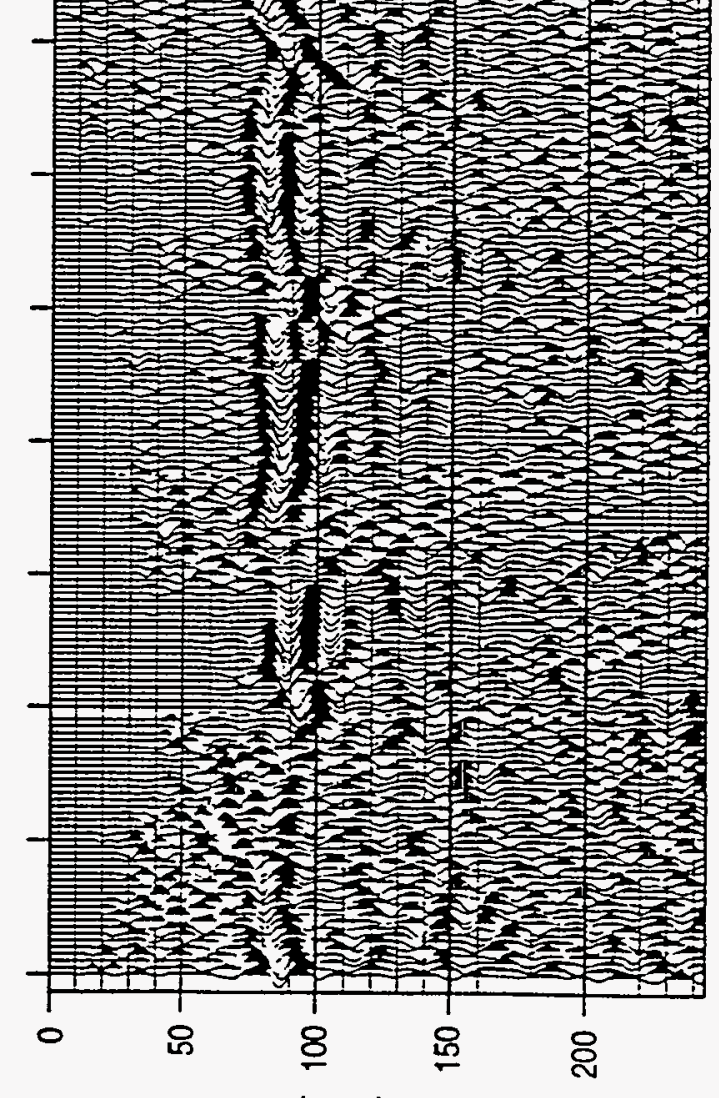

(วәsw) әш!! 


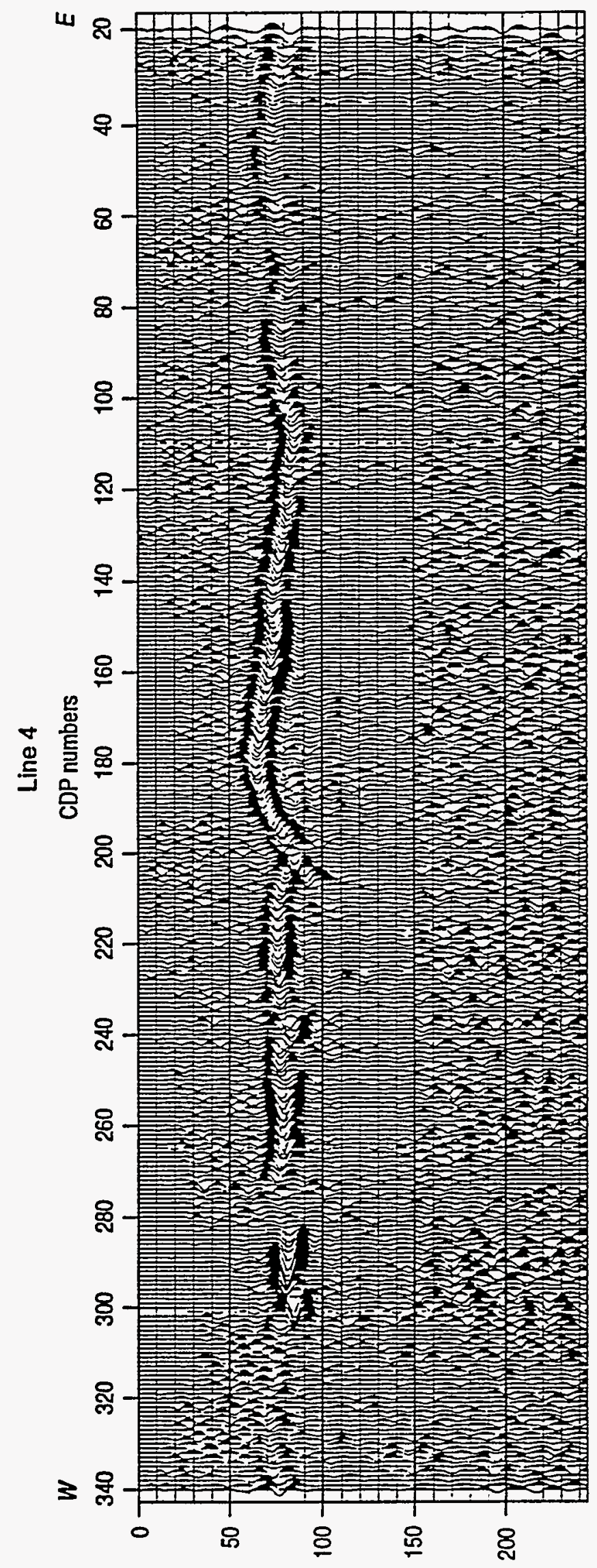

(วəsw) อแ!!

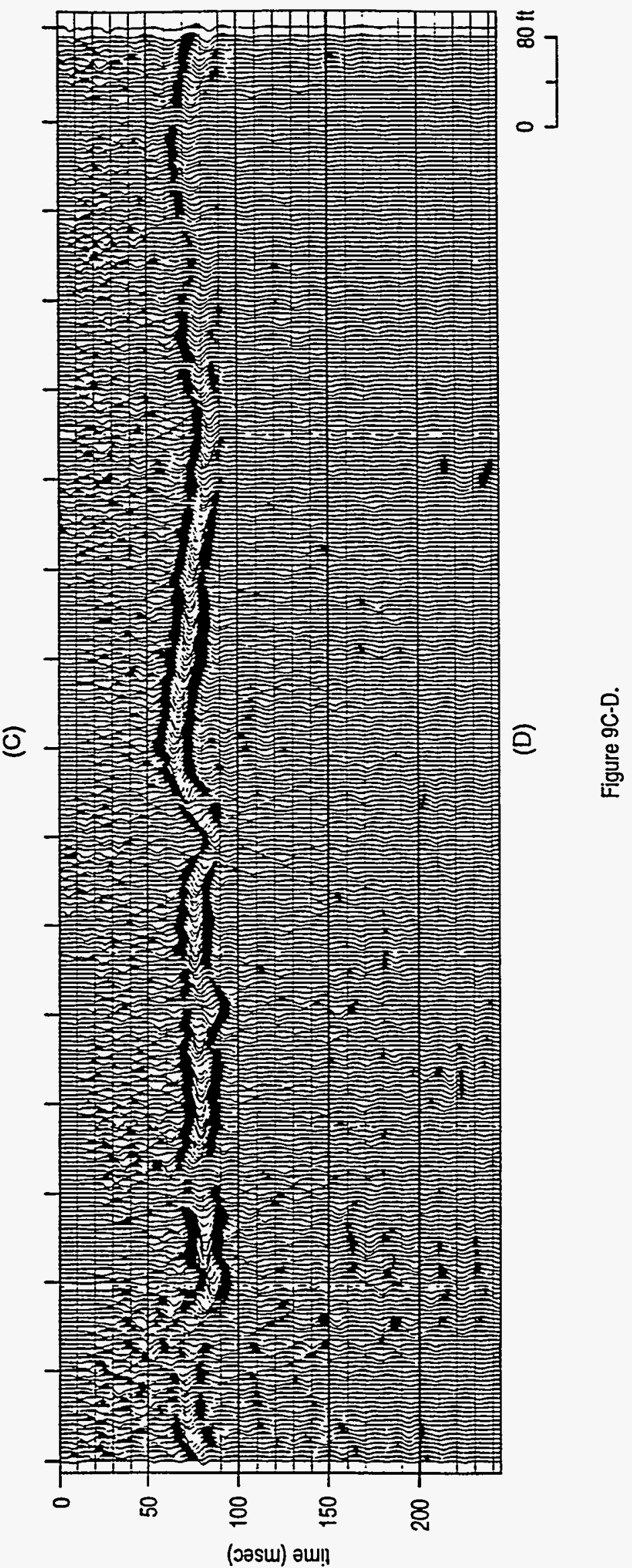

A-5-37 


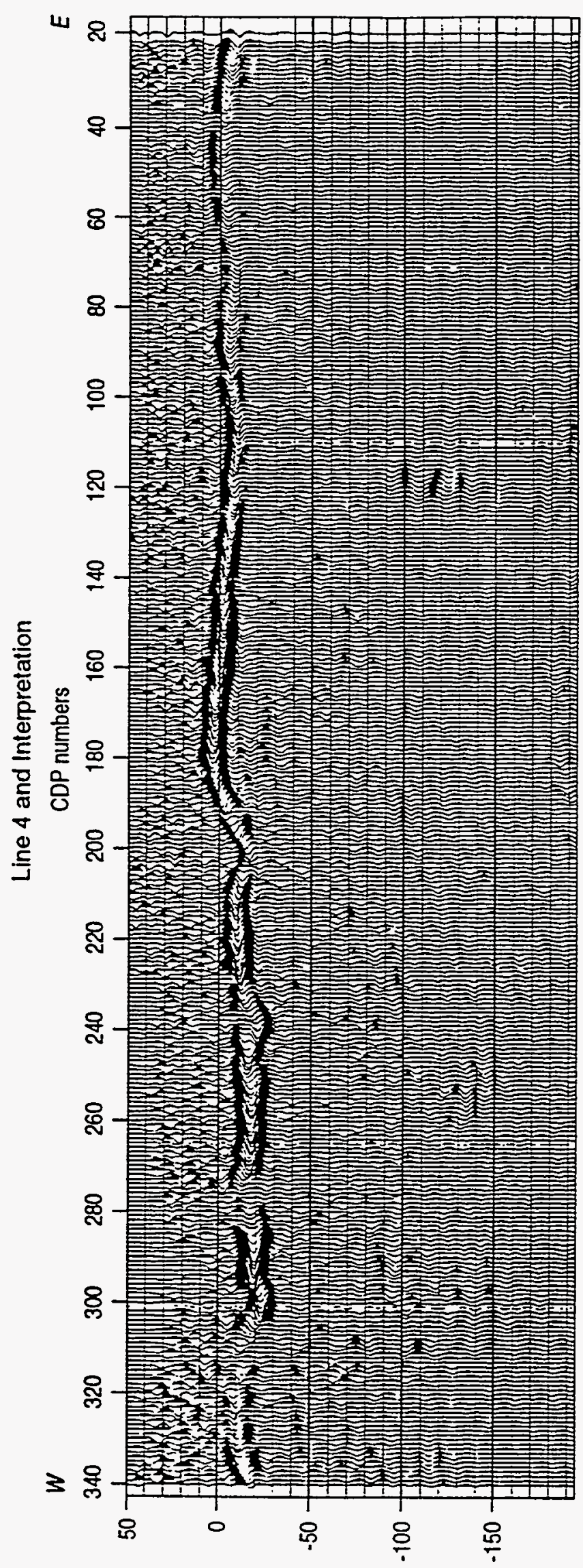

(ㄱ) บัำеләра

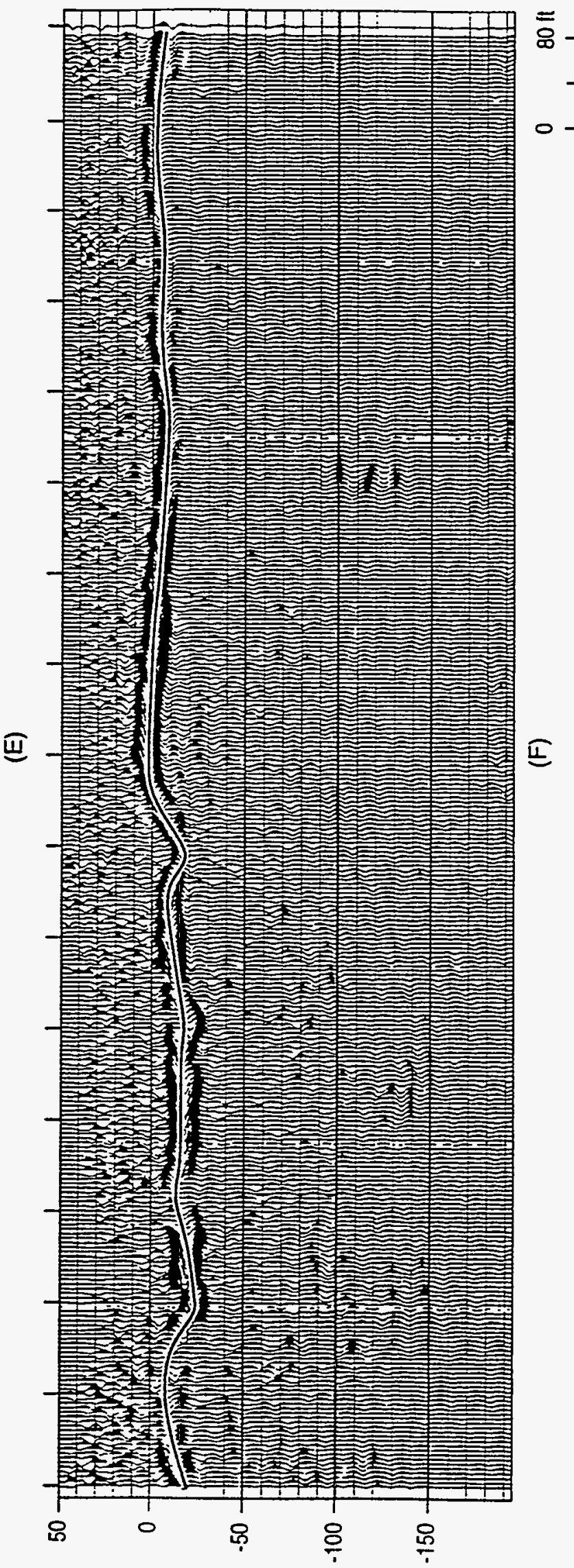

(1) บоำกวәа

눟
峁
혼 
Line 4 and Interpretation

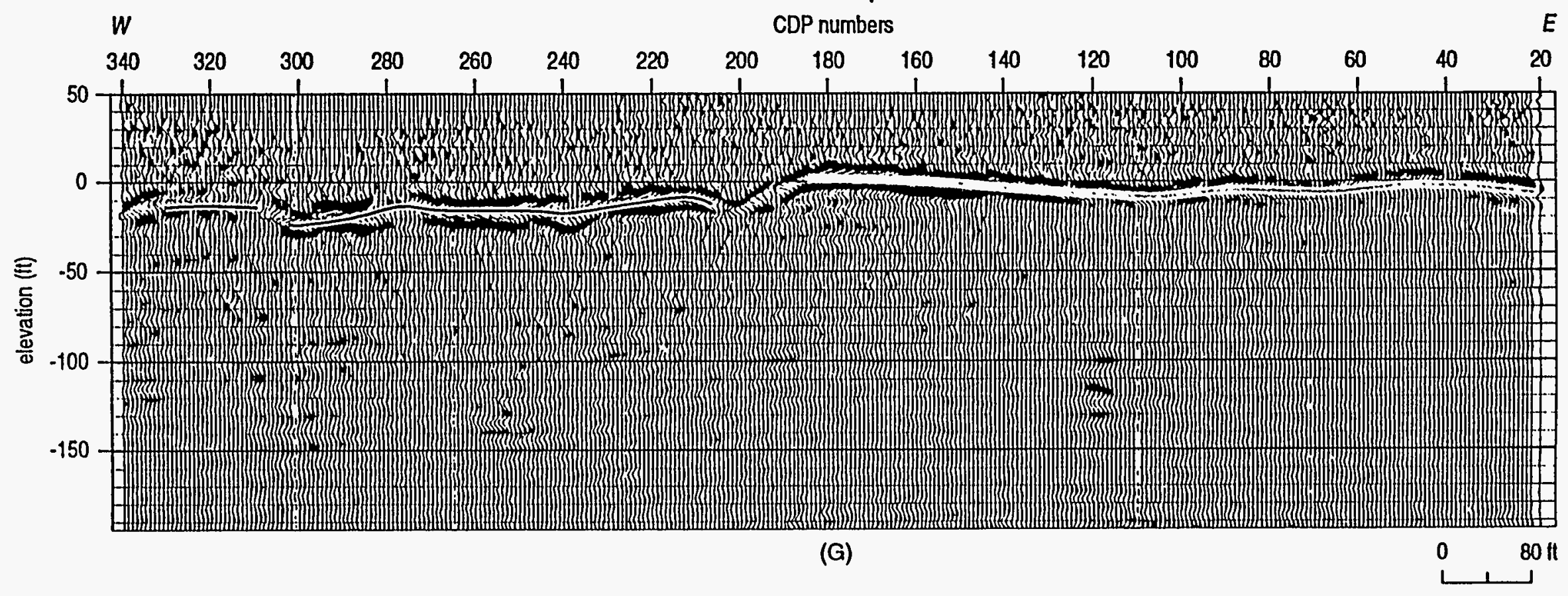

Figure 9A-G. Line 4, 24-fold, CDP slacked section. A) Elevation correcled to multiple sloping datums. B) Same CDP data as (A) elevation corrected to a single flat 48 ft sea level datum. C) Deconvolved (B). D) F-k migrated (C). E) Depth converted (D) using the stacking velocilies. F) Interpreted (E) assuming the shallowest reflection is from the same rellector across the line. G) Interpretation of $(E)$ if the shallowest reflection is discontinuous at the apparent offset. 


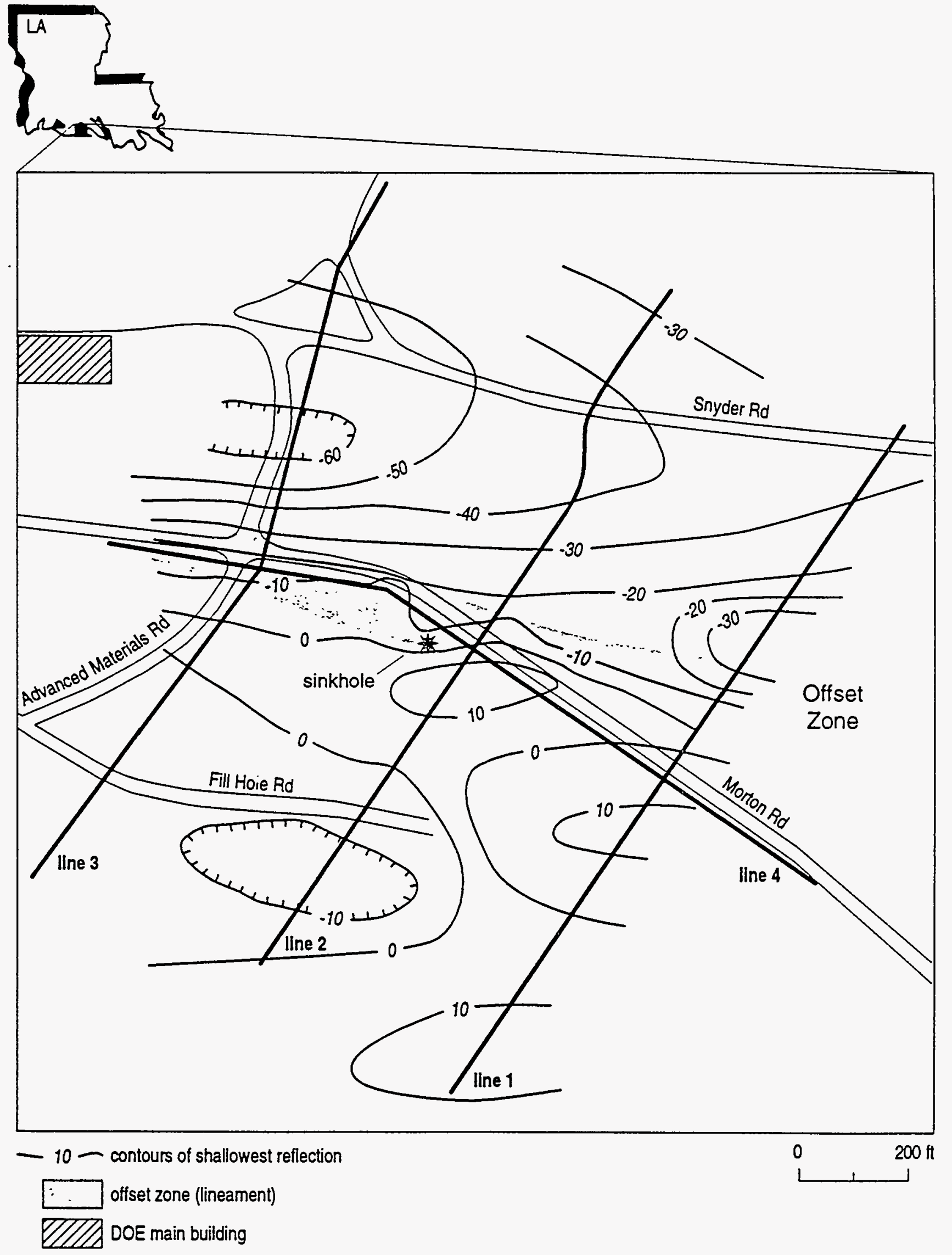

Figure 10. Linear projection of apparent offset and wavelet change on seismic lines 1,2,3, and 4 . The lineament intersects the sinkhole and the steep sided ditch on line 1 . Based on projections from mine maps, the lineament is consistent with the mine face of both the upper and lower cavities. Control points for the shallowest reflection contours are directly extracted from seismic sections $6 F$ through $9 F$. 


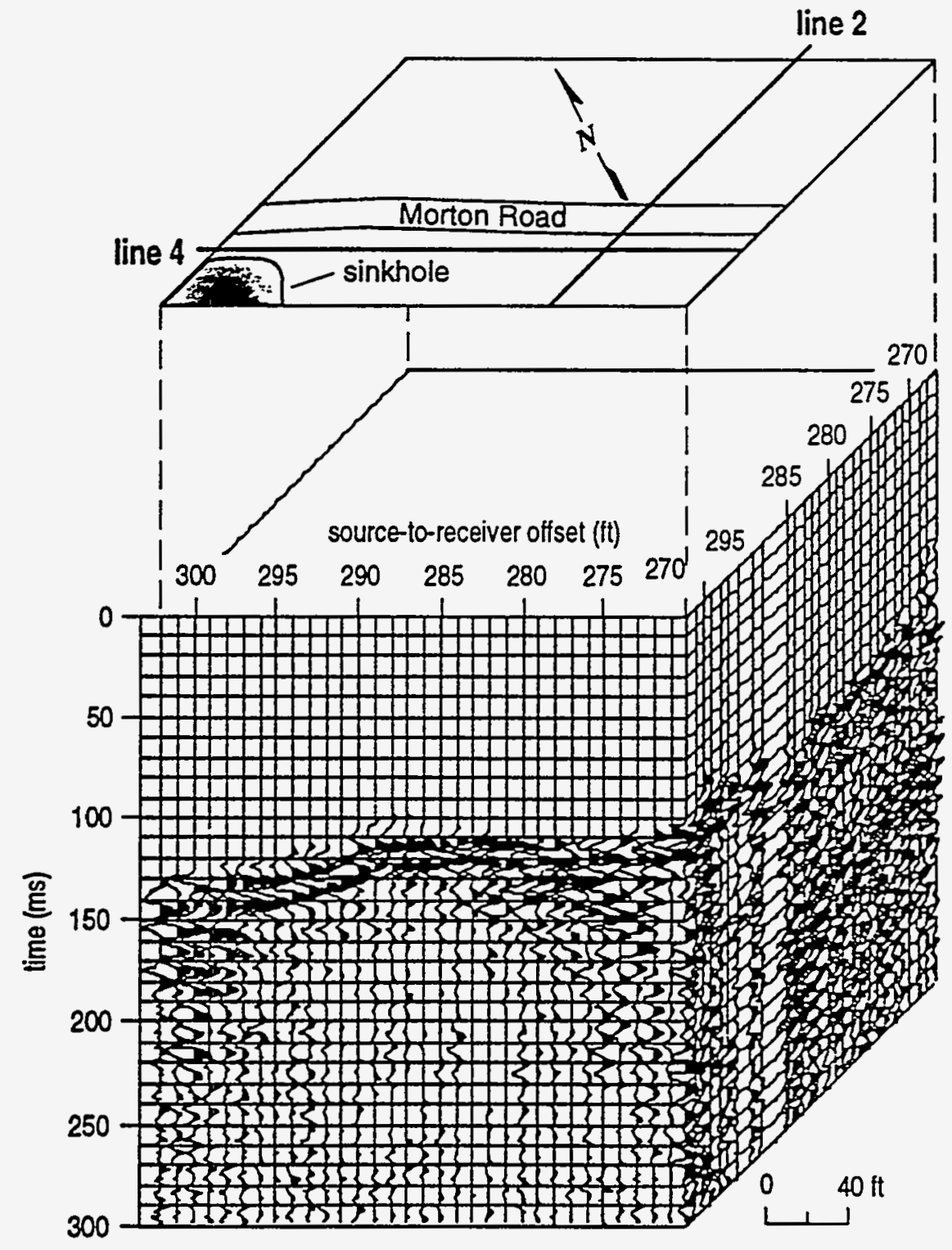

Figure 11. One-fold, 3-D volumetric seismic section with the relative location of the sinkhole and Morton Road overlain. This 3-D slice clearly traces the subsurface expression of the sinkhole. Processing parameters including velocity correction, statics, muting, and filtering were assigned based on analysis of the 2-D data in the immediate area. 


\section{APPENDIX 6}

\section{TOMOGRAPHIC STUDY}

This appendix contains two memos, dated August 29 and December 1, 1994. Please note that the text and conclusions of the Augsut 29 memo are valid, however, the December 1 memo contains 2 figures that supercede figures 2-5 in the August 29 memo. 
date: $\quad$ August 29, 1994

to: $\quad$ J. K. Linn, 6113

from: $\quad$ R.S. Harding, Jr., 6114

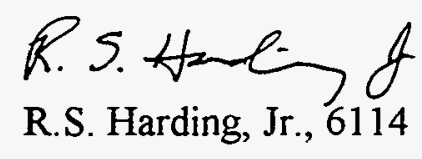

subject: $\quad$ Borehole seismic survey, Weeks Island SPR sinkhole

This letter summarizes work results to date on the borehole seismic survey conducted at the Weeks Island sinkhole site in early July 1994. Although data processing is still in progress, a number of observations can be made based on a preliminary analysis of the data.

\section{Purpose:}

The primary purpose of the borehole seismic survey was to provide crosswell seismic tomography images of the upper part of the salt in the area of the sinkhole. Of particular interest was whether this technique could assist in detecting and mapping postulated dissolution features in the salt. Because the four observation boreholes used in the survey were limited in depth penetration into the salt, tomography images could only be obtained for the upper 40 feet of the salt. Although seismic tomography is still primarily a research tool, it is emerging as a commercial technology for a variety of geotechnical, environmental and energy-related applications. A general description of the theory and practice of crosswell seismic tomography is included in a later section of this report.

Important secondary goals of the borehole seismic survey were:

(1) To identify the prominent seismic reflector imaged by the Kansas Geological Survey in a shallow high resolution surface reflection survey at Weeks Island in March of this year.

(2) To image the water table and, if possible, the top of the salt in the sinkhole area.

(3) To image postulated subsurface collapse features related to the sinkhole.

Data acquisition at the site was designed to provide raw data for crossswell seismic P-wave velocity tomograms, vertical seismic profiles (VSP), and crosswell reflection images. As of this writing, two preliminary crosswell seismic velocity tomograms of the salt and a preliminary singlewell VSP have been processed. The data acquisition and processing procedures used in generating the tomography and VSP images are described briefly below. A discussion of the interpretation of these results is also provided. The effort to process additional VSP, crosswell reflection, and surface reflection images is ongoing and is discussed under the section below on work in progress. 


\section{Procedure:}

The borehole seismic data acquisition contractor was Bolt Technology, Inc., of Houston, Texas. Bolt Technology has extensive experience providing crosswell seismic measurement services and equipment to the petroleum and geotechnical industries. Field data reduction and processing was performed by a consultant, Dr. John W. Fairborn of Well Seismic Computing Services. Dr. Fairborn, formerly of Chevron Oil Field Research Company in La Habra, California, has performed research in seismic imaging for over 30 years, with emphasis in recent years in crosswell seismic tomography. Dr. Fairborn performed data reduction and processing using a workstation-based commercial seismic processing software package (ProMax ${ }^{\mathrm{TM}}$ ), sold by Advance Geophysical Corp. of Englewood, Colorado.

\section{Crosswell data acquisition and processing:}

The raw data for crosswell seismic (P-wave) velocity tomography consist of the observed travel times of seismic waves that propagate from multiple energy source positions in one borehole, to multiple receiver positions in another borehole. In tomography data processing, the planar area between the two boreholes is divided into pixels, and the seismic $\mathrm{P}$ wave velocity in each pixel is computed iteratively from the first arrival travel time observations. Iteration is complete when the calculated travel times match the observed times to within a predetermined convergence criterion. The 2-D display of seismic velocities within the pixels is called a "tomogram". As in medical applications of tomography (CAT-scanning), the image is produced from the observations through computerized tomographic inversion. Unlike medical tomography, in crosswell seismic tomography the region to be imaged is not completely surrounded by energy sources and receivers. This condition makes image generation mathematically unstable and non-unique. Seismic travel times measured at Weeks Island were put into a tomographic inversion program (described by Aldridge and Oldenburg, Journal of Seismic Exploration, v. 2, 1993) which employs smoothing techniques to add stability to the inversion process. The smoothing results in some loss of resolution in the tomograms.

At Weeks Island, crosswell seismic data were recorded using two borehole pairs at the sinkhole site; $\mathrm{BH}-4$ to $\mathrm{BH}-3$, and $\mathrm{BH}-5$ to $\mathrm{BH}-6$ (figure 1). The imaging planes formed by the two borehole pairs intersect each other near the center of the sinkhole. The horizontal distance from $\mathrm{BH}-4$ to BH-3 is 145 feet, the distance from BH-5 to BH-6 is 150 feet. The total drilled depth of all the observation wells was 250 feet below ground surface. After casing and cementing the effective total depth of these holes was roughly 240 feet. The two receiver boreholes, BH-3 and BH-6, were initially cased with an intermediate string of $105 / 8$ " (O.D.) steel casing to about 20 feet below the top of the salt. These holes were then drilled and cased to total depth with a smaller diameter (6" I.D.) steel liner. The source boreholes, $\mathrm{BH}-4$ and $\mathrm{BH}-5$, were cased to total depth with $85 / 8^{\prime \prime}$ and 6 1/2" (O.D.) steel casing, respectively.

During the crosswell survey, recordings of seismic data were made with source and receiver depths from approximately 5 to 235 feet. The vertical interval between successive source and successive receiver positions was nominally 5 feet. Receiver coverage was increased to 2.5 foot intervals below the top of salt. A research prototype axial vibrator developed at Chevron was used as the borehole seismic source for the survey. The axial vibrator was chosen because it functions efficiently in dry (fluid-free) boreholes, and therefore does not generate tube wave noise. 
The borehole vibrator generated linearly swept frequencies from 10 to $640 \mathrm{~Hz}$. The sweep length was 6 seconds. The correlated records were .5 seconds in length. The receivers used in the survey are a Sandia-designed 5-level triaxial accelerometer package deployed on a fiber optic wireline. The receivers are manufactured by Oyo/Geospace, Inc. of Houston, Texas.

The signal-to-noise ratio of the data was generally good, in spite of considerable surface activity during the survey (figure 9). Since both the receiver and source boreholes were dry, tube waves were completely absent. Source and receiver formation coupling was usually good. However, coupling deteriorated when source and receivers occupied depths where the intermediate casing string overlapped the deeper liner in the receiver well, particularly in BH-3. The coupling difficulties in BH-3 may have some adverse impact on image quality in the BH-3/BH-4 tomogram, particularly at the salt/sediment interface.

The average center-frequency of crosswell data averaged around $250 \mathrm{Hertz}$ (figure 10). High frequencies were more prevalent and signal-to-noise ratio was better when source and receiver positions were below the water table. In picking the first arrivals, the precision (standard deviation) of the time picks is estimated at less than one millisecond. The tomography inversion was performed using only the data from below the water table.

In processing, a reference velocity model was used to stabilize the inversion. The reference model was constructed using independent sources of information about seismic velocity structure at the site, including sonic logs and a vertical velocity profile from the VSP. The reference model was a 3-layer model consisting of the vadose zone, the soil below the water table, and the salt. Velocity was constant in each of the 3 layers. In the inversion which generates the tomogram, the velocity is forced to remain equal to the reference model velocity, unless the data forces it to deviate from the reference model. Salt velocity is roughly $13,000 \mathrm{ft} . / \mathrm{sec}$. based on open hole sonic log data from several of the site boreholes. Sonic log signals were absent in the overburden. VSP travel time data taken at the site indicate the seismic $P$ wave velocity in saturated undisturbed soil at the site is approximately 6,100 to $6,500 \mathrm{ft}$./sec. It was anticipated that sufficiently large dissolution cavities in the salt, when filled with saturated soil, would produce low velocity anomalies in the otherwise uniform salt.

\section{Observations/Results}

\section{Interpretation of crosswell tomograms}

Figures 2 and 3 are the processed $\mathrm{P}$ wave velocity tomograms for the borehole pairs BH-3 and $\mathrm{BH}-4$, and $\mathrm{BH}-5$ and $\mathrm{BH}-6$, respectively. Five iterations of the inversion program were sufficient to obtain convergence and generate these images. While review of the raw data is still going on, it is not anticipated that the tomograms would change significantly from those shown here if revisions to the first arrival picks are made. These tomograms show the depth range from 170 to 230 feet below ground surface, and show only the velocity variations within the salt. Source depths from ground surface to 230 feet, and receiver depths from 90 feet (water table depth) to 230 feet were used in generating these images. Seismic $P$ wave velocities are color coded with the highest velocities in red and yellow and the lowest velocities in blue and green. 
The tomograms clearly display low velocity features in the upper 20 feet of the salt. This is a strong indication that substantial salt dissolution exists in this depth interval. A vertical line through the center of the sinkhole intersects the $\mathrm{BH}-3 / \mathrm{BH}-5$ tomogram at an interwell distance of 55 feet, and the BH-5/BH-6 tomogram at an interwell distance of 53 feet. The shallowest low velocity anomaly in the $\mathrm{BH}-5 / \mathrm{BH}-6$ tomogram intersects the top of the salt more or less directly beneath the sinkhole. In the $\mathrm{BH}-3 / \mathrm{BH}-4$ tomogram the shallowest velocity anomaly is centered about 17 feet south (toward $\mathrm{BH}-3$ ) of the sinkhole centerline. If these features correspond to dissolution cavities, it should be noted that the boundaries of the dissolution are not well resolved by this technique. A continuum of velocities is present across these anomalies, and it is difficult to relate a specific velocity to the dissolution surface (sediment/salt contact) without additional information. The anomalies may only be a good indicator of the center of the dissolution features in the imaging planes. Judgements as to the spatial limits of the postulated dissolution cavities are interpretive until verfied by drilling.

Modeling studies indicate that the spatial resolving power of crosswell seismic tomography is best when there is a broad range of incident angles made by rays as they cross the tomogram pixels. The broadest range of incident angles is typically in the mid-depth interval of the tomogram, in this case roughly from 115 feet, down to about 215 feet. Deeper in the tomogram, the resolving power is rapidly degraded. Thus the lack of prominent low velocity anomalies below 215 feet does not necessarily mean that dissolution features are absent below that depth in the imaging planes. Note that the tomogram velocities in the deeper portion of the images are substantially below salt velocity, especially in the $\mathrm{BH}-3 / \mathrm{BH}-4$ tomogram. This is a strong indication that substantial dissolution exists, but is not spatially resolved, at these depths. Dissolution occurring as vertical or near-vertical "chimney"-like features would be difficult for tomographic imaging to resolve, even if they lie within the central portion of the tomogram.

The spectral content and signal-to-noise ratio of the crosswell data at Weeks Island were easily adequate to detect the velocity variations in the salt that were imaged in the tomograms. The average center frequency of crosswell data was around $250 \mathrm{Hertz}$, and the precision (standard deviation) of the time picks was well below one millisecond. Given the relevant source-to-receiver raypath distances, and velocity reduction (roughly $27 \%$ ) present in the tomograms, we would expect travel time delays on the order of 4 milliseconds. A travel time difference of this magnitude is easily detectable with the data obtained at Weeks Island.

Figures 4 and 5 show the low velocity anomalies in map view at depths of 195 and 205 feet, respectively. The mapped (color shaded) areas enclose the low velocity portions of the anomalies at the two depth levels. A reasonable interpretation, in my opinion, is that somewhere within these areas salt is replaced by saturated soil due to dissolution and overburden collapse. Velocity values were extrapolated outside the tomographic image planes using linear kriging. Figures 4 and 5 indicate a westward shift of the deeper dissolution cavity relative to the shallower one. Some of this westward shift may result from lateral smearing of the lower anomaly on the BH-5/BH- 6 tomogram. 


\section{Vertical Seismic Profile (VSP):}

Raw data for a VSP were acquired in borehole BH- 5 by using a 20 cubic inch airgun deployed at the surface as the seismic energy source (figure 6). This seismic source provided ample energy for observing both first arrival events and reflected events. The borehole receivers were placed at 2.5 $\mathrm{ft}$. vertical interval from 5 to $230 \mathrm{ft}$. below ground surface. With this recording geometry it was possible to construct a time-depth table (figure 7) which shows the vertical seismic (one-way) travel time from ground surface for each receiver depth. This information is useful for converting surface reflection two-way times to depth.

After wavefield separation and filtering of the VSP image (figure 8), two upgoing reflected events are clearly visible. The depths of the two reflecting horizons are indicated by the intersection of the reflection event with the trajectory of first arrival travel times. The deeper of the two events originates at a depth of 190 feet, which the logs show is the top of the salt. The shallower event originates roughly from 90 to 100 feet, near the assumed depth of the water table. The VSP data give further strong evidence that the reflection imaged at Weeks Island by the Kansas Geological Survey originated at the water table.

Note that the shallow reflection is higher amplitude than the deeper reflection. This is to be expected, since reflection amplitude is greatest where there is greatest contrast in seismic velocity and bulk density. From the VSP and sonic data, it is evident that the strongest velocity contrast occurs at a depth of roughly 90 feet. Above this depth the interval velocity is around $1,667 \mathrm{ft} / \mathrm{sec}$. Below 90 feet the interval velocity increases to around $6,500 \mathrm{ft} / \mathrm{sec}$, nearly a factor of 4 . At the salt, velocity increases from 6,500 to $13,000 \mathrm{ft} / \mathrm{sec}$, or only a factor of 2 . Likewise, we would expect that bulk density would increase in passing from unsaturated to saturated soil, though there is no direct measurement to verify this. The bulk density contrast from saturated soil to salt would not be expected to be particularly large. Thus it is expected that the shallow reflection would have higher amplitude than the deeper one.

\section{Work in progress:}

VSP's were also recorded in the $\mathrm{BH}-3$ and $\mathrm{BH}-6$, and processing of these data sets is in still in progress at this time. The preliminary indication is that the data from these VSPs will support the conclusions of the BH-5 survey. Future processing will also focus on generating crosswell reflection images of the water table and top of salt. High signal-to-noise reflections from these horizons were recorded during the crosswell survey, and could provide valuable corroboration of the tomography, surface reflection, and borehole data.

\section{Conclusions:}

Crosswell tomography imaged low velocity features to a depth of about 210 feet, or about 20 feet below the top of salt. These features are interpreted to correspond to salt dissolution cavities. The two-dimensional tomography images were extrapolated in order to map the upper salt dissolution in three dimensions. These maps are interpretive in nature.

As expected, spatial resolution of target features was problematic below a depth of about 215 feet, due to the depth limitation of the observation boreholes. If possible, the way to improve 
resolving power at depth is to increase the depth of the observation boreholes. Tomogram velocities significantly lower than salt velocity are present down to the bottom of the imaging planes at 230 feet. These provide a strong indication of the presence of dissolution features within the imaging planes at least down to this depth.

The VSP in BH-5 was successful in identifying the origin of the reflection in the Kansas Geological Survey data as the water table. This information will significantly enhance efforts to interpret the reflection data as the project proceeds.

Continued processing of the crosswell, VSP, and surface reflection data taken during the Weeks Island borehole seismic survey holds the potential for improved images of the top of salt and water table in the immediate vicinity of the sinkhole.

copies:

J.T. Neal, 6113

R.G. Keefe, 6114

M.W. Scott, 6114 
Sandia National Laboratories

Weeks Island Sinkhole Crosswell Seismic Survey

July 1994
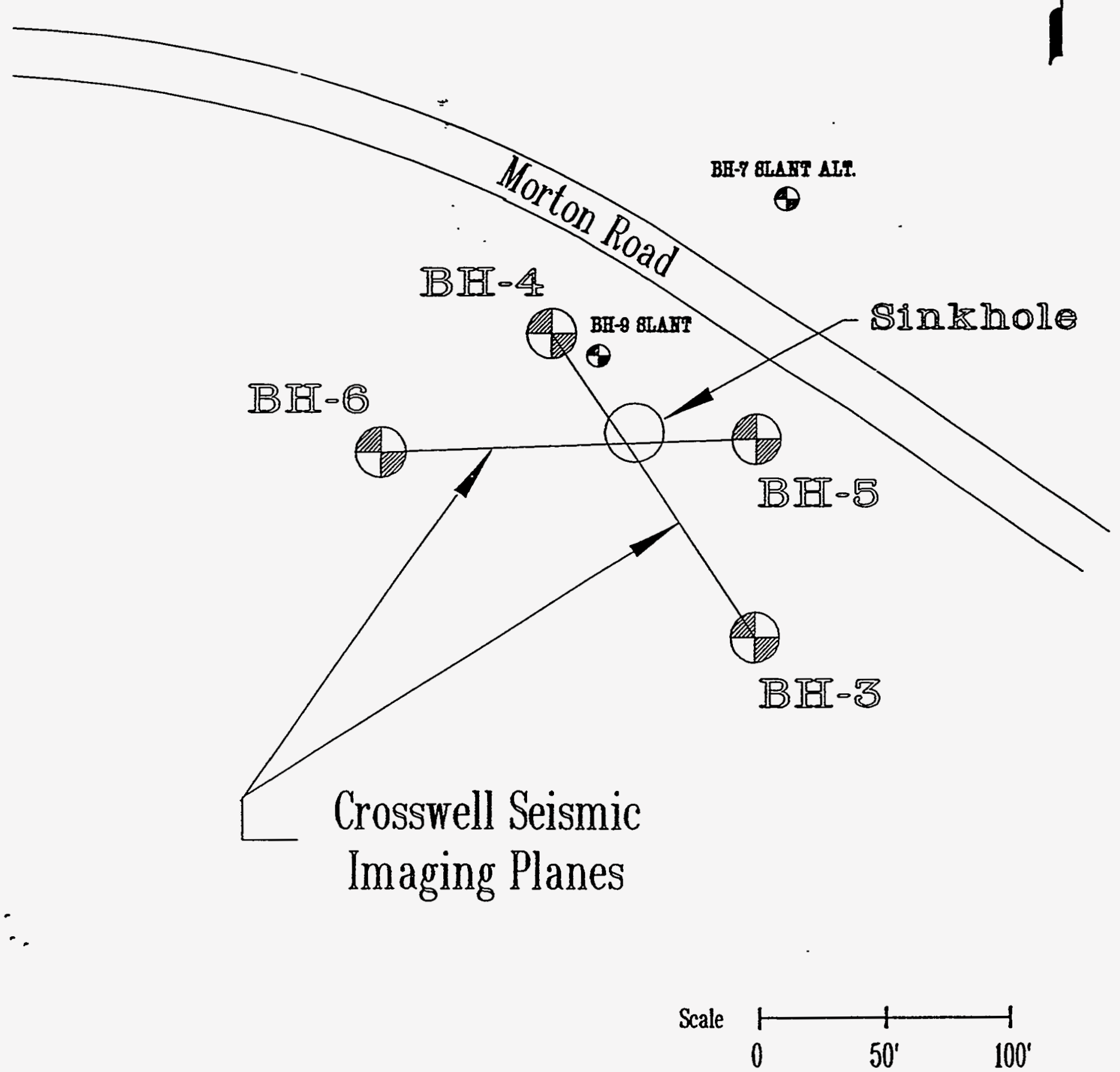

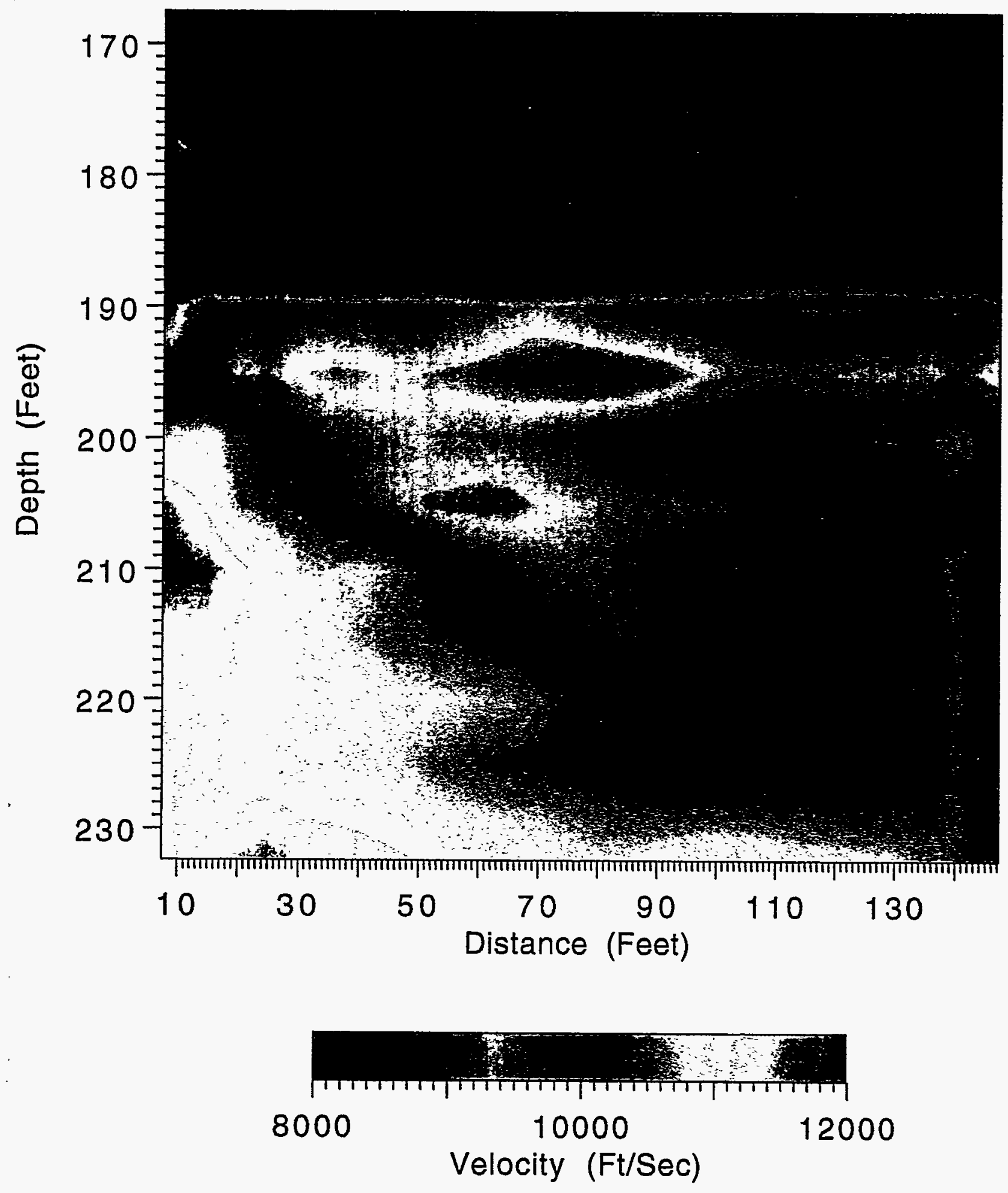

Figure 2

A-6-9 

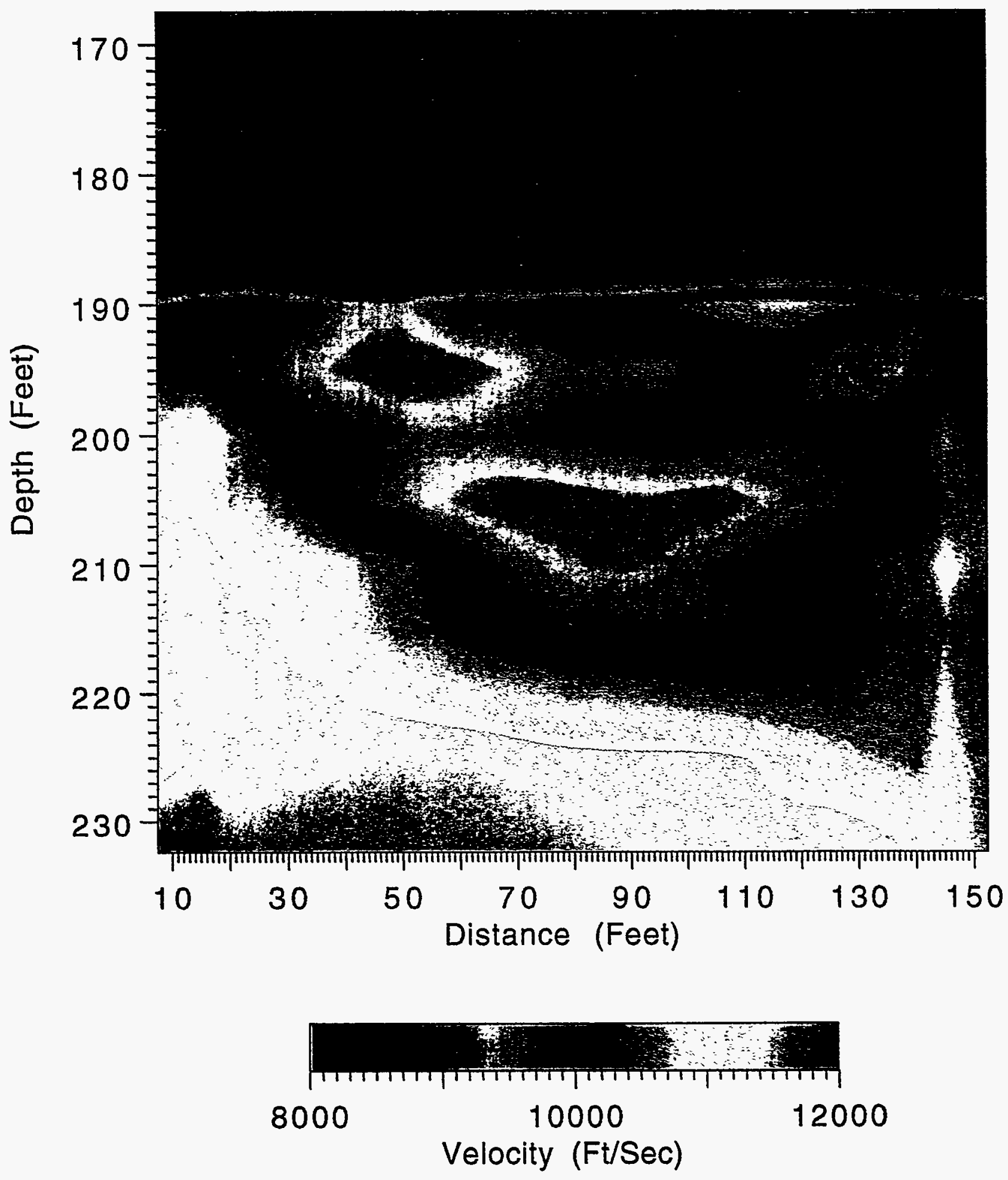

Figure 3

A-6-10 


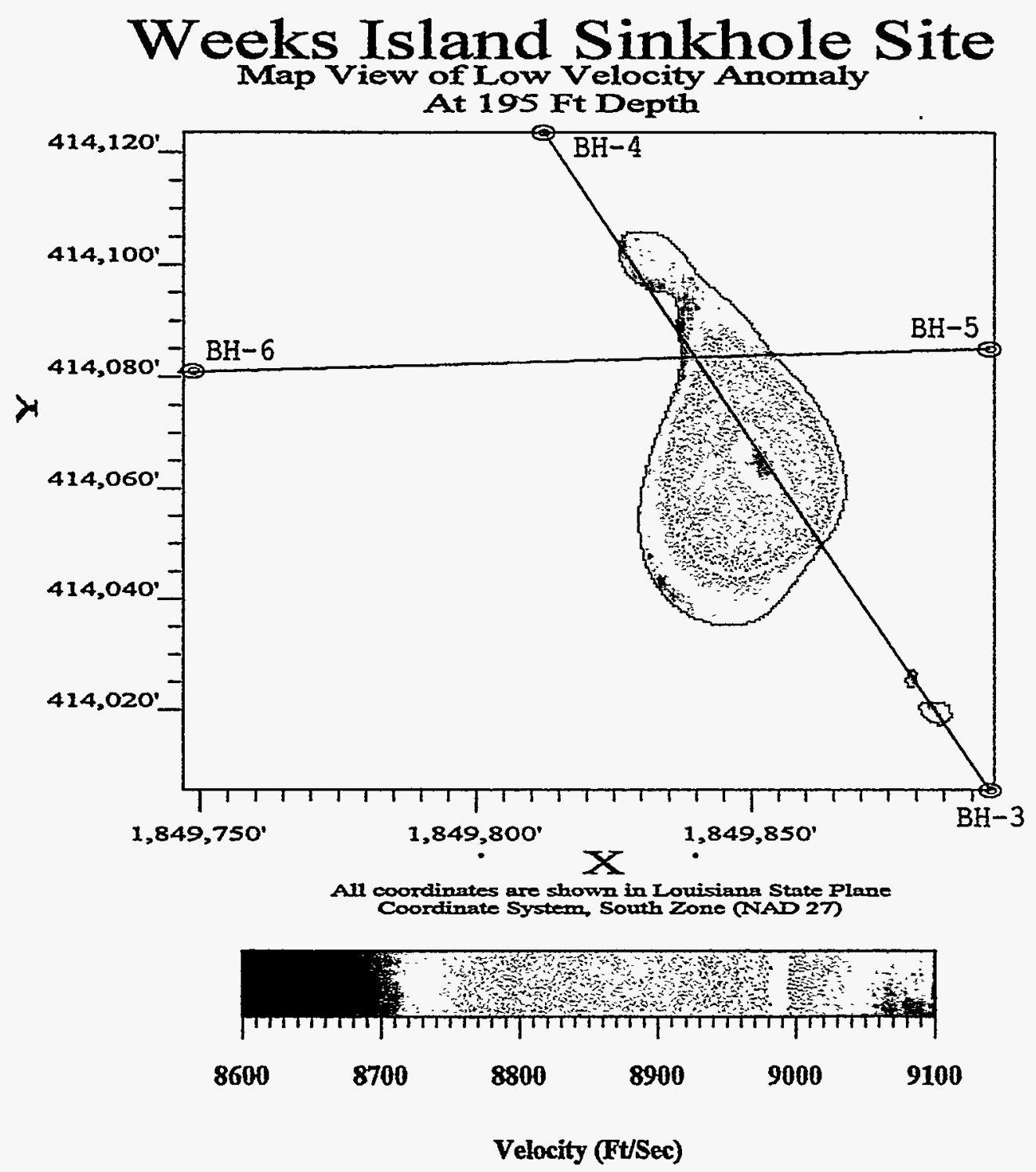

Figure 4 


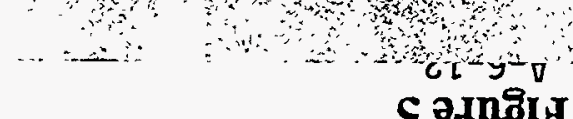

S ว.มnถి!ด

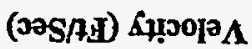
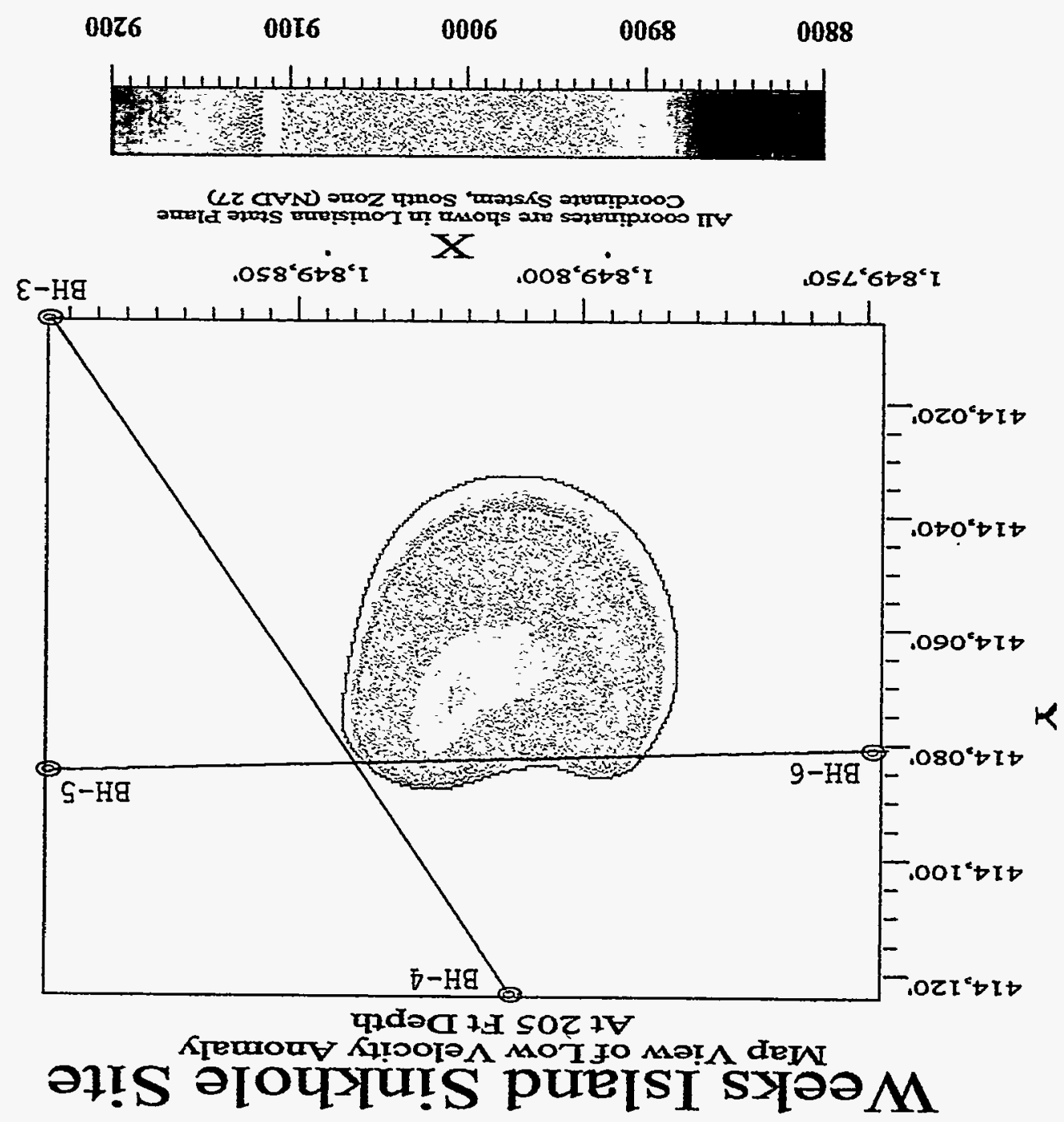


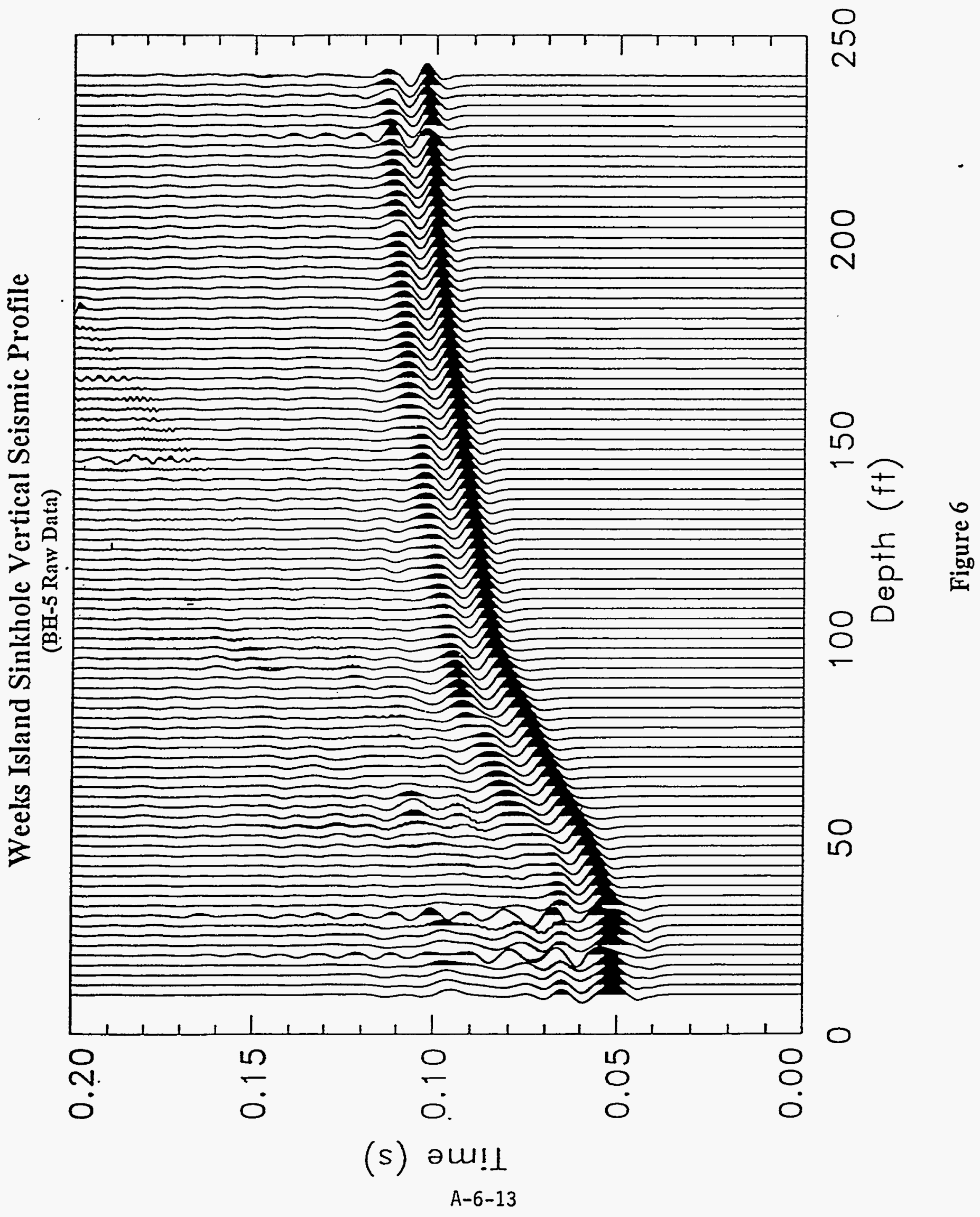




\section{BH-5 Time-depth curve}

(one-way traveltimes)

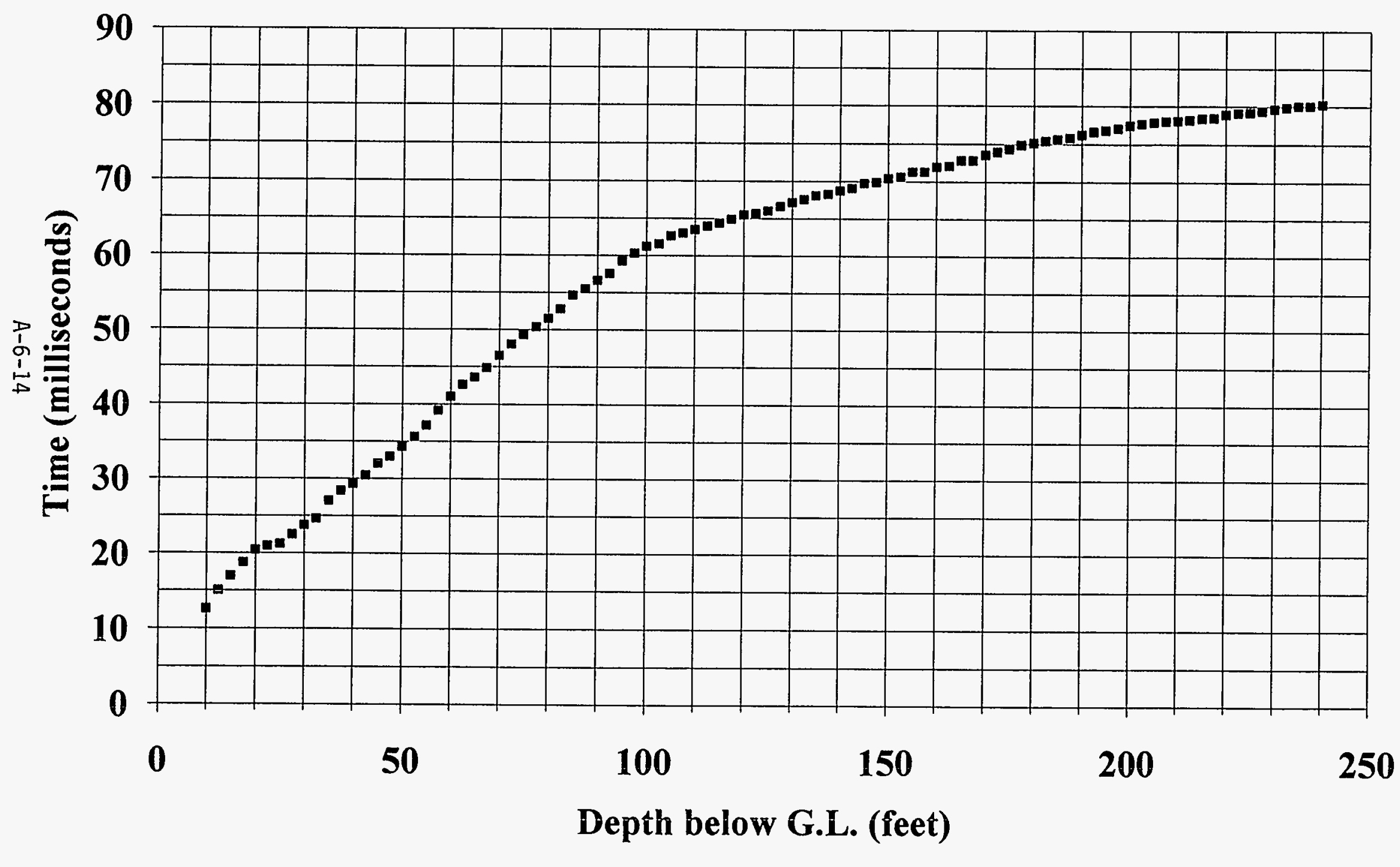




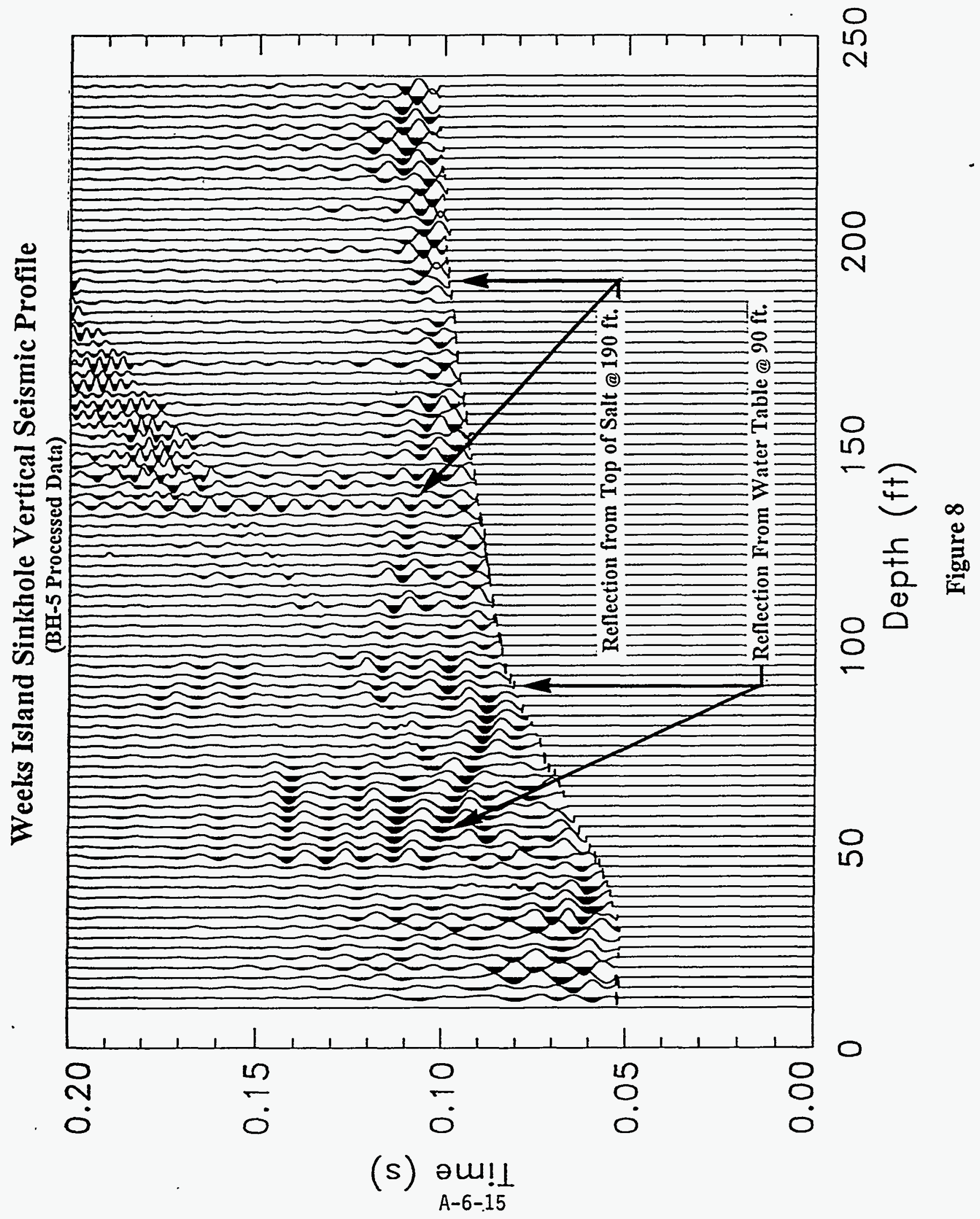




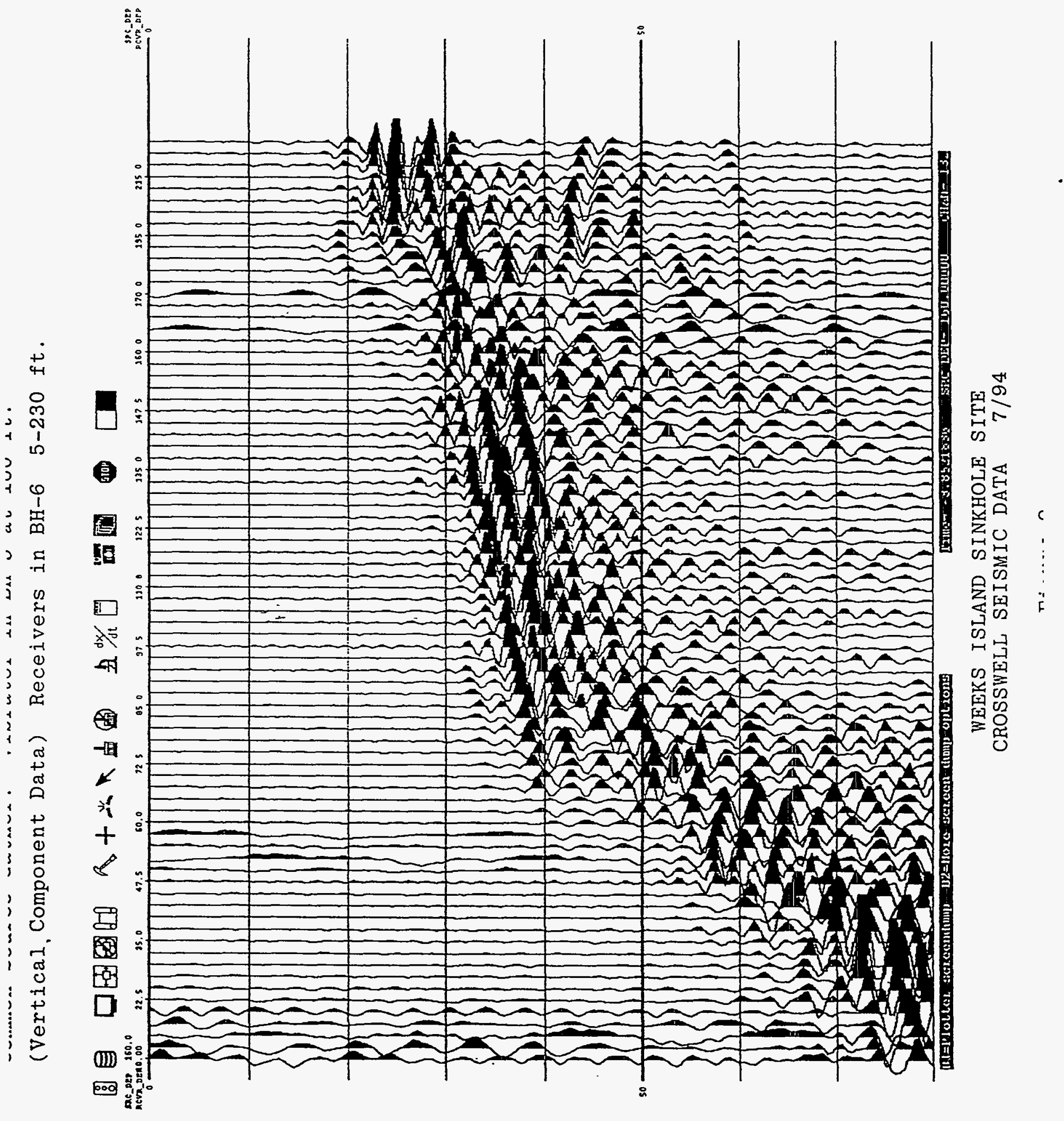




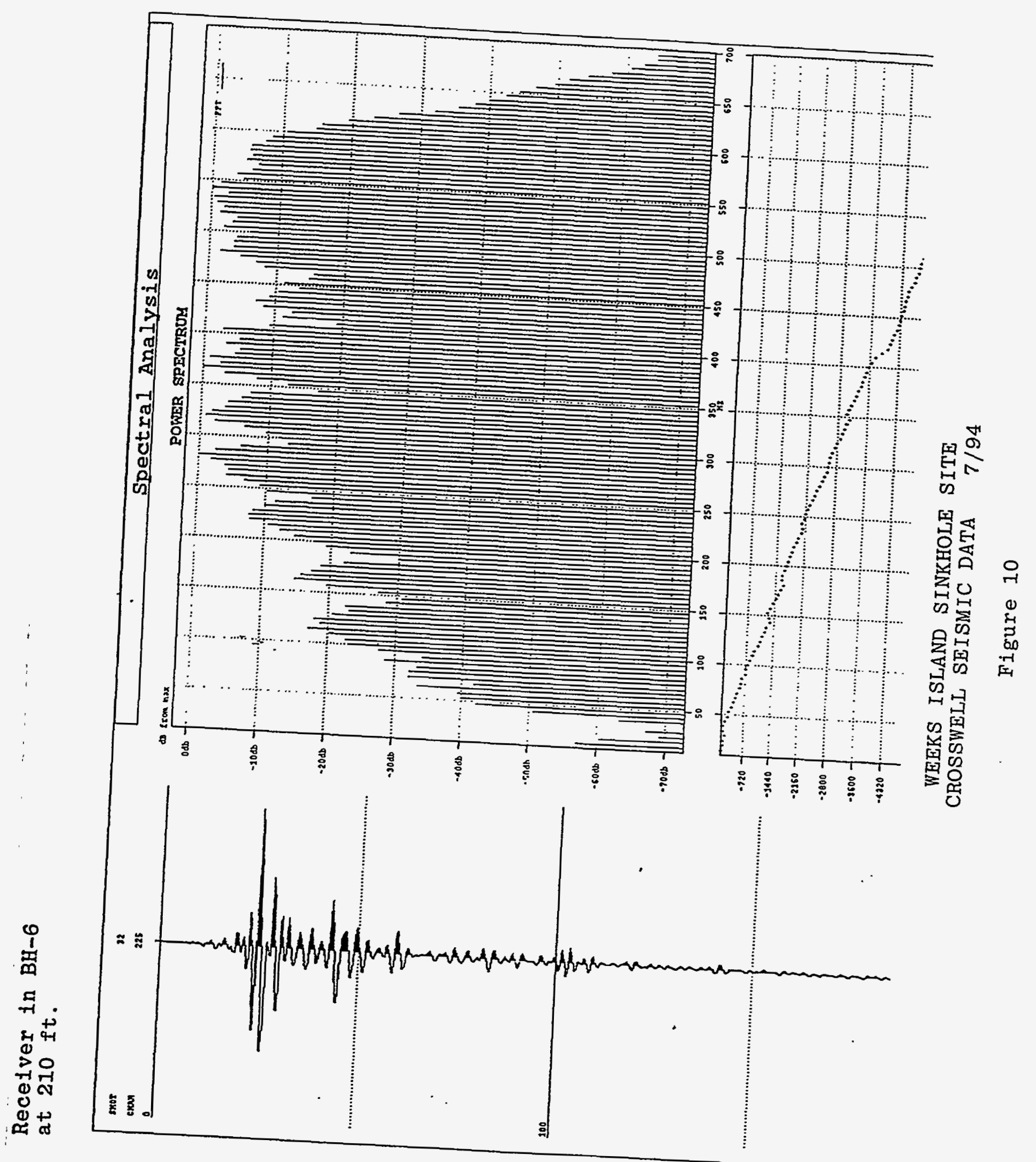


Sandia National Laboratories

Albuquerque, New Mexico 87185

date: $\quad$ December 1,1994

to: $\quad$ J.K. Linn, 6113

from: $\quad$ R.S. Harding, Jr., 6114

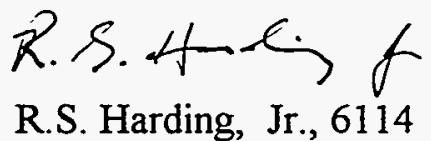

subject: $\quad$ Final P-wave velocity tomograms from Weeks Island

Please find attached two final P-wave velocity tomograms from the Weeks Island sinkhole borehole seismic survey. While differences do exist between these tomograms and earlier preliminary tomograms, the conclusions to be drawn remain essentially the same as in my August 29,1994 memo to you. Both final tomograms display low velocity anomalies in the upper portion of the salt that we believe are evidence of dissolution. Modeling indicates the resolution of these dissolution features is best in the upper 15 feet of the salt, and that the velocities inside the dissolution zones are overestimated by the tomography process. Below the upper 15 feet of salt, resolution deteriorates and there is potential for significant lateral smearing of the anomalies. Hence the lower limits of the dissolution are not well determined by tomography. These final tomograms supercede the earlier versions. Thus figures 2-5 in my August 29, 1994 memo to you should be disregarded.

The reason these tomograms differ from earlier versions is the first break picks used as input to tomographic inversion. Input for these tomograms were picks from horizontal receiver components, while earlier versions used vertical component data. It was found that, particularly for critical receiver levels within the salt, the horizontal components gave higher signal-to-noise ratio first arrival energy, often at earlier arrival times, than were evident in the vertical component data.

w/attachments

copy

M.C. Walck, Actg. Mgr. - 6114 

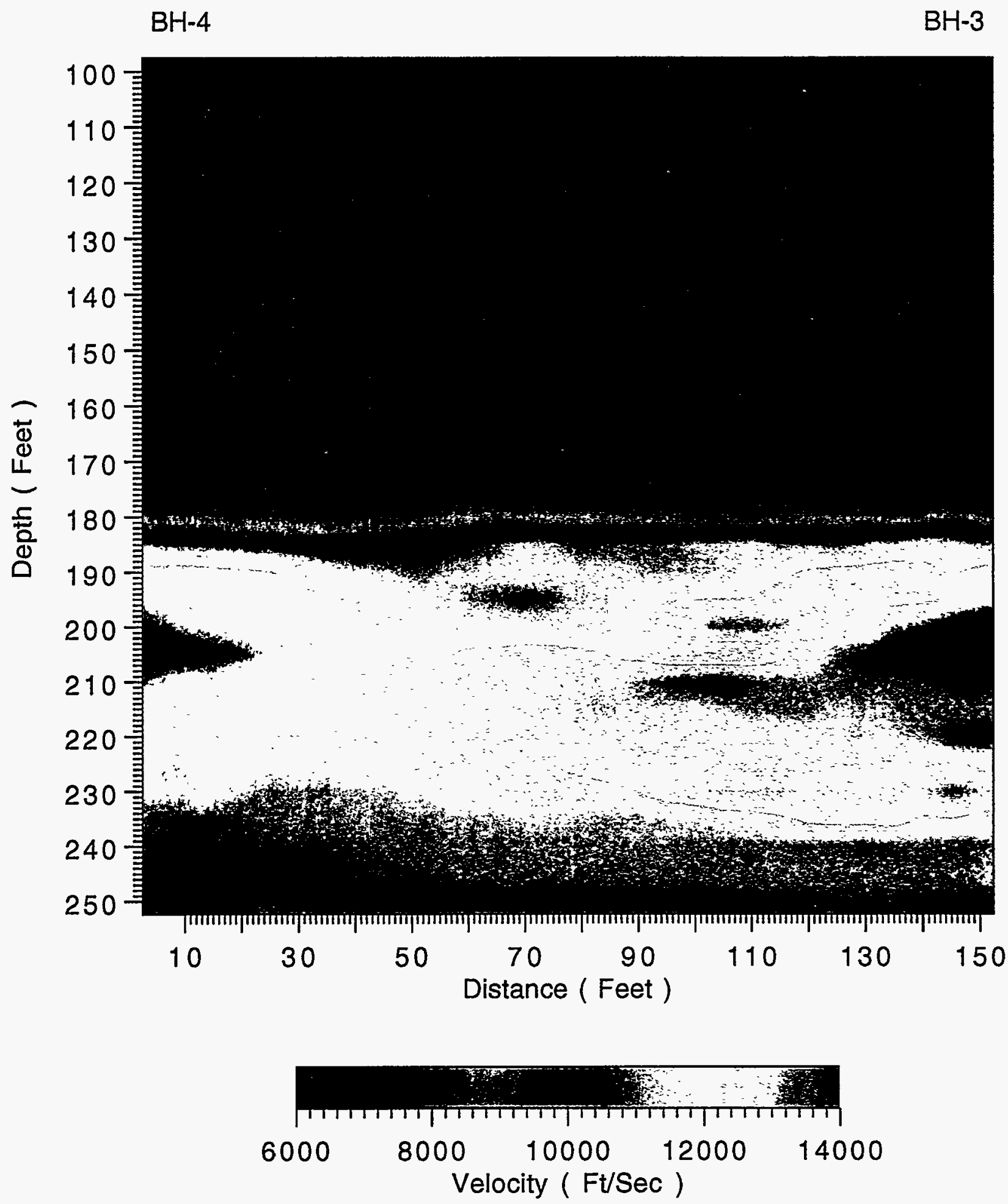

A-6-19 

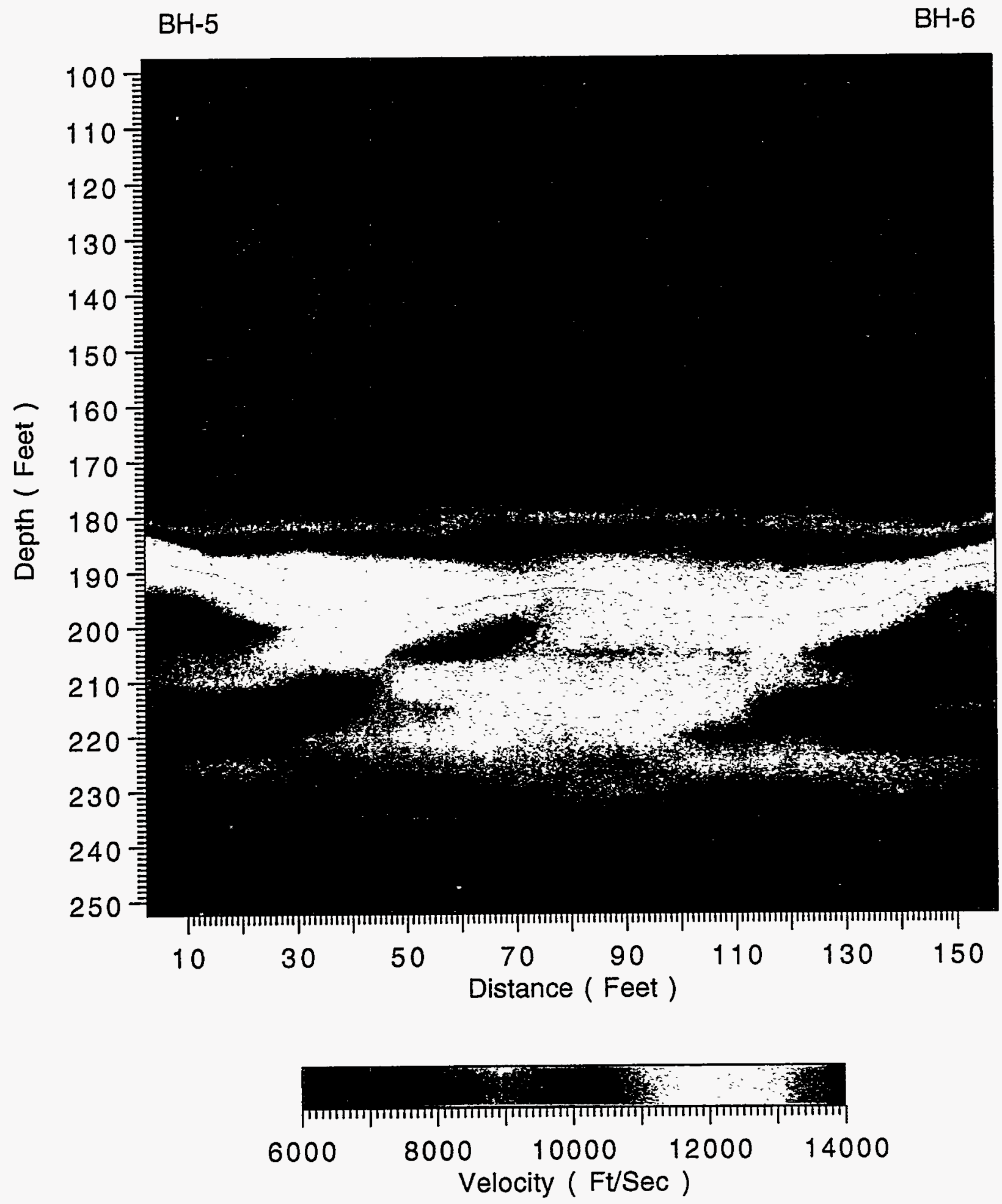


\section{APPENDIX 7}

\section{NEAR-SURFACE GAS MAPPING PROGRAM}

\section{$A-7-1$}


date: March 15, 1994

\$: Jim K. Linn, Manager Dept. 6113

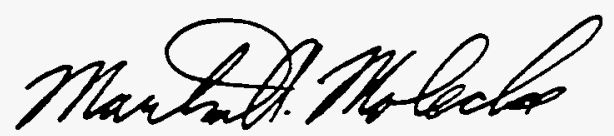

trom: Martin A. Molecke, MS 0706, Dept. 6113

844-3487

wbject: My Contribution to theWeeks Island Sinkhole Investigation Paper: Appendix on the Near-Surface Gas Mapping Program

THE NEAR-SURFACE GAS MAPPING PROGRAM AND OTHER GEOCHEMICAL TECHNIQUES FOR WEEKS ISLAND SINKHOLE DIAGNOSTIC PURPOSES

\section{Executive Summary:}

We describe and evaluate several chemical and geochemical techniques that appear to have appreciable promise for investigating the relationship of the sinkhole to the storage integrity of the Strategic Petroleum Reserve facility at Weeks Island. These evaluations are to technically supplement and enhance the parallel geophysical investigations to be conducted in the overall Weeks Island sinkhole investigation. The chemical and geochemical techniques include: 1. nearsurface gas mapping of hydrogen and hydrocarbon gases in and near the vicinity of the sinkhole; 2. subsurface gas sampling and analyses of gases from near the top of the salt dome, (a) in drilling returns, (b) below the planned vertical and slant coreholes, above the oil storage; (c) in situ gas permeability testing along the lengths of coreholes in salt; and, 3. brine isotopic analyses of samples from the bottom of the slant hole(s). Our major objective is to conduct only those techniques with the most technical and cost-effectiveness advantages and the least risks, to provide diagnostic evidence of a probable subsurface fracture zone or area of enhanced gas permeability between the Weeks Island sinkhole feature and the oil storage mine below. We summarize the advantages of each proposed technique and our recommended courses of action in a Table, in this appendix. 
Our major recommendation for a chemical, diagnostic technique is near-surface gas mapping. This procedure can analyze and map near-surface concentrations of gases associated with the crude oil stored at the site. Hydrogen would provide the primary "clear" indicator for gas leakage pathways, methane and other hydrocarbon gases, and their concentration ratios, would provide the secondary, backup information. Localized areas of high gas concentrations can be indicative of enhanced gas pathways from the stored oil to the surface via subsurface fractures or zones of higher permeability. The possibility exists that this near-surface gas mapping procedure may also be useful and applicable at other SPR sites. This supposition, of course, remains to be demonstrated. Perceived advantages, disadvantages, and preliminary details of the near-surface gas mapping program were presented to the Weeks Island Risk Abatement Strategy Group in February, 1994. Based on their favorable response, we have initiated a subcontract to conduct this work at Weeks Island within the next two months.

After evaluating potential Project advantages and disadvantages, we also recommend obtaining and analyzing subsurface gas and brine samples from the salt at the bottom of the slant hole(s). Obtained gases could provide a baseline, comparative (to the near-surface) set of gas information and a supplemental indicator of fracturing in the salt directly below the sinkhole and above the oil storage. Gas sampling and analyses as a function of time may also provide a good monitor on fracture growth. Brine isotopic analyses of a few of the samples from the bottom of the slant hole(s) would tie results to other, previous (and new samples from the fill and sump holes) brine isotopic analyses obtained at or near the Weeks Island site (Knauth, 1987; Thoms, 1989); these brine data are unique because of their source location.

Based on our evaluations, we do not advise the conduct of gas analyses from drilling returns nor from down hole, positive pressure gas permeability tests in the salt. Planned laboratory tests on salt cores obtained will probably provide more benefit to the SPR Project.

\subsection{Introduction}

Several chemical and/or geochemical techniques, primarily near-surface hydrogen and hydrocarbon gas mapping and subsurface gas and brine analyses, appear to have appreciable promise for investigating the relationship of the sinkhole to the storage integrity of the Strategic Petroleum Reserve facility at Weeks Island Our major objective is to use the techniques with the most advantages and least risks to provide diagnostic evidence of a probable subsurface fracture zone or area of enhanced gas permeability between the Weeks Island sinkhole feature and the oil storage mine below. Measured gas data to be obtained could support the premise that such a fracture or higher permeability zone exists at present, that such zones may or may not be significant, or possibly that the site requires further monitoring to evaluate developing data trends. The chemical and geochemical evaluations described herein will supplement and enhance the parallel geophysical investigations to be conducted in the vicinity of the sinkhole, i.e., seismic studies, vertical and slant corings, salt core laboratory evaluations, and cross-borehole tomography.

Several chemical and/or geochemical techniques have been investigated for conduct at Weeks Island. These techniques are all technically feasible and defensible, and have been used successfully in related applications at other sites in Louisiana, Mississippi, and elsewhere (Jones and Drozd, 1983; Autin, 1984; Knauth, 1987; Overton, LSU, personal communication, 1994). Background technical information and details for each technique will be provided in the following sections. In this section, we summarize the major benefits for each technique, describe 
advantages or disadvantages for each, and present our proposed course of action for the SPR Project. Table 1. summarizes all techniques discussed and their merits.

\begin{tabular}{|c|c|c|}
\hline Technique & Advantages / \{Disadvantages\} & Recommendation \\
\hline $\begin{array}{c}\text { Near-Surface } \\
\text { Gas Mapping of }\left[\mathrm{H}_{2}\right] \\
\&\left[\mathrm{CH}_{4} / \text { Hydrocarbons }\right]\end{array}$ & $\begin{array}{l}\mathrm{H}_{2} \text { oil-source specific, primary leakage path indicator. } \\
\mathrm{CH}_{4} \text { /hydrocarbon ratios oil \& gas pathway indicator. } \\
\text { Procedure,equipment, personnel available \& relatively in- } \\
\text { expensive. \{Data may be inconclusive.\} }\end{array}$ & $\begin{array}{l}\text { Conduct ASAP } \\
\text { (contract in } \\
\text { process) }\end{array}$ \\
\hline $\begin{array}{l}\text { Subsurface Gas } \\
\text { Analyses: } 2 \text {. in retums } \\
\text { b. downhole } \\
\text { c. salt permeability }\end{array}$ & $\begin{array}{l}\text { 2. \& b. Comparative gas baseline to near-surface \& from } \\
\text { oil. Slant downhole gas most valuable, \& as F(time). } \\
\text { \{Drilling returns may be lost. Additional expense \& com- } \\
\text { plexity.\} c. In situ permeability measurements, fracture } \\
\text { finder during coring. \{lncreased core time, expense. man- } \\
\text { power. Duplicates laboratory salt core measurements.\} }\end{array}$ & $\begin{array}{l}\text { a. Don't conduct. } \\
\text { b. Conduct only in } \\
\text { slant hole, \& as } \\
\text { F(time). } \\
\text { c. Don't conduct; } \\
\text { secondary. }\end{array}$ \\
\hline $\begin{array}{l}\text { Brine Isotopic } \\
\text { Analyses }\end{array}$ & $\begin{array}{l}\text { Helps date brine (mixture) in salt. Supplements existing } \\
\text { brine analyses at Weeks Island. \{Minor expense. }\end{array}$ & $\begin{array}{l}\text { Obtain, analyze a } \\
\text { few samples. }\end{array}$ \\
\hline
\end{tabular}

1. Near-Surface Gas Mapping: The major chemical, diagnostic procedure planned for use at Weeks Island is a gas detection technique. This technique can analyze and map nearsurface concentrations of hydrogen and concentrations and ratios of light hydrocarbon gases, all associated with the crude oil stored at the site. Localized areas of high gas concentrations, with the appropriate interpretations and limitations, could be indicative of enhanced gas pathways from the stored oil to the surface via subsurface fractures or zones of higher permeability. These would be zones of concern for site integrity, possibly requiring SPR Project remediation measures.

Hydrogen gas originates in the oil and is not generated by other significant sources; it can serve as a specific indicator for gas leakage pathways. Hydrocarbon gases, particularly methane, can originate in the oil but also can be generated by near-surface microbial degradation reactions. As such, methane detection, by itself, does not provide a clear indicator of the gas source. The use of the near-surface gas mapping procedure at Weeks Island, with all specified gases, shows significant promise for success. Advantages for this technique include: a low overall cost for conduct (fielding, analyses, reporting), estimated at about \$10,000; a relatively brief period needed for conduct, about 6 days of field time; the availability of knowledgeable, experienced personnel and portable equipment to conduct this program; and, a minimal impact on other site operations from the conduct of this program. The only perceived disadvantage is that the resultant data obtained at Weeks Island may prove to be inconclusive. The perceived advantages, disadvantages, and preliminary details of the near-surface gas mapping program were presented to the Weeks lsland Risk Abatement Strategy Group in February, 1994. Based on the favorable response of this group, we have initiated a subcontract to conduct this work at Weeks Island within the next two months.

2. Subsurface Gas Analyses: Subsurface gases similar to those obtained in the nearsurface could also be quantified. These gases can be sampled from (a) "mud logging" drilling retums, if obtained, during vertical and slant hole corings, (b) downhole gas sampling in the same coreholes obtained during the coring process for selected regions in the bare salt and/or 
after the cross-borehole tomography, below the cased length(s), and as a function of time. These gas data could provide a baseline, comparative set of gas information, nearer to the stored oil. These subsurface gas analyses are, of course, dependent on the conduct of downhole coring for geophysical testing. Gas samples obtained at the open end of the slant corehole in salt could be directly compared to the near-surface gas composition data and could be a supplemental indicator of fracturing in the salt directly below the sinkhole and above the oil storage. Gas sampling and analyses in the slant hole as a function of time, e.g., several times within the next 6 months or longer, may provide a good monitor on fracture growth. Disadvantages to downhole gas sampling include expenses associated with collecting and analyzing the samples. Also, most of the sample data (except for the slant hole data) will be difficult to interpret in relationship to the sinkhole.

In addition, (c) positive-pressure borehole (drill stem) tests could be conducted to measure the in situ permeability of competent dome salt above the oil storage. Permeability to gas could be measured over multiple lengths of the salt while the coring was being conducted. The predominant goal for these measurements would be to locate significant fracture zones in the salt. The major advantage for this technique is that in situ salt permeabilities would be measured, not the permeabilities of stress-relieved salt cores in the laboratory. However, the disadvantages for these drill stem tests are significant. Significant additional time (plus procedural complexity and expense) would need to be added to the coring process, to accommodate multiple permeability measurements. Downhole packers would need to be obtained and used. Positive-pressure testing in the coreholes also entails a small risk of increasing the extent of fracturing in the salt; this is not desirable. In addition, downhole permeability information may be seen as duplicative of similar information obtained from planned laboratory analyses of individual salt core segments. We consider that the disadvantages for this technique significantly outweigh the advantages. We do not recommend that downhole, positive-pressure (drill stem) tests be conducted.

3. Brine Isotopic Analyses: If brine samples are obtained during the downhole coring procedures, then appropriate brine hydrogen and oxygen isotopic ratios should be analyzed, to help date the brine (mixtures). Brine samples should be obtained below the cased length of the vertical and slant coreholes, in the salt near the top of the dome. Similar to downhole gas analyses, the brine samples from the bottom of the slant hole are probably of most value. Advantages to the conduct of brine isotopic analyses are: to tie results to other, previous brine isotopic analyses obtained at or near the Weeks Island site (Knauth, 1987; Thoms, 1989); these brine data are unique because of their location and source; and, the overall cost to the SPR Project (described later) is small. Disadvantages include: a minor increase in difficulty during coring, to obtain these samples; and, isotopic analysis data are of a supplemental nature, they cannot be used to tie the sinkhole to the stored oil directly. The value of the data outweighs the disadvantages. A limited number of downhole brine samples in the salt should be obtained and isotopically analyzed.

\subsection{Near-Surface Gas Mapping}

\subsection{Overview}

Multiple field studies (Jones and Drozd, 1983) have demonstrated the applicability of geochemical prospecting for gas and oil deposits by mapping the near-surface concentrations of hydrocarbon gases and hydrogen, as quantified by gas chromatography. By using the compositions and ratios of the light hydrocarbon gases methane and propane, and to a lesser extent ethane 
and butane, one may predict whether gas or oil is more likely to be discovered. Methane concentrations at the near-surface are expected to be in the ppm range, the other hydrocarbons will probably be in the ppb range (Jones and Drozd, 1983). The hydrocarbon gas ratios (to methane), or "signature," can help discriminate between the petrogenic source (e.g., Weeks Island SPR crude vs. south Louisiana sweet crude, or degraded surface petroleum contaminants) or biogenic sources of gas (e.g., methane from microbially degraded vegetation or from old septic tank contamination at the former Weeks Island housing area, very near the sinkhole location). Hydrocarbon gas ratios measured at a depth of 13 feet (Jones and Drozd, 1983) closely matched similar ratios from the underlying (natural) crude oil reservoir, implying that the major gas migration to the near-surface must be by faults and fractures rather than by diffusion. If diffusion had been the dominant mechanism, a chromatographic, filtering effect for the gas compositions migrating through the earth (changing their ratios) would have been noticeable. However, some interpretative dificulties will still remain from (only) the methane and other hydrocarbon gas data; a "clear" mapping interpretation at Weeks Island may or may not be possible from these data because of expected significant sources of surface contaminant gases.

Near-surface hydrogen (concentration) mapping should help resolve this difficulty. Hydrogen has been related directly to hydrocarbon anomalies, as a direct petroleum indicator (Jones and Drozd, 1983), with field-measured, near-surface concentrations ranging from about one ppm up to hundreds of ppm. Overton (Louisiana State University, LSU, Institute of Environmental Studies, personal communication, 1994) stated that hydrogen is generated from the long-term reaction or conversion of long-chain aliphatic hydrocarbons in oil to aromatic organic compounds. Overton and coworkers at LSU have used the near-surface hydrogen gas "sniffing" technique to successfully prospect for petroleum deposits in Mississippi and Louisiana. They have mapped suspected oil-bearing vicinities with a portable gas chromatograph apparatus (to be described) and found areas where the detected hydrogen concentration rose from about a 1 to $2 \mathrm{ppm}$ background level to areas with 2 to $3 \times 10^{2} \mathrm{ppm}$, with local "hot spots" up to $10^{4} \mathrm{ppm}$. A drilling rig was positioned over the region of highest concentration and struck oil at approximately $6,000 \mathrm{ft}$. It is still currently an unknown whether hydrogen and hydrocarbon gases would still be detectable from Weeks Island SPR crude, oil that had been previously brought to the surface, transported through pipelines, depressurized and possibly degassed, then kept in storage. At our request, LSU has used their gas chromatographic apparatus on a crude oil sample (in Baton Rouge) three weeks after it was taken from a production well. Hydrogen and methane were found in high concentrations, both greater than $1000 \mathrm{ppm}$.

It is our supposition that the near-surface gas mapping technique, as used successfully in limited applications for oil exploration, can be readily adapted for use as a diagnostic tool for mapping the surface vicinity in and around the Weeks Island sinkhole. Gases from the SPR stored oil would presumably percolate to the surface through potential fractures or high permeability zones, either due to the high volatility of the light gases, by being driven by the slight gas overpressure (several psi) in the storage mine, or by being displaced outward by brine inflow into the oil storage area. Our expected result is that the measured gas concentrations can provide some quantitative data on both the extent and locations of any enhanced migration pathway from the oil stored in the mine up to the surface. The possibility exists that this near-surface gas mapping procedure may be useful and applicable at other SPR sites, as a leakage path detector. This supposition, of course, remains to be demonstrated.

We have initiated a test program to measure and map the near-surface concentrations of both hydrogen and the light hydrocarbon gases (including ratios) at Weeks Island; details are described below. Hydrogen would provide the primary "clear" indicator for the gas leakage pathways, methane and other hydrocarbon gases would provide the secondary, backup information. 
Hydrogen, being of very low molecular weight, can be expected to migrate upward faster than any of the hydrocarbon gases and has the significant benefit of being specific to its petrogenic origin. Mapped hydrogen concentrations should be relatively simple to interpret since hydrogen is not produced by microbial (biogenic) reactions, as is methane. Measured methane concentrations will include significant contributions from the oil and near-surface contaminants and surface reactions. Interpretations based only on hydrocarbon gases will be significantly more difficult to interpret as to source; information "masking" could result. Other gases associated with oil, e.g., hydrogen sulfide and carbon dioxide, can also be produced biogenically, and thus could also be difficult to interpret. Nitrogen gas, used to slightly pressurize the oil storage mine, is expected to be widely distributed near the ground surface due to close contact with air. Detecting significant changes in nitrogen concentrations near the surface (differences presumably due to subsurface leakage) may be quite difficult and will not be pursued.

\subsection{Experimental Program}

The near-surface gas (concentration) mapping study at the Weeks Island Strategic Petroleum Reserve site in, adjacent to, and in the vicinity of the sinkhole, requires highly specialized, portable gas chromatographic instrumentation. This sampling and analysis equipment must be capable of being small, light, rugged, and easily man-transportable into both cleared and uncleared brushy areas. The instrumentation must have the capability of concurrently quantifying hydrogen, helium, methane and other light hydrocarbon gases and will be configured with two fully functional and independently controlled, silicon microchip gas chromatographs, to be used simultaneously. The first gas chromatograph, with a molecular sieve column, will detect hydrogen, helium, and methane using a micro thermal conductivity detector. Gas concentrations greater than or equal to $1 \mathrm{ppm}$ are achievable. [Hydrogen and helium are not usually separated by portable gas chromatographs. Helium is usually a very small fraction of the hydrogen concentration near oil deposits. Helium has been confirmed in previous studies (Jones and Drozd, 1983) to be a deep fault or tectonic indicator, commonly found near oil deposits, but not necessarily associated with the oil.]

The second, gas chromatograph uses a 100 micron ID, 4-m capillary column to detect concentrations of methane, ethane, propanes and butanes. A small gas sample is sucked (through the sampling probe) into a test chamber or the instrument directly, then analyzed immediately. These hydrocarbon gases will be concentrated in the field so that a detection level down to about $10 \mathrm{ppb}$ is attained. This field concentration step requires about 10 minutes and will only be used on limited, selected samples (i.e., where higher concentrations of methane are detected), in order to determine the ratios of each hydrocarbon gas to methane. Each total gas sampling and analysis cycle must be conducted rapidly, i.e., in $1 / 4$ hour or less, since many samplings will be required to adequately map the site. The gas chromatographic instrument shall be calibrated for all the gases of interest. All gas data will be analyzed and recorded in the field with a portable computer. Gas concentration profiling over moderate surface areas is important for this study, not the measurement of absolute concentrations. It is important, however, that all samples be acquired under the same sampling protocol and depth.

The gas sampling probe tool must be capable of being easily pushed into the ground to a depth of about 3 feet, repeatedly. This gas sampling tool is fabricated from a metal tube about $1 / 4$ inch in diameter. This probe leaves no residual holes to be filled nor sample corings to be disposed of.

This field study will be conducted in several stages: The majority of analyses will be obtained in Task One and will require a minimum of four days of field work, including pre-site setup and preparation time. The field analysis team (two or three subcontractor personnel and a Sandian) will (a) conduct background gas sniffing analyses of the Weeks Island SPR oil in an oil 
pipeline at the site and possibly other, accessible surface locations. Duplicate gas samples from the oil, at minimum, are required. This analysis is to quantitatively affirm the presence of detectable hydrogen and/or helium and light hydrocarbons, including the ratio of each hydrocarbon to methane in SPR crude. Then, (b) a gas mapping baseline will be established over and adjacent to the sinkhole (the sinkhole will be filled with clean sand before this study is initiated). This would probably entail 4 or more gas samples obtained at positions around the sinkhole, at the top perimeter and at the top-center of the filled sinkhole. It also includes multiple near-surface samplings in a N-S and E-W pattern from the sinkhole, using the paths cleared in the underbrush for the surface geophysical testing. Al gas samples will be obtained from a uniform depth of approximately 3 feet. Estimates of the total number of these gas samplings for an adequate mapping database are not yet firm but will probably be several dozens; this will be determined in the field, by agreement between the contractor and Sandia representative. These gas samples would be taken from a few meters to several hundred meters from the sinkhole in all four directions; the total extent of these sampling sites, and exact locations (both in cleared areas and uncleared brushy areas), will again be determined in the field by agreement between the contractor (surface and environmental geology specialist) and the Sandia representative. The preliminary locations of these gas samplings are indicated on Figure 1 (as lines or zones).

Gas samples will (c) also be obtained adjacent to the cased coreholes to the salt (for geophysical testing), to monitor for further areas of enhanced gas migration. There will be a minimum of two gas samplings adjacent to each cased corehole (assuming that these holes have been cored when the gas mapping is conducted). Measurements (d) of the concentrations of hydrogen, helium, and light hydrocarbon gases on the land (i.e., at a depth of about 3 feet) adjacent to Shear Zone $E$ on Weeks Island, very near the sinkhole vicinity, could also yield evidence of the possible connection between the sinkhole and the underlying SPR oil. Surface transects across the surface lineation associated with Shear Zone E may indicate if anomalous gas concentrations coincide with the position of this subsurface feature. Transects crossing the surface lineation will be about $200 \mathrm{~m}$ in length, or less. The transects would be aligned near to, and about $100 \mathrm{~m}$ to the east and west of the sinkhole. Results will be assessed relative to existing surface and subsurface geological data. The total extent of these "Shear Zone E" sampling sites, and exact locations (both in cleared areas and uncleared brushy areas), will also be determined in the field, again by agreement between the contractor and Sandia representative. The approximate locations of these gas sampling are also shown in Figure 1. Several days of dry weather are needed before this field work can be performed.

Assuming Task One is successful, i.e., interpretable, Task Two of this test program will also gas map one or more areas at Weeks Island away from the sinkhole, possibly over an area away from the oil storage vicinity on the salt dome, probably south of the sinkhole. "Success" will be as agreed upon by both the contractor and Sandia representatives; Sandia will provide verbal authorization to the contractor to proceed with Task Two field work, with written confirmation to follow. This task will require a minimum of one additional day of field work, if authorized.

Task Two would provide further background and validity to Task One, to help prove any apparent gas patterns were not fortuitous "flukes," nor due to previously mapped (or unmapped) fracture zones on the dome. The exact number of sampling points (a minimum of two dozen), and locations, will be determined in the field (primarily by Dr. Whitney Autin, LSU, and the Sandia representative), after discussions with all involved parties. The specific total number of samples and amounts of time allocated between Task One and Task Two studies will be determined in the field. Task Two also includes the requirement to adequately document all test results. A summary report including all acquired data, compilations, interpretations, and technical status is to be submitted in draft form to Sandia, within four weeks of completion of the field studies. The 


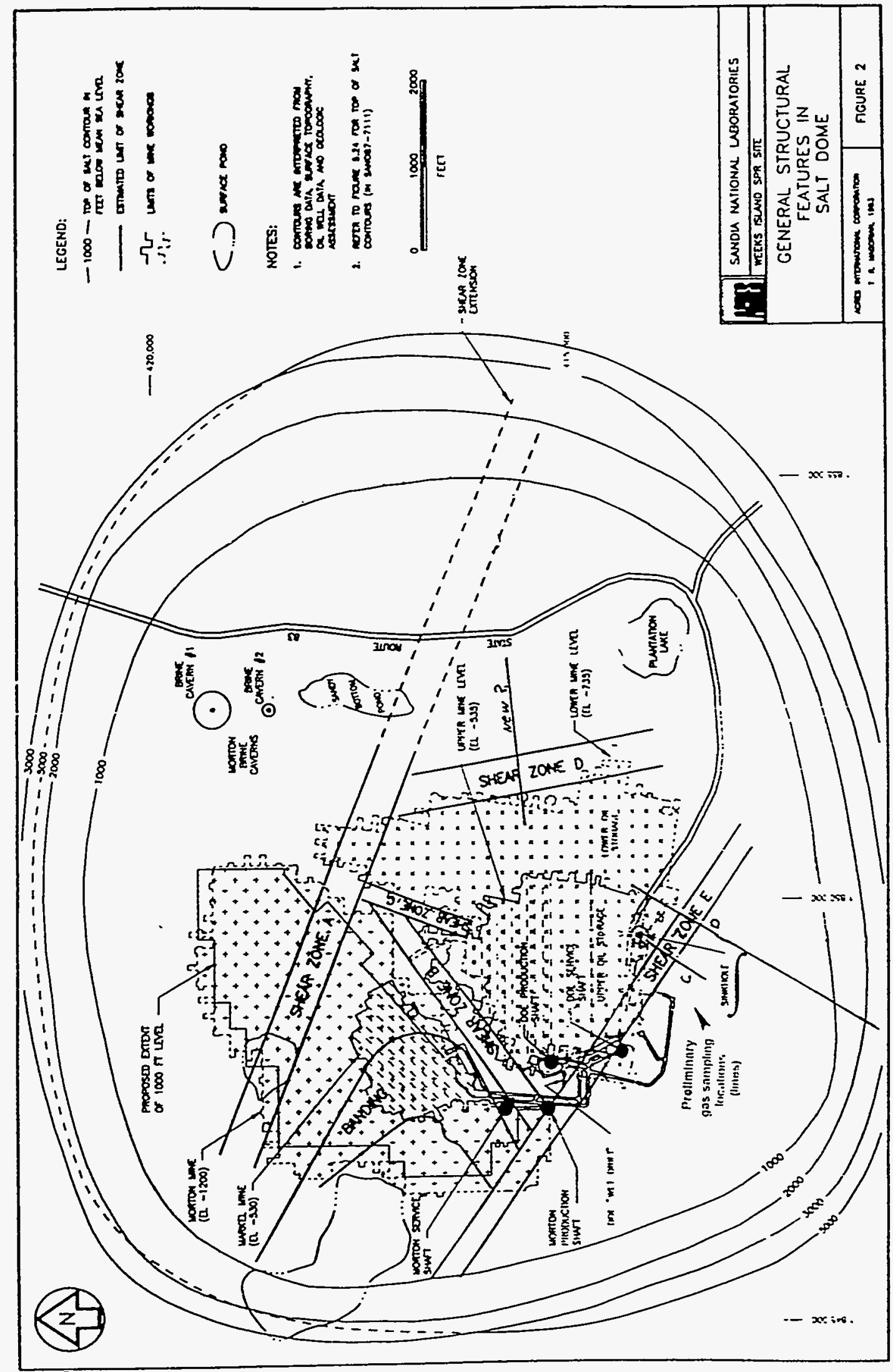

nations

Figure 1. Preliminary Gas Mapping Samplnng Locations a: :he lleeks Island SPR Site 
final draft of this document will be resubmitted to Sandia within three weeks of receipt of comments on the draft. Sandia reserves the right to formally publish the study resuits, with due credit being given to the contractor.

Assuming that Tasks One and Two are interpretable and worthwhile Task Three could provide further near-surface mapping surveys adjacent to the sinkhole and cased coreholes as a function of time, possibly two or three times per year. The purpose of this optional monitoring would be to determine if the fracture and or higher permeability patterns (if) found had changed, stabilized, or expanded as a function of time. Task three studies are only a proposal at present. Whether or not they are conducted will be based on results and further Project authorization. This technique appears to be simpler and more cost effective than coring more holes for additional geophysics testing.

\subsection{Subsurface Gas Analyses}

Subsurface gases similar to those obtained in the near-surface, i.e., hydrogen, helium, and the light hydrocarbons, could also be quantified in the vertical and slant (diagonal) coreholes into the Weeks Island salt. These gas data could provide more of a baseline set of gas information, nearer to the stored oil. Gas samples obtained at the open end of the slant corehole in salt could be directly compared to the near-surface gas composition data and could be a supplemental indicator of fracturing in the salt directly below the sinkhole and above the oil storage. Gas sampling and analyses in the slant hole as a function of time, e.g., several times within the next 6 months or longer, may provide a good monitor on fracture growth. Gas data from the vertical coreholes probably could not be used to directly quantify the extent of subsurface fracturing.

Subsurface, corehole gases can be sampled (a) during the coring procedures and (b) in bare salt, below the cased corehole length(s), in both vertical and diagonal holes. The corehole drilling contractor has been requested (Sattler and Harding, 1994) to (a) prepare for and assist in the sampling of any (specified) gases encountered in "mud logging" drilling returns during the coring procedures through the unconsolidated soil above the salt dome and into the salt. It is specifically recognized that there is a very low probability for obtaining drilling returns above the salt and, consequently, no gases to sample. The drilling fluids will probably not be recovered due to lost circulation zones in the unconsolidated soil (unsaturated and saturated); this has been the situation in wells drilled in the same formation (Sattler and Harding, 1994). Consequently, we do not advise that "mud logging" drilling returns be analyzed for gases.

Following coring of the vertical and diagonal holes, they will be cased to seal out fluids and allow for cross-borehole tomography procedures. We have requested that all (if more than one) diagonal coreholes be cored an additional 5 feet (through the bottom cement plug) into the intact, presumably competent salt. This additional length into the salt will allow for conduct of (b) a negative-pressure packer test (T. Magorian, consultant, personal communication, February 1994).

The negative-pressure tests (b) probably requires a packer or similar device to seal off the cased length from the bare salt. This isolated region of salt would then be evacuated, sucking out any gases trapped in the salt and, probably, also some brine (refer to the next section, for isotopic brine analyses). The gases obtained will be analyzed for hydrogen, helium, light hydrocarbons, and potentially other gases, for direct comparison to near-surface detected gases. The bare salt slant hole(s) can also be configured for intermediate or longer-term gas sampling and analyses, as a function of (limited) time; final plugging and abandonment of the coreholes will occur later (Sattler and Harding, 1994). Conduct of such samplings appears to be beneficial to the Weeks 
Island investigations. Project expenses for this subsurface gas sampling have not yet been finalized; they are, however, expected to be small if included with the coring work package (A. Sattler, Sandia National Laboratories, personal communication, March 1994). Details and schedules for these gas samplings and analyses have not yet been formulated.

In addition, positive-pressure borehole (drill stem) tests (c) have also been suggested ( $T$. Magorian, consultant, personal communication, February 1994), to ascertain the tightness (gas permeability) of presumably competent regions in salt, over multiple cored lengths, in both vertical and slant coreholes, while the coring was being conducted. Knowing the open, non-cased length in salt and the measured permeability, we could potentially detect and determine the size of any significant fracture zones. The advantages and predominant disadvantages of performing these drill stem tests was discussed in the introductory section. We consider that planned laboratory evaluations of recovered salt cores would be more worthwhile and cost effective for the SPR Project. We do not recommend that downhole, positive-pressure (drill stem) tests be conducted.

\subsection{Brine Isotopic Analyses}

There is a reasonable probability that occurrences of brine will be encountered during the coring of vertical and slant holes, particularly at the bottom of these holes and during the negative-pressure packer tests for subsurface gases. Brine samples should be obtained below the cased length of the vertical and slant coreholes, in presumably competent salt, near the top of the Weeks Island salt dome. We propose that some of the obtained brine samples should be analyzed for variations in the isotopic concentrations for stable oxygen and hydrogen isotopes, in order to help evaluate whether the brines are connate (formation water) or meteoric in nature. Any brine sample obtained in the slant corehole(s) directly under the vertical position of the sinkhole would be of primary interest. We would expect this brine to be connate. Any indication of meteoric water would imply some mixing with meteoric seawater (from the saturated soils directly above the dome) within the domal salt, a possible brine inflow pathway to the oil storage area. Any indication of connate and meteoric water mixing from brine isotopic analyses from either the slant corehole or an adjacent vertical corehole would not, however, provide definitive data on a brine pathway. It would only provide supplemental data, in support of geophysical results and/or nearsurface gas analyses.

The most important aspect of brine isotopic analyses from corehole samples is due to their uniqueness, due to their source location. Such information should be compared to other Weeks Island brine samples and analyses (Knauth, 1987; Thoms, 1989), including both isotopic analyses and bromide concentrations (another chemical indicator of brine origin), and interpretations made thereof. These other brine samples were obtained from Weeks Island mine fill hole and service shaft sumps, seeps, condensates, ceiling drips, and nearby surface waters. Brine analyses from the top of the salt dome would add to the overall data base and be worthwhile (R. Thoms, AGM, personal communication, February 1984), particularly for comparison to sump brine samples.

Thoms also suggested that Paul Knauth at Arizona State University (Knauth, 1987) conduct the analyses and coordinate the results with previous information. DynMcDermott (Jim McHenry, personal communication, February 1994) is presently planning to have Knauth conduct about 50 brine isotopic analyses. McHenry verbally agreed that 3 or 4 of these analyses can be allocated to the diagonal and/or vertical corehole brine evaluations described herein. DynMcDermott will pay for the analyses, then coordinate and share data. The additional expense to the SPR Project for analyzing the slant hole brine samples is thus minimal. 
We propose that brine samples from the bottom of the slant corehole(s), and possibly samples from the vertical coreholes be obtained at the end of coring for each hole (estimated to be in the late April - early May, 1994, time frame). The use of a baler device to obtain such samples has been discussed with Sandia drilling advisors (A. Sattler and R. Jacobsen, Sandia National Laboratories, personal communication, March 1994) and seems quite feasible. Each brine sample should be about $50 \mathrm{ml}$ (or larger) in volume, if possible, and contained in a glass bottle filled to the top and sealed with Teflon-lined cap, with no trapped air. The exact details on sampling remain to be finalized. Multiple samples can be obtained and archived. We recommend that only 3 or 4 brine samples, primarily from the slant hole(s), be isotopically analyzed.

MAM: 6113

\section{References:}

Autin, W.J. 1984 "Observations and Significance of Sinkhole Development at Jefferson Island." Geological Pamphlet \#7, LA Geological Survey.

Jones, V.T. and R.J. Drozd. 1983. "Predictions of Oil or Gas Potential by Near-Surface Geochemistry." The American Association of Petroleum Geologists Bulletin, vol. 67, No. 6. 932-952.

Knauth, L.P. 1987. "Stable Isotope Constraints on the Origin of Brine in the Weeks Island Strategic Petroleum Reserve," Arizona State University. Rev. 0.

Magorian, T. 1994. Consultant, personal communication with M.A. Molecke, Sandia National Laboratories.

McHenry, J. 1994. DynMcDermott, personal communication with M.A. Molecke, Sandia National Laboratories.

Overton, E.B. 1994. Louisiana State University, Institute of Environmental Studies, personal communication with M.A. Molecke, Sandia National Laboratories.

Sattler, A.R. and R.D. Jacobsen. 1994. Memorandum to J.T. Neal. March 1, 1994. "Response to Sinkhole Project Drilling Concerns of Morton International, Inc." Sandia National Laboratories.

Sattler, A. and R. Jacobsen. 1994. Sandia National Laboratories, personal communication with M.A. Molecke, Sandia National Laboratories.

Thoms, R.L. 1989. "Brine in the Weeks Island SPR Facility," report prepared for Sandia National Laboratories.

Thoms, R.L. 1994. AGM, personal communication with M.A. Molecke, Sandia National Laboratories.

Copy to:

MS 0706 A.R. Sattler

MS 0706 Dept. 6113 Staff

MS 0706 M.A. Molecke 


\section{APPENDIX 8}

NEAR-SURFACE GAS MAPPING RESULTS

A-8-1 


\section{Sandia National Laboratories}

date: August 5, 1994

Albuquerque, New Mexico 87185.0706

(505) 844-3487 FAX (505) 844-0240

to: J.K. Linn, MS 0706, Manager Dept. 6113

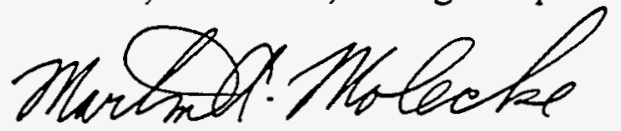

from: M. A. Molecke, MS 0706, Dept. 6113

subject: Revised Data Interpretations, Weeks Island Near-Surface Gas Mapping Survey

INTRODUCTION \& SUMMARY:

This memo summarizes the geochemical data acquired during the near-surface gas mapping survey at the Weeks Island Strategic Petroleum Reserve site in, and in the near vicinity of the sinkhole. The results and interpretations to date, as well as descriptions of the experimental equipment and procedures, are described in further detail in the attached report, "Weeks Island Soil Gas Survey Preliminary Observations," authored by Ken Carney, Louisiana State University, to Sandia, for the DOE SPR PMO diagnostic program at Weeks Island. Supporting interpretations provided by Whitney Autin, geologist at LSU, have also been incorporated.

It must be noted that the data and interpretations reported in this memo and attached LSU report are appreciably different than the earlier results reported in my memo to distribution, "Preliminary Data Interpretations, Weeks Island Near-Surface Gas Mapping Survey,"dated June 27, 1994. Reasons for modifications to, and corrections of the earlier draft, preliminary results will be described. We believe the present data and interpretations, while not yet entirely definitive, are now correct and defensible.

During May, June, and July 1994, Louisiana State University (LSU), Institute of Environmental Studies and Sandia National Laboratories conducted a near-surface gas mapping survey in the vicinity of the sinkhole and other nearby areas at the Weeks Island SPR site. Our intent was to adapt this technique, used successfully in limited applications for geochemical oil exploration, ${ }^{1,2,3,4.5}$ as a Weeks Island SPR sinkhole diagnostic tool. The major purpose of this gas mapping effort was to clearly detect and identify the sinkhole and possible subsurface fractures or other significant geologic features in the near vicinity of the SPR site. The technique used a field-portable, micro gas chromatograph to analyze for near-surface concentrations of gases associated with the crude oil stored at the SPR site. Hydrogen originating in the oil (and being oil-source specific) provided the primary survey indicator. Localized regions of high hydrogen concentration are indicative of enhanced gas leakage pathways from the stored oil to the surface via subsurface (salt dome and overlying sediment) fractures, zones of higher permeability, and/or zones of geologic structure possibly associated with fracture development processes.

- This gas mapping survey did not find a direct, gas-release pathway from the SPR oil to the immediate vicinity of, or in, the sinkhole. Our original assumptions that the sinkhole 
was functioning as a direct chimney vent to funnel gases to the surface through a presumed fracture network and could be detected by means of gas mapping, has not proven to be conclusive with the available gas data. It is possible that other factors occurring at the Weeks Island site, e.g., downward and lateral flow of groundwater in the sinkhole vicinity may have perturbed gas seepage patterns enough to mask a conclusive result. ${ }^{4}$

- However, we did find several regions of enhanced hydrogen concentration in the vicinity of the sinkhole and nearby SPR site areas that point to the repository as the source of the gas seeps. The most significant of these areas are as follows: Transect B, along Advanced Materials Rd., between Morton Rd and Snyder Rd.; mapped high hydrogen concentration level zones appear to correlate well with two previously observed surfaceseismic anomalies. Generally south of Morton Rd., along two perpendicular transects, C and $\mathrm{D}$, east of the sinkhole; these observed high-gas regions possibly may be indicative of the subsurface anomalous Shear Zone. Along discontinuous segments of Transects $F$ and $F^{\prime}$, north of Morton Rd., somewhat east of the sinkhole; data observations provide a weak correlation with observed seismic lows in the vicinity. Just north of the fill hole area; and, directly above the buried SPR pipeline. Each of these high-gas concentration areas will be déscribed in detail below.

- A clearer interpretation of the gas mapping data is obtained when these results are compared to and supplemented by other diagnostic work at Weeks Island, primarily the surface seismic results and geomorphological and geological evaluations (conducted by Whitney Autin, LSU, and others).

\section{EXPERIMENTAL TECHNIQUE:}

The near-surface gas mapping technique as conducted by LSU at Weeks Island, plus equipment, procedures, and associated data processing details are adequately described in the attached LSU report (dated July 29, 1994). This diagnostic work involved eight days of field sampling plus significant additional laboratory support and interpretation time. More than 250 gas samples, including replicates, were obtained and analyzed in the field. Major items of analytical equipment included a dual column, micro gas chromatograph, a microchip Molecular Sieve ( $5 \AA$ ) column, and a tubular gas sampling probe. Specific gas sampling location points are illustrated in Figure 1, the summary gas data plot in the attached LSU report, and Figure 2, showing the relationship between the gas mapping transects and the earlier surface seismic lines.

Significant improvements in analytical equipment, procedures and data processing were implemented in late June and July. These improvements occurred after the original draft, preliminary results were reported to DOE SPR PMO prior to, and on June 27, 1994 and, unavoidably, resulted in the need for a significant change in data interpretations relevant to the sinkhole.

The original gas mapping chromatographic data, obtained May 9-11 and 18-19, 1994, was interpreted as overlapping peaks of hydrogen (and helium, if any) partially coeluted with an unresolved mixture of light, branched hydrocarbons, e.g., isobutane and isopentane. Initial data analyses included calculating and plotting the "response ratios" of the chromatographic response (retention times, peak heights and shapes) of the hydrogen peak versus the unresolved light hydrocarbons peak. However, by early to mid-July subsequent data evaluations revealed that the two observed overlapping peaks were actually 
contaminant helium and soil-gas hydrogen. The helium originated from an (originally unnoticed) leak in the instrumentation tubing used for a dual carrier gas system. This problem was corrected (as described in the attached LSU report) and the data artifact removed from currently reported results. Draft results based on calculated "hydrogen response ratios" were totally replaced by results based solely on hydrogen concentration levels, as compared to a normalized gas background concentration. Subsequent field testing (replications and enhancements) on July 22 satisfactorily demonstrated that the gas chromatograph peak used for survey interpretation was solely hydrogen; soil-gas helium and volatile light hydrocarbons, if present, were below the detection limit of 5-10 ppmv. Methane and other biogenic or atmospheric gases were clearly separated chromatographically and do not confuse the resultant interpretations.

\section{RESULTS:}

All currently available, interpreted data are based on near-surface hydrogen gas concentration levels and are summarized in the color plot of Figure 1, part of the attached LSU report. Results summarized below are listed in estimated order of significance to the SPR sinkhole diagnostic program. Some data processing are still underway, particularly on SPR oil gas compositions and other field observed gases. Such supplemental data, plus further interpretations on the geochemical gas mapping data will be distributed in the near future.

Sampling Transect "A" (and sinkhole samples), shown in Figures 1 and 2, basically followed seismic Line \# 4, going east and west of the sinkhole, just south of Morton Rd. We took 32 samples, not including replicates, at $10 \mathrm{~m}$-spacing. We added the sinkhole samples to this transect, several around the immediate periphery of the sinkhole and others almost directly in the center of the (sand-filled) sinkhole. Low hydrogen concentrations were found at most near locations east and west of the sinkhole. The most striking feature of these results is the low gas readings in the sinkhole itself. [Note: These results are essentially opposite to the draft, preliminary results reported June 27 . Differences are due wholly to instrument leakage and helium contamination, as described.]

The present results can be interpreted as possibly due to a high gas permeability and release in the sand used to fill the sinkhole. Alternatively, it is alsu possible that if gases are being released from the SPR oil through fracturing below the immediate vicinity of the sinkhole, then they are being displaced somewhat from a true vertical pathway. Hydrological factors occurring at the Weeks Island site, e.g., downward and lateral flow of groundwater in the sinkhole vicinity may have perturbed gas seepage patterns enough from "plumb line" vertical to mask a conclusive result. While no calculations on the topic have been conducted in this study, similar concerns have been raised by others and are discussed elsewhere. ${ }^{4}$

Further gas sampling in a circular, concentric pattern (or patterns) around the sinkhole would be quite beneficial for resolving the concern of gas seep displacement slightly away from above the sinkhole due to hydrology. Unfortunately, the ground surface in the near vicinity (within 100 to $200 \mathrm{ft}$.) around the sinkhole and along Transect $\mathrm{A}$ has been blocked by drilling rigs and associated wooden planking since early June. No other samples or replicates for Transect A near the sinkhole (except for samples immediately surrounding and in the sinkhole) have been obtained since May.

The only significantly elevated hydrogen concentrations found along Transect A occurred at the eastern end of this transect, east of its intersection with Transect D. (Refer to results for Transect D for possible interpretation.) 
Transect "B" basically followed the northern half of seismic Line \# 3, along the eastern edge of Advanced Materials Rd., from Morton Rd. to the top of the "triangle" at the Snyder-Advanced Materials Rd. intersection. Multiple sample replicates were obtained along this transect; sampling was also decreased to $5-\mathrm{m}$ spacing for potential interpretive clarification. Two localized zones of high hydrogen levels were found at about the mid-length of Transect B and also centered in the "triangle" area. These two zones appear to correlate well with the two previously observed seismic anomalies along the northern half of Line \# 3, as indicated by the light, crossing lines shown on Figure 2. The lack of a general gradient of decreasing gas concentration levels from the sinkhole area to the north possibly suggests multiple gas seep sources at depth.

Transect "C" basically followed seismic Line \# 2, going north and south and about $70 \mathrm{ft}$. east of the sinkhole. There is localized zone of high gas concentration just north of the intersection with Transect $F$. This appears to correlate well with the location of a 2D seismic reflector low (subsurface disturbance) previously noted along seismic Line \#2; however, this data correlation may not be considered conclusive. [NOTE: Current results for the areas of Transect $C$ extending from about $+1-60 \mathrm{~m}$ north and south of the sinkhole are essentially opposite to the draft, preliminary results reported June 27, for the same reasons as described for the Transect A discrepancies. Similar to Transect A, no additional samples nor replicates along this segment of Transect $C$ have been available since early June, due to drilling activities.]

There is also a generally increasing trend in hydrogen concentration along the southern half of Transect $C$ and increasing south of Morton Rd. There are also regions of high hydrogen along the southern portion of Transect "D" (seismic Line \#1). Both Transects C and D cross the subsurface anomalous Shear Zone E; the observed high-gas regions south of Morton Rd. may be indicative of this Shear Zone. Alternatively, they may also be due to other, as yet unexplained reasons.

Transect " $F$ " lay's perpendicular to Transect $C$, seismic line $\# 2$ at the 550 (ft.) point, about $170 \mathrm{ft}$. north of Morton Rd. Transect "F"," parallel to Transect F, lays $85 \mathrm{ft}$. $(26 \mathrm{~m})$ north of Transect A, just below the tree line north of Morton Rd. Both of these transects were added in order to map a region of seismically detected "depressions" surrounding seismic Line \# 2 in this area. The observed, discontinuous areas of high hydrogen along Transects F' and F provide only a weak correlation with the seismic lows.

Transect "E," as shown in Figures 1 and 2, lies over and perpendicular to the buried SPR pipeline. The observed data indicated very high hydrogen concentrations over the pipeline. Further gas mapping over other segments of the pipeline, and/or other oil pipelines, should be performed to see if this is a reliable technique to locate pipelines. [Note: Hydrogen can slowly permeate through steel pipes. The high levels observed over the SPR pipeline are not indicative of an oil leak!]

Transect " $H$ " extends from $2 \mathrm{~m}$ to $22 \mathrm{~m}$ north of the fill hole area fence, centered between the two fill holes. The observed data indicated consistent high hydrogen concentration levels over the entire length of this transect. Further gas mapping, particularly between Transects C and D and south of Morton Rd., would be necessary to detail the overall extent of this high gas region.

Transect "G" extended from the northeast corner of the Weeks Island salt dome, approximately 6,000 ft. northeast of the sinkhole, to off the dome. Transect G starts 50 m east of LA Route 83 (about 1/4 mile south of its intersection with Snyder Rd, along a dirt sugar cane field road), going eastward to a Shell Oil Weeks Island facility. We originally intended to use this transect for obtaining a background gas level for the study. Hydrogen levels along Transect $G$, however, were consistently higher than levels located over the dome. This was attributed to contributions of (non SPR) Weeks Island oil deposits, 
which are most prevalent at the dome's edge. Further gas mapping over the dome, but away from the SPR site should be conducted to obtain a better background level determination.

\section{CURRENT CONCLUSIONS:}

This memo and the attached, detailed LSU report document and interpret the currently available, revised and corrected near-surface gas mapping data acquired in the vicinity of the sinkhole at the Weeks Island Strategic Petroleum Reserve site.

The near-surface gas mapping technique has been used successfully, in limited applications, for geochemical oil exploration. ${ }^{1,2,3,4}$ Our specific purpose to adapt its use as a Weeks Island SPR sinkhole diagnostic tool, ${ }^{2,5}$ to cleary detect the sinkhole and map immediately adjacent zones by oil-specific gas releases through a presumed fracture network, has not proven to be definitive.

- This gas mapping survey did not find a direct, gas-release pathway from the SPR oil to the immediate vicinity of, or in, the sinkhole. Our original assumptions that the sinkhole was functioning as a direct chimney vent to funnel gases to the surface through a presumed fracture network and could be detected by means of gas mapping. has not proven to be conclusive with the available gas data. Hydrological confounding effects on gas seepage might be of significance. Further sampling in concentric patterns about the immediate sinkhole vicinity might resolve the uncertainties.

- However, we did find several regions of enhanced hydrogen concentration in the vicinity of the sinkhole and nearby SPR site areas that point to the repository as the source of

the gas seeps. Correlation of any of the high gas zones directly with the sinkhole is difficult except to the extent that they apparently correspond well to one or more of the notable seismic features and/or surface indications of subsurface geologic anomalies.

Locations of other, potentially incipient sinkhole areas were not detected, nor proven by this technique.

- Observed patterns of the gas seeps, in conjunction with or in comparison to the geophysical diagnostic work at Weeks Island and results. suggest -- but not definitively -- a structural control associated with fracture development processes. Fracture permeability may be associated within and near any of the mapped geologic anomalous zones. It is possible that the patterns generated by the gas mapping survey data are surrogates of the overburden fracture pattern(s) produced by stresses that created the sinkhole.

- Further substantiation of the above interpretations and conclusions could potentially be obtained by a somewhat expanded near-surface gas mapping program -- particularly by using the enhanced analytical equipment and techniques implemented near the end of the current survey. Gas mapping results to date must be regarded as inconclusive for the originally intended SPR diagnostic effort. A limited amount of supplemental gas mapping (at a limited budget) could help resolve the current uncertainties.

Recommendations are as follow:

a.) More definitive determination of gas background level(s) over the dome area away from the SPR repository, for purposes of overall standardization of all data gathered. b.) Time dependent gas mapping sampling in the same areas found (above) to have high hydrogen levels. The purpose of this optional monitoring, possibly two or three times per 
year, would be to determine if the fracture and or higher permeability patterns detected had changed, stabilized, or expanded as a function of time.

c.) Further gas mapping in the immediate vicinity of the sinkhole, possibly over the entire repository and beyond, could help delineate the geographic extent of the high gas seep activity. This would help define the extent of what is possibly a fracture structure and/or subsidence feature in the sinkhole locale.

d.) Possible extension of this gas mapping technique to use at other SPR sites or pipelines. Applicability of gas mapping in the vicinity of oil storage caverns, as a leakage path detector, remains to be proven.

\section{REFERENCES:}

1. Jones, V.T. and R.J. Drozd. 1983. "Predictions of Oil or Gas Potential by Near-Surface Geochemistry." The American Association of Petroleum Geologists Bulletin, vol. 67, No. 6. 932-952.

2. Overton, E.B. and K. Carney. 1994. Louisiana State University, Institute of Environmental Studies, personal communications with M.A. Molecke, Sandia National Laboratories.

3. Boleneus, D. 1994. "Guidelines for Surface Geochemical Surveying." Oil \& Gas Journal, OGJ Special, June 6, 1994. 59-64.

4. Davidson, M.J. 1994. "On the Acceptance or Rejection of Surface Geochemical Exploration." Oil \& Gas Journal, OGJ Special, June 6, 1994. 70-76.

5. Molecke, M.A. Sandia National Laboratories, memo to distribution, "My Contribution to theWeeks Island Sinkhole Investigation Paper: Appendix on the Near-Surface Gas Mapping Program," March 15, 1994.

MAM: 6113

(attachment: to all) 


\title{
Weeks Island Soil Gas Survey Preliminary Observations
}

\author{
submitted to: \\ Martin A. Molecke \\ Sandia National Laboratories \\ by \\ Kenneth Carney \\ Louisiana State University \\ Institute for Environmental Studies
}

July 29,1994

\section{$\underline{\text { Summary }}$}

For five days over a two week period in May and for two additional days in June, a team from the Institute for Environmental Studies conducted a near surface soil gas survey for hydrogen and light hydrocarbons at the Weeks Island Strategic Petroleum Reserve site. The purpose of this survey was to identify possible subsurface fractures by the occurrence of localized areas of high near-surface soil gas concentrations of hydrogen and, possibly, other oil sourced hydrocarbons. The soil gas survey was one of a number of techniques requested by Sandia National Laboratories to probe the integrity of the SPR storage facility at Weeks Island.

A portable micro gas chromatograph $(\mu \mathrm{GC})$ equipped with a $5 \AA$ Molecular Sieve column ( $2 \mathrm{~m} \times 0.32 \mathrm{~mm}$ i.d.) was used to determine hydrogen in soil gas samples drawn from a depth of approximately 4 feet below the surface. The gas chromatograph separated the hydrogen and helium components from oil hydrocarbon vapors and, importantly, from methane derived from either oil or near surface biogenic sources. A second column was used to analyze $\mathrm{C} 1$ to $\mathrm{C} 4$ hydrocarbons simultaneously with the hydrogen determinations. Thus the soil gas was fingerprinted over a wide area; over 250 samples were analyzed. The samples were concentrated along 4 major transects (A-D) in the vicinity of the SPR facility, coinciding with seismic lines run by earlier workers, 1 major transect $(G)$ located away from the SPR facility near the edge of the Weeks Island salt dome, and three minor transects $(E, F, H)$ in the area near the SPR facility.

Over 250 soil gas samples were analyzed during three sampling events covering seven days of sampling. Further, approximately 10 samples were collected and analyzed in midJuly with better equipment capable of unequivocally separating the compounds of interest. 
This confirmed the interpretation that the lightest of the gasses contained in the soil gas was principally hydrogen and not helium. It is still possible that helium was present in the soil gas and that the detection limits of the instrumental setup used during this period were too high to detect its presence.

Soil gas concentrations were normalized to a baseline level for each of the three sampling events (May 9-11, May 18-19, and June 28-29). The normalized concentrations were then coded to represent 4 levels above baseline. These semiquantitative values were then overlaid onto a map of the area to define patterns and extents of enhanced gas pathways from the subsurface.

Results showed generally elevated levels south of transect A. Strong, localized zones of high concentrations found at the eastern end of transect $A$ and on the northern half of transect B may be correlated with observed seismic anomalies or with shear zone $E$. Unusually low readings at the sinkhole itself were not surprising, but the absence of elevated levels on transect A (except at the eastern extreme) was unexpected.

\section{Background}

The concept of using near surface soil gas concentrations has been used extensively for oil prospecting (1). Generally conclusions are based on concentration ratios rather than absolute concentration because of the numerous factors that can affect concentrations (e.g., soil type, moisture content, porosity, etc.). Using ratios reduces the effect of many of these phenomena and focuses variations in the results to spatial variations. Hydrogen has in the past been reported as a marker for petroleum reservoirs but the variation in analytical determinations for hydrogen have discouraged its use as an exploration tool. The high variability for hydrogen levels is certainly due in part to difficulties with holding and transporting samples. By analyzing for the gas on-site the sample is taken directly into the analyzer and sample transport effects are minimized. By reducing a principal external source of variability the potential for using hydrogen as a petroleum source marker is bolstered

In 1992 and 1993, the LSU team studied the use of soil gas hydrogen as an indicator of oil reservoirs in the Wilcox trend in south central Mississippi. Hydrogen was used as the

1 Overview of Geochemical Exploration Technology, Exploration Technologies, Inc. Houston, TX (1984). 
sole indicator. The data were coded into a 5 level quantitation system (background $=0$ and 4 levels above background). When compared with conventional geological maps of the area tested, the soil gas correlated well with known geological features. An exploration well drilled in an area with little prior information regarding the specific Wilcox geology confirmed that the soil gas hydrogen values had coincided with oil bearing geological features.

The plan for the Weeks Island survey originally was to repeat the Mississippi procedure exactly. Weeks Island presented several important differences from the southern Mississippi area. Most importantly, the soil gas at Weeks island seems to contain a much higher background level of hydrogen and hydrocarbons than the Mississippi area. Some of the volatile hydrocarbons (isobutane, isopentane) are branched or otherwise sterically excluded from the pores of the $5 \AA \mathrm{Mol}$ Sieve. As a result they are only very weakly retained and tend to partially coelute with the hydrogen peak. The column installed in this instrument was only $2 \mathrm{~m}$ and so also lacked the resolution to distinctly resolve hydrogen and helium. While the resolution was somewhat less than optimum, it was sufficient to fingerprint the soil gas vapors if the column were properly preconditioned.

Methane is fairly well retained at the column temperature used $\left(40^{\circ} \mathrm{C}\right)$ and elutes considerably later than helium, hydrogen and nitrogen. The hydrocarbons being used to fingerprint the soil gas vapors elute between hydrogen and nitrogen. Methane usually provides a marker to warn against samples containing near surface biogenic sources. Normally methane levels are below detection limits for the MolSieve system used here. Any anaerobic sources would produce large amounts of methane and thus a large, observable signal. Several household/farm waste dumps were discovered by monitoring the methane peak during the Mississippi project. The presence of such large background concentrations may prove troublesome in this regard, however.

\section{PROCEDURE}

The technique used at Weeks Island was basically an extension of a similar study conducted by LSU in 1992 and 1993 in south central Mississippi for identifying potentially productive oil reservoirs.

Sampling Procedure. 
The sampling procedure was to insert a gas sampling probe built from $\frac{1}{4}$ inch stainless steel into the soil and draw a volume of soil gas directly into the portable gas chromatograph. The sample was immediately analyzed at the site. The procedure was streamlined to allow the maximum number of samples to be analyzed in a single day. Calibration mixtures, used to assign retention times to the hydrogen and hydrocarbon peaks, were run at the beginning of each sampling day. Sample points were along previous seismic lines and a separate transect chosen to obtain background readings for Weeks Island was at the far removed from the SPR facility. The transects were labeled A$\mathrm{H}$ and are marked on the area map in Figure 1. Samples were analyzed out of numerical sequence to reduce the possibility

A specially made sharpened point was inserted into the bottom of the sampling rod and pressed into the ground. Using an appropriate means (for example the slide hammer), the probe was pressed into the soil to a consistent depth of $4 \frac{1}{2}$ feet. To the extent possible, the same sampling depth was used for all sample points. Precautions were taken to assure that the tube provided a tight seal with the soil against ambient air and that when air was withdrawn from the tube, it was replaced only by interstitial soil gas and not by air traveling down the outside of the tube. When the probe had been inserted to the desired depth, it was connected with small diameter Teflon tubing to the microGC sample line so that the microGC sampled directly from the probe. The tube was then raised by approximately 1 " to form a soil cavity below the end of the probe.

Between 20 and $50 \mathrm{ml}$ of gas was removed from the sampling tube to draw the soil gas into the analyzer. The sample was pulled into the analyzer with an air pump having a $50 \mathrm{ml}$ gastight syringe attached to the pump outlet. The sample was withdrawn by turning on the air pump and pulling the plunger of the gas tight syringe back to $40 \mathrm{ml}$. Using a syringe lowered the sample line pressure and assisted in the withdrawal of sample from the probe. It also provided a feel for the permeability of the soil.

\section{Chromatographic analysis.}

The samples were analyzed using a dual column gas chromatograph (Model P200D, MTI Analytical Instruments, Fremont, CA) equipped with a $2 \mathrm{~m} \times 0.32$ i.d. Molecular Sieve ( $5 \AA$ ) PLOT column and with a $25 \mathrm{~cm}$ micropacked HayeSep A column. The MS5 $\AA$ PLOT column, operated at $40^{\circ} \mathrm{C}$ with a carrier gas velocity of approximately $40 \mathrm{~cm} / \mathrm{second}$ was used to determine hydrogen and branched hydrocarbons (isobutane, isopentane). The micropacked HayeSep A column was operated at $100^{\circ} \mathrm{C}$ with a carrier gas velocity of 
approximately $12 \mathrm{~cm} /$ second and was used to determine $\mathrm{C} 1$ to $\mathrm{C} 4$ hydrocarbons. Both chromatographic modules used high sensitivity micro thermal conductivity detectors. In to maximize overall sensitivity to hydrogen and light hydrocarbons the unit used a dual carrier gas system with nitrogen as the carrier gas for the PLOT column (hydrogen detection) and helium as the carrier gas for the HayeSep column (hydrocarbon detection). Detection limits for all compounds were in the 5 to 10 ppmv range.

\section{Data Processing.}

Soil gas concentrations can vary considerably due mainly to weather considerations. Recent rainfalls, for example, significantly depress hydrogen levels. Low pressure systems can also result in changes in near surface gas concentrations. Therefore, data acquired in different sampling events (separated by days or weeks) must be normalized to the prevailing background level before comparisons can be made. Originally, we intended to use transect $\mathrm{G}$, located at the edge of the Weeks Island salt dome, as the background level for the study. Levels for that transect, however, were consistently higher than levels located over the dome. This was attributed to contributions of native Weeks Island production, which would be most prevalent at the dome's edge. The most appropriate area for background measurements relevant to the area around the sinkhole would be an area similarly situated geologically over the dome, but removed from SPR storage areas. One such area lies to the northwest of the SPR facility, but was not available within the time constraints of this project. For the purposes of this presentation, the background was estimated as the 25th percentile of measurements for all sample points obtained during a given sampling event. All values were normalized to the thus defined background. Further, the data were recoded in terms of integral multiples of the background level. Data are thus reported in terms of "background", "2x background", "3x background", etc., encompassing five levels in all. The levels can then be conveniently color coded for presentation in a map.

\section{RESULTS}

A map showing the distribution of measured soil gas hydrogen is shown in Figure 1. The levels are displayed in five colors. The map represents background level and four additional levels above background. Levels are integral factors over background. Thus, 1 is at or below the background level, 2 is less than twice the background level, and so forth. The data points were acquired in a somewhat block randomized fashion. On very few occasions were adjacent sample points measured in sequence. Usually adjacent sample points were taken one day apart. Transects that were measured in sequence were E, F, G and some of the B replicates. Replicate analyses are represented by overlapping marks. 
Most of the replicate analyses were taken on transect B. A substantial number of replicates were taken at the sinkhole and at point A1 and A4. Replicates at A1 and A4 were not obtained after May 19 because of the presence of drilling equipment. Replicates were also taken at some point on every other transect as well, with the exceptions of transects $E$ and F.

The most striking feature of these results is the low readings in the sinkhole itself. In hindsight this is not entirely surprising; the sinkhole was regularly filled with sand so the original surface soil was approximately 30 to 50 feet below the point actually measured. Sand is much more permeable than the native soil so the steady state concentrations could be expected to be lower on that account alone. Additionally, however, the permeation of air into the sand adds an additional sink to the hydrogen concentration. Hydrogen is extremely unstable in oxidizing environments. A porous fill material such as sand should lower the anoxic horizon below the 3-4 feet normally seen in loamy soils.

Low hydrogen concentrations were found at most locations near the sinkhole. The low levels in areas closest to the sinkhole could derive from their proximity to the exceptionally low hydrogen concentrations in the sinkhole. Notable clusters of high readings are located:

1. along transect $B$, north of the midpoint between Morton Rd. and Snyder Rd.;

2. on transect $A$, east of the intersection with transect $D$;

3. on transect $D$, at the intersection with transect $A$, and generally south of the line extending from Fill Hole Rd.;

4. on transect $C$, increasing south from the sinkhole;

5. on transect $C$, at the intersection with transect $F$ and north;

6. on transect $\mathrm{F}^{\prime}$, at discontinuous points;

6. the whole of transect E;

7. the 4 points of transect $\mathrm{H}$.

The sources of these zones of high concentrations are not obvious. The areas south of transect $A$ and at the intersection of transects $A$ and $D$ may correspond with the location of shear zone $E$. Furthermore, the high readings on the northern leg of transect $C$ correlate with the location of seismic anomalies at ends of transect $F$. Note also that high zones on transect $B$ correlate with an anomaly along that line and are not seen south of the line defined by those seismic anomalies.

Correlation of any of the high zones directly with the sinkhole is difficult except to the extent that it may be related to one of these anomalous features. One would expect that if this is so then a region of high levels should be found near the sinkhole and traceable to one of these high level areas. Where is the area of highs that one expects to be associated in some way with the sinkhole? The high zone associated with the sinkhole, if indeed there is one, is clearly not symmetrically disposed. If it were, some sign of it should have 
appeared on transect $A$. There is possibly some indication of a high zone on transect $C$, but the data are not conclusive. A "circular transect" around the sinkhole at a distance of perhaps 15 meters should locate a high zone associated with the sinkhole.

The occurrence of consistently high levels at the fill hole presents the obvious question, . do the high levels at this point derive from the fill hole? And further, does the broad area of highs south of transect A derive from fill hole gasses? This question could be answered by a transect running obliquely from transect $\mathrm{D}$ to transect $\mathrm{C}$. To the extent that any gradients can be observed in this scant data set, they do not appear totally consistent with a pipeline or fill hole source, especially north of transect $\mathrm{A}$.

An important concern with this data is the absence of a truly relevant background. The use of the lower quartile of readings as the background, though reasonable, is somewhat circular. Analysis of the data is still ongoing but an accurate, relevant background would increase the certainty of any conclusions drawn from any subsequent work.

Whitney Autin has suggested that the area to the North of transect A has significant surface features that correlate with the seismic anomalies. They also correlate with the soil gas results insofar as the data overlap with the area of his observations. The soil gas high zones may be associated with a single deep source channeled up through preferential pathways, but they may also be independent phenomena. This could be clarified by focusing on the high zones north of transect A and attempting to establish relationships between these areas. Also, the surface geology suggests some concern about an area extending slightly beyond Snyder Rd. but otherwise covering the area between Snyder Rd. and Morton Rd. roughly as far east as the end of transect A and west to Advanced Materials $\mathrm{Rd}$.

Chromatograms from the earliest samples clearly showed a second peak partially coeluting with hydrogen from the MS5 $\AA$ column. This second peak was interpreted as an unresolved mixture of isobutane and isopentane. Analysis of known mixtures of isobutane and isopentane were consistent with that interpretation. Subsequent evaluation, however, revealed that the peak was helium contamination from the dual carrier gas system. The samples were being contaminated by helium leaking through a valve in carrier gas manifold of the HayeSep column. Coincidentally, the resolution between helium and hydrogen was virtually the same as the resolution between hydrogen and isobutane. The three components elute from the MolSieve column in the order: helium, hydrogen, isobutane/isopentane (composite). The problem was corrected and the artifact was 
removed from the data set. Because helium is present in the crude oil in significant quantities, an additional sampling trip was made to Weeks Island in mid-July to verify the composition of the soil gas. In this case, analyses were performed with a much improved version of the MS5Å column that was able to resolve helium, hydrogen and the isoparaffins. Furthermore, the dual carrier system was not used, eliminating the possibility of sample contamination by helium carrier gas. The trip was hampered somewhat by poor weather but these analyses clearly showed that neither helium nor branched paraffins were detected in the soil gas. These components may still be present in the soil gas, but at levels below the detection limit of the instrumental setup used here (5-10 ppmv).

Information that will be helpful in improving the sampling technique was obtained on the last trip to Weeks island also. More sensitivity and better reproducibility can be obtained by evacuating the sampling probe and allowing the pressure inside to recover by replenishment from the interstitial soil gas for 5 minutes. Furthermore the variability between sample point can be reduced by driving the probe further into the soil and withdrawing it approximately 1 foot instead of 1 ", thereby creating a larger soil cavity below the probe. This provides a greater degree of "depth averaging" which should reduce the variability between sample points that arise from small scale differences in soil porosity and permeability.

\section{CONCLUSIONS}

The gas monitoring project at Weeks Island proved to be much more involved than previous applications of this technique. The added complexity of the samples and degradation of the chromatographic column compromised the strength of conclusions that can be drawn from the results. As with most chromatographic applications one has more confidence in the results if one can separate and identify the individual components of the sample mixture.

The absence of an obvious high concentration zone associated with the sinkhole is surprising, although it is easily conceivable that we simply missed it with our sampling plan. Several areas of high concentrations were found that correspond with notable seismic features and/or surface indications of subsurface anomalies. In short, the gas survey has not found a "smoking gun" but we seem to have a few shell casings.

In order to substantiate the results we would suggest that portions of all transects be re-sampled and analyzed with the higher resolution microGC that we have recently obtained. Repeating selected sample points with the higher quality instrument would add 
confidence to the data thus far obtained. We would also stress the importance of defining a well-known background, especially if data collection were to extend beyond 2 to 4 days. Additionally the new instrumentation should be configured to detect lower concentrations of helium as it may provide an additional marker for the SPR oil. 
Sinkhole

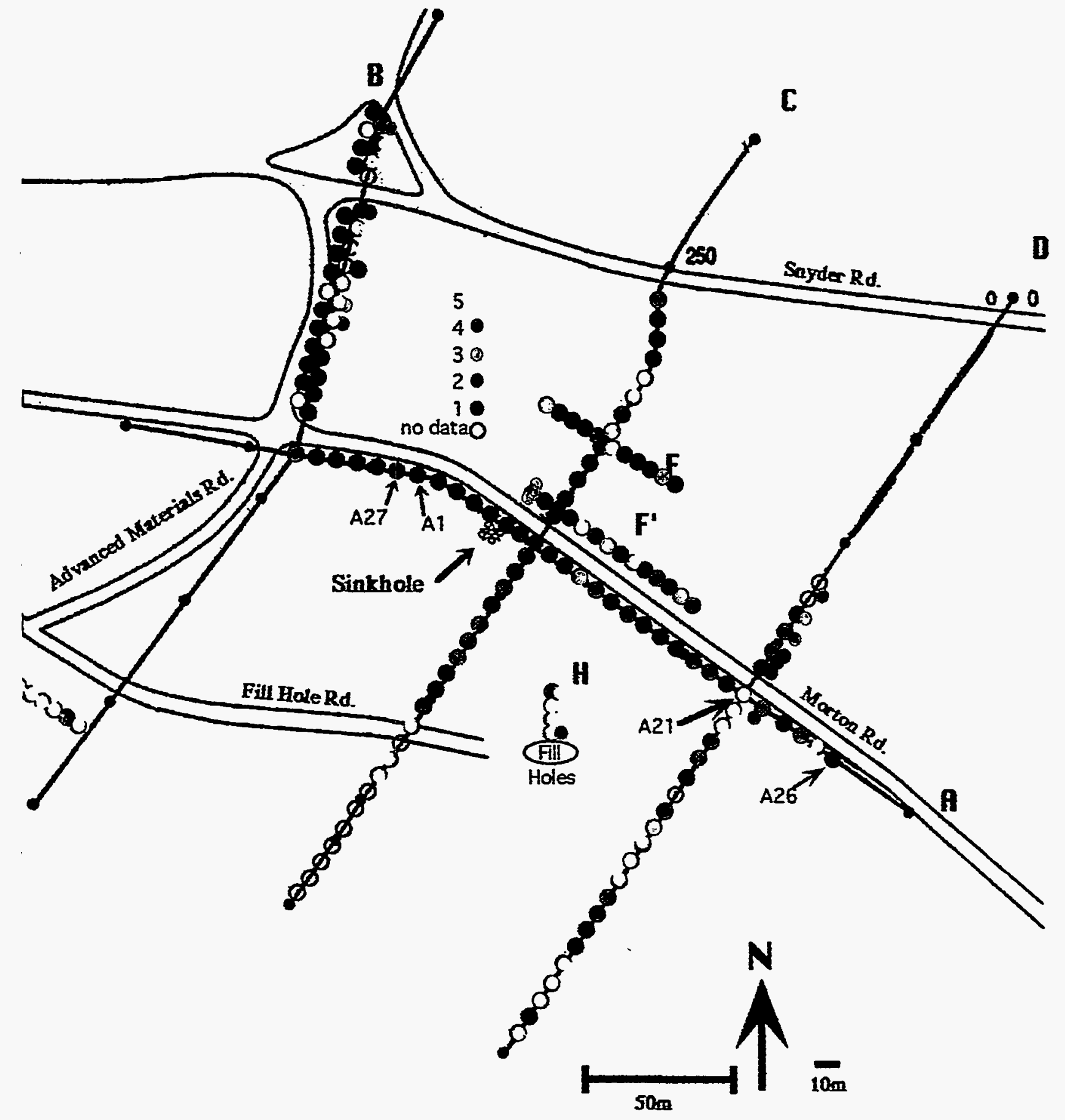

Figure 1

Week Island SPR Site Gas Mapping Survey Data A-8-17 
• 


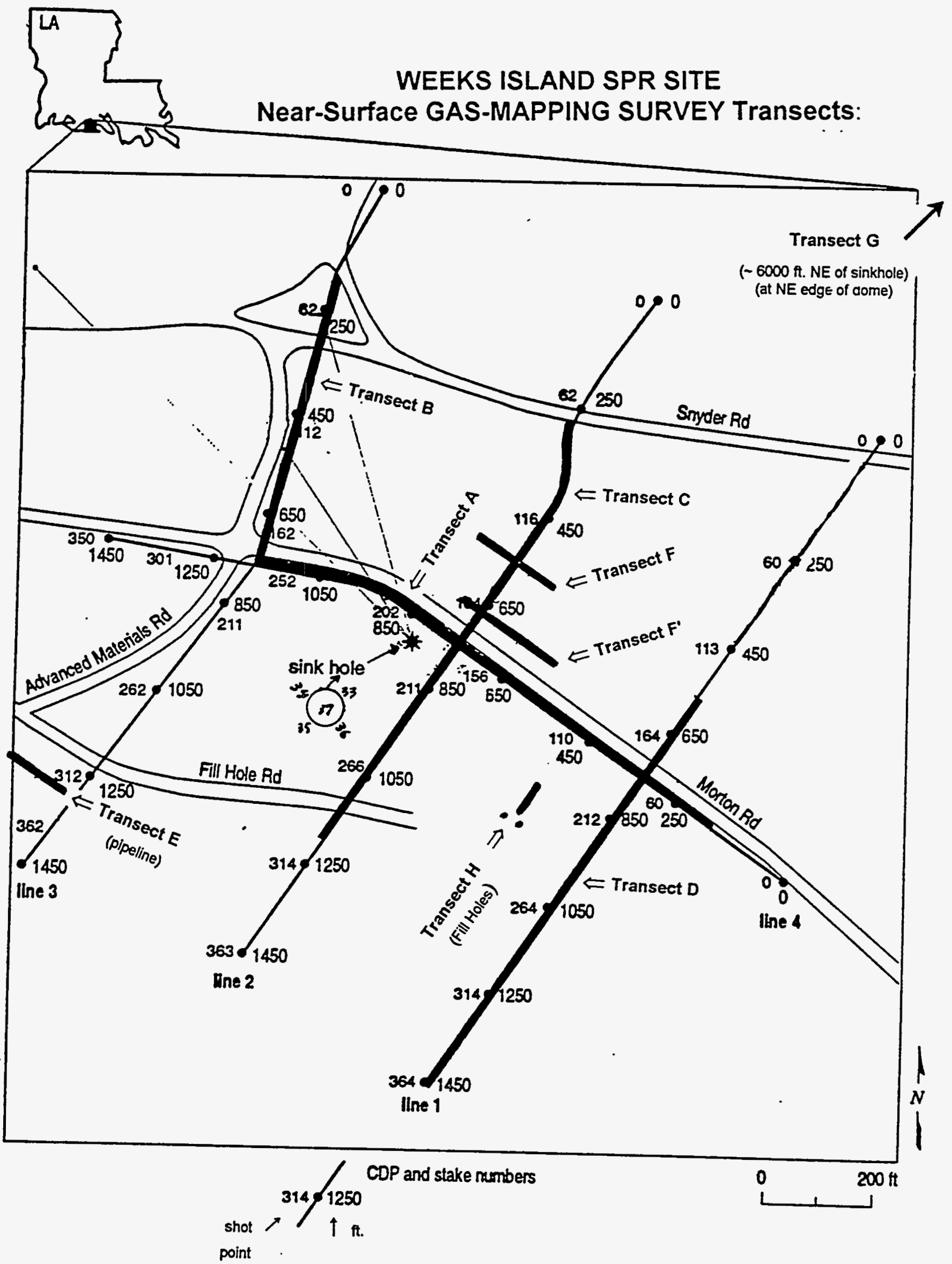

Figure 2. Site Map \& Seismic Lines \# 1-4 
Revised Data Interpretations, Weeks Island Near-Surface Gas Mapping Survey

MAM: 6113

(attachment: to all)

Copy to:

L.J. Rousseau, DOE SPR PMO, FE-443

R.E. Myers, DOE SPR PMO, FE-4422

M.B. Jackson, DOE SPR WI, FE-4421.3

R.N. Phillips, EF-WI/DM

D. Buck, DOE SPR HQ, FE-421

J. McHenry, DynMcDermott, EF 20

W.J. Autin, LSU IES
K.R. Carney, LSU IES

E.B. Overton, LSU IES

6100 MS 0701 R.W. Lynch

6111 MS 0706 A.R. Sattler

6113 MS 0706 Dept. Staff (9)

6114 MS 0705 R.S. Harding

6113 MS 0706 M.A. Molecke 


\section{APPENDIX 9}

\section{FLUID FLOW MEASUREMENTS}

$A-9-1$ 


\section{Sandia National Laboratories}

date: August 17, 1994

Albuquerque, New Mexico 87185

to: Jim Linn, 6113

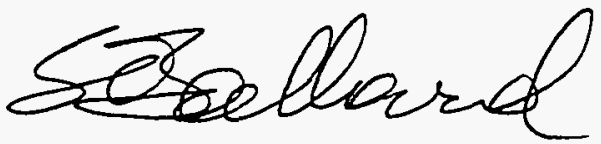

from: Sandy Ballard, 6116

subject: Groundwater flow velocity measurements beneath the Weeks Island Sinkhole.

As part of a larger effort to characterize the sinkhole at the Weeks Island Strategic Petroleum Reserve facility, an In Situ Permeable Flow Sensor was emplaced into borehole BH7a to measure the direction and magnitude of the groundwater flow velocity in the throat of the sinkhole. The goal of this effort was to help distinguish between two competing hypotheses regarding the significance of the sinkhole. One hypothesis is that the sinkhole is part of a fissure or topographic canyon in the top of the salt which is carrying water horizontally off the top of the dome. The other possibility is that there exists a hydrologic connection between fresh water above the salt and the petroleum reserve. Measurements of groundwater flow directly in the conduit, below the top of the salt, can help to resolve this issue. If predominantly horizontal flow is observed then flow of water off the salt dome is probable whereas if predominantly downwardly directed flow is detected then flow into the reserve is likely.

\section{Procedure}

In Situ Permeable Flow Sensors are new, Sandia-developed instruments which use a thermal perturbation technique to directly measure the magnitude and direction of the full three dimensional groundwater flow velocity vector characteristic of an approximately $1 \mathrm{~m}^{3}$ volume of the subsurface (Ballard et al., 1994). The technology was developed over the last several years with funding from the DOE Office of Technology Development, EM50. It is anticipated that this technology will be used primarily in the area of environmental characterization and monitoring.

The basic principle of operation of this technology is to bury a 30 inch long by 2 inch diameter heated cylinder with an array of surface mounted temperature sensors in direct contact with the formation at the point where the flow velocity measurement is to be made. The heat emanating from the probe warms the ground and the water surrounding the instrument. In the absence of any flow past the device, the temperature distribution on the surface of the cylinder will be independent of azimuthal position on the probe and symmetric about the vertical midpoint on the probe. The ends of the probe will be cooler than the vertical midpoint because heat transfer away from the ends of a finite length heated cylinder is more efficient than from the midsection. If there is flow past the device then the heat emanating from the surface of the probe will be advected around the device by the flowing water which will influence the surface temperature in two ways: the probe will be somewhat cooler overall than when there is no flow and the upstream side of the probe will be cooler than the downstream side. Figures $1 \mathrm{a}$ and $1 \mathrm{~b}$ 

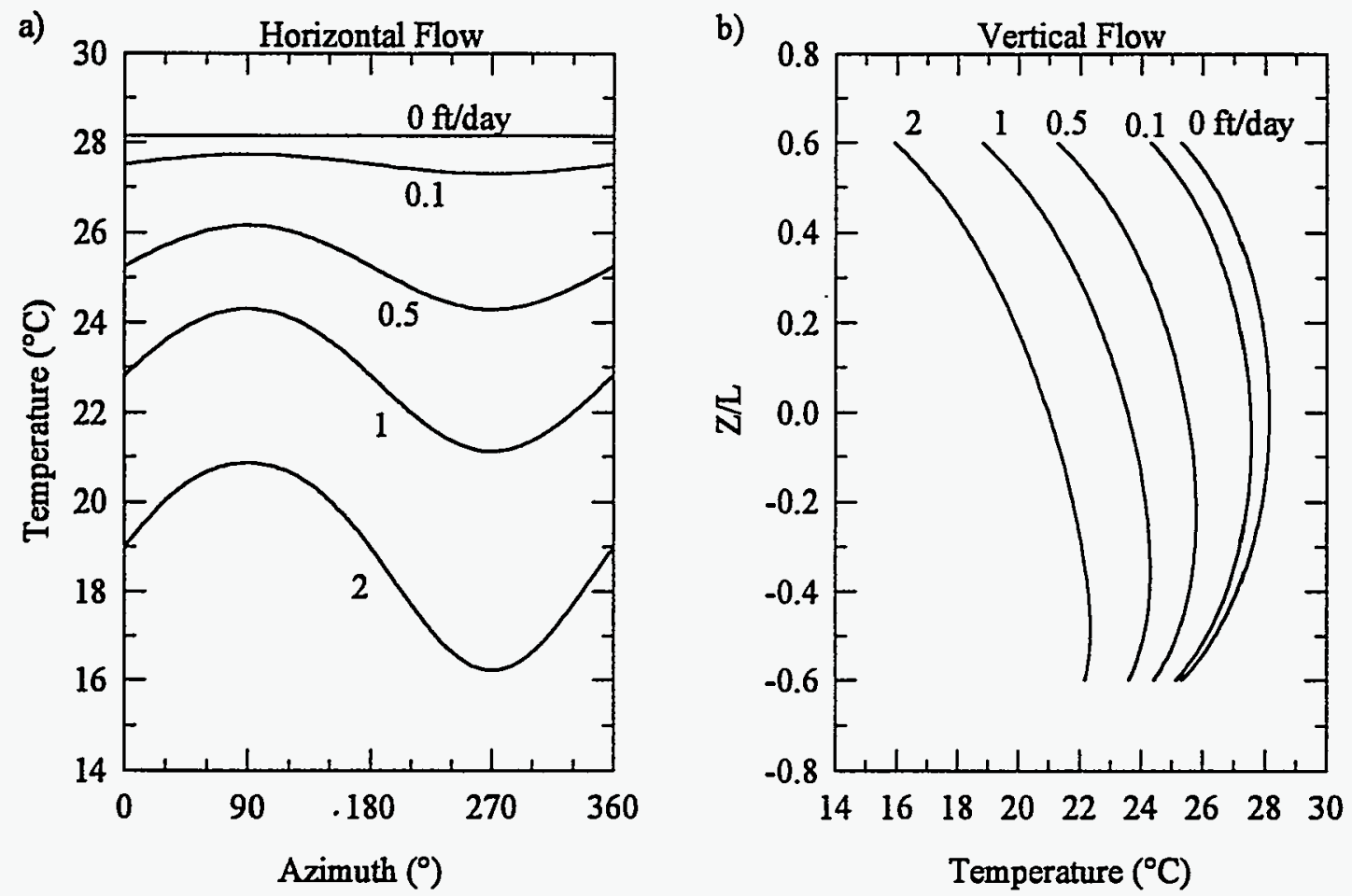

Figure 1 - Theoretical surface temperature distributions expected on a probe buried in a a) horizontal and b) vertical flow field.

illustrate the theoretical temperature distributions expected in horizontal and vertical flow fields, respectively. The direction and magnitude of the full three dimensional groundwater flow velocity vector can be determined by calculating the flow velocity which results in the best fit between the observed temperature distribution on the surface of the probe and the theoretical temperature distribution calculated according to a formula derived by Romero (in press). For a complete description of the technology see Ballard et al. (1994).

An In Situ Permeable Flow Sensor was emplaced in borehole BH7a on July 3, 1994, which was only a few days after the hole was drilled. BH7a is a slant hole which intersected the top of the salt at a true vertical depth of approximately 190 feet below the ground surface. The hole penetrated through approximately 60 vertical feet of salt at an angle of approximately $20^{\circ}$ from the vertical before encountering sand again at a true vertical depth of approximately 250 feet. To emplace the probe, HQ casing was lowered down the hole until sand which had flowed a few feet up into the salt was encountered. Brine was pumped down the casing and the casing was flushed 13 feet past the salt/sand interface in this fashion. The flow meter was lowered down the inside of the casing and flushed out past the end of the casing with brine. The casing was removed and the sand collapsed around the probe, leaving it permanently buried in intimate contact with the formation. The probe was connected to a data acquisition system at the surface via electrical cables housed in 1 inch diameter PVC conduit. This conduit was marked in such a way that the horizontal (azimuthal) orientation of the probe was known after emplacement. The thermal disturbance introduced into the subsurface by pumping brine into the ground was allowed 
to decay overnight and the heater on the probe was activated on July 4th. The probe began providing useful flow information on July 5 th. Data were remotely collected from the probe via modem and telephone connection on a continuous basis until July 21st when operations ceased.

\section{$\underline{\text { Results }}$}

Figure 2 shows the temperatures measured by the 30 temperature sensors on the surface of the probe as a function of time. Before activation of the heater, the temperature of the subsurface was approximately $23{ }^{\circ} \mathrm{C}$. When the heater was activated on July 4 th, the temperature of the surface of the probe increased dramatically with the temperature at some locations increasing much more than at other locations. In most applications, the temperature reaches a steady state after a day or two. In this case, however, the temperature of the probe continued to increase for two weeks, even though the power output of the heater remained constant. In addition, the spread of temperatures decreased with time. Figure 3 illustrates the vertical temperature distribution on the surface of the probe as a function of time. Each curve in Figure 3 shows the temperature distribution on a different day. The most important feature to note is that throughout the time that measurements were made, the top of the probe was relatively cool and the bottom

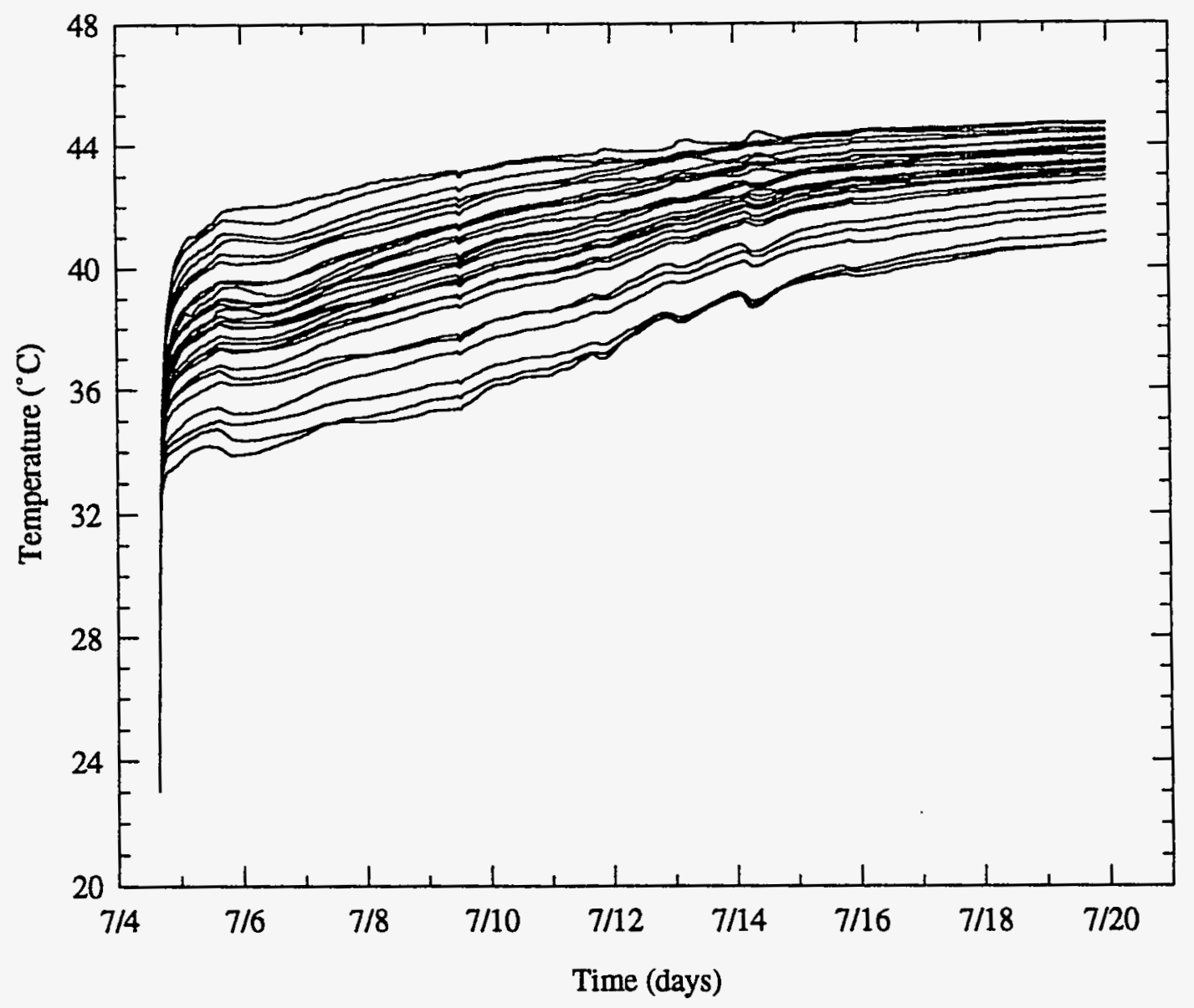

Figure 2 - Temperature of the 30 temperature sensors on the surface of the probe as a function of time. 


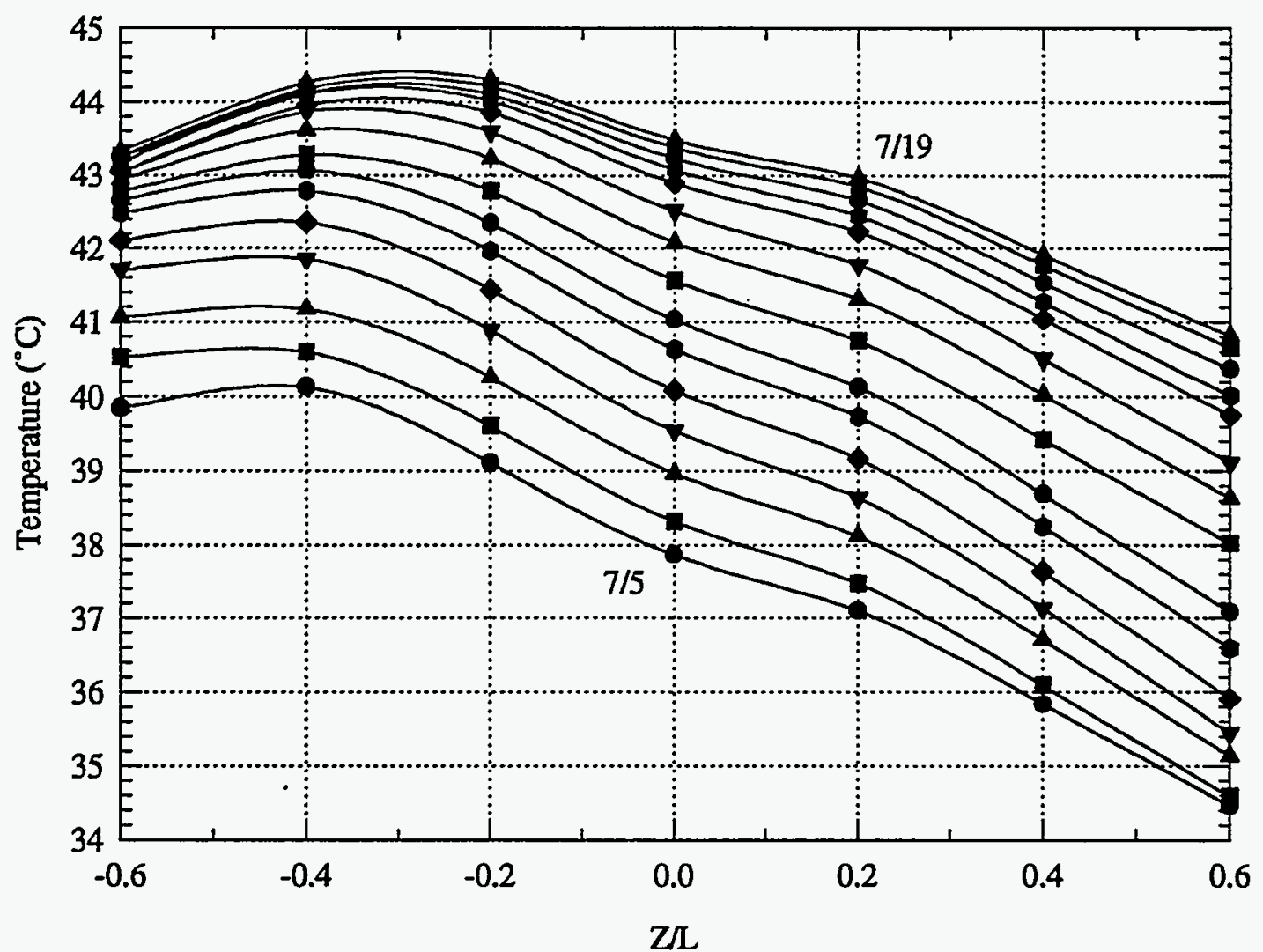

Figure 3 - Vertical temperature distribution on the surface of the probe as a function of time. The symbols represent the measured value at seven of the temperature measurement locations while the curves are cubic spline fits to the data. On the horizontal axis, 0 represents the vertical midpoint of the probe while -1 and 1 would represent the bottom and top of the probe, respectively.

of the probe relatively warm, indicating that the heat emanating from the probe was being advected downward by groundwater flowing vertically downward past the probe. A small component of flow oriented in a direction perpendicular to the long axis of the probe was also observed but is consistent with the fact that probe was not oriented vertically in the ground. The temperature data are unambiguous. Substantial, downwardly directed flow, with insignificant horizontal flow, was observed throughout the data collection period. The fact that the probe increased in temperature and the vertical temperature distribution became more symmetric with time indicates that the downward flow velocity decreased in magnitude significantly during the course of the measurement period.

Generally, the magnitude of the flow velocity past the probe is calculated from the relative temperature distribution on the surface of the probe (Romero, in press; Ballard et al., 1994). The absolute temperature relative to the background formation temperature is ignored. This scheme works well for vertical flow velocities up to about $1.5 \mathrm{ft} /$ day but fails at higher velocities. The approach adopted here (this is the first time that the instrument has been exposed to such large vertical flows) has been to calculate the flow velocity from the absolute temperature of the probe. In this mode of operation, the instrument is being used in a manner analogous to a hot wire 
anemometer. The parameters of the inversion were adjusted so that the results of the two techniques agree at the end of the data collection period when the flow was less than $1.5 \mathrm{f} /$ day.

Figure 4 illustrates the magnitude of the downwardly directed flow velocity as a function of time. At first the magnitude of the flow was around $4 \mathrm{ft} /$ day but then decreased roughly exponentially over the two week data collection period to about 0.5 to $1.0 \mathrm{f} /$ day. The exponential nature of the decrease in velocity suggests that the decrease is due to an artificial phenomenon related to drilling the borehole, brine injection or probe emplacement and does not result from an event with a longer time scale such as an increase in the cross sectional area of the conduit. Several possibilities exist. One is that several thousand gallons of brine with rhodamine dye were injected into the borehole on July $2 \mathrm{nd}$, the day before the probe was emplaced, and several hundred gallons of brine were injected during emplacement of the probe on July 3rd. Since the bottom of the conduit is constricted, most of this injected fluid probably flowed upward as it was injected, raising the hydraulic head above the position of the probe. Such an increase in head would temporarily increase the downward flow velocity in the conduit after injection ended. One can estimate how long it would take such an increase in velocity to decay away. If the water is flowing out of the bottom of the conduit at a rate of 2 gallons/minute (this is the rate at which brine is appearing in the mine) then 2000 gallons of water would flow out of the conduit in roughly 1000 minutes or 1 day. Given these considerations it is unlikely that this can explain the observed decrease in velocity, which took place over a roughly two week period.

Another possible explanation for the decrease in velocity with time is that a localized, high

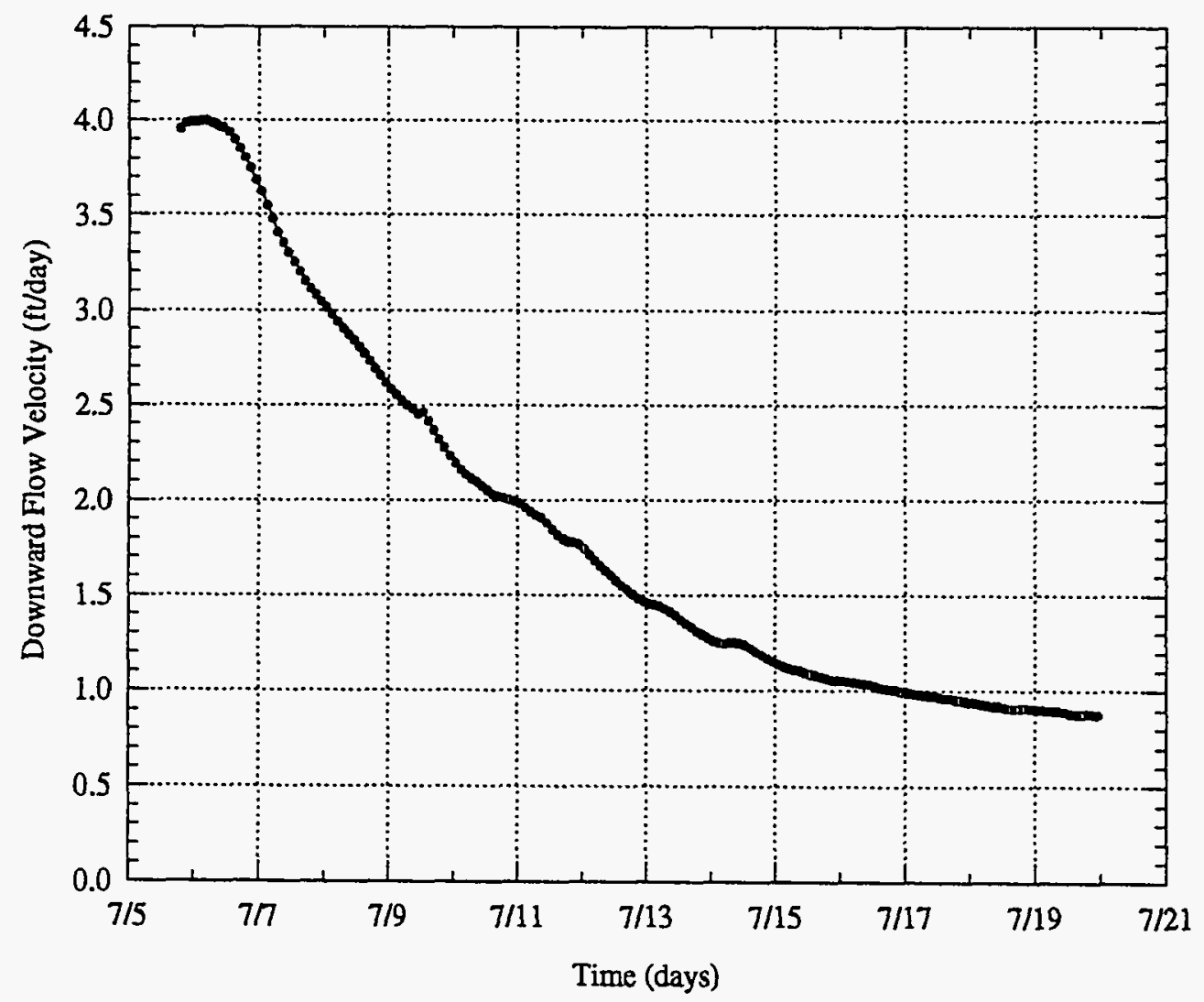

Figure 4 - Magnitude of the downwardly directed vertical flow velocity as a function of time. 
permeability conduit was created through the unconsolidated sand at the time of drilling and probe emplacement. The increase in permeability would have been created by the dislocation of some of the sand and by the removal of relatively fine grained material from the sand during brine flushing. Downward flow would have been focused into this high permeability conduit immediately surrounding the probe. The permeability would have decreased after probe emplacement as the sand recompacted around the probe. Once again, the time scale seems too long for this possibility to be accurate given the highly dynamic nature of the sand in the conduit.

Another observation worthy of note is that the flow sensor was apparently being carried downhole by sand flowing downward in the conduit. As previously mentioned, the probe was connected to the surface by 1 inch diameter PVC pipe. Figure 5 shows the downward displacement of the top of this pipe as a function of time. The data indicate that the pipe was being carried into the hole at a rate of 1 inch/day. A second flow sensor, which was emplaced in borehole BH9 at a depth of approximately 180 feet below the sinkhole, is also being carried downhole at a rate of 1 inch/day. At the time of this writing, no groundwater flow velocity data have yet been obtained from this probe. There is also a pipe which was inserted directly into the sinkhole at the ground surface and the bottom of which is now at a depth of approximately 85 feet. The pipe is also moving downward at about 1 inch/day (Dick Berry, pers. comm.). Altogether there are three observation points, at depths of 85,180 and 250 below ground surface, where downward flow of sand of about 1 inch/day has been observed.

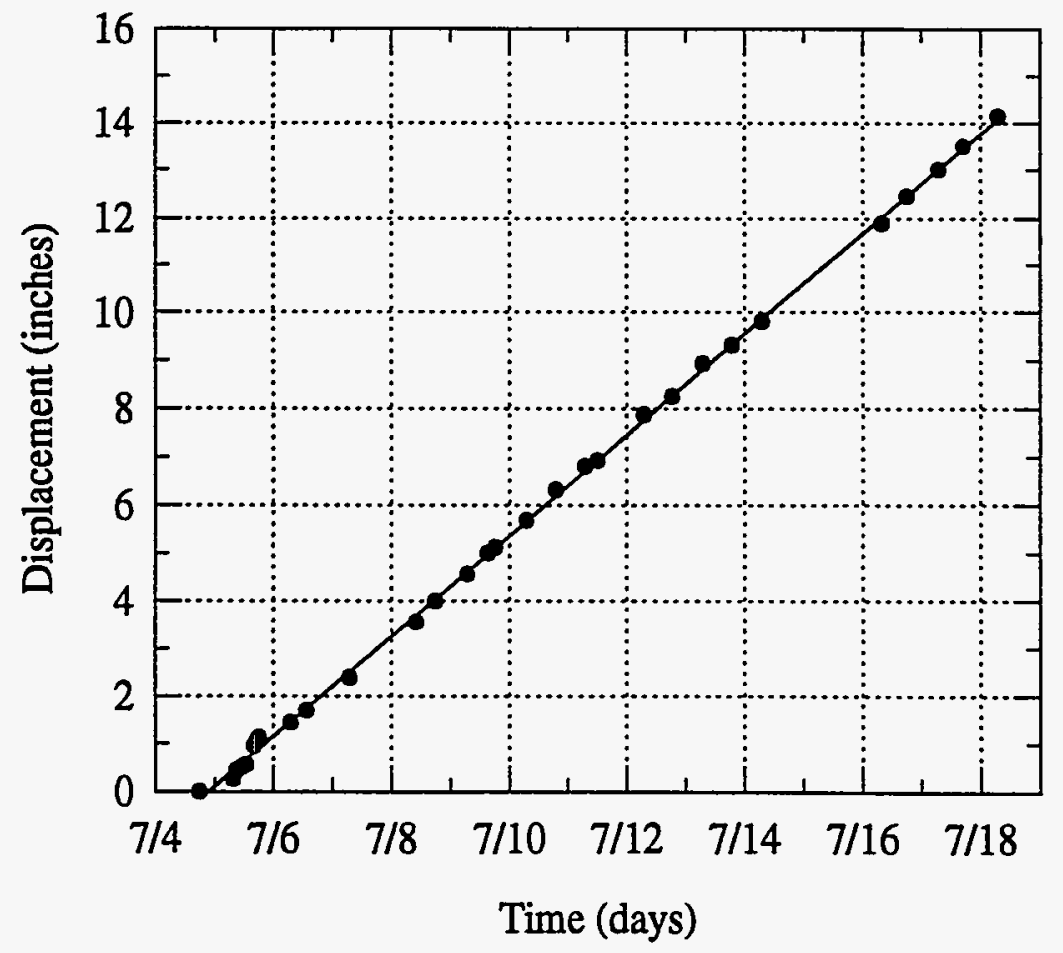

Figure 5 - Tool displacement downhole. Symbols are measured values and the line is a linear least squares fit to the data. The tool was moving downhole at a rate of 1.05 inches/day. 


\section{Conclusion}

The downward flow of both groundwater and sand observed in BH7a strongly suggests that groundwater is leaking into the oil repository. The alternative explanation, that the sinkhole is connected to a channel in the top of salt where water is flowing off the dome would seem to require horizontal flow; only vertical flow was observed. One can use the groundwater flow velocity to calculate the size of the conduit. If brine is being introduced into the repository at a rate of 2 gallons/minute $\left(385 \mathrm{ft}^{3} / \mathrm{day}\right)$ via a conduit where the flow velocity is $0.75 \mathrm{ft} / \mathrm{day}$ then the conduit must have a cross sectional area of approximately $500 \mathrm{ft}^{2}$. If the conduit is circular then it would have a diameter of approximately $25 \mathrm{ft}$. The observation that sand is flowing downward at a similar rate at depths of 85,180 and 250 below the surface suggests that the cross sectional area of the conduit is reasonably constant down to at least 250 feet depth.

\section{References}

Ballard, S., G. T. Barker and R. L. Nichols, 1994, The In Situ Permeable Flow Sensor: A device for measuring groundwater flow velocity, SAND93-2765, Sandia National Laboratories, Albuquerque, New Mexico.

Romero, L. A., in press, Forced convection past a slender body in a saturated porous medium, accepted by Journal of Applied Mathematics. 


\section{APPENDIX 10 \\ DYE INJECTION}

A-10-1 
WEERS ISLAND MINE

DYE INJECTION

PURPOSE

Rembco Engineering Corporation, under contract to DynMcDermott Petroleum operations Company, injected dyed tracer dye into boreholes $\mathrm{BH}-7 \mathrm{~A}$ and $\mathrm{BH}-9$ during June and July 1994 as a part of the Weeks Island Diagnostic Monitoring Program. The dye injection was performed to establish irrefutable proof of a hydrologic connection between the oil storage chamber at Weeks Island and the overlying aquifer.

\section{PROCEDURE}

The basic procedure for injection of dye into the sinkhole dissolution zone is to $\mathrm{mix}$ a $10 \%$ concentration of Rhodamine WT in saturated brine on the surface. This concentration is the highest concentration achievable. The dye is then pumped down the borehole, using a tremie tube, while monitoring the brine level in the well casing to ensure that injection pressures are kept low. Actual procedure used is provided in Attachment No. 1.

See Attachment No. 1

Attempts at injecting dye into the bore of borehole $\mathrm{BH}-9$ resulted in a backflow of brine in the annulus of the well casing. After receiving approval from SPR New orleans, the tremie tube was jetted into the formation to attempt to improve dye take. These actions eventually resulted in a sustained flow of $5 \mathrm{gpm}$ of dye. A total of 2000 gallons of dye saturated brine were injected using this procedure.

Samples of brine will be taken from the fill hole sump on a daily basis for analysis for Rhodamine WT.

\section{OBSERVATIONS / RESULTS}

No tracer dye has been identified in the fill hole sump to this date. It is anticipated that a dye transit time of at least one month will be necessary. Consequently, the findings to date are as expected. Logs from contractor daily reports are provided as attachment No. 2 . 
ATTACHMENT NO. 1

DYE PLACEMENT PROCEDURES

A-10-3 
June 22, 1994

Revision 1

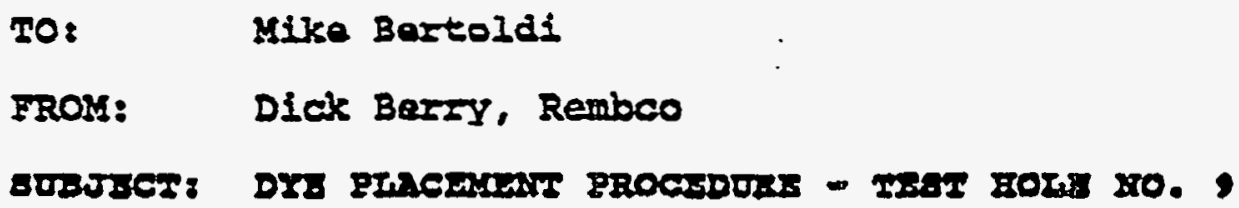

3ho four-inch (4n) diameter slant caning will be left ampty with a ramovable cap. It should backilil with groundwater/brine to the groundwater lovel.

For dye placement, 100 pounds of Rhodamine wr dye will be gravity sed at about a lot concentration in saturatend brine. In all, 2,000 gallons of dye solution will be placed diractly on top of the salt, in the proximity of the top of the potential leak area. Once begun, dye placement will be continuous. The dye solution will be followed by 1,000 gallor, of 1001 satrarated brine.

Two (2) mixing tanks will be used to allow continuoug elow. A pump will move the dye through a 0.5 inch ID plastic tramia tube zan to the bottom of the hole. Plow rate will bo monsurad with a conatant raading float mator. Iiquid level in the four-inch (4") casing will be monitored with a conductivity probe lowered down the casing. The probe is 0.25 ' lianeter stift cable some 400-foet (400') zong. Plow pressure w1ll be calculated frou the rise in liquid level in .the casing.

\section{PROCEDURE}

1) Insert the tremie tube to the bottom of the casing (175 - 185 faet). Ilft off six-ineher $\left(6^{\mathrm{p}}\right)$ and secure.

2) Insart the conductivity probe paraliel to the tramio tuba and measure the liquid lavel. Take initial rasdings of flow va level.

3) Bugin fanding brine at 1 gpm to stabilize and f1II tha system.

4) Introduce the dye baginning at 1 gpm. Allow Ifquid lovel to stabiliza. Read stable conditions for one (I) minute. Recore all Llow zate and Ilqgid Imvel readings. 
5) Incrase dye infection rate at 0.5 gpm increments, each time allowing the liguid lavel to stabilize for at least one (I) minute.

6) The rate of dye introduction will be increased to a maximum of $10 \mathrm{grm}$. If a condition is rexched where the Iiquid Ievel continues to rise and does not stablilze. the rate will bo backed orf to the next lowest rate and continued until all the dye is introduced.

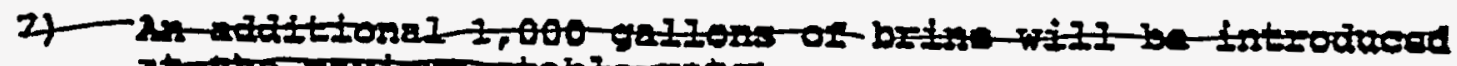

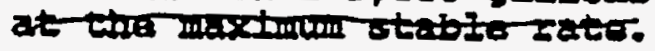

8) The equipment will bo dirmantled. The conductivity probe will be removed. Wo tramie pipe will be Ieft securad. In the hole. The cap $w 112$ be raplaced on the pipe, which will be left in that condition for further observation.

ce: BOb Gump, BE-25

Marabali Jackcan, EF-TI

Jim Iirm, sandia

Iim LCANIry, EF-20

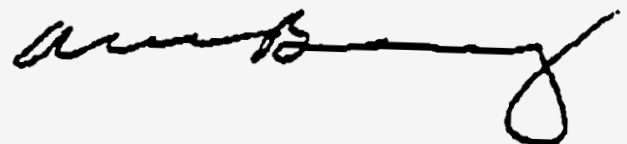

Ren K1213, ER-20

Bab HYors, FE-4422

Richara PhiIlipg, ER-WI

Iarey Rousseau, FB-443

D111 Shourbaji, ER-4421 
To: Mike Bertold

FROK: DICK BerzY - Rembco

SUBUECT: DYE PLACELENT PROCEDURES - TEST HOLE NO. 9 MODIFICATION

At the end of the dye injection, only enough dye will be fad into the casing to displace its contents into the formation.<smiles>CCCCCCCCCCCCCCCCCCCCC</smiles>

CC: Bob Gump, EF-25

IfarabalI Jacksor, EF-FI Jim Iinn, Sandia

IIn Metlenry, EF-20

Kes H118, ET-20

Bob Nyars, FE-4422

Richard Fbil11ps, ER-WT

Larry Rousseau, FT-443

B1II Showrbaji, FE-4421 
ATTACHMENT NO. 2

DAILY LOGS

$$
\text { A-10-7 }
$$


JUL- $20-Y 4$ IHU II:IL

or Rin $\operatorname{li}^{3}$ Date $4 / 27$.

CHKD. Br.............DATE

suarar Sinlehuie ìjue Test

$4010+1$

SHIET No. $\frac{2}{a(13}$ or.] Jon No. Qर्या 3

Tine Rete hivel alew Pressure $Q$ Total $Q$ Goumunt

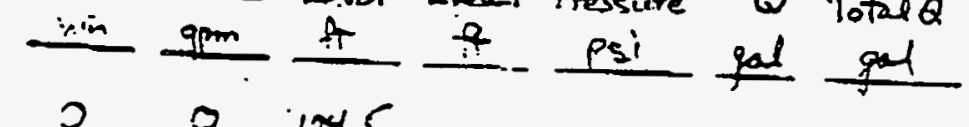

$$
\begin{aligned}
& \begin{array}{ccc}
0 & 0 & 124.5 \\
5.5 & 1.0 & 97.7
\end{array} \\
& \begin{array}{llllllll}
7.0 & 1.0 & 97.7 & 5.8 & 3.4 & 5.5 & .5 .5 & \text { pressure simitie }
\end{array}
\end{aligned}
$$

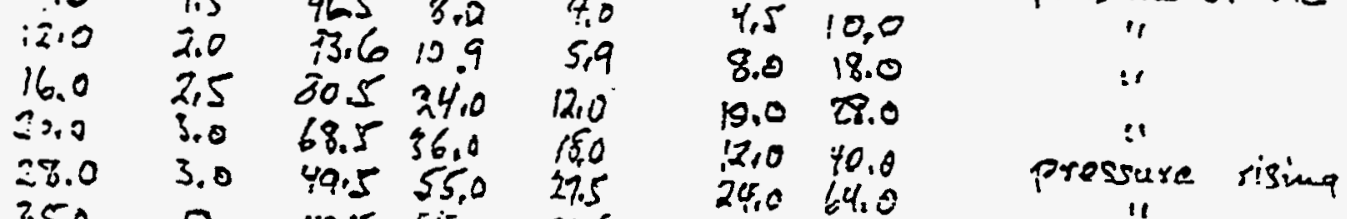

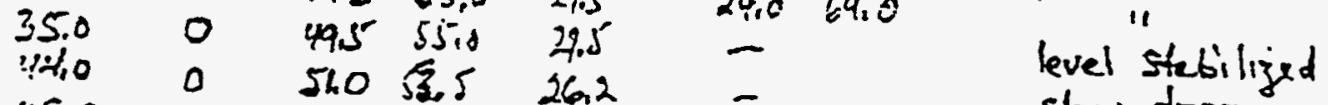

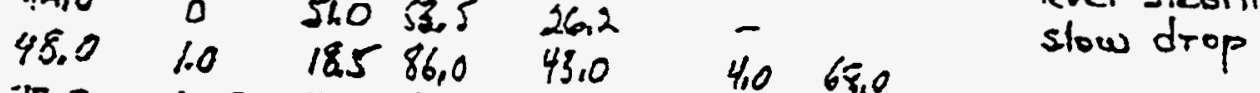

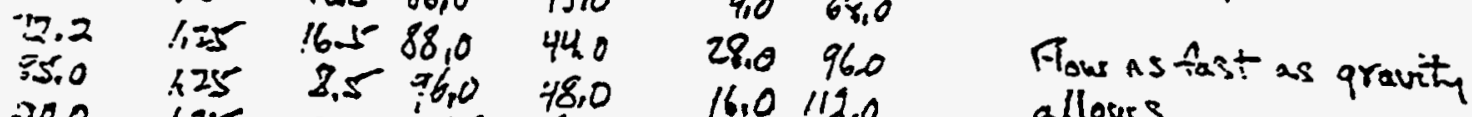

$$
\begin{aligned}
& \begin{array}{lllllll}
70.0 & 125 & 0,5 & 76,0 & 78,0 & 16,0112,0 & \text { allous }
\end{array}
\end{aligned}
$$

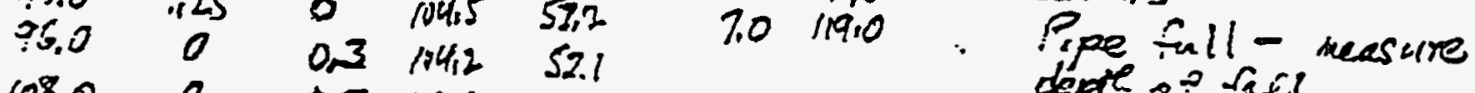

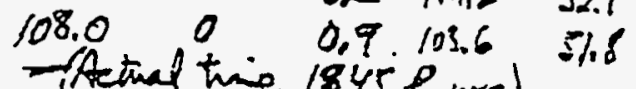

$$
\begin{aligned}
& \text { depore o rael } \\
& \text { About } 6 \text { ib of dye t.tal. }
\end{aligned}
$$

$6 / 28$

Ser attachad thie rejurt fo dye injectar data.

After firct wash througle in casing, about $25 \mathrm{gal}$ of dye Arlution was injected and them blochage ocanned aguin. litash down of injection pipe costruned throgh wery hud layer on bleckage, and flow washed thingugh. Dye arso

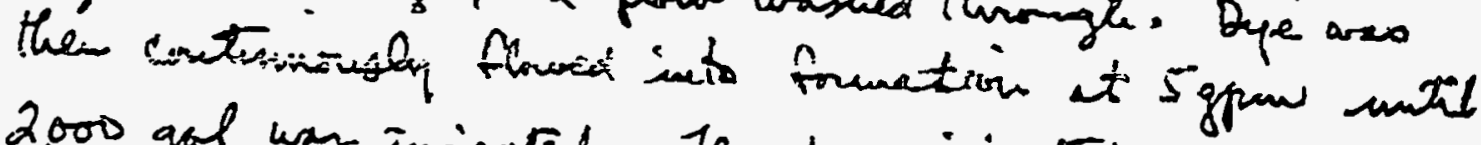
2,000 gol wast injected. Heo dye injected was Rhod amine wT. Tien $(10)$ tho mane dissolued in 200 gol of brime.

$$
\text { A-10-8 }
$$




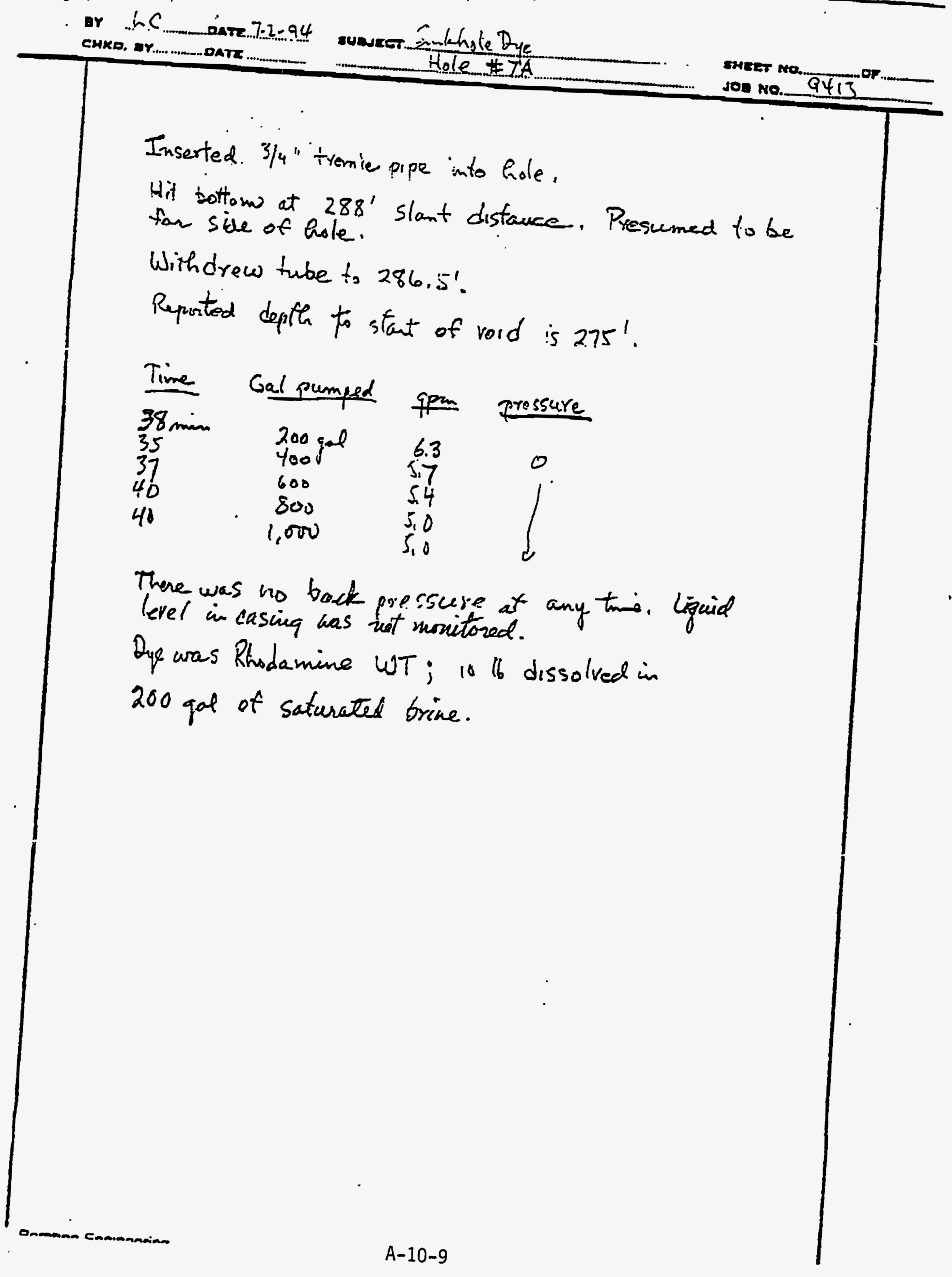




\section{APPENDIX 11}

\section{SURFACE SELF POTENTIAL SURVEY}

A-11-1 
date:

to:

from:

July 29, 1994

J. K Linn, 6113

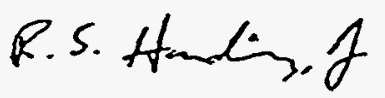

subject: $\quad$ Surface self potential survey, Weeks Island SPR sinkhole

This letter briefly summarizes the results of the surface self potential (SP) survey conducted at the Weeks Island sinkhole site July $15-18,1994$. Please find attached the full text of a preliminary report on this work dated July 25,1994 , by Robert F. Corwin, the consulting geophysicist who conducted the survey.

The primary purpose of the SP survey at the Weeks Island sinkhole site was to establish whether this technique could provide a rapid and relatively inexpensive means of locating water table drawdown features related to sinkhole development. This technique is the only geophysical surveying method in which the signal response is derived primarily from groundwater movement. In this application, SP surveying is based on the streaming potential effect, in which a DC electric field is established by fluid flow through permeable soil and rock. The physics of streaming potential and further background on SP surveying will be provided in the final repori, to be submitted by August 25, 1994.

Based on the attached preliminary report, the following observations can be made:

(1) SP data quality were generally good over the roughly 9,000 line feet of data acquired. Although significant cultural noise was present within the surveyed area, standard potential field data analysis techniques were sufficient to separate signal from the noise.

(2) The data analysis indicates significant streaming potentials ( $100 \mathrm{mV}$ peak-to-peak) in the area of the sinkhole and the two seismic anomalies north of Morton Road.

(3) Matching synthetic data with the observed SP field indicates that the anomalous streaming potentials are likely to result from vertical fluid flow along a set of vertical or near-vertical planar surfaces, probably shear zones or faults. 
(4) At the sinkhole site, the depth to the field source is very shallow (about $5 \mathrm{ft}$ ), indicating probable vadose zone flow. North of Morton Road, close to the seismic anomalies, the top of the field source appears to coincide roughly with the water table depth (90 f).

These findings are consistent with the results obtained from surface seismic and other. geotechnical data gathered at the Weeks Island sinkhole site. Thus it appears that the SP method is potentially quite valuable as a reconnaissance tool for identifying the location of anomalous groundwater movement at Weeks Island. However the method will be most useful when the the SP results are combined with other sources of information, e.g., from borehole hydrologic measurements and surface seismic reflection data.

copies:

J.T. Neal, 6113

M.W. Scott, 6114 
July 25,1994

Mr. Richard S. Harding, Jr.

Dept. 6114 M/S 0705

Sandia National Laboratories

P.O. Box 5800

Albuguerque, New Mexico 87185

Dear Mr. Harding:

This letter presents a brief, preliminary summary of the results of the self-potential (SP) survey conducted at the Weeks Island, Louisiana site on 16 through $18 \mathrm{JulP}$ 1994. The locations of SP survey lines $S P-1$ through $S P-12$ are shown on $F$ igure 1 . Lines $S P-1$ through SP-5 were the initial lines laid out by Sandia. Lines SP6 through SP-12 were added in the field to provide additional coverage and detail in areas of interest. Total SP coverage was about 9000 line-ft at a nominal station spacing of $25 \mathrm{ft}$.

Figure 2 shows hand-drawn preliminary SP contours based on the data listings and profiles provided to you at the conclusion of the field survey. The contours are overlaid on the base map of Figure 1 . Note that the nominal contour spacing is 20 millivolts (mV) ir the western portion of the survey area and $10 \mathrm{mV}$ in the eastern portion. SP data quality for this survey was very good, and incividual SP readings were reproducible within a few mV (less than one contour interval).

Very large-amplitude SP variations, probably related to artificial sources, were measured over much of the slirvey area. A positive source of this type was located west of the western end of line SP-1 (Morton Road). A negative artificial point source was located near the northern end of line SP-3 (on Snyder Road), and a Iinear negative source was associated with a power cable running along Fill pole Road.

A shorter-wavelength anomaly appeared to: De superimposed on the long-wavelength variations in the central portion of the survey area. This short-wavelength anomaly is characterized by the +120 $\mathrm{mV}$ positive closure centered about $150 \mathrm{ft}$ northwest of the sinkhole and the $-30 \mathrm{mV}$ negative area about $100 \mathrm{ft}$ east of seismic feature \#3. As shown on Figure 2. Profile $A-A^{\prime}$ was drawn through these areas.

Figure 3 shows the measured SP data along Profile A-A', along with a trend line that represents the assumed long-wavelength sP data in the absence of the short-wavelength anomaiy. Subtracting the trend line from the measured data produces the "residual" short-wavelength SP anomaly profile shown on Figure 3 . A 
preliminary source model for the residual anomaly was determined using vertical dipolar sheet sources as described by D.V.

Fitterman. Such sources are often observed where fluid is moving along or between fault or fracture zones. It was found that three sheets ( $S 1, S 2$, and $S 3$ ) were needed to provide an acceptable fit between the observed and modeled residual profiles. Sheet

parameters are sumnarized in the table below, and sheet locations are shown on Figures 2,3 , and 4 .

$\begin{array}{cccccc}\begin{array}{c}\text { Sheet } \\ \text { no }\end{array} & \begin{array}{c}\text { X (ft on } \\ \text { Profile } A-A^{*} \text { ) }\end{array} & \begin{array}{c}\text { Depth to } \\ \text { top (ft) }\end{array} & \begin{array}{c}\text { Depth to } \\ \text { base (ft) }\end{array} & \begin{array}{c}\text { Balf-length } \\ \text { (ft) }\end{array} & \begin{array}{c}\text { Current } \\ \text { (mA/sq ft) }\end{array} \\ \text { S1 } & 330 & 5 & 540 & 50 & -150 \\ \text { S2 } & 420 & 5 & 540 & 50 & -150 \\ \text { S3 } & 600 & 90 & 540 & 50 & -400\end{array}$

The $\mathrm{X}$-coordinate and depth to the top of each sheet are reasonably well constrained, but the, other parameters are poorly determined. Specifically, no attempt was made to vary the 50-ft half-length of the sheets to study the effects of the sheets in locations other than directly along Profile $A-A^{\prime}$.

The locations, orientation, and depths of the sheets appear to be related to the sinkhole and to seismic features $\# 2$ and 3 . The general location and approximate north-south orientation of the sheets correspond to the southeastern corner and eastern boundary of the upper mine level. The (poorly determined) depth to the bottom of the sheets corresponds to that of the upper mine level.

ineets S1 and S2 bracket the sinkhole, and the depth of 5 ft to the top of the sheets corresponds to a surface feature. A : cossible preliminary geologic interpretation of these sheets is :hat they represent the boundaries of a fracture zone within thich vadose and deeper water is moving downward. Sheet S3 runs letween seismic features $\# 2$ and $\# 3$. The $90 \mathrm{ft}$ depth to the top of his sheet corresponds to that of the water table and of the eismic features. A preliminary geologic interpretation of this heet is that it represents a fracture, carrying downward water low, that has not propagated to the surface.

ore details regarding the SP data acquisition, modeling, and nterpretation will be provided in our final report. Please let $e$ know if you have any questions regarding the preliminary nformation provided in this letter.

very truly yours,

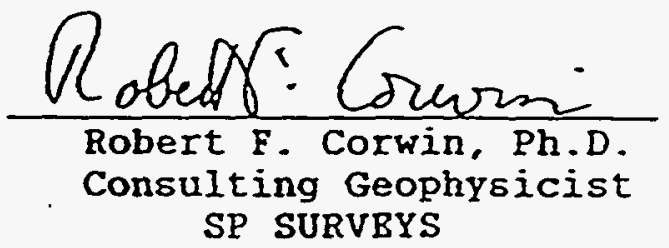




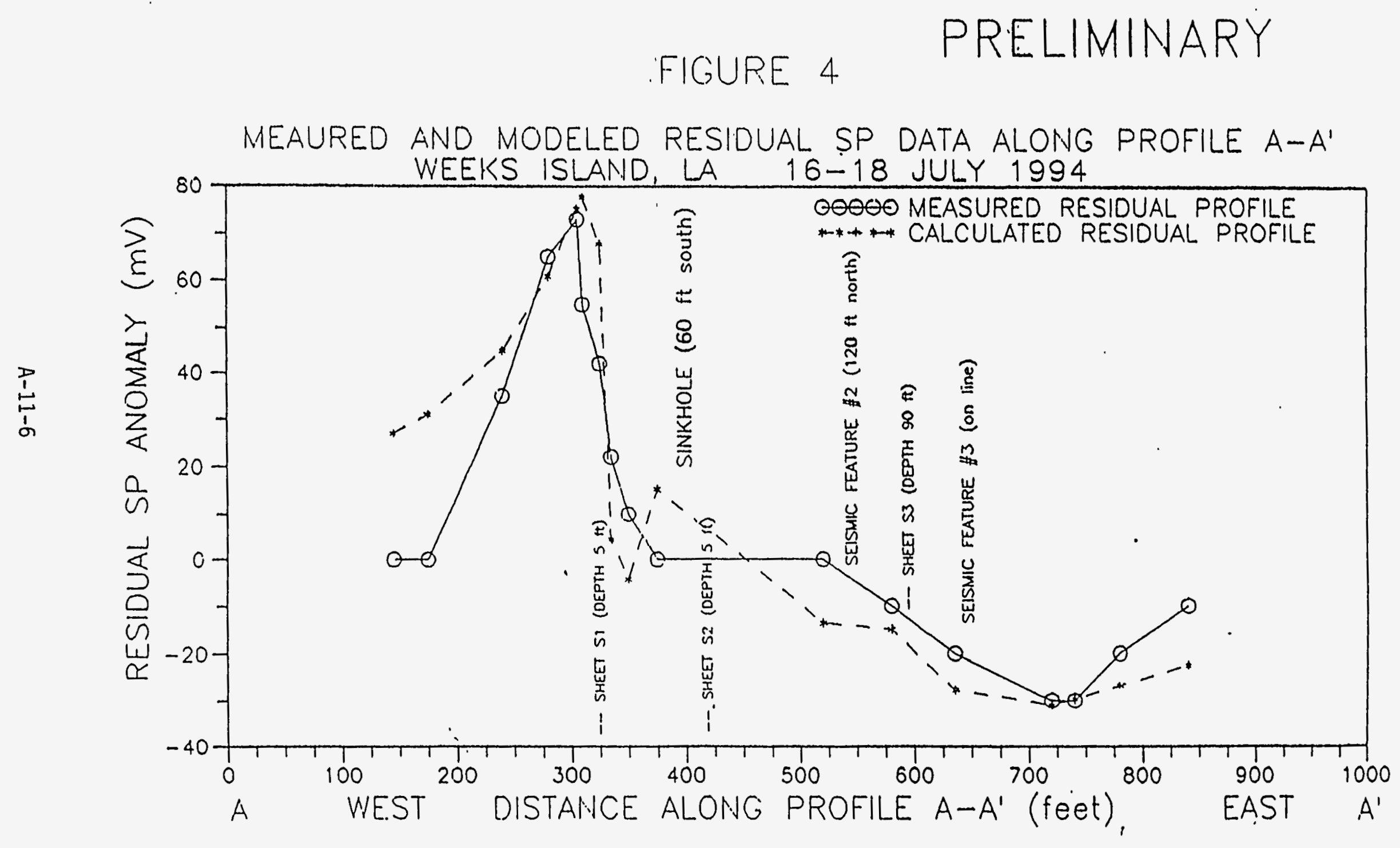




\section{FIGURE 3}

\section{PRELIMINARY}

SP DATA ALONG PROFILE A-A'

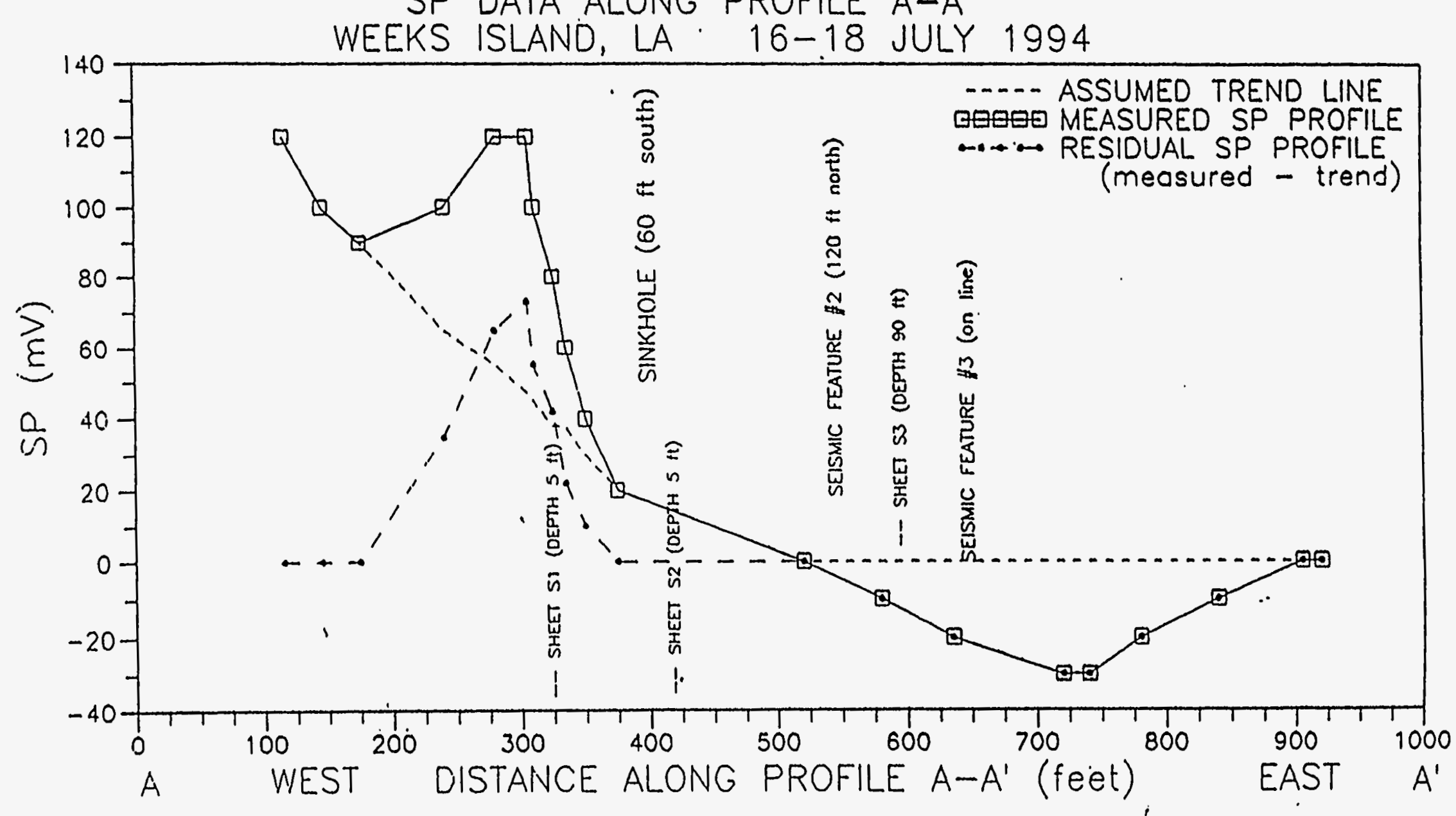




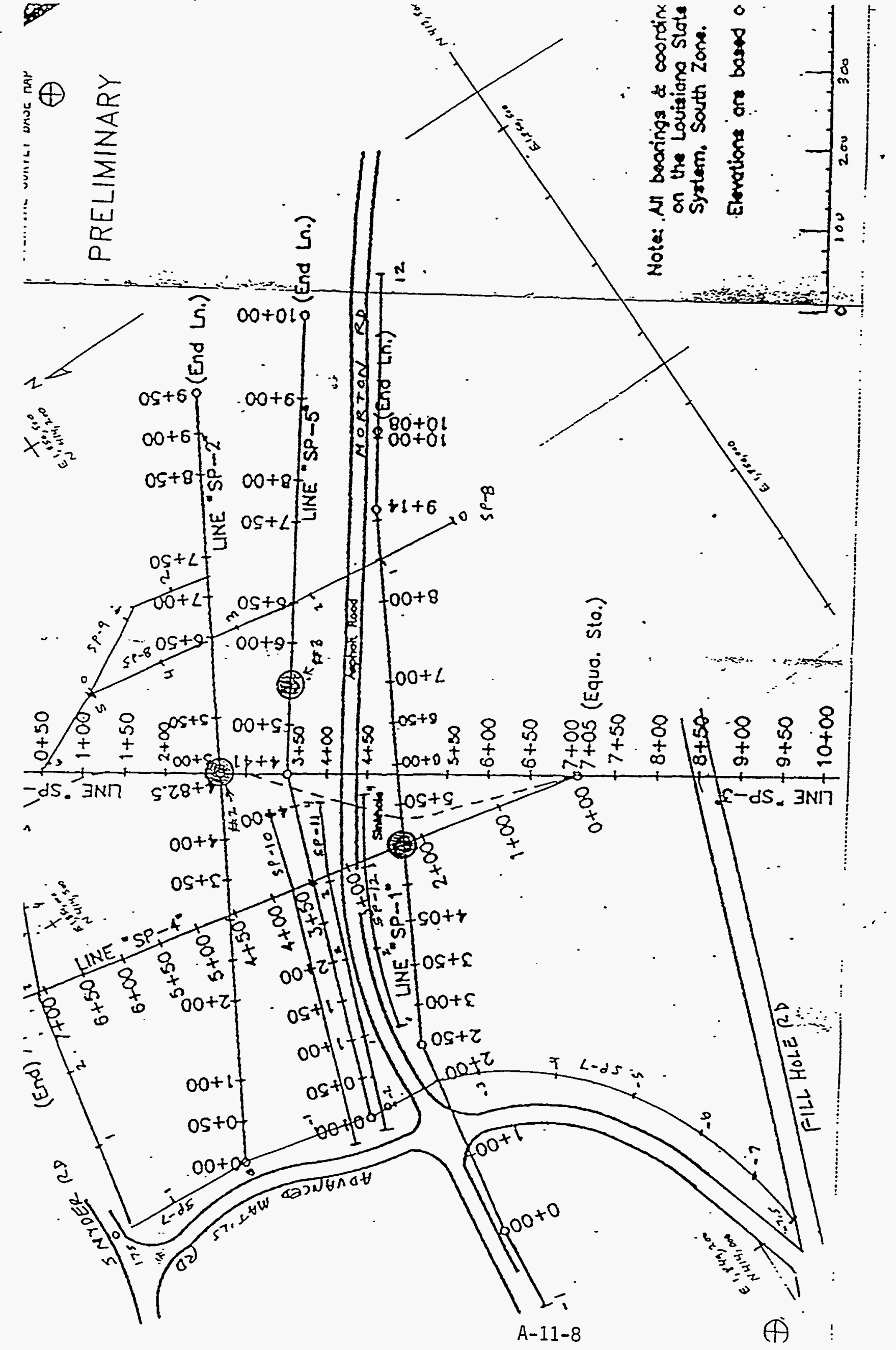




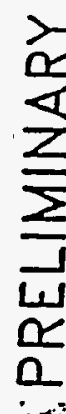

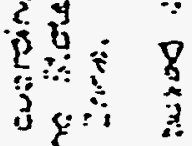

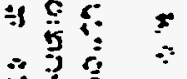

$\because 3$

.

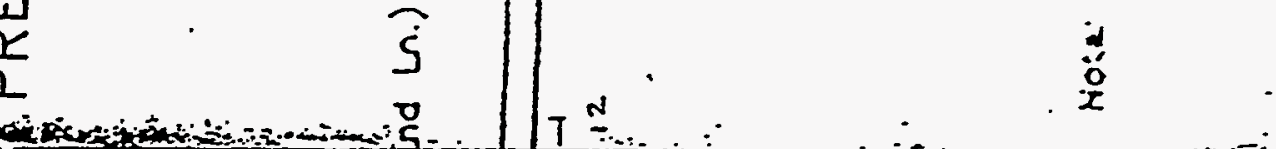

$\therefore \quad 50+0 ! 9$

$\because \because \frac{0}{5}$

$11: 0 \mathrm{~s}+60^{3}-100+6$ $1 ; 00+6$ $1 ! 3 \operatorname{setcos} 90+8$

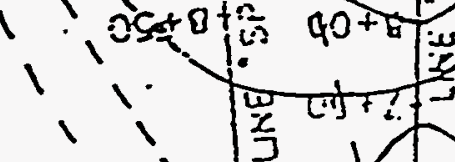

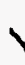
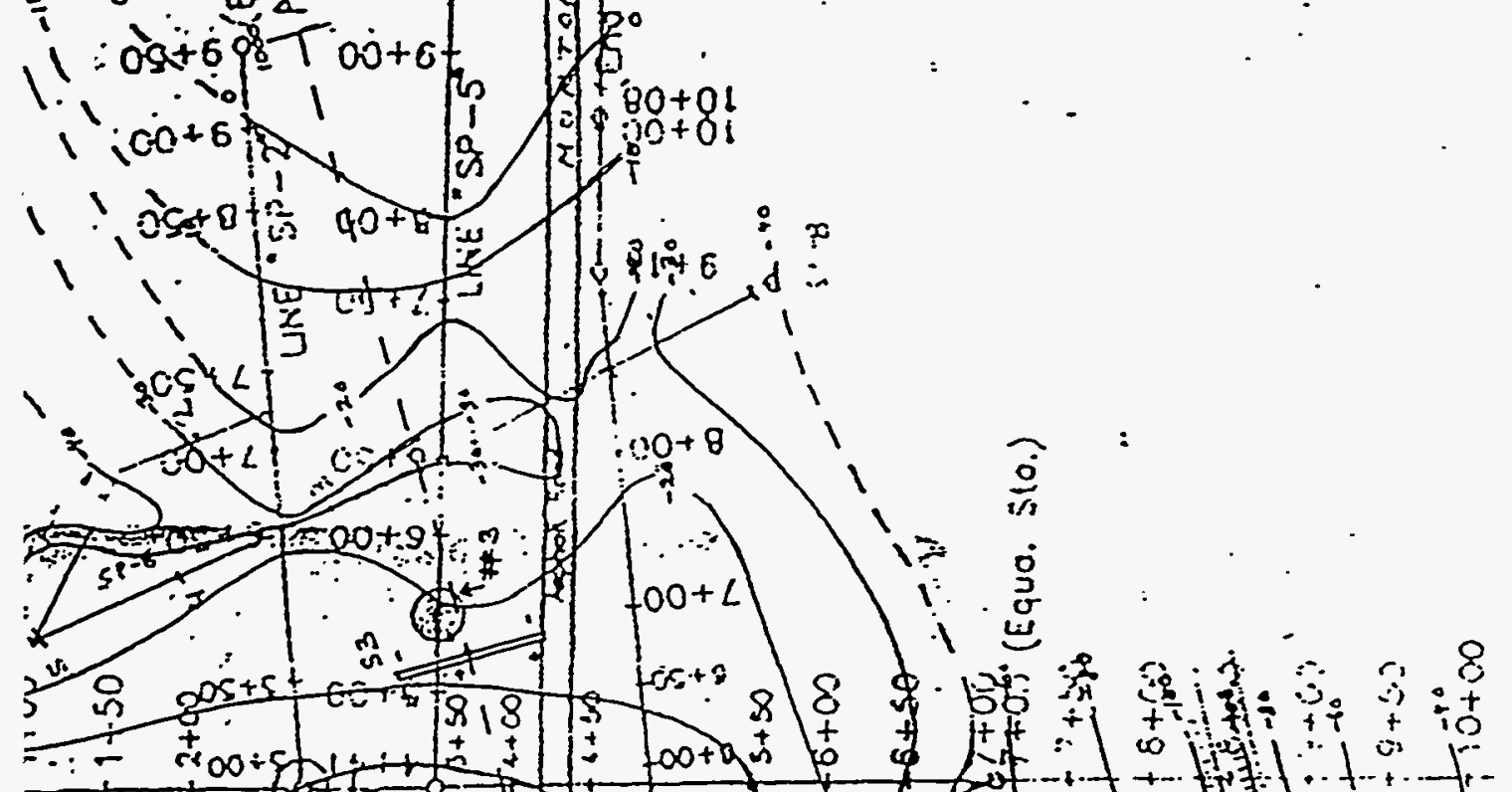

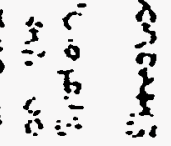

a 20

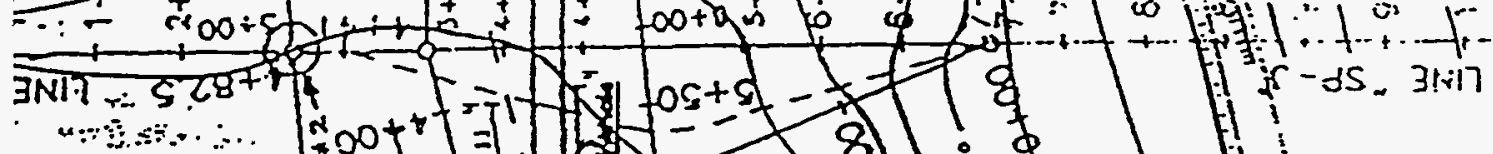
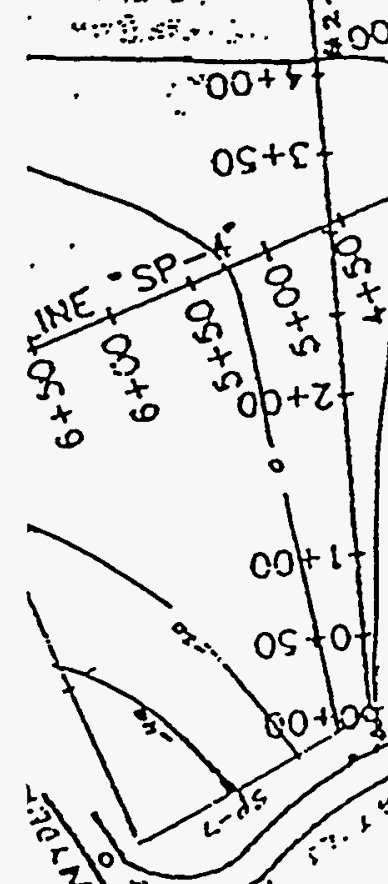

$$
\text { 2 }
$$

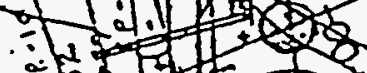
(1)
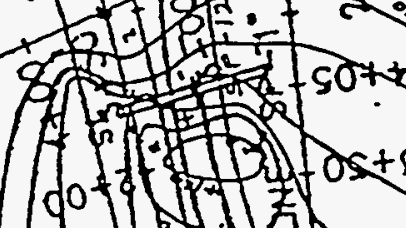

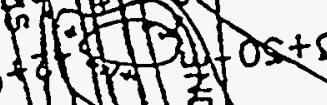
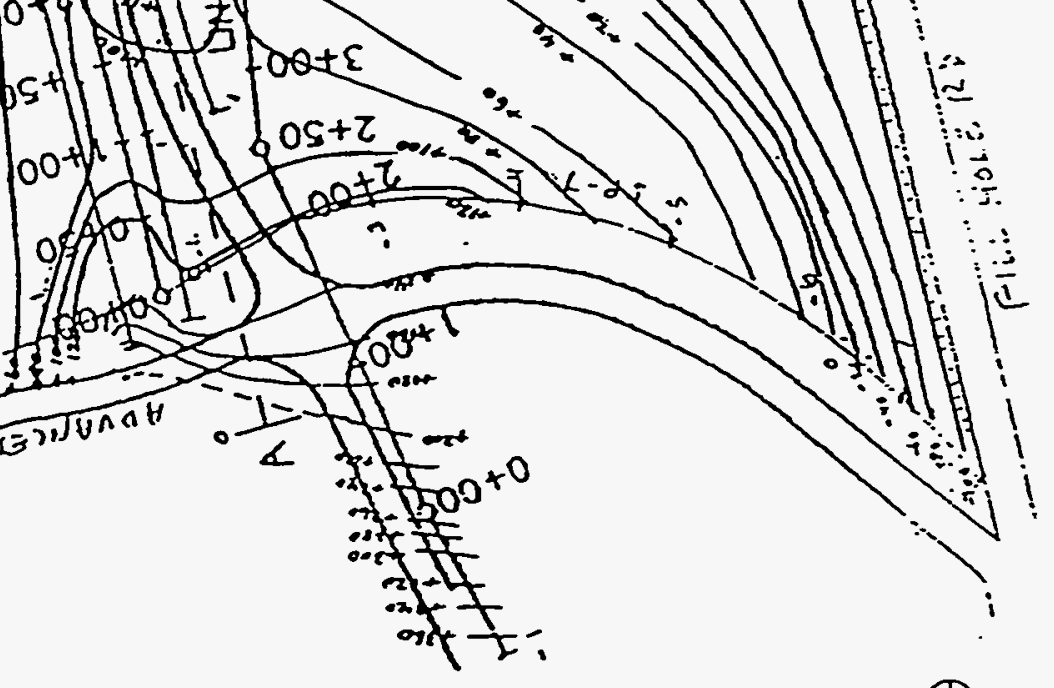
APPENDIX 12

CAPILLARY PRESSURE IN WEEKS ISLAND SAND

A-12-1 
date: March 17, 1994

Abuquerque, Now Maxioo 871850706

to: Distribution

from: R. W. Ostensen 0706

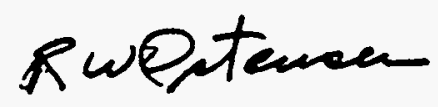

subject: Capillary pressure in Weeks Island sand

Pressurization of the Weeks Island mine raises the possibility that oil could begin migrating up through any - fissures above the salt and below the sinkhole. Capillary pressure is one mochanism that could belp keep the oil at Weeks Island from entering the sand-fill in fissures. The sand should be water-wet since it has been in long-term contact with brine, so capillary pressure would tend to keep the oil from entering the sand. I reviewed the question of capillary pressure in sands to see whether the capillary pressure could provide a sufficient barrier to oil migration, and this memo summarizes my conclusions.

Capillary pressure has been correlated using the Leverett J function (R. E. Collins, Flow of Fluids through Porous Media, Pet. Pub. Co., Tulsa, 1976), which can be written (in consistent units) as

$$
P_{c}=\sigma(\varphi / k)^{1 / 2} \mathrm{~J}\left(S_{w}\right)
$$

where $\sigma$ is the surface tension in an oil-water system, $\varphi$ is the sand porosity, $\mathbf{k}$ is the permeability and J, the Leverett function, which depends only on the saturation of the wetting phase, $\mathrm{S}_{\mathrm{w}}$. This correlation appears to be quite accurate for unconsolidated sands, where the I function is almost a constant over the range $S_{w}=.2$ to 1 , and equals about 0.42 at $S_{w}=1$.

This can be applied to Weeks Island by using data on permeability of sands from samples taken above the salt, as discussed in SAND86-7181, Additional Geotechnical Studies. Strategic Petroleum Reserve, Dec 1986, by Acres Int. Corp. Two boreholes were drilled down to the salt and various logs and samples taken. They report that most of the material above the salt is sand, with alternating layers of a tan sand and a coarse, rust-orange sand and gravel mix. It appears that very roughly 90 percent of the sand was the finer, tan sand. Samples of sand were combined for permeability measurements. The results from the two boles were about the same (pg E-18), with an average conductivity of $3 \times 10^{-4} \mathrm{~cm} / \mathrm{sec}$ (geohydrology units). The conductivity, $K$, is related to permeability by

$$
\mathrm{K}=\mathrm{kpg} / \mu
$$


where $k$ is permeability, $g$ is acceleration of gravity, $\rho$ is fluid density and $\mu$ is fluid viscoxity. By assuming the tests were done in fresh water $\left(\rho=1.0 \mathrm{gm} / \mathrm{cm}^{3}, \mu=0.01\right.$ Poise, $\left.g=980 \mathrm{~cm} / \mathrm{s}^{2}\right)$, the permeability is found to be $3 \times 10^{-9} \mathrm{~cm}^{2}$, or 0.3 Darcies (1 Darcy $=10^{-8} \mathrm{~cm}^{2}$ ).

The authors of SAND86-7181 suggest this is a low value for sand as coarse as this and indicate that mixing sand samples prior to the permeability measurements makes the data unreliable for fluid flow modeling. Nevertheless, the data can be used to extimate capillary pressure, by using the Leverett correlation, above, especially since permeability appears under a square root so the estimate of capillary pressure is not strongly sensitive to errors in estimated permeability. The surface tension is reported to be 50 dynes/ $\mathrm{cm}^{2}$ in an octane-water system (Handbook of Chemistry and Physics, $48 \mathrm{Ed}$., Pg F-29). If porosity is assumed to be 0.3 , the capillary pressure becomes

$$
\begin{aligned}
P_{c} & =50\left(0.3 / 3 \times 10^{-9}\right) 1 / 20.42, \\
& =2.1 \times 10^{5} \mathrm{dynes} / \mathrm{cm}^{2} \\
& =3.0 \mathrm{psi}
\end{aligned}
$$

Given the uncertainty in the data and in the state of sand dribbling into a fissure in salt, coe can extimate the capillary pressure to be in a range from somewhat below 1 psi to somewhat above 10 psi. These pressures are too low to provide a reliable barrier to oil migration into the fissures and out of the mine if the system is pressurized to retard inflow and retuce further fracturing. This indicates that great care might be noedod in employing the pressurization strategy in order to avoid release of oil.

Two things limit the pressure that could be applied to the oil in the mine. First the overpressure must be kept low enough that oil would not be pumped through fissures if they became oil-filled. Second, the inflow rate of water must be sufficient to prevent outflow of oil caused by bouyancy. I am working on estimates for the second limit. Simple estimates for the first limit can be derived from density estimates. The head of water down to the top of the salt is about $90 \mathrm{psi}\left(0.45 \mathrm{psift} \times 200^{\prime}\right.$ below sea level). The pressure difference through an oil-filled fissure in 375 fect of salt would be about 138 psi ( 0.37 psift x 375). If we apply a 20 percent safety margin to the oil head, we could overpressurize the top of the mine by 200 psig ( $90+$ $0.8 \times 138$ ). If we could be assured that all fissures were water-filled, the water in them would be close to saturated brine with a density of 0.52 psi/th, so the system could be pressurized to 246 psig $(90+$ $0.8 * 0.52 * 375$ ) with the same 20 percent safety margin. Thus, allowing for the possibility of oil filling the fissures requires about 46 psi lower overpressure. To completely balance incoming brine, we would nood 285 psig overpressure $(90+0.52 * 375)$, so a 200 psig overpressure would reduce the inflow rate by $70 \%$, 
which is a significant improvement. In addition, this degroe of pressurization is likchy to have a very beneficial effect on the local frecturing rate in the salt.

As a sidelight to this, the geotechnical report referenced above indicates that a five foot thick layer of marine clay lies immodiately above the salt. This layer can be assumod to be impervious to flow, for all practical purposes. (The geotechnical report indicates that circulation was lost after penetrating the clay in one of their two borcholes, and $200 \mathrm{gpm}$ of drilling mud could not fill the bole.) If the clay is resistant to frecturing, this suggests that water leakage into the salt would be through one of the many penetrations of the clay (over 100 of them), drilled into the salt over the hast 75 years. Perhaps the location of any sinkholes could be correlated to the locations of old boreboles or mine shafts. If the clay still forms an impermeable barrier, except for these penetrations, perhaps there is a way to replug the boles to stop further inflow. It might be worthwile to pursue these speculations a little further. 
APPENDIX 13

\section{GROUTING}

A-13-1 
Grouting from the surface has been discussed by the SPR as a possible mitigative measure to be taken in the advent that a leak into the oil storage chamber has been identified. The use of grouting to stop water inflow into underground workings has been used at Weeks Island since the program inception. The technique is relatively well understood, the grouting materials and equipment are readily available, and the contracts are in place (in theory) to perform grouting at Weeks Island. While there is no formal plan for grouting from the surface to stop inflow into the oil storage chamber, a contract modification has been initiated with Dynatec Mining Corporation (the SPR Grouting Engineer) to produce such a plan.

\section{A13.1 HISTORICAL PERSPECTIVE}

Grouting has been successfully used on the SPR to stop water inflow into the DOE Mine facility as well as at numerous other locations throughout the world. However, very few instances exist to evaluate the effectiveness of surface grouting to stop leakage into salt mines. The best documented instance of surface grouting and its effect on stopping water inflow into an underground facility is the case of Weeks Island.

During mine conversion during 1978 the mining contractor who was developing the new Morton Mine at Weeks Island encountered a water inflow. The water inflow was initially ignored by the mining contractor since minor inflow commonly occurs during salt mining operations. The inflow, however, continued in its intensity and began increasing in quantity. Alarmed by the increases, the Morton Salt Company directed Frontier Kemper (FK) to mobilize a surface grouting rig and underground grouting facilities.

The grouting program initiated by FK included both surface grouting and underground grouting. Since the target was relatively well located (a suspected shear zone above the top of the Markel Wet drift) a surface grouting program seemed to have a promising potential for success.

During surface grouting operations, a total of twelve surface grout holes were drilled over the Markel Wet Drift during 1977 and 1978 (1). These holes included one inclined borehole and one core hole. Most of the holes were initially drilled approximately ten feet into salt and were subsequently grouted with one or more of the following grouts: cement bentonite slurry, sodium silicate, Geoseal resin polymer, Saline Seal hot brine, and TACSS polyurethane. At no time during this period was acrylamide used to grout surface boreholes. Grout take from these operations included: 74,000 gallons of cement grout, 35,000 pounds of Saline Seal, 27,000 gallons of sodium silicate, 1,000 gallons of Geoseal, and an unspecified amount of TACSS. During the program boreholes were extended to approximately 50 feet from the top of salt in stages (each stage being grouted and drilled out).

Little information exists regarding the effects of the grouting program on the brine inflow, however, the grouting operations performed prior to 1978 appear to have been totally ineffectual (2). According to Cementation, the inflow rate actually accelerated and approached $120 \mathrm{gal} / \mathrm{hr}$. During 1978, Cementation undertook grouting operations to seal the Markel Wet Drift Leak. All grouting performed by Cementation took place underground, some using acrylamide (3).

The general consensus of individuals involved with the grouting program was that the Frontier Kemper grouting was improperly performed using the wrong grouts $(4,5)$. 
Participants believed that the cement mixtures were too lean to be effective and that the other grouts used were ineffective. The opinions regarding the effectiveness of lean cement grouts, hot brines, and sodium silicates are shared by the SPR Grouting Engineer (3) and the Standby Grouting Contractor (6).

In addition to the grout type problems and mixtures it is clear that targeting the surface grout holes and placing the grout at the appropriate target was a major problem effecting the success of the program. It was suggested (8) that at least ten feet of the top of salt was highly fractured. Given this situation it is difficult to determine whether the boreholes drilled were within the area which makes up the source of the inflow. This highly permeable lost circulation zone was verified at other locations over the dome during drilling of the subsidence monuments.

\section{A13.2 PROBABLE SUCCESS OF SURFACE GROUTING}

While there have been significant advances in grouting technology during the past fifteen years, many of the problems experienced in attempting to grout the Markel Wet Drift would likely be present today. In actuality, the likelihood of success in successfully stopping water inflow into the oil storage chamber today is significantly lower than that of grouting the Wet Drift.

The most significant problem associated with successfully grouting an inflow source into the oil storage chamber is determining success or failure. In an underground opening which can be accessed for measurement, success is dictated in a relatively rapid manner by a stop in the inflow. In the oil storage chamber, however, there is no access to measure inflow. It is entirely possible that any inflow entering the oil storage chamber will not show for years. This depends upon the size of the inflow, the volume of the chamber into which it is flowing, and whether other inflow is occurring. Based upon the dye injection test performed at the sinkhole (9) the transit time of a leak into the oil storage chamber is unknown (if a leak exists and is emptying into the fillhole sump). Consequently, the point in time to stop grouting is unkn $w$ w. This might be remedied, to an extent, by injecting dye into the inclined exploration hole which is scheduled to be drilled. Again, however, inflow from any pooling in the mine could continue for years.

The targeting problem is clearly a significant problem in attempting to grout a leak into the oil storage chamber. If there is no indication of the presence of an anomaly (inflow cone) in the top of salt the likelihood of success in grouting is almost nil. There is no reason to believe that, without pumping enough grout in the area of the sinkhole to form an artificial caprock, any inflow into the sinkhole could be affected. While the aforementioned technique is possible, the costs and potential environmental problems related to drilling holes on a tight pattern over a large area are significant. The possible cost of such a program could be well over a million dollars. Additionally, significant brush clearing in this environmentally sensitive area would be necessary.

If a target is located in the top of salt it would be possible to grout such a channel, however, there is no guarantee that a single channel exists. Quite to the contrary, it is likely that a single cone is present with numerous small feeders. Given this scenario, any successful grouting may be short lived. It seems likely that the grouting of a known inflow channel in the top of salt, however, has a significant possibility of success. 
There is, however, some risk attached with grouting an inflow channel in the top of salt. Preliminary modeling studies (10) suggest that the time required for an inflow into an underground opening is highly impacted by the amount of granular material contained in the channel. If the channel is unfilled, the leak becomes uncontrollable within days. With sand filling the channel, the leak could continue for years without reaching uncontrollable proportions. This finding implies that if the leak is nearly sealed by grouting and the channel fracture material is either dislodged in grouting or is slowly lost after grouting, the channel could become unfilled with a cap preventing further soil entry. This situation may result in a grouting induced uncontrolled inflow.

\section{A13.3 OTHER MITIGATIVE OPTIONS}

One other option for mitigation of a possible leak into the oil storage chamber is to form a cutoff wall around part of the dome to limit water inflow and potential oil outflow.

There are two methods to place a cutoff wall around the sinkhole area. The two methods are the construction of a slurry wall and the formation of a grout curtain. Both of these options suffer from the same two major disadvantages. The disadvantages include the need to know how large of an area to construct the cutoff wall around and the extremely high cost of such a wall.

Typical slurry wall construction involves the digging of a nominal $50 \mathrm{ft}$-deep slurry trench which must be keyed into an impermeable layer to be effective. While slurry walls deeper than $100 \mathrm{ft}$ have been constructed they have proven "state of the art" and extremely expensive. Additionally they have been reported to cost approximately $\$ 1,000,000$ per mile for a $50 \mathrm{ft}$ wall (11). Since the nominal depth to an impermeable layer would be in excess of 200 feet and the sediments are not conducive to retaining fluids (circulation losses during drilling were high), the construction of a slurry wall is believed to be impossible without gigantic expenditures.

Since the Weeks Island soils are primarily silty sands, the prospect of constructing a grout curtain around the inflow is relatively low. Costs are expected to be high and due to the number of drill holes necessary the environmental damage is believed to be unacceptable. This, combined with the inability to determine how large of an area to wall off, makes the concept of a grout curtain impractical.

Construction of a cutoff wall is not recommended due to the improbability of success, high cost, and environmental risk associated with its construction.

\section{A13.4 CONCLUSIONS}

Based upon an evaluation of grouting as a possible mitigation technique for a leak into the oil storage chamber, grouting from the surface is not likely to be successful unless a piping channel in salt is identified. Blind grouting to form an artificial caprock is extremely costly with little likelihood of success.

Should a channel be identified, an attempt can be made to grout the channel. A plan by the grouting engineer (Dynatec Mining Corporation) for such an undertaking would need to be developed. Further, if grouting is attempted, it might be more effective prior to pressuring the mine. Mine pressurization could drive oil up into fractures, possibly diminishing adhesion of grout. 


\section{APPENDIX 13 REFERENCES}

1 Letter D. P. McInerny (Frontier Kemper Constnuctors Project Manager) to R. J. Lark (Morton Salt Construction). Subject: Markel Grouting Program. Dated: 5 December 1978.

2 Letter D. E. Hart (Vice President Cementation Company of America) to M. F. Winkel (Morton Salt Company). Dated: 19 December 1978.

3 Personal communications D. E. Hart to J. M. McHenry.

4 Meeting minutes (rough draft) between: L. Rousseau, R. Rommel, P. Kelsall, R. Figlik, H. Peterson, R. Fiedler, J.

Goodbrake, J. Martinez, E. Thiele, D. Miall. Meeting Date: 22 December 1978. Minutes dated: 5 February 1979.

5 Letter R. Rommel (Parsons-Gilbane) to File. Subject: Weeks Island Complex Ground Water Inflow - Grouting Program. Dated: 15 December 1978.

6 Personal communications R. Berry to J. McHenry

7 Draft Report. AGM Incorporated. "Weeks Island Sinkhole". Letter R. Thoms to J. Neal. Dated 23 February 1994.

8 Letter R. L. Giudici to Unknown. Dated: 30 November 1978. Logged as: Received Parsons-Gilbane Log 8968.

9 "Status Report - Evaluation of Changes in Sinkhole at Weeks Island SPR Storage Site". Document No. WIE6400.51A0. DynMcDermott Petroleum Operations Company. October 1993.

10 Preliminary findings. Simplified Model of a leak into a salt mine. B. Ehgartner. Sandia. Presented at RAC Technical Committee Meeting in Albuquerque, NM on 16 February 1994.

11 Personal communications Dr. Adam Faschion (University of New Orleans) to J. McHenry. 
DRAFT

WEEKS ISLAND MINE

SURFACE GROUTING PLAN

DOCUMENT NO. WIL-6400.67

REVISION 0

PREPARED BY DYNMCDERMOTT PETROLEUM OPERATIONS COMPANY

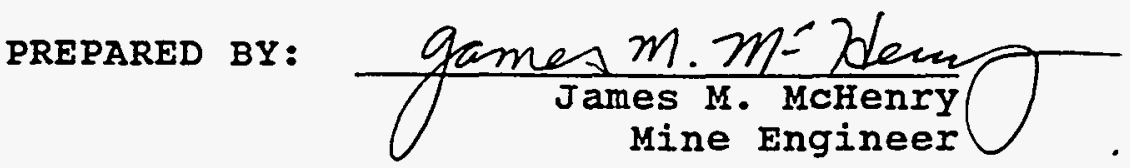

APPROVED BY:

KEN MILLS MANAGER,

.. CAVERN / MINE ENGINEERING

APPROVED BY:

ROBERT GUM

MANAGER,

OPERATIONS ENGINEERING

Grouting Plan to be included in repent.

$A-13-6$ 


\section{0}

During late 1992 a sinkhole was discovered overlying the upper level of the SPR Oil Storage Chamber on Weeks Island. since that time, numerous geotechnical and geohydrological investigations have been undertaken to ascertain the cause of the sinkhole and to evaluate the probability of a connection between the sinkhole and the oil storage chamber.

Evidence from the geotechnical / geohydrological studies implies that one or more connections between the aquifer and the oil storage chamber exist. This evidence includes:

1. An increase in the inflow rate into the fill hole sump

2. Continued increase in the volume of the surface sinkhole.

3. Anomalies in the surface seismic survey suggestive of a groundwater depression overlying the sinkhole.

4. The presence of data peaks in the hydrogen gas sniffing, above background, at the sinkhole and at least one other location.

5. The presence of a sediment filled void in the top of salt directly under the surface sinkhole, at 75 feet into salt.

6. A vertical water velocity within the throat of the void in the top of salt.

7. A vertical flow of soil through the throat oif the void in the top of salt.

8. A drift in the isotopic content of the waters in the fill hole sump, from 1987 to the present, from presumed connate water toward the meteoric water Iine.

9. A depression in the top of salt evidenced by cross hole seismic tomography.

All of these factors, combined, lead to the unmistakable conclusion that water is leaking into the upper level of the oil storage chamber.

Based upon the aforementioned information, DynMcDermott has solicited technical opinion from its contractors (Rembco Engineering and Dynatec Mining Corporation), Sandia National Labs, and Acres American Inc. as to appropriate mitigative reactions to the leak into the oil storage chamber. This grouting plan includes the plan developed from these mitigative measures. The meeting did not develop a consensus among the parties present and the recommendations proposed by DynMcDermott are somewhat controversial. With this understanding, DynMcDermott proposes the following plan of action for grouting. 
Mitigation of the inflow into the oil storage chamber has been conceptualized as consisting of three primary elements:

I. Injection of brine into the throat of the dissolution channel in salt.

II. Identification extent of the dissolution zone in salt by exploratory arilling. Exploratory holes will be grouted at the completion of the exploratory drilling phase..

III. Grout throat of sinkhole and attempt to seal as much of the dissolution zone as possible with grout.

\subsection{PHASE I ACTIVITIES}

The first step in mitigation of the inflow at Weeks Island involves using existing boreholes to inject saturated brine into the suspected throat of the sinkhole to ensure that all brine within the bore of the sinkhole below -176 MSL is saturated. These actions would, if successful, result in a decrease in the solutioning rate within the fracture system connecting the aquifer to the oil storage chamber.

The brine injection would be implemented for a test period of at least two months to evaluate its effectiveness. This test would be to inject brine down the bore of hole BH-7A at rates of approximately $3 \mathrm{gpm}$. The extent of the brine plume will be evaluated by sampling borehole $\mathrm{BH}-9$ for changes in salinity.

It is expected that the inflow rate into the fill hole sump may increase at the beginning of the test, due to slightly increasing the pressure of the fluid in the bore of the sinkhole. This change in rate is likely to be permanent, however, it is anticipated that if this is the only point of brine entry, the dissolution should decrease markedly. Consequently, signs of success include a stabilization of the brine inflow rate into the fill hole sump, a decrease in the volume of sand which must be dumped into the sinkhole on a weekly basis, and a recharge in the piezometric surface (if it is currently depressed). The first two of these success criteria will be available for monitoring without further drilling activities.

The costs of injecting brine (Appendix A) have been estimated to be approximately $\$ 30,000$ per month including purchased brine. If brine can be obtained by the DOE at no cost (currently under investigation) the approximate cost would be $\$ 10,000$. These temporary costs do not include an initial capital investment of approximately $\$ 2500$. 
This plan is believed to be implementable by the standby grouting contractor, Rembco Engineering, before August 5, 1994. DynMcDermott is has ordered a submersible pump to replace the temporary frac tank based system with a system that recirculates brine from the fill hole sump. The cost and time required to implement this system is currently under investigation.

DynMcDermott recommends delaying mobilization of the surface Grouting contractor for a period of two months to provide a check on the success of the brine injection into the throat of the dissolution channel. During this time period additional diagnostic evaluations could be performed to better define the sinkhole geometry and parameters for grouting.

2.2

PHASE II ACPIVITIES

The next step in the dissolution mitigation strategy proposed by DynMcDermott includes the implementation of additional diagnostics to better define the grouting target and groutability. These activities include a number of activities including:

1. Completion and interpretation of the cross hole tomography.

2. Completion of Self Potential Surveys.

3. Confirmation of the borehole wall location opposite the entry point in borehole $\mathrm{BH}-7 \mathrm{~A}$.

4. Installation of piezometers around the sinkhole and testing to assess the applicability of monitoring piezometric surface to identify grouting targets and to monitor grouting success.

5. Drilling of additional diagnostic boreholes to investigate the geometry of the sinkhole and the groutability of the soils filling the sinkhole.

\subsection{1 completion of cross Hole Tomography}

Preliminary results from crosshole seismic tomography were presented by Sandia during meetings on July 14,151994 in Albuquerque. The data gave some preliminary information on the size, location, and orientation of the dissolution channel in the top of salt. Completion of the remaining axis of the survey and interpretation of the data are mandatory to implementing a successful grouting strategy. This data will give the best estimate of the dissolution channel shape and size and will be the basis of future diagnostic driling. 
Self potential surveys are being used at Weeks Island to estimate the depth to ground water surface. Analysis of the data may indicate the presence of additional sinkholes or of intersecting fracture paths which may influence future grouting plans. The completion of these surveys and integration of this data with all other data is necessary to develop final grouting plans.

2.2.3 Determine Diameter of Dissolution zone at Well 7A

This task will be performed by Rembco Engineering as a part of the standby Grouting contract. This task gives the dimension of the sinkhole along the axis of borehole BH-7A. This data, combined with additional diagnostic drilling to ascertain the extent of the dissolution zone and the diameter of the zone perpendicular to $\mathrm{BH}-7 \mathrm{~A}$ will provide necessary information to grout the throat of the dissolution zone. This task will be performed by washing a pipe across the opening until rejection.

\subsubsection{Piezometer Installation}

This task will be performed under contract to DynMcDermott. The sow is currently in development and will use the general plan developed by hydrologists at $\mathrm{PB}-\mathrm{KBB}$ and sandia contract Personnel. The data from this testing will be used to ascertain whether the sinkhole's presence can be ascertained by a groundwater depression. Additionally, the holes can be used to determine whether brine injection is effective in displacing water leaking into the sinkhole. Finally, the technique can be evaluated as to its potential for use as an indicator of ongoing sinkhole development at other locations.

The task is expected to be performed either by the surface Grouting contractor or by subcontract to a water well drilling company in Louisiana. The generic plan for installation is given in Appendix-B:

\subsubsection{Drilling of Additional Diagnostic Holes}

To properly characterize the sinkhole for grouting, it will be necessary to drill boreholes which identify the shape and size of the dissolution channels as deep in salt as practical. All characterization holes are considered viable grouting holes. It is desirable to grout the dissolution zone as deep into salt as possible, however, there is risk associated with drilling activities connecting fractures and introducing uncontrolled flow into the throat of the 
sinkhole. DynMcDermott believes that this risk can be mitigated by grouting prior to anticipated breakthrough into the dissolution channel, if necessary. A plan to investigate the shape of the sinkhole as deep as practical is attached as Appendix $C$. The primary flaw with the deep grouting plan is that drill holes to these depths may not hit the dissolution channel. If this is the case, there is no alternative but to grout the channel above $-176 \mathrm{MSL}$.

DynMcDermott believes that all boreholes drilled near the dissolution zone must be cased into salt and properly hydrotested prior to penetration of the throat of the sinkhole. The risk associated with drilling uncased holes into an unknown dissolution channel is unacceptable. This policy, combined with the belief that a majority of the structure for which we are searching is vertical, lead to the conclusion that all holes should be angled boreholes.

Given this conclusion, DynMcDermott proposes that a borehole (DM-01) be drilled at an angle of approximately $45^{\circ}$, with respect to vertical, and aimed at the sinkhole throat at the same depth as borehole $\mathrm{BH}-7 \mathrm{~A}$ from a location northeast of borehole $\mathrm{BH}-3$. This hole should:

1. Test our ability to accurately drill a $45^{\circ}$ boretiole. Borehole will be surveyed for accuracy.

2. Penetrate the throat of the sinkhole perpendicular- to, and at the same depth as, borehole $B H-7 A$ and identify both sides of the dissolution feature.

3. Provide a second axis for grouting the throat of the sinkhole.

Additionally, DynMcDermott proposes drilling boreholes (DM02, DM-03, DM-04, and DM-05) as shown in Figure 2.2.5.1. These boreholes are intended to determine the shape and extent of the sinkhole throat at the same depth as borehole $\mathrm{BH}-7 \mathrm{~A}$ and to establish the presence of any high permeability zones in the salt near the sinkhole (i.e. additional fractures).

The initial borehole (DM-02) will be arilled parallel to borehole DM-OI and approximately 5 feet southwest of it. This borehole will be drilled through the sinkhole to a distance 50 horizontal feet beyond the vertical projection of the centerline of the dissolution zone. The borehole will be surveyed to determine its position and will be pump tested to determine its connection to zones of high permeability. If the borehole strikes the dissolution feature or a large fracture, the pump test should indicate a high permeability. If the borehole does not strike this feature, then the sinkhole can be assumed to be a distinct 
feature in this direction. If the borehole strikes a measurable feature (i.e. a void) then additional boreholes southwest of this borehole will need to be drilled at a distance to be determined by the drilling results from DM02 .

The next borehole (DM-03) will be drilled to ascertain the extent of the dissolution feature in a northeastern direction. The plan for this hole and any additional holes along this axis is similar to the plan enumerated in the previous paragraph. Boreholes DM-04 and DM-05 will be drilled in a similar fashion to bound the dissolution channel in two directions.

If the dissolution feature appears, from the aforementioned drilling, to have extent beyond what appears to be a single 5 foot piped channel, then the drilling completed at -176 MSL will need to be duplicated at greater depths. A determination as to the next depth to be drilled will be made from borehole information collected from drilling boreholes DM-0I through DM-05, plus any ancillary holes drilled. This will result in another decision point in the grouting program as to how to effectively grout the inflow.

If the dissolution feature is determined, from the drilling, to be a single, small diameter pipe (less than 5 feet) in salt then an attempt will be made to grout the throat of the sinkhole at $-176 \mathrm{MSI}$ using chemical grout. Plans for actual grout injection through the hole will be developed by the grouting engineer, based upon the dimensions of the sinkhole and the hydrotest information. DynMcDermott does not believe that an in-situ grout test program is warranted, due to the unknowns associated with grouting along the edge of the sinkhole versus grouting in the throat of the sinkhole. DynMcDermott recommends the use of acrylamide for this grouting application. Discussions of the merits and risks associated with the use of acrylamide are attached as Appendix D.

$2 \cdot 3$

PHASE III ACTIVITIES

Phase III of the grouting plan must, because of its very nature be very non-specific. This phase is implemented following one of three circumstances:

1. The Phase II diagnostic drilling indicates that the dissolution feature is not a single small diameter pipe type structure.

2. The diagnostic drilling indicates that the dissolution feature is a single small diameter pipe type structure and that the inflow has been substantially decreased by Phase II grouting. 
3. The diagnostic drilling indicates that the dissolution feature is a single small diameter pipe type structure and that the inflow has not been substantially decreased by Phase II grouting.

This phase in the grouting plan is a decision point. The decision made must be based upon:

1. Whether data indicates that the dissolution feature is groutable.

2. Whether a Department of Energy commitment exists to continue operation of the Weeks Island Facility

3. Whether funds exist to enter into a more comprehensive grouting program.

4. A technical judgement as to whether grouting above -176 MSI is likely to produce substantial benefits.

5. A technical judgement as to whether grouting below -176 MSI is likely to produce substantial benefit given the risk associated with drilling below the initial grout plug.

All of these elements must be balanced to determine the best course of action for the strategic Petroleum Reserve Weeks Island site.

\section{$2 \cdot 3 \cdot 1$ \\ No Single small Diameter Dissolution Feature}

This finding results from the diagnostic drilling identified in Phase II where either a large dissolution feature exists or a permeable fracture system exists along one axis of the throat of the sinkhole. This type of structure would be consistent with theories proposed by sandia that the sinkhole feature is the surface manifestation of subsidence induced tensile fracture near the top of the dome combined with an increase in salt dilatency deeper in the salt.

This type of finding would very likely imply that the sinkhole is not groutable and that further expenditures for grouting are not warranted. Given this outcome there are only three courses of action:

1. Accept the risk and draw down Weeks Island using a gas cap.

2. Draw down Weeks Island under a brine pressure fill / oil withdrawal mode.

3. Pressure the mine with oil or brine and continue operation of Weeks Island as a pressurized vessel. 
In this scenario there appears to be only one path for brine inflow into the oil storage chamber and that no additional permeable fracture system has been identified. Additionally, the brine inflow into the fill hole sump has been decreased, the surface sinkhole has stopped taking sand, or that sand has stopped flowing past borehole BH-7A. Any of these diagnostic outcomes lead to the conclusion that the grouting job has been partially successful. The decision tree identified above in section 2.3 can then be evaluated to determine further actions.

\subsubsection{Heeks Island To Be Decommissioned}

Assuming that the feature is groutable (proven by previous grouting success), that funds are available, and that the Strategic Petroleum Reserve has expressed a desire to decommission Weeks Island, then DynMcDermott believes that no further grouting is warranted at this time.

\subsubsection{Funds Are Not Available For Additional Grouting}

Assuming that the feature is groutable, that funds are not available, and that the strategic Petroleum Reserve wishes to remain at Weeks Island then DynMcDermott believes that significant risk is being taken by operating weeks Island for a significant time span with a small grout plug in place in the throat of the dissolution zone.

\subsubsection{SPR Wishes to Remain At Weeks Island}

Assuming that the feature is groutable, that funds are available, and that the strategic Petroleum Reserve wishes to remain at Weeks Island then DynMcDermott believes that additional remediation grouting is warranted. Based upon the meeting held during July between DynMcDermott and its consultants, there are two possible phase III remedial grouting methodologies. Again it should be understood that DynMcDermott's recommendations do not represent a consensus of the persons attending the grouting meeting.

\subsection{Grout sediments Above -176 MSI}

The first of these methodologies is to grout the dissolution feature above $-176 \mathrm{MSI}$. The method depends upon the ability to pump a low viscosity chemical grout (acrylamide) into sands filling the entire dissolution feature above $-176 \mathrm{MSI}$, making the grouted soil mass essentially impermeable.

This plan involves exploratory drilling to locate the boundaries of the sinkhole above -176 MSL, performing 


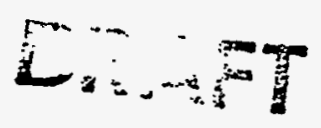

groutability testing, and grouting the entire volume of the dissolution zone. The disadvantage of this plan is that it must be $100 \%$ effective in sealing pathways in the sand filled section of the dissolution zone to effect an impact on the inflow rate (Appendix $c$ ). This results from the fact that the section of the dissolution zone which regulates flow rate cannot be within the section of the zone which is being grouted. This conclusion has been reached by evaluation of the brine pump rates accomplished during the drilling of borehole BH-7A. This brine injection indicates that brine can be pumped through the sands filling the sinkhole, with near zero pressure, at rates in excess 1 gpm per square inch of surface area. Consequently, a 5 foot diameter dissolution zone throat would be capable of flowing more than $2800 \mathrm{gpm}$. The advantage of this plan is that it does not incur the risk associated with drilling holes deep into the salt stock.

DynMcDermott does not recommend the drilling of uncased vertical boreholes into the dissolution feature for exploration or grouting. It is the opinion of DynMcDermott that until a substantial plug of grout is present in the bore of the dissolution zone and the sinkhole itself is no longer active, then setting up a drill rig over this area is unsafe.

DynMCDermott believes that the three stages of this grouting program, identified above, can be most economically accomplished in a single in-situ step. Consequently.: the program would be implemented by drilling angled holes at as flat an angle as possible $\left(45^{\circ}\right.$ if possible) to intersect the bore of the dissolution zone to grout the sinkhole from the bottom up. All holes will be securely cemented into salt and pressure tested prior to penetrating the bore of the sinkhole. The process would be to establish an initial grouting pattern (developed by the grouting engineer) and to grout the first ten to twenty feet above the sinkhole using this pattern. Secondary grout holes will then be drilled between these primary grout holes, brine tested for take, and grouted as necessary. The secondary boreholes replace the need for grout testing along the edge of the sinkhole. DynMcDermott believes that an in-situ test ensures that there are no differences in the test media and the grout media. Consequently, no separate grout test is recommended. The grouting would progress upward until the grout column has reached the top of salt.

Once at the top of salt, a cementitious cap can be emplaced if deemed necessary to provide structural rigidity to the grouted zone. This cap would be placed by injection of a microfine cement. DynMcDermott believes that this cementitious cap provides no definable benefit.

2.3.2.3.2 Grout sediments Below -176 MSL 
This grouting technique is the preferred grouting technique for effective long term grouting. It involves drilling flat angle holes to intercept the throat of the sinkhole at 20 foot vertical depth increments as deep as the trough can be located or until the flow tests indicate that the zone intercepted is the critical diameter (i.e. the point where the flow is restricted to $2 \mathrm{gpm}$ ). A complete grouting plan for this option is included as Appendix C.

\subsubsection{Single Dissolution Feature - Phase II Grouting Unsuccessful}

This scenario is that the phase II grouting indicated the presence of only a single dissolution feature with no additional channels or fractures and that the feature is small in diameter. DynMcDermott believes that this scenario indicates that deeper grouting is warranted and the grout plan identified in Appendix $C$ should be implemented.

3.0

PLAN CONCLUSIONS AND RECOMMENDATIONS

DynMcDermott believes that the proper mitigation of the sinkhole is accomplished by a stepped "grouting" operation. DynMcDermott uses the term "grouting" as it does in its standby Grouting contract to be: Services which include chemical grouting, cementitious grouting, underground restorative work to support grouting, testing, and bulkhead maintenance. To these ends this plan was prepared.

As can be seen in the other sections of this plan, DynMcDermott believes that the least expensive mitigative action to be taken at Weeks Island is to consider grouting from a staged approach. Consequently, this plan recommends:

1. Brine Injection to ascertain whether the inflow rate increase can be controlled.

2. Investigation of the throat of the dissolution feature at -176 MSL and the trial grouting of this location.

3. Grouting of the interval below $-176 \mathrm{MSL}$ to permanently interdict water inflow (if management believes that the costs result in adequate benefit). 


\section{$\angle I-\varepsilon I-\forall$}

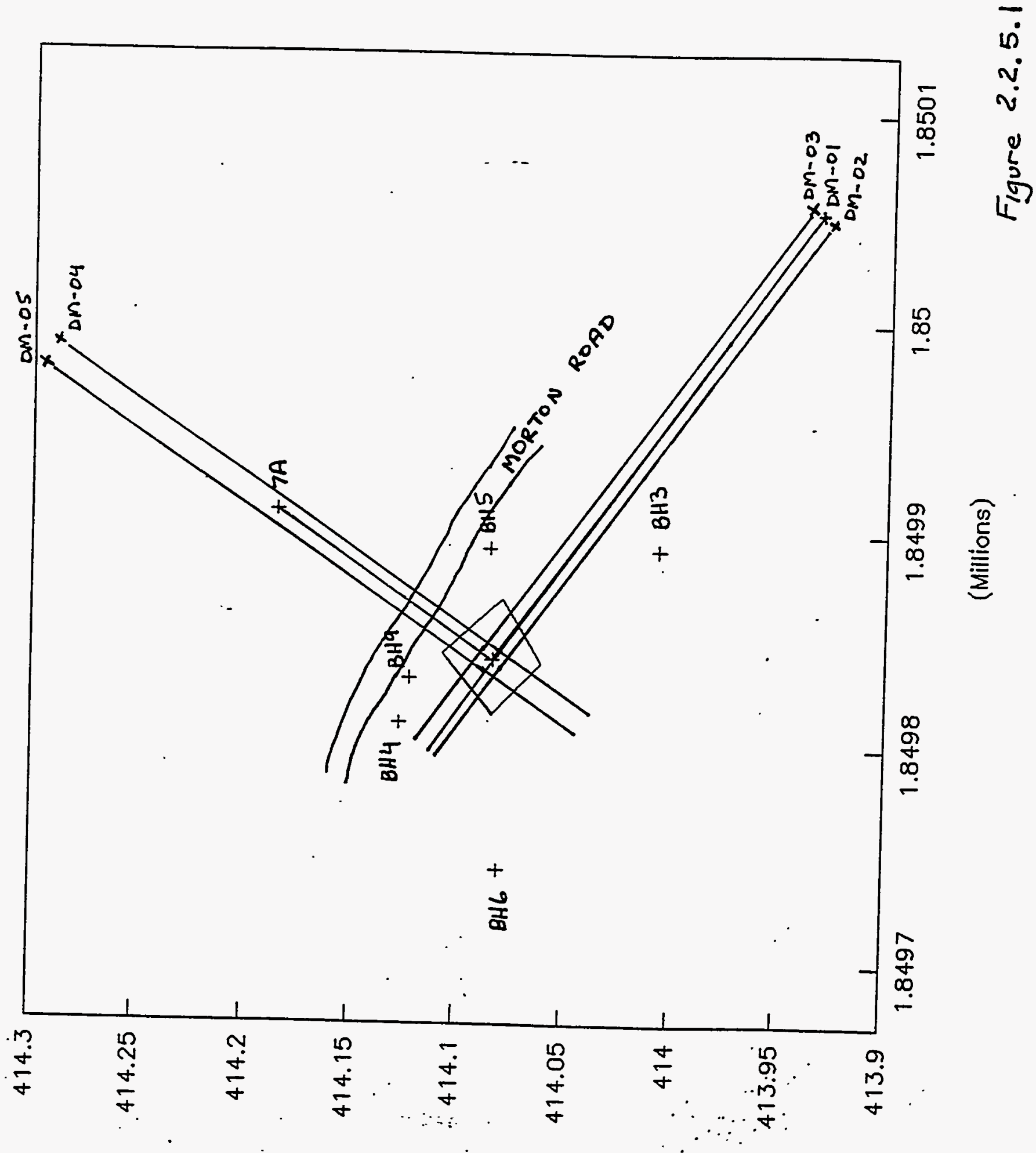

\section{IJ $\forall d a$ (spubsnoul)}

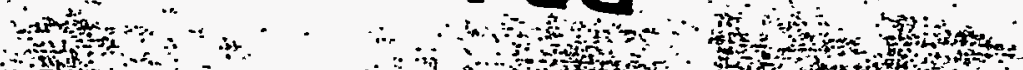


APPENDIX A

BRINE INJECTION INTO SINRHOLE STRUCTURE

COST ESTIMATE

(REMBCO ENGINEERING)

$A-13-18$ 
To: Mike Bertoldi

FROM: $\quad$ Dick Berry, Rembco

SUBJECT: MAINTAINED BRINE FLOW AT SINKHOLE BOREHOLE NO. $7 A$

It has been proposed to flow about three (3) gpm of saturated brine into the apparent hole in the crevasse at Borehole \#7A - to prevent further possible solutioning of salt from the surface portion of the dome.

A system for this injection can consist of a single fivehunared (500) barrel frac tank for storing brine and a flow control system to flow three (3) gpm (or other flow from 0 $12 \mathrm{gpm}$ ) into the area. The system will have a closed overflow which will return any brine to the feed tank in the event of electrical or other failure. The system can operate unattended. A daily check will be made by: Rembco personnel. Brine supply is from Morton.

system budget costs are as follows:

FIXED COST:

Metering valve, 0 - 12 gpm

Booster pumps

$\$ 1,500$

Hoses, fittings, extension cords, etc.

Frac tank, delivery-return

150

contingency

DAILY OPERATING COST:

Saturated brine, $125 \mathrm{bbl} / \mathrm{day}$

Vacuum truck service

$\$ \quad 595$

Frac tank rental

Weekend labor 
EXAMPLES:

Cost for 1 month, 31 days

Cost for 2 months, +31 days

Cost for 3 months, +30 days
$\$ 28,395$

54,590

79,940

It will take about one week to assemble all components and be in operation.

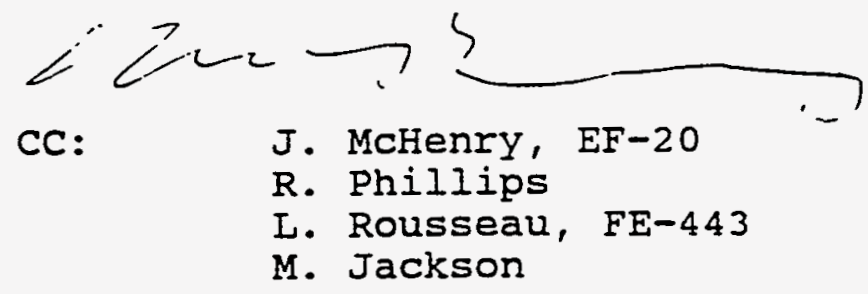


APPENDIX B

PIEZOMETER INSTALLATION PLAN

(PB-KBB INC)

A-13-21

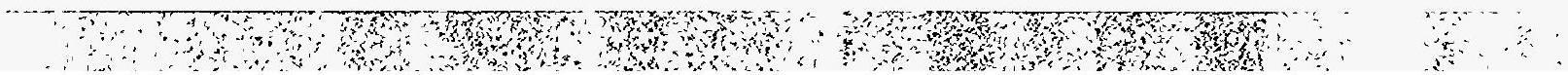


11757 Katy Freway 1600 Howston. Texes 77079 (7i3) 498-5590 Tulex \$782539

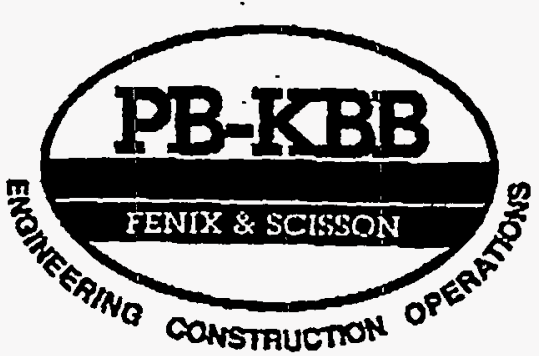

July 1, 1994

Mr. Larry koufs, 7, P.E. 7-8-9t

Configuration Cóntrol Manager

U.S. Department of Energy

Strategic Petroleum Reserve

900 Commerce Road East

New Orleans, Loulslana 70123

Subject:

Task Assionment No. 11

Contract No. DE-ACO1-91FEB2075

Weeks Island Remedial Work

Piezometer location at Weeks Island

Dear Larry:

As you requested, Charlie Smlth, Jim Neal arij I have worked out the preliminary locations for eight monitoring wells in the area of the sinkhole. The locations were selected to establish the water table in the area with consideration given to access and minimization of impact on the environment. The locations indicated are proposed and should be adjusted in the fleld as needed. A copy of the well location map generated by Charlie Smith is attached as extibit 1.

Consideration should be given to using the existing boreholes around the sinkhole for piezometers. Each well could be perforated in the interval above the salt and used for measuring the water table of the brine interval of the aquifer. If the existing boreholes are usad, the number of monitor wells around the sinkhole may be reduced.

Piezometer P-3 will be installed with 4" casing for a pump test; the 4" casing is needed for the pump. The remaining plezometer wells will be completed using $2^{*}$ casing for water level measurements. Generalized schematies of a $2^{\prime \prime}$ and $4^{*}$ well are attached as exhibits 2 and 3.

The wells are proposed to be completed with $10^{\prime}$ PVC slotted screens in the interval from about $-20^{\prime}$ to $-30^{\prime}$ elevation which should be the upper fresh water sands and gravels. The depth of each will change with the elevation of the location. Generally the elevation should range from about +90 ' to $+60^{\prime}$ making the piezometers ranging in tepth from about $90^{\prime}$ to about $120^{\prime}$. Fexibility is neoded in the drilling plan to allow the on site gedogist to determine the completion interval of each well.

The monitoring program will require daily water level measurements for several weeks to establish vartations in the level, if any. The measurements can be made using an E-line or conductivity meter for water level measuremerts that can be read to a tonth of an inch.

If a pump test is performed in Well No: $\mathrm{P} 3$ to determine the aquifer properties, then continuous water level recorders are needed for the adjacent wells. The recorders or recording system may be a rental 
Mr. Larry Rousseau, P.E.

July 1, 1994

Page Two

Item if the contractor does not have the equipment. A detailed pump test procedure can be devaloped If neaded by the testing contractor. In addition to the pump test, each plezometer well can be used for a slug test to determine the effective permaabilly at each location. A slug test procedure can also be developed if needed.

Once the piezometers are Installed, developed and the water level measured, then the general water table can be mapped. The mapping will detect a depression in the water table if it exists.

Please foel tree to call mo at (713) $589-5819$ if additional information is noeded.

Sincerely

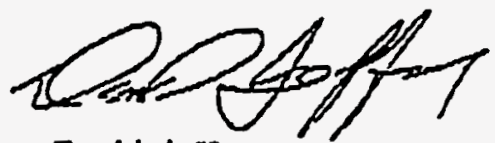

David Jeffery

Hydrogedlogist 


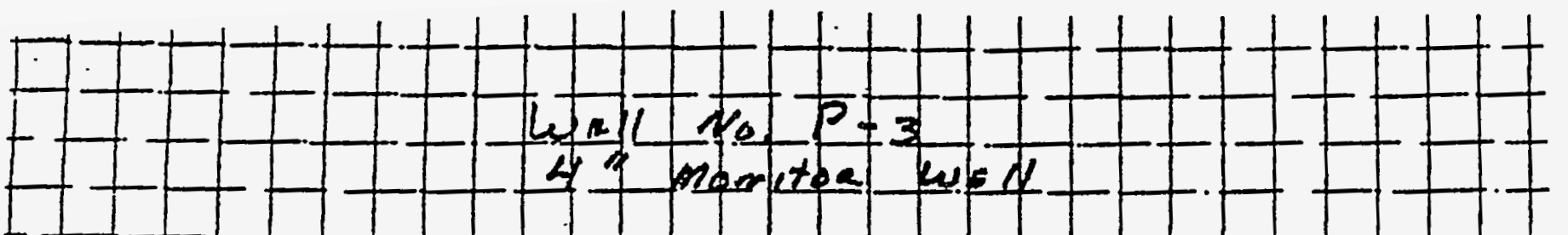

-+ fod.

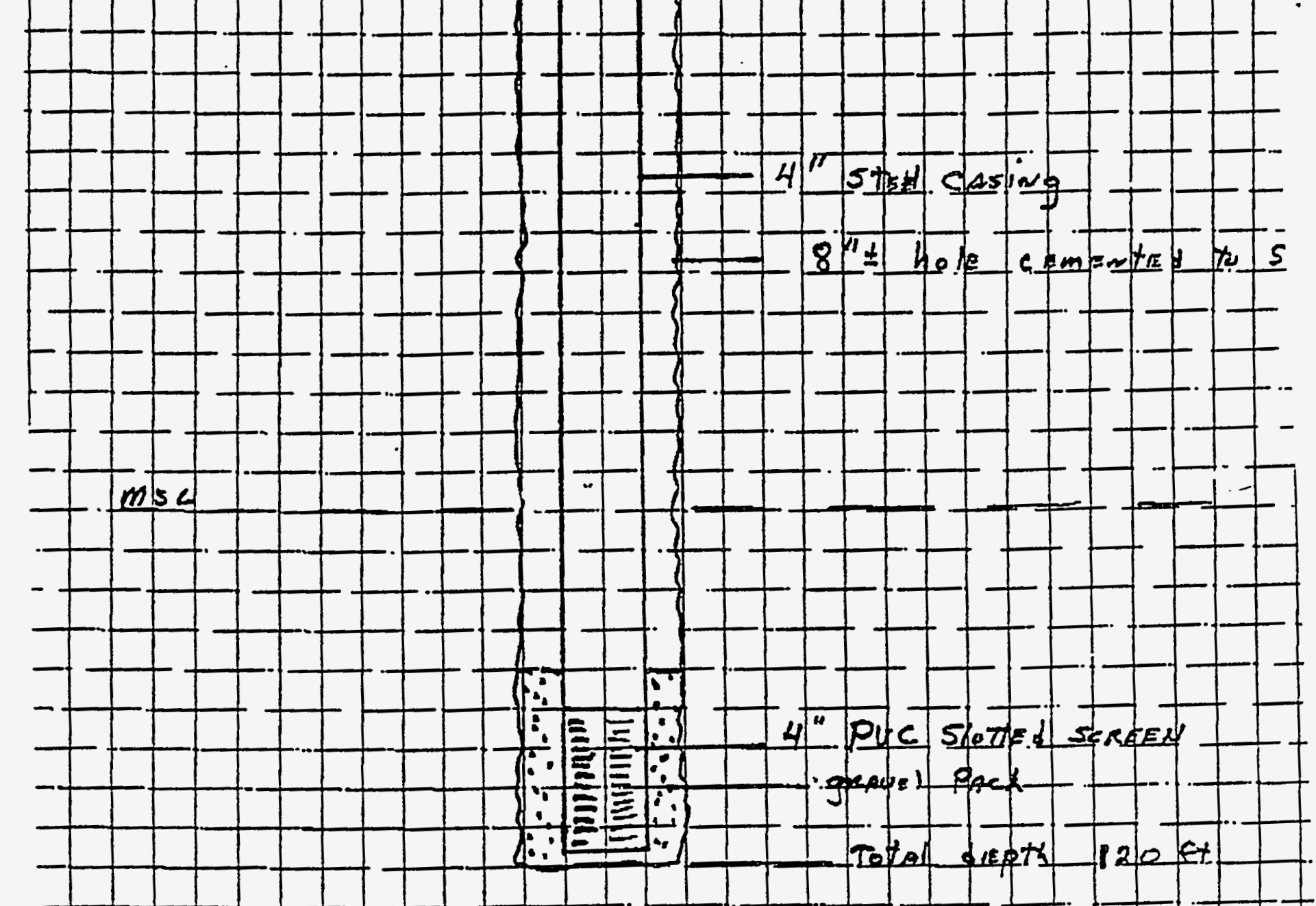




\section{MEMORANDUM}

TO:

Reghu

FPOM:

David Jafiery

SUESCT: Ground water tracers

There are many methods of tracing water flow which include temperature, spores, ions, gases, dyes, Isotopes and radionucleides. For ground water flow in a brine environmene, dyes, lons and some of the stable isotopes are generally used. The stable isotopes generally take a lonot time for anatysis and specialized equipment, so dyes and ions are considered best.

The common ions used are; chloride, bromide, lithium, ammonium, magnesium, potassium, lodide and organte anions. A lab anatysis is needed for most of the ions, but in some cases, the ions are very offectlve tracers.

A list of tracer dyes is attached with detection limits. Any one of the dyes would probably be suitable for use in the sinkhole and with brine. 
Sensitivity and Minimum Detectable Concentrations for the Irrcer Dyes

\begin{tabular}{|c|c|c|c|c|c|}
\hline Dye & 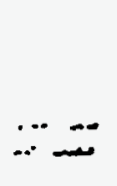 & 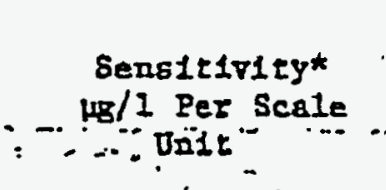 & $\begin{array}{l}\text { Beckeround } \\
\text { Reading*t } \\
\text { Scale Dnits } \\
0=100=\end{array}$ & & 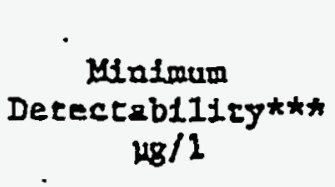 \\
\hline Amino $G$ Ac1d & & 0.27 & 19.0 & & 0.51 \\
\hline Photine CU & & 0.19 & 19.0 & & 0.36 \\
\hline Fluorescein & & 0.11 & 26.5 & & 0.29 \\
\hline Ifissamine $\mathrm{FE}$ & & 0.11 & 26.5 & & 0.29 \\
\hline Pyranine & & 0.033 & 26.5 & & 0.087 \\
\hline Rhodamine B & & 0.010 & 1.5 & & 0.010 \\
\hline Rhodamine WT & & 0.013 & 1.5 & & 0.013 \\
\hline Sulfo rhodamine & B & 0.061 & 1.5 & & 0.061 \\
\hline
\end{tabular}

For 2 Turner 111 filter fluorometer with high-sensltivity door and recommended filters and lamp at $21^{\circ} \mathrm{C}$.

* At a pH of 7.5 .

** For diatilled water.

*** For a 107 fncrease over background reading or I scale unte, whlchever is larger.

Adapted from Smart and Laidlaw (1977). 


\section{APPENDIX C}

PLAN FOR GROUTING SINKHOLE DISSOLUTION FEATURE

BELOW -176 MSL

(DYNATEC MINING CORP.) 


\author{
ADDENDUM \#2 \\ TO \\ GROUTING RESPONSE PLAN \\ TO TREAT WATER INFLOW \\ INTO \\ WEEKS IELAND EDR OIL STORAGE CHAMBER
}

Prepared for:

DynMcDermott Petroleum Operating Company 850 South Clearview Parkway New Oriaans, Louisiana 70123-3498

By:

Dynatec Mining Corporation 2200 South 4000 West Salt Lake City, UT 84120-1234

July 17,1994 


\section{ADDENDUM \#2 TO GROUT RESPONSE PLAN}

Page 1 of 6

TABLE OF CONTENTS

ITEM

PAGE

1.0 INTRODUCTION

2

2.0 NEW INFORMATION

2

3.0 GROUT CURTAIN LOCATION

2

4.0 LIOTION 3A FOR GHOUT. CUATAIN LOCATION AND CONSTRUCTION

5.0 MONITORING

6.0 SELECTION OF GROUT MATERIAL FOR INJECTION

7.0 SKETCH SK373-210

6 


\section{ADDENDUM \#2 TO GROUTING RESPONSE PLAN}

Page 2 of 6

\subsection{INTRODUCTION}

Six boreholes and mast of the associated testing program have been completed in the exploration and testing program conducted by Sandia in regard to the suspected water inflow into the oil storage chamber of the Weeks Island SPR. Meetings in the offices of Sandia National Laboratories in Albuquerque, New Mexico were held on July 14 and 15 , attended by representatlves from the DOE, DynMcDermot, Sandia, Rembco, Acres and Dynatec. At the meetings, the information obtained in the exploration driling and testing program was presented and discussed. Using this new information, Dynatec has modified the options presented in the May 17 Grout Response Plan and the June 27 Addendum. Option 3A shown in SK373-210 on page 6 is the recommended location and method of grout curtain construction.

\subsection{NEW INFORMATION}

The following information obtained from the exploration drilling and testing program should be a major consideration in determining the next steps in a grouting response plan:

2.1

Slant borehole BH 7A intersected what appears to be a sand filled verical fissure at a depth of 70 feet below top of salt, and at a location almost directly below the center line of the sinkhole. It is believed that this fissure has a minimum width of 5 feet. A core sample indicates that solutioning has occurred on the wall of the fissure. When the drill rods broke into the fissure loss of drilling fluid circulation (which was being pumped at a rate of 12 g.p.m.) occurred. Dye was injected into the sand filled fissure at a flow rate of 5 g.p.m. and at a pressure that appeared to be 5 p.s.i. above hydrostatic at the point of injection. Subsequent monitoring of the borehole/fissure intersection indicates that there is a downward flow of both water and sand. Sand flow appears to be less than 1 " per day.

2.2

Seismic survey results and salt solutioning calculations indicate that a sand filled vertical opening in the salt, 50 feet in diameter at the top of salt and 30 feet in diameter at a depth of 30 feet below the top of salt, could exist in a location almost directly beneath the center line of the sinkhole.

\subsection{GROUT CURTAIN LOCATION}

If a grout curtain is to be constructed in a location at or near the top of salt, then the horizontal dimension of the curtain in the sand filled opening could be greater than 30 foot in diameter (700 square feet). Since the sand filled opening at depth 70 feet below 
top of salt accepted 12 g.p.m. through a $3.76^{\mathrm{n}}$ diameter borehole at a pressure of less than 0 p.s.i. on surface, it can be argued that the permeability of the sand is high enough that it would permit a flow or at least 1 g.p.m. per square inch of area if a free flow zone (nil pressure) were to develop below it, and if there was a reservoir of sufficient capacity to support such a flow above it. A 30 foot dlameter area of this sand would therefore have the permeability to permit 100,000 g.p.m. to flow through it. Any grout curtain in this location would, therefore, have to have $100 \%$ efficiency to stop a flow of 2 g.p.m. (i.e. a curtain that is $99 \%$ efficient would still permit a flow of 1000 g.p.m.) It should be noted that even if the above scenario is in error by a factor of 100, a flow of 10 g.p.m. Would be permitted. This simplistic interpretation of permeablity should be checked by obtaining a screen analysis of what is believed to be a sample of the typical sand and performing a theoretical calculation, or by laboratory testing of the rate of flow through samples of the sand, or by further water injection test $B H 7 A$ and $B H$, or all 3 methods.

The best location, theoretically, for a grout curtain is at a horizon where ground conditions restrict the flow to a volume equal to the flow into the oil storage chamber, i.e. 2 g.p.m. At such a location, any further restriction due to grouting reduces the volume of inflow into the oil storage chamber. There is a possiblity that at such a location the minimum size of grout curtain, the minimum number of holes and minimum volume of grout, compared to cther locations, would be required.

The disadvantage of the so-called best location is that it could be difficult to intersect what may be very small targets with long boreholes from surface. Borehole depth limitations imposed by regulatory agencies and an owner could also be a factor.

Regardless of the advantages and disadvantage of such a location, it is necessary to obtain further information about conditions at and below depth 70 feet below top of salt if the location is to be considered. It is probably not possible to find a horizon where the theoretical 2 g.p.m. restriction exists. However, it is highly likely that a horizon can be found where the existing permeability would restrict flow to a very small percentage of the potential flow through a 30 foot diameter sand filled opening.

\subsection{OPTION 3A FOR GROUT CURTAIN LOCATION AND CONSTRUCTION}

\section{SEE SK373-210}

This further modification to Option 3 is designed to use all proposed boreholes for the combined purposes of fissure delineation, brine injection and other testing, plus grouting. The design attempts to ensure that all holes will contribute efficiently to the ultimate grout curtain seal. 
The advantages obtained through the use of 45 degree boreholes cannot be over emphasized. All positive information to date confirms that both the water leak conduit and the structure in the salt are vertical. The ideal attitude for boreholes to be used for fissure delineation, brine injection testing and grout injection is, therefore, horizontal. Since this not practical, the next choice is to dril at as flat an angle as practical and 45 degrees appears to be a good compromise provided satisfactory drilling and casing equipment and methods are employed.

In regard to the first action in the exploration and grouting program, the procedure proposed at the July 15 meeting of extending BH $7 A$ to delineate the south wall of the fissure is a logical one. A second hole at an azimuth of 90 degrees to BH 7A is aiso logical. Every effort should be made to ensure that this hole is drilled at an angle of 45 degrees. Brine acceptance tests should be performed over a horizontal distance of 50 feet on both sides of a vertical extension of the center line of the sinkhole. The information obtained from these 2 exploration holes should determine the layout for the next hole or the next series of holes. If it is determined that the structure and the conduit are linear, then all further boreholes should be parallel and at right angles to the structure.

The second horizon that shuuld be investigated is at 100 feet below top of salt, i.e. i.'e driller should step back approximately 30 feet in order to drill the next line of primary holes at $\mathbf{2 0}$ feet from the holes intersecting the fissure at 70 feet below top of salt.

The final location and procedure for construction of the curtain would be determined from the information obtained as the drilling proceeds.

\subsection{MONITORING}

The progress of the grouting operation would be monitored at the jobsite, commencing after some of the primary holes have been injected and some of the secondary holes have been drilled. Brine acceptance tests and the quantity of grout that can be injected in secondary and possibly tertiary holes will indicate the spread of grout in the curtain and give an indication of the quality of the seal achleved.

It is doubtful that piezometers in the overlying sediments will be of value in monitoring seal quality if the sand permeability is as high as indicated. i.e. a flow of 2 g.p.m. may result in nil draw down or one that is too small to accurately measure, particularly with the seasonal differences in precipitation. However, their importance in monitoring a change in conditions for any reason should dictate their use.

The only positive measure of the effectiveness of the curtain will be the measurement at another location of the volume of brine that has leaked into the oil storage reservoir. 


\subsection{SELECTION OF GROUT MATEAIALS FOR INJECTION Page 5 of 6}

For the conditions encountered to date (sand filled opening in the salt) it would appear that a chemical grout with the lowest practical viscosity in its liquid form before forming a gel is the grout of choice. A controllable grout time in a range of up to several hours would be preferable.

It is probable that little could be gained in drilling special holes outside the zone to be grouted for testing grout travel in the sand. It is not the longest distance or even the median distance of grout travel that determines the effectiveness of the grout cover. The shortest distance that grout travels is the determining factor. The spacing of primary holes is normally set from the estimated average permeability of the formation and secondary, tertiary and possibly further fill in holes are used during curtain construction to check for grout travel between grouted holes and to fill in the zones where a gap in the curtain exists. Since conditions in the sand must be considered non-uniform and the sand is disturbed and/or moving, accurate determination of a minimum permeability using a test program would be a difficult to impossible task.

The other condition that may be encountered within the grout curtain is clean fissures in the salt. Grout materials and methods for this condition has already been discussed in the May 17 Grout Response Plan.

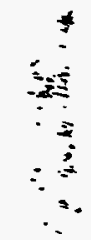




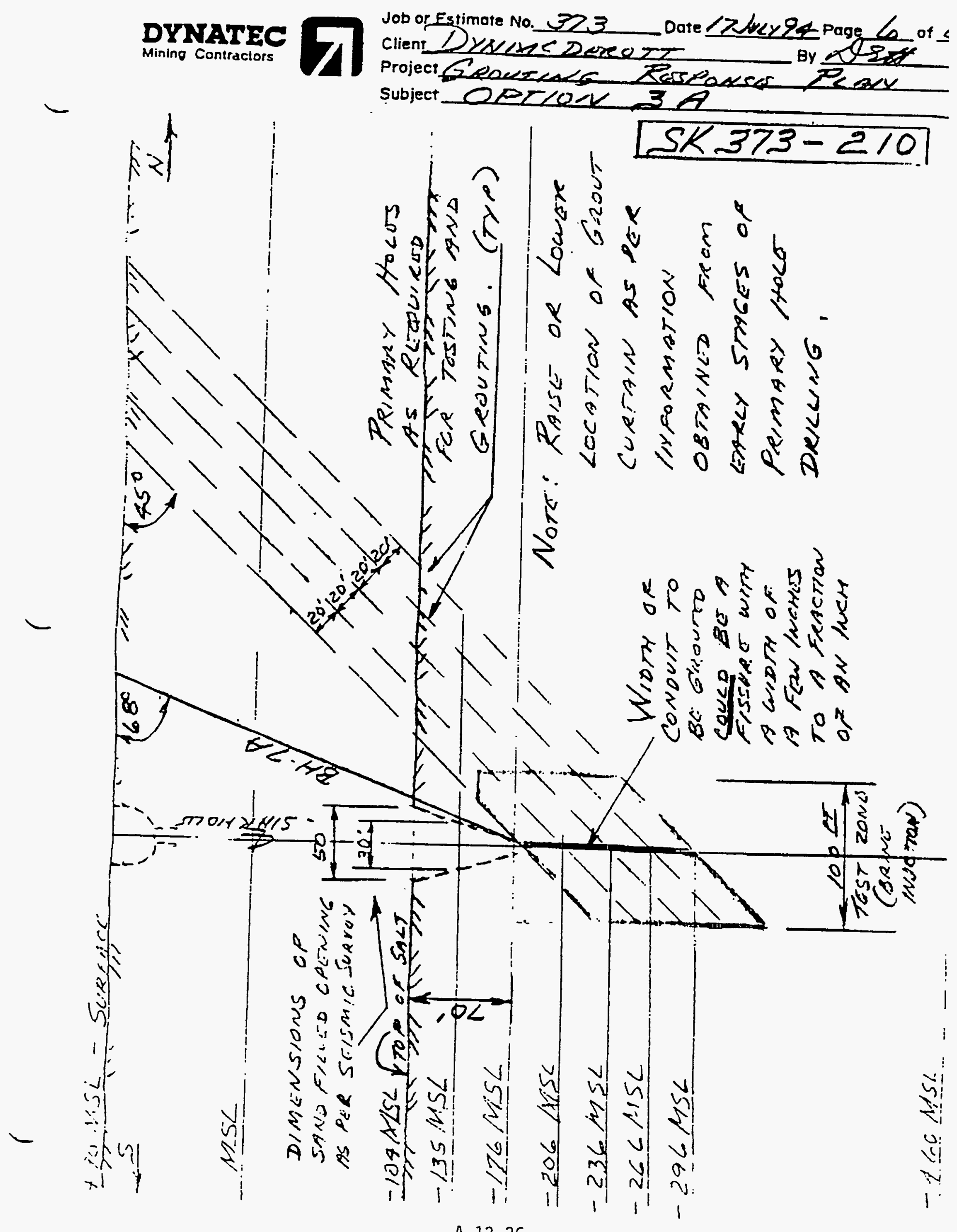




\section{APPENDIX D}

\section{DISCUSSION OF MERITS OF ACRYLAMIDE \\ AS GROUT SELECTION FOR SINKHOLE}

\section{(DYNMCDERMOTT PETROLEUM OPERATIONS)}

(REMBCO ENGINEERING) 


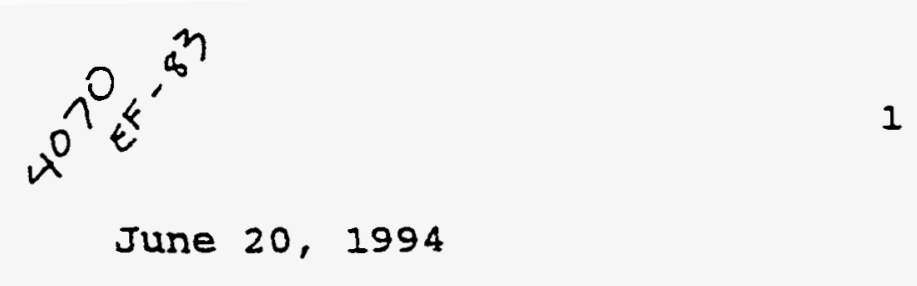

To: Mike Bertoldi

FROM: $\quad$ Dick Berry, Rembco

SUBJECT: IOT VISCOSITY GROUT CHOICES AT WEERS ISLAND

For grouting in the finely fractured salt in the mine and for use in sealing the salt - soil interface in the sinkhole area, there are only three (3) low viscosity (water thin) chemical grouts available. They are the tried and true $A V-100$ acrylamide (in old literature reported as $A M-9)$, a product under potential ban in the sewer grouting industry. One substitute product is AC-400, a magnesium acrylate grout with lower toxicity. Another newer lower toxicity product is $\mathrm{AV}-118$, an acrylic monomer mixture.

Various parameters and properties of the three (3) grout systems are shown below:

\section{LOF VISCOSITY GROUT COMPARISON}

$\begin{array}{lll}\text { AV- } 100 & \text { AV-118 } & \text { AC-400 } \\ \text { ACrylamide } & \text { ACIYlic } & \text { ACrylate }\end{array}$
Gel time limits short, seconds long, hours

Min. conc. for stable gel, $\%$

Long term stability, years

Nature of cure and set Cure time/gel time

Strength of gel, index at $25 \%$ strain, index

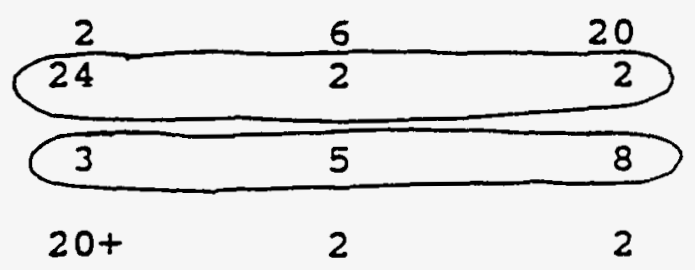

1.0

1.25

$1.25-1.75$

100

50

50

$100^{-}$

50

30

50

10

Fresh water/brine cycling, index 100

Environmental consideration

Cured grout hazard

to environment

to personnel

$\begin{array}{lll}\text { None } & \text { None } & \text { None } \\ \text { Safe } & \text { Safe } & \text { Safe }\end{array}$

Uncured material hazard

to environment

to personnel

$\begin{array}{cll}\text { None } & \text { None } & \text { None } \\ \text { Moderate } & \text { Minor } & \text { Minor }\end{array}$


The substitute grouts are not good substitutes for the mine.

The long term stability of both $A C-400$ and $A V-118$ are suspect. We have made tests regarding the situation. The lowest concentration at which these grouts will gel is also a major factor.

In using grouts to seal brine or water in cracks or decrease permeability in soil, the injected grout dilutes to some extent in the surrounding liquid. It is important that the system gels and cures at as low a concentration as possible so large quantities do not flow away become lost. Acrylamide, with its ability to cure at only $3 \%$ concentration, has a sizeable advantage over AV-118 at about $5 \frac{8}{6}$ and $\mathrm{AC}-400$ at $8 \%$.

The advantages of Acrylamide are so significant as to nearly rule out the other products. The only hitch is a possible future ban on its use by the EPA, and a present ruling against present use from DynMcDermott/DOE.

\section{POSEIBLE LIABILITIES FROM USE OF ACYIANIDE}

About ten (10) years ago, the EPA commissioned studies acylamide based on several incidents in manufacturing plants where personnel had been exposed to high concentrations. These studits involved acrylamide in all its considerable end uses. The draft study was released in 1986. The study concluded there was a hazard to exposed personnel but no effects to the environment. Subsequently, osHA reviewed the study and industry handling procedures, found them reasonable, and has consistently refused to act to ban use. MSHA also declined to act. subsequently, EPA specifically targeted the sewer grouting industry as the area with greatest possibility for personnel exposure and issued a draft ban of its use. Excerpts from the latest distributed draft (October 2, 1991) are attached. Issuance of the ban has been scheduled since July, 1992 but has never occurred. The latest threat was issued on April 25, 1994.

In the two attached excerpts, EPA expresses specific problems with geotechnical grouting in salt domes and potash mines. In the proposed rule, they cite substitutes as low-viscosity urethanes and low viscosity polyacrylamides. Low viscosity (and high viscosity) urethanes have been proved unstable in salt brines. The low viscosity polyacrylamide cyanogel has been withdrawn from the market completely. The two (2) low viscosity acrylate, and acrylic grouts, $A V-118$ and $A C-$ 400 , both contain NMA and would be banned with a three (3) year delay if all the provisions of the initial ban are implemented. 
Within EPA's study, one (1) hazard cited was breathing vapors from the solid products. Exposure to the solid product can be in the form of dust from bags, even though present bags are designed to be emptied through a pouring spot placed under the surface of liquid. The other potential exposure is from spilled acrylamide solution where the liquid may evaporate in a closed space such as a sewer grout van truck, leaving a solid residue.

The other potential hazard is from physical contact with acrylamide solutions (acrylamide selectively affects nerve endings) absorbed through the skin. One should protect against contact and ingestion (presumably as a result of hand to food contact).

The threatened ban has selectively restricted use of acrylamide primarily among public entities and around drinking water dams or facilities. It still has substantial use in sewer grouting. The mining industry uses it extensively.

A new acrylic polymer not of the proposed ban type is being used in Western potash mines, principally in Canada. It is a product of Allied Colloids (CEFCO in the U.S.) available through Avanti as AV130. We know of no commercial data in salt mines. The product limitation as we re:ently experienced it in Mobile, AL. at scott Paper, is that gel times less than three (3) minutes or greater than 1 - 1.5 hours were not obtainable. We have a new version of the product on the way to us which, according to Avanti, overcomes part of the Iimitation and will give a range of thirty (30) seconds to two (2) hours.

At Weeks Island, the only persons at risk would be the operating personnel. At present, these are all Rembco personnel. Rembco has a training program for all grouting, as well as special hazard communication orientation for all other personnel who may have close contact to the grouting area. Beyond education, protective measures include use of chemical masks for solid product handiers, goggles, boots, wet suits and gloves for grouters, and face shields for those at the point of injection. Waste disposal is detailed. All others venturing into the grouting area during operations must be trained and suitably attired.

Rembco selectively uses acrylamide as the grout of first choice in other industrial situations where there will be no exposure of the clients personnel.

I believe there is negligible risk in the use of acrylamide at weeks Island although anyone seems to be able to sue anyone else today. There has been no lawsuit tried in the United States which was ever sustained. 


\section{SUMMARY}

Areas in the mine grouted by us and others using acrylamide have been permanent. other grout use has been problematic with some documented failures and other suspect areas.

We have selectively been authorized to use acrylamide when operating conditions became difficult, but use has generally been restricted. We need re-consideration for use of the only good grout.

Terragel, an acrylate from celtite, since withdrawn from the market, was used in the production shaft in 1980 with the area being largely re-done with acrylamide in the following two (2) years. TAcss, a urethane polymer, was used in the Markel Wet Drift in 1978 - 1979, during the aftermath of the large leakage when the drift was being driven and the bulkhead erected. After the drift was completed, the areas grouted with TACSS were over-grouted with acrylamide. 


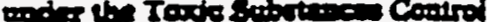
Ad 7 .

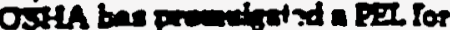

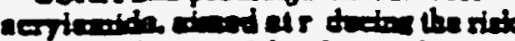

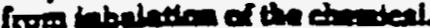

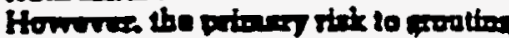

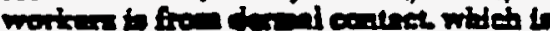

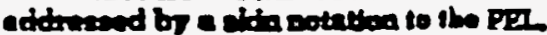

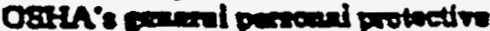

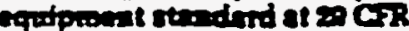

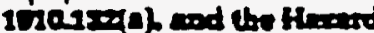
Com...

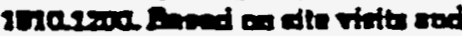

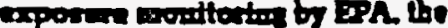

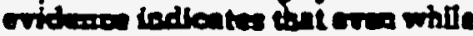
werter foll personel protactin

- equipreat techading a meptrator.

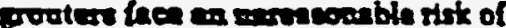
iatur.

The ovideres getherd th EPA duthe

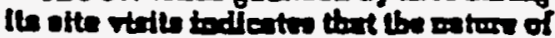

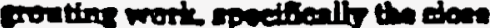
quartere be which the rosk lo pariormed

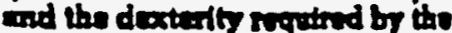

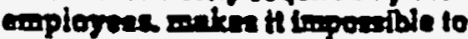
porvere a bondowe binl of dermel

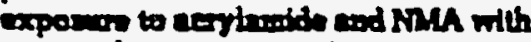
perrodel protective covioment.

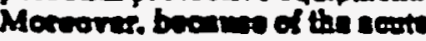

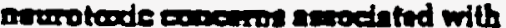
both acringide ood NMA Infrequent or uver freddeptal cortact with the two

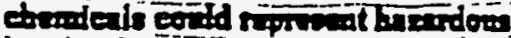
Invile of exposine

If the moridater the ven of perrond

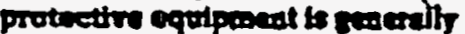
ecenpted as the Inst moct bu the

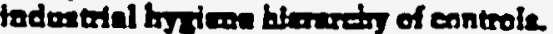

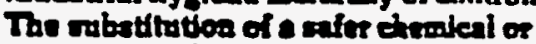
proceses is to be prefmed oner sototion wided atteript to knep the toxdo

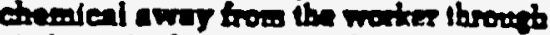
rich conthods as porwoad protecthe

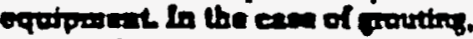
persond protacotre equiponent ena

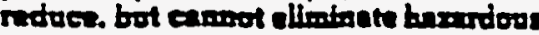
cxposanes.

in oddition to the differdtee entris frow the ure of pervesal protectre

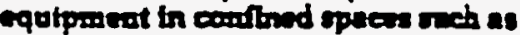

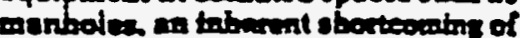

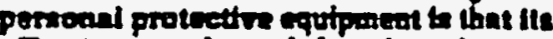

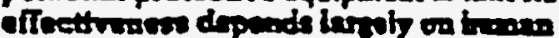
behavior. Given the lon neviotoxte unargins of exposene ateocfated with the une of scrylamide and MMA provats an unuescosible riak of bijug world exist men if presonal protecthe equiparent covid aliminats poposines th ment are.

EPA'e flading that one of the nime employes observed drefin the firld

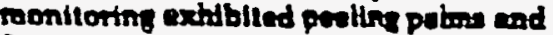

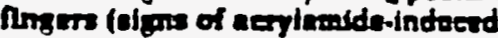
peripheril arurotoxiesty). and one other worker reparted petor epteoden of poeling palme and fingen. Jends suppon to EPA 's beliof that porsmal proteetive equiprnment emot adequately protect

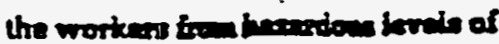
copour

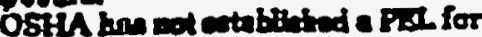

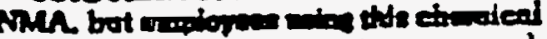

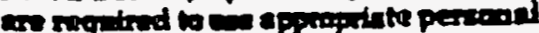
protecthe eq dineert en $8 \mathrm{CrR}$

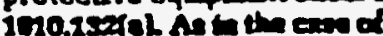

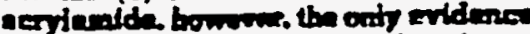
avellable to BPA cotabthates that the

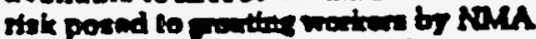

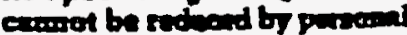

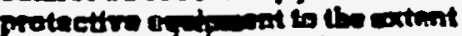

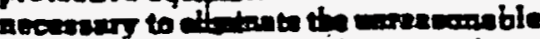

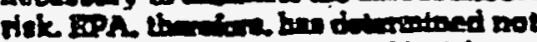

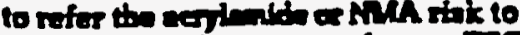
OrFin bet rethe to promingen a TBCA

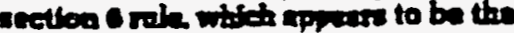

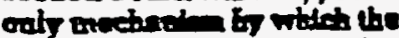

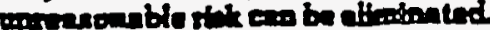

EPA's decidea not to nfirr the

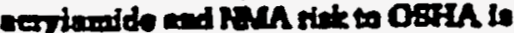

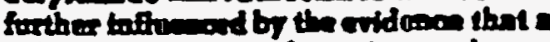

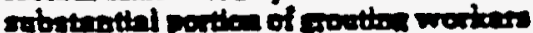
are state wid ex depal wexkes to

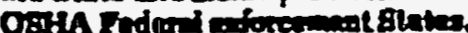

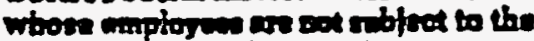

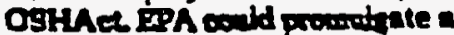

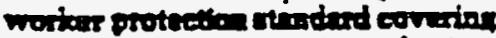

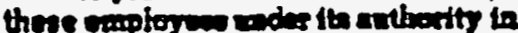

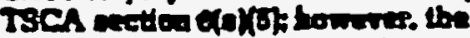

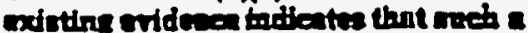
rale woutd rot adronotaly reduce the

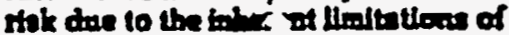

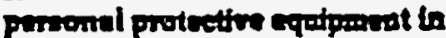
poutter oponters.

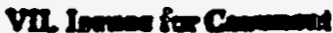

EPA ls propontang a total ban of cerlamida rod Noh prowts with a s-

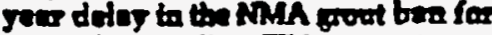

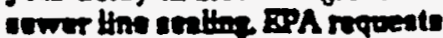
cownent ou thd approaet, expectally the iminth of the NMA poot bien dalay.

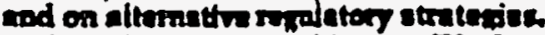
roch to thow dhemed b Uoth IV of

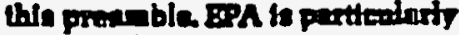

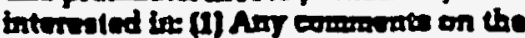
option to bas co firade and MMA

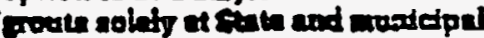
olles not covmed by an Osih-approved gtate pten ind 14 the proponed bas of

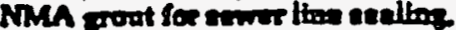
bedoding ons ocominats on tho propoend los the of the detar.

Addtenalf, EPA requests combert on Envel othat boves pertaining to this

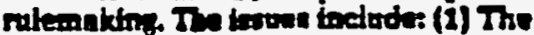
avallabiltty of substitute forote for seil

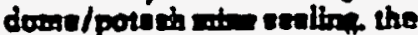
Inporinnea of thin applleation and any inforsation os potential costs to soctely If nubatitute frouts do not perform adequatety to this appltentors (2) any puformanca data on actiate grouts le.f. Inspeetion of provious sewer smiing jobs performod with acertate soot): (3) any preformance data on the new polyacrylumida and LV-unthane rrouts for sewer sealin of other

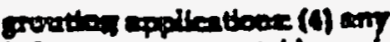

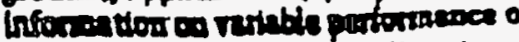

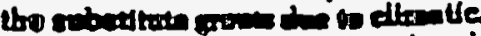

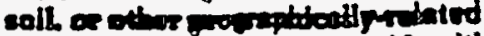

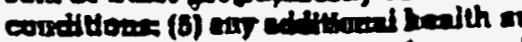

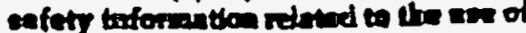

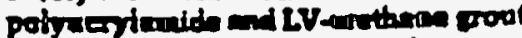

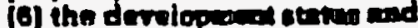
cosiperattos comb of way ather new

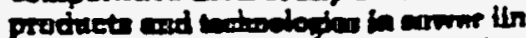

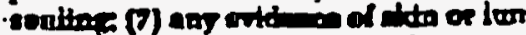

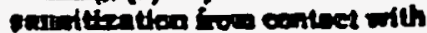

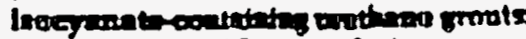

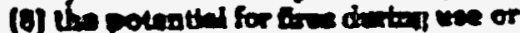

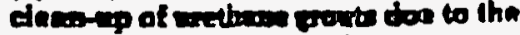

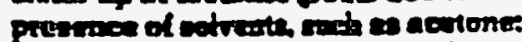
(D) the ndoquecy of exdethes conptores-

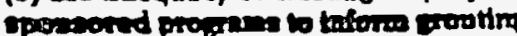

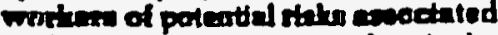

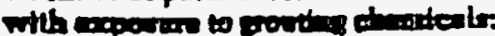

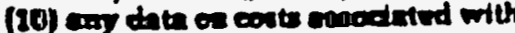

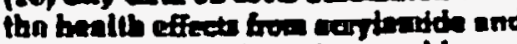
NMP expones (then dme corid

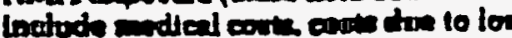

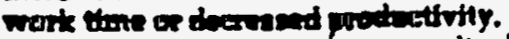

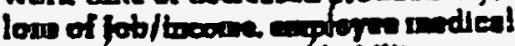

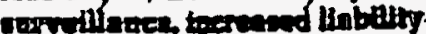
broc anes, otes (11) the ent of

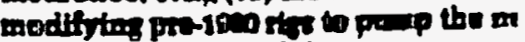

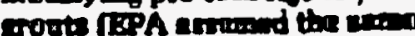

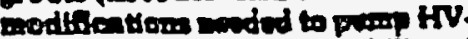
crothenet: (22) the applientids of sos Wind of ancrket-buned bremthos (an

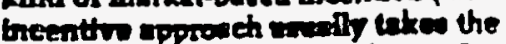

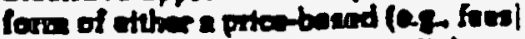
or 0 eremting thed (of, pornits) molationk and (19) be offictive date the forit min (BOPA fe propenten thot II is diss strot the date of pratication is

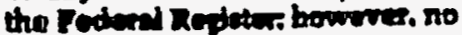

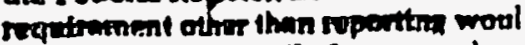
broome effectto mill 18 ep wore dary afler the effuetre dete).

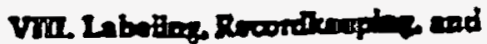
ropertios

B) 18 daye affer the efiluctura dale o thla mia. NMA propt nemefnerume. Inporting and datribatore woold the regutind to lahel or meve the integril of fhe label en, ench cootater. of wroo and persom who have pornersion o: controt of ecritabitite frout and also required to label contatmors of groot.

is A betteres thim to 0 numb need for hbolin to mimme convplanes with the protibittone m the manofecture. temportation itotribution and une of eeryiamide end NMA frouts Laboling - nvenerary mochantrm to divect maeri toward eomplianee wih the prohibitle on unes of ecrytamide end NMA neort

NMA grout mertulactonm inporter and distributors would aloo be montire to setaln recorde at ihetr companies' domestic headonartion heations of ull shimments of MMA soola for a pernod 2 youre from tbe date of oblpmant. 
newptox(afig) and ons other rosker imported past eptrentme of prealine paims

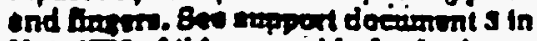
Unit XoV of thlo presioble for forther Hiscustion.

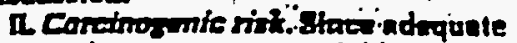
bemen data wese aet rivitable.

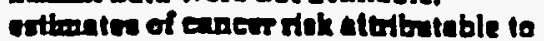

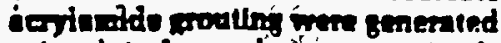

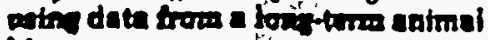
blowenay.

Betimaied upper borand IIfotme

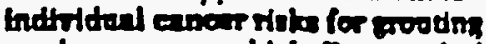
wotkems are vers high Even with the nnomption that groutting nay not oceur - bours dally or darirg cortaln times of - the year. propotem bave 1 in 100101 in 8.000 probabilits of deretopim manees orex theis Uffotims. EPA wrthates o tolul

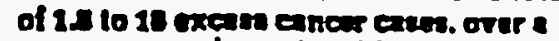
To-yenr pmided alterbutable to the usen of arriand de groot sese rupport docement Itr Unil XIV of this prentenble for further

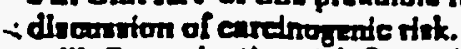

IIL Anprovoctive riak Reproduetive risks from acoriamide geveitm were cotionated throvegt the wos of animni dafe. Reprodicetire riak entimations are expreserd as MOEn. Baced an FPA ononitored exposurve for prouting workom. and a NOZ, of a.s22 m/ $/ \mathrm{kg} /$ day. the MOEs for reprodietive effects range from 0.2 to 7 . Ees support documont s in Unil XaV of this proumble for furthar discassion of reproductive rate.

b. NMA. EPA bas not quantifind non. cuner hanallh rioks ansodeted with the ues of MMA proule. Homever. In tento with mice treated with both aeryiamide and NMA. the anurotoxte potemital of MMA appinan to be lower than that of acrytamide. Eridomes of deveinpmental and rmproducttre toxdelty oxists: however. EPA hus no quantilativn dals for there offocts. EPA bolieves the roxietlles of acryinanide and NRAA are qualitativaly tha anmis, aithoogh they differ quantitetivaly.

Baned on date from the $1900 \mathrm{NTP}$ cardinonindelty toansy, EPA carried out a quanthetive. doessesponse accenciment for NMA. EPA caleolated uppes-bound cancer rik probubtlisties in the ranpe of 1 in 2.000 to 1 in 10000 lor individuals ualins AMM groul Thase cancer risks are boont en order of mannltude lower than oe!tmated eancer rinks for fadividuals wation ecrilamide groul. See support document i in Unll XTV of this preamble for further. difcursion of NMA riake.

\section{B. Bunafits of Acryomide and NMA grous and the A raitobility of Substituter}

1. Benefits of acrytamidie and NMA grou, uae. Although aeryiamide grout is uend more widely loodne then NMA groxl, the two govis are gentrelly uned in the anme applieatom. and they exhibit many of tha same performanes charactaristica. Acpianiolo sioul'e most popular end uas to is the rotiablititation of uewrer synterta a davilopment. bromght obout by tacreasing concerne over the inflitration and inflow of water Into sowrer syatean. Chenical proutina provides a mearr of aeeling and repairing the sewer syotern without contly exearation.

A eryianide grout is the mont widely uxed ehemleal goout for newer rehabilth tion becnuge of lla low enat. quiek and conerollable "get" or "ant up" time (the lime It Inkes for the grout to polymerizel. long bintory of reliable performunes. and very low viscosity. NMen groute also nei quickly, have low vireconily, and have proven equaliy effective as ncryiamide for nowor line soalinge although they are priced stinghty bigher.

Both netylemide and NMA grouts are Inas contly than somitute chmical proots. They are aien repported to be exsier to use than soms of the sabetilute gromils. although nther aubstitutes am neported to be funt as easy to work with as acryismide and NMA grout. The use of certairi subatitute groust appenre to requise mire attention to the datnits of propur atorage. grovt mixing ratlos. and emeral handling practices.

Neverthaiess. the substitute chemical provits are corrently mad in ail of the sente major commerciol epplieations as noyinmide and NMA grouth. The oniy cormmercial appilieation for which nome of the carrentily available vabstitute products has been used sucecesfully is realling sail domes and potah mines. an opisodic and vers aninor (lem than 1 percent of tolal retriamide srovt) applieation. Ovmail. EPA finds that the differences in bmefits to sociely of acryiamide and NMA grouse mintive to the avaliable subst tutes are emall.

2 Avollobility of substikures. Several iypes of chemical eabelllutar nre corrently used for grouting. The two. mott promixing substtutes.

poiyneryiamide and low-visconlty (LV) weithanes wore reeently commerciallized and hava thas fer onily been uned in enwer applications. Two other types of rubstitute grove aeryiates and hiphviscmily (HV) urethanes. have been on tha market for many years: and are corrently med for all major eommercial applications of nerinmide and MMA mouth. HV.urethane mouts are uned primartly for stroctural water control. munhole sealing ond gentectinical epplientione, wherese ecryjate prouts are used mors for sewer rehabilitation. expncially remotn nawer main line ocaling. The neww groutx. potyecrianide and LV.urothemen are expected to fend widerpored wae ia all

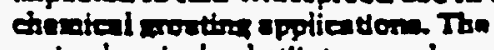
mate etrmical subututes are decribed botow.

- Aarfater. Agrinte proote llke

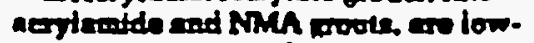

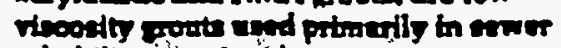

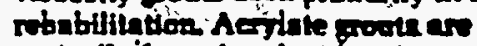
ipplealy forminted with elther

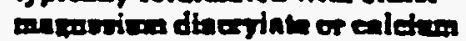
acyinte. and lenere amonts of lithium

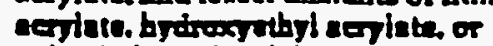
poisethylome sirood diangiate. Groutere opply ecryintem ening the seme inctintquex; eatalyot spniems and mpripuext en actianids.

Nithorest some vane of acoplate pouts corppiatin of theceld wank gets that do not protuce a good rmal ihts may ba attribatable to bnovifiedent solida coneentrattoos. Mixing of fers then the recomereaded perome solide contemt way ocew when wim in to whedertize

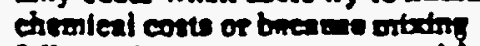
followe the seme preetion und for ecyinmide gromth. whers a lower pereentace of solids will attil produes a atrons gat. Based oo information from

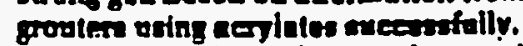
FPA belleves that whan used properiy. acriate groute ang vematile and an be adapted io nummetes end usea.

b. HV.Uruthome HV ane thanes are vin diframt frovit serilando and the otber groutth. All wiphene groots ars componed of isocyiante-lesminated

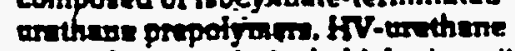
grode have e relittruiy high viacosits" and requise s soivent desn-op. The prooth am formulated exthet as a wnieraetlvated yntom or a chemically-eured iprtem althouath the watromactivated wethanes are roort comismonily oeed.

Unlike mont of the other rabotllates. tha $H V$-urethanes carrot be pumped through the enme equipment used for cojlomitio grouta. The teetrnique and ogripresent invoived in pomping HV.

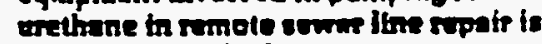
difformt from the low-viscosity grosts. Thurofon. with the exrrent technolons. provtens owleching from acyimide for NMU) to HV-urethane woold nowd to

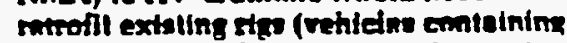
poot whxima end infecting equipment) of extutential expense. Reelizing theod'

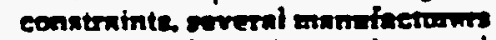
developed LV aresthines that can be. pouped with moeh of the same oquipment exrently uned for coryiamide (and NMAa) grovie.

For momhole realine. HV-urethanes are growing in me. Curnently, ol percent a all mantois senting operaitiom an porforemed uning tht grovel. compered to 93 pereent wilt serytumide. HV. urethane grouts are equally effretive on 
pwoant by acridate cowie. The tolal complineses cont for a bera of ecriamide

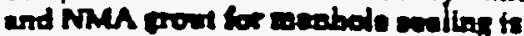

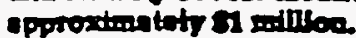

c Sirvatras al moles coptrol. HV.

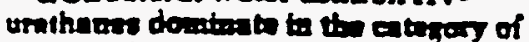
itresteral water eostrol, nocouster for rowhty ep pureent of all grout ased in

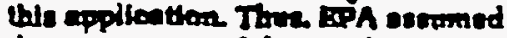

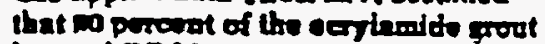
beond (NMA grost ta oot ewrendy - uned ta this appitearten/ will be ropinaed

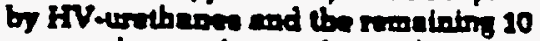
purcuse br acriater. The toral compliane cost for a bas of ser lasoide aod NMA forat for this appliention to ens milliom.

d. Gootrahntrol appllcotfons. Bxied on toduntry parcuptoon and the available mienereh ea tbe spedfic hruns of concers ENA anrened bat 60 percest of the acyiandd poot borned in this use entegury (NM) prot is not curroutly veed b th's eppliention) will be repineed with $H$ V resaining 10 procent with serilates. The fotal coroplinnes cost for s ban of mayienide and NMA proot for this appliextion is sazoce As proviounty notad homerve, becule of uncertainties with the une of stibstitutes in aslt dowes end poturt andnes. there uny be rowe stgriflent conts in the protecterted catecory that here not been crptured.

- 2 Candurion. The toral mentitized complimes coste of the propoend repulntor ane in the rumes of 4.4 million to $5 \% .1$ billilor deperding on the substitution semerio for semor line conline. Based on e popudatton of 1000 - erouters. thits mownte to a cont of ipproxionately 25001084.000 per yeat to protect aned frouting worter from vary bigh individual newotoxde and cardronvide rtake The largest portion of theme ceste are ettributable to the ban of corlandde and NMA provte for ener

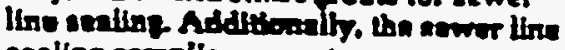

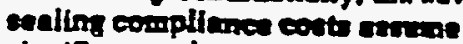
dicnifeant subattution of seylundde and NMA growto with polyrerytanide and LV.unthemes sibstitutes with HV-dretheenes and acrilater for this appilication woold reade in ureats higher

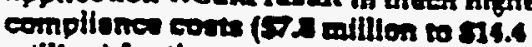
million) for the propond aetron.

EPA expects biaf the deferred ban of NMA for emwer the enalbes will lewen the eeonomic bordia oo mentapelities and frodtirs comterctom by allowis thea suffieient oppostuonty to fally cvalunte min cubattute grovers, and prepere for mny Eapital trrentinents which may be meopetiated by a ben of cayienide und NMA froute.

Orerall. EPA experete that this proposed role. while hering an tmpact on the cost of ealing sener imes. will nat have a ripifteat advene trapict on

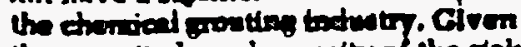

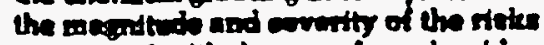

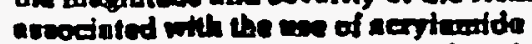
and NMA pontin ERA baltwres that the

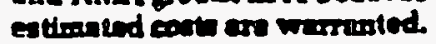

\section{TV. Otber Oprom Co Lidered}

EPA comidand other ryptatory optow as altresnatres to this proposed nide. bat becad on the avatiable

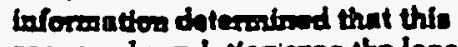

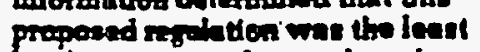
budracores to edequateh redect the

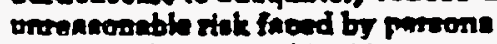
untog acrilunde end NMM foote.

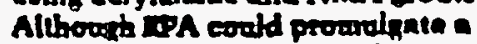
wotker potsetion stendard eovinin Biate and ro dapal amploy ender ito Tsan antbotty, ged biliever, as

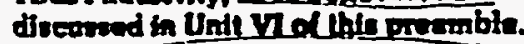

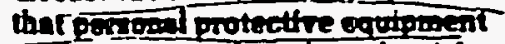

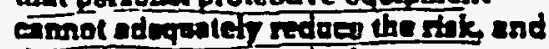
Liolaben for hech tho leant budencoses requtrement that will ndequataty redues the riak A disconsion of the other options condidered b given bolow.

I. Ben oantomide groot only at sites not corrend by CSHA. EPA contdered imporise ban on the ues of acyiaride grout soiety et Biate end muntedpal sttes pot covernd by an OSFIA-appioved Statr plan Trin option assumen a compicte ben of NMA frovet abeo. becase thes be comsity no Oesth workpiace standind for NMA. Fotimated comptiones oonta for this optios are in the range of exeosod to 879000 . dopending on the semer Hine sabetifution comarte at altes whem both acrilrmide and NMA prout are probibited.

EPA botiones thet 1 bed of neryiaraide growten oaty at glete and municipal stes not conerd by en OSTLA-npproved State pina ta cotenteble for neverel necorre. Fint enforementent of an explacide powt bere conty at stien in 27 states (l.e thoce without ad OgRA. approved giate pien) entght pour axtrumb diffeult sine acoliendde pouts woidd atill be on the buriket. Addithombs, a ban of acolarotde groot ve onty by gtate aod werictpal workes to those 20 Sinte: (approxtiont ff 100 is 200 workers] - moda afferd eo adatuenal protection to those nestandde frouttros workers in the pertruik poctor. who afill lace cuesconsble riake don to the canvithable dermal expownes encoumernd while grouting. Morwover. allowirs one popalation of grouters to

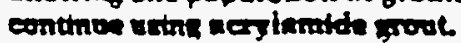
provishd thers adhere to thr OBfA morkplaes stendard whlle baming onother population of eroutere from using the growt altogether would amount to nonuniform reguletion of the chemical soming tadestry by dilcrent Fed

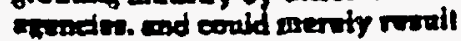
incenend potrattation of provitin

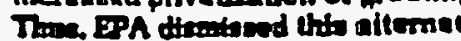
conctudtry braterd that a sotal ba ecylautde and NMA foout is nee to onse the burdem of eomplianet monilonthe, sdequately protect all

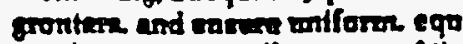
repuletton acoess all enctors of thi chemien monting bodutry.

2 Bon oll unes of enarianjots and all ores of NMA snowh excep MMA prove wo in cound time seal This mptios ts etrilin to the prope cetlon exerpt teat ANMA frout wi not be rututeted at all for sumer! wa. Inthanted remalhind compl coste for this optted an about iz million. An adyantage of this opti that the cosaplisne cowte aro epproxtrantely 221 bedillon to 912 million (or 48 fo 84 pertent) lese 1 amualiend compilinsice coste of $E$ prefernd optlon dopending on th availability and coste of acry hem NMA subutitutes. This cmet redue due to the reletively high incrme conts of a ban on NMA prout in 21 lines after 3 years. DPA comidere option brezuse NMA posos rilall loss rink! workess than aeginm and sewer line use of frout porses comewhat less risk to woskers thi anshole use.

Nithough this option would elis the highest risk noot (neylemide men. and eliminale acplamide at NMLA proute for the highent risk 4 (manhole operstlom) at thd time does not bellow this optton will vaffieimtly reduce risks to grouth motkets. In the event of a ban on

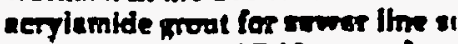
and no action on NMA grout for 1 opplicarion. EPA expretis AMMA gr be the primary oubstitert. As notl abore. while the riste frode wing pout an lower then those ecsocd. with the ure of aendanide groot. risk to thdividual grootting worker NMA groot is atid bhth. At this tin DPA believes the conblatition of Wigh isk and the presence of sub which pore lower risk potontisl. particatarty the poigneryazide a wothure groute, waments metrict both acriandde and NMMA groula yown line senlim.

3. Ban the use of acrylomide on MSA grouts for manhole ovolim . Thle option would allow eontinue merntiteted use of ateryionide an

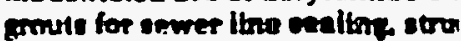
water control. and grotechnical opplleations. Eatminted complien corte for this option ane approxim 92 million. 


\section{Ms. M. Smith}

Director, Environmental, Safety, and Health

U. S. Department of Energy

Strategic Petroleum Reserve

Project Management Office

900 Commerce Road East

New Orleans, LA 70123

Dear Ms. Smith:

Subject: $\quad$ Contract DE-AC96-93P018000;

Proposed Ban on Acrylamide and N-methyloacrylamide Grouts

In order to assist the U. S. Department of Energy with their assessment of the use of acrylamide grout at the Weeks Island SPR site for filling vugs, fissures, and stabilizing faults in the salt dome, DynMcDermott Petroleum Operations Company (DM) was asked to research the federal regulations and contact regulatory agencies. The attached proposed rules concerning banning acrylamide grout use appeared in the October 2, 1991, Federal Register. According to Mr. E. Brooks, EPA Office of Prevention, Pesticides, and Toxic Substances (202) 260-3754, EPA expects to promulgate the final rule during November, 1994. Acrylamide is regulated under TSCA due to its carcinogenic and toxic characteristics based on dermal exposure and inhalation. He knew of no restrictions based on proximity to ground water or potable water. He has no data on life expectancy of acrylamide in salt or potash environments. DOE would have six months from the date of the final rule promulgation before acrylamide stored on site would be banned from use. Since $\mathrm{N}$-methyloacrylamide is an order of magnitude less toxic and will not be banned for at least three years, Mr. Brooks suggested that Nmethyloacryiamide be considered for use on the SPR and referenced Mr. D. McGiller. CEO Avanti for details about the AV 118 product.

OSHA sets air contaminant exposure limits. The acrylamide exposure limit was set at $0.3 \mathrm{mg} / \mathrm{cubic}$ meters of air. 
According to the attached lists, acrylamide is an Extremely Hazardous Substance. Any listed chemical brought on site that has not been reported (such as acrylamide) and exceeds the threshold planning quantity must be reported to the local emergency planning committee and the Louisiana Dept. of Public Safety and Corrections Office of State Police Emergency Response Committee via submittal of the SARA Title III Tier Two report form and an MSDS within 90 days. The threshold planning quantity (TPQ) for acrylamide as a solid with a particle size less than 1,000 microns, in solution, or molten form is $1,000 \mathrm{lbs}$, otherwise the TPQ for acrylamide is 10,000 lbs (See 40 CFR Part $355.30 \mathrm{e})$. Notification of a release in excess of the reportable release quantity $(5,000$ lbs) is also required. The EPCRA hotline confirmed the above limits for acrylamide.

According to the RCRA hotline, acrylamide product is not regulated under RCRA. Acrylamide's RCRA waste number is listed in 40 CFR Table 302.4 as U007. Sources at LDEQ (Roselle Simar-ARMM, Celeste Bonacast-GW Protection, David Hughes-

Regulatory Compliance), LDNR (Pierre Catrou-Office of Conservation), and DOTD (B. Bolourchi-Water Resources) indicated that they know of no State of Louisiana regulations regarding acrylamide grout. According to B. Bolourchi, only cement or cement bentonite has been allowed for grouting that may contact source of drinking water. He suggested that DOE meet with representatives from LDEQ, LDNR, DOTD, and EPA Region 6 to discuss the SPR WI site's use of acrylamide.

For further discussion, please contact E. Hollander at 734-4830.

Sincerely,

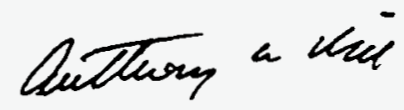

for William E. Bozzo

Attachments:

as stated 


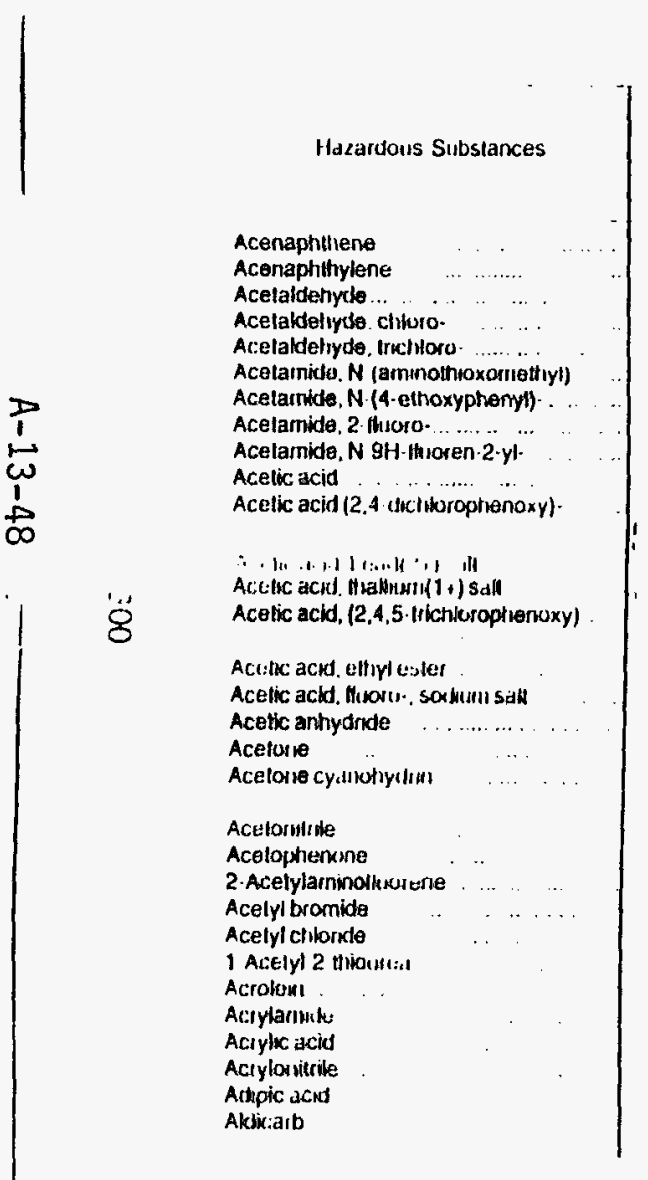

Tabi e 302 4-List or Halahious Substances and Reportabie Quantities

[Nole: All Comments/Notes Are Located at the End of This Table]

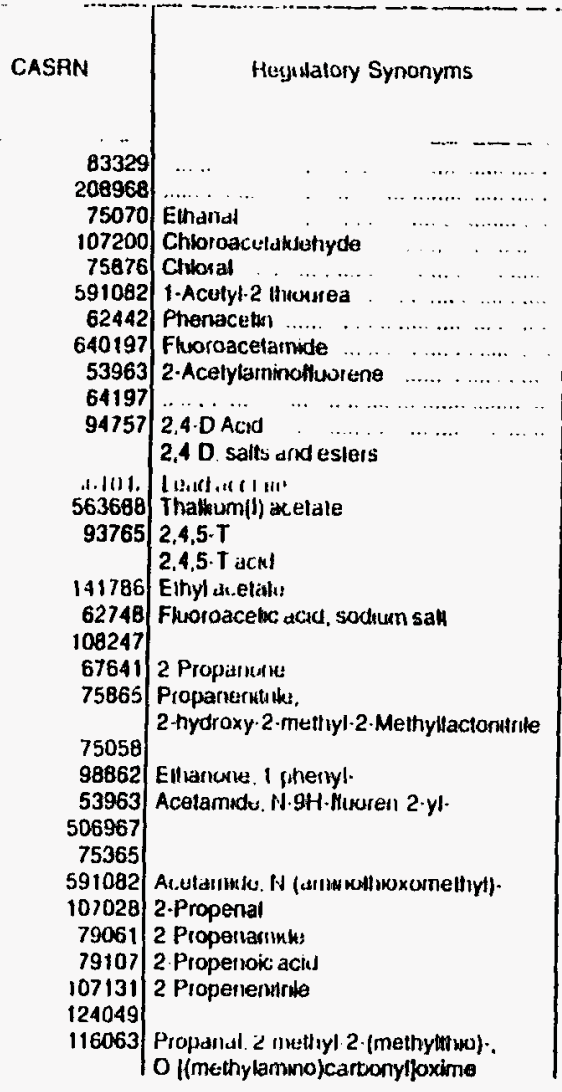

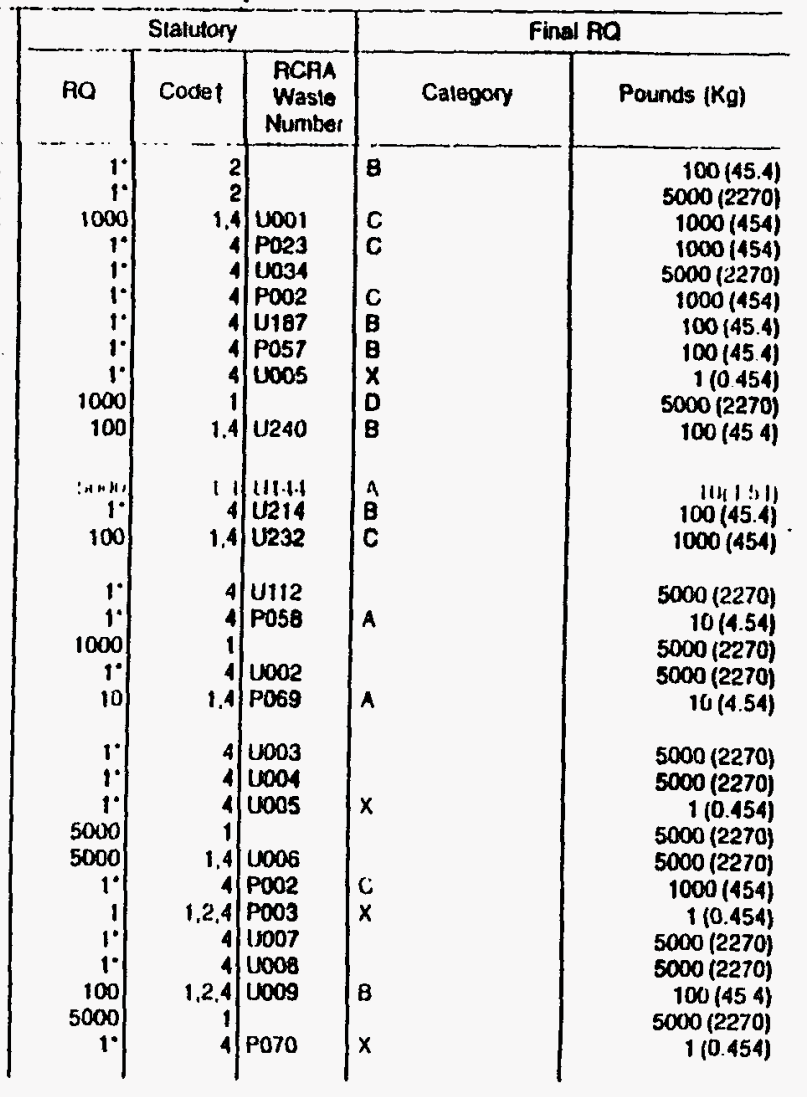


decision on promulgation of the final land applicetion rrie to taks into account the eftect of tho process changes under cansideration far theses rules on the seaviliong lenls of dioxin and burnecontamination in the sludge. Onos this datermintion bes been. made, the Agency will.xwoviluats tho risk from sludos Innd appilication and will bu shlo to chouca if recosenry. the appropinte enguleterg. or noureguliterg mechavien lo sddians the siturtion. The Ageney expocts to.mits this dotarminnilan in 2905.

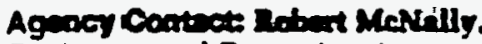
Envirommented Prot cton Ageoch. Office of Prevmtion. Peoticides. and Toxic Sobstionces, Wastaington, DC 20160, SE, 20e 2003015

Fin: 2010-Acos

3742 usE or ham

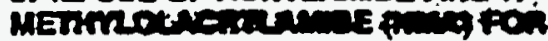
GRovring.

Signtilemon: ...:-

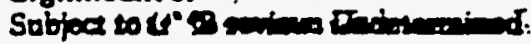

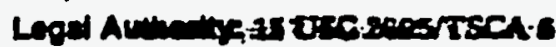

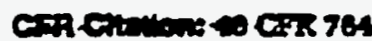

\section{Legl bond?}

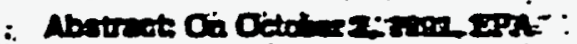

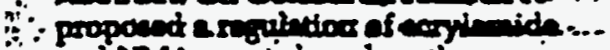

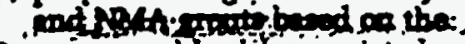

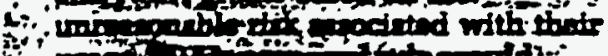

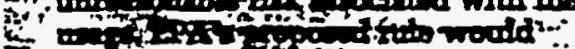

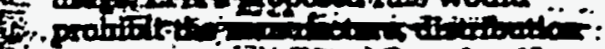

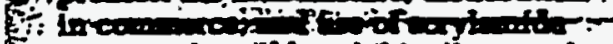

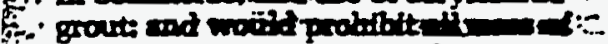

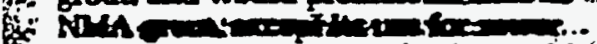

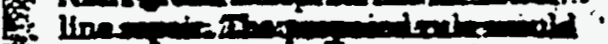

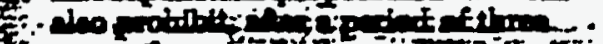

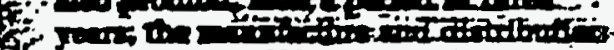

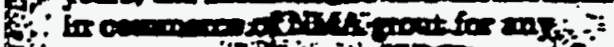

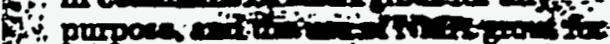

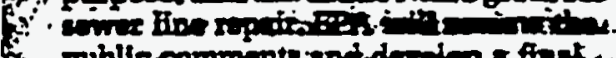

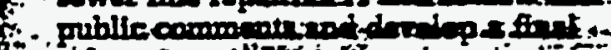
ب rila. 然

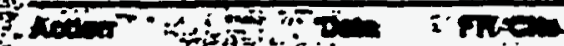

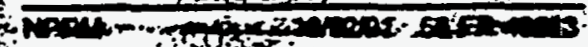
Fan a

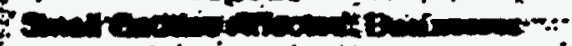

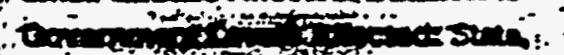
Lon

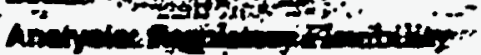

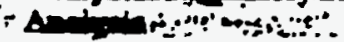
idoumitm

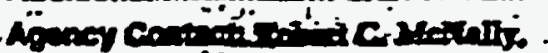

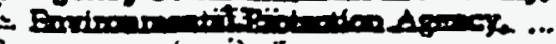

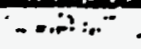

$=$

jit:

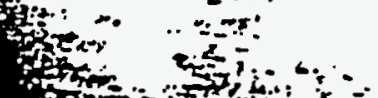

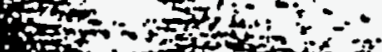

int
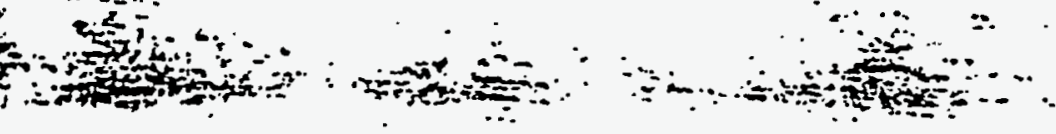

Office of Provention. Pextisides, and Tcosic Subrtuncee SE, Wasinington. DC 20460. 202 260-3945

RIN: $2070-A C 17$

3743. POLYCHLORINATED

BIPHENYL (PCBS) TRANSFORAER RECLASETCATION RitLE

Signifteanea:

Subfect 10 OMB roview: Undetermined

Lol Awhorley 15 USC 2685/rSCA 64)

CFR Cltation: 40 CFR 701

Legal Deadine: Nons

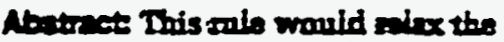

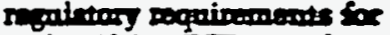
Toclascifying PCS trinfoconem to a

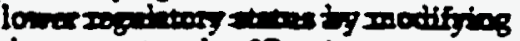

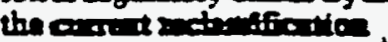

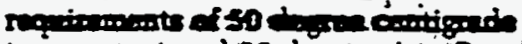

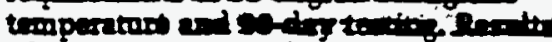
of a preliminary andyste indicole thet

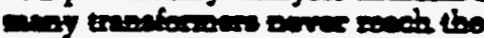

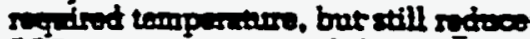

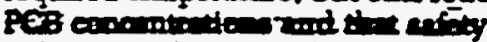

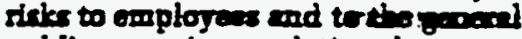
pulbe cocur in mond th ther. continued adherenos to the can. reguinttons.

Tranterin

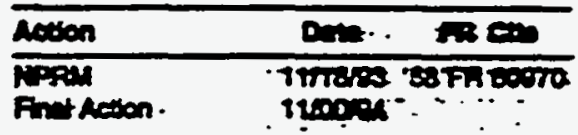

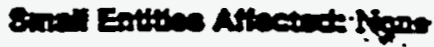

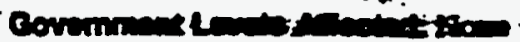

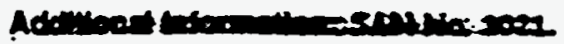

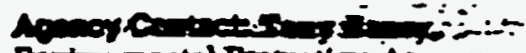

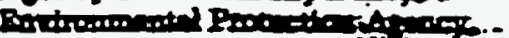

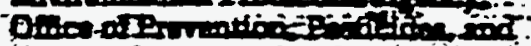

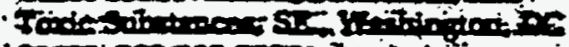
201001 20030 Din.2020nac39

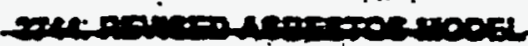

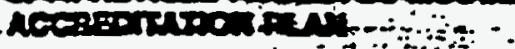

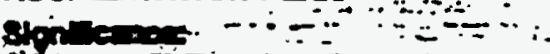

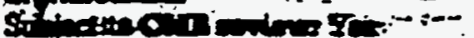

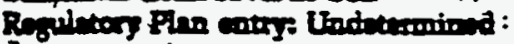

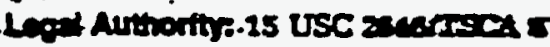

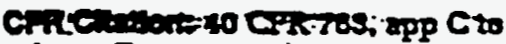
a.:.

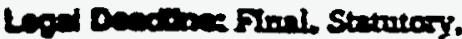
Now be $2 . . .5$ I000:

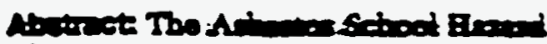
Abet: int R-vithoctortion Act

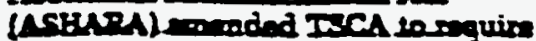

thet EPA rovise its esbestos model accreditation plan to extend training. and accreditation requiraments to include persons performing certato astbestoserelated work in public and commercial buildlags, to increse the minimum number of training bours roprinod for cocoditution porpoces and to effect ethar chonges pocom to implewent the encondmenter Inis ection will increase regulatory conts for the oweres and manngers of poulte. and commercial building but will also reduce abbestos exposures in then. buildings.

Timatible:

\begin{tabular}{|c|c|c|}
\hline Acton & Ders & fin \\
\hline 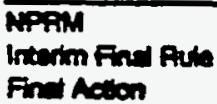 & $\begin{array}{l}\cos 33 x \\
\cos n 10 \\
\operatorname{coses}\end{array}$ & $\begin{array}{l}57 \text { FP } 200 \times 3 \\
50 \text { Fin ort? }\end{array}$ \\
\hline
\end{tabular}

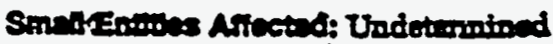

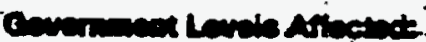

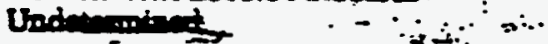

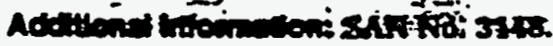

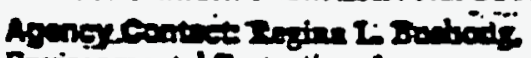
Eavirumonolel Protector A gancy. .

Ofice of Prumatloe. Focticider and

Toxie Subtrocen (15-786):

Watingtom DC 20480, 2022000001

Puit: 2004aces

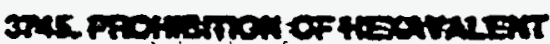

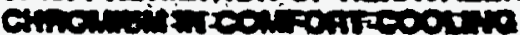

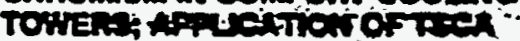

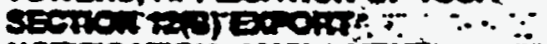

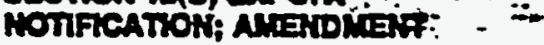

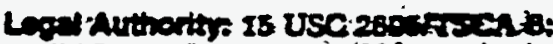

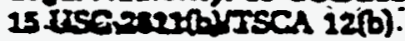

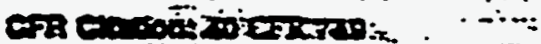

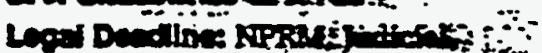

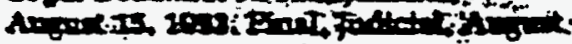
15. 198 :

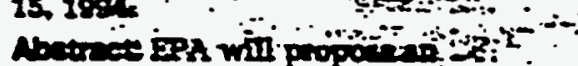

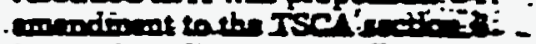

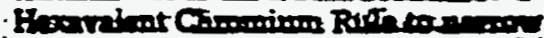

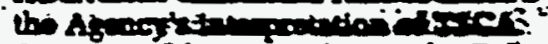

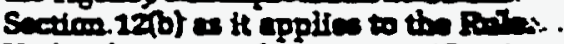

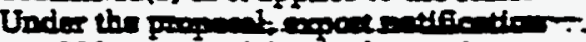
would be raquined for the hoorent

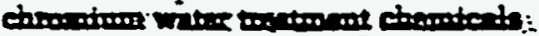
Intborthm ary cocopound cont intiog

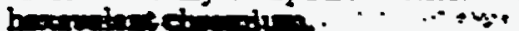

T3.

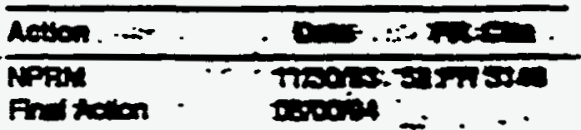

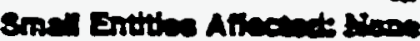

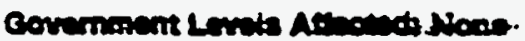




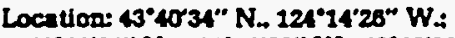
$43^{\circ} 40^{\circ} 4^{\prime \prime}$ N. $224^{\circ} 13^{\prime} 30^{\circ}$ W: $43^{\circ} 40^{\circ} 20^{\prime \prime} \mathrm{N}$ $124^{\circ} 13^{\prime} 50^{\circ} \mathrm{W} \mathrm{W}$ i $43^{\circ} 4020^{\circ} \mathrm{N}$ : $124^{\circ} 14^{\prime} 28^{\circ} \mathrm{W} \mathrm{W}$. (NAD 83)

Size: 0.14 equire natical miles Depth: 32 meters (average)

Primary Use: Dredged mnterial

Period of Use: Continuing use.

Restrictlons: Disposal shall be limited to dredged material determined to be suituble for unconfined disposal from the Umpqu Batuny and River and adjacent arene.

[FR Doc 91-23012 Fuled 10-1-91: 2.45 am] rum cos cmente

\section{CFR Part 784}

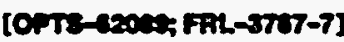

\section{Fin 2070nec17}

Proposed Ban on Aarieride and it invityfleterytinide Qrouts

Acracer: Environmental Protection Agency (EPA). ACtrone Notice of proposed rulemaking.

summerr: This proposed rule would prohibit the manufacture, importation. distribution in commerce. and use of acrylamide grout and would prohibit all uses of N-methylolacrylamide $\left(2^{,}, \mathrm{NA}\right)$ grout. except its une for sewer line repair. The proposed ruie would elso probibit, after a period of 3 yearn. the manufacture. importation, and distribution in commerce of NMA grout for any purpose. and the use of NMA grout for sewer line repair. The proposed action is necessary to protect grouters from the neurotoxic and carcinogenic risks arising from significant dermal and inhalation exposures to these grouts encountered with their use, even while wearing personal protective equipment. EPA is issuing the proposed rule under the authority of sections $6(a)$ and $B(a)$ of the Toxic Substances Control Act (TSCA). This proposed ruie is based on a determination that use of acrylamide and NMA grouts presents an unreesonable risk of injury to human health. and that pollution prevention through a ban on their manufacture. importation, diatribution in commerce, and uie. and appropriate labeling of the grouts. is necesnary to protect adequately against these risks. EPA estimates that a 3-year delay of the ban on NMA grout use for sewer line repair will substantially ease the potential economic burden on the sewer sealing industry, without posing an

unreasonable risk to workers during that 3-year period.

oarns: Written comments in response to this proposed rule munt be received on or before December 2, 1991. If persons request time for oral comment. EPA will hold an informal hearing in Washington. DC. The exact date. time. and location of the hearing will be mede available by telephoning the Environmental Assistance Division at the telephone number listed under FOR FURTHER INPORMATION CONTACT. Written requests to participate in the informal learing must be received by December 2. 1991. For further information regarding the hearing, see Unit XII of this preamble.

abomis:ars Submit written comments. in triplicate, identified by the docket number OPIS-62008. by mail to: TSCA Public Docket Offico (IS-783), Im. NECOOS. Otince of Toxic Substances. U.S. Environmental Protection Agency, $401 \mathrm{M}$ St. SW. Washington, DC 20460. For further information regarding the submission of comments containing confidential business information. see Unit $X$ of this preamble.

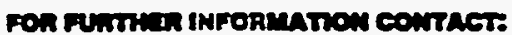

David ]. Kling Acting Director. Environmental Asaistance Division (TS789). Office of Toxic Substances. Environmental Protection Agency, im.

B-513, 401 M Sl, SW. Warhington, DC 20460. (202) 554-1404. TDD: (202) 554

0551.

surmenantaTr mponinatrow:

\section{Authority}

If EPA determines that there is a reasonable basis to conclude that the manufacture. procesning, distribution in commerce, use, or disposal of a chemical substance, or that any combination of such activities. presents or will present an unreasonable risik of Injury to human heaith or the environment. section $6(a)$ of TSCA authorizes IPA to apply one or more of the following requirements to such substance, to the extent necessary to protect againat the risk: prohibit or limit the manufncture, processing, or diatribution in commerce: require labeling; prohibit or otherwise regulate any manner or method of commercial use or disposel: and require that chemical manufacturers notify the public of unreasonable risk associated with a chemical aubstence. Under TSCA. importation is included in the definitlon of manufacture. TSCA section 6 requires EPA to apply the least burdensome requirements to protect adequately against the risk.

This proposed rule will affect both private grouters and State and municipal workers engaged in grouting operations. Because acrylamide and NMA grouts have been sold as commercial products. grouting operations using these products are considered commercial activities. subject to section $6(a)(5)$ of TSCA.

EPA is also proposing limited recordkeeping and reporting requirements under ISCA section $8(a)$. Section 8(a) authorizes EPA to require persons who manufacture or process chemical substances and mixtures to maintain records and submit roports for many purposes, including records and reports necessary for effective enforcement of ISCA requirements.

\section{Background}

1. Aarylamide grout. Aarylamide gront was fint introduced into U.S. commeros in 1855. It quickly became poprelar-because of its low cost and superior. performance properties compured to other grouts then on the murket. in the $1870^{\circ} \mathrm{a}$, demand for acrylamide grout grew as a result of an increase in aswer repair (rehabilitation) activitien. In 1978, production of acrylamide grout in the U.S. ceased because of the producar's concern for its potential rivk to humen heaith. In response, users of acriamide grout either obtained acrylamide geont from foreign sources, switched to other chemical grouth, or reduced/atopped grouting. Acrylamide grout continues to be the chemical prout selected most often for use in sewer operntionn. Ábout 650,000 pounds of acrylamide grout were consured in 1989. roughly 45 percent of the total chemical grout usage.

Acrylamide grouts generally consint of a 19:1 mixture of acyilamide and a crosslinking agent. When preparing the grout for use. water and small amounts of other chemicals are added. Theas chemicals include catalyete, actirators or accelerators, and inhibltore. When the acrylamide grout polymerires or "gels." it solidifies into a stiff gel that is impervious to water. in gel form, the grout contuine lese than 0.05 percent free acrylamide.

Grouters typically inject acrylamide grout in and around concrete, rock, and soil to increase the absolute strength of the mass and to restrict the flow of water through a structure or the grouted area. Approximately 87 percent of all acryiamide grout is used in sewer rehabilitation: 76 percent in sewer line repair and 11 percent in manhole sealing. Sewer rehabilitation helps minimize the demands on sewage treatment capacity and wastewater treatment costs by reducing the inflow of rainwater and nonpoint run-off and the infiltration of groundwater through cracks. hoies, and joints in the sewer system.

In sewer rehabilitation of lateral and main lines. leaking pipes and joints are sealed remotely using equipment that

$S-310999 \quad 0009100 \times 01-\infty C T-91-10: 46.07)$

$$
\begin{gathered}
\text { 4702.FMT...[16.301...12-28-90 } \\
\text { A-13-50 }
\end{gathered}
$$


incorporates a clósed-circuit television syatem, an inflatable packer, and a grout delivery system. The camera provides pictures of the inside of the sewer line to a worker who controls the packer and the grout delivery syatem from a control board inside the service truck. Exposure to grouts from this use typically occurs during grout mixing, and equipment disassembly and cléantup operations. In manhole sealing, a' woiker enters the manhole and uses a hand-held device to inject the grout into holes drilled in the side of the manhoie. The grout flows into the soil surounding the manhole. sealling cracks and preventing water Infiltration. Worker exposure occurs in all phases of this operstion (grout mixing, injection, equipment disassembly, and clean-up).

Acrylamide grout has two other minor uses. Eight percent is used for structural water control and five percent for geotechnical applications. In structural water control. the grout is used to repair leaking concrete structures. These projects inciude seepage control. sealing cracks in sewege aeratton basins, and repairing dams. In geotechnical applications, the grout is applied to soil or rock formations. Geotechnical grouting includes water cut-aff in mines and reservoirn, sealing underground salt domes and potash mines, and isolating hazardous waste sites. Both structural water control and geotechnical grouting operations involve manual injection techniques. Worker exposures may occur during grout mixing, injection. equipment disasembly, and clean-up.

2. NMA grout. NMA is a derivative of crylamide. Sixty thousend pounds of NMA grout are conuumed yearly. accounting for three percent of the current chemical grout market. NMA grout is used exclusively in sewer rehabilltation and manhole sealing. The equipment and processes necessary for sower rehabilitation and manhole sealing with NMA grout are the same as those described sbove for the use of acrylamide grout although a different chemical catalyat is used. Individual worker exponure to NMA grout during its use is belleved to be comparable to that which is experienced by workers who use acrylamide grouts.

3. OSHA actions. In 1971. the Occupational Safety and Health Administration (OSHA) of the U.S. Department of Labor. under the Dccupational Safety and Heaith Act (OSHAct), establiahed an occupational otandard for ecrylamide with a permissible exposure limit (PEL) of 0.3 milligrams/cubic mater ( $\mathrm{mg} / \mathrm{m}^{2}$ ) for an B-hour time-weighted average (TWA). and a skin notation to reduce dermal exposure. However, OSHA established no workplace standard for NMA. The acrylamide standard was intended to reduce inhalation and dermal exposures. specificslly to protect workers from neurotoxic risks. In developing the PEI. OSHA did not consider carcinogenic riske. In January of 1889, OSHA lowered the acrylamide PEl to $0.03 \mathrm{mg} / \mathrm{m}^{2}$ for an 8-hour,TWA, with a skin notation, in responie to carcinogenic risk evidence.

In addition to the acryiamide PEL and skin notation. producers and users of acrylamide and NMA grouts are subject to the provisions of OSHA's Hazard Communication Standard (28 CFR 1810.1200). The Standard is intended to provide health hazand information to employees exposed to hezardous chemicale. The Standard requires that bage and containers of hazardous materials, such as acrylamide and NMA grouts, be lebeled and accompanied by material safety deta sheets. and that worker training programs be instituted.

Employen are also subject to OSHA's personal protective equipment standard (29 CFR 1910.132(a)]. An employer may be issued a citation for violation of this standard if it fails to provide appropriate personal protective equipment to its employees. and enforce the use of the equipment.

\section{Rogulatory Asveament}

Under section $\theta(c)(1)$ of TSCA. EPA must convider the following factors in determining whether ectivities involving a chemical substance present an unreasonable risk:

1. The effects of such substance on health and the magnitude of the exposure of human beings to such substance.

2. The effects of such substance on the environment and the magnitude of the exposure of the enviranment to such substance.

3. The benefits of such substance for various uses and the availability of subsiitutes for such uses.

4. The reasonably ascertainable economic consequences of the rule, after consideration of the effect on the national economy, small business. technological innovation. the environment. and public heaith.

\section{A. Risk Analysis}

1. Health effects of acrylamide and NMA.- a. Acrylamide. Acrylamide is a human neurotoxin. There is firm evidence of its neurotoxicity based on effects observed in both the peripheral and central nervous systems. the cumulative effects of chronic exposures. and dose-response relationships observed in animal studies. Predominant among the effects in humans are signs of peripheral nerve damage, including tingling of the hands and feet. muscle weakness, loss of muncular coordination, and decreseed tendon reflexes. Central nervous system effer include drowsiness, tremors, slursed speech, and hallucinations. The repor of humen neurotoxicity from acrylam exposiure alsó indicate that although most individuals recovered completel once exposure was stopped. some severely affected persons did not, thu suggenting irrevercible effects.

Acrylamide exposure aleo poses potential cancer effects in humans. These potential effects are based on $t$ following evidence from animal studic benign and maligment twmor formatior tumor formation in two animal specie: tumor formation observed in both sex and at multiple sites, and a doseresponse relationship observed in a Iifetime bioassay. Acrylemide's genotoxicity provides additional supp for the:conclusion that acylamide ma be a human carcinogenic agent. Acrylamide has been shown to be a mutagenic agent in both in viro and is vitro tests. In addition acyiamide hat been shown to be a germ cell mutagen mice.

Three human studies wers conducts to examing the relationship of worker exposure to acrylamide and cancer mortalifusc Overall, the reanits of the studies:do not indicate an excess of cancers from exporure to acrylamide. Howevier. this may be due to limitatio in the design of the studies.

Consequently, the results of the huma studies alone are inedequate under EPA's Guidelines for Cercinogen Riak Assessment (51 FR 34012. September 2 1986) to judge the human carcinogenic of acrylamide.

Based on all available evidence. EP. has concluded that there is aufficient weight-of-evidence to identify acrylamide a a probable human carcinogen (Group B2) ae defined in EPA's Guidelines for Carcinogen Rlsk Assessment.

Reproduclive and developmental effects have also been observed in several animal studies. Available animal data indicate that acrylamide can act directiy on the reproductive system. Acrylamide has aiso been shown to produce developmental and postnatal effects in mouse and rat offspring following administration to pregnant dams.

b. NMA. The heaith effects associati with exposure to NMA are comparabli to those associated with acrylamide exposure. They include carcinogenicit. neurotoxicity. and developmental and reproductive effects. The results of a 2 
year National Toxicology Program (NTT) enimet studyos how thet AMMAt carcinogenic in both sexes of the mouse. Preliminary analyois of these data as weil as supporting information from genotoxicity studies and structure activity considerations indicate a close similarity to acrylamide. which has been classified as a probable humsn carcinogen (Group B2). Prechronic studies conducted by NIP prior to the 2year study measured several neurotoxic endpoints in laboratory rodents following NMA dosing. Neurotoxic effects included loss of muscular coordination, tremors. and hyperresctivity. NMA is reported to be a less potent neurotoxin than acrylamide (See support document 4 in Unit XIV of this preamble).

Reproductive toxicity and developmental effects of NMA were aiso observed in laboratory mice studies. Bxposure resuited in degeneration of the epithelie of the seminiferous tubules, including opermatids and spermatocytes. as well as reduced numbers of apermatozos and testicular weight. Developmental abnormalities included deareased litter size in female mice mated to treated males. This decrease was a result of significant increases in resorptions.

2. Magnitude of exposure to acrylamide and NMA grouts. Due to the identical end uses of ecrylamide and NMA grouts, and the fact that the same equipment and techniques are used to process and apply both grouts. EPA believes the magnitude of individual exposures to acrylamide and NMA grouts is aimilar.

The exposure information presented below focuses on the major end uses of acrylamide and NMA grouts: Sewer line sealing and manhole sealing. For the minor uses of the two grouts. structural water control and geotechnical grouting operations. EPA is unaware of the existence of monitoring data. However. because both of these operations involve manual injection techniques. worker exposures could be as high as those encountered during manhole sealing operations.

a. Dermal exposure. Based on data collected during EPA's 1888 monitoring sfudy at four grouting sites (see support document 2 in Unit XIV of this preamble). and considering the nature of the operations involved in different sewer grouting tasks. EPA has concluded that it is virtually impossible for grouting workers who use acrylamide grout not to be exposed dermally. As noted in a letter dated March 5. 1891. from Gerard F. Scannell in Linda f. Fisher, a apecial field evaluation of acryiamide grouting operations by OSHA's Salt Lake

Teohaicat Eenter "cenfirmed tho

potential occurrence of significant worker exposures to acryismide."

Grouters who perform manhole sealing uaing grout injection devices are required to work in tightly confined areas for extended periods. using techniques that inevitably result in extennive dermal exposures. The conditions in manhole operations expose the worker to chemical runoff and splashes during the injection process. despite the use of personal protective equipment In the EPA field study, workers were observed wearing disposable coverailo, eye gogeles, halfmakk air purifying respirators, and rubber gloves during the manhole grouting. The wearing of additional perconal protecttve equipment would substantially impair the grouter's ability to perform grouting operations, and is generally regarded as impractical.

EPA's monitoring study measured dermal exposure levels at manhole sealing sites ranging from 2.8 milligrams/hour (mg/h) to $5.0 \mathrm{mg} / \mathrm{h}$. The latter exposure level for acrylamide (assuming an 8-hour work day and 70 kilogram worker weight) is close to its neurotoxic no observed effect level (NOE), thus providing elmost no margin between exposure and levels at which neurotoxic effects might be seen.

The dermal exposures for workers performing sewer line repair are not an high as those of workers engaged in manhole sealing operations, since dermal contact caused by chemical runoff and aplashes during these remotecontrolled operations is generally minimal. However, dermal contact during mixing, gel testing, equipment disassembly, and clean-up does occur during sewer line repair operations. EPA's monitoring study found dermsl exposure levels ranging from $0.61 \mathrm{mg} / \mathrm{h}$ to $1.8 \mathrm{mg} / \mathrm{h}$ for these workers. despite their use of coveralls and gloves.

b. Inhalation exposure. Acrylamide grout is a dry powder which the workers $m i x$ with an aqueoun catalyat at the grouting site. When the workers pour acrylemide grout into the mixing tenk. some of the powder may become airbome. thus leading to inhalation exposures. Although the grout is genersily sold fr $^{-}$bage with a special dispensing liner intended to reduce the amount of grout which can become airborne at the time of mixing, the EPA monitoring team observed airbome acrylamide grout dust when workers poured the grout into the mixing tank at one of the four sites surveyed.

Inhalation exposures may also occur as a result of grout spills which are not properly cleaned up. When the water from the grout solution evaporates. the remaining dy acrytamidepomdier any become airborne, and subject to Inhalation by workers in the aree. Baced on the EPA field study, the 8-hour TWA exposures found in the breathing zones of workers ranged from $0.000 \mathrm{mg} / \mathrm{m}^{2}$ to $0.12 \mathrm{mg} / \mathrm{m}^{3}$. Haif of the air samples (3 out of 6) collected at the sewrer grouting sites exceeded the current OSHA PEL of $0.03 \mathrm{mg} / \mathrm{m}^{3}, 8$-hour TWA.

3. Environmental effects. Section 6 (c) of TSCA requires that in promulgating rules under section 6(a), EPA must make a statement pertaining to the environmental effects and magmitudo of environmental exposure as part of the unreasonable risk finding. EPA has not identified any environmental riak from the une of acrylamide and NMM grouts. EPA bases the unrensombie sisk finding of this proposal solely on risios to human health.

4. Human risk.-a. Aarglamido. For exposure to acrylamide gront, three endpoints were quantified: Neurotoxic. cancer, and reproductive riaks.

i. Neurotoxic risk. Acrybumide grout use resuits in substantial newrotoxdc risk. Acrylamide is a humnn neurotoxin that affects both sensory and motor nerves. Nerve fibers in the most distal portions of the limbs are verully affected first. leading to wrenkness of the feet ayd legs, loss of coordinntion and tendon reflex, and numbness of the toed and fingers.

Because data on humen neurotoxicity are primarily limited to case reports of unquantified exposure levele. a quentitative risk assesument for neurotoxicity must rely on the best available animal date. From the best available animal data. EPA calculated chronic exposure NOER's in the range of 0.2 to $2.0 \mathrm{mg} / \mathrm{kg} / \mathrm{day}$ t the range reflecting species differences. As a way of measuring neurotoxic rinks. EPA used National Institute for Occupational Safety and Health (NIOSH), EPA, and industry-supplied data to calculate margins of exposure (MOBo) for exposed grouters. The neurotoxic MOE is a measure of the extent by which the neurotoxic NOEL as determined in a laboratory study, exceeds the exposure dose. Lower MOEs pose greater concern. MOEs for sewer grouting workers are less than 10 . thus indicaling that the 1.800 acrylamide grouting workers may be exposed to levels of acrylamide close to the estimated human effect level. This is further supported by the finding that one of the nine employees observed during EPA's field monitoring survey exhibited peeling palms and fingers (signs of scrylamide-induced peripheral 
neurotoxicity] and one other worker reported past episodes of peeling paims and fingers. See suppost document 3 in Unit XIV of this preamble for further discussion.

ii. Carcinogènic risk. Since adequate human data werénot available. estimates of cáncer risk attributable to ecrylamide grouting were generated using data from a long-term animal bioansay.

Estimated upperbound lifetime individual cancer sisks for grouting workers are very high. Even with the assumption that grouting may not occur $B$ hours daily or during certain times of the year. grouters have $a 1$ in 100 to 1 in 1,000 probabillty of developing cancer over their lifotime. EPA estimates a total of 1.8 to 18 excess cancer cases, over a 70-year period, attributable to the use of acrylamide grout. See suppost document 3 in Unit XIV of this preamble for further diecunsion of carcinogenic risk.

iil. Reproductive rish. Reproductive risks from acrylamide grouting were estimated through the use of animal dite. Reproductive risk estimations are expressed as MOEs. Based on EPA monitored exposures for grouting worker, and a NOEl of $0.112 \mathrm{mg} / \mathrm{kg} /$ day, the MOEs for reproductive effects range from 0.8 to 7 . See support document 3 in Unit $X Y /$ of this preamble for further discusaion of reproductive risk.

b. NMA. EPA has not quantified noncancer health risks ansociated with the use of NMA grouts. However, in tests with mice treated with both acrylamide and NMA, the neurotoxic potential of NMA appears to be lower than that of acrylamide. Evidence of developmental and reproductive toxicity exints:

however, EPA has no quantitative data for these effects. EPA believes the toxicities of acrylamide and NMA are qualitatively the same, although they differ quantitatively.

Based on date from the 1889 NTP cercinogenicity bioassey. EPA carried out a quantitallve, dase-response assessment for NMA. EPA caiculated upper-bound carcer sisk probabilitles in the range of 1 in 1.000 to 1 in 10.000 for individunis using NMA grout. These cancer risks are about an order of magnitude lower than eatimated cancer risks for individuals uning acrylamide grout. See support document 4 in Unit XIV of this preamble for further discussion of NMA riske.

\section{B. Benefits of Acrylamide and NMA grouts and the Availability of Substitutes}

1. Bencfits of ocrylomide and NMA grout use. Although acrylemide grout is used more widely loday than NMA grout, the two grouts are generally used in the same applications, and they exhibit many of the same performance characteristics. Acrylamide grout's most popular end use is in the rehabilitation of sewer systems. a development brought aboùt by ìç̄easing concerns over the infiltration and inflow of water into sewer systems. Chemical grouting provides a means of sealing and repairing the sewer system without costly excavation.

Acrylamide grout is the most widely used chemical grout for sewer rebabilitation because of its low cost. quick and controllable "gel" or "set up" time (the time it takes for the grout to polymerize), long history of reliable performance, and very low viscosity. NMA grouts also gel quickly, have low viscosity, and have proven equally effective as acrylamide for sewer line sealing, although they are priced slightly higher.

Both acrylamide and NMA grouts are less costly than substitute chemical. grouts. They are also reported to be easier to use than some of the substitute grouts, although other substitutes are reported to be junt as easy to work with as acrylamide and NMA grout. The use of certain substitute grouts appears to require more attention to the details of proper storage, grout mixing ratios, and general handling practices.

Nevertheless, the substitute chemical grouts are currently used in all of the same major commercial applications as acrylamide and NMA grouts. The only commercial application for which none of the currently available aubstitute products has been used successfully is sealing sait domes and potash mines, on episodic and very minor (less than 1 percent of total acrylamide grout) application. Overall. EPA finds that the differences in benefits to society of acrylamide and NMA grouts relative to the available subutitutes are small.

2. Availability of substitutes. Several types of chemical substitutes are currently used for grouting. The two most promising substitutes.

polyacrylamide and low-viscosity (LV) urethanes were recently commercialized and have thus far only been used in sewer applications- Two other types of substilute grout, acrylates and highviscosity (HV) urethanes, have been on the market for many years, and are currently used for all major commercial epplications of acrylamide and NMA grouta. HV-urethene grouts are used primarily for structural water control. manhole sealing and geotechnical applications, whereas acrylate grouts are used more for sewer rehabilitation. especially remote sewer main line sealing. The newer grouts. polyacrylamide and LV-urethanes, are expected to find widespread use in all chemical grouting applications. The main chemical subutitutes are describe below:

a. Acrylates. Acrylate grouts. like acrylemide and NMA groots, are lowviscosity grouts used primarily in sewe rehabilitation Acrylats groute are typically formulated with either: magnesium diacrylate or calcium scryiate. and lesser amounts of lithium acrylate. hydroxycthyl acrylate or polyethylene glycol dinaryiate. Grouter apply acylates uring the enme techniques. catalyst system and equipment as acryiamide.

Although some usen of acyia's grouts complain of fleceid weak gols that do not produce a good eeal. this may be attributable to inrufficient solic concentrations. Mixing at leas than the recommended percent solids content may occur when users try to minimize chemical costs or because mixing follows the same practices used for ecrylamide groute, where a lower percentage of solids will still produce $\varepsilon$ strong gel. Based on informntion from grouters using acryiates smccessfully. EPA believes that, when used properly. acrylate grouts are vernatile and can br adaplad to numerous end uses.

b. HV-Urethanes. HV-urethanes are very different from acrylamide and the other grouts. All urethane grouts are composed of isocyanate-terminated urethane prepolymers. HV-urethane grouts have a relatively high viscosity and require a solvent cloan-up. The grouts ere formulated either as a water activated system or a chemically-curec syatem, although the wateractivated urethanes are most commonly used.

Unlike most of the other substitutes. the HV-urethanes carinot be pumped through the same equipment used for acrylamide grouts. The technique and equipment involved in pumping HVurethane in remote sewer line repair is different from the low-viscosity grouts. Therefore, with the current technology. grouters switching from acrylamide (or NMA) to HV-urethane would need to retrofit:existing rige (vehicles containin grout mixing and injecting equipment) $\varepsilon$ substantial expense. Realizing these constraints, several manufacturers developed $\mathrm{VV}$-urethanes that can be pumped with much of the same equipment currently used for acryiamic (and NMA) grouts.

For manhole sealing. HV-urethanes are growing in use. Currently, 50 percer of all manhole sealing operations are performed using this grout. compared t: 35 percent with acrylamide. HV. urethane grouts are equally effective ar 
acrylamide for manhole sealing, and preferable for use above the soil freeze line, because they are better able to withstand freeze-thaw cycles without fracturing.

HV-urethane grouts are also well suited to structural water control and geotechnical applications. Within the structural water control category, HVurethane is the material of choice. accounting for 90 percent of all applications in this end use. In geotechnical applications. HV-urethene grout can maintain its integrity in shifting soils, soils above the freeze line. and areas experiencing vibrations or straes.

c. LV-Urethanes. LV-urethane grouts are aleo composed of TDI-based urethane prepolymers; however. these grouts have a low-viscosity similar to acrylamide and NMA grouts. LV. urethanes are also mixed with water at the same ratio as acrylamide and NMA. thus necessitating only minor equipment modifications to currently existing rigs. Inttial experience with LV-urethanes indicates that they are eany-to-use grouts with performance comparable to that of acrylamide, NMA, and HVurethanes. Because of their reduced viscosity, the LV-urethanes flow through long hoses much more easily than the HV-urethanes. Finaily, some LVurethanes are reported to be less adhesive than $H V$-urethanes, thereby earing the movement of the grout packer through the sewer lines.

Although LV-urethanes have not been widely used, nor used in non-sewer applications, their physical/chemical properties indicato that they could be a viable substitute for acrylamide and NMA in virtually any grouting application.

d. Polyacrylamide. Polyacrylamide grout is a recently developed grout containing polyacryiamide and water. The grout has a low viscosity after mixing similar to acrylamide and NMA grouts. This grout was commercially introduced in July 1991 after the successful completion of sewer grouting field tests in four Sinten. These test indicated that polysarylamide grout is an easy-to-use grout with performance comparable to that of acrylamide and NMA grout. As with the LV-urethanes. minor equipment modifications to existing rigs are necessury in order to use the poiyacrylamide grout. However. these modiffcations are very minor compared to what is necessary when substituting to the HV-urethenes.

3. Possibie hazords of substitutes.

EPA has analyzed available date on the heaith effects and exposure potentials of the mejor substitutes for acrylamide and NMA grouts. While some of the substitutes may present some risk, EPA has concluded from the available information that none of the substitutes appear to present as great a potential for risk as acrylamide or NMA grouts. The conciusions of EPA's ansiysis for the substitute grouts follows. See support document 5 in Unit XIV of this preamble for a further discussion of the risks of substitute grouts.

a. Acrylates. Although acrylates as a class are considered suspect carcinogens. the overail evidence available to EPA pertaining to carcinogenic potential indicates a lower concern for acrylates relative to scrylamide, by both the dermal and inhintion routes. Acrylate inhalation studies in laboratory animals resulted in no overt sigms of neurotoxicity, and no reproductive toxicity has been attributed to the acryiates used in grout formulations. Dermal exposure to acrylate grouts may resuit in irritation and sensitization in some individuals: however. acrylate grout generaily present a lower hezard and risk potential than acrylamide and NMA grouts.

b. $H V$ and $L V$-urethanes. Several urethane grouts (both HV and LV) contain small amounts (i.e. less than 2 percent of total formula. on) of toluene diisocyanate (TDI) and/or methylene biophenyl isocyenate (MDI). There is sufficient evidence for the

carcinogenicity of TDI in test animals by the oral route: however, no data are available for dermal and inhalation exposures. the primary routes of exposure for grouters. EPA has some dnta which suggest that effects from exposure to TDI by one route may not be predictive of possible effects from other exposure routes.

TDI and MDI are strong sensitizers and respiratory irritants. Respiratory tract sensitization. resulting in bronchial asthme. occurs in approximately 10 percent of exposed individuals. Inhalation exposure, however, is mitigated by the process of co-injecting water with the grout. where it is expected that the urethane prepolymer will undergo rapid reaction with water. EPA-modeled wórat-čase TDI inhalation exposures to grouting workers are considerably lower than the OSHA ceiling value for exposure to TDI. and the recommended American Council of Governmental Industrial Hygienists (ACGIH) threshold limit value for both TDI and MDI.

Exposure to TDI and MDI does not appear to result in neurotoxic or reproductive heaith effects. although no studies have been conducted specifically for these effects. Risk of dermal sensitization from contact with isocyanates, and fire potential due to the use of flammable solvents for clean-up are also believed to be low. However.

EPA is requesting any additional informstion which may be availeble on these potential hazands (see Unit VII of this preamble). Overall, the EPA

believes urethane grouts present a lower risk potential than acrylamide and NMA grouts.

c. Polyacrylamide. The neurotoxic effects of acrylamide are ansociated with acrylamide monomer.

Polymerization results in a compound that is not toxic. The recently commercialized polyacryinmide grout contains less than 0.01 percent monomeric acryiamide. Throforere, EPA believes that the neurotodic potential of polyacrylamide grouts is nogligible. In addition. the relatively high molecular weight of polyacrylamide sigaificantly decreases absorption of the chemical by any expo:ure route.

\section{Economic Effects of the Propased Rule}

EPA has evaluated the economic effects of the proposed rule by estimating the costs of switching from the regulated grouts to substitute grouts. The major coste considered are for the grout material and equipmont modifications. The factors considened for grout material costs include cost of final mixed solution, transportation coste. amount of acrylamide dinplaced by substitute. longevity, and wanted batches. Equipment modification conting factors include equipment retrofits, hose replacement, equipment clenn-up costs. training costs, and storago/handling. See support document 1 in Unit XIV of this preamble for a more datailed discussion of the economic effects of the proposed rule.

1. Economic consequences for each application. Due to the disparity in costs between the alternative chemical grouts and the different substitution scenarios for the four uses of acrylamide and NMA grouts. the economic consequences of the proposed regulation are separated by application. The total compliance costs given below are annualized over a 15-year period.

a. Sewer line sealing. This rule proposes to ban the use of acrylamide grout for sewer line sealing immediately, and to ban the use of NMA grout in this application after 3 years. EPA has determined that allowing continued use of NMA for sewer line sealing for 3 years will substantially reduce the costs of this proposed action.

If both grouts were subject to an immediate ban in sewer line applications. it is expected that they 
would be replaced by some mix of polyacrylamide. LV-urethanes, and acrylate grouts. While HV-urethanes could'also be used in this application. EPA does not believe that grouters will switch to them for sewer lins sealing. because their use would result in much greater substitution costs than any of the, other chemical substitutes (See sensitivity analysis of sewer line costs discussion below). However, because of the limited experience with polyacrylamide and LV.urethane grouts. and concerns about the performance of acrylates, EPA has analyzed several substitution scenarios for sewer line sealing in the event of a bun on acrylamide and NMA groute. While it is often difficult to project future market shares of products which have just begun to penetrate the market. EPA believes the following scenarios provide a reasonable estimation of the range of costs likely to be incurred for sewer line sealing as a result of this proposed regulation.

The three substitution acenarios evaluated are as followe: (1) Polyacrylamide captures 100 percent of the market: (2) LV-urethanes capture 70 percent of the market and acrylates capture 30 yercent; and (3) LV-urethanes capture 30 percent of the market and acrylates capture 70 percent. For polyacrylamide substitution, it is assumed that this product's combination of price and performance advantages relative to the other subutitutes lead to it taking 100 percent of the market. For LVurethane substitution, EPA analyzed two scenarios. For these two scenarios it is assumed that some unforeseen problem arises with the polyacrylamide greut, and that the repiacernent market is shered by LV-urethane grout and acrylate grout. Acrylates are much cheaper to use. but many grouters have experienced problems with the grout's performance.

The estimated annualized costs of a ban on both acrylemide and NMA grouts for sewer line sealing is $\$ 3.8$ million per year for the firat scenario. $\$ 10.7$ million per year for the second scenarto, and 55.5 million for the third scenario. Over 65 percent of thees costs are attributable to increased grout costs.

EPA is proposing to allow continued use of NMA in sewer line sealing for 3 years. EPA estimates that such a delay will substantially reduce the costs of this proposed action. without posing an unressonable risk to workers using NMA grout during the 3-year delay. The delay eases the economic burden in two ways. Firat. the delay allows for a $3-$ year period in which sewer line grouters will not incur the costs of using some mix of polyacrylamide. LV-urethanes. and acrylates in place of both acrylamide and NMA. It is projected that during this 3-year period. almost all current use of acrylamide grout in sewer line sealing will be replaced with NMA grout. The costs of this switch are reasonably low. totalling about $\$ 1.0$ million per year. Second. the 3-year delay will allow individual groutess the opportunity to become more familiar with the new grouts which have just recently been commercialized. EPA expects that during this period. grouters will undertake an evaluation of the substitute grouts. and plan for any chniges they munt make to switch over to these products.

EPA's estimate of the 15-year annualized costs of the proposed action for sewer line seailing is $\$ 3.0$ million for total polyecrylamide aubstitution, and 54.2 million to $\$ 7.9$ million for LV. urethane/acrylate aubstitution. Using the midpoint of the latter range. EPA estimates the 15-year annualized costs of the proposed action for sewer line sealing to be $\$ 3$ million to $\$ 8$ million per year. This estimate accounts for savings due to a delay in many of the costs associated with a switch to the substitute grouts. However, this cost analysis is based on the current assessment of grouting products which are new to the market and have not yet been widely used. While those in the industry who have worked with the new grouts are confident about their periormance. greater costs than are shown here could actually be incurred. Similarly, additional experience with these grouts may lead to improvements in formulation or in application practices which result in additional cost savinge.

Sensitivity analysis of sewer line costs. The above cost analysis assumes that the two recently commercialized grouts. polyacrylamide and LV. urethanes. will take over a substantial portion of the sewer line sealing market. This assumption is based on information received from grout manufacturers. dintributors, and end-users. While this information represents the best available data, EPA is aware that polyacrylamide and LV.urethane grouts have not been widely used. and that some unforeseen difficulties could arise with their use in the future. As such. EPA is including additional cost estimates of the proposed action for sewer line sealing. without consideration of these new grouts as subntitutes for acrylamide and NMA grouts. See support document 1 in Unit XIV of this presmble for further diacussion of the resuits of this anaiysis.
For the sensitivity analysis of sewer line costs, it is assumed that HV. urethanes and acrylates are the only available substitutes for acrylamide and NMA grouts. In the case of HVurethane/acrylate subatitution for sewer line sealing, the substitution scenarios are the same as those used for LV. urethanes: (1) 70 percent $H V$-irethane grout, 30 percent acrylate grout: and (2) 30 percent HV-urethane grout. 70 percent acrylate grout The annualized costs of an immediate ben on both acrylamide and NMA grouts in sawer line sealing would be an estimated 518.3 million per year for the first scenario. and an extimated $\$ 88$ million per yen in the second scenario. The inereased coste when using HV-urethnnes is primarily due to estimated losses in worker productivity when switching from acrylamide or NMA grouts to HV. urethanes, and additional equipment modifications needed to pump the highviscosity grouts. In fact, over 60 percent of the above costs are attributable to an estimated decrease in labor productivity. while 25 percent are attributable to equipment retrofit and maintenance costs.

Taking into account the 3-year delay in banning WMA grout, EPA's eatimate of the 15-year annualized costs of the proposed têtion for sewer line sealling is reduced to $\$ 8.5$ million to $\$ 13.1$ million per year. This estimate accounts for the savings due to a delay in many of the costs associated with a switch to highviscosity urethanes, but does not consider any cost savinge from the use of the LV-urethane or polyacrylamide grouts. However, as discursed in Unit IIIIC)(1)(a) above. EPA does expect that these new grouts will find widespread use for sewer line sealing, and that theis use will result in significantly reduced costs for the proposed action.

b. Manhole sealing. Both HV. urethenes and acrylates are currentiy used to seal manholes. Although it seems plausible that LV-urethanes and polyacrylamide grouts could also be used to seal manholes. they are not currentiy used in this application, and EPA did not project potential market shares for these grouts in this application.

Past consumption patterns indicate a growing shift towards HV-urethanes for this application. In fact. more HVurethanes are currently used for manhole sealing than acrylamide. Based on this information. and the proven effectiveness of $H V$-urethanes for this applicstion. EPA assumed that 80 percent of the ecrylamide and NMA grout banned would be replaced by HV. urethane grouts. and the remaining 10 
percent by ecrylate grouts. The total compliance cost for a ban of acrylamide and NMA grout for manhole sealing is approximately $\$ 1$ million.

c. Structural water control. HV. urethanes dominate in the category of structural water control. accounting for roughly 80 percent of all grout uned in this application. Thus. EPA assumed that 80 percent of the acryiamide grout banned (NMA grout is not currently used in this application) will be replaced by HV-urethanes and the remaining 10 percent by acrylates. The total compliance cost for a ban of acrylamide and NMA grout for this application is So.3 million.

d. Geotochnical applications. Based on industry perception, and the available research on the specific issues of concern. EPA asrumed that 80 percent of the acrylamide grout banned in this use category (NMA grout is not currently used in this application) will be replaced with $H V$-urethanes and the remaining 10 percent with acrylates. The total compliance cost for a ban of acrylamide and NMA grout for this application is $\$ 88,000$. As previousily noted, however, because of uncertainties with the use of substitutes in salt domes and potesh mines. there may be some sigmificant costs in the geotechnical category that have not been captured.

2. Conciusion. The total annualized compliance costs of the proposed regulation are in the range of $\$ 4.4$ million to 57.4 million, depending on the substitution scenario for sewer line sealing. Based on a population of 1.800 grouters. this amounts to a cost of approximately $\$ 2,500$ to $\$ 4,000$ per year to protect each grouting worker from very high individual neurotoxic and carcinogenic risks. The largest portion of these costs are attributable to the ban of acrylamide and NMA grouts for sewer line sealing. Additionally, the sewer line sealing compliance costs assume significant substitution of acrylamide and NMA grouts with polyacrylamide and LV-urethanes. Substitution with HV-urethanes and acrylates for this application would result in much higher compliance costs 157.8 million to 514.4 million) for the proposed action.

EPA expects that the delayed ban of NMA for sewer ifne sealing will lessen the economic burden on municipalities and grouting contractors by allowing them sufficient opportunity to fully evaiuate new substitute grouts, and prepare for any capital investments which may be necessitateri by a ban of acrylamide and NMA grouts.

Overall. EPA expects that this proposed rule. while having an impact on the cost of sealing sewer lines. will not have a significant adverse impact on the chemical grouting industry. Given the magnitude and severity of the risks associated with the use of acrylamide and NMA grouts. EPA believes that the estimated costs are warranted.

\section{Other Options Considered}

EPA considered other regulatory options as alternatives to this proposed rule. but based on the available information determined that this proposed regulation was the least burdensome to adequately reduce the unreasonable riak faced by persons uning acrylamide and NMA grouts. Although EPA could promnigate a worker protection atendind covering State and municipal employees under its TSCA autharity. EPA believes, as discussed in Unit VI of this preamble. that personal protective equipment cannot adequately reduce the risic, and that $\mathrm{a}$ ban is. in fact, the least burdensome requirement that will adequately reduce the riak. $A$ discussion of the other options considered is given below.

1. Ban acrylamide grout only at sites not covered by OSHA. EPA considered imposing a ban on the use of acrylamide grout solely at State and municipal sites not covered by p 7 OSHA-approved State plan. This option assumes a complete ban of NMA grout also. because there is currently no OSHA workplace standard for NMA. Estimated compliance costs for his option are in the range of $\$ 40,000$ to $\$ 740,000$. depending on the sewer line substitution scenario at sites where both acrylamide and NMA grout are prohibited.

EPA believes that $\mathrm{a}$ ban of acrylamide grouting only at State and municipal sites not covered by an OSHA-approved State plan is untenable for several reasons. First. enforcement of an acryiamide grout ban oniy at aites in 27 States (i.e. those without an OSHA. approved State plan) might prove extremely difficult bince acrylamide grouts would still be on the market. Additionally, a ban of acrylamide grout use oniy by State and municipal workers in those 27 States

(approximately 180-10 200 workers) would afford no additional protection to those acrylamide grouting workers in the private sector, who atill face unreasonable risks due to the unavoidable dermal exposures encountered while grouting. Moreover. allowing one population of grouters to continue using acrylamide grout. provided they adhere to the OSHA workplace standard. while banning another popuiation of grouters from using the grout altogether would amount to nonuniform regulation of the chemical grouting industry by different Pederal agencies. and could merely resuit in increased privatization of grouting work. Thus. EPA dismissed this alternative. concluding instead that a total ban of acrylamide and NMA grout is neceseary to ease the burdens of complinnce monitoring. adequately protect all gronters, and ensure uniform, equitable regulation across all sectors of the chemical grouting industry.

2. Ban all uses of acrylanida grout, and all uses of NMA grout, except allow NMA grout use in sewar line sealing. This option is similar to the proposed action. except that NMA grout would not be restricted at all for sewer line use. Estimated annualfeed complinnce costs for this option are about 223 million. An advantage of this option is that the compliance costs are approximately $\$ 2.1$ million to $\$ 121$ million (or 48 to 84 percent) leas than the annualized compliance costs of EPA's preferred option. depending on the availability and costs of acrylamide and NMA substitutes. This cost reduction is due to the relatively high incremental costs of a ban on NMA grout in sewer lines after 3 years. EPA connidered this option because NMA poses relatively less risk to workers than acylamide. and sewer line use of grout poses somewhat leas risk to workers then manhole use.

Although this option wouid eliminate the highest risk grout (acryiamide) for alj uses. and eliminate acrylamide and NMA grouts for the highest riak une (manhole operations), at this time EPA does not believe this option will sufficiently reduce risks to grouting workers. In the event of $\mathrm{a}$ ban on acrylamide grout for sewer line sealing. end no ection on NMA grout for this application. EPA expects NMA grout to be the primary substitute. As noted above. while the risks from using NMA grout are lower than those associated with the use of acrylamide grout, the risk to individual grouting workern usins NMA grout is still high. At this time. EPA believes the combination of this high risk and the presence of subatitutee which pose lower risk potentinl. particulariy the polyecrylamide and LV. urethane grouts. werrante restrictions of both acrylamide and NMA groute for sewer line sealing.

3. Ban the use of acrylamide and NMA grouts for manhole sealing only. This option would allow continued. unrestricted use of acrylamide and NM grouts for sewer line sealing, structural water control. and geotechnical applications. Estimated compliance costs for this option are approximately $\$ 1$ million. 
EPA does not believe this option will sufficiently reduce the risien faced by grouters for all applications of acrylamide and NMA grouts. Although manhole sealing does present the highest risks to grouters who use acrylamide and NMA. EPA believes other applications (0.8+ main and lateral line sealing) also present unireasonable risks. Reducing rivks from one application does not obviate the need for reducing risks from other applications.

Based on the available information. there are no uses of acrylamide or NMA grouts for which substitute grouts are not availlable, with the passible exception of water cut-off in salt domes and potash mines. Therefore, to sufficiently protect all grouters, a total ban of acryilumide and NMA grouts is preferable to a ban only for manhole sealing.

4. Ban acrylamide grout only. This option would prohibit all uses of acrylamide grout, but allow continued unrestricted use of NMA grout. EPA's eatimated compliance costs for this option are approximately $\$ 12$ million.

EPA does not believe this option will sufficiently reduce rikks to grouting workers. In the event of a ban only on acrylamide grout, EPA expects NMA grout to be the primary substitute. Although the risks ansociated with NMA grout use appear to be an order of magnitude lower than those associated with acrylamide grout use, the risk to individual grouting workers is still high. Glven the availability of substitute chemical grouts. especially the recently commercialized polyecrylamide and $\mathrm{LV}$. urethane grouts, which are easy to use and present lower risk potential than acrylamide end NMA groute, a ben of both grouts is preferable to a ban of acrylamide alone.

5. Immediate ban of all uses of both grouts. This option is similar to the proposed action, except that the prohibition on NMA grout use for sewer line sealing would be effective at the snme time as the other proposed prohibitione on acrylamide and NMA grout, instead of 3 years later. EPA's best eatimate of compliance coste for this option are in the range of 55.1 million to 50.4 million. However, this estimate assumes complete familiarity with the recently commercialized substitutes. If there are uncertainties with the newer grouts. compliance costs for this option couid be somewhat higher.

Although EPA believes that good substitute chemical grouts exist for sealing sewer lines, EPs. determined that an immeoilate ban of both acrylamide and NMA grouts for all applications is not necessary to adequately reduce the unreasonable risk from the une of acrylamide and NMA grouts. Since the unreasonable risk finding under TSCA requires EPA to consider not only the riak of an activity. but the cost of controlling the risk. EPA weighed the cost of an immediate ban of both grouts for sewer line repair sgainst the risk of continued use of one of the grouts for this epplication. Because of the relatively high cost of an immediate ban of both groute, and the lower risk associated with the use of NMA grouts. relative to acrylamide. EPA determined that continued use of NMA grout for sewer line repair for a period of 3 years will not present an unreasonable risk.

Delaying the ben of NMA grout for this application will afford those in the industry an opportunity to become more femillar with the new grouts which have just recently been commercialized, and plan for eny changes they munt make to awitch over to these products.

Thu, EPA belleves a 3-year deleyed ban of NMA grout for sewer line sealing. with an immediate ban of all other NMA grout uses, and all uees of acrylamide grout, will ease the economic burden on the sewer sealing industry while adequately protecting grouters from the unreasonable riaks of burylamide and NMA grouts.

\section{Finding of Unvenconnble Risk}

EPA has weighed the health risks from continued use of acrylamide and NMA grouts against the costs attributable to the proposed regulation. EPA has concluded that avoidance of the aignificant individual cancer risks at the current exposure levele and the serious neurotoxic risks associated with grouting operations outweigh the cost to society of the proposed regulation. Therefore. EPA finds that the use of ecrylamide and NMA grouts presents an unreasonable risk of injury to human health. In brief. the finding is based on the following:

1. The health effects from exposure to acrylamide and NMA grouts are serious. Acrylamide is a demonstrated human neurotoxin and a probable human carcinogen (Granp B2). The magnitude of exposure during grouting operations. even when perzonal protective equipment is worn. piaces all grouters at very high neurotoxic risk. and estimated excess lifetime cancer risks in the range of 1 in 100 to 1 in 1,000. The health effects associated with exposure to NMA are identical to those associated with acryiamide exposure, and EPA believes the magnitude of individual exposure to acrylamide and NMA grouts is also the same. Grouters using NMA are exposed to high neurotoxic risk, and estimated excess lifetime cancer riaks in the range of 1 in 1.000 to 1 in 10.000

2. The Agency has determined that the bealth risk from acyinmide and NMA grouts outweigh the benafits of continued use of the two grouts. Effective substitute grouts are available. already in use, and in soms applications gaining market share over acrylnmide and NMA grouts. The available information indicates that risk from exposure to the substitute grouts is lower than that from exposure to either acrylamide or NMA grouta.

3. The reasonably ancertainable economic consequences of the rule. after comsideration of the effect on the nntional economy, swall business. technological innovition, the environment; and public health, are not unduly bundensome for those affected by the proposed regulation. The cost of banning acrylamide and NMA grouts. including the labeling reporting and recordkeeping requirements, is reasonable in view of the high risk associated with their continued use.

\section{Andydis Undes TSCA Enction $9(a)$}

TSCA section $\mathrm{g}(\mathrm{a})$ provides that. if EPA determines that an unreasosable risk exists. and determines, in the Administrator's discretion, that the risk may be prevented or reduced to a sufficient extent by action taken under a Federal law not administered by EPA. EPA shall submit a report to the agency administering such law, deseribing the risk and the activities presenting such risk. If the other agency responds by declaring that the activities described do not present an unreasonable risk, or if the agency initiates action to protect against the risk. EPA is preciuded from acting ageinst the risk under TSCA.

The risk to workers frum continued use of acrylemide and NMA grouts in the private sector can be reduced to some extent by OSHA under the OSHAct. However. EPA has determined that even though OSHA has employed its statutory authority to protect workers from the hazards of acyliamide. an unressonable risk of injury to grouting workers remains, which should be addressed under TSCA section A EPA has consulted with OSHA on this matter. and OSHA is in agreement with EPA's position (as noted in the letter of March 5. 1991. from Gerard F. Scannell to Linda J. Fisher. in which OSHA cites "the advantage of substituting acrylamide and NMA with safer materiais to mitigate the potential hazards from improper work practices." and plediges "cooperation in support of EPA's proposed action to address the hazarcis related to acrylamide and NMA 
under the Toxic Substances Control Act").

OSHA has promuigated a PRL for acrylamide. aimed at reducing the risk from inhalation of the chemical. However, the primary risk to grouting workers is from dermal contact, which is addressed by a sicin notation to the PIL . OSHA's general personsl protective equipment standard at 28 CFR 1910.132(a), and the Hazand Communication Standard at 29 CFR 1910.1200. Based on site vinitu and exposure monitoring by EPA, the evidence indicates that even while wearing full personal protective equipment, including a respirator. grovters face an unreasonable risk of injury.

The evidence gathered by EPA during its site visits indicates that the nature of grouting work apecifically the ciose quarters in which the wotk is performed and the dexterity required by the employees. makes it impossible to prevent a hazardous level of dermal exposure to acrylamide und NMA with personal protective equipment. Moreover, becaure of the acute neurotoxic concerns associated with both acrylamide and NMA. infrequent or even incidental contact with the two chemicals could represent hazhrious levels of exposure.

In the workplace. the une of personal protective equipment is generally accepted as the laut resort in the industrial hygiene hierarchy of controls. The substitution of a aner chemical or process is to be preferred over solutions which attempt to keep the toxic chemical awey from the worker through such methode as personal protective equipment. In the case of grouting. personal protective equipment can reduce. but cannot eliminate hezandous exposures.

In addition to the difflculties arising from the use of persond protective equipment in confined apaces auch as manholes. an inherent shortcoming of personal protective equipment is that ite effectiveness depends largely on human behavior. Given the low neurotoxic margins of exposure associated with the use of acrylamide and NMA grouts, an unreasonable risk of injury would exist even if personal protective equipment could eliminate exposures in most cases.

EPA's finding that one of the nine employees observed during the field monitoring exhiblted peeling paims and fingers (signs of acryiamide-induced peripheral neurotoxicity), and one other worker reported prior episodes of peeiing paims and fingers. lends support to EPA's belief that personal protective equipment cannot adequately prolect

S-310999 $\quad 017(01) \times 01-0 C T-91-10: 47: 46)$ the workers from hazandous levels of exposure.

OSHA has not establinhed a PRI for NMA, but employees using this chemical are required to use appropriate personal protective equipment under 29 CFR 1910.132(a). As in the case of acrylamide. however. the onily evidence available to EPA establishes that the risk posed to grouting workers by NMA cannot be reduced by personal protective equipment to the extent necessary to eliminate the unreasonable risk. EPA. therefore, has determined not to refer the acrylamide or NMA risk to OSHA. but rather to promulgate a TSCA section 6 rule. which appears to be the only mechanism by which the unreasonable risk can be eliminated. EPA's decision not to refer the acrylamide and NMA riak to OSHA is further influenced by the evidence that a substantial portion of grouting worker ore Stete and municipal workers in OSHA Federal enforcement States. whose empioyees are not subject to the OSHAct. EPA could promulgate a worker protection standard covering these employees under its authority in TSCA section $6(a)(5)$; bowever, the existing evidence indicates that such a rule would not adequately reduce the risk due to the inherent limitations of personal protective equipment in grouting operations.

\section{Iavues for Commont}

EPA is proposing a total ban of acrylamide and NMA grouts with a $3-$ year delay in the NMA grout ban for sewer line sealing. EPA requests comment on this approach, especially the length of the NMA grout ban delay. and on altemative regulatory strategies. such as those discussed in Unit IV of this preamble. EPA is particularly interested in: (1) Any comments on the option to ban acryiamide and NMA grouts solely at State and municipal sites not covered by an OSHA-epproved State plan. and (2) the proposed ban of NMA grout for sewer line sealing. including any comments on the proposed length of the delay.

Additionally. EPA requests comment on several other isuues pertaining to this rulemaking. The tmues include: (1) The availability of aubatitute grouts for sait dome/potash mine sealing, the

importance of this application. and any information on potential costs to society if substitute grouts do not perform adequately in this application: (2) any performance data on acrylate grouts (e.g. inspections of previous sewer sealing jobs periormed with acrylate grout): (3) any performance data on the new polyacrylamide and LV-urethane grouts for sewer sealing or other grouting applications: (4) any information on variable performnnce of the substitute grouts due to climntic soil. or other geographically-ralnted conditions: (5) any additional heaith and safety information related to the use of polyacrylamide and LV-urethene grouts: (6) the development status and comparative costs of any other now products and technologies in sewer line sealing (7) any evidence of akin of lung sensitization from contact with isocyanete-containing wrethrue grouts: (8) the potential for fires during use or clean-up of urethane grouts doe to the presence of solvents. such as costones (9) the adequacy of existing employer. sponsored programs to inform gouting workers of potential riaks eseocinted with exposure to grouting chanicals: (10) any data on conts aseocinted with the health effects from acylamide and NMA exposure (these date conid include medical costs, costes due to lost work time or decreased productivity. loss of job/income. employes medical surveillance, increased linbillty insurance, etc.): (11) the cost of modifying pre-1880 rigs to promp the new grouts (EPA asnumed the same modificationn needed to pump HV. urethanes): (12) the applicability of some kind of market- jased incentive (an incentive approach usurily tates the form of either a price-based (e.8m fees). or a quantity-based (e.8. parmito) regulation): and (13) the effective date of the fingl rule (EPA is proposing that it be 45 days after the date of publlication in the Foderal Register, howerer, no requirement other than reporting would become effective until 15 or more days after the effective date).

\section{Labeling, Recondkenpions, and} Reporting

By 15 days aiter the effective date of this rule. NMA grout manufincturers. importers, and distributors would bo required to lebel. or ensure the integrity of the label on. each container of grout. and persons who have possassion or control of acrylamide grout are aiso required to label containers of grout. EPA believes there is a strong need for labeling to ensure compliance with the prohibilions on the manufacture. importation, distribution, and use of acrylamide and NMA grouts. Labeling is a necessary mechanism to direct uners toward compilance with the prohibitions on uses of acrylamide and NMA grout.

NMA grout manufacturera, importers. and distributors would also be required to retain records at their companies' domestic headquarters locations of all shipments of NMA grouts for a period of 2 years from the date of shipment. 
Records would include the amount of grout manufactured or imparted, date manufactured or imported, amount sold. date sold. and to whom sold (and to whom shipped, if different).

Manufacturem. importers. and distributom would comply with the labeling and recordkeeping requirements by 15 days after the effective date of the final rule.

Distributom of acrylamide and NMA grout would also be required to provide an initial report to the appropriate EPA region. identifying their headquarters and shipment office locations through which their grout is sold. The initial report would also need to contain a list of cuntomern, and total amount and type of zrout sold to ench cuntomer, for the year immediately preceding the report due date. Distributors would be required to comply with the initial reposting requirements by the effective date of the final rule, or within 30 calendar days after the dintributor first begins distribution of NMA grout. whichever is later. An updated liat would be required when changes in ownership. headquarters, or shipment office occur. and would be required to be submitted to the appropriate EPA Regional Office no later than 10 calendar days after the chenge occurs.

The recordkeeping and reporting requirements will be necessary for effective enforcement of the rule. They will enable EPA to ensure compliance with the rule and conduct inspections effectively. Examination of reports submitted by grout dlstributors will enable EPA to track movement and use patterns, will help ensure that

distributors are maintaining records of shipments of NMA grout, and will aid in identifying sites where a potential violation may exist. Recordkeeping of shipments of grouts will further aid in identifying sites where there is a potential for violation.

As described above, this proposed rule would impose limited recordkeeping requirements on persone who manufacture, import, or diatribute NMA grouts in commerce, and limited reporting requirements on pernons distributing acrylamide or NMA grouts in commerce. EPA believes there are only two U.S. companies distributing acrylamide and NMA grouts in commerce, and that one of these two companies is also the sole importer of both grouts. The other company is believed to be solely engaged in distribution of the grouts without any importing activities.

Section 8(a) of TSCA gives EPA euthority to require persons who manufacture (under TSCA the term manufacture includes importation) or process chiemical substrinces and mixtures to maintain records and submit reports for many purposes, including records and reports necessary for effective enforcement of TSCA requiremente. Small manufacturers and processors are generally exempt from recordkeeping and reporting under section 8(a). However, section B[a](3][A](i)](I) provides that. when. as here. the chemical substance or mixture involved is the subject of a rule proposed or promulgated under ISCA section 6, small manufacturers and processors also can be required to report and keep reconds.

EPA also has anthority under TSCA section 6 to require recordkeeping and reporting related to the other regulatory requirements imposed by EPA under section 6 . This is particulariy important where, as here, such recordis and reports are necescary for effective enforcement of the section 6 rule and would apply to persons who are not covered by section B(a), Le- those who are not

manufacturess or processors. In this case. section 6 provides the authority to apply the recondkeeping and reporting requirements to distributors of acrylamide and NMA grouts who are not also manufacturers and processors of such mixturer: subject to section $8(a)$. EPA has used thi. section 6 recordkeeping and reporting authority previously in its polychlorinated biphenyl, asbestos, and hexavalent chromium rules promulgated under TSCA section 6 in 40 CFR parts $731,763$. and 749. respectively.

\section{Enforcoment}

Section 15 of TSCA makes it unlawful to fail or refuse to comply with any proviaion of a rule promulgated under section 6 of TSCA. Therefore, failure to comply with the ruie would be a violation of section 15 of TSCA. In addition. section 15 of TSCA makes it uniawful for any person to: (1) Use for commercial purposes a chemical substance which such person knew or had reason to know was distributed in commerce in violation of a rule under section $b_{i}(2)$ fail or refuse to establish nnd maintain records. submit reports. or permit access to or copying of records. as required by TSCA: or (3) fail or refuse to permit entry or inspection as required by eection 11 of TSCA.

Violators may be subject to both civil and criminal liability. Under the penaity provision of section 18 of TSCA. any person who violates section 15 could be subject to a civil penalty of up to $\$ 25.000$ for each violation. Each day of operation In violation of this rule would constitute a separate violation. Knowing or willful violations of the rule could lead to the imposition of criminal penulties of up to $\$ 25,000$ and imprisonment for up to 1 year for each day of violation. in addition, other remedies are available tc EPA under sections 7 and 17 of TSCA. such as seeking an injunction to restrain violators of the rule and seiring any chemical substance or mixture manufactured or imported in violation o the rule.

Individuals. as well as corporations. could be subject to enforcement actions. Sections 15 and 16 of TSCA apply to "any person". who violates various provisions of TSCA. EPA may, at ils discretion, proceed against individuals as well as companies. in particular. EPA may proceed against indivituals who. report false or minlending information o: cause it to be reported.

\section{Confidentiality}

A person may assert a ciaim of confidentiality for any information. including public comments. submitted tc EPA in connection with the proposed rule or in connection with the rale after it is promulgated. Any person who submits a confidential public comment must also submit a nonconfidential version. Any claim of confidentiality must accompany the information when it is submitted to EPA. Persons may claim information confidential by circling, brecketing, or underlining it. and marking it with "CONFIDENIIAL" or some ot titer appropriate designation. EPA will dísclose information subject tc a claim of eonfidentiality only to the extent peimitted by section 14 of ISCA and $40 \mathrm{CFR}$ part 2 subpart B. If a persor does not assert a claim ofconfidentiality for information at the time it is submitted to EPA. EPA may make the information public without further notice to that person.

\section{x. Export Notification}

Section 12(b) of TSCA requires that any person who exports or intends to export a chemical substance or mixture for which a rule has been proposed or promulgated under section 6 must notif EPA of such exportation or intent to export. Since this rule applies only to acrylamide and NMA grouts, which are mixtures under TSCA. only export of grouts containing ecrylamide or NMA. as opposed to other mixtures containins these substances. would be subject to the TSCA section 12(b) export notification requirements.

EPA anticipates that the burden of th export notification requirements will be minimal. Companies are required only : provide notification the first time they export or intend to export to eech country in a calendar year. The 
notification consints of the company's name and addreas, chemical name. TSCA section that triggered the notification (in this case section 6 ). countries that are the receivers. and the export date or intended export date (see 40 CFR 707.60 thru 707.75).

\section{Henring Procedirres}

If persons request time for oral comment. EPA will hoid informal hearings in Wasnington. DC. Any informal hearing will be conducted in accordances with EPA's "Procedures for Conducting Rulemaking Under Section 6 of the Toxic Substances Control Act" ( 40 CFR part 750). Persons or organizations deairing to participate in the informal hearing must file a written request to participate. The written request to participate must be sent to the Environmental Assistance Division at the address listed under FOR FURTHIRR INFORMATION CONTACT. The written request to participate inust include: (1) A brief statement of the interest of the person or organization in the proceeding (2) a brief outline of the points to be addressed; (3) an estimate of the time required: and (4) if the request comes from an urganization, a nonbinding list of the persons to take part in the presentation. Organizations are requested to bring with them. to the extent possible, employees with individual expertise in and reaponsibility for each of the areas to be addressed. Organizations which do not file main comments in the rulemaking will not be allowed to participate at the henring, uniess the Record and Hearing Clesk grants a waiver of this tequirement in writing.

The date for the receipt of the written request to participate in the hearing is set forth in the DATES section of the preamble to this document.

\section{Officind Rulemiking Record}

In accordance with the requirements of section 19(a)(3) of TSCA. EPA has established a record for this ruiemaking [docket number OPTS-62089]. This record includes batic information considered by the Agency in developing the proposed rule. and will include comments on the proposed rule and additional supporting information. A public version of the record is available in the TSCA Public Docket Office from 6 a.m. to noon and 1 p.m. to 4 p.m.. Monday through Friday, exciuding legal holidays. The TSCA Public Docket Office is located at EPA headquarters. Rm. NE-G004, 401 M St.. SW. Washington. DC 20460.

5-310999 Do19(1)01-OCT-91-10:47:53)

\section{Support Documents}

1. Economic Analyais of a Proposed Ben on Chemical Grouts Containing Acrylamide and N-methylolecrylamide. U.S. EPA. Office of Toxic Substances. Economics and Technology Division. Regulatory Impacts Branch. November 1990. Addendum July, 1891.

2. Assessment of Alrborne Exposure and Dermal Contact to Aerylamide During Chemical Grouting Operations. Office of Toxic Substances, Exposure Evaluation Division. Field Studies Branch. EPA 5 60/5-B7-009. July 1987.

3. Assessment of Health Risks from Exponure to Acrylamide. U.S. EPA. Office of Toxic Substances, Existing Chemical Assesument Division. June 1990.

4. Riuk Assessment of Nmethylolacrylamide. U.S. EPA. Office of Toxic Substances. Existing Chemical Assessment Division. June 1990.

5. Relative Risks of Acrylamide Grout Substitutes Report. U.S. EPA. Office of Toxic Substances, Existing Chemical Aseessment Diviaion. May 1980.

\section{Reguintory Aseasement}

\section{Requiroments}

\section{A. Executive Order 12291}

Under E.O. 12291. EPA must judge whether a rule is "major" and therefore subject to the requirement of $a$ Regulatory impact Anaiysis. This proposed rule is not major because it would not resuit in any of the adverse impacts set forth in section 1 of E.O. 12291 as grounds for finding a rule to be major. The industry-wide annualized cost would be less than 510 million. which is considerably less than the 5100 million eatablished as the criterion for a major rule in the Order.

\section{B. Regulatory Flexibility Act}

Pursuent to the provisions of 5 U.S.C. 605(b), this proposed rule. if promuigated, will not have a significant economic impact on a substantial number of amall entities.

\section{Paperwork Reduction Act}

As required by the general requirements (sectlon $1320.4(\mathrm{~B})$ ) of the Paperwork Reduction Act (PRA), EPA must inform potential respondents that the information collection requirements in this proposed rule are not subject to Office of Management and Budget

(OMB) review. Collections of information which are submitted to nine or fewer persons do not require OMB review under the PRA.

\section{List of Subjects in 40 CFR Part 784}

Acrylamide. N-methylolacrylamide. Environmental protection.
Recordkeeping and reporting requirements.

Dated: September 24. 1991. Willing K. Roilly.

\section{Adminiztrator.}

Therefore, it is proposed that Chapter I of 40 CFR be amended by adding part 764 to read as follown:

PART 7EA-ACAYUMIOE AND SUBSTIUTED ACRYLAMIOE

subperti A-D-[Recorved] subpert E-Epactic Uae Requiremerto Sec. 784.125 Chemical grouts contuining ecrylamide or N-me thylolacrytamide.

Anthosity: 15 U.S.C 2006 and 2000.

Subparts A-D-fRe:sorved\}

Subpart E-Spective Use Requiremente \$784.125 Crienical grouts containing

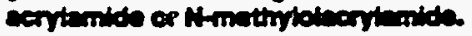

(a) Scope. Chemical groute that contain either acrylamide (CAS No. 7808-1) or N-methylolacrylamide (NMA) (CAS No. 92A-12-5] are subject to this section.

(b) Purpose. This aection imposes requirerzents on persons engaged in certain cummercial activities involving chemical grouts to prevent unreasonablo risks of neurotoxic effects and cancer to persons who use certain materiale in grouting operations.

(c) Applicability. This section applies to any person engaged in the manufacture, importation, or distribution in commerce of chemical grouts and to persons who use such grouts for commercia! purposes.

(d) Definitions. In addition to the terms defined in section 3 of the Act. the following definitions also apply for purposes of this subpart:

(1) Acrylamide grout means a chemical grout that contains 5 percent or more (by weight) of acrylamide.

(2) Act means the Toxic Substances Control Act. 15 U.S.C. 2802 et seq.

(3) Chemical grout means any chemical substance or mixture which reacts in combination with other chemicais to form a substance that secils holes, cracks, or crevices in underground or other structures, or otherwise stabilizes soil to prevent or reduce the flow or seepage of water or other substances into or through such structures or soils.

(4) Commercial use, commercial purpose. and commercial activity mean those uses. purposes. and activities oy any person related to the distribution in commerce of the chemical substance or any mixture containing the chemical 
Bubstance: the use of the chemical substance or any mixture containing the chemical substance in a commercial enterprise providing saleable goods or a service to another person: the use of the chemical substance or any mixture containing the chemical substance by any State or political subdivision thereof: and any commercial distribution, including for test marketing.

(5) Geotechnical applications means the injection of chemical grouts into soil or rock to restrict the flow of water or other substances through soil or rock formations, including but not limited to their we in mines and reservoirs.

(b) Label means any written printed. or graphic material díplayed on or affixed to containers of acrylamide or NMA grout.

(7) Manhole sealing means the use of chemical grouts to seal leaks in or around manholes or any other chamber used to gain access to sower systems.

(b) NMA grout means a chemical grout that contains 5 percent or more (by weight) of N-mathylolecrylamide.

$(\theta)$ Pernon means any natural person. firm. company, cosporation joint venture, partnership, sole proprietorship. association or other buviness antity: any Slate or political subdivision thereof: any municipality; any interstate body: and any department. agency, or instrumentality of the Federal government.

(10) Sewer line repair means the use of chemical grouts in or around main and lateral sewer line systems to seal joints or leaks in these systems.

(11) Structural water control means the use of chemical grouts for sealing nonsewer subterranean or other concrete structures, including but not limited to basements, parking structures. subway tubes, dams and seawaile.

(e) Prohibition on the manufacture. importation, and distribution of acrylamide grouts in commerce. Effective (Insert date 15 days after thr effective date of the final rule], all persons are prohiblted from

manufacturing, importing, or distributing in commerce any acrylamide grout for any purpose, including but not limited to its use for sewer line repair. menhole sealing, structural water control, and geotechnical applications.

in Prohibitions on the commercial ust of acrylamide grouts. Effective linsert date 180 days after the effective date of the final rule|, all persons are prohibiled from using acrylamide grout for any commercial purpose. including but not limiled to its use for sewer line repair. manhole sealing, structural water control, and geotechnical appilications. (g) Prohibition on the commercial use of NMA grouts. (1) Effective (insert date 180 days.after the effective date of the final rule], all pernons are prohibited from any commercial use of NMA grout. except for its use in sewer line repair. This prohibition includes, but is not limited to, its use for manhole sealing. structural water control, and

geotechnical applications.

(2) Effective linsert date 3 years after the effective date of the final rule], all persons are prohibited from using NMA grout for any commercial purpose. including sewer line repair.

(h) Prohibition on the menufacture. importation, and distribution of NMA grouts in commerce. Effective linsert date 3 years after the effective date of the finai rule], all persons are probibited from manufacturing, importing, or distributing in commerce any NMMA grout for any purpose. including but not limited to its use for sewer line repair. manhole sealing, structural water control, and geotechnical applications.

(i) Labeling. (1) Any person who has any inventory on hend, or in theis posseasion or control of any acrylamide grout after linsert date 15 days after the effective date of the final rule] shall affix a label or keep an existing label affixed to each container of grout. regardless of aize. The label shall consiat of the following language:

WARNING: The U.S. Environmental Protection Agency has banned the manufacture. importation, and distribution in U.S. commerce of this product under section $\theta$ of the Toxic Subatances Control Act (15 U.S.C. 2005) as of (inaert date 15 days after the effective date of the final rule?.

Diatribution of this product in commerce after this date and intentionally removing or tarpering with thl label are violntions of Pederal law. All uses of this product are probiblted as of (insert date 180 days after effective date of the final relel.

(2) Any person who manufactures. imports, or distributes in commerce any NMA grout after (insert date 15 days after the effective date of the final rule] chall affix a label or keep an existing label affixed to each container of grout. regardless of size. The label sheil consist of the following language:

WARNING: The U.S. Environmental Prolection Agency has benned all uses of this product. except for sewer line repair, as of (insert date 180 days after effective date of the final rulel. This prohibition includes. but is not limited to. its use for manhole senling. structusal water control. and geotechnical applications. An of |inaerz date 3 yearz afler effective date of the final rulel, the U.S.

Environmenial Protection Agency has banned the manufecture, importation. diatribution in commerce, and all uses of this product under section 6 of the Toxic Substances Cnntrol Act (15 U.S.C.2805). Intentionaily removing or tumparing with this label are vialations of Federal law.

(3) The first word of the warning statement shall be capitalired, and the type size for the first word shall be no smaller than 10-point type for a label less than or equal to 10 equare inches in area. 12-point type for a label sbove 10 but less than or equal to 15 square inches in area. 14-point type for $a$ label above 15 but less than or equal to 30 square inches in area, and 16-point type for a label grester than 30 squere inches in ares. The type size of the remeinder of the warning statement thall be no smaller than 6-point type. All required label text shall be in Bugilich and of oufficient prominenes end shnll be placed with ouch conspicuouaneses. relative to other label text and graphic material, to ensure that the wasning statement ls read and understood by the ordinary individual under cuntomary conditions of purchase and we.

(4) Compliance with the Labeling provisions of this section does not relieve a penon from compliances with requirements establinhed under the Federal Hazurdous Subutnnces Act i15 U.S.C. 1261) or the Hazand Communication Standard (29 CFR 1910.1200 ) es/ablished uniser the Occupational safety and Health Act (20) U.S.C. 851 et seq.)

(i) Recordkeeping. (1) Any person whi manufactures, imports, or distributes in commerce any NMA grout after [insert date 15 days after the effective date of the final rule] muat retain at the headquarters of the company in one location documentation of information showing:

(i) The amount of grout manufactured. imported and the date of mnnufacture/ import.

(ii) The name, address, and telephone number of any person to whom the grouts were sold and shipped.

(iii) The amount of grout shipped and the date of shipment.

(2) This information must be retained for 2 years from the date of shipment.

(k) Reporting. (1) Each person who distributes in commerce acrylamide or NMA grout shall report to the Regional Administrator of the EPA region in which the company headquartera is located. The report must be received no later than linsert effective date of the final rulel, or 30 days after the person first begins to distribute the grout in commerce. whichever is later, and must include:

(i) The distributor's name, addreas. and telephone number. the name of a contact at their company headquarters. and the shipment office locstions througin which their grout is sold. 
(ii) A list of customers, with customer addresses. and total amount and type of grout sold to each cuntomer for the year immediately preceding the report due date.

(2) The report identified in paragraph (k)(1) of this section must be updated as changes occur in the company headquarters or shipment office information. The updated report must be submitted to the Regional Administrator and must be postmarked no later than 10 calendar days after the change occurs.

(3) Any person required to submit a report under thlo section may assert $a$ claim of confidentiality for the information submitted. Any claim of confidentiality must accompany the information when it is submitted to EPA. EPA will disclose information subject to a ciaim of confidentiality onily to the extent permitted by section 14 of TSCA and $40 \mathrm{CFR}$ part 2 subpart $B$. If a perron does not assert a claim of confidentiality for information at the time it is oubmitted to EPA. EPA may make the information public without further notice to that person.

(1) Enforcement. (1) Failure to comply with any provision of this section is a violation of section 15 of the Act (15 U.S.C. $2814^{\circ}$ :

(2) Failure or refusal to establish and maintain records or to permit access to or copying of records, as required by the Act, is a violation of section 15 of the Act (15 U.S.C. 2614).

(3) Failure or refuasl to permit entry or inspection as required by section 11 of the Act (15 U.S.C. 2610) is a violation of section 15 of the Act (15 U.S.C. 2814).

(4) Violatore may be subject to the civil and criminal penalties in section 16 of the Act (15 U.S.C. 2615) for each violation. (m) Lnspections. EPA will conduct inspections under section 11 of the Act (15 U.S.C. 2010) to ensure compliance with this section.

[FR Doc 91-23706 Filed 10-1-97; 8:45 am] muns cose enteres

\section{FEDERAL COMMUNICATIONS COMMISSION}

\section{CrR Part 90}

\section{[PA Docket Mo. 91-170]}

\section{Spoctrum Effleiency in the Prtvate Land Mobtis Radlo Bands in Ues Prior to $106 \mathrm{e}$}

Aancrs Federal Communications Commission.

Aornow Proposed rule: order extending comment period.

sunanr: The chief. Private Radio Bureau has adopted an order extending time periods in which to file comments and reply comments to the Notice of Inquiry $58 \mathrm{FR} 31087$. Juiy 9, 1981, in this proceeding. The new dates are January 15. 1982 for comments and March 2, 1992 for reply comments. The extension would allow applicants to provide the Commission with a more complete record in this proceeding.

DATE: Comments on the Notice of

Inquiry must be filed on or before January 15. 1992 and reply comments must be filed on or before March 2, 1992. abonesers: Federal Communications Commission, $1919 \mathrm{M}$ Street. NW. Washington. DC 20554.

FOn FUnTHER IMFONHATION CONTACT:

Doron Fertig. Policy and Planning

Branch. Land Mobile and Microwave
Division. Private Raaiis Bureau (202) 632-6487.

Order Extanding Comment and Rapily Comment Poriods

Adopted: September 17, $19 \mathrm{~m}$. Released: September 23, 1991. By the Chief. Private Radio Bureau.

1. On July 2, 1981, the Commission released a Notice of Inquiry, 6 FCC Rad 4128 (1891). (Notice), in this proceeding. The specified deadlines for comments and reply comments were October 25 , 1991 and December 13, 1991. respectively.

2. On November 14. 1991 , the Private Radio Bureau will hold a conference to discuss methods of satiafying the growing needs of private redio users in an ers of increasing scarcity of spectrum. Industry representatives and policy makers will focus on the broad concerns raised in the Notice. An extension of the comment and reply comment deadline would provide members of the land mobile community the opportunity to prepare comments based in part on the conference and. thus. would provide the Commission with a more complete recond in this proceeding. We conclude, therefore, that an extension of time is in the public interest. Accordingly, it is ordered. based on the authority in $\mathbf{0 . 5 3 2}$ of the Commission's Rules and Regulations. 47 CFR 0.331. that the deadline for filing comments in the subject Notice of Inquiry is extended to Jenunry 15, 1992 and the deadline for filling reply comments is extended to March 21992

Federal Communications Commisalon

Ralph A. Haller.

Chief. Private Rodio Bureau.

[FR Doc. 23731 Filed 10-1-91: B:45 am] rime coor s718-0r-4 


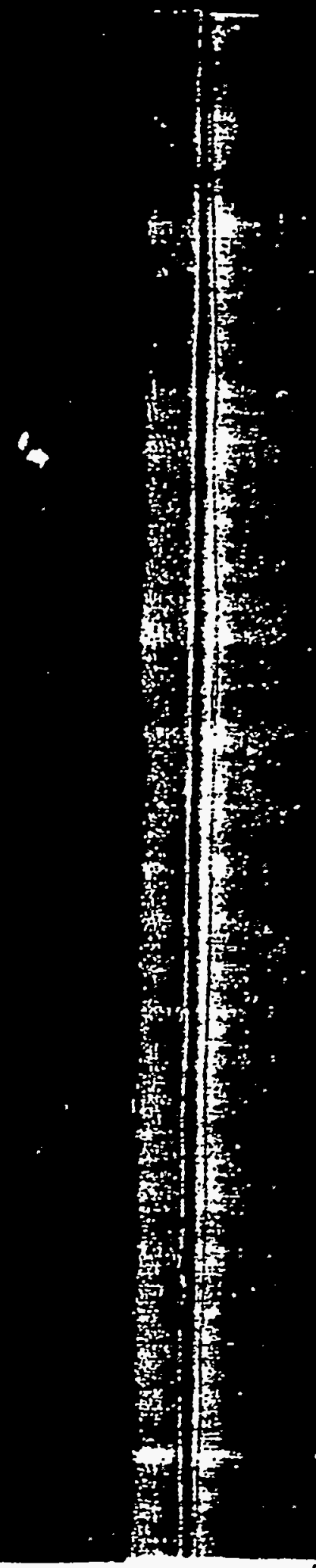

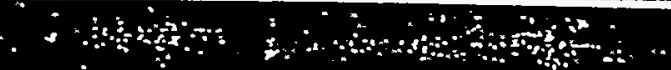

$\therefore$ and

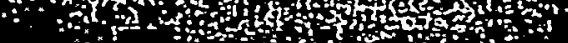

$\therefore$.

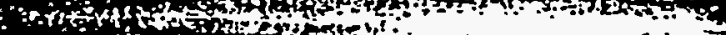

$\therefore$ A

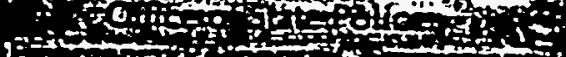
1)

-

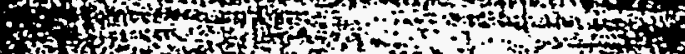

2.

Hot.

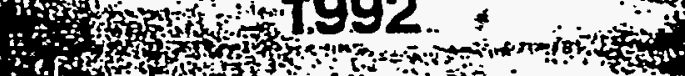

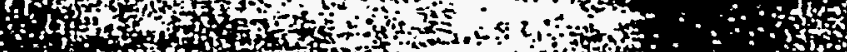

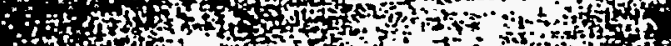

and

$\therefore$ sulu Materials Information Deve,

reparedness and Response

4 treparedness and Response Actsos

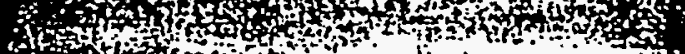

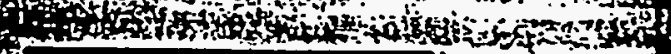

$0 \%$

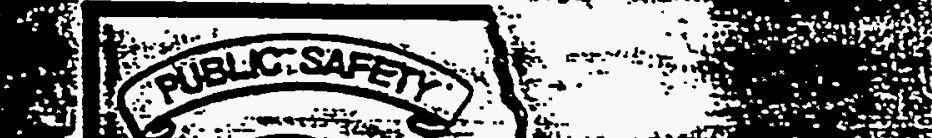

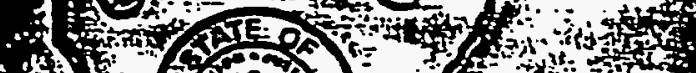

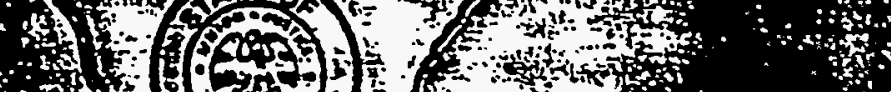

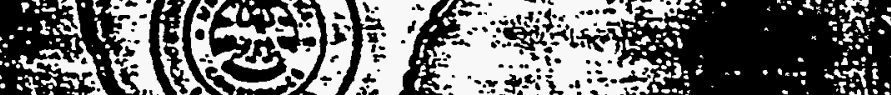
The con

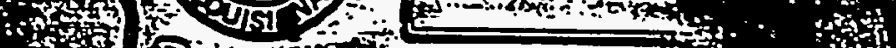

ris

W COACE OE D

$\therefore$ 证

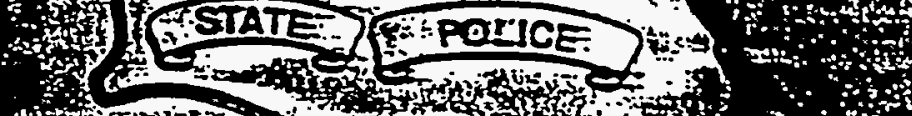

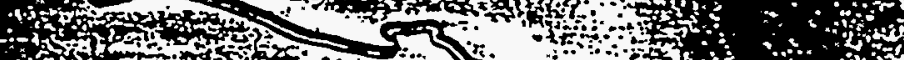

$\therefore$ is 1 of

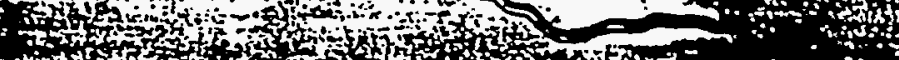

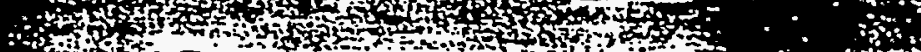

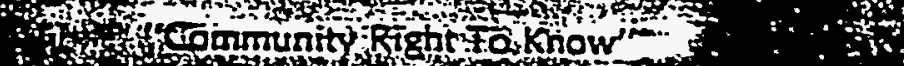

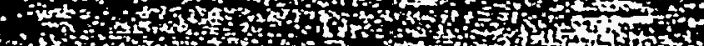

,

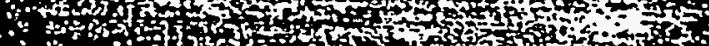

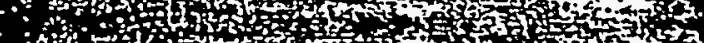

$\because 37$.

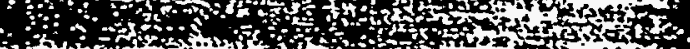

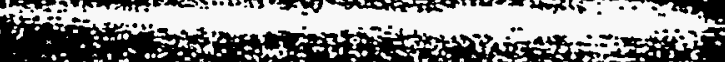

a d ond

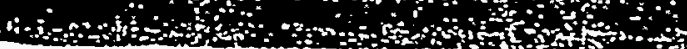




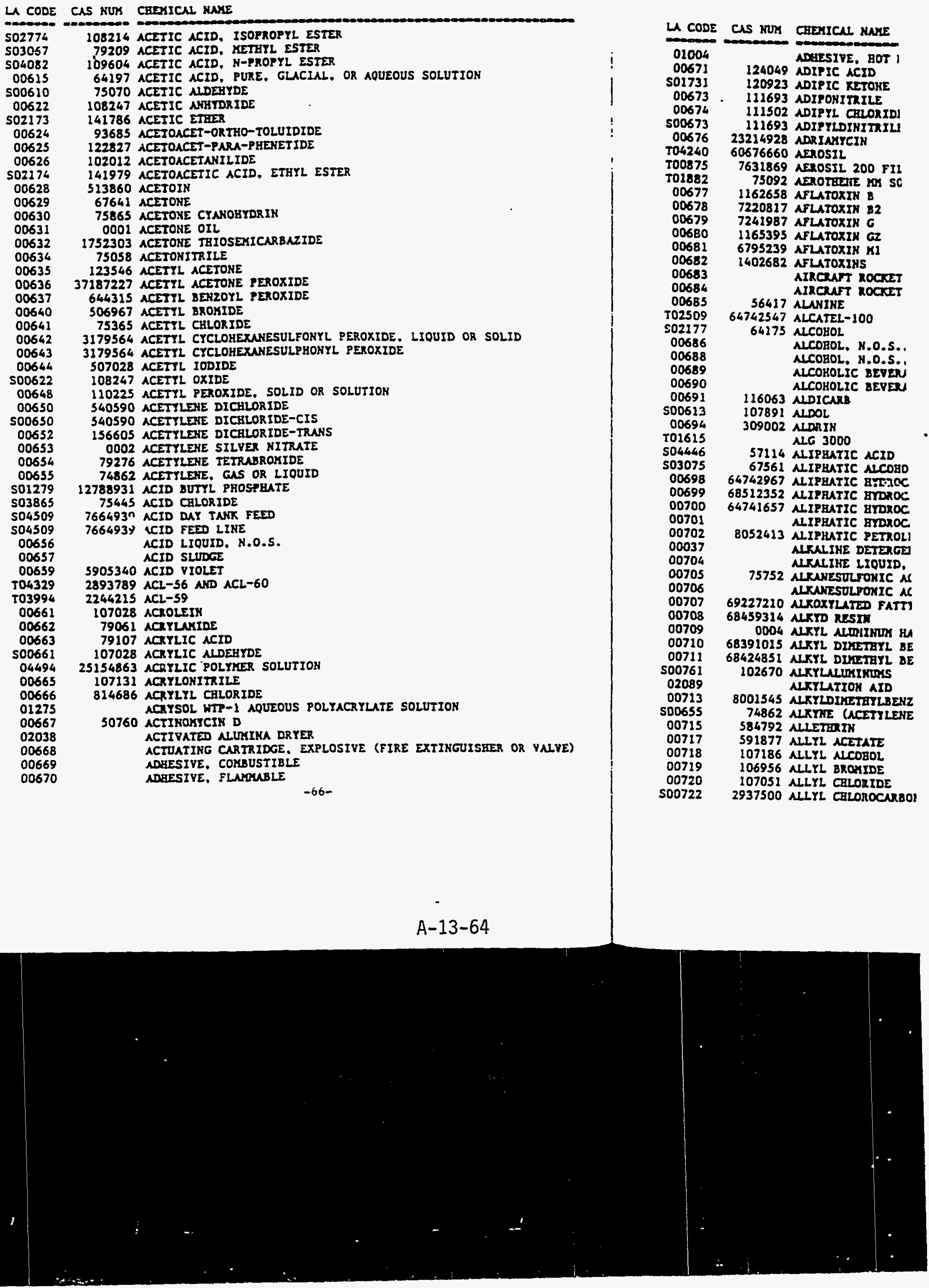




\section{$\$ 355.50$ Penalties.}

(a) Civil penalties. Any person who fails to comply with the requirements of $\$ 355.40$ shall be subject to civil penalties of up to $\$ 25,000$ for each violation in accordance with section 325(b)(1) of the Act.

(b) Civil penalties for continuing violations. Any person who fails to comply with the requirements of $\$ 355.40$ shall be subject to civil penaities of up to $\$ 25.000$ for each day during which the violation continues. in accordance with section $325(\mathrm{~b})(2)$ of the Act. In the case of a second or subsequent violation, any such person may be subject to civil penalties of up to $\$ 75,000$ for each day the violation continues. in accordance with section 325(b)(2) of the Act.

(c) Criminal penalties. Any person who knowingiy and willfully fails to provide notice in accordance with $\$ 355.40$ shall, upon conviction. be fined not more than $\$ 25.000$ or imprisoned for not more than two (2) years, or both lor. in the case of a second $\mathrm{nm}$ subsequent conviction. shall be fined not more than $\$ 50.000$ or im risoned for not more than five (5) years. or both) in accordance with section $325(b)(4)$ ui the Act.

\section{Appendix A to Part 355-The List of Extremely Hazardous Substances and their Threshold Planning Quantties}

[Alphabetical Order]

\begin{tabular}{|c|c|c|c|c|}
\hline CAS No. & Chemical name & Notes & $\begin{array}{ll}\text { Reportadle } & \vdots \\
\text { quantry* } & 1 \\
\text { (pounos) } & !\end{array}$ & $\begin{array}{l}\text { Thresnoid } \\
\text { ptamning } \\
\text { quantuty } \\
\text { (pouncs) }\end{array}$ \\
\hline $75-86-51$ & Acetone Cyanonvann & & 101 & 1.000 \\
\hline $1752-30-31$ & 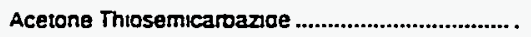 & e & 1: & 1.000110 .000 \\
\hline $107-02-81$ & Acroleln & & 1 & 500 \\
\hline$=79-06-11$ & 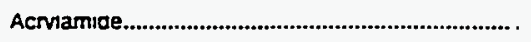 & a. 1 & 5.0001 & $1000 / 10.000$ \\
\hline $107-13-11$ & 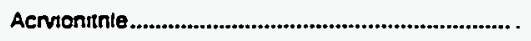 & a. 1 & 1001 & 10.000 \\
\hline $814-68-61$ & 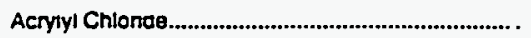 & e. $n$ & $1 !$ & 100 \\
\hline $111-69-31$ & Adidonitnte & e: 1 & 11 & 1.000 \\
\hline $116-06-31$ & Aldieard & $=$ & 11 & $100 / 10.000$ \\
\hline $309-00-21$ & Aldnn & $a$ & 11 & $\$ 00 / 10.000$ \\
\hline $107-18-6 i$ & Allyl Alconot & & 1001 & 1.000 \\
\hline $107-11-91$ & Allyhamine & e & 11 & 500 \\
\hline $20859-73-81$ & Aluminum Phosonice & כ & 1001 & 500 \\
\hline $54-62-61$ & 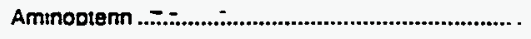 & $\cong$ & 11 & $500 / 10.000$ \\
\hline $78-53-5 i$ & Amuton & e & $1 \cdot$ & $\$ 00$ \\
\hline $3734-97-21$ & 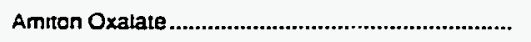 & $\simeq$ & $1 \cdot$ & $: 00 / 10.000$ \\
\hline $7664-41-7$ & 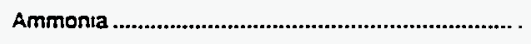 & & 1001 & 500 \\
\hline $300-62-91$ & 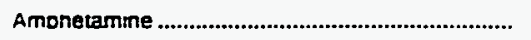 & $\underline{z}$ & i: & $: .000$ \\
\hline $62-53-31$ & 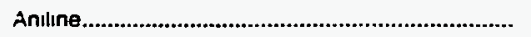 & $=.1$ & $\Xi .0001$ & $: .000$ \\
\hline $88-05-11$ & 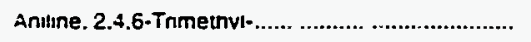 & $\geq$ & $\cdot$ & $\$ \infty$ \\
\hline$-783-70-2$ & Antimony Pentatudonde ................... ... .................. & $\equiv$ & $\cdot$ & $\equiv 00$ \\
\hline $1397-94-0$, & 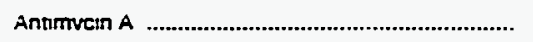 & $=2$ & : & $: .000110 .000$ \\
\hline $86-88-41$ & 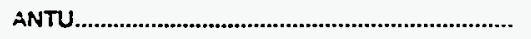 & & 00501 & $2 / 10.000$ \\
\hline$: 303-28-2 !$ & Arsenic dentoxice & $=$ & $\cdot$ & $.00 / 10.000$ \\
\hline $1327-53-31$ & 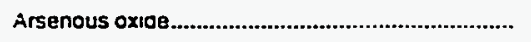 & $=. n$ & $\cdot$ & $: 00 / 10.000$ \\
\hline $784-1$ & 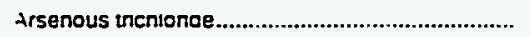 & $=$ & $\cdot$ & $\equiv 00$ \\
\hline
\end{tabular}


53 FR 7024 printed in FULr cormat.

\author{
ENVIRONMENTAL PROTECIION AGENCY \\ AGEMCL:: Environmental Protection Agency (EPA). \\ [OPTS-00088; FRI-3338-1] \\ 53 FR 7024
}

Mareh 4, 1988

Acrylamide Fanlth Rigk Asscssmant: Availability and Reguest for coments ACIION: Notice of Availability and Request for comments.

SUMMARY: This notice announces the availability of a araft Health Risk

Assessment of Acrylamide. The Assessment roviews acrylamide's carcinogenic genotoxic, reproductive, developmental, and neurotoxic effects. Thi mamuf: and processing of acrylamide and its use as a soil grout to repair sowar are the principal exposure estegories examined. Heaith risks associated wj these exposures are prespntad. Comments on the Ascossment are requasted fi publise.

DATE: Comments must be recelvad by April $30,1988$.

ADDRESs; submit written comments to: Richard Hefter, Existing Chemical Assessment Division (TS-778), Rm. E-403, Envirommental Protection Agency, st. . SW. , Washington, DC 20460

FOR FURMISR INFORHATION CONTACT:Michael K. Stabl, Acting Director, TSCA Assistance office (IS-799), office of Toxic Substances, Environontal Prot Agercy, Rm. E-543, 401 K St., SW., Fashington, DC 20460, Telephone:

$(202-554-1404)$.

TEXT: SUPPLMRNTARY INFORMATION: The Offlee of Toxic substances (OTS) hes completed a comprehensive Healtr RIsk Assessment or Acrylamide, and as par its preparation for a review of the Assessment by HPA's Science Advisory $B$ (SAB) comments are being solicited from the public. Coments received will summarized and made available to the SAB. The Assessment will be revised a necessary based on SAB and public review.

Copies of the Assessment can be obtained from the TSCA Assistance Offic FOR FURTHER INFORMATION CONTACT above.

Datad: February 26, 1988.

Charles I. Elkios,

DIrector, OII1ce or Toxic substances. [FR DOC. 88-4867 Filed 3-3-8B; 8:45 am]

BIIIING CODE 6560-50-31 


\section{APPENDIX 14}

STABLE ISOTOPE CONSTRAINTS ON THE ORIGIN OF BRINE IN THE WEEKS ISLAND STRATEGIC PETROLEUM RESERVE 
STABLE ISOTOPE CONSTRAINTS ON THE ORIGIN OF BRINE IN THE WEEKS ISLAND STRATEGIC PETROLEUM RESERVE

\author{
by \\ L. Paul Knauth \\ Department of Geology \\ Box 871404 \\ Arizona State University \\ Tempe. Arizona 85287-1404 \\ (602) $965-2867$ \\ Knauth@asuacad.edu
}

September 14, 1994

A-14-2 


\section{INTRODUCTION}

This report is an update of 3 previously submitted reports, "Stable isotope constraints on the origin of brine in the Weeks Island Strategic Petroleum Reserve" (Knauth, 1987) and 2 "Updates" (Knauth, 1989, 1990). Several new brine samples from the fill holes, the service shaft, mine drips, and surface waters have been isotopically analyzed. In this update, isotopic analyses are used to evaluate potential inflow of external water into the main storage facility, the Markel Mine area, and the adjacent mine chambers.

\section{NOMENCLATURE AND BACKGROUND}

There is a small amount of the heavier stable isotope of oxygen $\left({ }^{18} \mathrm{O}\right)$ and hydrogen ( $D$, deuterium) in all natural waters. The amounts of these isotopes in water samples are highly variable and depend upon the source and history of the water. In effect, the stable isotopes can often be used as natural tracers to understand the source(s) of mine leaks, aquifer contamination, and other problems involving surface-ground water interactions. A brief introduction to the methodology was given in the initial report (Knauth, 1987). Applications to mine leaks in the Gulf Coast are given in Knauth et al. (1980) and Knauth and Kumar . (1983).

\section{HISTORY}

Following discovery of brine under the oil in the Weeks Island facility, samples were sent to Arizona State University (ASU) in 1987 for isotopic analyses. The brine samples bore the isotopic signature of external ground water, so an isotopic survey was quickly performed on various surface, aquifer, and mine waters. The results are reproduced in Fig. 1.

As shown in the figure, data for the fill holes fell on a line connecting the overlying groundwater values (labeled "aquifer") with "connate" leaks that had been sampled prior to in-filling of the mine with oil. This suggested that the brine discovered under the oil was about $80-90 \%$ external, aquifer water and $10-20 \%$ connate water. Surface waters such as overlying lakes and ponds, bay waters, and the intercoastal canal did not seem to be involved.

Following submission of this report, it was discovered that water used to test the pipe-line across the Atchafalaya Basin had been injected into the mine prior to in-filling with oil. Concems over a possible leak diminished rapidly, but this scenario did not necessarily explain the isotope data. It is unlikely that the bayou water used to fill the pipe-line water would have had an isotopic composition similar to the local ground water at Weeks Island; the position of the fill hole water on an isotopic mixing line between ground water and connate water is fortuitous under this scenario. 
Brine continued to flow into the fill holes following pump-downs throughout 1987-1989. The oxygen isotopic composition shifted steadily toward the overlying aquifer value, but the $\mathrm{D} / \mathrm{H}$ ratio was slightly lower than expected for a simple leak scenario. In an updated report, Knauth (1989) attributed the D/H variations to possible water/rock interactions that could occur during transit through the overlying clay and salt and concluded that the leak scenario was still the most likely explanation. Thoms (1989) had submitted a report indicating that the brine inflow to the fill holes was most likely the slow flow-back of water displaced by injection of the oil. Thoms's scenario was compatible with the isotopic changes if certain values were assumed for the original pipe-line water and the water that slowly comes out the oil itself.

Brine in the fill-holes was sampled twice in 1990. Isotopically analyses were performed on these samples together with several bayou samples taken along the pipe-line. Sampling of the bayous was designed to provide some constraint on the isotopic composition the water that might have been used to fill the pipe-line, the water that was probably injected into the mine prior to oil-infilling.

The fill-hole samples continued to show an isotopic evolution toward meteoric water values, but not directly toward the overlying aquifer value. Knauth (1990) explored this evolution in terms of Thoms's (1989) "no leak" scenario. The isotopic data could be plausibly interpreted in terms of this scenario, but concerns were expressed over the critical dependence on the hydrogen isotopes. If the hydrogen isotopes were being affected only minimally by water/rock or water/oil interactions, the isotopic data could still be readily interpreted in terms of an external leak.

Brine has continued to flow into the fill holes, and a sink hole has now developed over the dome. Fill hole samples taken in 1992 and 1993 were transmitted to ASU in May and June 1994. Further samples of the fill holes have apparently been taken in 1994, but these have not yet been transmitted to ASU for isotopic analysis.

\section{RESULTS}

The new data are given in Table 1. Table 2 is an updated data table for all data to date for the Weeks Island Strategic Petroleum Reserve. Figure 2 contains the new data together with relevant data from the previous investigations, plotted on a scale similar to that of Fig. 1.

\section{DISCUSSION}

Although the brine in the fill holes is the most urgent subject, the leaks in the Markel Area will be discussed first because they provide information critical to interpretation of the Fill Hole isotope data. 


\section{MARKEL AREA}

The Markel Incline is a connecting passage to a newer mine level in the old Weeks Island mine. During opening of this passage the late 1970's, a large water leak developed. Dye injected in surface waters over the dome by the mine operators appeared in the passage within a few days (J. Goodbrake and M.B. Mirza, personal communication, 1978). Most of the inflow was stopped by grouting, but small drips and pools are still present. At least some of this inflow is clearly external, meteoric water.

Isotopic data for Markel samples dating back to 1979 are plotted in Fig. 3. One group of data plots near a mixing line between the overlying groundwater (labeled "aquifer") and the highly ${ }^{18} \mathrm{O}$-rich connate brines sampled in the mine prior to oil-in-filling. The LP-2 Packer sample appears to be a mixture of about $20 \%$ connate water and $80 \%$ aquifer water (see Knauth, 1987, for the methodology of deducing mixtures from isotope data). The 1990 sample is a mix of about $90 \%$ aquifer water and $10 \%$ connate. The 1994 samples appear to be greater than $90 \%$ aquifer water. The Markel leaks apparently represent external leaks that have contacted connate "pockets" while passing through the salt.

A more peculiar group of Markel samples from 1979-1989 has $\delta^{18} \mathrm{O}$ values similar to the aquifer but depleted in D by $5-15 \%$ (Fig. 3 ). Inasmuch as the 1979 samples were taken from the leaks that transmitted dye from the surface, it is clear that these are external leaks. Clearly, something altered the hydrogen isotopic composition during transit through the salt-sediment interface or through the salt itself. Methane is associated with the leaks (see letter from R. Berry appended to Knauth, 1990). Methane is known to be strongly depleted in $D$, so isotopic exchange between water molecules and methane is the likely explanation for the lowering of $\delta \mathrm{D}$. The methane may originate from bacteria at the salt-sediment interface (a common occurrence over salt domes) or from connate methane bleeding into the flow path.

The 1981 Markel samples (Fig. 3) are different from all others. They are somewhat depleted in both ${ }^{18} \mathrm{O}$ and $\mathrm{D}$ relative to the aquifer. These samples were transmitted to ASU by Terri Ortiz (Sandia) during preparation of the facility for receiving oil. They were apparently from pools that had been standing for some time. One sample was badly contaminated with diesel fuel. These samples are unreliable because they had ample opportunity to receive condensation water, and were likely affected by isotopic exchange with diesel fuel combustion products. Knauth et al. (1980) showed that standing pools in an active salt mine undergo massive isotopic exchange with water vapor and $\mathrm{CO}_{2}$ derived from combustion of diesel fuel. For these reasons, the 1981 data are considered irrelevant to the present problem and will not be considered further.

The Markel data demonstrate clearly that the hydrogen isotope composition of ground water is sometimes subject to alteration (probably by isotopic exchange with methane) during its passage through the salt-sediment 
(c) The possibility that $\delta \mathrm{D}$ is altered by slow isotopic exchange of hydrogen in the water molecules with hydrogen in the oil molecules was evaluated by reanalyzing two brine samples that have been in intimate contact with oil since 1987. These samples were taken from the service shaft and WIP-13 and are basically bottles of oil with a few milliliters of brine visible at the bottom. The samples were analyzed in 1987 and have been stored in the isotope lab at ASU since then. If the trend in Fig. 6 is due to slow isotopic exchange between brine and oil, the 2 stored samples should show changes in $\delta D$ after 8 years of oilbrine contact. The old and new analyses are shown in Table 3.

\begin{tabular}{|l|l|}
\hline Date & $\delta \mathrm{D}$ \\
\hline WIP-13, 4/13/87 & -20 (Average of 3 analyses, \pm 2 ) \\
\hline WIP-13, re-analysis, 1995 & -20 (Average of 2 analyses, \pm 1 ) \\
\hline Service Shaft $12 / 23 / 85$ & -24 \\
\hline Service Shaft, re-analysis, 1995 & -22 \\
\hline
\end{tabular}

Table 3

The re-analyses of both samples are within experimental error of the initial analyses. This suggests that isotopic exchange with the oil is not occurring at room temperature. It is therefore not likely that the changes with time in $\delta D$ for the fill hole sampies is due to isotopic exchange with the oil.

(d) In view of the Markel results discussed above, there is a real possibility that $\delta D$ of the fill hole samples was affected by isotopic exchange with methane during transit of external water through the salt. If so, the steady decline in $\delta \mathrm{D}$ from 1987 to 1990 (Fig. 4) would imply that greater input of methane-bearing water occurred during this interval. This might have occurred by growth of microbial populations or by progressive draining of connate methane into progressively enlarging pathways through the salt. The change in trajectory in 1991 (Fig. 4) could signify final drainage of connate methane and/or increased flow rates that increased the water/methane ratio to the point that isotopic exchange no longer produced a significant effect on $\delta D$.

Possibility \#2. An external leak developed between 1990 and 1992. Prior to 1990 , there was no leak and the brine evolved isotopically (Fig. 3) in response to mixing of back-flow brine (from the initial injection of pipe-line water) with water settling out of the oil (Thoms scenario discussed in Knauth, 1990). Sometime after the 1990 sampling, groundwater above the salt dome began to leak into the oil-filled cavern. Since that time, the brine has been evolving isotopically toward the aquifer values (Fig. 4). 
This interpretation takes the hydrogen isotope measurements at face value; the change in trajectory on Fig: 4 is considered to be an accurate reflection of brine evolution. From 1987 to 1990 the brine appeared to be evolving toward lower $\delta \mathrm{D}$ and $\delta^{18} \mathrm{O}$ values, but not toward the aquifer value. As discussed in Knauth (1990) this could be explained in terms of Thoms's (1989) interpretation that the brine under the oil is a mixture of pipe-line water and water that settled out of the oil. The pipe-line water was displaced to the other side of the cavern floor by injection of oil, and flowed back to the fill holes throughout 1987-1990. During transit across the floor of the mine, the underflow became more enriched in water that settled out from the oil.

Based on the curve in Fig. 6, $\delta \mathrm{D}$ appears to have changed trajectory about 1500 days after the initial samples were taken. This would place the start of the external leak at about July, 1991. The sinkhole was discovered on May 18,1992 . The actual age is unknown, but Neal (Draft 14 Feb 94) indicates that it was probably not there in April, 1990. Neal estimates that it probably formed in the summer or fall of 1990 .

\section{CONCLUSIONS REGARDING FILL HOLES}

Since early 1992 the isotopic composition of brine in the fill holes has been evolving toward that of groundwater sampled over the salt dome. The data provide compelling evidence that external water has been leaking into the facility since at least March, 1992. It is also highly likely that the leak existed since July, 1991, based on projections of the trends in Figs. 4 and 6 . Prior to this time, the data are somewhat equivocal. A "no leak" scenario prior to 1991 is possible if the hydrogen isotope data are taken at face value. In this case, the combined oxygen and hydrogen data can then be reasonably interpreted in terms of the Thoms (1989) scenario. This interpretation requires special assumptions regarding the amount and isotopic composition of pipe-line water injected into the dome prior to oil in-filling and also assumptions regarding the amount and isotopic composition of water that settled out of the oil. A possibly simpler interpretation is that the hydrogen isotopes in the water exchanged isotopically with methane along its entry path. This clearly has happened in the case of the external leaks in the Markel Incline. If so, the steady evolution of the more reliable oxygen isotope data for fill hole water toward the overlying groundwater values suggest that the leak has existed since 1987.

\section{SANDRIK AND LARK DRIPS}

In the accessible mine area there are roof drips that may represent slow drainage of connate water and/or possible leaks of overlying groundwater into the facility. At least 2 localities the drips are funneled by plastic sheeting into collection bottles. Isotopic data for the so-called "Lark" and "Sandrik" collectors are shown in Fig. 7. 
Data for the Lark drips plot near the meteoric water line and must be external leaks. The 1994 datum is slightly depleted in $\mathrm{D}$ relative to the overlying groundwater ("aquifer"), possibly in response to isotopic exchange with methane (discussed above). The 1987 sample is somewhat enriched in 180 relative to the aquifer value, but the sample is so close to the meteoric water line that any interpretation not involving an external leak is improbable. The collectors accumulate water over a long time, and possible condensation and exchange with ambient water vapor could alter the isotopic composition slightly.

Data from the Sandrik collector are enormously enriched in ${ }^{18} \mathrm{O}$ relative to other waters in the facility and are very similar to connate brines sampled in the Weeks Island mine prior to brine in-filling (Knauth et al., 1980). These leaks are clearly composed primarily of connate brine. Connate brine is less of a threat to a salt mine because it probably represents a limited amount of brine trapped in the salt for tens of millions of years. However, connate fluids may be preferentially present in anomalous, sediment-rich parts of the salt stock. If such zones extend to the periphery of the stock, drainage of the connate brine could induce inflow of external waters. For this reason, it is recommended that the Sandrik leak be isotopically monitored for a possible shift toward the meteoric water line. This would indicate that external waters are starting to enter the facility along a new flow path.

\section{CONCLUSION}

The isotopic evolution of brines taken from the fill holes yields compelling evidence that an external leak into the oil-filled mine has existed since at least March, 1992 and probably since July, 1991. Prior to that time, interpretation of the data is somewhat uncertain. They can be reasonably interpreted in terms of a "no-leak" scenario if assumptions are made about the amounts and isotopic composition of pipe-line water injected into the mine and of immiscible water contained within the oil itself. These assumptions are bothersome, and this leaves viable the original interpretation that an external leak has existed since 1987. 
interface or through the salt itself. Water that flows in rapidly or down paths that are methane-free will not be affected (LP-2 Packer, 1990, and 1994 samples). Inasmuch as there is no oxygen in methane, $\delta^{18} \mathrm{O}$ is not affected. This may explain some aspects of the important fill-hole data discussed below.

\section{FILL HOLES}

Data for the fill holes from 1987-1993 are shown on an enlarged graph in Fig. 4. From 1987 to 1990 the data evolved steadily toward more ${ }^{18} \mathrm{O}$ - and Ddepleted values. From 1992 to 1993 , the data became more D-rich as ${ }^{18} \mathrm{O}$ continued to decrease. The current trajectory is directly toward the values of the overlying aquifer (as sampled in the well over the fill-holes and Morton Salt Co. Well \#7). Possible explanations for this remarkable change in trajectory are given below.

Possibility \#1. There has been an external leak since 1987. $\delta^{18} \mathrm{O}$ has been evolving steadily toward the aquifer value as the overlying ground-water continues to leak into the facility. The changes in $\delta D$ are relatively small, and are not reliable because of (a) routine analytical error, (b) contamination of the water sample with acetate or other organic compounds that could interfere with standard isotopic analysis, (c) isotopic exchange with the oil, or (d) isotopic exchange with methane as the water penetrated the salt stock.

(a) Figure 5 shows the change in $\delta^{18} \mathrm{O}$ plotted as a function of time. $\delta^{18} \mathrm{O}$ appears to be evolving relentlessly toward the aquifer value. $\delta \mathrm{D}$ vs time is shown in Fig. 6. The data scatter for $\delta D$ is much larger than for $\delta^{18} \mathrm{O}$. This is due, in part, to analytical error. For routine analyses, our lab guarantees $\pm 2 \%$ for $\delta D$ and \pm 0.2 for $\delta^{18} \mathrm{O}$. In practice, $\delta D$ is usually better than $\pm 1 \%$, as evidenced by the tight cluster of data for the aquifer and replicate analyses of fillhole samples. Although there is a large variation in the 3 samples taken in 1989, most duplicate analyses are within $\pm 1 \%$ of each other. It is therefore unlikely that the trend in Fig. 6 is entirely an artifact of the analytical method.

(b) Water samples are reacted with uranium at $700^{\circ} \mathrm{C}$ in order to liberate hydrogen for isotopic analysis. If acetate or other organics are present in the water in significant quantities, then these will react also with the uranium to produce contaminant hydrogen derived from organic molecules. Although isotopic analysis of water is routine, this is the first time anyone has done a hydrogen isotope investigation of water in a situation like this. In the absence of chemical analyses, contamination in amounts sufficient enough to affect $\delta \mathrm{D}$ is a distinct possibility. However, any such contamination should be uniformly present in all the samples and no trend with time (Fig. 6) should exist. Contamination is more likely a cause of data scatter than an explanation for the time-trend. 


\section{REFERENCES}

Neal, J.T. (1994) Dissolution Features over the Weeks Island, La., salt mines: origin, development, and detection. DRAFT 14 Feb 94 . Sandia National Labs.

Knauth, L.P. 1987) Stable isotope constraints on the origin of brine in the weeks Island Strategic Petroleum Reserve, Rev.1, 8/13/89. Submitted to C.

Chabannes, PB-KBB, Inc.

Knauth, L.P. (1989) Stable isotope constraints on the origin of brine in the weeks Island Strategic Petroleum Reserve, 11/25/89. Submitted to J. McHenry, Boeing Petroleum Services.

Knauth, L.P. (1990) Stable isotope constraints on the origin of brine in the weeks Island Strategic Petroleum Reserve, 11/15/90. Submitted to J. McHenry, Boeing Petroleum Services.

Knauth, L.P. and Kumar. M.B. (1983) Isotopic character and origin of brine leaks in the Avery Island salt mine, south Louisiana, U.S.A. Jour. Hydrology, 66, 343350.

Knauth, L.P., Kumar, M.B. and Martinez, J.D. (1980) Isotope geochemistry of water in Gulf Coast salt domes. Jour. Geophysical Research, 85, 4863-4871.

Thoms, R.L. (1989) Brine in the Weeks island SPR Facility. Report prepared for Sandia National Laboratories, submitted to J.K. Linn. 
TABLE 1

\begin{tabular}{|c|c|c|c|c|}
\hline SAMPLE & Month & Year & $0-18$ & DELTA D CATEGORY \\
\hline West Fill Hole & 15-May & 1993 & -3.3 & \begin{tabular}{|c|}
$-22:$ Fill Hole \\
\end{tabular} \\
\hline East Fill Hole & 15-Oct & 1993 & -3.7 & -22 Fill Hole \\
\hline West Fill Hole & 16-Mar & 1992 & -3.2 & $\cdot-23$ ifill Hole \\
\hline West Fill Hole & 24-Jan & 1993 & -3.6 & -22 Fill Hole \\
\hline Wip-37 & 28-Mar & 1994 & -4.2 & -19 Service Shaft \\
\hline Wip-37 & $17-$ Oct & 1993 & -4.4 & -21 Service Shaft \\
\hline Wip-38 & 17-Oct & 1993 & -4.2 & -22 Service Shaft \\
\hline Service Shaft Seep 1 & 28-Mar & 1994 & -1.2 & -17 Service Shaft \\
\hline Sandrik Drift No. 2 & 28-Mar & 1994 & 7.9 & $-4:$ Mine \\
\hline Markel Wet Drift & 28-Mar & 1994 & -3.1 & -18 Mine \\
\hline Seep B- Lark Drift & 28-Mar & 1994 & -4.3 & $-23:$ Mine \\
\hline Weeks Bay & & 1994 & -4.7 & $-26 ;$ Surface \\
\hline Intercoastal Waterway & & 1994 & -6.3 & -37 :Surface \\
\hline Bayou Warehouse, Wks Islano & & 1994 & -3.9 & -23 Surface \\
\hline Markel Wet Drift \#3 & & 1994 & -4.3 & -22 :Mine \\
\hline Markel Wet Drift \#5 & & 1994 & -4.4 & -22 Mine \\
\hline
\end{tabular}


Table 2

\begin{tabular}{|c|c|c|c|c|c|}
\hline SAMPLE & Month & Year & $0-18$ & DELTAD & CATEGORY \\
\hline & & & & & \\
\hline Water Well \#7 & 27-May & 1987 & -4 & -19.9 & Aquifer \\
\hline Fill Hole Well & 27-May & 1987 & $-4.4:$ & -19.8 & Aquifer \\
\hline Fill Hole Well & & 1989 & $-4.4 i$ & -20.2 & Aquifer \\
\hline Fill Hole Well & $21-$ Sep & 1990 & -4.4 & -21.1 & Aquifer \\
\hline Condensation & 22-Jun & 1987 & -6.1 : & -42.7 & Condensation \\
\hline Condensation & 22-Jun & 1987 & $-6:$ & -42.2 & Condensation \\
\hline Cavern Vent & & 1987 & 4: & -3.5 & Condensation \\
\hline West Fill Hole & $4 / 28 / 87$ & 1987 & -1.7 & -18.7 & Fill Hole \\
\hline East Fill Hole & $4 / 28 / 87$ & 1987 & -1.7 & -18.5 & Fill Hole \\
\hline West Fill Hole & $4 / 28 / 87$ & 1987 & -1.8 & -18.3 & Fill Hole \\
\hline East Fill Hole & $4 / 28 / 87$ & 1987 & -1.7 & -18.6 & Fill Hole \\
\hline East Fill Hole & $4 / 28 / 87$ & 1987 & -1.8 & -17.4 & fifill Hole \\
\hline West Fill Hole & $4 / 28 / 87$ & 1987 & -1.7 & -18.4 & 4!Fill Hole \\
\hline East Fill Hole & $1 / 20 / 88$ & $1988 !$ & -1.9 & -20.1 & Fill Hole \\
\hline East Fill Hole & $2 / 4 / 88$ & 1988 & -1.8 & -20.1 & Fill Hole \\
\hline \#7 PD89-B & $5 / 15 / 89$ & 1989 & -2.1 & -22.2 & Fill Hole \\
\hline \#8 PD89-M & $5 / 15 / 89$ & 1989 & -2.2 & -18.9 & Fill Hole \\
\hline \#9 PD89-E & $5 / 15 / 89$ & 1989 & -2.2 & -19.7 & Fill Hole \\
\hline West Fill Hole & $3 / 6 / 90$ & 1990 & -2.5 & -22.5 & 5 Fill Hole \\
\hline Brine Sampling exercise & $9 / 15 / 90$ & 1990 & -2.6 & -23.1 & :Fill Hole \\
\hline West Fill Hole & $3 / 16 / 92$ & $1992_{i}$ & -3.2 & -23 & :Fill Hole \\
\hline West Fill Hole & $1 / 24 / 93$ & 1993 & -3.6 & -22 & Fill Hole \\
\hline West Fill Hole & $5 / 15 / 93$ & 1993 & -3.3 & -22 & Fill Hole \\
\hline East Fill Hole & $10 / 15 / 93$ & $1993 !$ & -3.7 & & Fill Hole \\
\hline Lark Roof collector & 6-May & 1987 & -3.7 & -23.4 & Mine \\
\hline Sandrik Trap 2 & 25-Jun & 1987 & 7.9 & & Mine \\
\hline Sandrik 4 & 6-May & $1987 i$ & 7 & -8.3 & Mine \\
\hline Sandrik roof coll \#1 & 25-Jun & 1987 & 8.1 & -14.2 & Mine \\
\hline Sandrik Drift No. 2 & 28-Mar & 1994 & 7.9 . & & Mine \\
\hline Seep B-Lark Drift & 28-Mar & 1994 & -4.3 & -23 & Mine \\
\hline LP-2 Packer & 25-Nov & 1986 & -0.7 & -15.6 & Mine \\
\hline Markel Floor Hole right & 25-Jun & 1987 & -3.8 & -29.7 & Mine \\
\hline Markel MWD-1 & 13-Sep & 1989 & -4.1 & -24.5 & Mine \\
\hline Markel Wet Drift-back part & 28-Mar & 1990 & -2.4 & -15.6 & Mine \\
\hline Markel Wet Drift & 28-Mar & 1994 & -3.1 & -18 & Mine \\
\hline Markel Wet Drift \#3 & & 1994 & -4.3 & -22 & Mine \\
\hline Markel Wet Drift \#5 & & 1994 & -4.4 & -22 & Mine \\
\hline SJ 1994 TK\#4 & & 1987 & -0.2 & -6.9 & Oil \\
\hline SJ 2008 TK \#6 & & $1987^{1}$ & -1.3 & -14.6 & Oil \\
\hline
\end{tabular}


Table 2

\begin{tabular}{|c|c|c|c|c|}
\hline SAMPLE & Month & Year & $0-18$ & DELTAD CATEGORY \\
\hline Rain water \#1 & 8-Jun! & 1987 & -2.3 & -5.6 Rain \\
\hline Rain water \#2 & 8-Jun: & 1987 & -1.4 & -7.8 Rain \\
\hline Service Shaft Sump & 20-Dec & 1985 & -3.2 & -19.4 Service Shaft \\
\hline Service Shaft Sump & 23-Dec! & 1985 & -3.5 & -24.3 Service Shaft \\
\hline Service Shaft Sump & 30-Dec! & 1985 & -3.5 & -19.4 Service Shaft \\
\hline Wip 13 & 13-Apri & 1987 & -4.1 & -18.6 Service Shaft \\
\hline WIP 13 & 13-Apri & 1987 & & -22 Service Shaft \\
\hline WIP 13 & 13-Apr! & 1987 & & -19 ! Service Shaft \\
\hline Service Shaft & 8-Jun: & 1987 & -2.9 & -15.3 Service Shaft \\
\hline SS 1 & 13-Sep & 1989 & -3.6 & -30.2 Service Shaft \\
\hline \#6 WIP-13 & 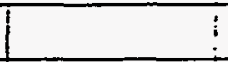 & 1989 & -2.8 & -19.7 Service Shaft \\
\hline Service Shaft Trap \#1 & 19-Apr: & 1990 & -2.9 & -22 Service Shaft \\
\hline Wip-37 & 17-Oct: & 1993 & -4.4 & -21 Service Shaft \\
\hline Wip-38 & 17-Oct. & 1993 & -4.2 & -22 Service Shaft \\
\hline Service Shaft Seep 1 & 28-Mar: & 1994 & -1.2 & -17 Service Shaft \\
\hline Wip-37 & 28-Mar: & 1994 & -4.2 & -19 Service Shaft \\
\hline Chemical Slip & 27-May & 1987 & -2.5 & -15.4 ! Surface \\
\hline SW Markel Pond & 27-May & 1987 & -0.5 & -6.5 Surface \\
\hline Plantation Lake & 27-May & 1987 & 0.4 & -2.3 Surface \\
\hline Fire Pond & 27-May & 1987 & -0.6 & -7.5 Surface \\
\hline Intercoastal Canal & 27-May & 1987 & -2.4 & -16.7 Surface \\
\hline Intercoastal Waterway & $\vdots$ & 1994: & -6.3 & -37 Surface \\
\hline Sandy Bottom Pond & 27-May: & 1987 & 0 & -5.3. Surface \\
\hline Dairy Lake & 27-May: & 1987 & -0.5 & -7.1 Surface \\
\hline Bay Sample & & 1987 & -2.3 & $-13.8:$ Surface \\
\hline \#1 MLV-9 & May & 1989 & -4.4 & -26.3; Surface \\
\hline \#3 MLV-13 & $\vdots$ & 1989 & -6 & -41.9: Surface \\
\hline \#4 St. James & & 1989 & -6 & -41.9 Surface \\
\hline \#2 MLV-9 & & 1989 & -3.8 & -22.3 ! Surface \\
\hline$\# 5$ MLV-6 & & 1989 & -4.2 & -25.8 Surface \\
\hline Pipeline W-levee & 7-Aug: & 1990 & -5.5 & -34 Surface \\
\hline Pipeline Row-Belle R & 7-Aug: & 1990 & -3.5 & -23.1 Surface \\
\hline Pipeline Row-Bayou Lafouch & 7-Aug: & 1990 & -6.1 & -41.5 Surface \\
\hline Pipeline Row-Miss. R. St. Jam! & 7-Aug: & 1990 & -6.2 & $-39.8 \mid$ Surface \\
\hline Pipeline Row-Bayou Tech & 19-Sep & 1990 & -4.9 & -30.1 Surface \\
\hline Weeks Bay & & 1994 & -4.7 & -26 Surface \\
\hline \multirow[t]{3}{*}{ Bayou Warehouse, Wks Island } & & 1994 & -3.9 & $-23 \cdot$ Surface \\
\hline & & & & $\therefore$ \\
\hline & & & & $\vdots$ \\
\hline Salt Mine, 1979 & & 1979 & 9.5 & -10.2 Old Mine \\
\hline
\end{tabular}


Table 2

\begin{tabular}{|c|c|c|c|c|}
\hline SAMPLE & Month & Year & $0-18$ & DELTA D CATEGORY \\
\hline Salt Mine, 1979 & & 1979 & 9.6 & -16.6 Old Mine \\
\hline Salt Mine, 1979 & & 1979 & 8.8. & -11.8: Old Mine \\
\hline Salt Mine, 1979 & & 1979 & 8.5 & -2.3: Old Mine \\
\hline WI-1GE Leak & & 1982 & 9.9 & -5.1 Old Mine \\
\hline Markel Incline 1 & & 1979 & -3.8 & -29.6:Markel \\
\hline Markel Incline 2 & & 1979 & -4 & -32.5:Markel \\
\hline Markel, behind bulkhead & & 1981 & -5.7 & -28.9:Markel \\
\hline Markel Pool & & 1981 & -5.1 & -30 Markel \\
\hline Markel, J. Martin sample & & 1982 & -4.2 & -26.9 Markel \\
\hline
\end{tabular}




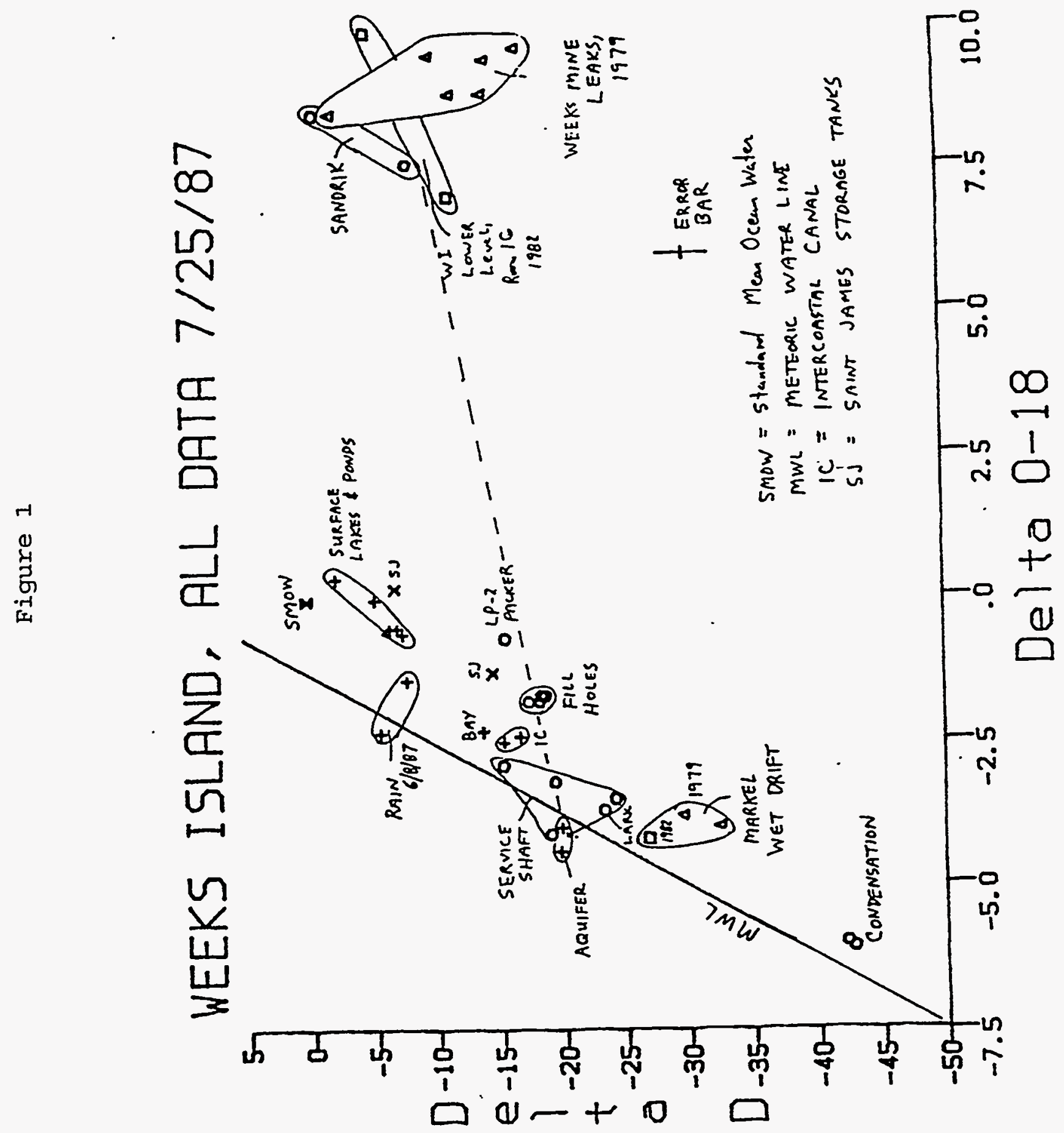




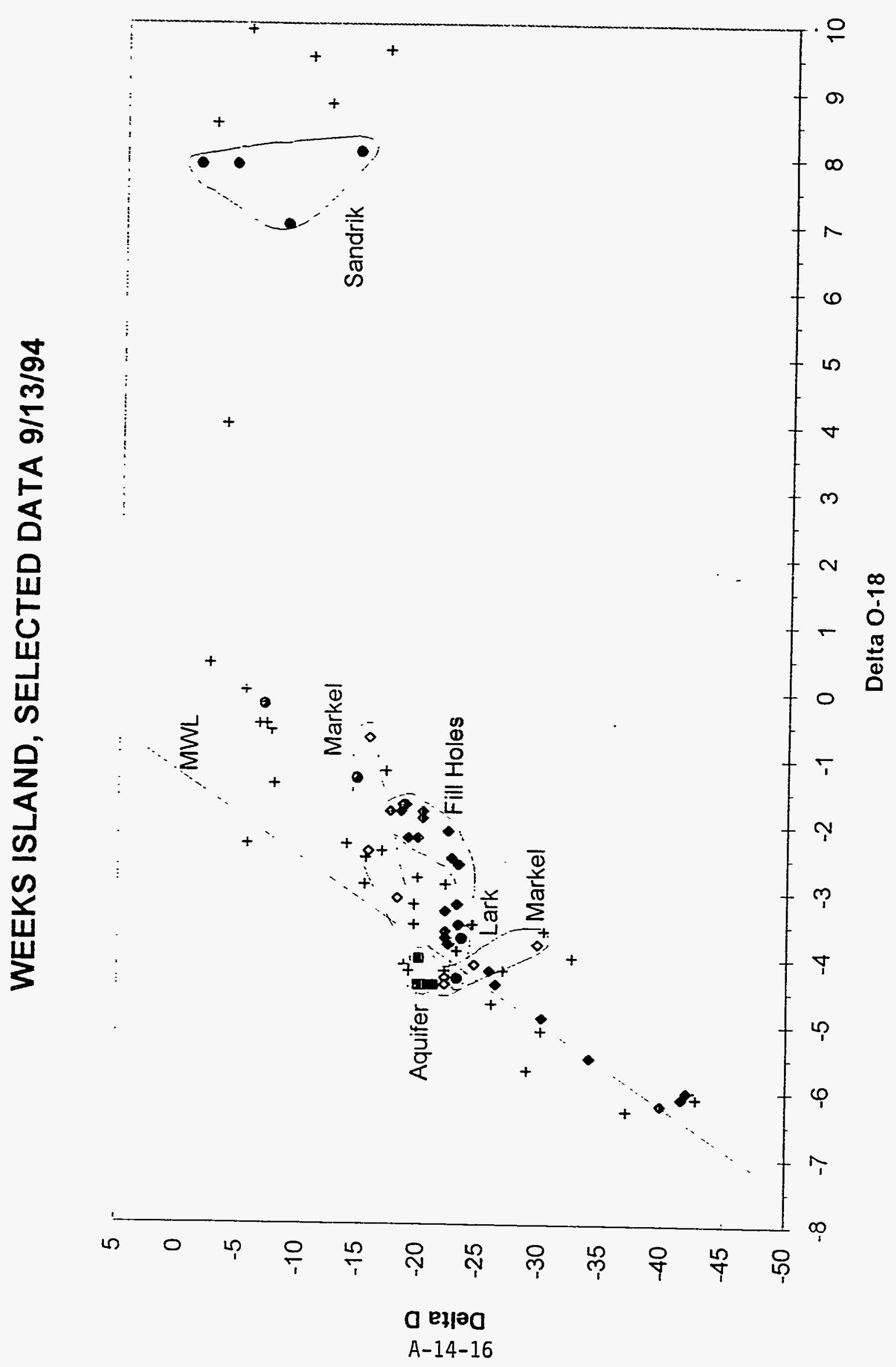




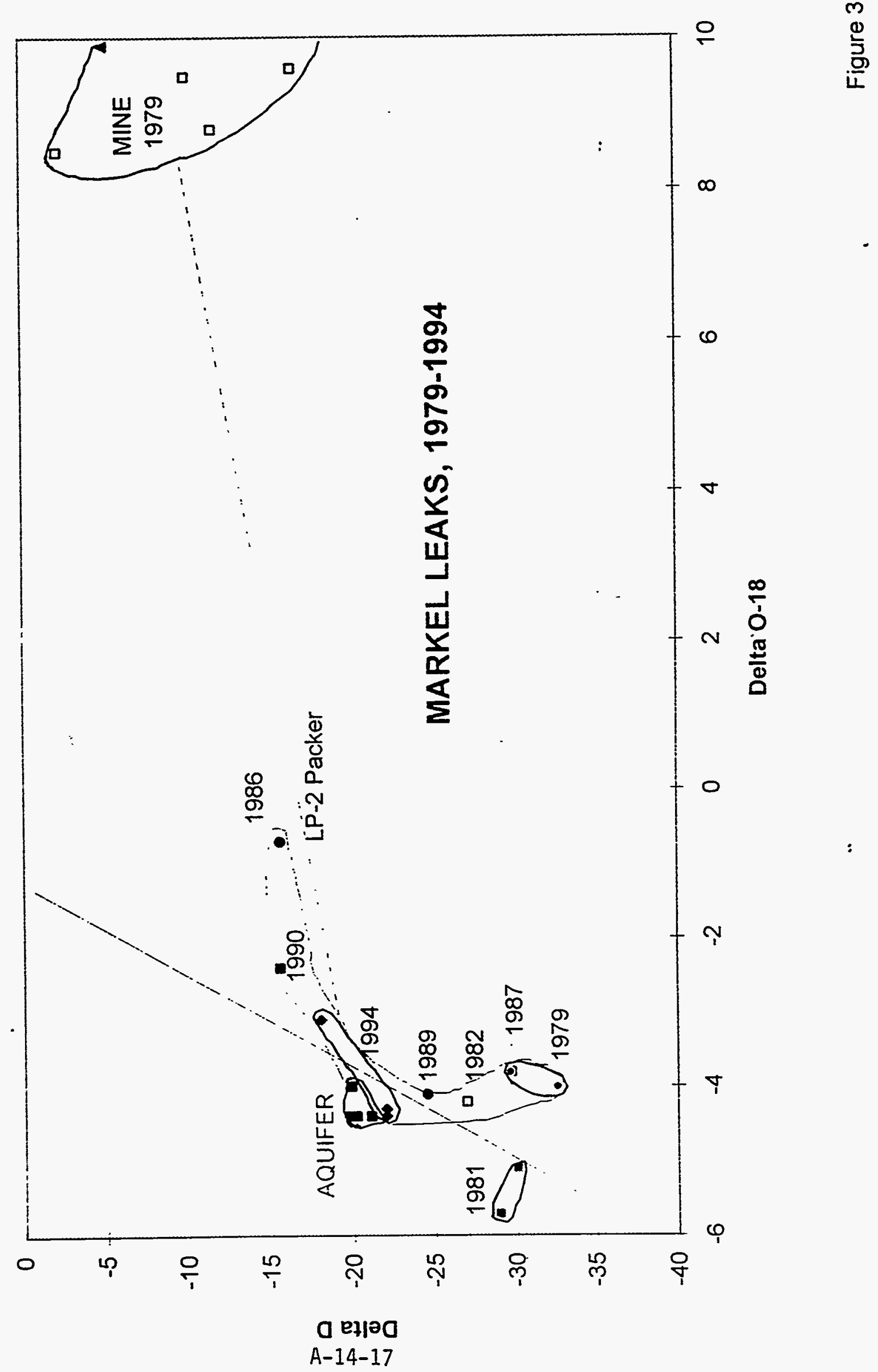




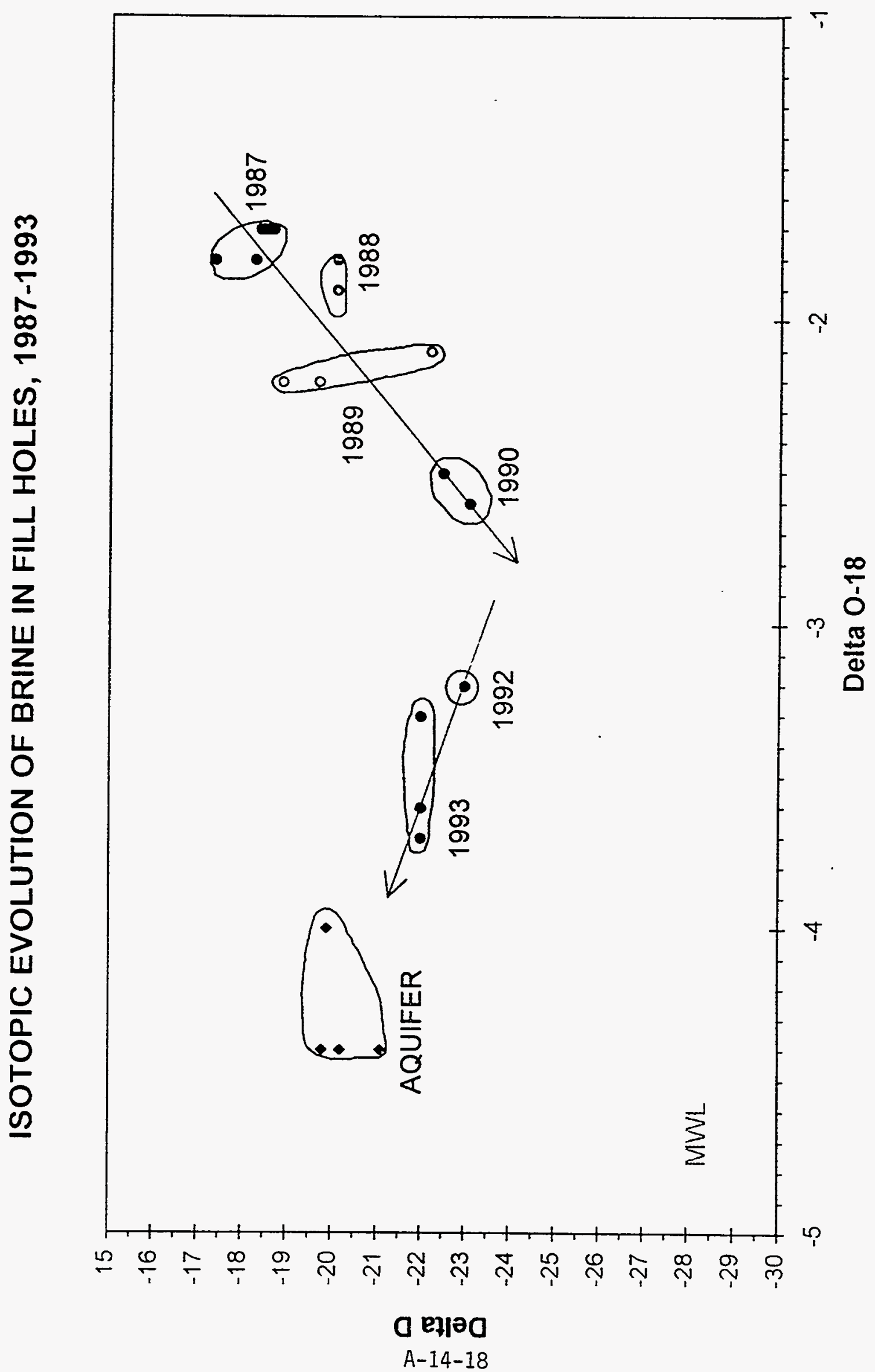




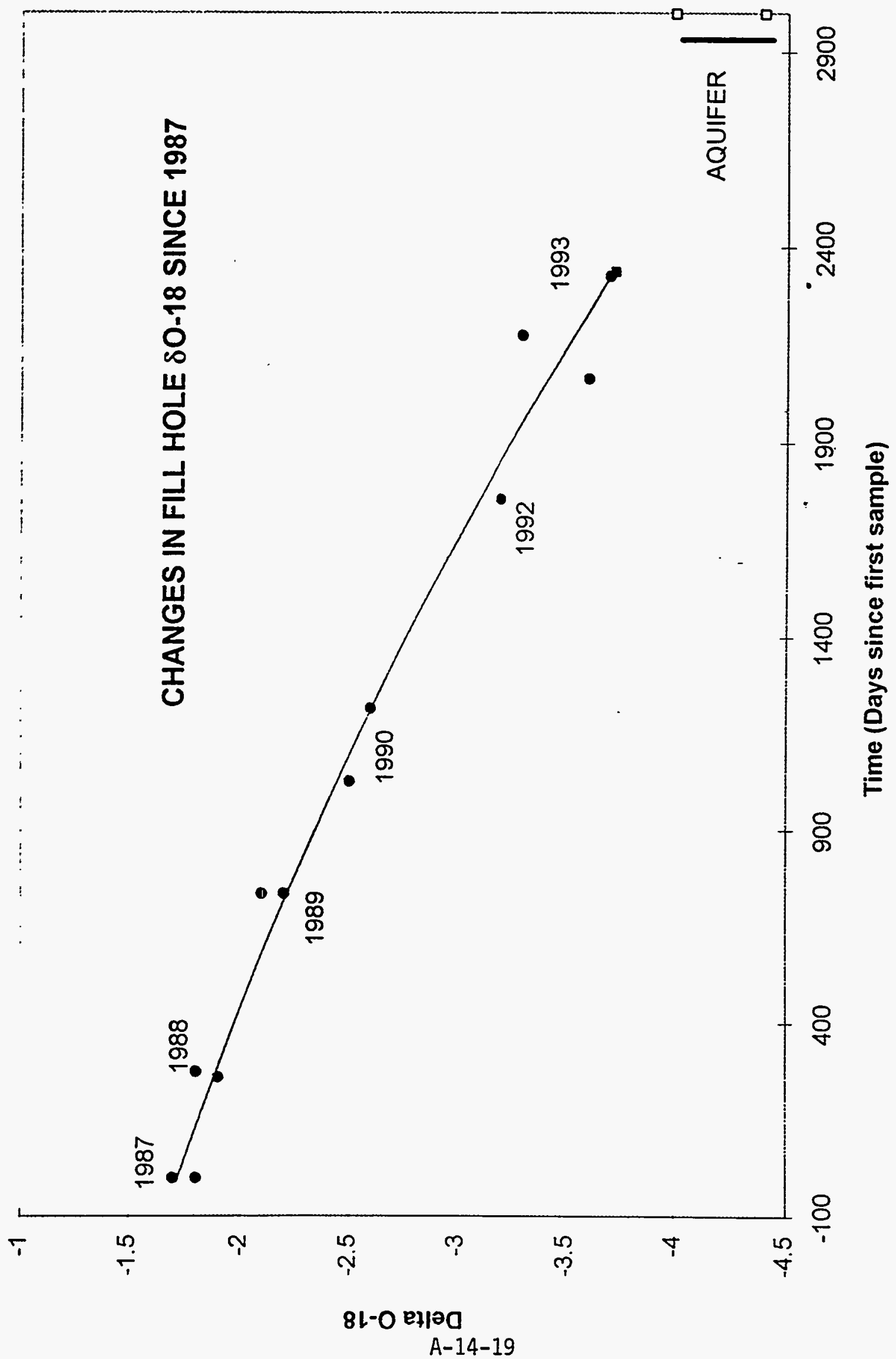

$\infty$
0
$\frac{0}{5}$
$\frac{0}{11}$ 


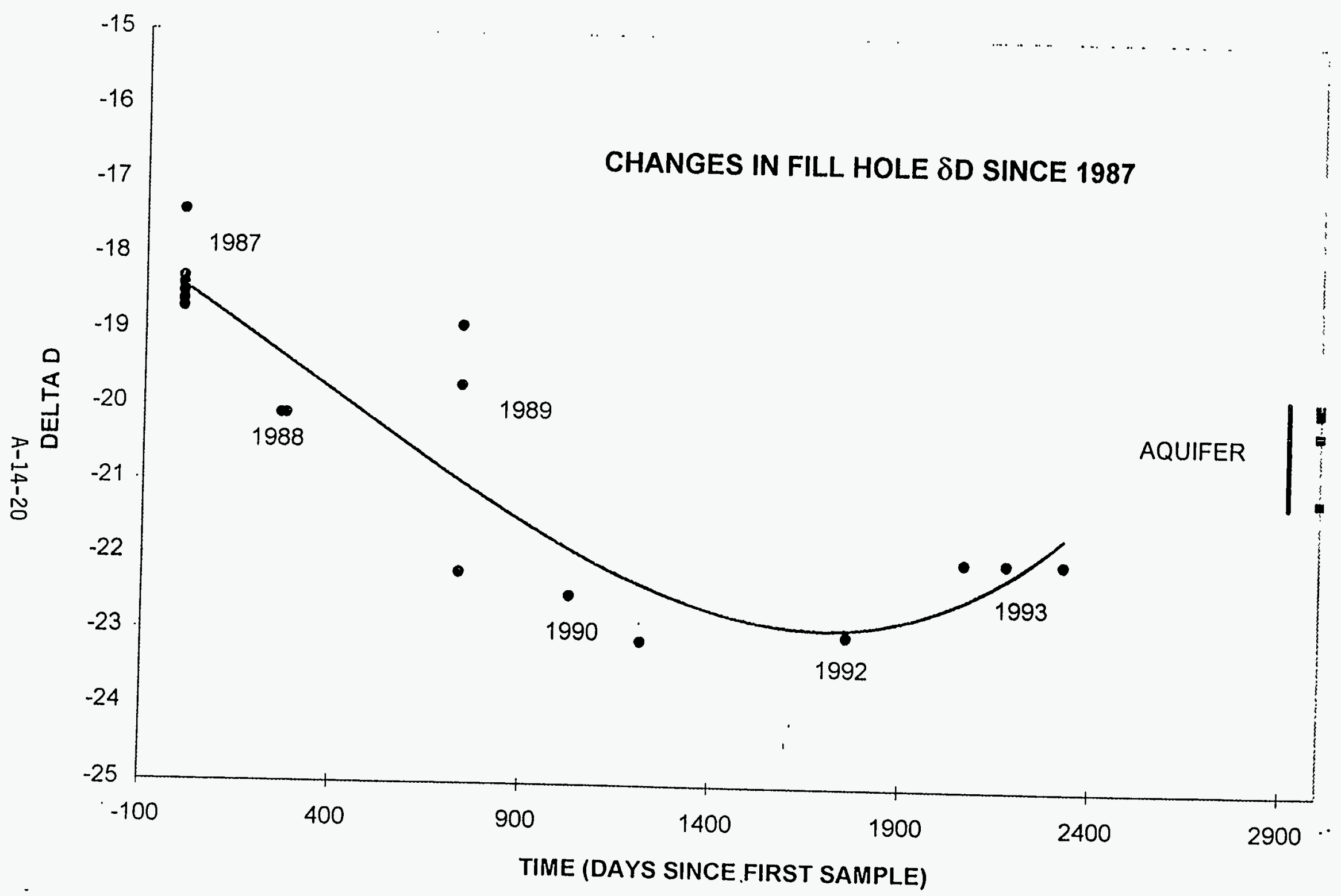




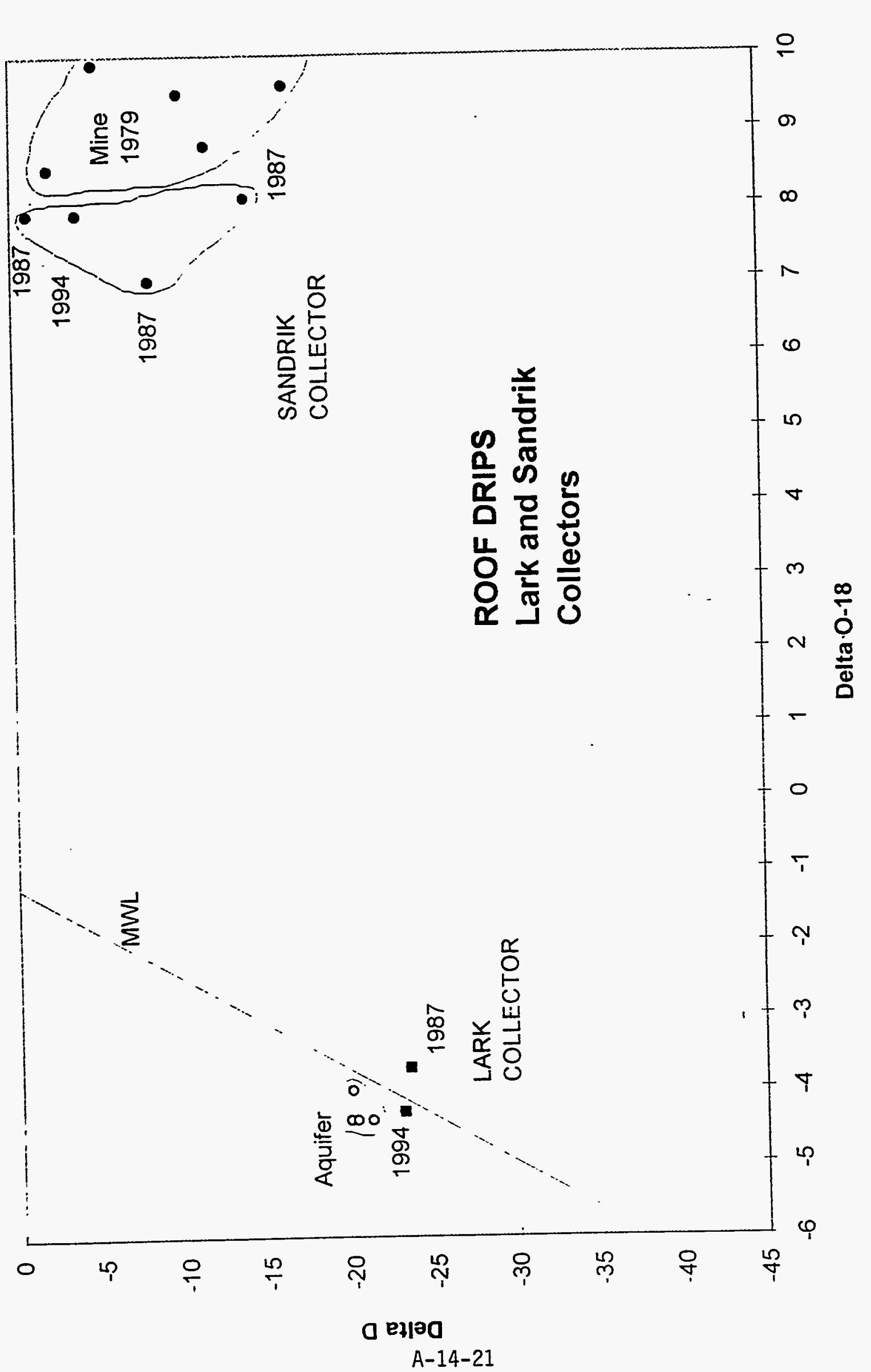

ヘ 
APPENDIX 15

BRINE INJECTION, SINKHOLE MONITORING AND BACKFILLING

A-15-1 


\section{VERTICAL DIPLACEMENT}

Differential leveling was based on a March 28 baseline. The relative elevation was assumed to be stable after allowing the monument to settle one reek after the rashing to install each segment. The general trend showed an increasing rate through July 05. A general decrease was apparent in the subsequent fall rates. This may have been partially related to 3000 gallons of a brine and dye mixture which was injected into two separate bore holes near the sink hole. Additional decreases that were measured in mid-August may also have been affected by a continuous low rate injection of saturated brine through one of the bore holes.

The brine injections may have minimized any mechanisms which may be enhancing the dissolution of salt near the top of the dome. Vertical displacement rates have fallen to near zero since late August

The following pages show the tabulated results and both the total elevation change and rate of elevation change.

\section{SINK HOLE MONITORING}

Continual quantitative monitoring of the installed monument within the sink hole located at the Weeks Island Storage Facility shows a general decrease in movement. The general decrease started mid-July and may have been enhanced by the current brine injection at Bore Hole 7a. The brine injection initiated August 05.

The monitored monument is an installed length of one-inch pipe within a two-inch casing. Both are steel with coupled joints. The installation was concluded after the backfiling of the sink hole and monitoring has been continuous since March 28. The monitoring includes horizontal chaining and differential leveling on a weekly basis.

The following data is the summary of the collected information. The mos current data suggests the vertical movement component within the sink hole has decreased. A corresponding decrease in horizontal displacement is also erident.

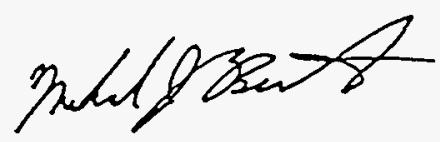


SINK HOLE MONUMENT

SUMMARY-RATE OF ELEVATION CHANGE

\begin{tabular}{|c|c|c|c|c|c|c|c|}
\hline Date & $\begin{array}{l}\text { Average } \\
\text { Elev. Change }\end{array}$ & $\begin{array}{l}\text { Rate ft/day } \\
1 \text { pipe }\end{array}$ & Casing & $\begin{array}{l}\text { Ref. Elevic } \\
1 \text { plpes }\end{array}$ & $\begin{array}{l}\text { hange } \\
2^{2} \text { Casing }\end{array}$ & $\begin{array}{l}\text { Net Chan } \\
1 \text { Pipe }\end{array}$ & 2 Casing \\
\hline 28-Mar-94 & & & & 0.00 & 0.00 & & \\
\hline 01-Apr-94 & -0.21 & -0.21 & -0.21 & -0.84 & -0.84 & -0.84 & -0.84 \\
\hline 04-Apr-94 & -0.26 & -0.32 & & -0.96 & -0.96 & -1.80 & -1.80 \\
\hline 11-Apr-94 & -0.23 & -0.21 & & -1.45 & -1.45 & -3.25 & -3.25 \\
\hline 18-Apr-94 & -0.21 & -0.18 & -0.18 & -1.25 & -1.25 & -4.50 & -4.50 \\
\hline 25-Apr-94 & -0.28 & -0.49 & -0.34 & -3.44 & -2.41 & -7.94 & -6.91 \\
\hline 27-Apr-94 & -0.29 & -0.40 & -0.32 & -0.80 & -0.64 & -8.74 & -7.55 \\
\hline 03-May-94 & -0.32 & -0.44 & -0.30 & -2.62 & -1.80 & -11.36 & -9.35 \\
\hline 06-May-94 & -0.33 & -0.55 & -0.38 & -1.64 & -1.14 & -13.00 & -10.49 \\
\hline 09-May-94 & -0.34 & -0.44 & -0.35 & -1.24 & -1.05 & -14.24 & -11.54 \\
\hline 16-May-94 & -0.37 & -0.57 & -0.31 & -4.02 & -3.09 & -18.26 & -14.63 \\
\hline 23-May-94 & -0.38 & -0.47 & -0.50 & -3.26 & -3.48 & -21.52 & -18.11 \\
\hline 27-May-94 & -0.41 & -0.75 & -0.75 & -3.00 & -3.00 & -24.52 & -21.11 \\
\hline 31-May-94 & -0.40 & -0.34 & -0.33 & -1.35 & -1.33 & -25.87 & -22.44 \\
\hline 07-Jun-94 & -0.41 & -0.49 & -0.49 & -2.96 & -2.96 & -28.83 & -25.40 \\
\hline 09-Jun-94 & -0.41 & -0.40 & -0.40 & -1.21 & -1.19 & -30.04 & -26.59 \\
\hline 13-Jun-94 & -0.42 & -0.54 & -0.54 & -2.17 & -2.17 & -32.21 & -28.76 \\
\hline 20-Jun-94 & -0.43 & -0.50 & -0.50 & -3.53 & -3.53 & -35.74 & -32.29 \\
\hline 27-Jun-94 & -0.44 & -0.65 & -0.65 & -4.58 & -4.58 & -40.32 & -36.87 \\
\hline 30-Jun-94 & -0.43 & -0.10 & -0.10 & -0.30 & -0.31 & -40.62 & -37.18 \\
\hline 05-Jul-94 & -0.44 & -0.60 & -0.65 & -3.02 & -3.24 & -43.64 & -40.42 \\
\hline $11-J u l-94$ & -0.44 & -0.35 & -0.36 & -2.08 & -2.16 & -45.72 & -42.58 \\
\hline 18-Jul-94 & -0.43 & -0.37 & -0.38 & -2.60 & -2.69 & -48.32 & -45.27 \\
\hline 25-Jul-94 & -0.43 & -0.36 & -0.37 & -2.54 & -2.57 & -50.86 & -47.84 \\
\hline 01-Aug-94 & -0.43 & -0.47 & -0.21 & -3.30 & -1.44 & -54.16 & -49.28 \\
\hline 08-Aug-94 & -0.42 & -0.31 & -0.18 & -2.19 & -1.26 & -56.35 & -50.54 \\
\hline 15-Aug-94 & -0.41 & -0.22 & -0.18 & -1.52 & -1.23 & -57.87 & -51.77 \\
\hline 22-Aug-94 & -0.40 & -0.10 & -0.06 & -0.68 & -0.43 & -58.55 & -52.20 \\
\hline 29-Aug-94 & -0.38 & -0.02 & 0.00 & -0.11 & 0.02 & -58.66 & -52.18 \\
\hline $06-$ Sep-94 & -0.36 & -0.02 & -0.02 & -0.19 & -0.17 & -58.85 & -52.35 \\
\hline
\end{tabular}




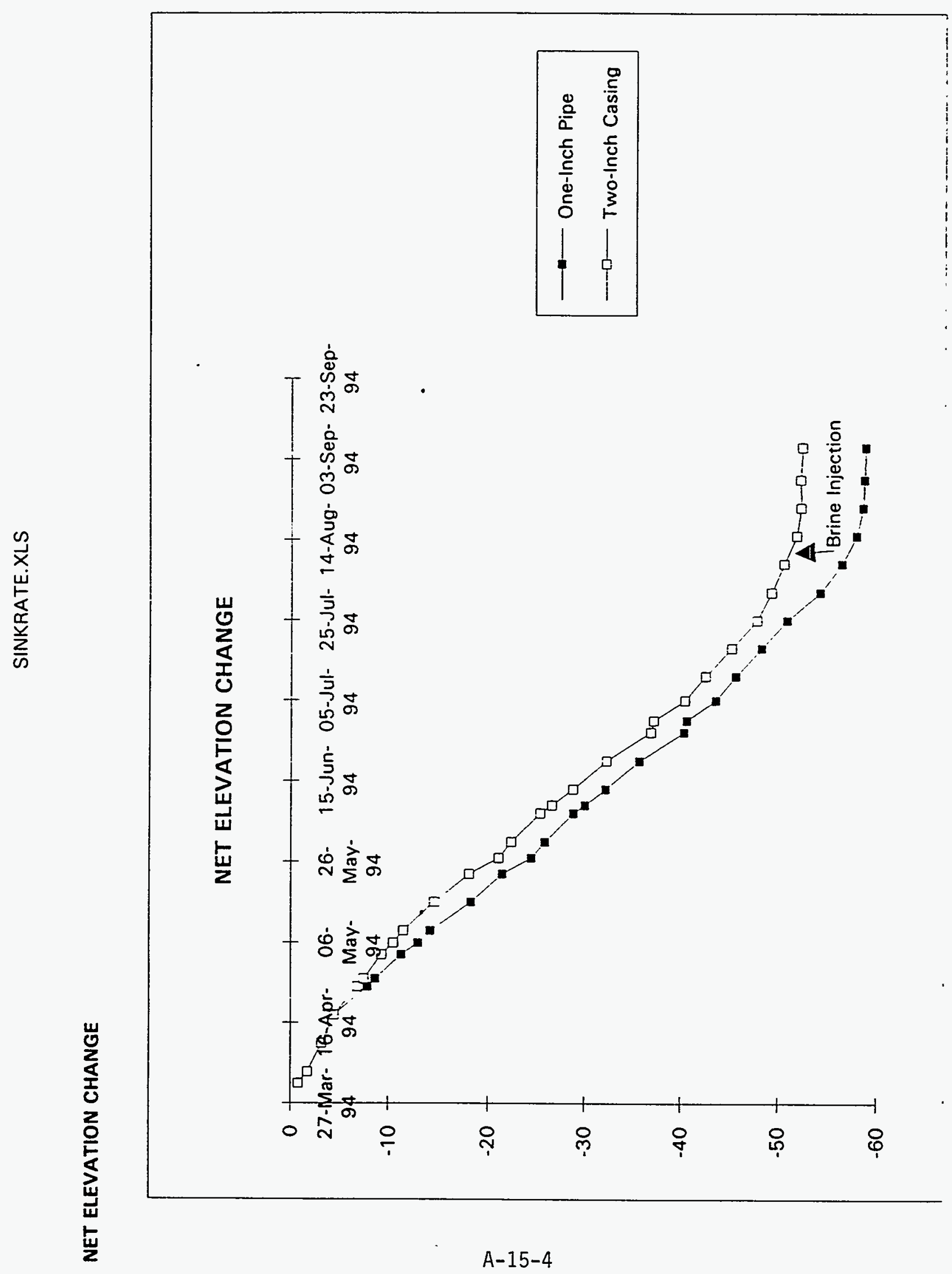




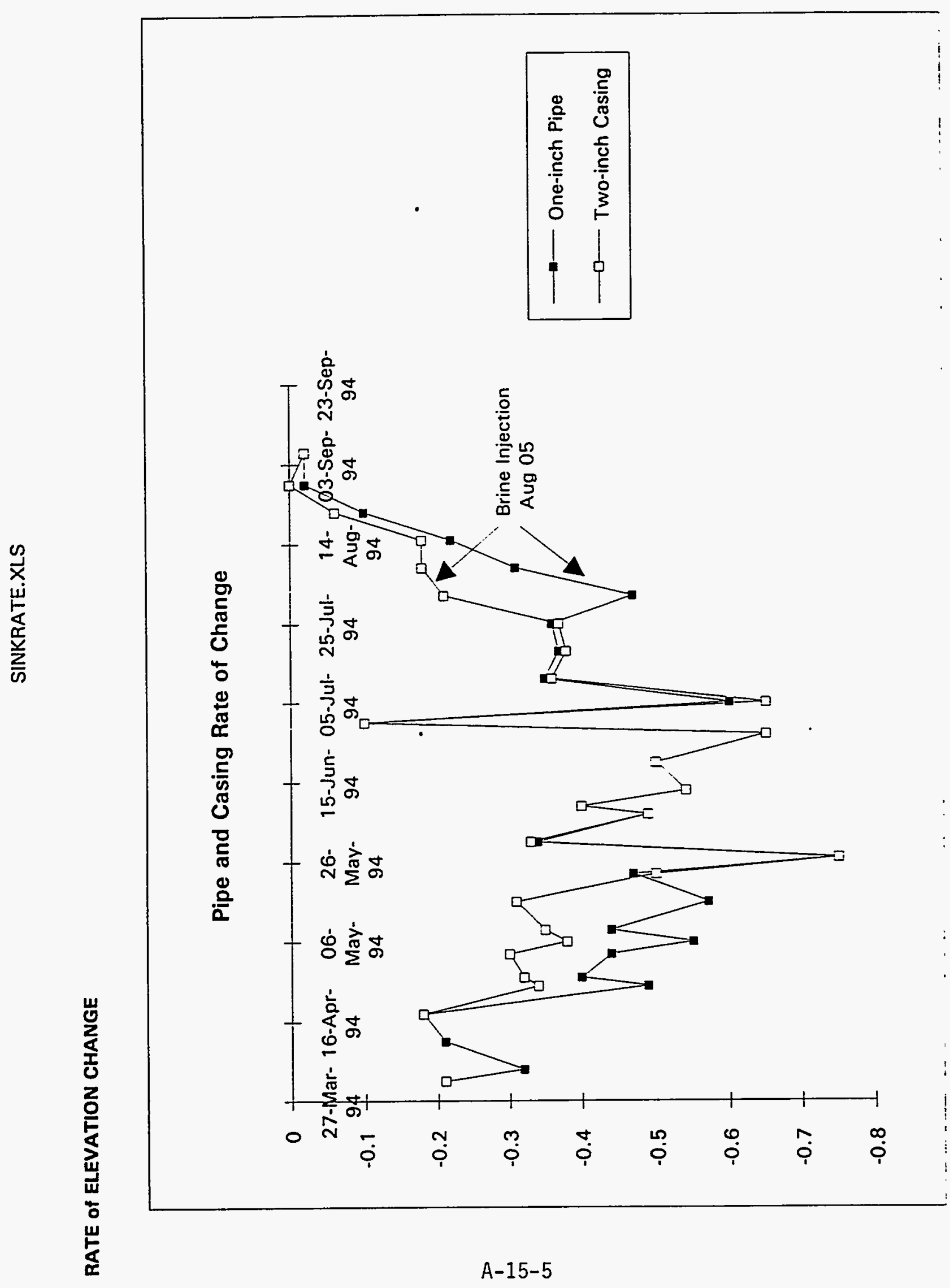

吕 


\section{DEPTH of MONUMENT}

The relative vertical change of the monument may be related to the elevation of the lowest portions of both the one-inch pipe and two-inch casing. External factors such as precipitation should be minimized as the depth of the monument has increased. The general trend shows the two segments have declined at the same approximate elevation until August 01 . The one-inch pipe showed a significant change from the near elevation of the bottom of the casing. The differential drop continued throughout August 15. Only one other period late April and early May had an unusual difference between the segments. 


\section{MONUMENT ELEVATION - DEPTH}

Note: The $\mathbf{1 5 . 6}$ fixed refernce discrepancy was applied to calculate true elevation.

\begin{tabular}{|c|c|c|c|c|}
\hline & Ref. Elev. C & hange & Elevation-D & epth \\
\hline Date & 1" Pipe & $2^{n}$ Casing & 1" Pipe & 2" Casing \\
\hline 28-Mar-94 & 0.00 & 0.00 & 51.73 & 48.70 \\
\hline 01-Apr-94 & .0 .84 & -0.84 & 50.89 & 47.86 \\
\hline 04-Apr-94 & -0.96 & -0.96 & 49.93 & 46.90 \\
\hline 11-Apr-94 & -1.45 & -1.45 & 48.48 & 45.45 \\
\hline 18-Apr-94 & -1.25 & -1.25 & 47.23 & 44.20 \\
\hline 25-Apr-94 & -3.44 & -2.41 & 43.79 & 41.79 \\
\hline 27-Apr-94 & -0.80 & -0.64 & 42.99 & 41.15 \\
\hline 03-May-94 & -2.62 & -1.80 & 40.37 & 39.35 \\
\hline 06-Мay-94 & -1.64 & -1.14 & 38.73 & 38.21 \\
\hline 09-May-94 & -1.24 & -1.05 & 37.49 & 37.16 \\
\hline 16-May-94 & -4.02 & -3.09 & 33.47 & 34.07 \\
\hline 23-May-94 & -3.26 & -3.48 & 30.21 & 30.59 \\
\hline 27-May-94 & -3.00 & -3.00 & 27.21 & 27.59 \\
\hline 31-May-94 & -1.35 & -1.33 & 25.86 & 26.26 \\
\hline 07-Jun-94 & -2.96 & -2.96 & 22.90 & 23.30 \\
\hline 09-Jun-94 & -1.21 & -1.19 & 21.69 & 22.11 \\
\hline 13-Jun-94 & -2.17 & -2.17 & 19.52 & 19.94 \\
\hline 20-Jun-94 & -3.53 & -3.53 & 15.99 & 16.41 \\
\hline 27-Jun-94 & -4.58 & -4.58 & 11.41 & 11.83 \\
\hline 30-Jun-94 & -0.30 & -0.31 & 11.11 & 11.52 \\
\hline 05-Jul-94 & -3.02 & -3.24 & 8.09 & 8.28 \\
\hline 11-Jul-94 & -2.08 & -2.16 & 6.01 & 6.12 \\
\hline 18-Jul-94 & -2.60 & -2.69 & 3.41 & 3.43 \\
\hline 25-Jul-94 & -2.54 & -2.57 & 0.87 & 0.86 \\
\hline 01-Aug-94 & -3.30 & -1.44 & -2.43 & -0.58 \\
\hline 08-Aug-94 & -2.19 & -1.26 & -4.62 & -1.84 \\
\hline 15-Aug-94 & -1.52 & -1.23 & -6.14 & -3.07 \\
\hline 22-Aug-94 & -0.68 & -0.43 & -6.82 & -3.50 \\
\hline 29-Aug-94 & -0.11 & 0.02 & -6.93 & -3.48 \\
\hline 06-Sep-94 & -0.19 & -0.17 & -7.12 & -3.65 \\
\hline
\end{tabular}

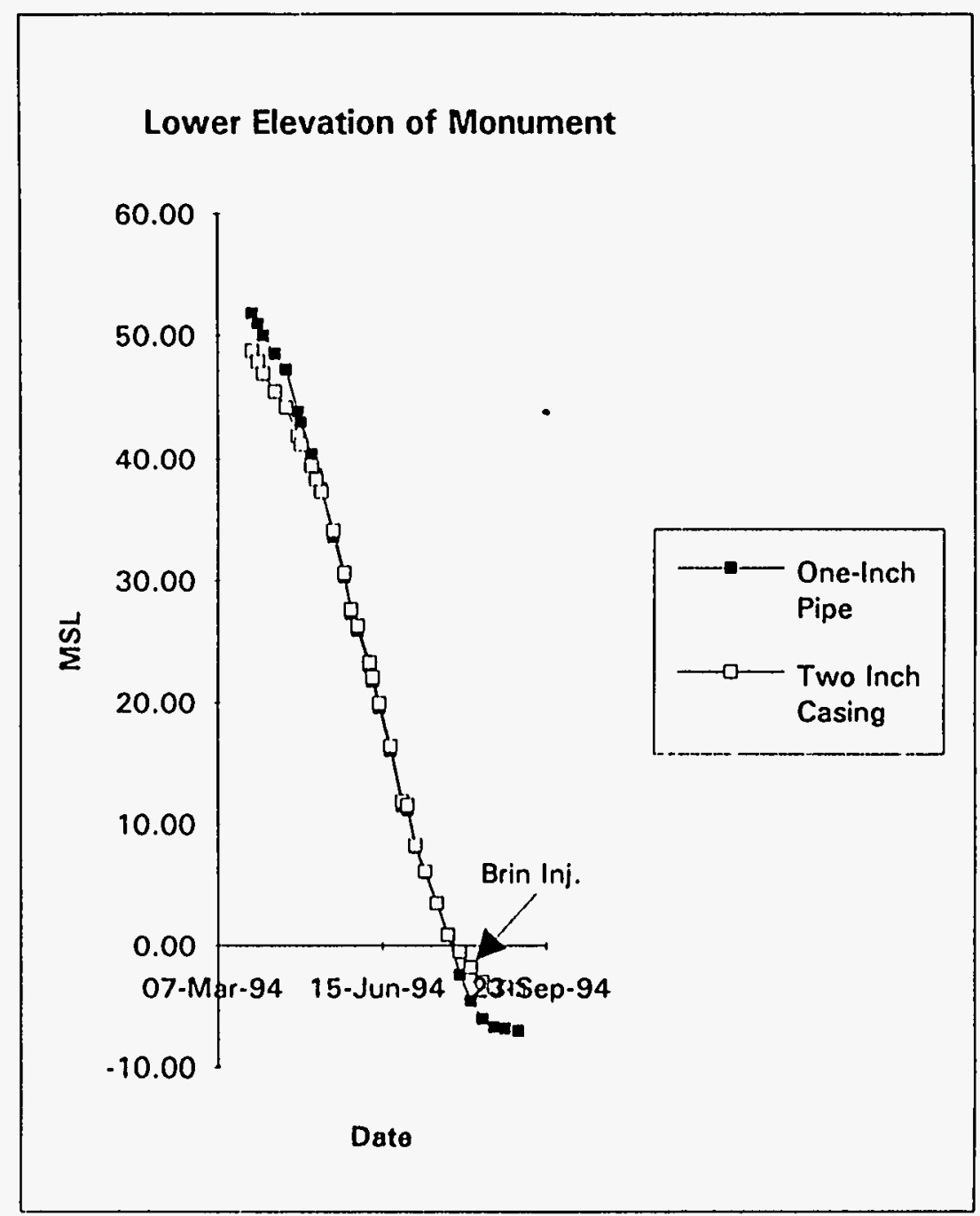




\section{HORIZONTAL CHAINING}

Fixed reference chaining of the monument was initiated to evaluate any type of lateral displacement of the monument. Chaining has been affected by several external problems related to the disturbance of three of the fixed monuments near the sink hole. The southeast monument was disturbed during the backfiring operation, but the current location was used as a fixed reference. The northwest monument was hit by a fork lift during the Sandia drilling operation on June 09 . The tilted position is being used as a new fixed reference. The northeast monument was destroyed by Morton brush hogging on Sept. 06.

The general trends of the horizontal displacement reflect the changes in vertical displacement. The following information depicts the changes and rates for each horizontal dimension. 


\section{SINK HOLE MONUMENT \\ DIMENSIONAL MONITORING - Northwest Dimension}

Chain Distance to Monument

\begin{tabular}{|c|c|}
\hline DATE & Feet \\
\hline 21-Mar-94 & 20.40 \\
\hline 28-Mar-94 & 20.58 \\
\hline 25-Apr-94 & 22.23 \\
\hline $27-A p r-94$ & 22.23 \\
\hline 03-May-94 & 22.23 \\
\hline 09-May-94 & 23.13 \\
\hline 16-May-94 & 23.31 \\
\hline 23-May-94 & 23.56 \\
\hline 31-May-94 & 24.08 \\
\hline 09-Jun-94 & 24.40 \\
\hline 13-Jun-94 & 24.55 \\
\hline 20-Jun-94 & 25.04 \\
\hline 27-Jun-94 & 25.73 \\
\hline $05-J u l-94$ & 27.04 \\
\hline 11-Jul-94 & 27.18 \\
\hline 18-Jul-94 & 27.83 \\
\hline $25-J u l-94$ & 27.75 \\
\hline $01-$ Aug-94 & 27.98 \\
\hline 08-Aug-94 & 27.83 \\
\hline 15-Aug-94 & 27.91 \\
\hline 22-Aug-94 & 27.98 \\
\hline 29-Aug-94 & 27.92 \\
\hline 06-Sep-94 & 28.21 \\
\hline
\end{tabular}

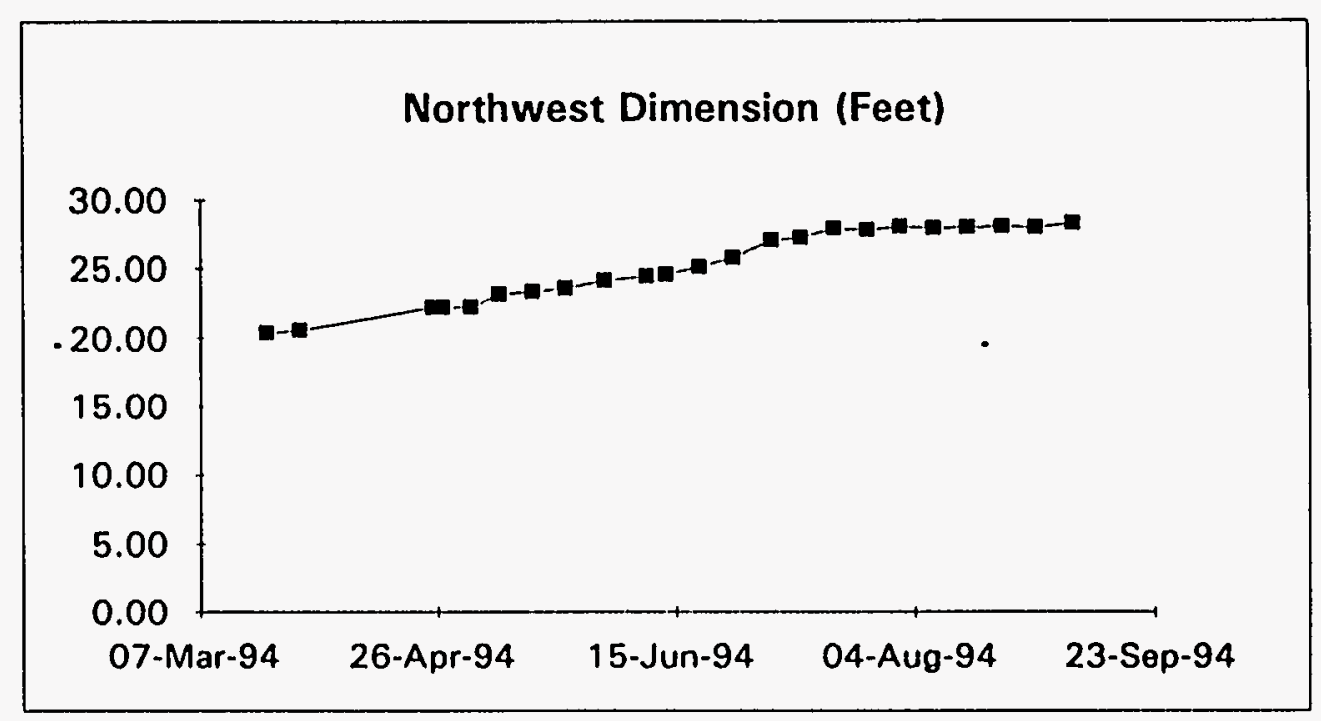

June 09th, NW monument disturbed by drilling operation. 
SINK HOLE MONUMENT

DIMENSIONAL MONITORING - Northwest Dimension Daily Rate

Chain Distance to Monument

\begin{tabular}{|c|c|}
\hline & Feet/Day \\
\hline 21-Mar-94 & \\
\hline 28-Mar-94 & 0.03 \\
\hline 25-Apr-94 & 0.06 \\
\hline 27-Apr-94 & 0.00 \\
\hline 03-May-94 & 0.00 \\
\hline 09-May-94 & 0.15 \\
\hline 16-May-94 & 0.03 \\
\hline 23-May-94 & 0.04 \\
\hline 31-Маy-94 & 0.06 \\
\hline 09-Jun-94 & 0.04 \\
\hline 13-Jun-94 & 0.04 \\
\hline 20-Jun-94 & 0.07 \\
\hline 27-Jun-94 & 0.10 \\
\hline 05-Jul-94 & 0.16 \\
\hline $11-J u l-94$ & 0.02 \\
\hline 18-Jul-94 & 0.09 \\
\hline 25-Jul-94 & -0.01 \\
\hline $01-A u g-94$ & 0.03 \\
\hline 08-Aug-94 & -0.02 \\
\hline 15-Aug-94 & 0.01 \\
\hline 22-Aug-94 & 0.01 \\
\hline 29-Aug-94 & -0.01 \\
\hline 06-Sep-94 & 0.04 \\
\hline
\end{tabular}

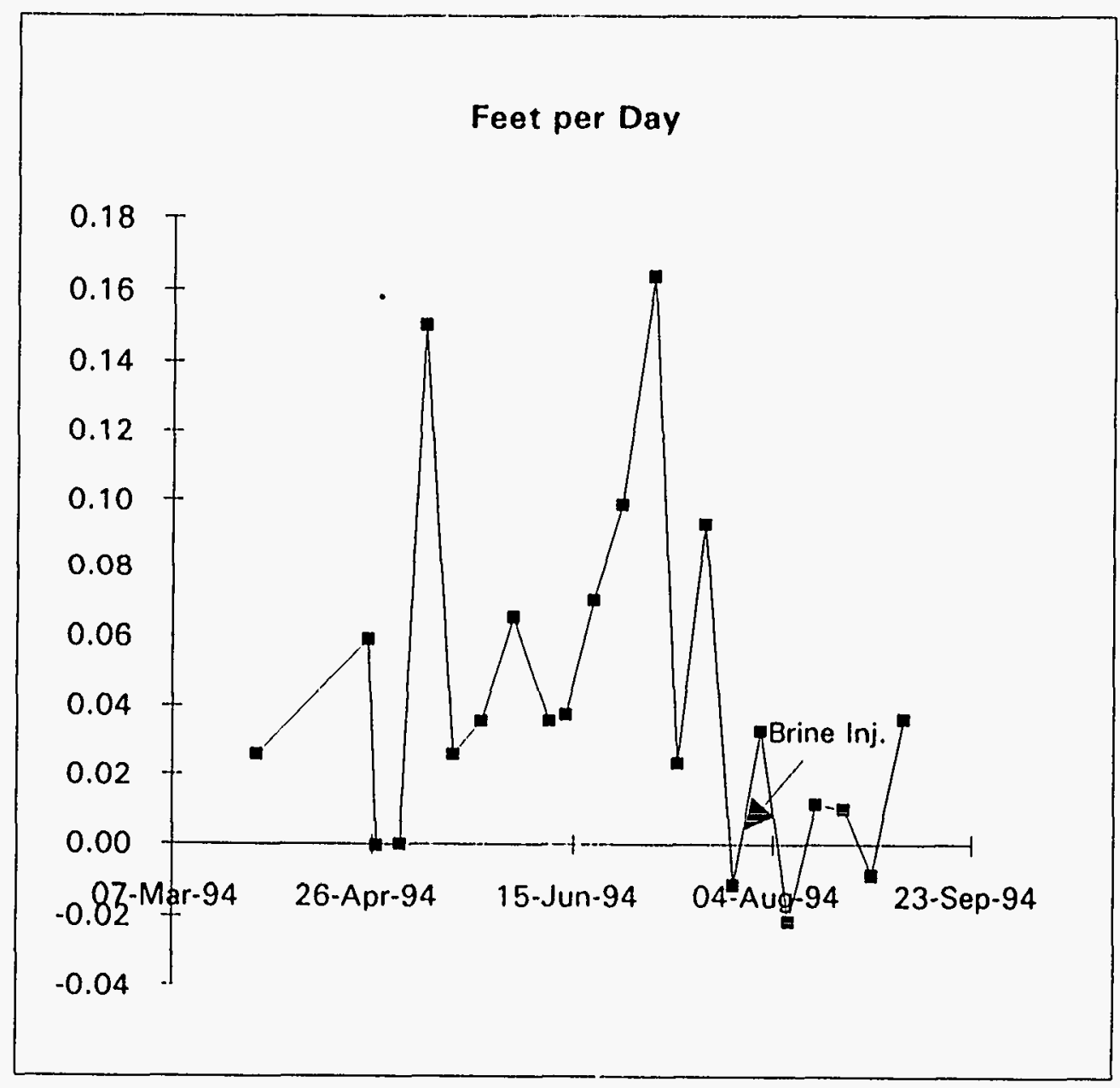


SINKNE.XLS

\section{SINK HOLE MONUMENT \\ DIMENSIONAL MONITORING - Northeast Dimension}

\begin{tabular}{|c|c|}
\hline \multicolumn{2}{|c|}{ Chain Distance to Monument } \\
\hline DATE & Feet \\
\hline 21-Mar-94 & 25.81 \\
\hline 28-Mar-94 & 25.91 \\
\hline 25-Apr-94 & 26.04 \\
\hline 27-Apr-94 & 26.04 \\
\hline 03-May-94 & 26.20 \\
\hline 09-May-94 & 26.54 \\
\hline 16-May-94 & 26.74 \\
\hline 23-May-94 & 27.11 \\
\hline 31-May-94 & 27.72 \\
\hline 09-Jun-94 & 28.58 \\
\hline 13-Jun-94 & 28.78 \\
\hline 20-Jun-94 & 29.87 \\
\hline 27-Jun-94 & 30.91 \\
\hline 05-Jul-94 & 31.85 \\
\hline 11-Jul-94 & 32.06 \\
\hline 18-Jul-94 & 32.58 \\
\hline 25-Jul-94 & 32.13 \\
\hline 01-Aug-94 & 30.98 \\
\hline 08-Aug-94 & 31.42 \\
\hline 15-Aug-94 & 31.18 \\
\hline 22-Aug-94 & 31.08 \\
\hline 29-Aug-94 & 31.06 \\
\hline
\end{tabular}

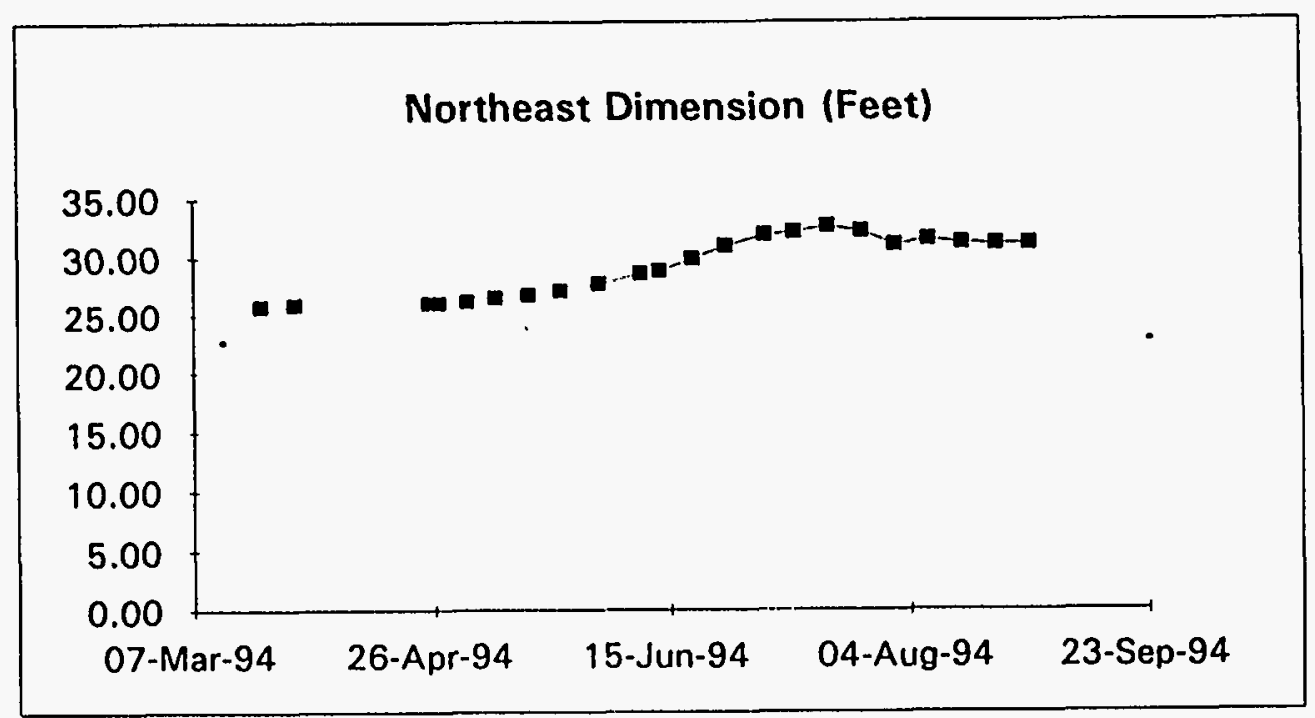

Sept 06th, NE monument destroyed by brush hog (Morton) 
SINK HOLE MONUMENT

\section{DIMENSIONAL MONITORING - Northeast Dimension Daily Rate}

Chain Distance to Monument

\begin{tabular}{|c|c|}
\hline DATE & Feet/Day \\
\hline 21-Mar-94 & \\
\hline 28-Mar-94 & 0.01 \\
\hline 25-Apr-94 & 0.00 \\
\hline 27-Apr-94 & 0.00 \\
\hline 03-May-94 & 0.03 \\
\hline 09-Мау-94 & 0.06 \\
\hline 16-Мау-94 & 0.03 \\
\hline 23-May-94 & 0.05 \\
\hline 31-May-94 & 0.08 \\
\hline 09-Jun-94 & 0.10 \\
\hline 13-Jun-94 & 0.05 \\
\hline 20-Jun-94 & 0.16 \\
\hline 27-Jun-94 & 0.15 \\
\hline 05-Jul-94 & 0.12 \\
\hline 11-Jul-94 & 0.04 \\
\hline 18-Jul-94 & 0.07 \\
\hline 25-Jul-94 & -0.06 \\
\hline 01-Aug-94 & -0.16 \\
\hline 08-Aug-94 & 0.06 \\
\hline 15-Aug-94 & -0.03 \\
\hline 22-Aug-94 & -0.01 \\
\hline 29-Aug-94 & 0.00 \\
\hline
\end{tabular}

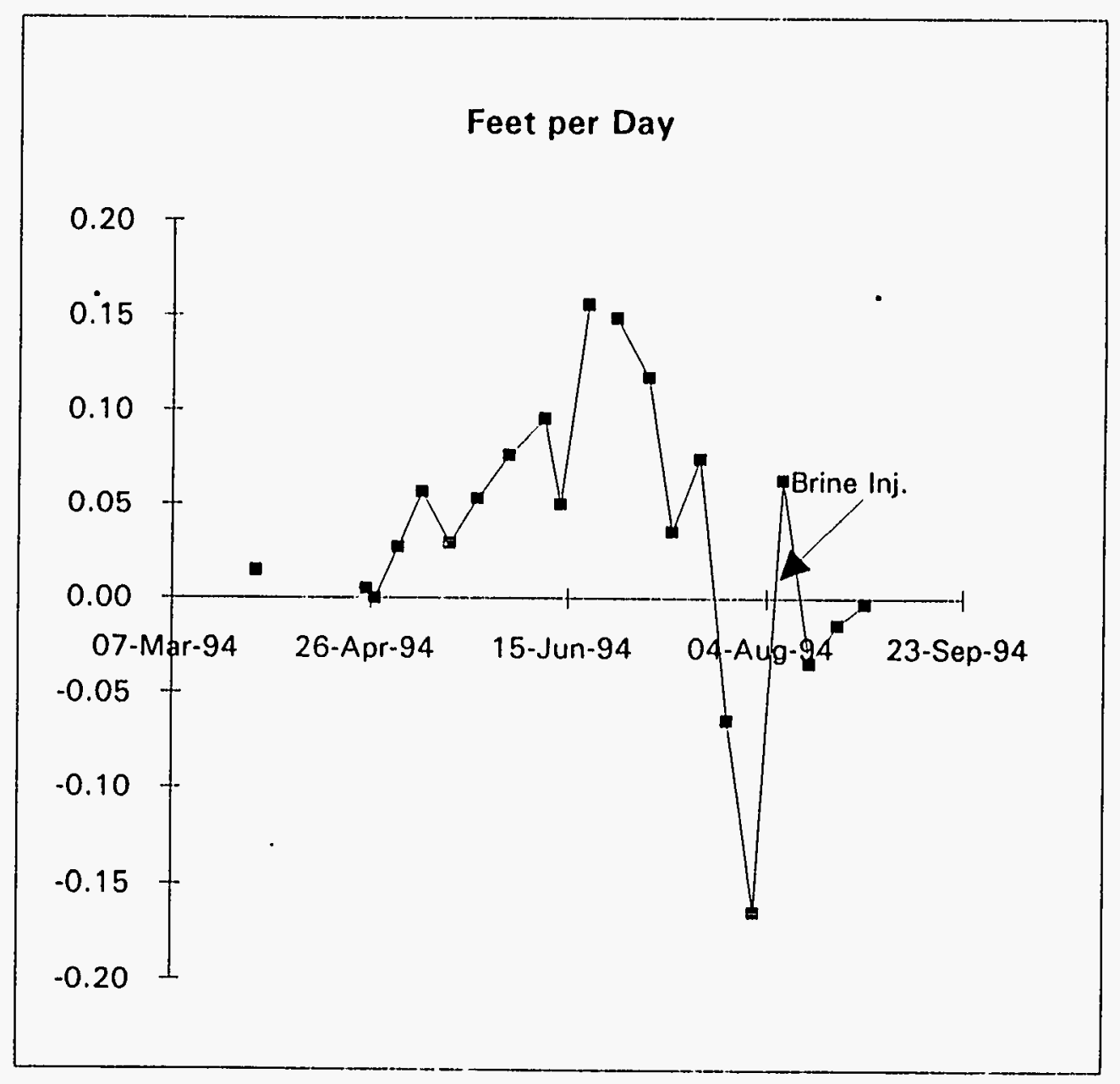




\section{SINK HOLE MONUMENT \\ DIMENSIONAL MONITORING - Southwest Dimension}

\begin{tabular}{|c|c|}
\hline $\begin{array}{c}\text { Chain Distance } \\
\text { DATE }\end{array}$ & $\begin{array}{l}\text { Monument } \\
\text { Feet }\end{array}$ \\
\hline 21-Mar-94 & 28.80 \\
\hline 28-Mar-94 & 28.71 \\
\hline 25-Apr-94 & 27.98 \\
\hline 27-Apr-94 & 27.98 \\
\hline 03-May-94 & 27.59 \\
\hline 09-May-94 & 27.44 \\
\hline 16-May-94 & 26.91 \\
\hline 23-May-94 & 26.45 \\
\hline 31-May-94 & 25.84 \\
\hline 09-Jun-94 & 25.16 \\
\hline 13-Jun-94 & 24.63 \\
\hline 20-Jun-94 & 25.04 \\
\hline 27-Jun-94 & 25.73 \\
\hline 05-Jul-94 & 21.79 \\
\hline $11-J u l-94$ & 21.62 \\
\hline 18-Jul-94 & 21.38 \\
\hline 25-Jul-94 & 21.42 \\
\hline 01-Aug-94 & 21.87 \\
\hline 08-Aug-94 & 22.10 \\
\hline 15-Aug-94 & 22.20 \\
\hline 22-Aug-94 & 22.40 \\
\hline 29-Aug-94 & 22.46 \\
\hline $06-S e p-94$ & 22.71 \\
\hline
\end{tabular}

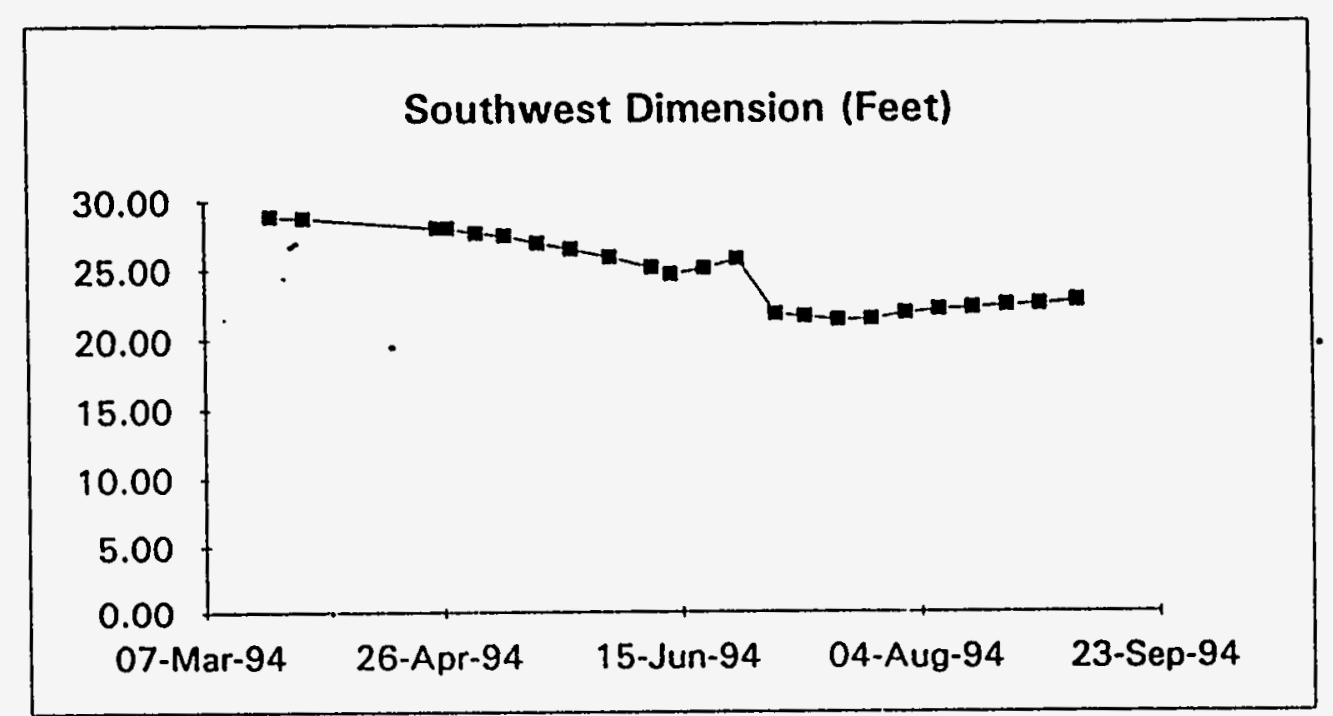




\section{SINK HOLE MONUMENT}

DIMENSIONAL MONITORING - Southwest Dimension Daily Rate

Chain Distance to Monument

\begin{tabular}{|c|c|}
\hline DATE & Feet/Day \\
\hline 21-Mar-94 & \\
\hline 28-Mar-94 & -0.01 \\
\hline 25-Apr-94 & -0.03 \\
\hline 27-Apr-94 & 0.00 \\
\hline 03-May-94 & -0.06 \\
\hline 09-May-94 & -0.02 \\
\hline 16-May-94 & -0.08 \\
\hline 23-Мay-94 & -0.07 \\
\hline 31-May-94 & -0.08 \\
\hline 09-Jun-94 & -0.08 \\
\hline 13-Jun-94 & -0.13 \\
\hline 20-Jun-94 & 0.06 \\
\hline 27-Jun-94 & 0.10 \\
\hline 05-Jul-94 & -0.49 \\
\hline $11-J u l-94$ & -0.03 \\
\hline 18-Jul-94 & -0.03 \\
\hline $25-J u 1-94$ & 0.01 \\
\hline 01-Aug-94 & 0.06 \\
\hline 08-Aug-94 & 0.03 \\
\hline 15-Aug-94 & 0.01 \\
\hline 22-Aug-94 & 0.03 \\
\hline 29-Aug-94 & 0.01 \\
\hline 06-Sep-94 & 0.03 \\
\hline
\end{tabular}

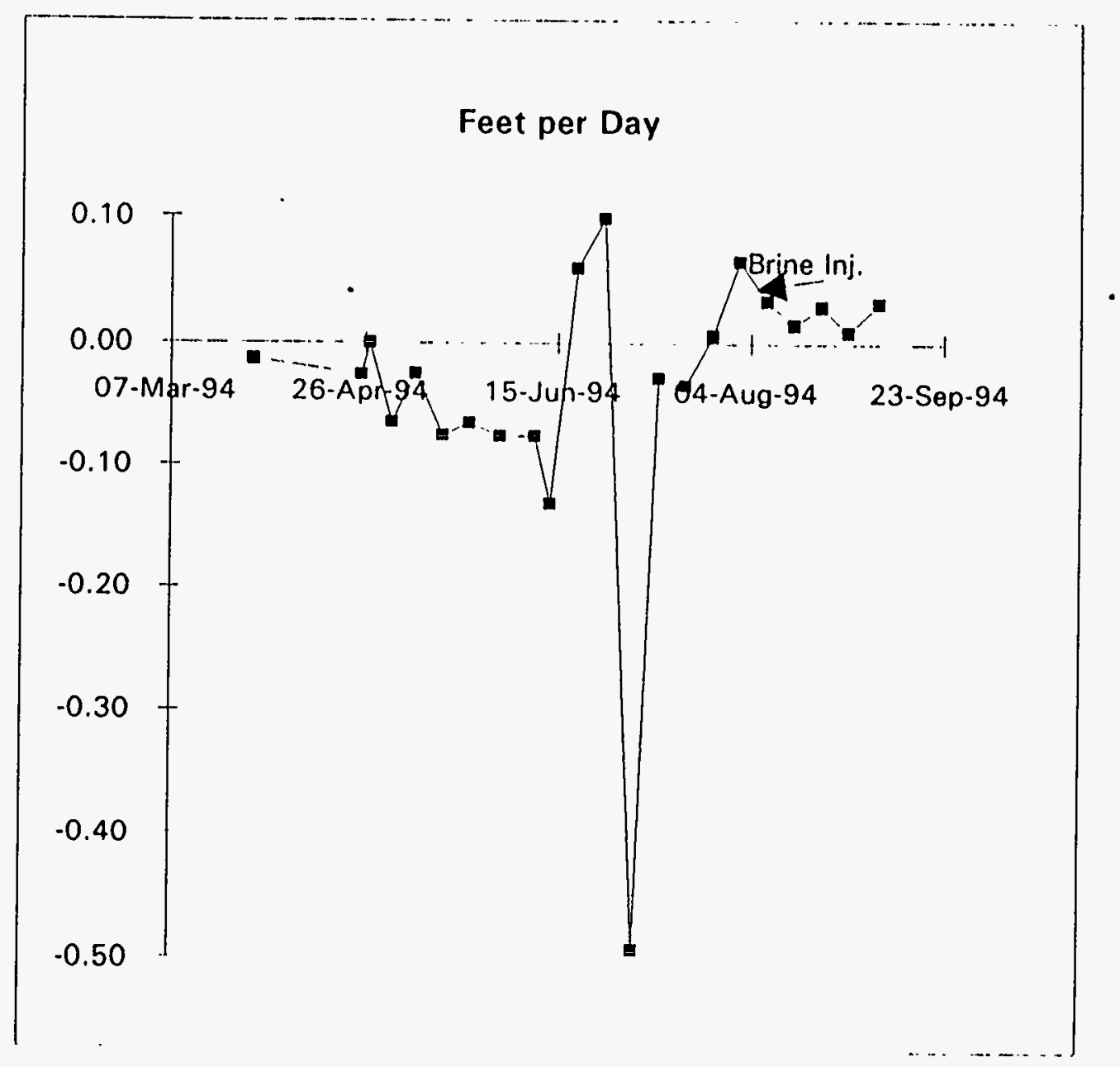


SINKSE.XLS

\section{SINK HOLE MONUMENT}

\section{DIMENSIONAL MONITORING - Southeast Dimension}

Chain Distance to Monument

\begin{tabular}{|c|c|}
\hline & Feet \\
\hline 21-Mar-94 & 26.02 \\
\hline 28-Mar-94 & 25.83 \\
\hline 25-Apr-94 & 24.08 \\
\hline 27-Apr-94 & 24.08 \\
\hline 03-Маy-94 & 23.48 \\
\hline 09-May-94 & 23.19 \\
\hline 16-Мау-94 & 22.84 \\
\hline 23-Мау-94 & 22.52 \\
\hline 31-May-94 & 21.58 \\
\hline 09-Jun-94 & 21.52 \\
\hline 13-Jun-94 & 21.26 \\
\hline 20-Jun-94 & 21.14 \\
\hline 27-Jun-94 & 20.51 \\
\hline 05-Jul-94 & 19.75 \\
\hline 11-Jul-94 & 19.54 \\
\hline 18-Jul-94 & 19.10 \\
\hline 25-Jul-94 & 18.83 \\
\hline 01-Aug-94 & 18.79 \\
\hline 08-Aug-94 & 18.33 \\
\hline 15-Aug-94 & 18.32 \\
\hline 22-Aug-94 & 18.28 \\
\hline 29-Aug-94 & 18.31 \\
\hline $06-$ Sep-94 & 18.25 \\
\hline
\end{tabular}

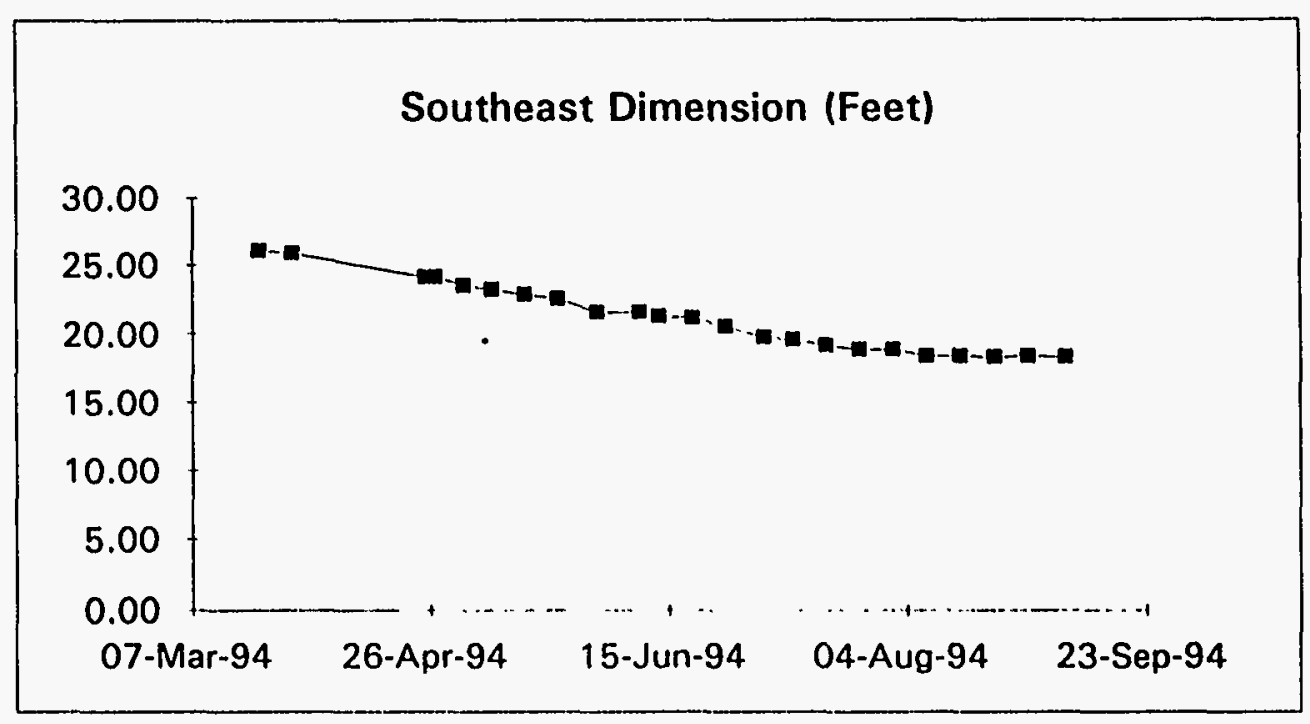


SINK HOLE MONUMENT

DIMENSIONAL MONITORING - Southeast Dimension Daily Rate

Chain Distance to Monument

\begin{tabular}{|c|c|}
\hline DATE & Feet/Day \\
\hline 21-Mar-94 & \\
\hline 28-Mar-94 & -0.03 \\
\hline 25-Apr-94 & -0.06 \\
\hline 27-Apr-94 & 0.00 \\
\hline 03-May-94 & -0.10 \\
\hline 09-May-94 & -0.05 \\
\hline 16-May-94 & -0.05 \\
\hline 23-May-94 & -0.05 \\
\hline 31-May-94 & -0.12 \\
\hline 09-Jun-94 & -0.01 \\
\hline 13-Jun-94 & -0.06 \\
\hline 20-Jun-94 & -0.02 \\
\hline 27-Jun-94 & -0.09 \\
\hline 05-Jul-94 & -0.10 \\
\hline $11-J u i-94$ & -0.04 \\
\hline 18-Jul-94 & -0.06 \\
\hline 25-Jul-94 & -0.04 \\
\hline 01-Aug-94 & -0.01 \\
\hline 08-Aug-94 & -0.07 \\
\hline 15-Aug-94 & 0.00 \\
\hline 22-Aug-94 & -0.01 \\
\hline 29-Aug-94 & 0.00 \\
\hline 06-Sep-94 & -0.01 \\
\hline
\end{tabular}

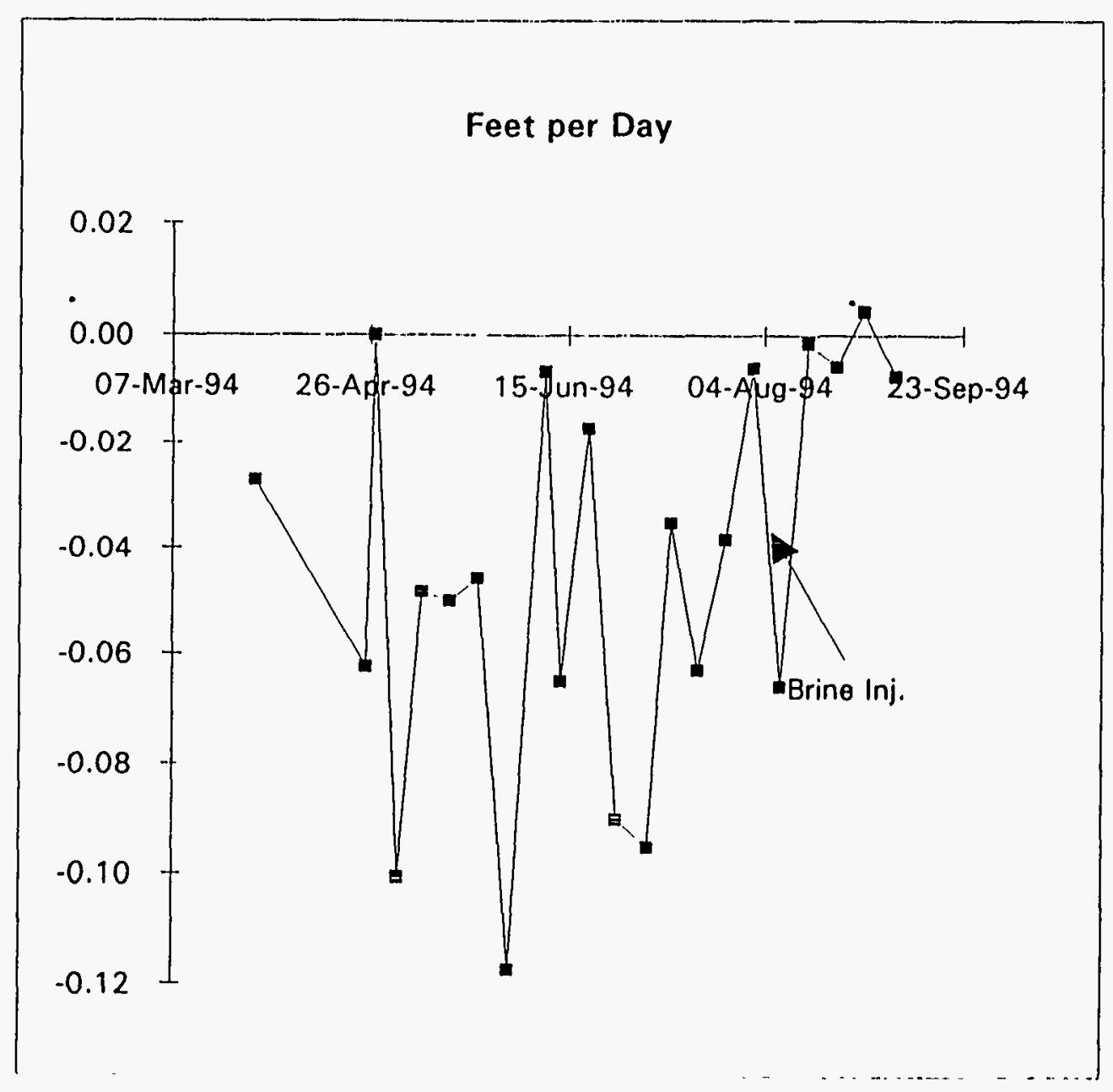




\section{VOLUME of BACKFILL}

Total current backfill volume within the sink hole is 1209 cubic yards. The rate of volume placement is affected by intermittent crowning of the fill material. The present volume approximates the general contour of the periphery of the surface depression and should be representative of the total displaced volume. The volume should reflect a similar volume being created in the sediments or the salt to soil interface. No place of additional material since August 12 has occurred. This may relate to the several brine injections near the sink hole. The brine may be displacing the media for salt dissolution at the top of the dome. 
SINK HOLE MONUMENT

VOLUME of FILL

\begin{tabular}{|c|c|c|c|}
\hline DATE & Cubic Yards & Total & Yd./Day \\
\hline 11-Mar-94 & 778 & 778 & \\
\hline 16-Mar-94 & 157 & 935 & \\
\hline $01-A p r-94$ & 19 & 954 & 1.06 \\
\hline 20-Apr-94 & 16 & 970 & \\
\hline 21-Apr-94 & 4 & 974 & 1.00 \\
\hline 28-Apr-94 & 18 & 992 & 2.57 \\
\hline 03-May-94 & 18 & 1010 & 3.60 \\
\hline 11-May-94 & 18 & 1028 & 2.25 \\
\hline 19-May-94 & 15 & 1043 & 1.88 \\
\hline 27-May-94 & 18 & 1061 & 2.25 \\
\hline 06-Jun-94 & 18 & 1079 & 1.80 \\
\hline 13-Jun-94 & 19 & 1098 & 2.71 \\
\hline 20-Jun-94 & 21 & 1119 & 3.00 \\
\hline 27-Jun-94 & 18 & 1137 & 2.57 \\
\hline 12-Jul-94 & 17 & 1154 & 1.13 \\
\hline 20-Jul-94 & 19 & 1173 & 2.38 \\
\hline 25-Jul-94 & 18 & 1191 & 3.60 \\
\hline 12-Aug-94 & 18 & 1209 & 1.00 \\
\hline
\end{tabular}

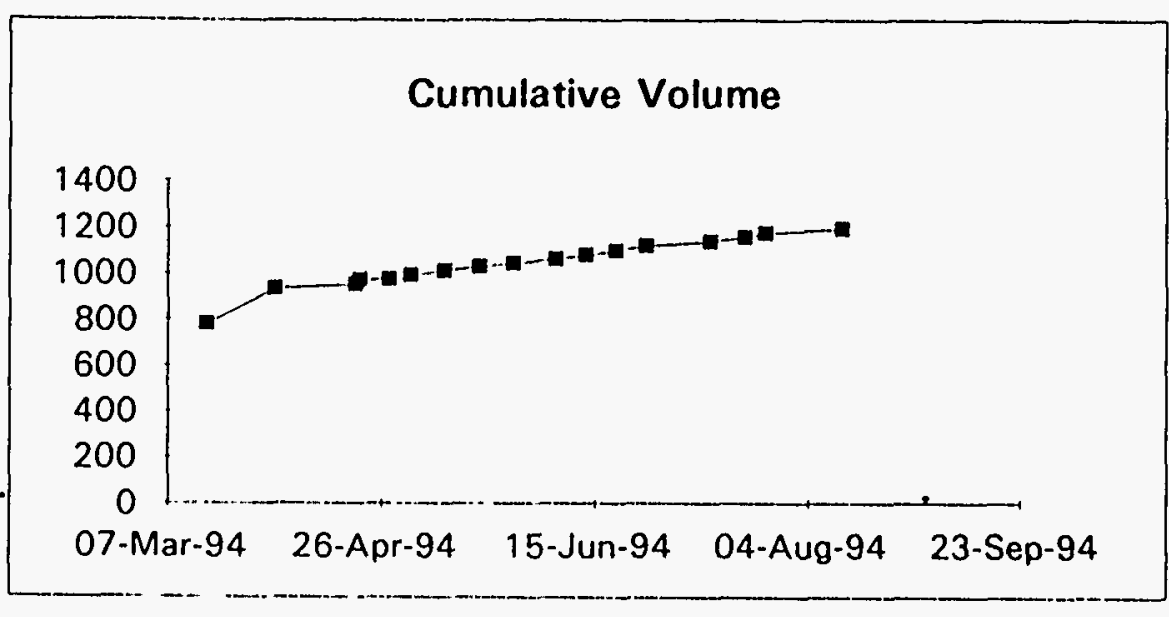

\section{Cubic Yards/Day}

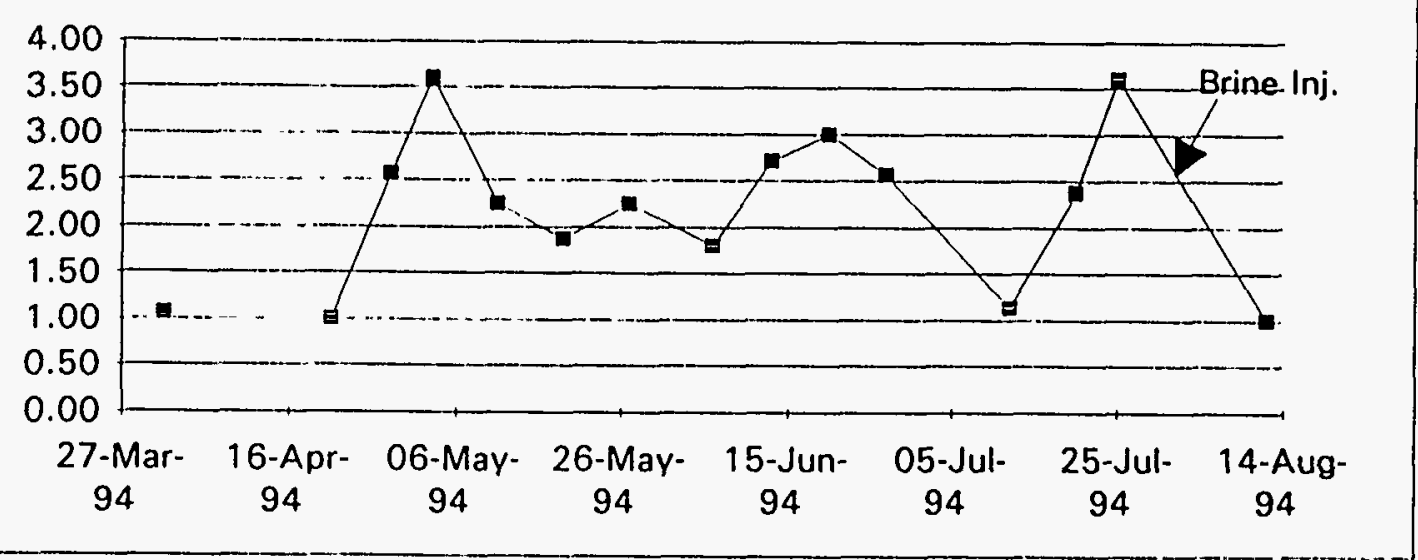




\section{FIELD NOTES}

Typical differential level records were developed throughout the current monitoring program. The notes are related to individual pipe and casing segments intermittently extended from March 21 through August 25.

The first installed pipe elevation was 3.03 feet above the casing. Both segments initially declined simultaneously, but differential rate required various extensions to be added separately. Differing time frames for the additions were also implemented to maintain adequate monitoring. For recording purposes, the sequential additions to both pipes and casing were jointly tabulated.

The reference elevations (monuments) were supplied by John Jakabik \& Associates during various surveys. After monitoring was commenced, a subsequent survey showed a 15.6 foot fixed reference error in the initial Jakabik survey. The initial reference has been used to maintain consistent records. 

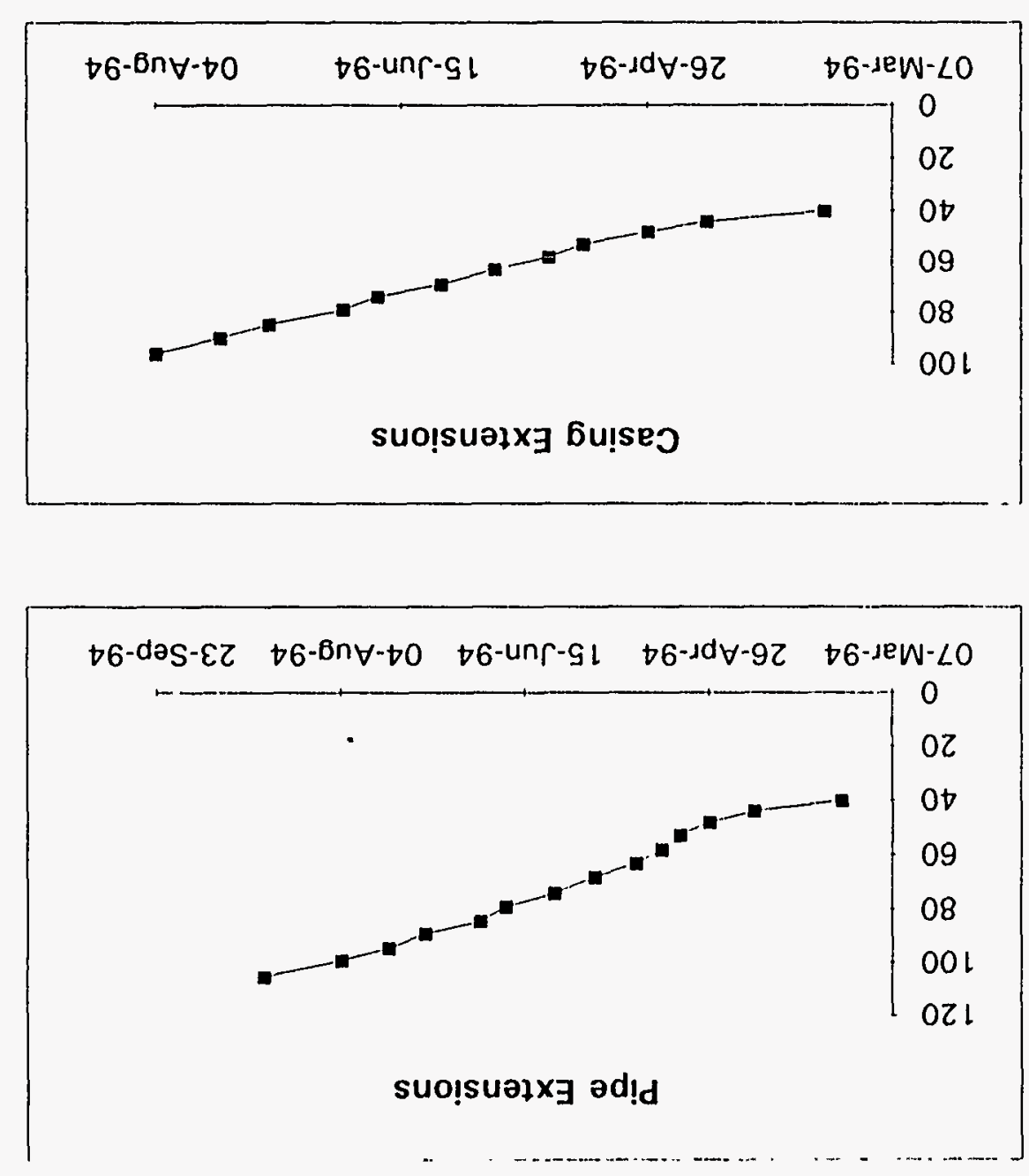

\begin{tabular}{|c|c|c|}
\hline 9 & 96 & $\nabla 6-6 \bar{n} \forall-\downarrow 0$ \\
\hline G & 06 & $\nabla 6-1 n r-2 z$ \\
\hline 9 & 98 & $t 6-|n \Gamma-2|$ \\
\hline G & $6 L$ & $\nabla 6-u n f-\angle 2$ \\
\hline $\mathbf{G}$ & $t L$ & $\nabla 6-u n r-0 z$ \\
\hline 9 & 69 & t6-unp- $\angle 0$ \\
\hline $\mathbf{G}$ & $\varepsilon 9$ & $D 6-\Lambda \mathrm{e} W-\angle Z$ \\
\hline 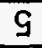 & 89 & t6-^eW-9l \\
\hline G & $E G$ & $76-\Lambda \mathrm{eW}-60$ \\
\hline$\nabla$ & $8 t$ & $76-1 d \forall-9 Z$ \\
\hline$t$ & $b t$ & $\nabla 6-1 d \forall-\nabla l$ \\
\hline & Ot & $76-1 \mathrm{w}-12$ \\
\hline
\end{tabular}

$\exists \perp \forall 0$

空

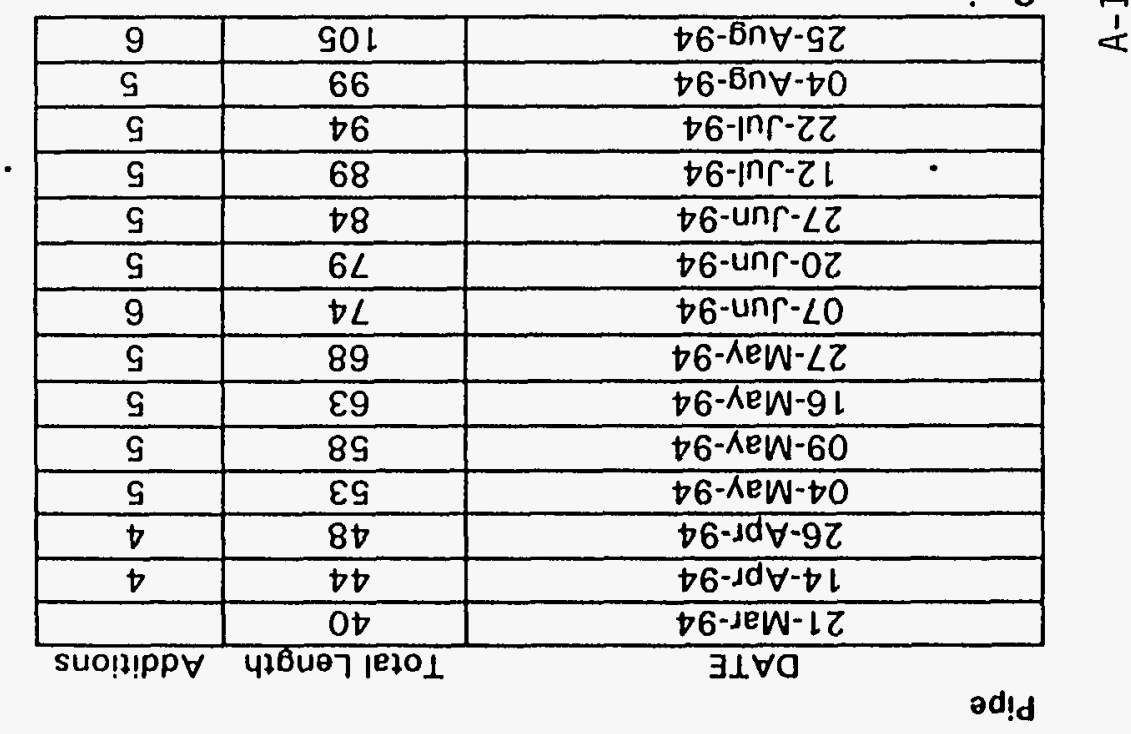

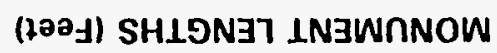


SINK HOLE MONUMENT (1)

ELEVATION MONITORING

Based on Monument: $X=1,849,843.26, Y=414,106.94$, Elev. $103.02 \mathrm{ft}$

First Reference Elevetion: 3.03 Feet above Casing, Elevation Top of Monument, Fixed Casing Reference

Note: The elevation represents the first initial elevation shot after the monument was installed.

After the pipe and casing were extended this elevation was transposed to the casing

This relative elevation was tracked until filling operations and subsidence of the

monument obscured the fixed reference point.

\begin{tabular}{|c|c|c|c|c|c|c|c|c|c|}
\hline DATE & Station Elev. & B.S & H.I. & F.S. & Elov. & Diff & Total Change & Rato/Day & Comments \\
\hline \multirow[t]{3}{*}{28 -Mar 94} & 103,02 & & & & & & & & \\
\hline & & 3.35 & 106.37 & & & & & & \\
\hline & & & & 0,96 & .107 .33 & & & & Inverted Rod $x$ Zero at Top \\
\hline \multirow[t]{6}{*}{$01-A p r \cdot 04$} & 103.02 & & & & & & & & \\
\hline & & $4: 4: 11$ & 107.13 & & & & & & \\
\hline & & & & 3.64 & 106,49 & .0 .84 & -0.84 & +0.21 & Shat by Jakibuk $\because \mathrm{Q}$ \\
\hline & & & & & & & & & C.Top of Casing $+3.03^{\prime}$ to Top. \\
\hline & & & & & & & & & Fill placed into hole after shot \\
\hline & & & & & & & & & $\therefore$ Fill placed ad acent to monument \\
\hline \multirow{3}{*}{04 Apr 94} & 103,02 & & & & & & & & \\
\hline & & $2 \% 248$ & 105.50 & & & & & & \\
\hline & & & & 0.03 & 105.53 & 0.96 & $+1,80$ & 0.32 & Inverted Rod ti Zero at Top \\
\hline \multirow[t]{4}{*}{ 11:Ap 94} & Q. 103.02 & & & & & & & & \\
\hline & & 1320 & 106.22 & & & & & & \\
\hline & & & & 2.14 & 104.08 & $\because, 45$ & -325 & 0.21 & Normal Rod Monument too low \\
\hline & & & & & & & & & to stioot elévation \\
\hline \multirow[t]{3}{*}{ 18.4pr.94 } & \%, 103,02 & & & & & & & & \\
\hline & & 2.81 & $106: 83$ & & & & & & \\
\hline & & & & 3.00 & 102.83 & $-1,26$ & -4.50 & -0.18 & Normal Rod \\
\hline \multirow[t]{3}{*}{$26 \times A \mathrm{prc} 94$} & 103.02 & & & & & & & & \\
\hline & & 3.80 & 106.82 & & & & & & \\
\hline & & & & 6.40 & $\because 100,42$ & .2 .41 & $\times 6,91$ & 0.34 & Normal Rod \\
\hline \multirow[t]{3}{*}{ Win Ap 84} & $\%, 103: 02$ & & & & & & & & \\
\hline & & 33:39 & 106.41 & & & & & & \\
\hline & & & & $6: 63$ & 99.78 & .0 .64 & $=7.56$ & -0.32 & Normal Rod: \\
\hline
\end{tabular}


SINK HOLE MONUMENT (2)

ELEVATION MONITORING

Besed on Monument: $X=1,849,843.26, Y=414,106.94$, Elev. $103.02 \mathrm{ft}$

Second Reference Elevation: 3.16 Feet above Casing, Elevation Top of Monument (Extension 4/14/94)

\begin{tabular}{|c|c|c|c|c|c|c|c|c|c|}
\hline DATE & Station Elev. & B.S & H.I. & F.S. & Elov. & Diff & Total Change & Rate/Day & Comments \\
\hline 18-Apr-94: & m 103,02 & & & & & & & & \\
\hline & & 281 & 105.83 & & & & & & \\
\hline & & & & 1.01 & 106.84 & & & & invertad Rod-Zoro at Top \\
\hline $25, A p r+84$ & 103.02 & & & & & & & & \\
\hline & & 3.80 & $\because 106.82$ & & & & & & \\
\hline & & & & 3.42 & 103,40 & +3.44 & -3.44 & .0 .49 & Normal Rod \\
\hline $27-A p r-94$ & 20303.02 & & & & & & & & \\
\hline & & 33,39 & 106.41 & & & & & & \\
\hline & & & & 3.81 & 102.60 & .0 .80 & -4.24 & $.0,40$ & Normal Rod \\
\hline
\end{tabular}

ELEVATION MONITORING

Based on Monument: $X=1,849,843.26, Y=414,106.94$, Elev. $103.02 \mathrm{ft}$

Second Reference Elevation: Top of Casing (Extension 4/14/94)

啰

\begin{tabular}{|c|c|c|c|c|c|c|c|c|c|}
\hline DATE & Station Elev. & B.S & H.I. & F.S. & Elev. & Diff & Total Change & Rate/Day & Comments \\
\hline $18 \times A p r+94$ & $10103: 02$ & & & & & & & & \\
\hline & & 2828 & 106.83 & & & & & & \\
\hline & & & & 2.16 & 103.68 & & & & Normol Rod \\
\hline - $2 \mathrm{~b}-\mathrm{A} p+-\theta 4$ & 3103.02 & & & & & & & & \\
\hline & & 8.80 & $106: 82$ & & & & & & \\
\hline & & & & B. 6 B & 101.27 & .2 .41 & -2.41 & -0.34 & Normal Rod \\
\hline 27 Apr+94 & 1: 103,02 & & & & & & & & \\
\hline & & 3339 & 106,41 & & & & & & \\
\hline & & & & $\because 5.78$ & 100.63 & .0 .64 & .3 .05 & .0 .32 & Normal Rod \\
\hline
\end{tabular}


SINK HOLE MONUMENT (3)

ELEVATION MONITORING

Based on Monument: $X=1,849,843.26, Y=414,106.94$, Elov. $103.02 \mathrm{ft}$

Third Reference Elovation: 1.85 Feet above Casing, Elevetion Top of Monument (Extension 4/26/94)

\begin{tabular}{|c|c|c|c|c|c|c|c|c|c|}
\hline DATE & Station Elov. & B.S & H.I. & F.S. & Elev. & Dilf & Total Chango & Rato/Day & Commonis \\
\hline 27 Apr 94 & 103,02 & & & & & & & & \\
\hline & & 3.39 & 108,41 & & & & & & \\
\hline & & & & 0,14 & 106: 65 & & & & Inverted Rod. \\
\hline$\therefore 03+M a y+84$ & 103.02 & & & & & & & & \\
\hline & & $3: 72$ & $\therefore 106,74$ & & & & & & \\
\hline & & & & 2.81 & .103 .93 & $+2 ; 62$ & -2.62 & 0.44 & Normal Rod $\quad$ nै \\
\hline O06-M $8 y=94$ & 10.02: & & & & & & & & \\
\hline & & 3,83 & $106: 85$ & & & & & & \\
\hline & & & & 4.66 & 102.29 & $\therefore \cdots 1.64$ & $\therefore:-4.26$ & $\because 0.65$ & Normal Rod No \\
\hline $09 \mathrm{MaY}_{94}$ & $10103: 02$ & & & & & & & & \\
\hline & & 3.21 & 106.23 & & & & & & \\
\hline & & & & 5.27 & 100.96 & .1 .33 & $+5: 68$ & $-0.44:$ & Normal Rod \\
\hline
\end{tabular}

SINK HOLE MONUMENT (3)

ELEVATION MONITORING

$\vec{G}$ Based on Monument: $X=1,849,843.26, Y=414,106.94$, Elov. $103.02 \mathrm{ft}$

Third Reference Elevation: Top of Casing (Extension 4/26/94)

\begin{tabular}{|c|c|c|c|c|c|c|c|c|c|}
\hline DATE & Station Elev. & B.S & H.I. & F.S. & Elev. & Diff & Total Change & Rate/Day & Comments \\
\hline \multirow[t]{3}{*}{ 27:Apt:94 } & ४४ 103.02 & & & & & & & & \\
\hline & & 33,39 & 106,41 & & & & & & \\
\hline & & & & \$.71 & $104: 70$ & & & & Notmal Rod $\mathrm{s}$ W \\
\hline \multirow[t]{3}{*}{ OOS-MaY 44} & $\longdiv { 1 0 3 . 0 2 }$ & & & & & & & & \\
\hline & & अ? 32 & 106.74 & & & & & & \\
\hline & & & & 388 & 102.90 & $+1,80$ & .1 .80 & $\times 0,30$ & Normal Rod \\
\hline \multirow[t]{3}{*}{ OOGMAV 94} & 1\%103:02 & & & & & & & & \\
\hline & & 3883 & 106.85 & & & & & & \\
\hline & & & & 6.09 & 101.76 & $\because-1+14$ & $\ldots-2.94$ & -0.38 & Normal Rod, $1 \%$ O \\
\hline \multirow[t]{3}{*}{ OO9Mayco4 } & 10103.02 & & & & & & & & \\
\hline & & 321 & 106:23 & & & & & & \\
\hline & & & & $6: 52$ & 100.71 & -1.06 & -3.98 & .0 .36 & an \\
\hline
\end{tabular}


SINK HOLE MONUMENT (4)

ELEVATION MONITORING

Based on Monument: $X=1,849,843.26, Y=414,106.94$, Elev. $103.02 \mathrm{ft}$

Fourth Reference Elevation: 1.39 Feet above Cesing. Elevation Top of Monument (Extension 5/04/94)

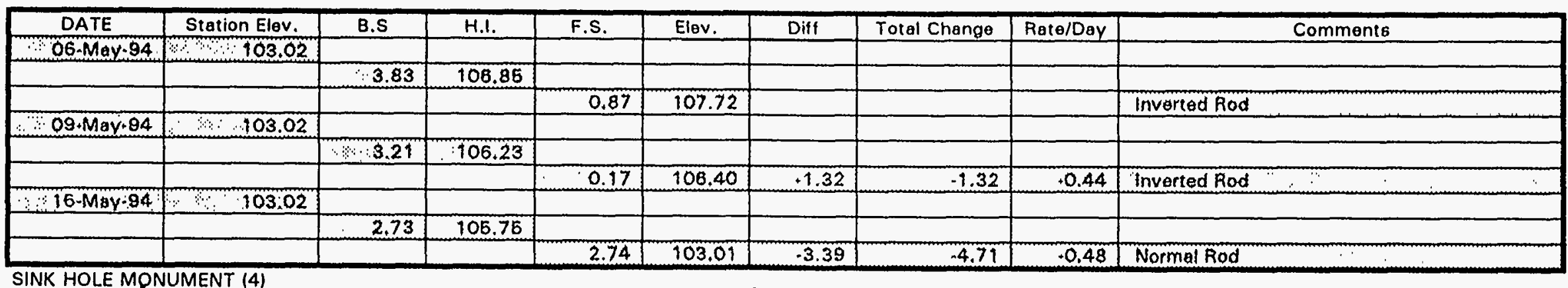

SINK HOLE MONUMENT (4)

ELEVATION MONITORING

Based on Monument: $X=1,849,843.26, Y=414,106.94$, Elev. $103.02 \mathrm{ft}$

Fourth Reference Elevation: Top of Casing (Extension 5/09/94)

$P$
1
1
1
0

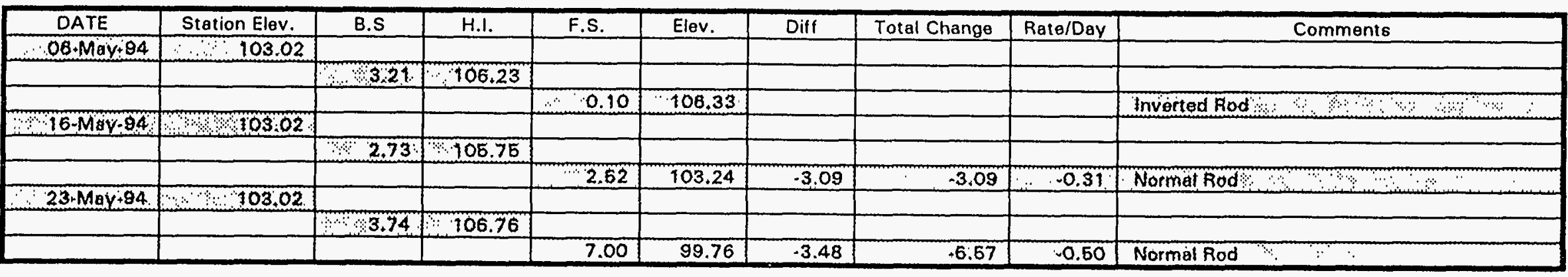


SINK HOLE MONUMENT (6)

ELEVATION MONITORING

Based on Monument: $X=1,849,843.26, Y=414,106.94$, Elov, $103.02 \mathrm{ft}$

Fifth Reference Elevation: 6.99 Feet above Casing, Elevation Top of Monument (Extension 5/09/94)

\begin{tabular}{|c|c|c|c|c|c|c|c|c|c|}
\hline DATE & Station Elov. & B.S & H.I. & F.S. & Elov. & Diff & Total Change & Rate/Day & Comments \\
\hline OQ.MaY 94 & 1.103 .02 & & & & & & & & \\
\hline & & \%) $3: 83$ & 106,85 & & & & & & \\
\hline & & & & 9.50 & 112.35 & & & & 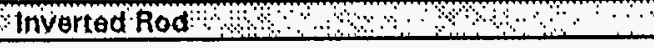 \\
\hline $16 \mathrm{May} 9 \mathrm{~g}$ & $18,103.02$ & & & & & & & & \\
\hline & & 12273 & 106.7.6: & & & & & & \\
\hline & & & & 2.68 & 108.33 & +4.02 & $\therefore \quad \therefore \quad 4.02$ & 0.57 & Inverted Rod \\
\hline 23-May-04 & 103.02 & & & & & & & & \\
\hline & & -3,74: & 106.76 & & & & & & \\
\hline & & & & $\because 1.69$ & 105.07 & -3.26 & -7.28 & .0 .47 & Normal Rod \\
\hline
\end{tabular}

SINK HOLE MONUMENT (Б)

ELEVATION MONITORING

Based on Monument: $X=1,849,843.26, Y=414,106.94$, Elev. $103.02 \mathrm{ft}$

Fifth Reference Elevation: Top of Cesing (Extension 5/16/94)

$T$
1
1
1
0

\begin{tabular}{|c|c|c|c|c|c|c|c|c|c|}
\hline DATE & Station Elev. & B.S & H.I. & F.S. & Elev. & Diff & Total Change & Rate/Day & Comments \\
\hline $233 \mathrm{MaV}: 94$ & $1.1 \% 103.02$ & & & & & & & & \\
\hline & & & & 3.140 & $105: 36$ & & & & Normol Rod/ $\mathrm{Q}$, \\
\hline $279 M 8 y=84$ & 3ै1103:02 & & & & & & & & \\
\hline & & & & 44.97 & 102.36 & .3 .00 & $\therefore 3.00$ & .0 .76 & Normal Rod \\
\hline
\end{tabular}


SINK HOLE MONUMENT (6)

ELEVATION MONITORING

Based on Monument: $X=1,849,843.26, Y=414,106.94$, Elev. $103.02 \mathrm{ft}$

Sixth Reference Elovation: 3.23 Feat above Casing. Elevation Top of Monument (Extension 6/16/84)

\begin{tabular}{|c|c|c|c|c|c|c|c|c|c|}
\hline DATE & Station Elev. & B.S & H.I. & F.S. & Elev. & Diff & Total Change & Rate/Day & Comments \\
\hline & & & & 3.66 & 110.41 & & & & invertad Rod \\
\hline $27+\mathrm{May}+94$ & 103.02 & & & & & & & & \\
\hline & & & & 0.07 & 107.40 & .3 .00 & .3 .00 & .0 .76 & Inverted Rod \\
\hline
\end{tabular}

\section{SINK HOLE MONUMENT $(6$}

ELEVATION MONITORING

Based on Monument: $X=1,849,843.26, Y=414,106.94$, Elev. $103.02 \mathrm{ft}$

Sixth Reference Elevation: Top of Casing (Extension 5/27/94)

Based on Monument: $X=1,849,869.06, Y=414,078.56$, Elev. 101.69 ft (June 09, 1994)

\begin{tabular}{|c|c|c|c|c|c|c|c|c|c|}
\hline \multirow{3}{*}{\begin{tabular}{l|l}
$D$ & DATE \\
& $27 \cdot \mathrm{May}+84$
\end{tabular}} & Station Elev. & 8.5 & H.I. & F.S. & Elov. & Diff & Total Change & Rate/Day & Comments \\
\hline & 103.02 & & & & & & & & \\
\hline & & 3.74 & 106.76 & & & & & & \\
\hline & & & & 0.42 & 107.18 & & & & Inverted Rod \\
\hline 34 May: 94 & $2,103.02$ & & & & & & & & \\
\hline & & 3.85 & 106.87 & & & & & & \\
\hline & & & & 1.02 & 105.85 & .1 .33 & -1.33 & .0 .33 & Normal Rod \\
\hline 06 -Junt 94 & ब1 103.02 & & & & & & & & \\
\hline & & 3.05 & 106.07 & & & & & & \\
\hline & & & & 3.18 & 102.88 & +2.96 & -4.28 & .0 .49 & Inverted Rod \\
\hline 09 Jun 94 & 101.69 & & & & & & & & \\
\hline & & 5.18 & 106.85 & & & & & & \\
\hline & & & & 5.16 & 101.88 & -1.21 & .5 .49 & .0 .40 & Normal Rod \\
\hline
\end{tabular}


SINK HOLE MONUMENT (7)

ELEVATION MONITORING

Bosod on Monument: $X-1,849,843.26, Y=414,106.94$, Elov. $103.02 \mathrm{ft}$

Seventh Reference Elevation: 4.18 Feet above Casing, Elovation Top of Monument (Extension 5/27/94)

Besed on Monument: $X=1,849,869.08, Y=414,078.66$, Elov. $101.69 \mathrm{ft}$ (June 09, 1994)

\begin{tabular}{|c|c|c|c|c|c|c|c|c|c|}
\hline DATE & Station Elov. & B.S & H.I. & F.S. & Elev. & Diff & Total Change & Rate/Day & Comments \\
\hline \multirow[t]{3}{*}{ 27May 94} & $1 \times 103: 02$ & & & & & & & & \\
\hline & & 103.74 & 106.76 & & & & & & \\
\hline & & & & 5,42 & 112.18 & & & & fnverted Rod $/$ l \\
\hline \multirow[t]{3}{*}{ 31May: 94} & 2 1.03.02 & & & & & & & & \\
\hline & & 3.85 & 106.87 & & & & & & \\
\hline & & & & 3.3 .96 & $\because .110 .83$ & $\square .1 .35$ & $-1,35$ & $\because \cdot 0,34:$ & Inverted hod: \\
\hline \multirow[t]{3}{*}{$8.08 . J u n i \theta 4$} & $1814103: 02$ & & & & & & & & \\
\hline & & 13.05: & 106.07 & & & & & & \\
\hline & & & & 1.80 & 107.87 & $\cdots+2: 96$ & $\quad 431$ & 10.49 & Thiverted Rod $/ \mathrm{Q} / \mathrm{Q}$ \\
\hline \multirow{3}{*}{80090004} & \%11016969 & & & & & & & & \\
\hline & & \%5:1B & 106.86 & & & & & & \\
\hline & & & & $\because 0.17$ & 106.68 & -1.19 & .5 .50 & .0 .40 & NormailRod \\
\hline
\end{tabular}

7 SINK HOLE MONUMENT (7)

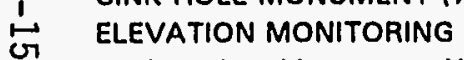

I Based on Monument: $X=1,849,869.06, Y=414,078.66$, Elev. $101.69 \mathrm{ft}$

Seventh Reference Elevation: Top of Casing (Extension 6/07/94)

\begin{tabular}{|c|c|c|c|c|c|c|c|c|c|}
\hline DATE & Stotion Elov. & B.S & H.t. & F.S. & Elov. & Diff & Total Chango & Rato/Day & Comments \\
\hline \multirow[t]{3}{*}{ O09:jon 94} & $101 \div 69$ & & & & & & & & \\
\hline & & B.10 & $100.8 B$ & & & & & & \\
\hline & & & & 1,16 & $108: 00$ & & & & Inverted Rod: $:$ आ० \\
\hline \multirow[t]{3}{*}{ 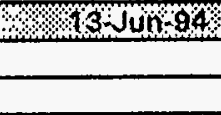 } & $10 \% 101,69$ & & & & & & & & \\
\hline & & 6.23 & 106.92 & & & & & & \\
\hline & & & & 1.09 & 106.83 & .2 .17 & -2.17 & -0.54 & Normal Rod \\
\hline \multirow[t]{3}{*}{ 20. Junis94 } & OP101:69 & & & & & & & & \\
\hline & & \#,6:28: & $0: 106: 97$ & & & & & & \\
\hline & & & & 4.67 & $.102 .30^{\circ}$ & +3.53 & $\because \quad 5,69$ & $\because n 0: 50$ & Normiall Rod wn m \\
\hline \multirow[t]{3}{*}{ 1.27. Jun 24} & 1000169 & & & & & & & & \\
\hline & & 4.81 & 108.60 & & & & & & \\
\hline & & & & 8.88 & 97.72 & .4 .68 & -10.28 & -0.68 & Normal Rod \\
\hline
\end{tabular}


SINK HOLE MONUMENT (8)

ELEVATION MONITORING

Based on Monument: $X=1,849,869.06, Y=414,078.56$, Elev. $101.69 \mathrm{ft}$

Eighth Reference Elevation: 9.64 Feet above Casing, Elevetion Top of Monument (Extension 6/07/94)

\begin{tabular}{|c|c|c|c|c|c|c|c|c|c|}
\hline DATE & Station Elav. & B.S & $\mathrm{H.I}$. & F.S. & Elev. & Diff & Total Change & Rate/Day & Comments \\
\hline \multirow[t]{3}{*}{ O9uJunte4 } & 3101,69 & & & & & & & & \\
\hline & & 5.16 & 106.85 & & & & & & \\
\hline & & & & 6.82 & 112.66 & & & & Invertad Rod \\
\hline \multirow[t]{3}{*}{$13 . J u n-84$} & 101.68 & & & & & & & & \\
\hline & & 5.23 & 106.92 & & & & & & \\
\hline & & & & 3.58 & 110.50 & +2.17 & -2.17 & .0 .54 & Inverted Rod \\
\hline \multirow[t]{3}{*}{$20-J 10 n-94$} & 101.69 & & & & & & & & \\
\hline & & 5.28 & 106.97 & & & & & & \\
\hline & & & & 0.00 & 106.97 & -3.63 & -6.69 & -0.50 & Inverted Rod \\
\hline \multirow[t]{3}{*}{$27 \cdot \sqrt{U n} \cdot 94$} & 101.69 & & & & & & & & \\
\hline & & 4.91 & 106.60 & & & & & & \\
\hline & & & & 4.21 & 102.39 & .4 .58 & -10.28 & -0.65 & Normal Rod \\
\hline
\end{tabular}

SINK HOLE MONUMENT $(8$
ELEVATION MONITORING

Based on Monument: $X=1,849,869.06, Y=414,078.66$, Elev. $101.69 \mathrm{ft}$

Eighth Reference Elevation: Top of Casing (Extension 6/20/94)

\begin{tabular}{|c|c|c|c|c|c|c|c|c|c|}
\hline DATE & Station Elev. & B.S & H.I. & F.S. & Elev. & Diff & Total Change & Rate/Day & Comments \\
\hline 27.5 un 94 & $3 \% 101,69$ & & & & & & & & \\
\hline & & 4.91 & 106.60 & & & & & & \\
\hline & & & & $3: 68$ & 102.92 & & & & Normat Rod \\
\hline 30 ilun +94 & 12101,69 & & & & & & & & \\
\hline & & $6 \cdot 6.38$ & $107: 07$ & & & & & & \\
\hline & & & & $\therefore 4.46$ & 102.61 & 0.31 & 0.31 & -0.10 & Normal Rod,$\ldots$ \\
\hline
\end{tabular}


SINK HOLE MONUMENT (9)

ELEVATION MONITORING

Based on Monument: $X=1,849,869.06, Y=414,078.66$, Elev. $101.69 \mathrm{ft}$

Ninth Reference Elevation: 0.03 Feet above Casing, Elevation Top of Monument (Extension 6/20/94)

\begin{tabular}{|c|c|c|c|c|c|c|c|c|c|}
\hline DATE & Station Elov. & B.S & H.I. & F.S. & Elev. & Diff & Total Change & Rate/Day & Comments \\
\hline 1.27 $=$ urt 94 & $1+101,69$ & & & & & & & & \\
\hline & & 24.91 & 110B:60 & & & & & & \\
\hline & & & & 7.02 & $\$ 107.62$ & & & & Inverted Rod \\
\hline $330, j u n$ 84: & अ४\$101:69: & & & & & & & & \\
\hline & & : $6 ; 38$ & 107.07 & & & & & & \\
\hline & & & & 0.26 & $\therefore 107: 32$ & $\therefore 0.30$ & $\therefore \quad-0.30$ & 0.10 & Inverted Rod \\
\hline
\end{tabular}

\section{SINK HOLE MONUMENT (9)}

ELEVATION MONITORING

Besed on Monument: $X=1,849,869.06, Y=414,078.56$. Elev. $101.69 \mathrm{ft}$ (June 09, 1994)

Ninth Reference Elevation: Top of Cesing (Extension 6/27/94)

\begin{tabular}{|c|c|c|c|c|c|c|c|c|c|}
\hline DATE & Station Elev. & B.S & H.I. & F.S. & Elov. & Diff & Total Change & Rate/Day & Comments \\
\hline $30 \sqrt{01094}$ & 12810169 & & & & & & & & \\
\hline & & 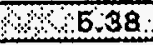 & 107,07 & & & & & & \\
\hline & & & & 0.52 & 107.59 & & & & Invertad Rod _ 8 W \\
\hline$\therefore 06.341804$ & $30101: 89$ & & & & & & & & \\
\hline & & 3,523 & $106: 92$ & & & & & & \\
\hline & & & & 6. 2.67 & 104.35 & $\div 3: 24$ & 30324 & 0,65 & Normal Rod \\
\hline $11+j a t: 84$ & 101.69 & & & & & & & & \\
\hline & & 610 & \%o6. 19 & & & & & & \\
\hline & & & & 460 & 102,19 & -216 & (1) & 0,36 & Nornal hod \\
\hline 1810ulta & \$४ 10169 & & & & & & & & \\
\hline & & $3,6,26$ & 106:95: & & & & & & \\
\hline & & & & $7: 46$ & 99:50 & +269 & $\because 08: 08$ & 0.38 & Normal Ród \\
\hline
\end{tabular}


SINK HOLE MONUMENT (10)

ELEVATION MONITORING

Besed on Monument: $X=1,849,869.06, Y=414,078.56$. Elev. $101.69 \mathrm{ft}$

Tenth Reference Elevation: 6.86 Feet above Casing, Elevation Top of Monument (Extension 6/27/94)

\begin{tabular}{|c|c|c|c|c|c|c|c|c|c|}
\hline DATE & Station Elov. & B.S & H.I. & F.S. & Elev. & Diff & Total Change & Rate/Day & Comments \\
\hline 30 Jun-34: & r 10169 & & & & & & & & \\
\hline & & $\quad 5.38$ & 107.07 & & & & & & \\
\hline & & & & 6,14 & 112.21 & & & & Inverted Rod \\
\hline $06+\sqrt{u 1}+04$ & $101: 69$ & & & & & & & & \\
\hline & & 5.23 & 106.92 & & & & & & \\
\hline & & & & 2.27 & 109,19 & +3.02 & -3.02 & +0.60 & Inverted Rod \\
\hline $11 . J 41-94$ & Mof 10969 & & & & & & & & \\
\hline & & 5,10 & 106.79 & & & & & & \\
\hline & & & & 0.31 & 107.11 & -2.08 & -5.10 & -0.35 & Inverted Rood \\
\hline 18.Jul. 94 . & 101.68 & & & & & & & & \\
\hline & & $\therefore \quad \cdots 5+26$ & 106.95 & & & & & & \\
\hline & & & & 2.45 & 104.60 & -2.60 & .7 .71 & -0.37 & Normal Rod \\
\hline
\end{tabular}

SINK HOLE MONUMENT (10)

I ELEVATION MONITORING

G Based on Monument: $X=1,849,869.06, Y=414,078.66$, Elev. $101.69 \mathrm{ft}$

$\omega$ Tenth Reference Elevation: Top of Casing (Extension 7/12/94)

\begin{tabular}{|c|c|c|c|c|c|c|c|c|c|}
\hline DATE & Station Elov. & B.S & H.I. & F.S. & Elev. & Diff & Total Change & Rate/Day & Comments \\
\hline \multirow[t]{3}{*}{$8,18: 341-84$} & ४ 10169 & & & & & & & & \\
\hline & & 5.6 .26 & 106.95 & & & & & & \\
\hline & & & & 1.60 & 106.36 & & & & Normal Rod $\mathrm{l}$ W \\
\hline \multirow[t]{3}{*}{$25 \cdot J u l .84$} & 101.69 & & & & & & & & \\
\hline & & 64471 & 106.40 & & & & & & \\
\hline & & & & 3.63 & 102.77 & +2.57 & .2 .67 & -0.37 & Normal Rod" \\
\hline
\end{tabular}


SINK HOLE MONUMENT (11)

ELEVATION MONITORING

Based on Monument: $X=1,849,869.06, Y=414,078.66$, Elev. $101.69 \mathrm{ft}$

Eleventh Reference Elevation: 1.31 Feet above Casing, Elevation Top of Monument (Extension 7/12/94)

\begin{tabular}{|c|c|c|c|c|c|c|c|c|c|}
\hline DATE & Station Elov. & B.S & H.I. & F.S. & Elov. & Diff & Total Change & Rate/Day & Comments \\
\hline (18) 1094 & $2 \times 101 \% 69$ & & & & & & & & \\
\hline & & \$15:26: & $108: 95$ & & & & & & \\
\hline & & & & 2,30 & $109: 25$ & & & & Invorted Rod an m \\
\hline $25 \mathrm{Juj} 1 \mathrm{\theta 4}$ & \$101.88 & & & & & & & & \\
\hline & & 2471 & $106,40^{\circ}$ & & & & & & \\
\hline & & & & 0.31 & 108.71 & .2 .64 & -2.54 & $\because 0.36$ & Inverted Rod: : \\
\hline
\end{tabular}

SINK HOLE MONUMENT (11)

ELEVATION MONITORING

Based on Monument: $X=1,849,869.06, Y=414,078.56$, Elev. $101.69 \mathrm{ft}$ (June 09, 1994)

Eleventh Reference Elevation: Top of Casing (Extension 7/22/94)

\begin{tabular}{|c|c|c|c|c|c|c|c|c|c|}
\hline DATE & Station Elev. & B.S & H.I. & F.S. & Elev. & Diff & Total Change & Rate/Day & Comments \\
\hline \multirow{3}{*}{$7.26 \checkmark 30196$} & 160169 & & & & & & & & \\
\hline & & $2 \% 471$ & 108.40 & & & & & & \\
\hline & & & & 1.54 & 107.94 & & & & Ufrvertad Rod \\
\hline \multirow[t]{3}{*}{ OOlingiga } & 18.10169 & & & & & & & & \\
\hline & & 1.6.52 & 107,01 & & & & & & \\
\hline & & & & 180.61 & 106.50 & $1+144$ & $10+1.44$ & 1\%,0.21 & 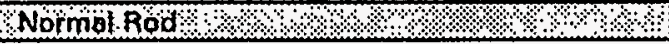 \\
\hline OB:AUG 94 & $810<68$ & & & & & & & & \\
\hline & & 84.56 & $106 \% 25$ & & & & & & \\
\hline & & & & tio\% & .105 .24 & $+1,26$ & 102.70 & $6 \% 0.18$ & NotmatRod \\
\hline
\end{tabular}


SINK HOLE MONUMENT (12)

ELEVATION MONITORING

Based on Monument: $X=1,849,869.06, Y=414,078.66$, Elev. $101.69 \mathrm{ft}$

Twelth Reference Elevetion: 1.60 Feet above Cesing, Elevation Top of Monument (Extension 7/22/94)

\begin{tabular}{|c|c|c|c|c|c|c|c|c|c|}
\hline DATE & Station Elev. & B.S & H.I. & F.S. & Elev. & Diff & Total Change & Rate/Day & Comments \\
\hline & & & & 6.50 & 111.90 & & & & Inverted hod. \\
\hline \multirow[t]{2}{*}{ O1.Aujit 94} & 101.69 & & & & & & & & \\
\hline & & & & 1.69 & 108.60 & +3.30 & -3.30 & .0 .47 & $\therefore$ : \\
\hline \multirow[t]{3}{*}{ O08.Aug. 94} & $8,101,69$ & & & & & & & & \\
\hline & & 44.58 & 106.25 & & & & & & \\
\hline & & & & 0.16 & 106.41 & -2.19 & .5 .49 & 0.31 & Inverted Rod 1,3 \\
\hline
\end{tabular}

- SINK HOLE MONUMENT (12)

ELEVATION MONITORING

Based on Monument: $X=1,849,869.06, Y=414,078.66$, Elev. $101.69 \mathrm{ft}$

Twelth Reterence Elevation: Top of Casing (Extension 8/04/84)

Based on Monument: $X=1,849,838.73, Y=414,060.91$. Elev. $101.47 \mathrm{ft}$ (September 06,1994)

\begin{tabular}{|c|c|c|c|c|c|c|c|c|c|}
\hline DATE & Stotion Elov. & 8.5 & H.I. & F.S. & Elov. & DIIt & Total Change & Rote/Day & Comments \\
\hline \multirow[t]{3}{*}{$08-A 40.84$} & 101,69 & & & & & & & & \\
\hline & & 4.56 & 108.25 & & & & & & \\
\hline & & & & 4.16 & 110.40 & & & & Invartad Rod \\
\hline \multirow[t]{3}{*}{$15-A$ aijg. 84} & 101.69 & & & & & & & & \\
\hline & & 4.77 & 108.46 & & & & & & \\
\hline & & & & 271 & $109+17$ & +1.23 & $\therefore \quad 4,23$ & 0.18 & 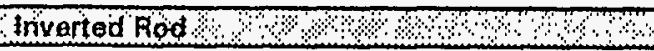 \\
\hline \multirow[t]{3}{*}{ 22:Auo:84 } & 101:68 & & & & & & & & \\
\hline & & 5,07 & 106.76 & & & & & & \\
\hline & & & & $\because 1.98$ & 108,74 & -0.43 & -1.66 & -0.06 & W \\
\hline \multirow[t]{3}{*}{$29+A 4 g+94$} & 1010169 & & & & & & & & \\
\hline & & E.38 & 107.07 & & & & & & \\
\hline & & & & 1,89 & 108.76 & 0.02 & +1.64 & 0.00 & Inverted Rod \\
\hline \multirow[t]{3}{*}{$08-5 e p-94$} & 101.47 & & & & & & & & \\
\hline & & $6: 36$ & 108,83 & & & & & & \\
\hline & & & & 1.75 & 108.68 & .0 .17 & +1.82 & $\because 0.02$ & Inverted had \\
\hline
\end{tabular}




\section{MON13.XLS}

SINK HOLE MONUMENT (13)

ELEVATION MONITORING

Based on Monument: $X=1,849,869.06, Y=414,078.66$, Elev. $101.69 \mathrm{ft}$

Thirteenth Reference Elovation: X.xx Feet above Casing, Elevation Top of Monument (Extension 8/04/94)

Based on Monument: $X=1,849,838.73, Y=414,060.91$, Elev. $101.47 \mathrm{ft}$ (September 06, 1994)

\begin{tabular}{|c|c|c|c|c|c|c|c|c|c|}
\hline DATE & Station Elev. & B.S & H.I. & F.S. & Elev. & Diff & Total Change & Rate/Dav & Comments \\
\hline OB.Audi94 & 9.10169 & & & & & & & & \\
\hline & & 4466 & 106,25 & & & & & & \\
\hline & & & & 534 & Wrise & & & & 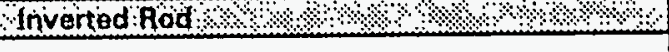 \\
\hline 16:Alig: 94 & 1.101 .69 & & & & & & & & \\
\hline & & 4477 & 108.46 & & & & & & \\
\hline & & & & 3.60 & 110.06 & (l) & - $1: 52$ & -0.22 & liverted Rod, ß $=$ W \\
\hline Q2224Augis4 & \$2 & $5.07 \%$ & 10686 & & & & & & \\
\hline & & & & 1283 & 109,39 & $+0: 68$ & $5+220$ & $\$ 0.10$ & Shverted:Rod $/$ । \\
\hline 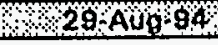 & $10101 / 69$ & & & & & & & & \\
\hline & & 2.5 .38 & 10707 & कर & (500.58 & 0.11 & 3:32: & $\because 1,-007$ & Triverted:Rón \\
\hline ०06:500+94 & 1.101:47 & & & & & & & & Inverted Rod \\
\hline & & 160,06 & 10688 & & & & & & \\
\hline & & & & 2.25 & $109: 08$ & 0.18 & $.2-60$ & 00.02 & thverted:hod \\
\hline
\end{tabular}


SINK HOLE MONUMENT (14)

ELEVATION MONITORING

Besed on Monument: $X=1,849,869.06, Y=414,078.66$, Elev. $101.69 \mathrm{ft}$

Forteenth Reference Elevation: X.xx Feet above Cesing. Elevation Top of Monument (Extension 8/26/94)

Besed on Monument: $X=1,849,838.73, Y=414,060.91$, Elev. $101.47 \mathrm{ft}$ (September 06, 1994)

\begin{tabular}{|c|c|c|c|c|c|c|c|c|c|}
\hline DATE & Station Elov. & B.S & H.I. & F.S. & Elev. & Diff & Total Change & Rate/Day & Comments \\
\hline & & 6.38 & 107.07 & & & & & & \\
\hline & & & & 7.27 & 114.34 & & & & Inverted hod: \\
\hline O6-Sop-94 & 101.47 & & & & & & & & \\
\hline & & & & 7.31 & 914.14 & .0 .20 & 114.14 & .0 .02 & Inverted fod \\
\hline
\end{tabular}




\section{BRINE INJECTION -- BORE HOLE 7A}

Specific remediation aspects regarding the mitigation of the effects of the sink hole included the manipulation of subsurface brine coricentration. This methodology was developed to minimize the dissolution of salt that may relate to the physical conditions that caused the development of the sink hole. This is a current synopsis of the current status of the brine injection through bore hole 7A.

Four vertical holes were placed adjacent to the quadrant boundaries of the sink hole. Two additional angled holes were drilled to directy intersect the investigative areas of the hypothetical salt to soil annulus of the depression. Bore hole 9 (angled) was planned to intersect the area at the highest theoretical subsurface elevation. Bore hole 7A (angled) intersected a distinct feature below the soil to salt transition. Hole 9 was dedicated to dye injection and a subsequent dye injection involved bore hole 7A.

Rembco Engineering, a subcontractor to DynMcDermott initiated a development program to induce saturated brine through bore hole $7 \mathrm{~A}$. This program should minimize the subsurface mechanism causing the sink hole. The saturated brine will displace any fresh or brackish water which may be dissolving salt.

A decrease in placed fill material and slower movement of the sink hole monument may wholly or partially correspond to the brine induction. This repor depicts the quantitative aspects of the current brine induction as of September 19, 1994. An average induction rate of $2.29 \mathrm{gpm}$ has been maintained since August 05. 1994.

Comparisons of the relative movements of the monument and the present status of the fill additions were shown in a previous memorandum, entitled "Sink Hole Monitoring." Detailed comparisons will be made in the future to further understand if any direct relationship can derived.

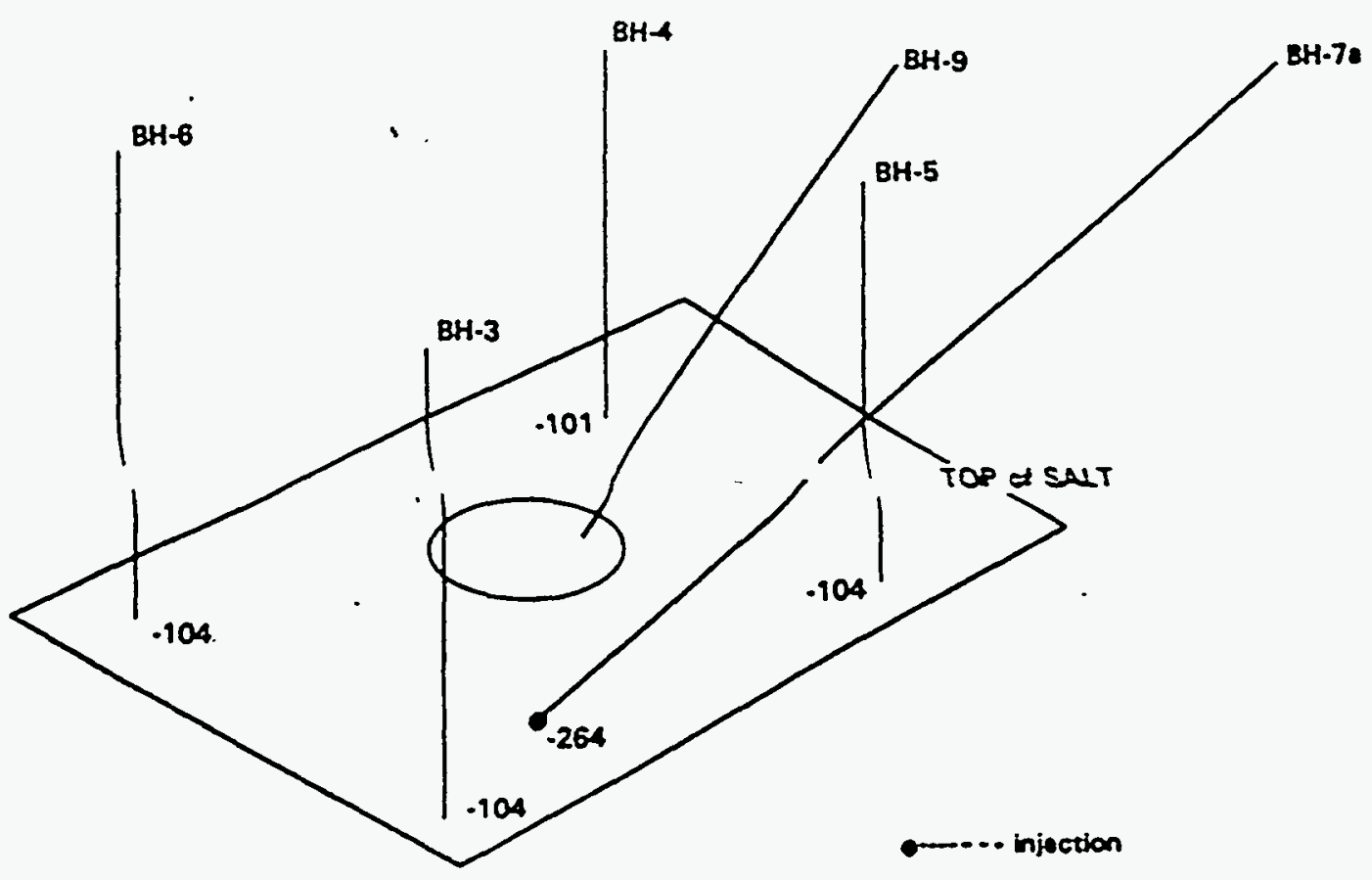




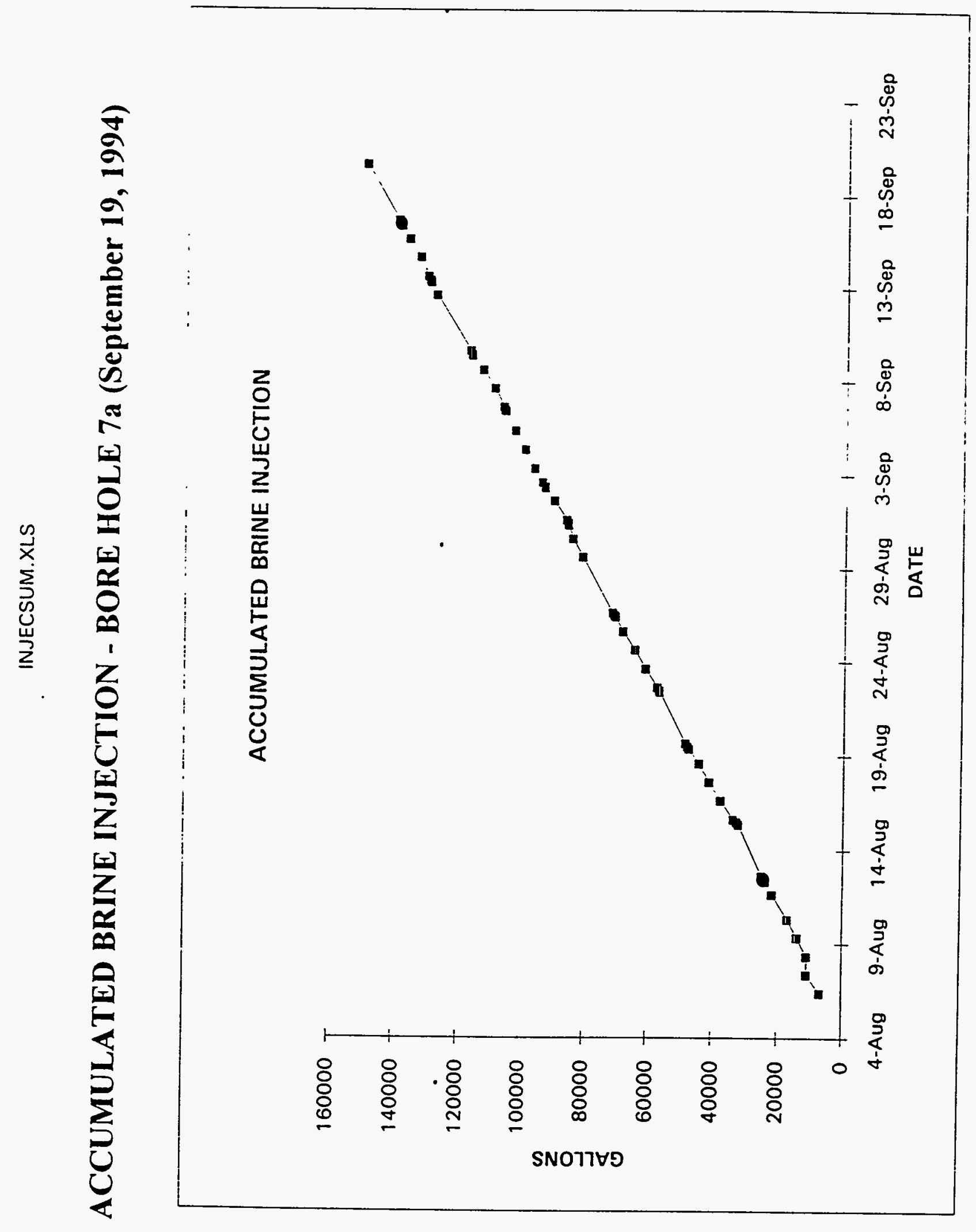

A-15-36 


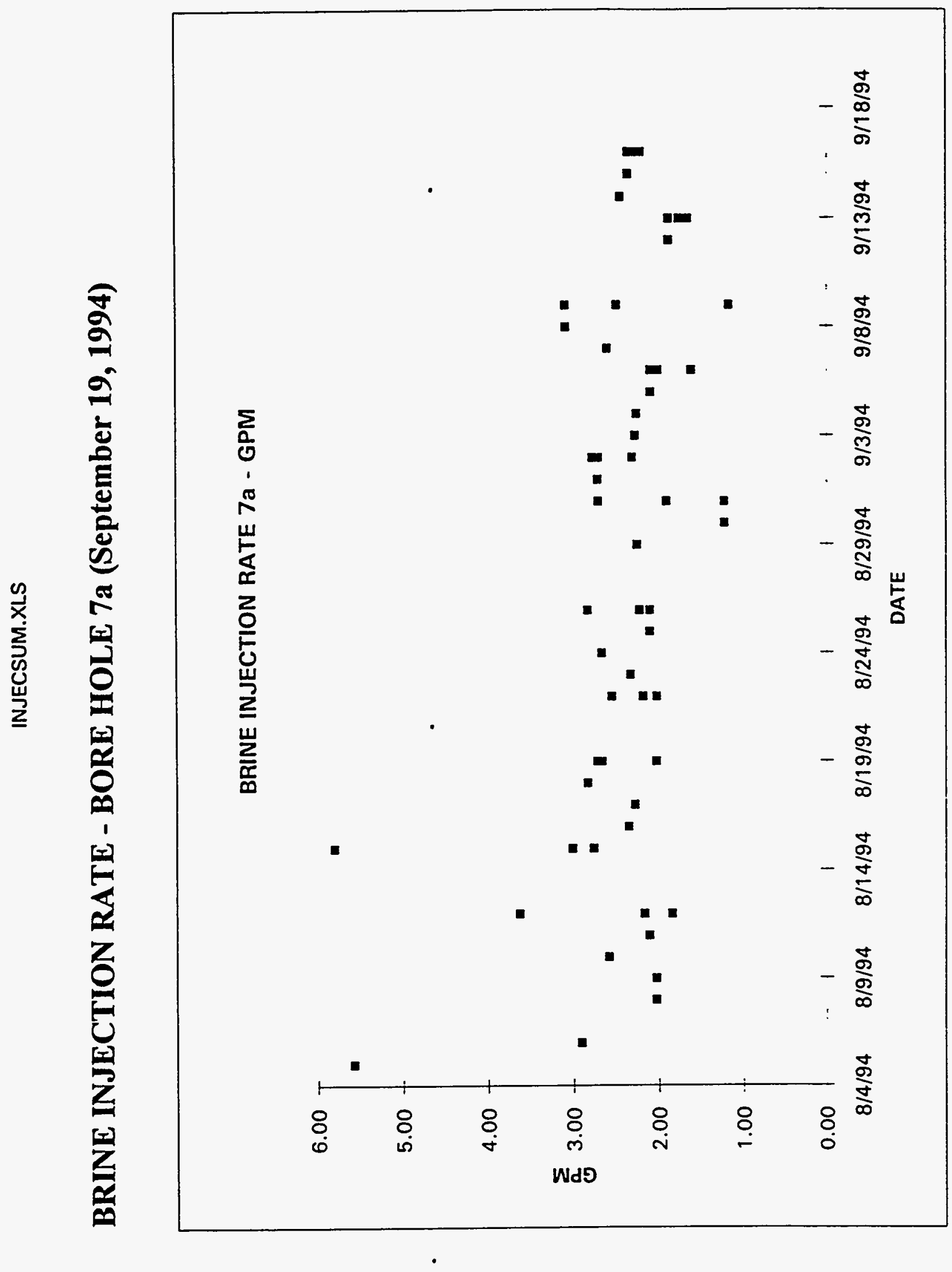

๑)

A-15-37 


\begin{tabular}{|c|c|c|c|c|}
\hline \multicolumn{5}{|c|}{ BRINE INJECTION -- BORE HOLE 7a } \\
\hline \multicolumn{5}{|c|}{ SALINITY TESTING } \\
\hline & & & & $!$ \\
\hline DATE & TANK & LOADS & LBS/GAL & CHLORIDES,ppm \\
\hline 5-Sep-94| & 1 & 3 & $10.0+$ & 184000 \\
\hline 8-Aug-94! & 1 & 4 & $10.0+$ & 185000 \\
\hline 8-Aug-94! & 1 & 1 & $10.0+$ & 186000 \\
\hline 12-Aug-941 & 2 & 3 & $10.0+$ & 184000 \\
\hline 15-Aug-941 & 3 & 3 & $10.0+$ & 185000 \\
\hline 19-Aug-94! & 4 & 3 & $90.0+$ & 185000 \\
\hline 22-Aug-94 & 5 & 2 & $10.0+$ & 185000 \\
\hline 26-Aug-941 & 6 & 3 & $10.0+$ & 185000 \\
\hline 3i-Aug-94 & 7 & 4 & $10.0+$ & 186000 \\
\hline 2-Sep-94 & 8 & 2 & $10.0+$ & 184000 \\
\hline 6-Sep-94 & 9 & 3 & $10.0+$ & 186000 \\
\hline 9-Sep-94 & 10 & 2 & 10.1 & 186000 \\
\hline 13-Sep-94 & 11 & 4 & 10.1 & 187000 \\
\hline 16-Sep-94i & 12 & 3 & $10+$ & 185000 \\
\hline
\end{tabular}




\begin{tabular}{|c|c|c|c|c|c|c|c|c|}
\hline \multicolumn{9}{|c|}{ BORE HOLE 7A - BRINE INJECTION } \\
\hline \multicolumn{9}{|c|}{ PIRST PRAC TANK } \\
\hline & & & & & & & & \\
\hline DATE & TIME $\because$ & $\begin{array}{l}\text { COMBINED } \\
\text { TIME }\end{array}$ & $\begin{array}{l}\text { RATE } \\
\text { METER : }\end{array}$ & $\begin{array}{l}\text { MANUAL } \\
\text { STRAP }\end{array}$ & $\begin{array}{l}\text { CALCULATED } \\
\text { RATE }\end{array}$ & GALS & $\begin{array}{l}\text { CUMM } \\
\text { GALS }\end{array}$ & COMMENTS \\
\hline \multirow{2}{*}{$8 / 5 / 94$} & 1:00 PM & $8 / 5 / 9413: 00$ & & 44 & & & & Three loads $(330 \mathrm{bb} / \mathrm{s})$. \\
\hline & & & 5.7 & & 5.57 & 6688 & 6688 & \\
\hline \multirow[t]{2}{*}{$8 / 6 / 94$} & $9: 00$ AM & $8 / 6 / 949: 00$ & & 76 & & & & Siphoning (brine ran low) \\
\hline & & & 2.2 & & 2.90 & 4180 & 10868 & \\
\hline \multirow[t]{2}{*}{$8 / 7 / 94$} & $9: 00 \mathrm{AM}$ & $8 / 7 / 949: 00$ & & 96 & & & & Four Loads (440 bbls.), SPR (60 bbls.) \\
\hline & & & of & & & & & \\
\hline \multirow[t]{2}{*}{$8 / 8 / 94$} & $8: 00 \mathrm{AM}$ & $8 / 8 / 948: 00$ & & 12 & & & & \\
\hline & & & 2.2 & & 2.03 & 2926 & 13794 & \\
\hline \multirow[t]{2}{*}{$8 / 9 / 94$} & $8: 00$ AM & $8 / 9 / 948: 00$ & & 26 & & & & Gravity Feed \\
\hline & & & 2.2 & & 2.03 & 2926 & 16720 & \\
\hline \multirow[t]{2}{*}{$8 / 10 / 94$} & $8: 00$ AM & $8 / 10 / 948: 00$ & & 40 & & & & Moved Flow Valve \\
\hline & & & 2.5 & & 2.58 & 4807 & 21527 & \\
\hline \multirow[t]{2}{*}{$8 / 11 / 94$} & 3:00 PM & $8 / 11 / 9415: 00$ & & 63 & & & & \\
\hline & & & & & 2.11 & 2107 & 23634 & \\
\hline \multirow[t]{2}{*}{$8 / 12 / 94$} & $7: 40 \mathrm{AM}$ & $8 / 12 / 947: 40$ & & 74 & & & & \\
\hline & & & & & 3.62 & 435 & 24069 & \\
\hline \multirow[t]{2}{*}{$8 / 12 / 94$} & 9:40 AM & $8 / 12 / 949: 40$ & & 77 & & & & \\
\hline & & & & & & & & \\
\hline
\end{tabular}


BORETA.XLS

\begin{tabular}{|c|c|c|c|c|c|c|c|c|}
\hline \multicolumn{7}{|c|}{ BORE IIOIE 7A - BRINE INJECTION } & \multirow{3}{*}{\multicolumn{2}{|c|}{$\cdots \quad-\quad-\cdots$}} \\
\hline \multirow{2}{*}{\multicolumn{7}{|c|}{ SECONI) PRAC TANK }} & & \\
\hline & & & & & & & & \\
\hline DATE & TIME & $\begin{array}{l}\text { COMBINED } \\
\text { TIME }\end{array}$ & $\begin{array}{l}\text { RATE } \\
\text { METER }\end{array}$ & $\begin{array}{l}\text { MANUAL } \\
\text { STRAP }\end{array}$ & $\begin{array}{l}\text { CALCULATED } \\
\text { RATE }\end{array}$ & GALS & $\begin{array}{l}\text { CUMM } \\
\text { GALS }\end{array}$ & COMMENTS \\
\hline $8 / 12 / 94$ & $9: 40$ AM & $8 / 12 / 949: 40$ & & 25 & & & & \\
\hline & & & & & 2.16 & 627 & 24696 & Three Loads (330 bbls.) \\
\hline $8 / 12 / 94$ & $2: 30 \mathrm{PM}$ & $8 / 12 / 94 \quad 14: 30$ & & 28 & & & & \\
\hline & & & & & 1.85 & 7315 & 32011 & \\
\hline $8 / 15 / 94$ & $8: 34$ AM & $8 / 15 / 948: 34$ & 1.8 & 63 & & & & \\
\hline & & & & & 3.00 & 619 & 32630 & \\
\hline $8 / 15 / 94$ & 12:00 PM & 8/15/94 12:00 & & 66 & & & & \\
\hline & & & & & & & & \\
\hline
\end{tabular}

7
1
0
1
0 


\begin{tabular}{|c|c|c|c|c|c|c|c|c|}
\hline \multicolumn{9}{|c|}{ BORE HOLE 7A - BRINE INJECTION } \\
\hline \multicolumn{9}{|c|}{ THIRD FRAC TANK } \\
\hline & & & & & & & & \\
\hline DATE & TIME & $\begin{array}{l}\text { COMBINED } \\
: \text { TIME }\end{array}$ & $\begin{array}{l}\text { RATE } \\
\text { METER }\end{array}$ & $\begin{array}{l}\text { MANUAL } \\
\text { STRAP }\end{array}$ & $\begin{array}{l}\text { CALCULATED } \\
\text { RATE }\end{array}$ & GALS & $\begin{array}{l}\text { CUMM } \\
\text { GALS }\end{array}$ & COMMENTS \\
\hline \multirow{2}{*}{$8 / 15 / 94$} & 12:00 PM & $8 / 15 / 9412: 00$ & & 14 & & & & \\
\hline & & & & & 5.81 & 1045 & 33675 & Three Loads $1330 \mathrm{bb} / \mathrm{s})$. \\
\hline \multirow[t]{2}{*}{$8 / 15 / 94$} & 3:00 PM & $8 / 15 / 94 \quad 15: 00$ & & 19 & & & & \\
\hline & & & & & 2.76 & 3971 & 37646 & \\
\hline \multirow[t]{2}{*}{$8 / 16 / 94$} & 3:00 PM & $8 / 16 / 94 \quad 15: 00$ & 3.3 & 38 & & & & \\
\hline & & & & & 2.35 & 3344 & 40990 & \\
\hline \multirow[t]{2}{*}{$8 / 17 / 94$} & $2: 45 \mathrm{PM}$ & $8 / 1 7 \longdiv { 9 4 } 1 4: 45$ & 2.8 & 54 & & & & \\
\hline & & & & & 2.27 & 3135 & 44125 & \\
\hline \multirow[t]{2}{*}{$8 / 18 / 94$} & 1:44 PM & $8 / 18 / 9413: 44$ & 2.5 & 69 & & & & \\
\hline & & & & & 2.82 & 3135 & 47260 & \\
\hline \multirow[t]{2}{*}{$8 / 19 / 94$} & 8:15 AM & $8 / 19 / 948: 15$ & & 84 & & & & \\
\hline & & & & & 2.65 & 491 & 47751 & \\
\hline $8 / 19 / 94$ & $11: 20 \mathrm{AM}$ & $8 / 19 / 9411: 20$ & & 86 & & & & \\
\hline
\end{tabular}


BORE7A.XLS

\begin{tabular}{|c|c|c|c|c|c|c|c|c|}
\hline BORE I & Ol.E 7A & - BRINE IN & ECTION & & & & & \\
\hline FOUR'Il & PRAC ' & ANK & & & & & & \\
\hline DATE & TIME & $\begin{array}{l}\text { COMBINED } \\
\text { TIME }\end{array}$ & $\begin{array}{l}\text { RATE } \\
\text { METER }\end{array}$ & $\begin{array}{l}\text { MANUAL } \\
\text { STRAP }\end{array}$ & $\begin{array}{l}\text { CALCULATED } \\
\text { RATE }\end{array}$ & GALS & $\begin{array}{l}\text { CUMM } \\
\text { GALS }\end{array}$ & COMMENTS \\
\hline $8 / 19 / 94$ & $11: 20 \mathrm{AM}$ & $8 / 19 / 9411: 20$ & & 20 & & & & \\
\hline & & & 2.4 & & 2.71 & 627 & 48378 & Four Loads (440 bbls.) \\
\hline $8 / 19 / 94$ & 3:11 PM & $8 / 19 / 94 \quad 15: 11$ & & 23 & & & & \\
\hline & & & 1.8 & & 2.02 & 8047 & 56424 & \\
\hline $8 / 22 / 94$ & $9: 30$ AM & $8 / 22 / 949: 30$ & & 62 & & & & \\
\hline & & & 2.1 & & 2.02 & 182 & 56606 & \\
\hline $8 / 22 / 94$ & 11:00 AM & $8 / 22 / 9411: 00$ & & 62 & & & & \\
\hline
\end{tabular}




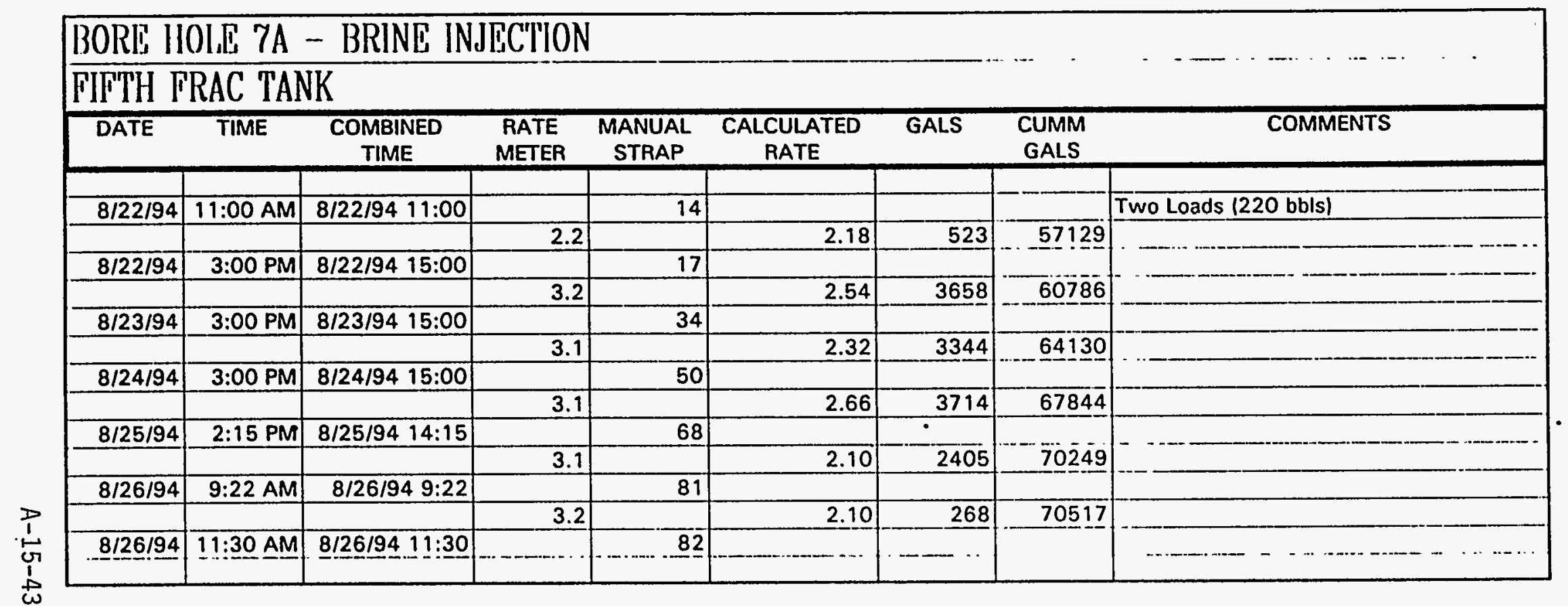


BORE7A.XLS

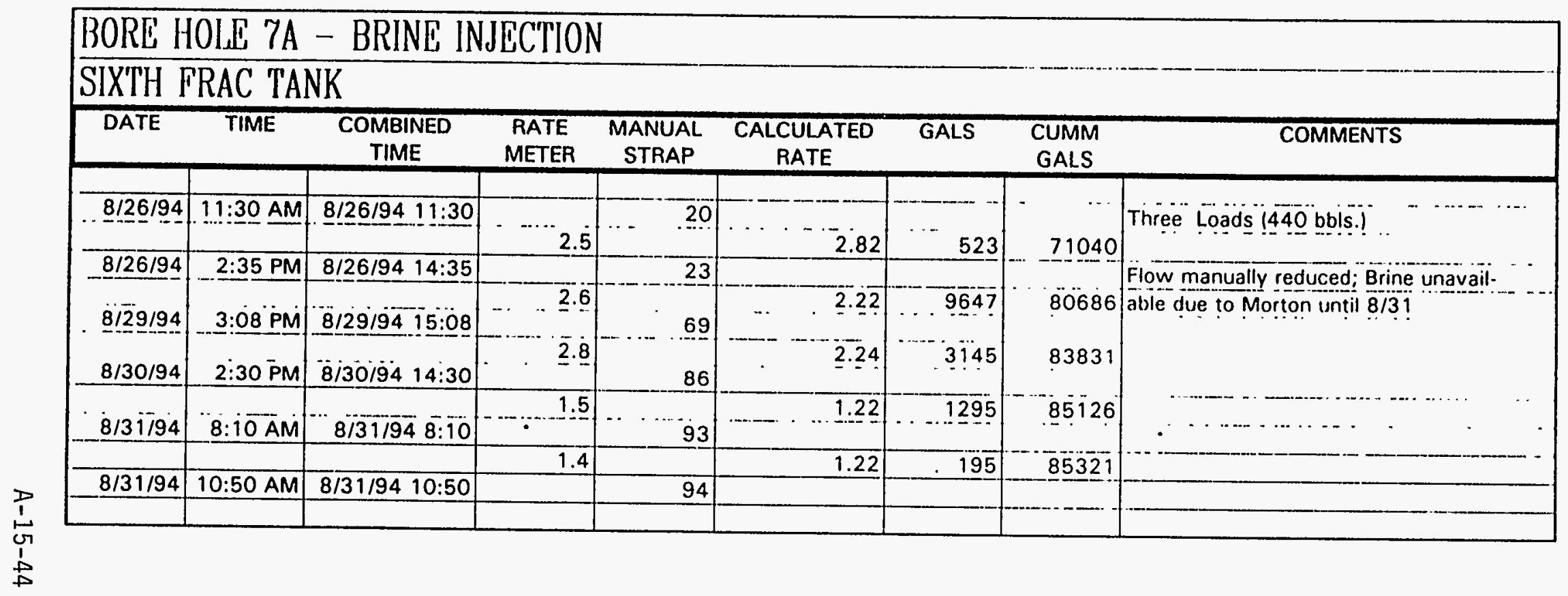


BORE7A.XLS

\begin{tabular}{|c|c|c|c|c|c|c|c|c|}
\hline \multicolumn{7}{|c|}{ BORE HOI.E 7A - BRINE INJBCPION } & \multirow{2}{*}{\multicolumn{2}{|c|}{ - }} \\
\hline \multicolumn{7}{|c|}{ SEVENTH FRAC TANK } & & \\
\hline DATE & TIME & $\begin{array}{l}\text { COMBINED } \\
\text { TIME }\end{array}$ & $\begin{array}{l}\text { RATE } \\
\text { METER }\end{array}$ & $\begin{array}{l}\text { MANUAL } \\
\text { STRAP }\end{array}$ & $\begin{array}{l}\text { CALCULATED } \\
\text { RATE }\end{array}$ & GALS & $\begin{array}{l}\text { CUMM } \\
\text { GALS }\end{array}$ & COMMENTS \\
\hline \multirow{2}{*}{$8 / 31 / 94$} & $10: 50 \mathrm{AM}$ & $8 / 31 / 94 \quad 10: 50$ & & 10 & & & & Four Loads (440 bbls.) \\
\hline & & & & & 1.90 & 418 & 85739 & \\
\hline \multirow[t]{2}{*}{$8 / 31 / 94$} & $2: 30 \mathrm{PM}$ & $8 / 31 / 94 \quad 14: 30$ & & 12 & & & & \\
\hline & & & & & 2.70 & 3971 & 89710 & \\
\hline \multirow[t]{2}{*}{$9 / 1 / 94$} & $3: 00 \mathrm{PM}$ & $9 / 1 / 9415: 00$ & & 31 & & & & \\
\hline & & & & & 2.70 & 2717 & 92427 & - \\
\hline \multirow[t]{2}{*}{$9 / 2 / 94$} & $7: 45$ AM & $9 / 2 / 947: 45$ & & 44 & & & & \\
\hline & & & & & 2.70 & 176 & 92603 & \\
\hline $9 / 2 / 94$ & $8: 50$ AM & $9 / 2 / 948: 50$ & & 45 & & & & \\
\hline & & & & & & & & \\
\hline
\end{tabular}

$P$
1
$\omega$
1
+
$G$ 
BORETA.XLS

\begin{tabular}{|c|c|c|c|c|c|c|c|c|}
\hline \multicolumn{9}{|c|}{ BORE HOLE 7A - BRINE' INJECIION } \\
\hline \multicolumn{9}{|c|}{ EIGIITH PRAC TANK } \\
\hline DATE & TIME & $\begin{array}{l}\text { COMBINED } \\
\text { TIME }\end{array}$ & $\begin{array}{l}\text { RATE } \\
\text { METER }\end{array}$ & $\begin{array}{l}\text { MANUAL } \\
\text { STRAP }\end{array}$ & $\begin{array}{l}\text { CALCULATED } \\
\text { RATE }\end{array}$ & GALS & $\begin{array}{l}\text { CUMM } \\
\text { GALS }\end{array}$ & COMMENTS \\
\hline $9 / 2 / 94$ & $8: 50$ AM & $9 / 2 / 948: 50$ & & 15 & & & & Two Loads (160 bbls.) \\
\hline $9 / 2 / 94$ & $2: 30 \mathrm{PM}$ & $9 / 2 / 9414: 30$ & $-\cdots+. .$. & $\cdots$ & 2.77 & 941 & 93543 & ... \\
\hline & & & & & 2.30 & 2508 & 96051 & \\
\hline $9 / 3 / 94$ & $8: 40 \mathrm{AM}$ & $9 / 3 / 948: 40$ & & 31 & & & & \\
\hline & & & & & 2.27 & 3240 & 99291 & \\
\hline $9 / 4 / 94$ & $8: 30$ AM & 9/4/948:30 & & 47 & & & & \\
\hline & & & & & 2.25 & 3240 & 102530 & \\
\hline $9 / 5 / 94$ & $8: 30$ AM & $9 / 5 / 948: 30$ & $\cdot$ & 62 & & & & $\because-$ \\
\hline & & & & & 2.09 & 3149 & 105679 & \\
\hline 9/6/94 & 9:40 AM & $9 / 6 / 949: 40$ & & 79 & & & & \\
\hline & & & & & 2.09 & 219 & 105898 & …- \\
\hline 9/6/94 & $11: 25$ AM & $9 / 6 / 9411: 25$ & & 80 & & & & $+\ldots$ \\
\hline
\end{tabular}


BORE7A.XLS

\begin{tabular}{|c|c|c|c|c|c|c|c|c|}
\hline \multicolumn{9}{|c|}{ BORE HOLE 7A - BRINE INJECTION } \\
\hline \multicolumn{9}{|c|}{ NINTH FRAC TANK } \\
\hline DATE & TIME & $\begin{array}{c}\text { COMBINED } \\
\text { TIME }\end{array}$ & $\begin{array}{c}\text { RATE } \\
\text { METER } \\
\end{array}$ & $\begin{array}{c}\text { MANUAL } \\
\text { STRAP }\end{array}$ & $\begin{array}{l}\text { CALCULATED } \\
\text { RATE }\end{array}$ & $\overline{\text { GALS }}$ & $\begin{array}{l}\text { CUMM } \\
\text { GALS }\end{array}$ & COMMENTS \\
\hline $9 / 6 / 94$ & $11: 25 \mathrm{AM}$ & $9 / 6 / 9411: 25$ & 2.7 & 9 & & & & Three Loads (330 bbls.) \\
\hline & & & & & 1.61 & $\overline{314}$ & 106211 & \\
\hline $9 / 6 / 94$ & 2:40 PM & $9 / 6 / 94 \quad 14: 40$ & 2.2 & 10 & & & & 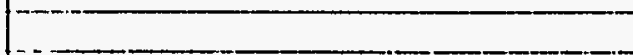 \\
\hline $9 / 7194$ & $3: 00 \mathrm{PM}$ & 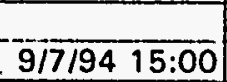 & 2.4 & 24 & $\ldots$ & 2926 & 109137 & 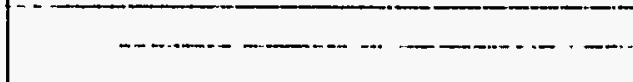 \\
\hline $9 / 8 / 94$ & $2: 30 \mathrm{PM}$ & $9 \overline{9 / 9} \overline{414: 30}$ & 2.5 & 42 & 2.59 & 3658 & 112795 & …- \\
\hline & & & & & 3.08 & $\overline{3449}$ & $116 \overline{243}$ & \\
\hline 9/9/94 & $9: 10 \mathrm{AM}$ & 9/9/949:10 & 2.5 & 58 & & & & \\
\hline & & & & & 3.08 & 247 & 116490 & \\
\hline 9/9/94 & 10:30 AM & 9/9/94 $10: 30$ & 2.8 & 59 & & & 10 & \\
\hline & & & & & & & & \\
\hline
\end{tabular}


BORE7A.XLS

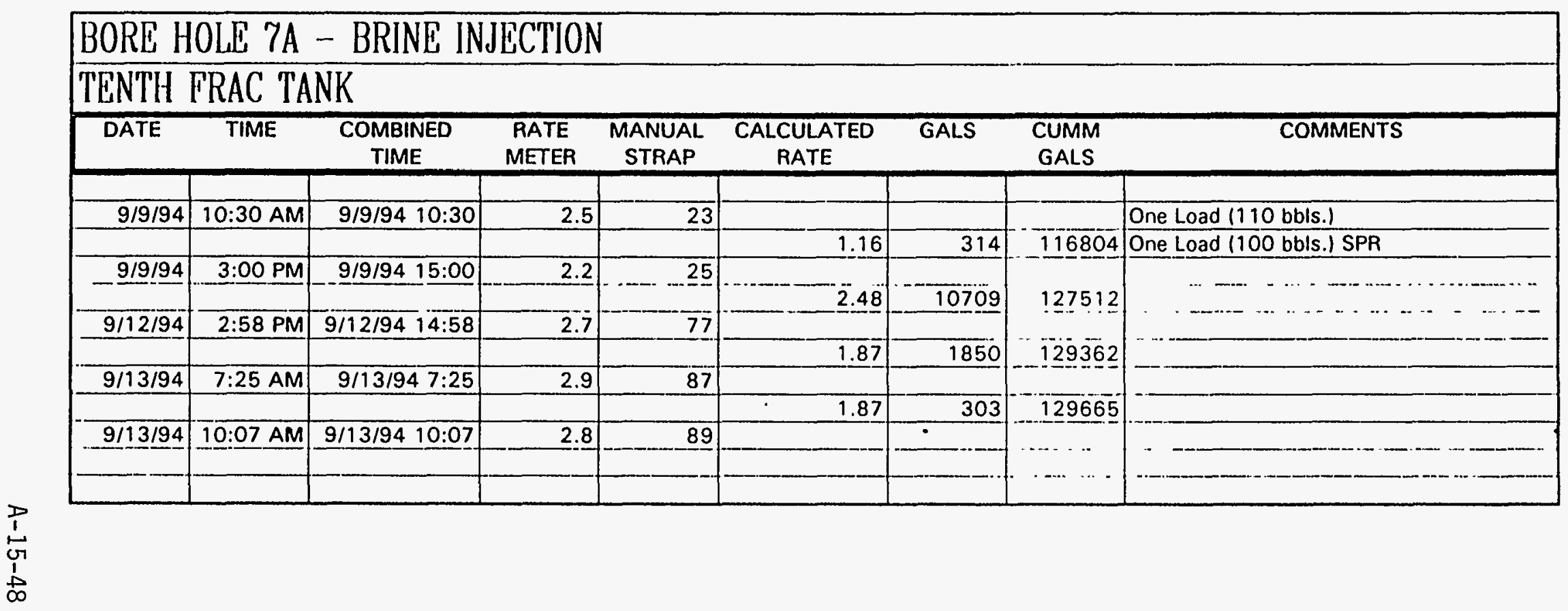


BORE7A.XLS

\begin{tabular}{|c|c|c|c|c|c|c|c|c|}
\hline \multicolumn{8}{|c|}{ BORE HOIF 7A - BRINE INJPCTION } & ELEVENTH FRAC TANK \\
\hline DATE & TIME & $\begin{array}{c}\text { COMBINED } \\
\text { TIME }\end{array}$ & $\begin{array}{l}\text { RATE } \\
\text { METER }\end{array}$ & $\begin{array}{l}\text { MANUAL } \\
\text { STRAP }\end{array}$ & $\begin{array}{l}\text { CALCULATED } \\
\text { - RATE }\end{array}$ & GALS & $\begin{array}{l}\text { CUMM } \\
\text { GALS }\end{array}$ & COMMENTS \\
\hline \multirow{2}{*}{$9 / 13 / 94$} & $10: 07$ AM & $9 / 13 / 9410: 07$ & 3.00 & 20 & & & & Three loads (280 bbls) Morton \\
\hline & & & & & 1.75 & 523 & 130188 & One Load (100 bbls) SPR \\
\hline \multirow[t]{2}{*}{$9 / 13 / 94$} & 3:05 PM & $9 / 13 / 9415: 05$ & 3.10 & 22 & & & & \\
\hline & & & & & 1.65 & 2404 & 132591 & \\
\hline \multirow[t]{2}{*}{$9 / 14 / 94$} & $3: 25 \mathrm{PM}$ & $9 / 14 / 94 \quad 15: 25$ & 3.10 & 34 & & & & \\
\hline & & & & & 2.44 & 3449 & 136040 & \\
\hline \multirow[t]{2}{*}{$9 / 15 / 94$} & 3:00 PM & $9 / 15 / 9415: 00$ & 3.00 & 50 & & & & \\
\hline & & & & & 2.34 & 2404 & 138443 & \\
\hline \multirow[t]{2}{*}{$9 / 16 / 94$} & 8:05 AM & 9/16/94 8:05 & 1.60 & 62 & & $\cdot$ & & \\
\hline & & & & & 2.35 & 305 & 138749 & \\
\hline $9 / 16 / 94$ & 10:15 AM & 9/16/94 10:15 & 1.50 & 63 & & & & \\
\hline & & & & & & & & \\
\hline
\end{tabular}


BORE7A.XLS

\begin{tabular}{|c|c|c|c|c|c|c|c|c|}
\hline BORE H & 0l.E 7A & - BRINE IN & ECTION & & & & & \\
\hline TWEI,VE & TH FRAC & PANK & & & & & & \\
\hline DATE & TIME & $\begin{array}{l}\text { COMBINED } \\
\text { TIME }\end{array}$ & $\begin{array}{l}\text { RATE } \\
\text { METER }\end{array}$ & $\begin{array}{l}\text { MANUAL } \\
\text { STRAP }\end{array}$ & $\begin{array}{l}\text { CALCULATED } \\
\text { RATE }\end{array}$ & GALS & $\begin{array}{l}\text { CUMM } \\
\text { GALS }\end{array}$ & COMMENTS \\
\hline $9 / 16 / 94$ & $10: 15 \mathrm{AM}$ & $9 / 16 / 9410: 15$ & & 16 & & & & \\
\hline & & & 2.4 & & 2.20 & 627 & 139376 & \\
\hline $9 / 16 / 94$ & $3: 00 \mathrm{PM}$ & $9 / 16 / 9415: 00$ & & 19 & & & & \\
\hline & & & 3.1 & & 2.27 & 9823 & 149199 & \\
\hline 9/19/94 & 2:58 PM & $9 / 19 / 94 \quad 14: 58$ & & $6 \underline{6}$ & & & & \\
\hline & & & & & & & & \\
\hline
\end{tabular}

